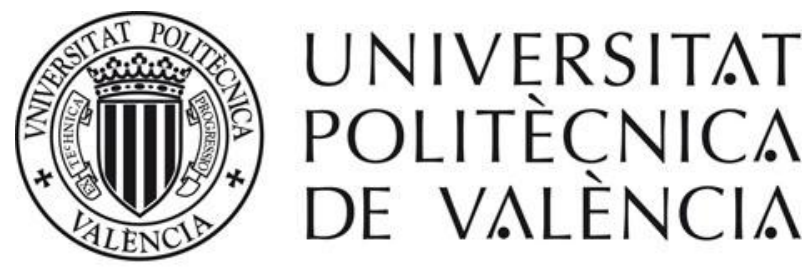

Departamento de Ingeniería de la Construcción y P.I.C.

\title{
ON SHEAR BEHAVIOR OF STRUCTURAL ELEMENTS MADE OF STEEL FIBER REINFORCED CONCRETE
}

\author{
Estefanía Cuenca Asensio \\ $\mathrm{PhD}$ thesis
}

$21^{\text {st }}$ December 2012

Prof. Dr. Pedro Serna Ros

Prof. Dr. Giovanni A. Plizzari
Prof. Dr. Antonio Marí Bernat Prof. Dr. Lucie Vandewalle Prof. Dr. Marco di Prisco Dr. Juan Navarro Gregori Dr. Bryan E. Barragán 
Estefanía Cuenca Asensio

Instituto de Ciencia y Tecnología del Hormigón,

ICITECH (4G Building)

Universitat Politècnica de València,

Camí de Vera s/n, 46022 Valencia, Spain

Tel.: +34 963877563 ext. 75632

E-mails: escueas@upvnet.upv.es;

cuenca.estefania@gmail.com 
"Caminante, son tus huellas el camino y nada más;

Caminante, no hay camino, se hace camino al andar. Al andar se hace el camino, y al volver la vista atrás se ve la senda que nunca se ha de volver a pisar. Caminante no hay camino sino estelas en la mar".

Antonio Machado

Proverbios y cantares (XXIX) 
"Queda prohibido no sonreir a los problemas,

No luchar por lo que quieres,

Abandonarlo todo por miedo,

No convertir en realidad tus sueños"'”.

Pablo Neruda 


\section{ACKNOWLEDGMENTS}

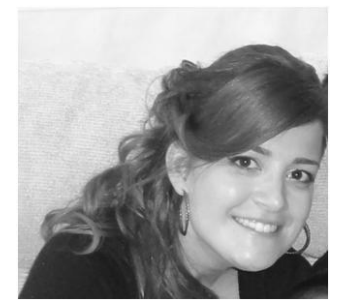

Quizás sea esta parte la más complicada de toda la tesis. Complicada porque se trata de plasmar en una hoja mi agradecimiento a todas y cada una de las personas que me han apoyado, me han escuchado y me han entendido a lo largo de este largo camino llamado tesis doctoral. Esta tesis va dedicada a ese pequeño pero selecto grupo de personas que me han dicho aquellas palabras que tanto necesitaba escuchar en determinados momentos, aquéllas que siempre, y digo siempre, han creído en mí y han estado a mi lado no sólo en los momentos buenos, que es lo fácil, sino también en los momentos difíciles. Gracias a todos aquellos que me habéis hecho feliz cada día, regalando sonrisas y cariño.

Quiero dar las gracias a mi director Pedro Serna Ros. Gracias Pedro por todo. Y todo es decir gracias por los conocimientos innumerables que me has transmitido, por haberme enseñado a querer a nuestras amigas las fibras, por haberme enseñado a "hablar" con el hormigón, para así poder entender mejor qué es lo que "siente" por dentro. Gracias Pedro por todos los valores que me has transmitido, por tu actitud frente a la vida, por tu simpatía, bondad, grandísima cercanía, cariño, gran humildad, por las risas, por tratarme desde el mismo primer día como de igual a igual, por apostar por mí desde el primer momento y por el soporte económico. Gracias Pedro por escucharme, por entenderme y por la flexibilidad, libertad y confianza que me has dado durante todo este tiempo, por esto y por mucho más... ¡Gracias Pedro!

Vorrei inoltre ringraziare il Professore Giovanni Plizzari. Grazie Giovanni per le conoscenze che mi hai trasmesso, per la professionalità dimostratami, per tutti i tuoi preziosi consigli e per avermi dato la possibilità di partecipare in prima persona ad un evento unico quale è stato il "Shear Workshop" di Salò. Vorrei soprattutto ringraziarti a livello umano, in quanto fin dal primo giorno in cui sono arrivata a Brescia sei sempre stato molto gentile e disponibile con me. Grazie anche per essere venuto a Valencia durante la nostra festa "Las Fallas" e per avermi mostrato come dietro a un grande professore come te, ci sia una bellissima persona, semplice onesta e con un grande cuore. 
Vorrei anche ringraziare tutte le persone che sono state i miei colleghi e i miei amici durante il mio stage di 6 mesi a Brescia, ovvero: Fausto Minelli, Luca Facconi, Federica Germano, Giuseppe Tiberti, Luca Martinelli, Francesco Bianchi e Carlo Vezzoli.

Un grandissimo grazie va anche a Giovanni, Pierangela, Domenica, Giuliana e Michele, per avermi fatto sentire come a casa fin dal primo giorno.

También quiero agradecer enormemente a toda la gran familia del ICITECH, profesores e investigadores. Gracias a los técnicos del laboratorio: Pascual, Javier, Juan Franqueza, Juan Monzó, Lino y Vicente Miguel; gracias también a Natalia Castrillón por su exquisito trato, eficiencia y cariño. Con el permiso de los demás, quiero agradecer especialmente a Paco Martorell, por trabajar codo con codo conmigo en el laboratorio durante todos estos años y por saber combinar como nadie el duro trabajo en el laboratorio con la alegría. Gracias Paco por ser mi amigo desde el primer día y haber hecho que fuera cada día al laboratorio con ganas e ilusión. Gracias a mis compañeros de batalla en el laboratorio: Giuseppe Sanitate, Elodie Figuet, Mariela Alvés de Oliveira, Andrea Pasetto, Ivo y Javier Echegaray. Un agradecimiento muy especial a mis compañeras y amigas MáCarmen Gil y Ana Escuriola por su simpatía y eficacia. Gracias a las amistades que se han "fraguado" en el ICITECH: Jaime, Isabel Gasch, Benja, Andrea, Carlos, Emilio, Joaquín y Julio. Muy, pero que muy, en especial a mi amiga Karen y mi amigo Javier Echegaray. Gracias Eche por tu constante apoyo, por hacerme reir, escucharme y por cuidarme tanto.

Muchísimas gracias a todos mis amigos y amigas, muy en especial a los que han estado siempre a mi lado muy pendientes de mi tesis: Jessi, Marivi, Cristina Sola, Estela y Vicente Ibarra.

Mi más sincero agradecimiento es para mis padres, Esteban y Dolores, que... iii os quiero tanto, que no sé que hacer!!! Gracias, gracias, gracias. Mil gracias por TODO: por hacer posible cumplir mis sueños, por estar siempre a mi lado, por vuestro amor, cariño y bondad, comprensión, apoyo incondicional, sabios consejos, por ser mi ejemplo a seguir y por ser... iiiloS MEJORES PADRES DEL MUNDO MUNDIAL !!! Y, ¿qué haría yo sin mi hermanita? Muchísimas gracias Nata por todo, por tu sinceridad, bondad, por tus sabios consejos, por cuidarme tanto y por ser una pieza ESENCIAL en mi vida. iiiÁnimo con las opos, que tú puedes!!! Gracias a mi abuelo Honorio que sé que me cuida desde arriba.

Grazie mille di tutto Antonio, grazie dal primo giorno ad oggi. Grazie per essere SEMPRE SEMPRE accanto a me. Grazie per tutto quello che sei per me!!!

Alaquàs, 12/12/12

Estefanía 


\section{ABSTRACT}

Research on shear in reinforced concrete has been carried out for about a century, so there are many published papers in existence related to this subject.

With the arrival on the market of new materials, such as Fiber Reinforced Concrete (FRC), studies began to focus on the shear behavior of elements made of this material.

The present thesis tries to shed some new light on the shear behavior of FRC elements by means of a thorough analysis of the most important studies in order to detect any deficiencies or issues that have not yet been examined.

Many researchers have presented new formulas for evaluating shear resistance and have compared them with others already in existence.

This thesis does not propose a new formula to add to the already long list, but the objective is to verify the reliability of the current codes by means of comparing experimental tests.

One of the issues dealt with was to verify the influence of flange size on shear and whether to include the flange factor in the design formulas (it appears in one shear formulation for FRC elements, but not in those for non-fiber elements).

Tests were also performed on beams made of concrete of different compressive strengths and fiber reinforcements (quantity and quality) to study their influence on shear, including the size effect.

Finally, FRC hollow core slabs were produced to achieve the benefits of fibers under shear forces, due to the impossibility of including transverse reinforcement in this type of slab.

On Shear Behavior of structural elements made of steel fiber reinforced concrete - PhD thesis 


\section{RESUMEN}

Durante el último siglo se han realizado numerosas investigaciones relativas al comportamiento a cortante de elementos estructurales de hormigón armado, las cuales han dado lugar a un gran número de publicaciones científicas. Con la llegada al mercado de nuevos materiales como el hormigón reforzado con fibras (HRF), también se ha estudiado el comportamiento a cortante de elementos producidos con este material.

La presente tesis doctoral trata de arrojar algunas luces sobre el comportamiento a cortante de elementos fabricados con HRF; para ello se ha llevado a cabo un profundo y exhaustivo análisis de la bibliografía más relevante, con el fin de detectar posibles deficiencias o problemas que todavía no han sido estudiados.

Un gran número de investigadores han presentado nuevas fórmulas para evaluar la resistencia a cortante y, a su vez, éstas han sido comparadas con otras existentes. En esta tesis doctoral no se propone una nueva fórmula de evaluación del cortante a añadir a la larga lista que ya existe, sino que se pretende verificar la fiabilidad de los códigos de diseño actuales por medio de comparaciones con ensayos experimentales.

Se pretende también verificar la influencia del tamaño del ala en la resistencia a cortante y si se debería introducir un factor para considerar dicho efecto en las fórmulas de diseño (este factor aparece en algunas formulaciones de cortante para elementos de HRF pero no aparece en las formulaciones de cortante para elementos sin fibras).

También se han llevado a cabo ensayos experimentales en vigas fabricadas con hormigones de diferentes resistencias a compresión y diferente cantidad y calidad de fibras para así estudiar su influencia en el cortante, así como también se ha estudiado el efecto tamaño en el cortante.

Finalmente, se fabricaron placas alveolares con HRF, con la finalidad de conseguir los beneficios de las fibras en el comportamiento a cortante, considerando la imposibilidad de colocar estribos en el interior de las placas alveolares.

On Shear Behavior of structural elements made of steel fiber reinforced concrete - PhD thesis 


\section{RESUM}

Durant l'últim segle s'han realitzat nombroses investigacions relatives al comportament a tallant d'elements estructurals de formigó armat, les quals han donat lloc a un gran nombre de publicacions científiques.

Amb l'arribada al mercat de nous materials com el formigó reforçat amb fibres (FRF), també s'ha estudiat el comportament a tallant d'elements produïts amb aquest material.

Aquesta tesi doctoral tracta de llançar algunes llums sobre el comportament a tallant d'elements fabricats amb HRF, per això s'ha dut a terme un profund i exhaustiu anàlisi de la bibliografia més rellevant, per tal de detectar possibles deficiències o problemes que encara no han estat estudiats.

Un gran nombre d'investigadors han presentat noves fórmules per avaluar la resistència a tallant $i$, al seu torn, aquestes han estat comparades amb altres existents. En aquesta tesi doctoral no es proposa una nova fórmula d'avaluació del tallant a afegir a la llarga llista que ja existeix, sinó que es pretén verificar la fiabilitat dels codis de disseny actuals mitjançant comparacions amb assajos experimentals.

Es pretén també verificar la influència del tamany de l'ala en la resistència a tallant i si s'hauria d'introduir un factor per considerar aquest efecte en les fórmules de disseny (aquest factor apareix en algunes formulacions de tallant per elements de FRF però no apareix en les formulacions de tallant per elements sense fibres).

També s'han dut a terme assaigs experimentals en bigues fabricades amb formigons de diferents resistències a compressió i diferent quantitat i qualitat de fibres per així estudiar la seua influència en el tallant, així com també s'ha estudiat l'efecte tamany al tallant.

Finalment, es van fabricar plaques alveolars amb FRF, amb la finalitat d'aconseguir els beneficis de les fibres en el comportament a tallant, considerant la impossibilitat de col.locar armadura transversal dins de les plaques alveolars.

On Shear Behavior of structural elements made of steel fiber reinforced concrete - PhD thesis 


\section{INDEX}

Part I

INTRODUCTION AND OBJECTIVES

Chapter 1

INTRODUCTION

1.1 Foreword 3

1.2 Contents.

Chapter 2

OBJECTIVES AND RESEARCH SIGNIFICANCE

2.1 Objectives.................................................................................................. 11

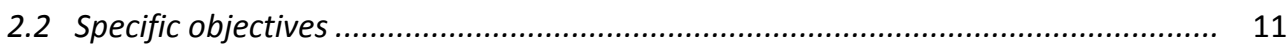

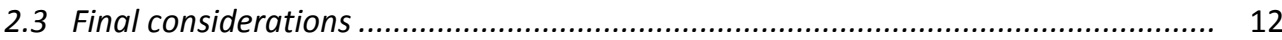

Part II

LITERATURE SURVEY ON SHEAR IN FRC BEAMS

Chapter 3

LITERATURE SURVEY ON SHEAR IN FRC BEAMS

3.1 Introduction

3.2 On steel fiber reinforced concrete (SFRC).

3.3 Fibers effects on shear behavior 
3.4 Steel fibers as shear reinforcement .......................................................... $\quad 30$

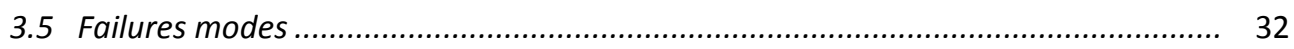

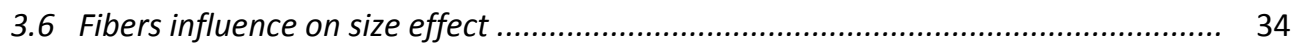

3.7 Fibers influence on serviceability limit state (SLS) and durability ........................ 37

3.8 Reduction of production cost .................................................................... 38

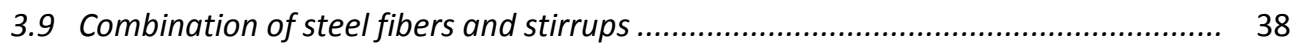

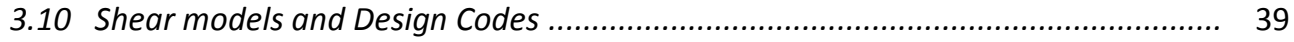

3.11 Parameters influencing in shear behavior of FRC beams................................. 47

3.12 Fibers influence on deflection ....................................................................... 53

3.13 Fibers influence on dowel action........................................................... 54

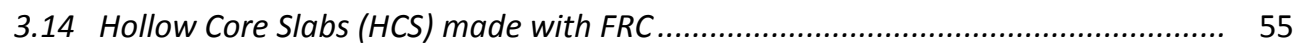

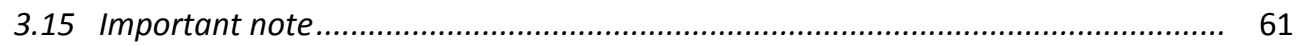

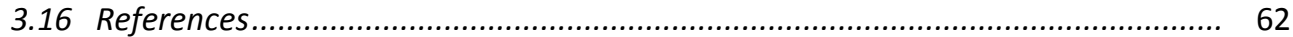

Part III

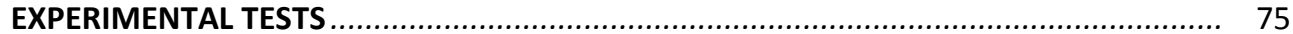

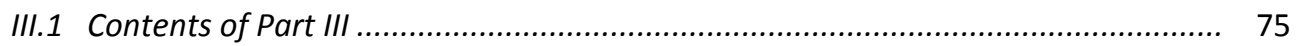

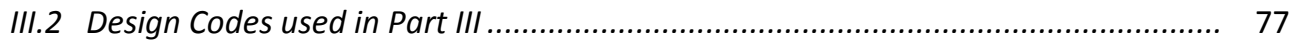

\section{Chapter 4}

EXPERIMENTAL TESTS IN PARAMETERS INFLUENCING ON SHEAR .......................... 81

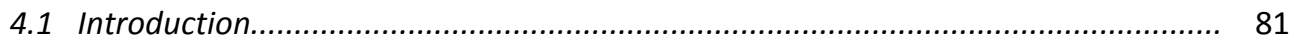

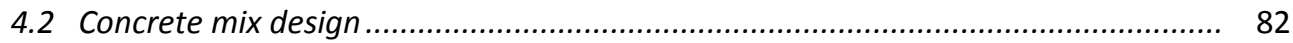

On Shear Behavior of structural elements made of steel fiber reinforced concrete-PhD thesis 
4.3 Concrete properties and production control ................................................. 84

4.4 Experimental program and the results analysis.................................................. 86

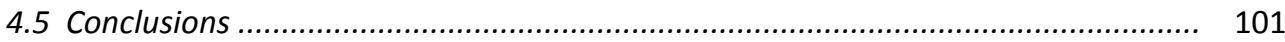

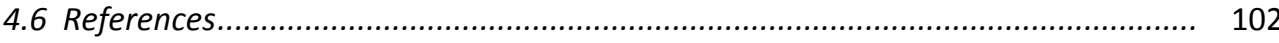

Chapter 5

EXPERIMENTAL TESTS ON FIBERS INFLUENCE ON THE SIZE EFFECT ON SHEAR

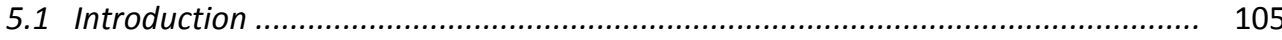

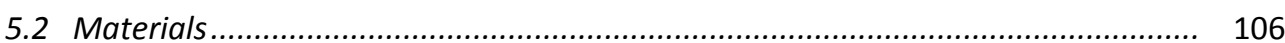

5.3 Concrete properties and production control ............................................... 108

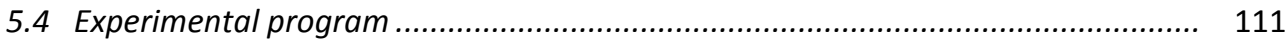

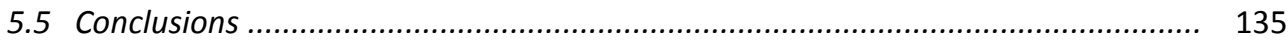

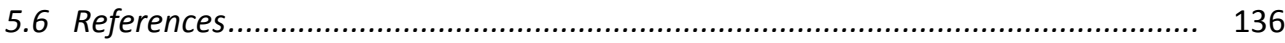

Chapter 6

EXPERIMENTAL TESTS TO STUDY THE INFLUENCE ON THE SHEAR BEHAVIOR OF FIBERS

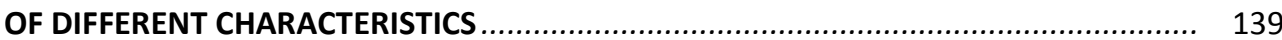

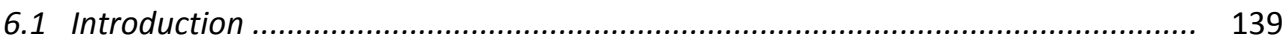

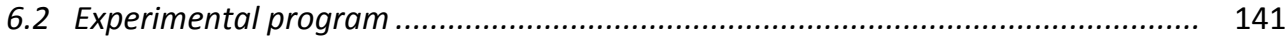

6.3 Results of the concretes characterization ........................................................ 145

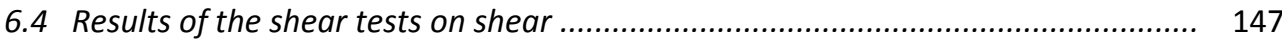

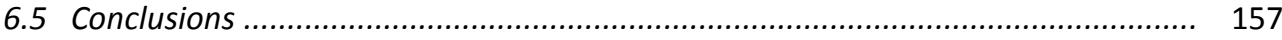

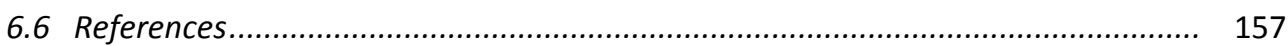

Chapter 7

EXPERIMENTAL TESTS ON HOLLOW CORE SLABS MADE WITH FRC $\ldots \ldots \ldots \ldots \ldots \ldots \ldots \ldots \ldots . . . . . . . . . . . .161$

On Shear Behavior of structural elements made of steel fiber reinforced concrete-PhD thesis 


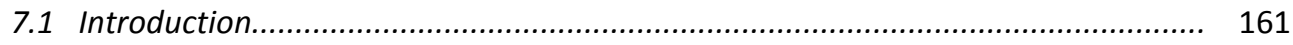

7.2 Experimental investigation ............................................................................ 162

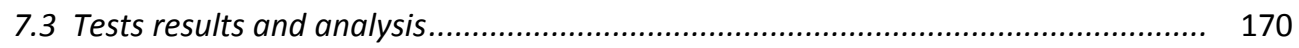

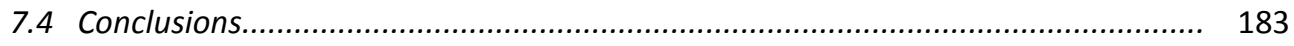

7.5 Publication of these results ......................................................................... 184

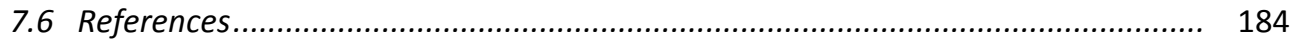

Part IV

SHEAR DATABASE

Chapter 8

SHEAR DATABASE AND STUDY OF THE PARAMETERS INFLUENCING SHEAR BEHAVIOR

8.1 Introduction

8.2 Data selection

8.3 Case 1: Beams made without shear reinforcement (concrete neither fibers nor stirrups)

8.4 Case 2: Beams with stirrups (no fibers) 199

8.5 Case 3: Beams with fibers (no stirrups) 200

8.6 Case 4: Beams with fibers and stirrups .................................................. 207

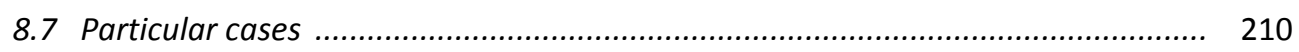

8.8 Conclusions according to the analyzed shear database.................................. 236

8.9 Suggestions for Design Codes according to shear.......................................... 244

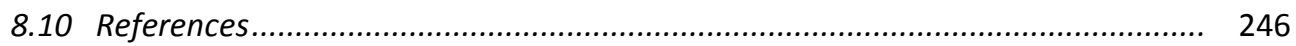


Part V

CONCLUSIONS AND RECOMMENDATIONS

Chapter 9

CONCLUSIONS

Chapter 10

RECOMMENDATIONS FOR FUTURE RESEARCH

Part VI

APPENDICES

Appendix A

LITERATURE SURVEY ON SHEAR BEHAVIOR IN CONCRETE ELEMENTS WITHOUT FIBERS

A.1 Basic Theory 257

A.2 Beams without shear reinforcement

A.3 Beam with shear reinforcement.

A.4 Parameters influencing shear behavior

A.5 Current Design Codes.

A.6 Comments and criticisms to the Design Codes

A.7 Hollow core slabs (HCS) made with concrete without fibers

A.8 Important note

A.9 References

Appendix B

FIBER REINFORCED CONCRETE 


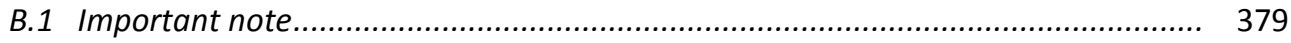

B.2 Other models according to different authors.................................................. 379

B.3 Comments to shear models and to Design Codes ....................................... 384

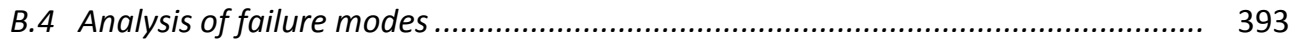

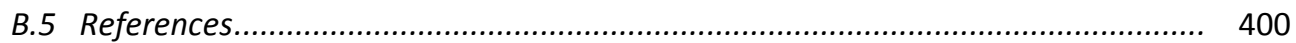

\section{Appendix C}

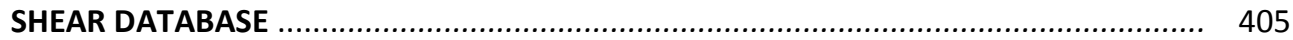




\section{Da解}

\section{IIntrodustion}

\section{and objeckinves}





\section{CHAPTER 1}

\section{INTRODUCTION}

\subsection{Foreword}

In 1955, the partial collapse of the Wilkins Air Force Depot warehouse in Shelby, Ohio, called into question the shear provisions of the $\mathrm{ACl}$ Building Code. This Code for many years had permitted, under service conditions, shear stresses in beams without stirrups equal to $0.03 \cdot f_{c}^{\prime}$, which meant an allowable working shear stress of $0.62 \mathrm{MPa}$ for the $20 \mathrm{MPa}$ Wilkins concrete. As a matter of fact, the beams in the Air Force warehouse failed due to a shear stress of about 0.5 MPa (see Fig.1.1), pointing to serious deficiencies in the design practice of the time. Further analyses demonstrated that tensile stresses due to the restraint of shrinkage and thermal movements explained why the low shear stresses applied caused the failure [1]. This accident led to a revision of the shear provisions in the $1956 \mathrm{ACl}$ Building Code and triggered a considerable number of studies on shear strength.

Even after many years of intensive research, the shear behavior of concrete structures is still not complete and is a topic of continuous debate between researchers and practitioners looking for models and methods to describe and determine the shear capacity of structural concrete members (Fig.1.2).

On Shear Behavior of structural elements made of steel fiber reinforced concrete - PhD thesis 

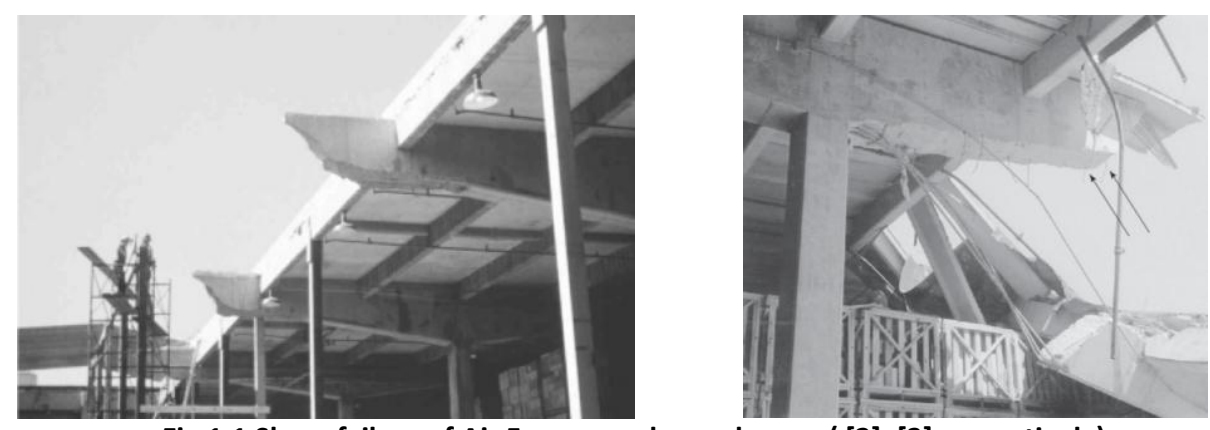

Fig.1.1 Shear failure of Air Force warehouse beams ( [2], [3] respectively)

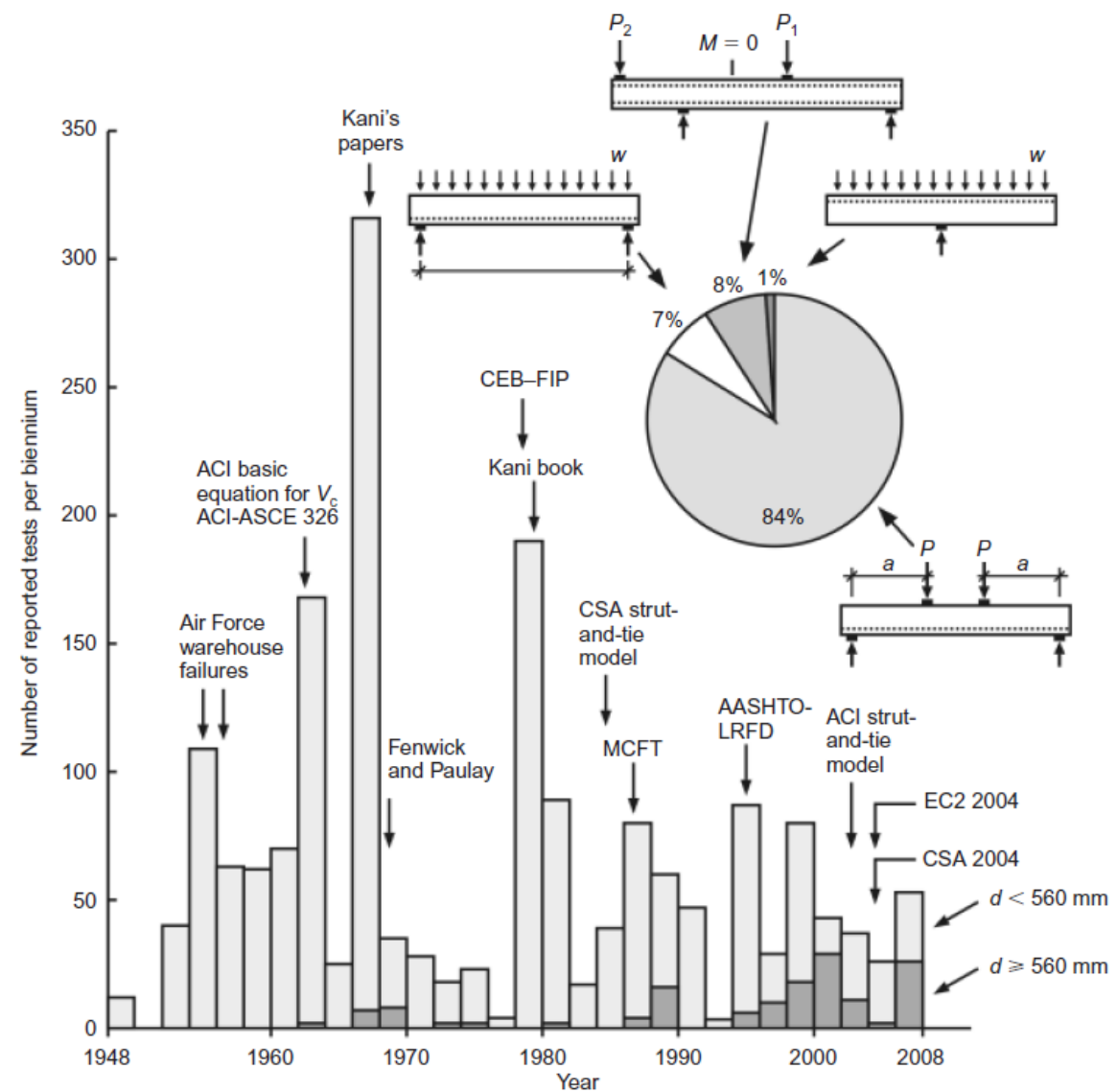

Fig.1.2 Shear research on members without shear reinforcement [2]

Some of the parameters usually considered in shear behavior are: element dimensions (for the size effect), presence of axial forces, amount of longitudinal reinforcement, 
concrete compressive strength, load conditions, cross-section shape and the shear span/depth ratio (a/d).

General shear models are now being extended to cover newer materials such as fiber reinforced concrete (FRC).

The following are some of the main concepts included in papers related to FRC elements subjected to shear forces:

- fibers are used to enhance the shear capacity of concrete, or to partially or totally replace stirrups in RC structural members ( [4], [5])

- $\quad F R C$ is characterized by enhanced toughness due to the bridging effects provided by fibers ( [5], [6])

- fibers provide substantial post-peak resistance and ductility ( [5], [7], [8])

- adding fibers means fewer brittle shear failures take place e.g., ( [9]- [10])

- test results indicate that adding fibers reduces maximum crack width, average crack width and average crack spacing ( [7], [11], [12], [13])

- $\quad F R C$ is suitable for structures where diffused stresses are present, and improves reinforcement in structures with both localized and diffused stresses in combination with rebars [5].

RILEM TC162-TDF [14] produced pioneer design guidelines in which the fibers' contribution to shear resistance is added to that of the concrete as a separate term, based on the fiber's toughness properties.

The approach presented in the first complete draft of the Model Code 2010 [15] for shear resistance of FRC members is based on the Eurocode 2 [16], used to determine shear contribution in concrete members without shear reinforcement, by adding a factor based on Minelli's proposal, which includes the FRC mechanical properties by modifying the effect of the longitudinal reinforcement ratio. Thus, by considering FRC as a composite with enhanced toughness, the fiber effects are included as a concrete contribution. This was done to obtain a more representative modeling of the actual effect of fibers, which basically make the concrete matrix tougher after cracking by improving both the transfer of residual tensile stresses and the aggregate interlock (the latter, by keeping cracks smaller). However, it should be noted that the two formulations require toughness properties. When combining fibers with stirrups, both Codes include an additional term to consider the effect of stirrups. The proposed model and the RILEM formulation were compared with of a wide experimental database. Although the fit is less promising when 
dealing with high strength concrete specimens or prestressed members, the RILEM results are slightly more refined for small-sized elements than for deep beams.

The ACl 318-11 Code [17] does not include a formula to calculate the shear strength of SFRC beams and only assumes a minimum shear strength which fibers can withstand. In 2006, Parra-Montesinos [18] ensured that hooked steel fibers in an FRC with a $0.75 \%$ by volume fraction of steel fibers can be used in lieu of minimum stirrup reinforcement in beams. A limit based on FRC toughness properties (that does not only depend on the amount of fibers) would be a better criterion to justify substitution of transverse reinforcement.

Other countries have produced design guidelines, including: France (AFGC-SETRA, 2002), Sweden (Stälfiberbeton, 1995), Germany (DAfStb, 2007), Austria (Richtlinie Faserbeton, 2002), Italy (CNR, 2006) and Spain (EHE: Appendix 14 [19]) (the latter based on RILEM guidelines [14]).

The FRC shear design workshop held in Salò (Italy) proved to be an interesting advance in the development of the Model Code provisions [15] and in inspiring future research into these topics. Lectures were included in a fib Bulletin [20].

\subsection{Contents}

This PhD thesis is divided into five parts:

The PART I: INTRODUCTION AND OBJECTIVES consists of Chapters 1 and 2:

- Chapter 1 is an introduction to the shear behavior of concrete structural elements, with and without fibers, with a brief historical review on the research to date on this topic. Also included are the main topics in papers related to FRC elements subjected to shear and the benefits on shear behavior of the addition of steel fibers. Current Codes are cited that include fibers' contribution to shear. Finally, there is a brief summary of the contents of this PhD thesis.

- $\quad$ Chapter 2 describes the objectives pursued in this thesis and its contribution to the research in its field.

PART II: STATE-OF-THE-ART describes the state-of-the-art of the shear behavior of structural concrete elements made with fiber reinforced concrete (Chapter 3). 
Chapter 3 describes the state-of-the-art of the shear behavior of concrete structural elements made with steel fibers. This chapter starts with a general introduction on steel fiber reinforced concrete, followed by the use of steel fibers as shear reinforcement.

PART III: EXPERIMENTAL TESTS deals with the experimental tests (Chapters 4 to 7).

- $\quad$ Chapter 4 presents the results of studies with large beams to assess the influence of the size effect.

- $\quad$ Chapter 5 examines the shear behavior of concrete containing fibers of different characteristics and different concrete compressive strengths.

- In Chapter 6 shear tests on prestressed beams are analyzed, with special attention to the possible influence of parameters such as flange size on shear strength.

- $\quad$ Chapter 7 describes a complete experimental program consisting of the shear behavior of hollow core slabs (HCS) made of fiber reinforced concrete.

PART IV: SHEAR DATABASE Chapter 8 focuses on the analysis of an extensive shear database of concrete elements with and without steel fibers, and studies the effect of each parameter on shear behavior and discusses the reliability of the Design Codes.

PART V: CONCLUSIONS AND FUTURE RESEARCH Chapter 10 contains the final conclusions and possible future lines of research.

PART VI: APPENDICES contains:

Appendix $\boldsymbol{A}$ describes the state-of-the-art in the shear behavior of plain concrete structural elements. The basic theory is first explained and Section A.3 contains a survey of the literature on beams with no shear reinforcement. Section A.4 has a survey on beams with traditional shear reinforcement (stirrups). In Section A.5 the parameters influencing shear behavior are analyzed. The current Design Codes are described in Section A. 6 and discussed in Section A.7. Finally, Section A.8 contains a table with a summary of the shear models designed by other authors.

Appendix B describes shear models according to different authors, with comments, Design Codes and an analysis of the failure modes proposed by several authors.

Appendix $C$ contains a complete shear database, analyzed in detail in Chapter 8.

On Shear Behavior of structural elements made of steel fiber reinforced concrete-PhD thesis 


\subsection{References}

[1] Bhide and Collins, "Influence of axial tension on the shear capacity of reinforced concrete members," ACl Structural Journal, vol. 86, no. 5, pp. 570-581, 1989.

[2] Collins, Bentz, Sherwood and Xie, "An adequate theory for the shear strength of reinforced concrete structures," Magazine of concrete research, vol. 60, no. 9, pp. 635-650, 2008.

[3] MacGregor and Wight, Reinforced concrete. Mechanics and Design, Pearson Prentice Hall, 2005.

[4] Imam, Vandewalle, Mortelmans and V. Gemert, "Shear domain of Fibre-Reinforced High-Strength Concrete Beams," Engineering Structures, vol. 19, no. 9, pp. 738-747, 1997.

[5] Di-Prisco, Plizzari and Vandewalle, "MC2010: Overview on the shear provisions for FRC," in Shear and punching shear in RC and FRC elements, vol. 57, 2010, pp. 61-76.

[6] Kim, Lee, Hwang and Kuchma, "Shear behavior model for steel fiber-reinforced concrete members without transverse reinforcements," Composites: Part B, vol. 43, pp. 2324-2334, 2012.

[7] Balázs, "A historical review of shear," in Shear and punching shear in RC and FRC elements, vol. 57, fib-Bulletin, 2010, pp. 1-13.

[8] Bencardino, Rizzuti, Spadea and Swamy, "Experimental evaluation of fiber reinforced concrete fracture properties," Composites: Part B, vol. 41, pp. 17-24, 2010.

[9] Minelli and Plizzari, "Shear strength of FRC members with little or no shear reinforcement: a new analytical model," in Shear and punching shear in RC and FRC elements, vol. 57, 2010, pp. 211-225.

[10] Cucchiara, La-Mendola and Papia, "Effectiveness of stirrups and steel fibers as shear reinforcement," Cement and Concrete Composites, vol. 26, no. 7, pp. 777-786, 2004. 
[11] Susetyo and Vecchio, "Effectiveness of steel fiber as minimum shear reinforcement: panel tests," in Shear and punching shear in RC and FRC elements, vol. 57, 2010, pp. 227-241.

[12] Kovács and Balázs, "Structural behavior of steel fiber reinforced concrete," Journal of Structural Concrete, pp. 57-63, 2003.

[13] Parra-Montesinos, Wight, Dinh and Cheng, "Use of steel fiber reinforcement for shear resistance in beams and slab-column connections," in Shear and punching shear in $R C$ and FRC elements, vol. 57, 2010, pp. 243-262.

[14] RILEM-TC-162-TDF, "Test and design methods for steel fibre reinforced concrete, Stress-strain design method. Final Recommendation," vol. 36, pp. 560-567, 2003.

[15] MC2010, fib Bulletin 55-56. Model Code - First complete draft, Vols. 55-56, fib, 2010.

[16] EC2, Eurocode 2: Design of Concrete Structures-EN 1992-1-1, 2005.

[17] ACl.Committee.318, Building Code requirements for structural concrete (ACl 318-11), American Concrete Institute, 2011.

[18] Parra-Montesinos, "Shear strength of beams with deformed steel fibers," Concrete International, vol. 28, no. 11, pp. 57-66, 2006.

[19] EHE-08, Instruccion de hormigon estructural EHE-08 (in spanish), Madrid, Spain: Ministerio de Fomento, 2008.

[20] fib-Bulletin57, Shear and punching shear in RC and FRC elements, Salò, Italy, 2010.

On Shear Behavior of structural elements made of steel fiber reinforced concrete - PhD thesis 


\section{CHAPTER 2}

\section{OBJECTIVES AND}

\section{RESEARCH SIGNIFICANCE}

\subsection{Objectives}

The main objective of this PhD thesis is to study the different parameters affecting the shear behavior of concrete reinforced with steel fibers. It also aims to determine the influence of the different parameters involved and examine certain design Codes, with particular reference to the role of fiber reinforcement.

\subsection{Specific objectives}

After a thorough study of the literature dealing with shear forces, the behavior of fiber reinforced concrete (FRC) beams was analyzed. Particular attention was devoted to the behavior of both precast elements and those made in situ in a number of experimental tests.

This $\mathrm{PhD}$ thesis tries to provide answers to some issues that are still the subject of enquiry in the research community.

On Shear Behavior of structural elements made of steel fiber reinforced concrete - PhD thesis 
The specific objectives are the following:

- To conduct a review of the literature with particular attention to how the phenomenon has been analyzed in both traditional reinforced concrete and prestressed elements. An additional aim is to compile an extensive bibliographical database to facilitate consistent parametric analysis.

- To analyze the influence of fibers in the context of size in the form of the shear behavior of large concrete beams.

- To study the influence of flange size in prestressed double-T beams.

- To analyze the different shear responses obtained from concretes of different toughness by the use of different fiber content and geometry. For this, the shear behavior, failure modes and the validity of design formulas recommended by a number of building codes were analyzed.

- To analyze the shear behavior of Hollow Core Slabs made of fiber reinforced concrete, which is of great interest due to the difficulties involved in fitting transverse reinforcement in these elements.

- Analysis of an extensive database to verify the standards in Current Codes.

\subsection{Final considerations}

Possible improvements of the current building codes was considered to be more important than proposing a new shear formula As Regan has pointed out [1]: "The most imposing analyses have often given excellent correlation with known results but failed miserably to predict behavior in untried circumstances. For simpler models the problem is mostly that of the need to neglect secondary factors, while what is secondary in one case may be primary in another. This is not to question the desirability of models, or of refined analysis at least as a research tool, but to point to the need for very careful verifications. It also points to the fact that significant improvements for design are very likely to be initiated by experimental observation".

This thesis will therefore focus on a deeper understanding of the parameters that influence shear strength and try to identify any possible defects in existing design formulas. 
On the other hand, "the use of steel fibers in concrete mixtures has not yet been fully utilized by the concrete industry for several reasons: steel fibers are often considered expensive and [2] the shear behavior of concrete containing steel fibers is still not fully understood. It is important to better understand and predict the shear behavior of SFRC for its wider applications in the concrete industry" [3].

Without any doubt Regan's claim [1] invites us to reflect and leaves no-one indifferent: "Research on shear: a benefit to humanity or a waste of time?"

\subsection{References}

[1] Regan, "Research on shear: a benefit to humanity or a waste of time?," The Structural Engineer, vol. 71, no. 19, 1993.

[2] Chanh, "Steel fiber reinforced concrete," Faculty of Civil Eng Ho Chi Min City University of Technology, pp. 108-116, 2004.

[3] Slater, Moni and Alam, "Predicting the shear strength of steel fiber reinforced concrete beams," Construction and Building Materials, vol. 26, pp. 423-436, 2012.

On Shear Behavior of structural elements made of steel fiber reinforced concrete - PhD thesis 


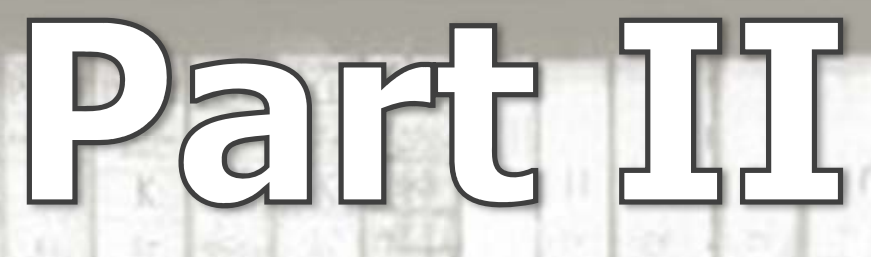

¿ñeparure survey

\section{on shear ing FRC}

elleñents 


\section{CHAPTER 3}

\section{LITERATURE SURVEY}

\section{ON SHEAR IN FRC BEAMS}

\subsection{Introduction}

This Chapter 3 appears as inspiration for the affirmation of Fenwick \& Paulay in 1968: "An inquiring designer will not only want to know how to apply a safe design procedure, but also wish to see the reason why a particular structural member is likely to fail in a particular mode" [1].

Therefore, this Chapter 3 seeks to know in depth the shear behavior of structural concrete elements made of fiber reinforced concrete in order to understand the failure modes and to understand existing formulations of the design codes thus may be suggestions, suggest any amendments or even propose new methods of calculation that more faithfully reproduce the behavior of these elements. So, Chapter 3 presents the state-of-the-art on the shear behavior of fiber reinforced concrete elements, complete and fully updated. Initially, the basic theory of shear will be explained; then, the shear behavior of concrete with and without transverse reinforcement, parameters influencing the shear behavior; codes (formulas, comments and criticisms) and finally, the shear behavior of hollow core

On Shear Behavior of structural elements made of steel fiber reinforced concrete-PhD thesis 
slabs. To have a better knowledge of the basis of shear, Appendix $A$ gives a complete background of the shear behavior in concrete, specifically for concrete without steel fibers.

\subsection{On steel fiber reinforced concrete (SFRC)}

\subsubsection{Introduction about FRC}

What is fiber-reinforced concrete (FRC)?

The Model Code 2010 [2] defines FRC as a "composite material characterized by a cement matrix and discrete fibers (discontinuous)".

The matrix is made of either concrete or mortar. Fibers can be made of steel, polymers, carbon, glass or natural materials, although this $\mathrm{PhD}$ will be entirely focused in steel fibers. FRC properties for structural applications can be obtained by using different fiber materials. From these properties, design constitutive laws can be obtained from the postcracking residual strength of the composite [2].

For structural applications with normal and high-strength concrete the material classification is based on the post-cracking residual strength.

For structural use, a minimum mechanical performance of FRC must be guaranteed. Fibers can be used to improve the behavior at SLS since they can reduce crack spacing and crack width, thereby improving durability. Fibers can be also used to improve the behavior at the ULS where they can partially or totally substitute conventional reinforcement. The mechanical properties of a cementitious matrix are modified when fibers are added. However, elastic properties and compressive strength (Fig.3.1) are not significantly affected by fibers, unless a high percentage of fibers is used [2].

Depending on their composition, fiber reinforced concretes (FRC) can show hardening or softening behavior in uniaxial tension (Fig.3.2-a). In the case of softening behavior (Fig.3.2a), the deformations localize in one crack. In the case of hardening behavior (Fig.3.2-b), multiple cracking occurs before reaching the peak load. Softening behavior in tension may correspond to hardening behavior in bending (Naaman and Reinhardt, HPFRCC).

In order to determine the post-cracking behavior of FRC, which is the most important property of FRC, various test methods are possible. 


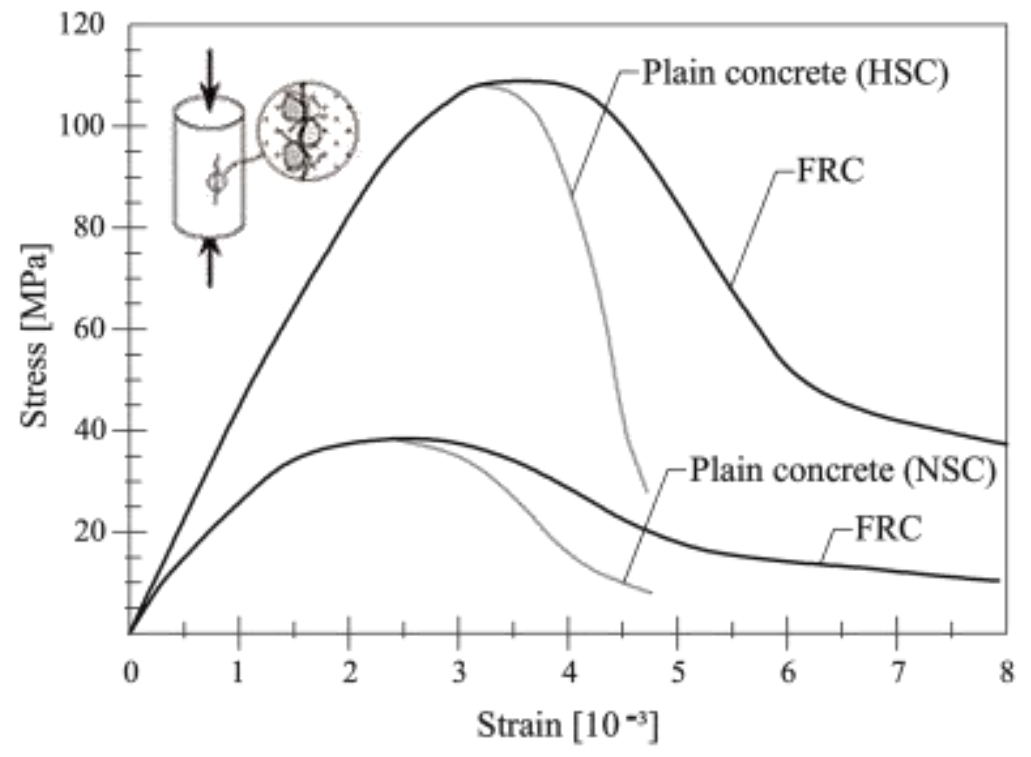

Fig.3. 1 Main differences between plain and fiber reinforced concrete having both normal and high strength under uniaxial compression [2].
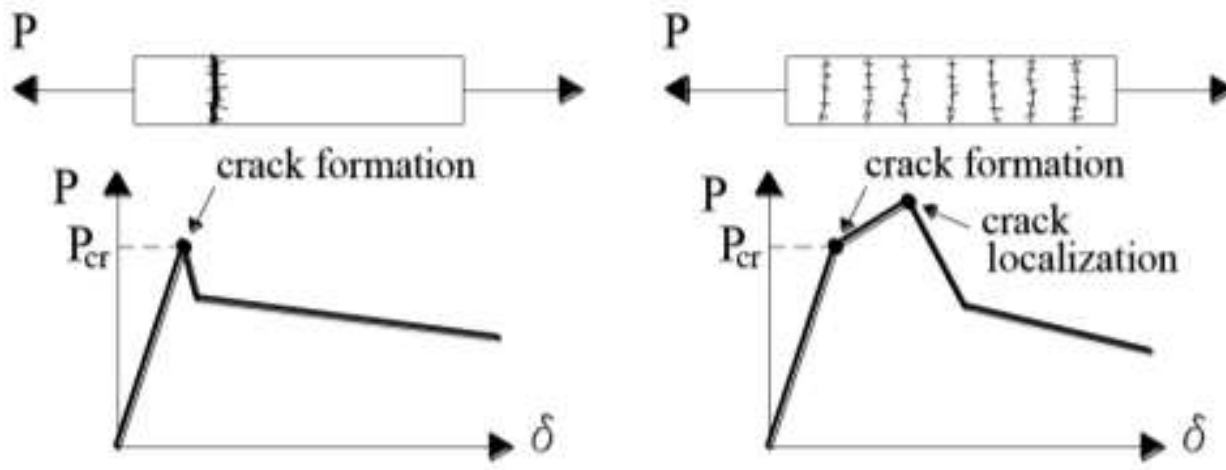

Fig.3. 2 Softening (a) and hardening (b) behavior in axial tension [2]

Nominal values of the material properties can be determined by performing a 3-point bending test on a notched beam according to EN 14651 (Fig. 3.3). The diagram of the applied force (F) versus a deformation is produced (Fig. 3.4). The deformation is generally expressed in terms of Crack Mouth Opening Displacement (CMOD). Parameters, $f_{R j}$, representing the residual flexural tensile strength for different values of $\mathrm{CMOD}_{\mathrm{j}}$, are evaluated from the F-CMOD relationship, as follows:

On Shear Behavior of structural elements made of steel fiber reinforced concrete-PhD thesis 


$$
f_{R, j}=\frac{3 F_{\mathrm{j}} l}{2 b h_{\mathrm{sp}}^{2}}
$$

where: $f_{R j}(\mathrm{MPa})$ : residual flexural tensile strength corresponding to $\mathrm{CMOD}=\mathrm{CMOD}_{\mathrm{j}} ; F_{j}(\mathrm{~N})$ : load corresponding to $\mathrm{CMOD}=\mathrm{CMOD}_{\mathrm{j}} ; I(\mathrm{~mm})$ : is the span length; $b(\mathrm{~mm})$ : specimen width; $h_{s p}(\mathrm{~mm})$ : distance between the notch tip and the top of the specimen $(125 \mathrm{~mm})$.
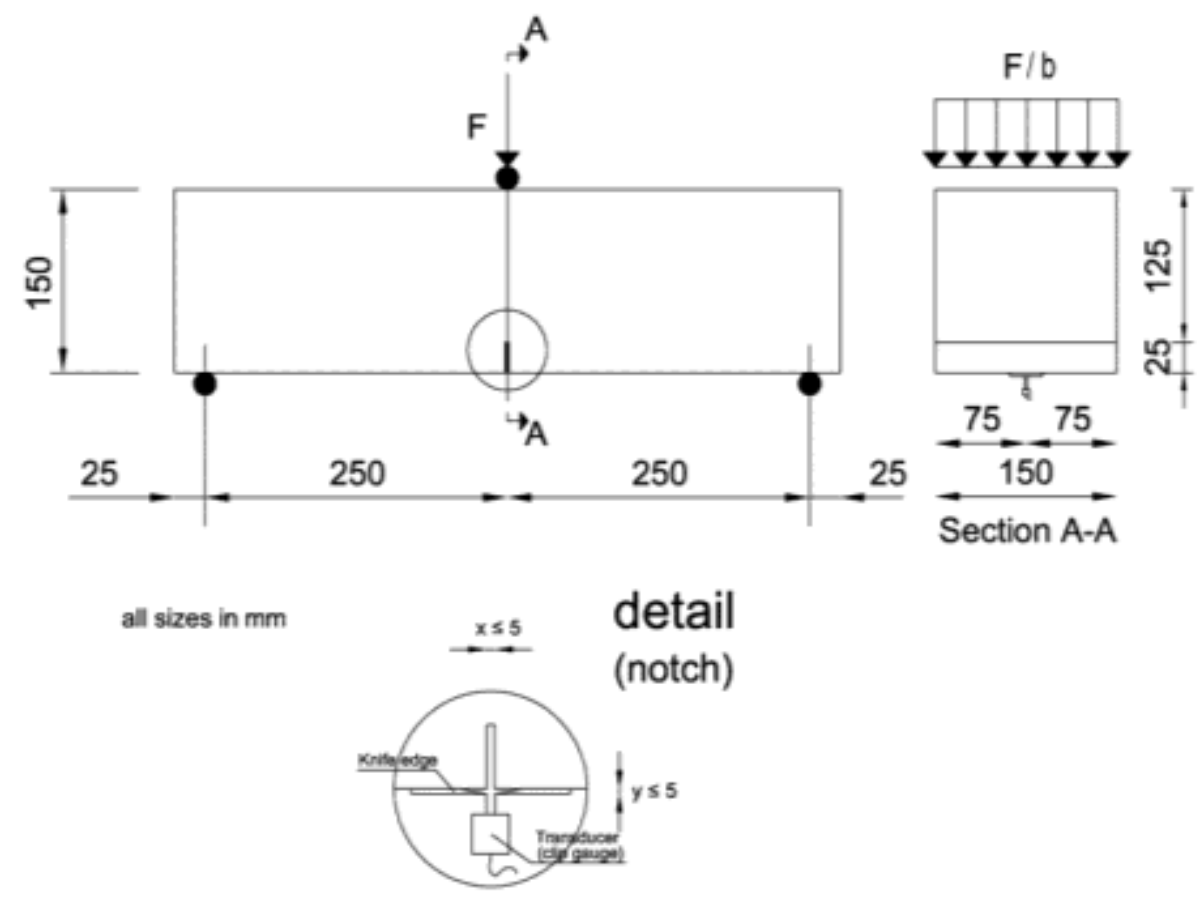

Fig.3. 3 Test set-up required by EN 14651 (dimensions in [mm]) [2]

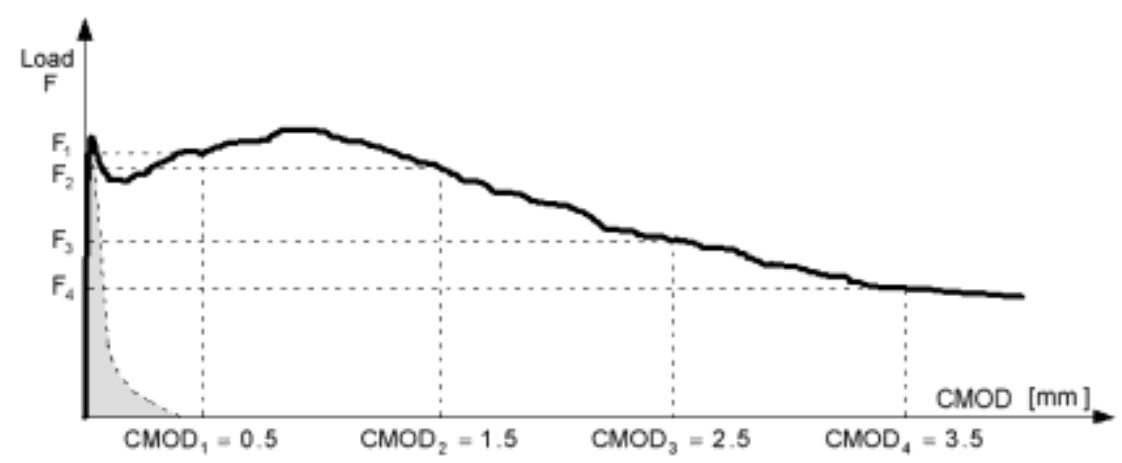

Fig.3. 4 Typical load F - CMOD curve for FRC [2] 


\subsubsection{Classification}

In order to classify the post-cracking strength of FRC, a linear elastic behavior can be assumed by considering the characteristic residual strength significant for serviceability $\left(f_{R 1 k}\right)$, and for ultimate conditions $\left(f_{R 3 k}\right)$. In particular two parameters, namely $f_{R 1 k}$ (representing the strength interval for $f_{R 1 k}$ ) and a letter $\boldsymbol{a}, \boldsymbol{b}, \boldsymbol{c}, \boldsymbol{d}$ or $\boldsymbol{e}$ (representing the ratio $f_{R 3 k} / f_{R 1 k}$ ), as adapted [3] (Fig. 3.5).

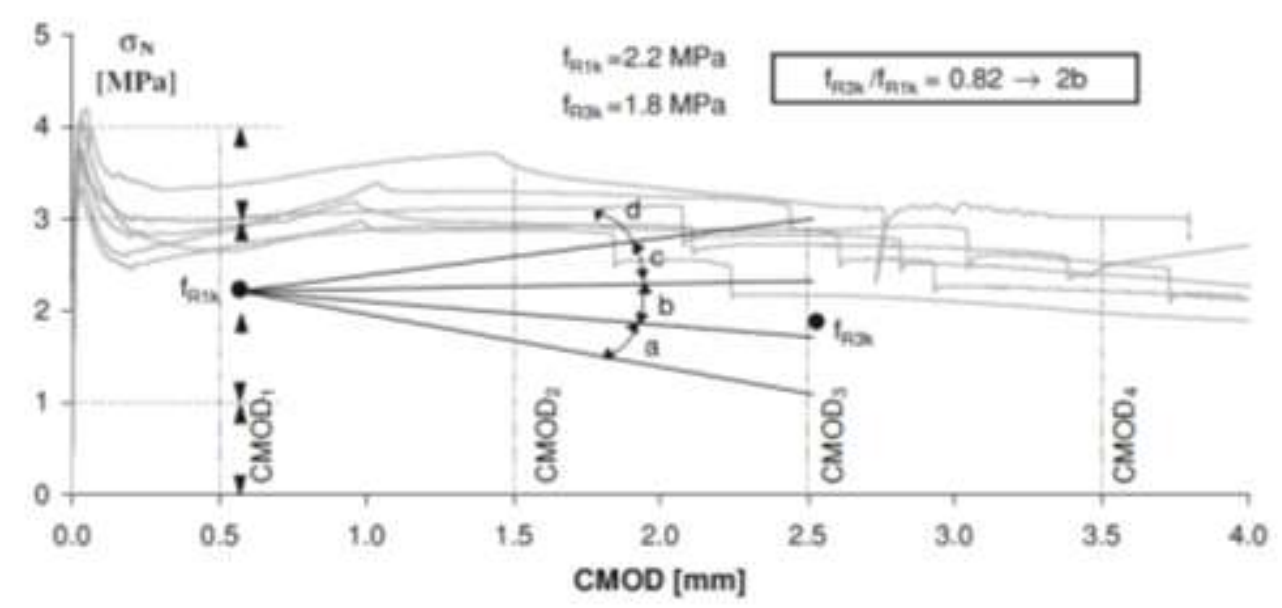

Fig.3. 5 Typical example of FRC classification [3]

The strength interval is defined by two subsequent numbers in the series:

$1.0,1.5,2.0,2.5,3.0,4.0,5.0,6.0,7.0,8.0, \ldots(\mathrm{MPa})$

while the letters $a, b, c, d$, e correspond to the residual strength ratios:

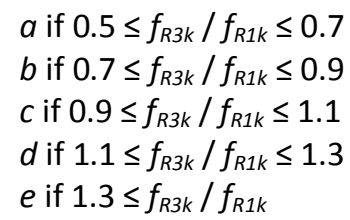

For structural use, the designer has to specify the residual strength class $f_{R 1 k}$ as well as the ratio $f_{R 3 k} / f_{R 1 k}$. Fiber reinforcement can substitute (also partially) conventional reinforcement (rebars) at Ultimate Limit State, if the following relationships are fulfilled:

$$
\begin{array}{r}
f_{R 1 k} / f_{L k}>0.4 \\
f_{R 3 k} / f_{R 1 k}>0.5
\end{array}
$$




\subsubsection{Constitutive laws}

A stress-crack opening law in uniaxial tension is defined for the post-cracking behavior of FRC. The rigid-plastic model takes the static equivalence into account, as shown in Fig. 3.6, i.e. $f_{\text {Ftu }}$ results from the assumption that the whole compressive force is concentrated in the top fiber of the section:

$$
M_{u}=\frac{f_{R 3} b h_{s p}^{2}}{6}=\frac{f_{F t u} b h_{s p}^{2}}{2}
$$

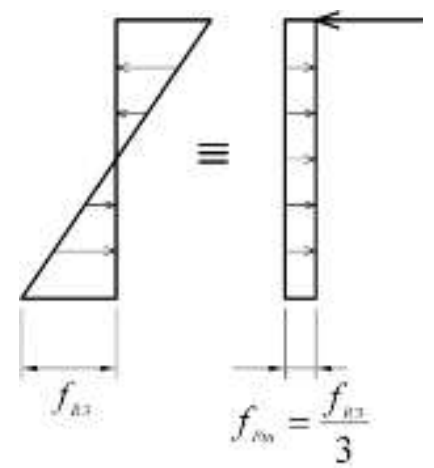

Fig.3. 6 Simplified model adopted to compute the ultimate tensile strength in uniaxial tension $f_{F t u}$ by means of the residual nominal bending strength $f_{R 3}$ [2]

Two simplified stress-crack opening constitutive laws may be deduced from the bending test results: a plastic rigid behavior, or a linear post-cracking behavior (hardening or softening), as schematically shown in Fig. 3.7, where $f_{\text {Fts }}$ represents the residual strength significant for serviceability crack openings, while $f_{\text {Ftu }}$ represents the residual strength significant for Ultimate Limit States when assuming the rigid-plastic behavior (Fig.3.7-a), $f_{\text {Ftu }}$ equal to $f_{R 3} / 3$.

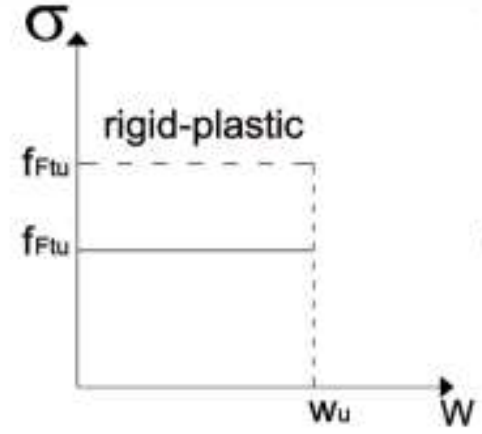

(a)

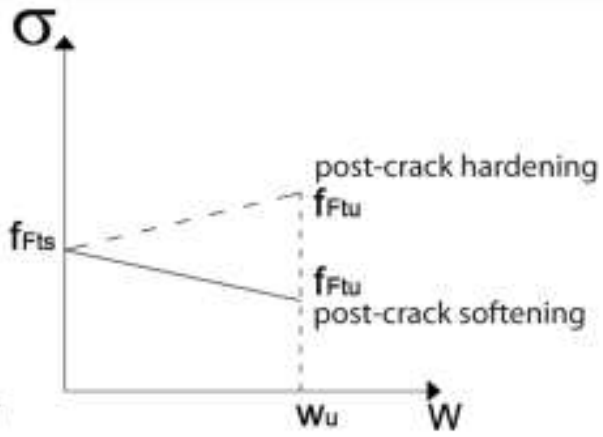

(b)

Fig.3. 7 Simplified post-cracking constitutive laws: stress-crack opening (continuous and dashed lines refer to softening and hardening post-cracking behavior respectively) [2] 
When considering softening materials, the definition of the stress-strain law is based on the identification of the crack width and on the corresponding structural characteristic length, $I_{c s}$, of the structural element. The strain can be assumed equal to:

$$
\varepsilon=w / I_{c s}
$$

In elements with conventional reinforcement (rebars), $I_{c s}$, may be evaluated as:

$$
I_{c s}=\min \left\{s_{r m}, y\right\}
$$

where:

$\boldsymbol{s}_{\boldsymbol{r m}}$ : mean distance value between cracks; $\boldsymbol{y}$ : distance between the neutral axis and the tensile side of the cross section, evaluated in the elastic cracked phase by neglecting the residual tensile strength of $\mathrm{FRC}$, and for a load configuration corresponding to the serviceability state of crack opening and crack spacing.

\subsubsection{Partial safety factors}

Design values for the post-cracking strength parameter at ULS, according to the MC2010 [2], can be determined as:

$$
\begin{aligned}
f_{\text {Ftsd }} & =f_{F t s k} / \gamma_{F} \\
f_{\text {Ftud }} & =f_{F t u k} / \gamma_{F}
\end{aligned}
$$

The recommended values for the partial safety factors are given in Table 3.1:

Table 3. 1 Partial Safety Factor [2]

\begin{tabular}{|c|c|}
\hline Material & Partial Safety factors \\
\hline FRC in compression & As plain concrete \\
\hline FRC in tension (limit of linearity) & As plain concrete \\
\hline $\begin{array}{c}\text { FRC in tension } \\
\text { (residual strength) }\end{array}$ & $\gamma_{F}=1.5$ \\
\hline
\end{tabular}

For serviceability limit states (SLS), the partial factors should be taken as 1.0. 


\subsection{Fibers effects on shear behavior}

\subsubsection{Fibers concept}

Even though structural behavior of FRC elements depends on the mechanical properties of the composite, fibers can be considered as reinforcement spread out all over the depth of a member [4].

\subsubsection{Effect of fibers on shear strength and stiffness}

The main effect of the steel fibers is related to the increase of the beam's shear strength and to the increase in the first-cracking load (corresponding to the first shear crack) [5].

The addition of steel fibers to the concrete allows for a substantial increase of the shear strength ( [5] - [32]). The effectiveness of fiber reinforcement to increase shear resistance, is dependent on several factor, including matrix properties, fiber properties (materials properties, aspect ratio, and shape), fiber content, and bond stress versus slip response of fibers [6].

Although the addition of stirrup reinforcement ( $30 \%$ greater than the minimum required in the $2011 \mathrm{ACl}$ Code) led to a 40\% increase in shear strength, the shear stress versus displacement response was still nearly linear up to failure [6].

In 1987, Narayanan et Al. [30] claimed that ultimate shear strength increased in higher rates when higher values of fiber aspect ratio were used but, using higher fiber content resulted in little improvement in shear strengths. On the other hand, other Authors claimed the opposite. In fact, Tan et Al. [28] found that the shear strength of concrete beams could be increased significantly by incorporating small quantities of steel fibers; Lim et Al. ( [22], [23]) said that the addition of fiber reinforcement increase shear capacity greatly and, Conforti et Al. [14] found that fibers, even in relatively low amount, greatly influence the shear behavior of beams by altering the collapse form shear to flexure, with enhanced bearing capacity and ductility.

Other Authors were beyond linking increases in shear capacity with the volume of fibers, thus the maximum shear capacity of reinforced SCC slender beams without stirrups can be significantly enhanced with fiber addition. When using a volume fraction of $1 \%$ of steel fibers, increases in shear capacity up to $128 \%$ with respect to the reference beams were 
achieved [33]; in shear tests on FRC specimens, for all fiber types, an almost linear increase in shear strength of the beam with increasing fiber volume fraction was noted. Furthermore, fiber reinforcement enhanced the shear capacity of RC beams, but a fiber volume fraction of $1 \%$ is seen as optimal; in fact, no benefits were noted when the fiber volume fraction was increase beyond $1 \%$ [18]. The increase of the shear strength was about $100 \%$ when the fiber content was increased from 0 to $2 \%$ [23]; the use of hooked steel fibers in a volume fraction greater than $0.75 \%$ led to an enhanced inclined cracking pattern (multiple cracks) and improved shear strength in beams (without stirrup reinforcement), of $0.33 \cdot \mathrm{Vf}_{\mathrm{c}}(\mathrm{MPa})$. The increase in shear strength associated with an increase in fiber content beyond $1 \%$ by volume, however, was relatively small [6]; the maximum increase of shear strength at first crack in fully prestressed beams due to the addition of fibers was 5.0, 10.0 and $20 \%$ for the volume fraction of fiber of $0.5,1.0$, and $1.5 \%$, respectively. In the case of partially prestressed beam specimens, the increase of peak load due to addition of fibers was found to be 12 and $17.5 \%$ for partially prestressed beams with fiber content of 1.0 and 1.5\%, respectively [7]. The addition of fiber reinforcement in full depth for partially prestressed concrete beams improved the shearresisting capacity by approximately 11 to $20 \%$ when compared with the corresponding control beams not containing fibers. The maximum benefit due to the addition of fibers was observed for high-strength prestressed concrete beams. The increase in the shear capacity due to the presence of fiber reinforcement only in the web portion, when compared with the control beams, was found to be 6,9 , and $14 \%$ for normal, moderately high strength, and high strength concrete beams, respectively. Hence, the addition of fibers only in the web portion of the T-beam is recommended for enhancing the shear capacity of the prestressed concrete beam [34].

As far as the beam stiffness is concerned, the presence of fiber reinforcement delays and controls dowel cracking and, thereby, improves the stiffness and deformation characteristics of the dowel crack zone. The first shear-crack load forms and ultimate dowel strength are both found to increase almost linearly with the flexural strength of the composite. The inclusion of steel fibers in concrete deep beams resulted in enhanced stiffness and increased spall resistance at all stages of loading up to failure; fibers also reduced crack width [12].

\subsubsection{Effect of fibers on ductility (postcracking response)}

Fibers increase ductility in FRC beams versus beams without fibers ( [5], [7], [15], [17], [19] - [21], [30], [35] - [42]); also, the increase in ductility of concrete in compression due to fiber addition depends, among other factors, on the amount, geometry, orientation and 
strength of the steel fibers and the bond between fibers and concrete [9]. The increase in ductility is due to the increase in post-cracking strength because of fibers addition ( [17], [19], [43], [44]). In order to get a ductile post-peak behavior, fibers having a higher aspect ratio are required [21].

Experimental results show that SFRC, beams $\left(V_{f}=0.64 \%\right)$ without stirrups show a similar, or even better, post-cracking behavior than the beams with the minimum amount of transverse reinforcement [45].

\subsubsection{Effect of fibers on shear cracking}

The fiber reinforcement is very effective in containing the dowel crack growth and reducing the strain gradient along the dowel crack. The main role to the fiber reinforcement is that of a crack arrester ( [20], [30]). Fibers control the propagation and widening of the dowel $\operatorname{crack}$ ( [6], [8], [11], [12], [19], [20], [35], [42], [46] - [48]). The reduction of crack spacing and widths increases aggregate interlock [6]. Steel fibers provide a better durability to the structure because crack openings are smaller [19].

Smaller crack widths were detected for beams with higher concrete compressive strength due to denser concrete matrix, better bond to the fibers and also due to the load transfer across the cracks [5]. The stabilization of the action of the fibers takes place at ULS with values close to a crack width of $1.2-1.4 \mathrm{~mm}$ [49]. The role of fibers was not confined to control of cracking in the dowel zone and enhancing the stability of the compression zone [20].

\subsubsection{Effect of fibers on yielding of longitudinal bars}

The presence of fibers increases the load level at which the longitudinal reinforcement yields [5]; therefore, the load bearing capacity of tensile members and bending beams increase with FRC [9].

\subsubsection{Effect of fibers on cracking distribution}

Addition of steel fibers improves the cracking behavior of concrete beams reinforced with longitudinal tension bars [11].

Increased fiber volumes allow the development of multiple cracking, distributed and complex in the critical area under shear ( [5], [10], [14], [31], [32], [36] - [39], [41], [47], [48], [50]) avoiding delaying the localization of a major shear-critical crack responsible of 
the early brittle collapse ( [4], [14], [15], [22]). This progressing cracking process indicates a redistribution of stresses beyond cracking ( [13], [46]) giving visible warning prior the structure collapse ( [14], [48]) and fibers also help to control cracking ( [20], [35]).

Steel fibers became effective after formation of shear crack and resist the principal tensile stressed until the complete pullout or yielding of fibers occurs at one critical crack [13]. After the occurrence of the first crack, fibers start working, carry the entire applied load and tend to avoid the localization of microcracks in macrocracks. Consequently, the postcracking strength increases and a considerable ductility can be achieved [17]. This may be attributed to the ability of the fibers to bridge and carry the stresses crossing the crack faces [21].

\subsubsection{Effect of fibers on rotation capacity}

The specimens without fibers had a larger rotation capacity than those with fibers. This decrease in deformation capacity is explained by localization of the deformations in one large crack in case of the SCSFRC specimens due to the higher bond between rebars and concrete. The maximum moment was approximately $10 \%$ larger in FRC beams than in those without fibers [9]. Fibers control rotation due to shear loads [20].

\subsubsection{Effect of fibers on tensile properties}

Steel fibers can greatly enhance the tensile properties of concrete ( [22], [35]) improve resistance to cracking [22] and increase the pullout resistance of tension reinforcement [35].

The ultimate tensile strength increases by the steel fibers [51]. So, for a beam loaded in shear, the characteristic diagonal shear cracks propagate through the beam as the concrete tensile strength is exceeded [21].

Fiber reinforcement enhances shear resistance by transferring tensile stresses across diagonal cracks [6]. Fibers improve the resistance of tensile cracks both in the web and in the tension zone [46].

On Shear Behavior of structural elements made of steel fiber reinforced concrete - PhD thesis 


\subsubsection{Effect of fibers on crack spacing}

Fibers reduce crack spacing ( [13], [42]) and consequently FRC beams have more stiffness and load carrying capacity ( [6], [8] - [12]). The reduction of crack spacing and widths increases aggregate interlock [6].

The crack spacing reduces in FRC beams; this is attributable to a more uniform redistribution of stresses in the FRC beams as compared to beams without fiber reinforcement [30].

The spacing between diagonal cracks was larger for beams with a larger effective depth. The average horizontal spacing between cracks, however, was approximately $0.4 \cdot d$, regardless of the beam depth [6].

\subsubsection{Effect of fibers on tension stiffening}

Tension stiffening reflects the ability of concrete to carry tension between cracks, which increase member stiffness before the reinforcement yields [52]. Tension stiffening in FRC depends on both, the behavior between cracks and, at the cracks [53].

While plain concrete is assumed to carry tension between the cracks only, FRC is able to carry significant tensile forces at a crack; in addition it stiffens the behavior between cracks. This effectively increases tension stiffening [54], improves crack control and permits use of higher-strength reinforcing steels while still maintaining control of crack widths [55] provides an additional strength after yielding of the reinforcement [56], depending on the type and dosage of fibers used. Results from tension-stiffening tests can be used to determine the average tensile strength carried by the cracked FRC, representing behavior between and at the cracks of a reinforced concrete member [57].

\subsubsection{Effect of fibers on characteristic length $\left(L_{r}\right)$}

De Montaignac et Al. [58] have recently published a paper related to the determination of the characteristic length. The Authors define the characteristic length $\left(\boldsymbol{L}_{r}\right)$ as the key parameter linking strains $(\boldsymbol{\varepsilon})$ and crack opening $(\boldsymbol{w})$. In an analytical model, $\boldsymbol{L}_{\boldsymbol{r}}$ is an indication of the crack spacing considered in calculations. No consensus has yet been achieved to determine $\boldsymbol{L}_{\boldsymbol{r}}$. This can be explained by the fact that $\boldsymbol{L}_{\boldsymbol{r}}$ is influenced by several parameters: type and volume of fibers, matrix strength, cross-section geometry, presence of conventional reinforcement (longitudinal or transverse), load level (service, ultimate), etc, 
At low load level, the crack spacing is small, especially if the structural member presents a hardening behavior or contains conventional reinforcement.

At high load level, the member behavior is governed by fewer, more widely spaced cracks before crack localization takes place. Some cracks may therefore close, transferring their accumulated openings to the governing cracks. This suggests the need to select different $L_{r}$ values for describing the overall behavior of structural members [58].

The influence of $L_{r}$ on a member response is illustrated in Fig.3.8, where $L_{r}$ varies from $h / 4$ to $\mathbf{2} \boldsymbol{h}$ for a $150 \mathrm{~mm}$ deep and $400 \mathrm{~mm}$ wide SFRC beam. The parametric analysis shows that increasing $L_{r}$ reduces the bending strength and thus estimates wider cracks for a given bending moment. Therefore, it is more conservative to adopt a larger $\boldsymbol{L}_{\boldsymbol{r}}$ for predicting crack width in service conditions or for predicting ultimate strength [58].

For SFRC members, some researchers have proposed the utilization of a constant value for $L_{r}$ (Table 3.2) while other researchers suggest that this value should vary depending on load.

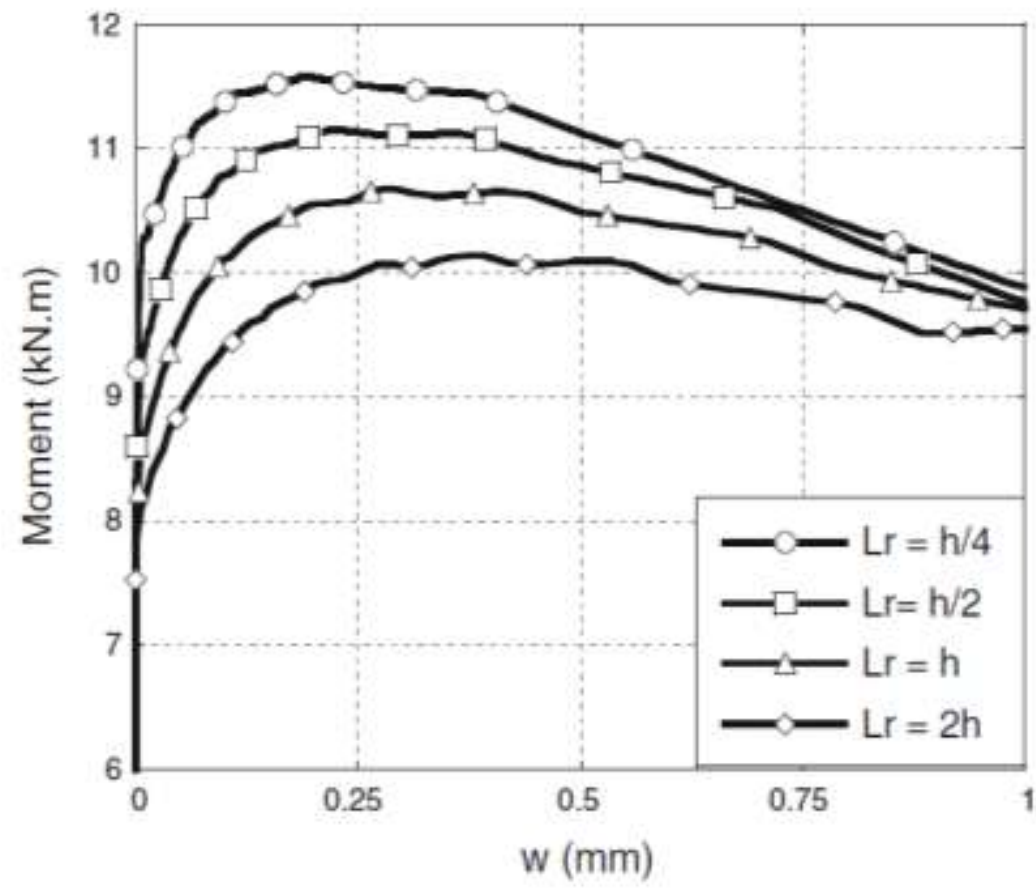

Fig.3. 8 Influence of $L_{r}$ on the flexural behavior of SFRC beam [58] 
Table 3. 2 Proposed values for $L_{r}$ [58]

\begin{tabular}{|c|c|c|c|}
\hline \multirow[t]{2}{*}{ Reinforcement } & \multicolumn{2}{|c|}{$\begin{array}{l}\text { Past studies for deflection, average curvature } \\
\text { and crack width }\end{array}$} & \multirow{2}{*}{$\begin{array}{l}\text { This study for } \\
\text { maximum crack } \\
\text { width }\end{array}$} \\
\hline & Rule & \begin{tabular}{|l|} 
References \\
\end{tabular} & \\
\hline \multirow[t]{4}{*}{ SFRC } & $h / 2$ & $\begin{array}{l}\text { RILEM [59]; Massicotte [60]; } \\
\text { Ultkjaer et al. [61]; Kooiman } \\
\text { [62]; Iyengar et al. [63]; } \\
\text { Pedersen [64]. }\end{array}$ & \multirow[t]{4}{*}{$2 h$} \\
\hline & $2 h / 3$ & AFGC [65] & \\
\hline & $h$ & fib [2]; CNR [66] & \\
\hline & $2 h$ & Strack [67] & \\
\hline \multirow{2}{*}{ SFRC and reinforcing bars } & $\operatorname{Min}\left[s_{m} ; h / 2\right]^{a}$ & Massicotte [60] & \multirow[t]{2}{*}{$\operatorname{Min}\left[s_{m} ; h\right]^{a}$} \\
\hline & $\operatorname{Min}\left[s_{m} ; y\right]^{a}$ & fib [2]; CNR [66] & \\
\hline
\end{tabular}

${ }^{a} s_{m}$ is estimated with the Eurocode 2 [68]

From this investigation, De Montaignac et Al. [58] concluded that:

- Incorporating fibers at a high dosage (0.75-1.25\% by volume) into concrete significantly improves the structural behavior of SFRC beams; this provides hardening behavior in bending, considerably limits crack opening in service conditions and gives a ductile behavior for ultimate conditions.

- The utilization of a single value of $\boldsymbol{L}_{r}$ for all loading stages in a sectional analysis of SFRC members yields good correlation with experimental values if the structural behavior is governed by the maximum crack width.

- $\quad$ Selecting $L_{r}$ equal to $2 \mathrm{~h}$ for SFRC members without conventional reinforcement and $\boldsymbol{L}_{\boldsymbol{r}}$ equal to the minimum of $\boldsymbol{h}$ and the average crack spacing $\boldsymbol{s}_{\boldsymbol{m}}$ for members with conventional reinforcement is recommended.

\subsection{Steel fibers as shear reinforcement}

In the literature, it is shown that FRC can substitute, at least partially, transverse reinforcement. For this reason, some Authors emphasize the usefulness of fibers for industrial applications.

\subsubsection{Fibers as minimum shear reinforcement}

The minimum transverse reinforcement requirement can be met by using fibers, in sufficient amount and with minimum performance in terms of toughness ( [4], [48], [69]).

So, fibers can effectively replace the minimum amount of transverse reinforcement ( [38], [48]) satisfying the minimum shear reinforcement criteria in $\mathrm{ACl} 318-11$ [70]. So, several 
laboratory experiments have demonstrated the effectiveness of steel fibers in substituting the minimum shear reinforcement for beams required by Codes, particularly in precast high-performance concrete structures [71].

According to $\mathrm{ACl} 318-11$ [70] until further data become available, a minimum $V_{f}$ of $0.75 \%$ is recommended ([6], [72]). On the other hand, the beams reinforced only with steel fibers $\left(V_{f}=0.64 \%\right)$ show a similar, or even better, post-cracking behavior than the beams with the minimum amount of transverse reinforcement [45].

According to the fib Model Code 2010 [2], it is possible to prevent the use of the minimum amount of conventional shear reinforcement (stirrups) if the following condition is fulfilled:

$$
f_{\text {Ftuk }} \geq \frac{\sqrt{f_{c k}}}{20}
$$

Where $f_{\text {Ftuk }}(\mathrm{MPa})$ is the characteristic value of the ultimate residual tensile strength for FRC, by considering $w_{u}=1.5 \mathrm{~mm}$. This allows limiting the development and the diffusion of the inclined cracking and, as a consequence, can ensure sufficient member ductility.

\subsubsection{Fibers totally replacing stirrups}

Fibers clearly acted as shear reinforcement ( [16], [19], [20], [73]) and they can be used to replace stirrups in beams without reduction of the moment capacity [74]; in precast pretensioned beams [75], the use of FRC can significantly reduce production costs [45] since handling and placing of reinforcement [71] are no longer required.

From a practical point of view, steel fibers can successfully replace the shear reinforcement, but it is senseless to use steel fibers as a complementary reinforcement of longitudinal bars [16].

\subsubsection{Fibers partially replacing stirrups}

Shear reinforcement may be, partially or totally, effectively substituted with steel fibers ( [34], [71]). Anyway, the use of fiber reinforcement can reduce the amount of shear stirrups required ( [22], [23]), even though this substitution may not be attractive from a practical point of view.

On Shear Behavior of structural elements made of steel fiber reinforced concrete - PhD thesis 


\subsubsection{Shear crack pattern in FRC elements}

The pattern of cracks developed in fiber reinforced concrete beams subjected to shear was found to be generally similar to those observed in the corresponding reinforced concrete beams with minimum amount of stirrups [30], when FRC satisfies the minimum performance requirements [74], reaching the maximum flexure capacity [37]; therefore, fibers represent an effective shear reinforcement [20].

\subsection{Failures modes.}

\subsubsection{Can fibers alter the collapse from shear to flexure?}

The inclusion of fibers can modify the brittle shear mechanism into a ductile flexural mechanism, thus allowing a larger dissipation of energy [47] and a significant increase of ductility and load-bearing capacity ( [14], [71]). Therefore catastrophic failures are avoided when using FRC.

This change of shear failure due to fibers was analyzed by different Authors ( [14], [20], [25], [30], [43], [47], [71], [74], [76]).

Some Authors assert this change in failure mode type, depending on the fiber content:

- $\quad$ Normal-strength concrete beams changed the failure mode form shear to flexure with a volume fraction of $2 \%$ of fibers, while high-strength concrete beams were subjected to a bending failure (no shear failure) with a volume fraction of about $1.5 \%$ of fibers. Furthermore, normal-strength concrete involved a large increase of shear resistance up to $1 \%$ of fibers, whereas most increase occurred at $0.5 \%$ of fibers in high-strength concrete [77]. However, as mentioned above, the key-parameter is FRC performance expressed in terms of post-cracking residual strength.

- $\quad$ The mode of failure changed from shear to flexure when the volume fraction of steel fibers used exceeds a certain amount, namely about 1\% ( [22], [23]).

- $\quad$ At least $1 \%$ fiber by volume is needed to avoid shear failure and to change the mode of failure from shear to flexure. Beyond a volume fraction of $1 \%$, little improvement in shear strength was noted [30].

- In T-beams and rectangular beams with $1.95 \%$ tension steel, $0.8 \%$ fiber volume produced flexural failure. In T-beams with 2 to $4 \%$ of tension steel and a fiber volume of 0.8 to $1.2 \%$, the shear strength was increased by about $80 \%$ with respect to a beam without fibers [20]. 
According to some Authors, due to the high flexural capacity of the beams, steel fibers alone could not change the modes of failure to the flexural type; while the use of steel fibers in combination with stirrups can change the mode of failure to shear-flexure type ( [78], [79]).

\subsubsection{Ductile failure mode due to fibers}

Steel fibers can make the failure mode more ductile [7] especially in high-strength concrete beams due to the material brittleness ( [13], [17]). As a result, the structural performance of high-strength concrete can be maximized [80].

In shear critical beams having stirrups, with or without fibers, or in beams having fibers only in the shear span but without stirrups, the mode of failure was altered from one of brittle shear to one of ductile flexure in both fully and partially prestressed beams [7].

The presence of steel fibers transformed the mode of failure of the tested beams into a more ductile one, especially for larger values of $a / d$ [29].

\subsubsection{Influence of fibers in compression zone}

While the primary flexure-shear crack in FRC beam has an angle close to that of PC beams, it deviated from the original path much earlier than the one in PC beams. This is due to the fact that higher stresses were required for the crack propagation in FRC beam. This premature deviation of primary flexure-shear crack led to a much larger compression zone in FRC beam, moving the arch action as the primary shear transfer mechanism. The larger compression zone, together with the higher compressive strains at failure of FRC materials ( [81], [82]), led to a concrete arch with greater strength and ductility under compression. In some cases, it can be clearly seen that shear failure was not caused by the primary flexure-shear crack. Contrary to PC beam, it was found that FRC beam exhibited much ductile behavior at the crushed compression zone [83].

The addition of steel fibers did not prevent longitudinal crack formation in the compressive zone in case of compressive failure, but it prevented concrete spalling [9].

On Shear Behavior of structural elements made of steel fiber reinforced concrete-PhD thesis 


\subsection{Fibers influence on size effect}

\subsubsection{Influence of depth in shear strength}

Size effect seems to play a decisive role for the shear capacity. In fact, the larger the structure, the greater is the energy release and the more fracture energy is needed to avoid a sudden failure [21].

The reduction in crack spacing due to the presence of fibers indicates that the use of fiber reinforcement could potentially lead to a reduction, or even elimination, of the shear size effect in beams without stirrup reinforcement, whose shear strength is known to decrease as the overall beam depth increases [6]. In fact, in FRC shear cracks are more controlled and stabilized for crescent loads and the ultimate load tends to reach the ultimate flexure load [15].

By increasing the size of the structural member, it increases the minimum quantity of fibers to be used as minimum reinforcement, contrary to what happens in the case of the classical minimum reinforcement (stirrups), in which size effect is not observed [84]. Fig.3.9, referring results of a numerical study with Vector2, evidence that the decreasing of the ultimate shear stress is less pronounced with increasing toughness provided by fibers. If fibers are added in sufficient quantity and with adequate toughness characteristics, the size effect could disappear completely obtaining ductile collapses (see details in [48]). Note that the plot shows a vertical line for an effective depth of $1 \mathrm{~m}$. In many cases, in fact, Codes require, from that depth on, the addition of distributed skin reinforcement in the two directions, basically for crack control. This requirement, as well as the one of the minimum shear reinforcement, can be met by using a relatively low amount of fibers, according to Fig.3.9 [48]. 


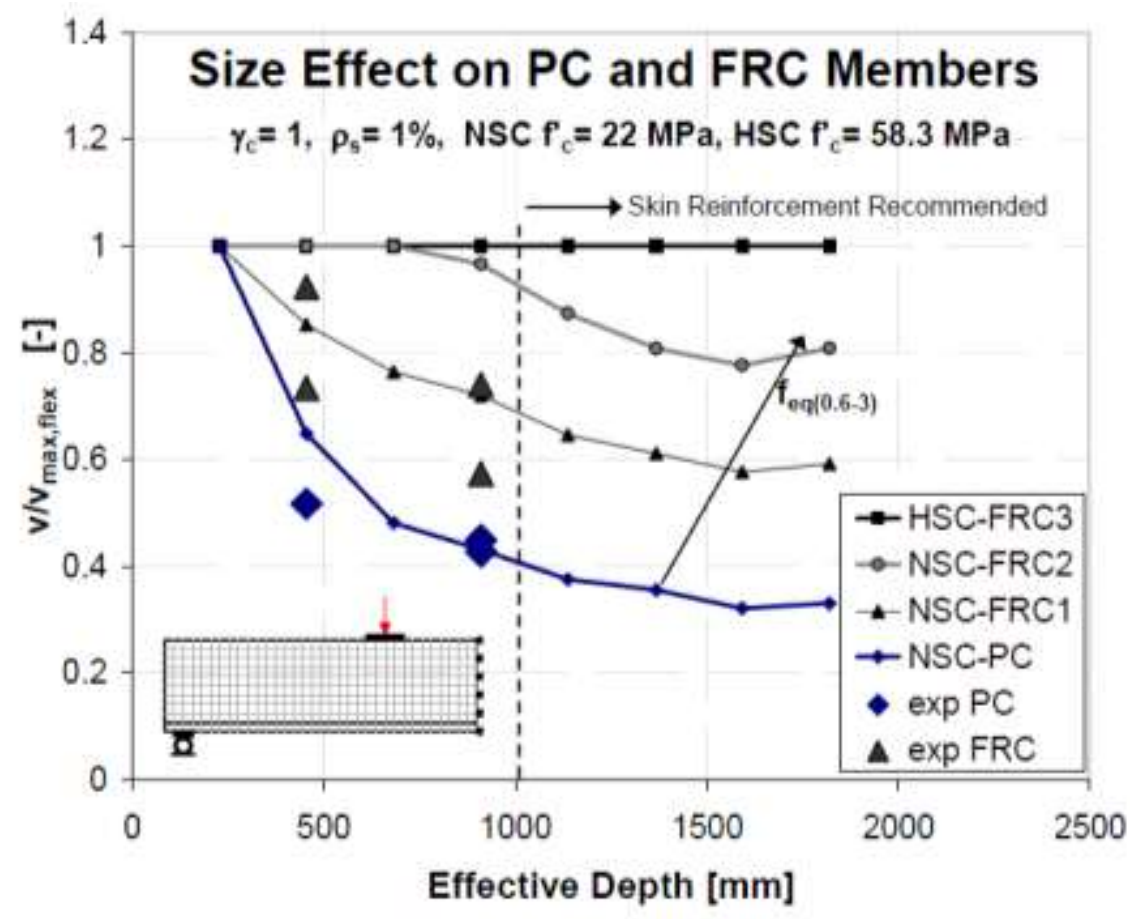

Fig.3. 9 Size effect in FRC beams without stirrups. Lines mean numerical analysis results and single points are experimental results [48]

Related to the fiber type, longer fibers, which are better anchored to the concrete, are preferred when the beam size increases. This allows carrying the residual for longer crack openings.

In the particular case of test carried out for Gustafsson \& Noghabai [21], it could be noticed that the failures of the smaller beams were considerably more ductile as compared to the larger beams. An indication of the difference in brittleness is given by the final cracks patterns. Some pictures of the beams with mixed fibers, S-MIX, M-MIX and LMIX are shown in Fig.3.10. The large number of visible diagonal cracks on the smallest beam, S-MIX, gives an indication of the failure ductility of this beam. On the other hand, for the largest beam, L-MIX, only one large diagonal crack is visible. This means that the residual strength of the fiber concrete was not sufficient to resist the large impulse load that was released as the crack started to develop. As a consequence, the beam failed in a considerably more brittle fashion [21].

On Shear Behavior of structural elements made of steel fiber reinforced concrete-PhD thesis 


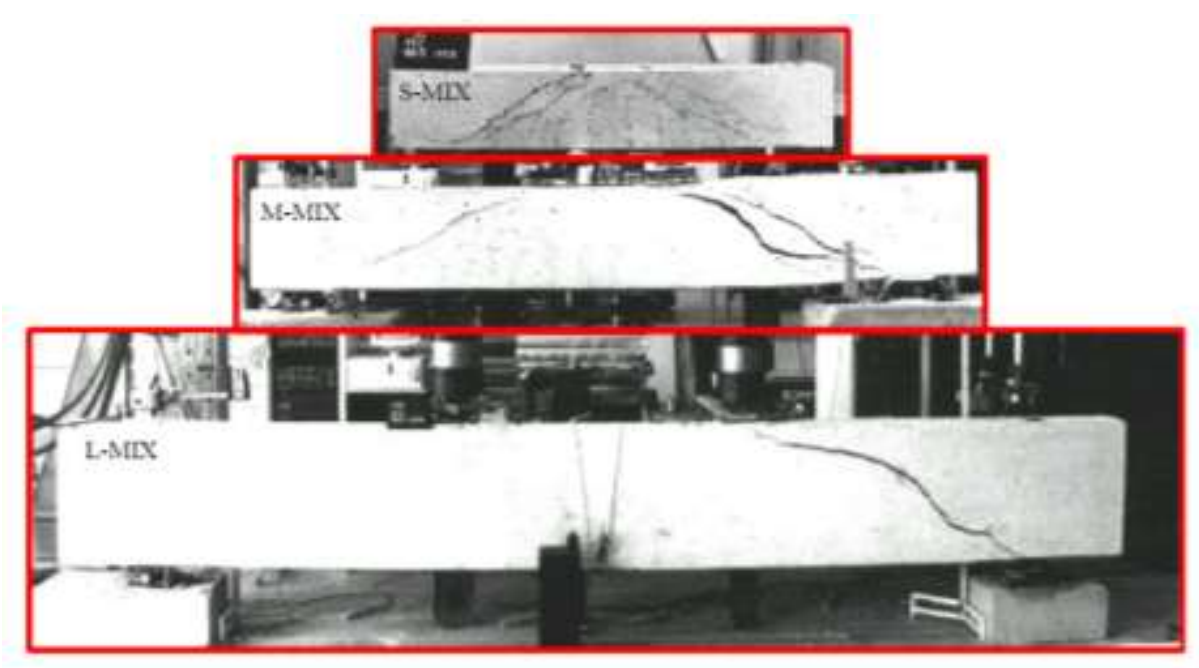

Fig.3. 10 A comparison between crack patterns of beams containing the mixed type of fibers, $S$ MIX, M-MIX-1 and L-MIX. Noticeable is that for the smallest beams there are an amount of diagonal cracks, whereas for the largest beam there is only one critical crack [21].

To define some basic fracture mechanical features, results from the uniaxial tensile test on S-MIX are shown in Figure 3.11. Up to the point where the tensile strength of the concrete is exceeded, the structure is elastically strained. When the tensile strength, $f_{c t}$, is exceeded a fracture zone is formed. At this stage all deformations are concentrated to this fracture zone while other parts of the structure are elastically unloaded. The size effect is due to the release of strain energy from the structure into the fracture zone, as the cracking zone extends. The larger the structure the greater is the energy release and the more fracture energy is needed to avoid a sudden failure. Earlier studies ( [85], [86]) have shown that the brittleness of a beam loaded in shear to some degree is proportional to the effective depth, $\boldsymbol{d}$. The larger the beam the greater amounts of strain energy is stored in the structure. When, eventually, the tensile strength is exceeded and a critical diagonal crack forms (Fig.3.11), the residual tensile stresses acting across the crack have to resist the impulse load that is connected to the energy release. The requirements on the tensile properties of the fibers concrete will increases as the beam size increases [21]. 


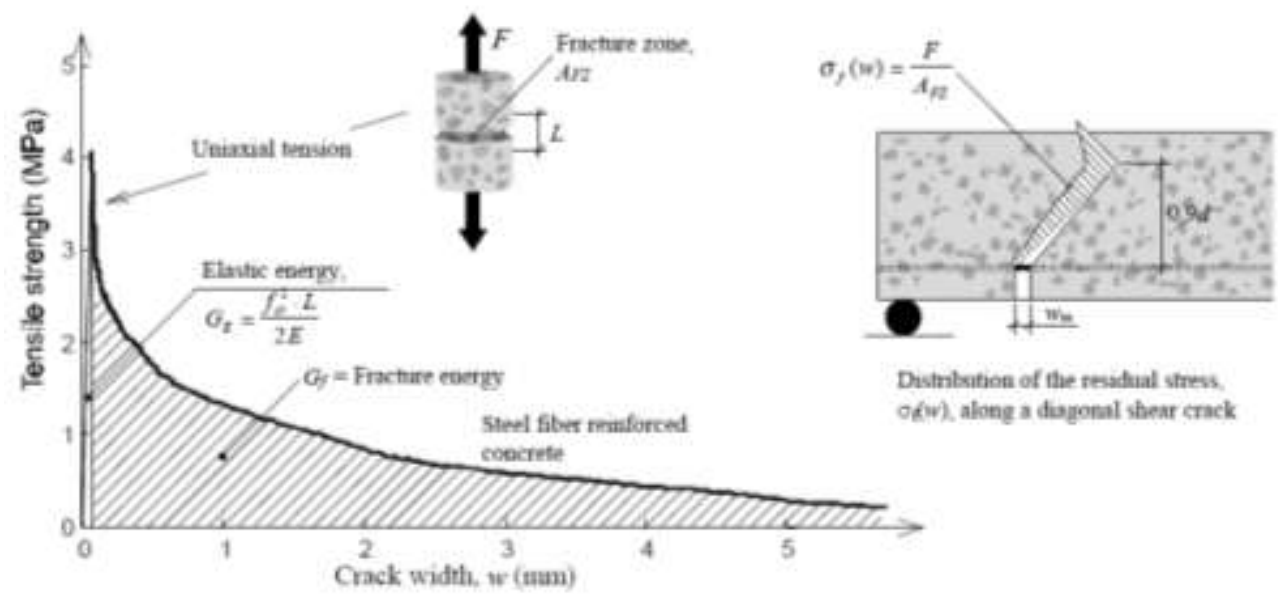

Fig.3. 11 Comparison of stress-strain relationship for plain and fiber reinforced concrete in tension. Also, some fracture mechanical properties are shown. $G_{E}$ equals the stored energy per unit area and $G_{f}$ is the fracture energy per unit area [21]

\subsubsection{Influence of depth on the shear crack width}

The inclusion of steel fibers in concrete deep beams resulted in enhanced stiffness and increased spall resistance at all stages of loading up to failure, and reduced crack widths [12].

For small beams a shorter type of fibers may be sufficient, whereas for larger beams, fibers that are better anchored and have a higher strength are required. Also, the requirements on the tensile properties of the fiber concrete will increase as the beam size increases [21].

\subsection{Fibers influence on serviceability limit state (SLS) and durability}

Tension-stiffening effects are useful for assessing postcracking behavior at service loads [53].

Steel fibers improve the Serviceability Limit State and the structural durability, because post-crack stiffness increases with the formation of closer cracks with smaller crack width ( [9], [15], [19], [45]).

Smaller fibers seem more effective for the smaller crack widths expected in service conditions [20].

On Shear Behavior of structural elements made of steel fiber reinforced concrete - PhD thesis 


\subsection{Reduction of production cost}

In prefabrication, fibers introduction is particularly appealing for facilitating the industrialization of the production and introducing an improvement in the overall characteristics and durability of the products. The possibility of substituting traditional transverse reinforcement (stirrups) for steel fibers in precast elements can significantly reduce production costs due to the reduction of labor cost since the handling and placing of reinforcement is no longer required. Moreover, reinforcement savings are often possible with the use of FRC ([37], [45], [71]).

\subsection{Combination of steel fibers and stirrups}

The addition of fibers to conventional stirrups leads to the following effects:

Crack spacing: Development of more closely spaced cracks, suggesting that a smaller characteristic length $\left(\boldsymbol{L}_{r}\right)$ should be used [58].

Shear strength: Shear strength significantly increases ( [45], [78]). On the other hand, the use of steel fibers as a complementary reinforcement of longitudinal bars does not have a considerable effect in the shear strength ( [16], [26], [73]). Steel fibers improve the shear resisting mechanism of the concrete represented by the aggregate interlocking and dowel action and behave as an additional transverse reinforcement; consequently the stresses in the stirrups are reduced [8]. It was found that either the combinations of $75 \%$ of full conventional stirrups and $1 \%$ fiber volume content or $50 \%$ of full conventional stirrups and $2 \%$ fiber content may be good optimized combinations for shear ductility and strength [23].

Crack control: Major improvement in crack control was observed in the beams with both types of reinforcement ( [26], [77]).

Stresses in stirrups and fibers: The appearance of inclined cracks is retarded and, consequently, the stirrups are tensioned later. Fiber effectiveness is higher in beams with stirrups. The strain in the stirrups in SFRC beams was smaller [10]. On the other hand, in the presence of stirrups and fibers, a further reduction in the working stress of fibers was experimentally observed ( [10], [47], [76], [87] - [89]).

The use of fiber reinforcement can reduce the amount of stirrups required and a combination of fibers and stirrups may satisfy strength and ductility requirements [22]. 


\subsection{Shear models and Design Codes}

\subsubsection{Design Codes}

Nowadays, the current Design Codes for shear are basically, the RILEM approach and the MC2010. RILEM has evolved, having presented different versions up to the current formulation. Firstly, RILEM approaches used equivalent flexural tensile strengths up to the current version which uses residual flexural tensile strengths according to EN 14651.

\subsubsection{Previous versions of RILEM approach}

\subsection{Original RILEM design method}

The original RILEM design method ( [89], [90]) calculated the shear capacity $(V)$ as consisting of 3 separate contributions:

$$
V=V_{c}+V_{s}+V_{f}
$$

where:

$V_{c}=$ shear resistance of the member without shear reinforcement

$V_{s}=$ contribution of the shear reinforcement (stirrups and/or inclined bars)

$V_{f}=$ contribution of steel fiber shear reinforcement.

The first term, $V_{c}$, is calculated the same way as in EC2 defined as:

$$
V_{c}=0.12 \cdot \xi \cdot\left(100 \cdot \rho_{l} \cdot f_{c k}\right)^{1 / 3} b \cdot d
$$

With: $f_{c k}=$ characteristic cylinder compressive strength; $b=$ width of the beam; $d=$ effective depth of the beam; $A_{s}=$ tensile reinforcement in the critical section; $\xi=s i z e$ factor $=\sqrt{ }(200 / d) \leq 2 ; \rho_{l}=$ tensile reinforcement ratio $=\left(A_{s} /(b \cdot d)\right) \leq 0.02$.

The second term, $V_{s}$, was also identical as in EC2 (assuming $\theta=45^{\circ}$ ):

where:

$$
V_{s}=\frac{A_{s w}}{s} \cdot 0.9 \cdot d \cdot f_{y w d}
$$

$f_{y w d}=$ design value of the yield strength of the stirrups 


$$
\frac{\mathrm{A}_{\mathrm{sw}}}{\mathrm{s}}=\frac{\text { Area of stirrups }}{\text { spacing between stirrups }}
$$

The third term, which was the contribution of the steel fibers $\left(V_{f}\right)$, had been experimentally determined.

with:

$$
V_{f}=k_{f} \cdot k_{1} \cdot \tau_{f d} \cdot b \cdot d
$$

$k_{f}$ =factor for taking into account the contribution of the flanges in a T-section; $k_{f}=1$ for rectangular sections

$k_{1}$ =factor for taking into account the size effect of the member=(1600-d)/1000 $\geq 1$

$$
\tau_{f d}=0.12 \cdot f_{e q, 3}
$$

\subsection{RILEM2 design method}

In the next RILEM version (RILEM2 design method [89], [91]), Eq.3.10 and Eq.3.14 remained unchanged compared with previous method (showed in Section 3.11.1.1.1), but in Eq.3. 11 the factor 0.12 took into account the influence of the shear span to depth ratio. By taking this factor constant, it is possible to make shear a problem for section design rather than for structural design. The factor is replaced by its original formula:

$$
0.15 \sqrt[3]{3 \cdot d / a}
$$

Also, the average value of the cylinder compressive strength is used instead of the characteristic one. As results Eq.3. 11 becomes:

$$
V_{c}=0.15 \sqrt[3]{3 \cdot d / a} \cdot \xi \cdot\left(100 \cdot \rho_{l} \cdot f_{c m}\right)^{1 / 3} b \cdot d
$$

with: $a=$ shear span; $f_{c m}=$ average cylinder compressive strength.

In Eq.3. 12; only the design value of the yield strength of the stirrups $\left(f_{y w d}\right)$ is changed into the average yield strength $\left(f_{y w m}\right)$, giving:

$$
V_{s}=\frac{A_{s w}}{s} \cdot 0.9 \cdot d \cdot f_{y w m}
$$


In Eq.3. 15, the parameter 0.12 was originally derived from the following formula:

$$
\tau_{f d}=\frac{d / a \cdot 0.5 \cdot \frac{f_{e q k, 3}}{0.7}}{\gamma_{c}}
$$

where:

$f_{\text {eqk }, 3}=$ characteristic equivalent flexural tensile strength;

$0.5=$ factor to convert the flexural tensile strength into the axial tensile strength;

0.7=factor to convert the characteristic equivalent flexural tensile strength into the average equivalent flexural tensile strength;

$\nu_{c}=$ partial safety factor equal to 1.5 to obtain the design value of the shear resistance $\tau_{f d}$.

Since the average flexural tensile strength is used, the factor 0.7 may be omitted. Also the partial safety coefficient $\left(\nu_{c}\right)$ will be left out in order to get a "real ultimate steel fiber contribution". The Eq.3. 14 results:

$$
V_{f}=k_{f} \cdot k_{1} \cdot 0.5 \cdot d / a \cdot f_{e q m, 3} \cdot b \cdot d
$$

\subsection{Material parameter: equivalent or residual flexural tensile strength}

The main material parameters for the design of FRC elements in RILEM guidelines [90] were the equivalent flexural tensile strength $f_{e q, 2}$ and $f_{e q, 3}$. The related strain to the value $f_{\text {eq, } 3}$ was $10 \%$. These parameters are replaced in the final draft [59] by the residual flexural tensile strength $f_{R, i}$. The equivalent flexural tensile strength is derived from the contribution of the steel fibers to the energy absorption capacity (area under the loaddeflection curve) while the residual flexural tensile strength is derived from the load at a specified Crack Mouth Opening Displacement (CMOD) or midspan deflection (Fig.3.12). The value which is used for the ULS is $f_{R k, 4}(C M O D=3.5 \mathrm{~mm})$ which is related to the strain of $25 \%$ [38].

On Shear Behavior of structural elements made of steel fiber reinforced concrete-PhD thesis 

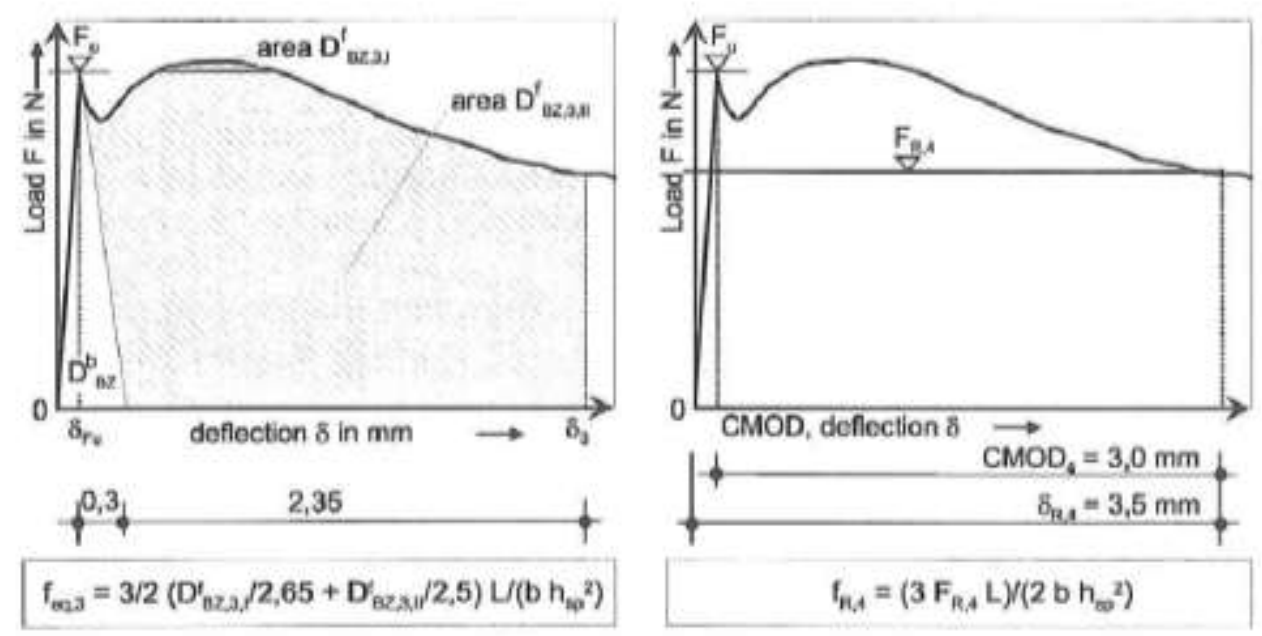

Fig.3. 12 Equivalent flexural tensile strength (left) and residual flexural tensile strength (right), [91]

Due to the change from the equivalent to the residual flexural tensile strength, it might be necessary to tune the design formulas. The relation between $f_{e q, I}$ and $f_{R, 1}$ for the fibers used within the Brite/Euram project is shown in Fig.3.13. For shear design $f_{\text {eq,3 }}$ replaced by $f_{R 4}$, by considering a factor $1 / 0.87$.

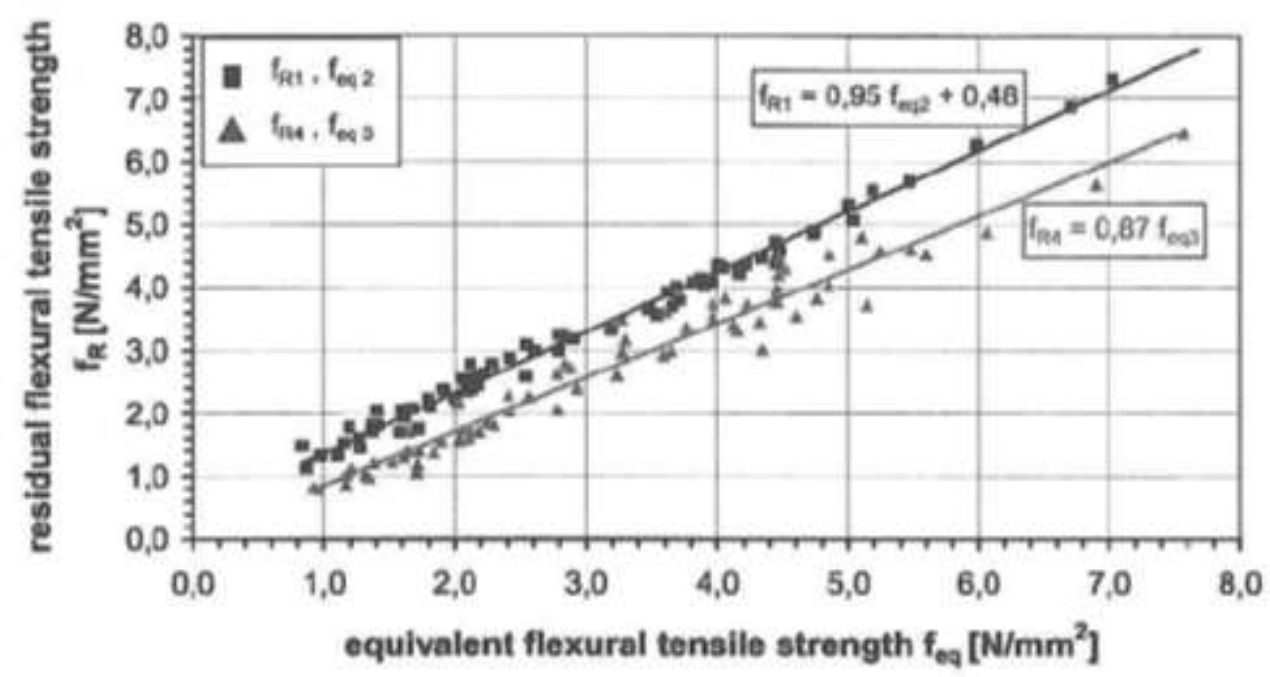

Fig.3. 13 Relation between equivalent flexural tensile strength and residual flexural tensile strength for the fibers used within the Brite/Euram project ( [91], [92])

The relation shown in Fig.3.13 depends on the post-cracking behavior of the FRC. 


\subsubsection{RILEM Current version 2003}

The formulation to calculate shear strength in beams made with FRC according to the current version of RILEM (2003) [59] is:

$$
\begin{gathered}
V=V_{c}+V_{s}+V_{f} \\
V_{c}=\left[0.12 \cdot \xi \cdot\left(100 \cdot \rho_{l} \cdot f_{c k}\right)^{1 / 3}+0.15 \cdot \sigma_{c}\right] b \cdot d
\end{gathered}
$$

In the case of prestressing " $h$ " should be used instead of " $d$ " in formula (Eq.3. 22)

with: $\xi=\sqrt{\frac{200}{d}} \leq 2 ; \rho_{l}=\frac{A_{s}}{b d} \leq 0.02 ; \sigma_{c}=\frac{N_{S d}}{A_{c}} \leq 0.02$

The second term, $V_{s}$, is also identical as in Eurocode 2 (assuming $\theta=45$ )

$$
\begin{gathered}
V_{s}=\frac{A_{s w}}{s} \cdot 0.9 \cdot d \cdot f_{y w d}(1+\cot \alpha) \cdot \sin \alpha \\
V_{f}=0.7 \cdot k_{f} \cdot \xi \cdot \tau_{f d} \cdot b \cdot d
\end{gathered}
$$

with:

$$
\tau_{f d}=0.12 \cdot f_{R, 4}
$$

$\tau_{f d}=$ design value of the increase in shear strength due to steel fibers;

$k_{f}=$ factor for taking into account the contribution of the flanges in a T-section:

$k_{f}=1+n\left(\frac{h_{f}}{b_{w}}\right)\left(\frac{h_{f}}{d}\right) ; \quad k_{f} \leq 1.5 ; n=\frac{b_{f}-b_{w}}{h_{f}} \leq 3 ; n \leq \frac{3 b_{w}}{h_{f}}$

with:

$h_{f}=$ height of the flanges;

$b_{f}=$ width of the flanges;

$b_{w}=$ width of the web;

$\alpha=$ angle of the shear reinforcement in relation to the longitudinal axis (45 $\leq \alpha \leq 90 \circ)$;

$\theta=$ angle of the concrete struts in relation to the longitudinal axis.

On Shear Behavior of structural elements made of steel fiber reinforced concrete-PhD thesis 


\subsubsection{EHE-08, $14^{\text {th }}$ Appendix}

The $14^{\text {th }}$ Appendix: "Recommendations for the use of FRC" of the EHE-08 [93] includes all matters concerning the FRC. This Appendix is comprised of the following parts: bases of the project, structural analysis, technological materials properties, durability, calculation, execution and control of the FRC. The design shear resistance $\left(V_{u 2}\right)$ has the following structure:

$$
V_{u 2}=V_{c u}+V_{f u}+V_{s u}
$$

The design shear resistance attributed to concrete $\left(V_{c u}\right)$ and the design shear resistance provided by shear reinforcement $\left(V_{\text {su }}\right)$ are both calculated in the same manner of concrete without fibers.

The design shear resistance attributed to fibers $\left(V_{f u}\right)$ is calculated with a formulation based on RILEM approach. The only difference is the way to calculate the calculating value of the increased shear strength due to the fibers $\left(\tau_{f d}\right)$, taking the value in the EHE-08:

$$
\tau_{f d}=0.5 \cdot f_{c t R, d}
$$

with: $f_{c t R, d}=0.33 \cdot f_{R 3, d}$ if a rectangular calculation diagram is assumed.

So, finally, the design shear resistance attributed to fibers $\left(V_{f u}\right)$ is calculated with the following expression:

$$
V_{f u}=0.7 \cdot \xi \cdot \tau_{f d} \cdot b_{0} \cdot d
$$

where: $\boldsymbol{\xi}$ factor that takes into account the size effect: $\xi=1+\sqrt{ }(200 / d) \leq 2.0$; $\boldsymbol{b}_{0}$ web width and $\boldsymbol{d}$ effective depth.

\subsubsection{MC2010 formulation for FRC}

3.10.1.4.1 Shear formulation for FRC according to the First Complete Draft of MC2010

Since FRC is a concrete having an enhanced toughness, the fiber contribution should be included within the concrete contribution (and not as a separate fiber shear contribution). That conclusion is based on the experiments and on the numerical evidence, which demonstrates the ability of simulating FRC structures by just adopting a proper tension softening model [71]. So, an equation for shear strength of FRC without transverse 
reinforcement (Minelli's formula [94]) was proposed and then, it was incorporated in the first complete draft of the Model Code 2010 [2]. It includes the shear contribution of fibers as an enhancement of the concrete contribution by modifying the longitudinal reinforcement ratio considered by EC2. As it increases, the longitudinal reinforcement limits the growth of shear-critical crack, allowing a greater transfer of stresses (whether tensile or shear). The proposed equation is based on FRC performance (residual postcracking strength), which is the more significant index for FRC structural design. It can be easily applied and transferred into practice [69].

The formula of MC2010 for FRC is based on the Minelli's formula [94]:

$$
V_{c}=\left[\frac{0.18}{\gamma_{c}} \xi \cdot\left(100 \rho_{l} \cdot\left(1+7.5 \cdot \frac{f_{F t u k}}{f_{c t k}}\right) \cdot f_{c k}\right)^{1 / 3}+0.15 \sigma_{c p}\right] b_{w} d
$$

where:

$\gamma_{c}$ is the partial safety factor for the concrete without fibers;

$\xi$ is a factor that takes into account the size effect and it is equal to: $\xi=\sqrt{\frac{200}{d}} \leq 2$;

$d(\mathrm{~mm})$ is the effective depth of the cross-section;

$\rho_{l}$ is the reinforcement ratio for longitudinal reinforcement equal to: $\rho_{l}=\frac{A_{s}}{b d} \leq 0.02$;

$A_{s l}\left(\mathrm{~mm}^{2}\right)$ is the cross-sectional area of the reinforcement which extends $\geq I_{b d}+d$ beyond the considered section;

$f_{\text {Ftuk }}(\mathrm{MPa})$ is the characteristic value of the ultimate residual tensile strength for FRC, by considering $w_{u}=1.5 \mathrm{~mm}$;

$f_{c t k}(\mathrm{MPa})$ is the characteristic value of the tensile strength for the concrete matrix;

$f_{c k}(\mathrm{MPa})$ is the characteristic value of cylindrical compressive strength;

$\sigma_{c p}=N_{E d} / A_{c}<0.2 \cdot f_{c d}(\mathrm{MPa})$ is the average stress acting on the concrete cross-section, $A_{c}$ $\left(\mathrm{mm}^{2}\right)$, for an axial force $N_{E d}(\mathrm{~N})$, due to loading or prestressing actions $\left(N_{E d}>0\right.$ for compression);

$b_{w}(\mathrm{~mm})$ is the smallest width of the cross-section in the tensile area. 
The shear resistance, $V_{R d, F}$, is assumed to be not smaller than the minimum value, $V_{R d, F m i n}$ defined as:

$$
V_{R d, F \min }=\left(v_{\min }+0.15 \cdot \sigma_{c p}\right) \cdot b_{w} \cdot d
$$

where: $v_{\min }=0.035 \cdot k^{3 / 2} \cdot f_{c k}^{1 / 2}$

3.10.1.4.2 Shear formulation for FRC according to the recent Draft of MC2010

A recent model computes the term $V_{R d F}$ as follows:

$$
V_{R d, F}=\frac{1}{\gamma_{F}}\left(k_{v} \sqrt{f_{c k}}+k_{f} f_{F t u k} \cot \theta\right) z b_{w}
$$

where $f_{\text {Ftuk }}$ is the characteristic value of the ultimate tensile strength for FRC, as determined by direct tensile tests, taken at the crack width at ultimate, $w_{u} ; k_{f}=0.8$ :

$$
\begin{array}{cc}
k_{v}=\frac{0.4}{1+1500 \varepsilon_{x}} \cdot \frac{1300}{1000+k_{d g} z} & \text { for } \rho_{w}<0.08 \sqrt{f_{c k} / f_{y k}} \\
k_{v}=\frac{0.4}{1+1500 \varepsilon_{x}} & \text { for } \rho_{w} \geq 0.08 \sqrt{f_{c k} / f_{y k}}
\end{array}
$$

In Eq.3. 32, $\varepsilon_{\mathrm{x}}$ is the longitudinal strain at the mid-depth of the effective shear depth, as determined by the same expressions for concrete without fibers; $\boldsymbol{z}$ is the internal lever arm (in $\mathrm{mm}$ ) between the flexural tensile and compressive forces and $\boldsymbol{k}_{d g}$, is an aggregate size influence parameter.

The aggregate size influence parameter in Eq.3. $32, \boldsymbol{k}_{d g}$, is given by:

$$
k_{d g}=\frac{32}{16+d_{g}} \geq 0.75
$$

where $\boldsymbol{d}_{\boldsymbol{g}}$ is the maximum aggregate size in $\mathrm{mm}$. If the size of the maximum aggregate particles is not less than $16 \mathrm{~mm}$, this parameter may be taken as $\boldsymbol{k}_{d g}=\mathbf{1 . 0}$.

The limits of the angle of the compressive stress field, $\theta$, relative to the longitudinal axis of the member are:

$$
\theta_{\min } \leq \theta \leq 45^{\circ}
$$

where the minimum inclination angle is: 


$$
\theta_{\min }=29^{\circ}+7000 \varepsilon_{x}
$$

For the determination of where $\boldsymbol{f}_{\text {Ftuk, }}$, the crack width at ultimate $\left(\boldsymbol{w}_{u}\right)$ is taken as:

$$
w_{u}=0.2+1000 \cdot \varepsilon_{x} \geq 0.125 \mathrm{~mm}
$$

\subsubsection{ACI-318 (2011): Recommendations for FRC}

The ACl Code 2011 [70] does not include a formula to calculate the shear strength of SFRC beams.

The provision in the $\mathrm{ACl}$ Code assumes a minimum shear strength for SFRC beams of $\mathbf{2} v \mathrm{fc}_{\mathrm{c}}$. From test results reported in the literature, Dinh et Al. [6] found that $3.6 \mathrm{~V} \mathrm{f}_{\mathrm{c}}$ was a lower bound for the shear strength of SFRC beams with a minimum fiber volume fraction of $0.75 \%$. Dinh et Al. [6] then established a minimum performance criterion for the SFRC such that the material used would not have a lower performance compared to those used in previous beam tests. The $\mathrm{ACl}$ Code Committee 318 thought that the difference between, in $\mathbf{3 . 6 V f _ { c }}$ and $\mathbf{2} \boldsymbol{V} f_{c}$, in combination with the strength reduction factor and factored loads, provides sufficient safety margin.

\subsection{Parameters influencing in shear behavior of FRC beams}

The parameters influencing in shear resistance in elements without transversal reinforcement are: shear slenderness, element dimensions (size effect), presence or not of axial forces (tensile or compressive), amount of longitudinal reinforcement (\%), compressive concrete strength, load conditions, cross-section shape and longitudinal reinforcement distribution inside the transversal section [37].

On the other hand, the parameters relevant to the structural part of FRC have the same effects as in reinforced concrete; the various parameters relevant to the fibers can be taken into account globally through the post-cracking tensile behavior of the fiber reinforced concrete used [19] and therefore the contribution of the fibers and their efficiency is the result of the global behavior of the fiber-reinforced concert, that is, of the superposition of the following factors: concrete, fibers, adherence loss and, in this case, also the conventional reinforcement [49].

In Li et Al.'s [95] experimental study, it was found that the material strength of steel FRC is significantly affected by the volume ratio, aspect ratio, and shape of the steel fiber. Also, the main variables studied for Imam's model were: shear span/depth ratio $(a / d)$, the steel fiber content $\left(V_{f}\right)$, and the percentage of the longitudinal flexural reinforcement $(\rho),[13]$.

On Shear Behavior of structural elements made of steel fiber reinforced concrete - PhD thesis 
Also finally it was concluded that steel fibers clearly enhance the ultimate shear strength of reinforced concrete beams, the extent of such increase depending on the shape of the cross section, the amount of tension steel, and the fiber volume [20].

Of all these influencing parameters, below will go into depth on some of them:

\subsubsection{Amount of fibers}

In general, crack widths clearly decreased with increasing fiber content [96]. Also, the volume percentages of fiber had a strong influence on the ultimate shear load. The toughness and ductility are improved with increasing volume percentages of fibers [97].

Susetyo et Al. [44] found that fiber volume content have a significant effect on shear behavior. A fiber volume content of approximately $1 \%$ was required to achieve satisfactory performance in terms of shear strength, deformation ductility, crack width, and crack spacing. Only a minor improvement was obtained, however, by increasing the fiber volume content from 1 to $1.5 \%$, possibly due to fiber saturation. A fiber volume content of $0.5 \%$ was found to be insufficient to guarantee adequate shear resistance and shear deformation response [44].

According to Dinh et Al. [6] an increase in fiber volume fraction resulted in an increase in shear strength, as expected. The increase in shear strength was significant when fibers were added in a $0.75 \%$ volume fraction compared to the beams with no fibers. The efficiency of fiber reinforcement for increasing shear strength, however, seemed to diminish when used in higher volume fraction, particularly beyond $1 \%$ by volume [6].

The contribution of the fibers to cracking control in terms of crack width is significant when the amount is doubled with most types of fibers [49].

The beams with fibers exhibited less deflection and larger ultimate load carrying capacity than those without fibers [13].

As a result of bending experiments on so many beams in a beam-loading machine, it is concluded that both the ultimate loads and the flexural toughnesses of reinforcedconcrete beams produce with concrete classes of C20 and C30 with SFs at a dosage of $30 \mathrm{~kg} / \mathrm{m}^{3}$ increase appreciably as compared to those reinforced concrete (RC) beams without steel fibers. Because doubling the mass of steel fibers (SFs) to a dosage of $60 \mathrm{~kg} / \mathrm{m}^{3}$ renders only small improvements in both the ultimate load and toughness, 
clearly the SFs dosage of $30 \mathrm{~kg} / \mathrm{m}^{3}$ is better than that of $60 \mathrm{~kg} / \mathrm{m}^{3}$ for the steel-fiber-added (SFARC) beams, also [98].

\subsubsection{Relation between casting procedure and fiber length}

In the extruded composites decreasing the fiber length improved the mechanical behavior of the composite. The opposite trend was obtained for the cast composites in which increasing fiber length enhanced the composite mechanical behavior. This contradictory trend is a result of difference in fiber failure mechanism, fiber distribution and fiber orientation in the two systems. The extrusion process improved fiber-matrix bond compared to the cast composites. This strong bond was a result of the extrusion process, in which the materials were formed under high shear and high compressive forces during production. The strong fiber-matrix bond in the extruded composites, led to shorter critical fiber length in this case than the critical fiber length in the cast composites [99].

\subsubsection{Fiber type}

Strength and geometry of fiber have a direct influence on the load bearing capacity of HSSFRC beams without bar reinforcement. Using high-strength fibers resulted in a clearly better ductile behavior and higher load levels in the post-cracking range, compared to normal strength ones. Specimens with high-strength fiber had lower number of broken fibers in the failed cross-sections, compared to those with normal strength ones. However, experiments show that using high-strengths fibers in bar reinforced HSC beams is not necessary as no increase in the load bearing capacity, compared to beams with normal-strength fibers, was observed [100].

Fibers with a high aspect ratio resulted in much improved post-cracking deformation capacities and crack control characteristics compared to fibers with a low aspect ratio. Panels containing short fibers were found to exhibit a higher shear resistance and a higher maximum concrete principal tensile stress than panels containing long fibers [44]. These findings indicate that fiber aspect ratio has a greater effect on the effectiveness of fiber reinforcement than fiber length and agrees well with the conclusions of Johnston and Skarendahl [101].

The short fibers $\left(L_{f}=6 \mathrm{~mm} ; D_{f}=0.15 \mathrm{~mm}\right)$ have a certain degree of influence on the pre-peak behavior, i.e. improves the elastic modulus and tensile strength. A probable reason for this is that these fibers start to act at an early stage of loading preventing micro-cracks from extending in the structure. The post-peak performance of this concrete, however, proved 
to be relatively poor resulting in a quite steep descending curve. In order to get a ductile post-peak behavior it seems as if longer fibers are required. The best fracture toughness was provided by the mixed fibers [21].

Hooked steel fibers with a length of $60 \mathrm{~mm}$ allowed a greater inclined crack opening before failure compared to that observed in beams with $30 \mathrm{~mm}$ long fibers, but they were prone to problems associated with fiber lumping along the longitudinal reinforcement. A horizontal clear spacing between reinforcement bars no less than the fibers length is recommended [6].

Likewise, the fiber tensile strength was found to have little influence on the shear response of the fiber-reinforced panels [44].

\subsubsection{Relation between fiber type and beam size}

The requirements on the fibers become greater as the beam dimensions increase. For small beams a shorter type of fibers may be sufficient, whereas for larger beams, fibers that are better anchored and have a higher strength are required [21].

\subsubsection{Depth of the beam}

Increasing the height of a rectangular SFRC beam, results in an increase in the ultimate shear load-carrying capacities and first-cracks loads. The first-crack deflections also increase with increasing height; however the ultimate-load deflections are relatively unaffected to this variation [102].

The effect of beam depth on beam shear strength for the range considered $(d=381$ and $610 \mathrm{~mm}$ ) was negligible. The increase in beam depth did have an effect on crack spacing, the deeper beams exhibiting wider spacing. When normalized by the effective beam depth, the average horizontal crack spacing was approximately the same (on the order of $0.4 d)[6]$.

\subsubsection{Flange width}

Increasing the flange width does not seem to affect the ultimate shear load-carrying capacities neither the first-crack load of the beams. However, the flange can result in a substantial increase of the shear capacity when comparisons are made with that of a rectangular beam. Increasing the flange widths of the T-beams does not have any 
significant effect on the deflections of the beams produced at ultimate or first-crack load [102].

The presence of a flange increases the ultimate shear load-carrying capacity significantly in comparison with a rectangular beam [38].

Fig 3.14 shows the influence of the flange width on the load-deflection response for the Series 3 beams of the Brite Euram project [92].

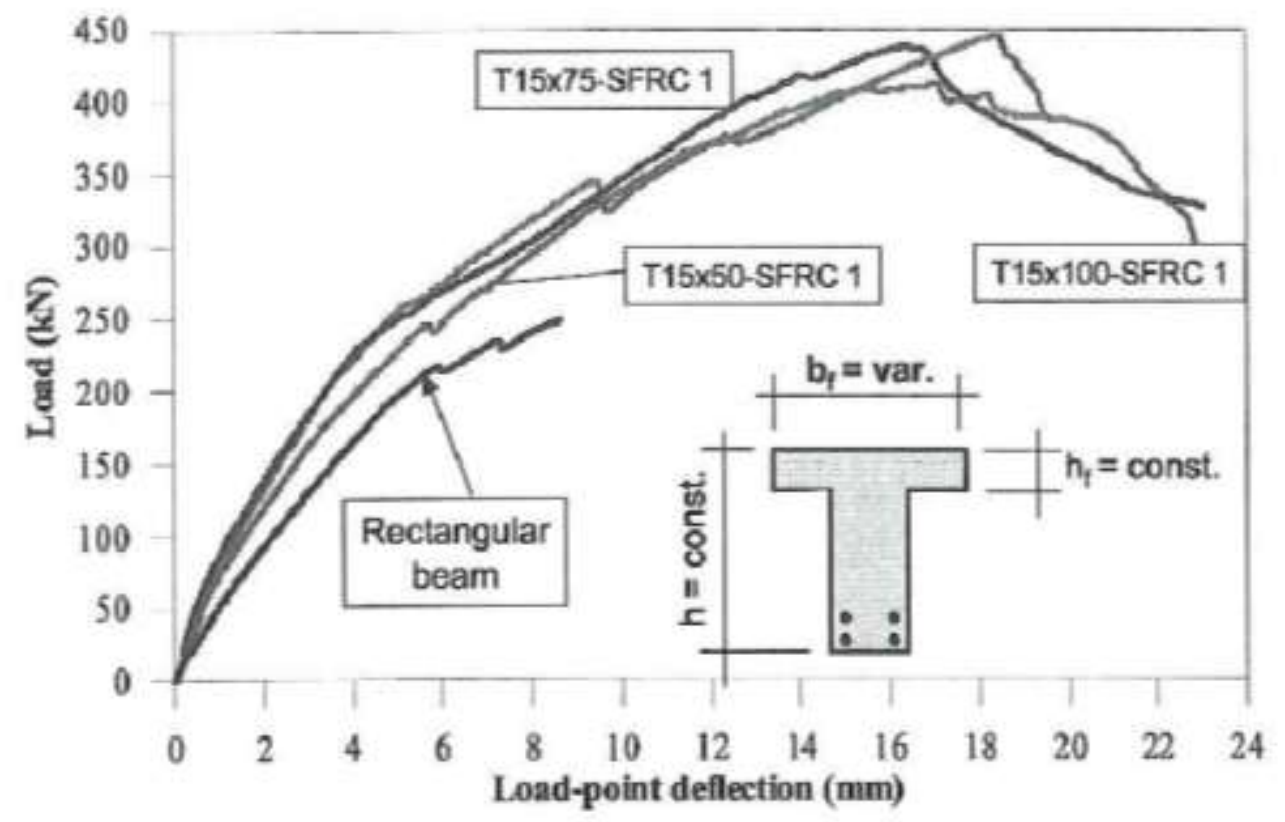

Fig.3. 14 Influence of the flange width on the load-deflection response (Series 3), [92]

\subsubsection{Flange depth}

Increasing the flange depth of the T-beams over a limit value, results in increased ultimate shear load-carrying capacities and first-crack loads. The same tendency is observed for the respective deflections [102].

The test results in T-beams without stirrups suggest that there is a limit in the flange depth beyond which there is a significant increase in the load-carrying capacity and ductility. For beams with lower flange depth and rectangular beams there can be found no significant influence of the flange depth on the first-crack and maximum load while there is a big increase of the loads for the beam with a large flange depth [38].

On Shear Behavior of structural elements made of steel fiber reinforced concrete - PhD thesis 
Fig 3.15 shows the influence of the flange height on the load-deflection response for the Series 3 beams of the Brite Euram project [92].

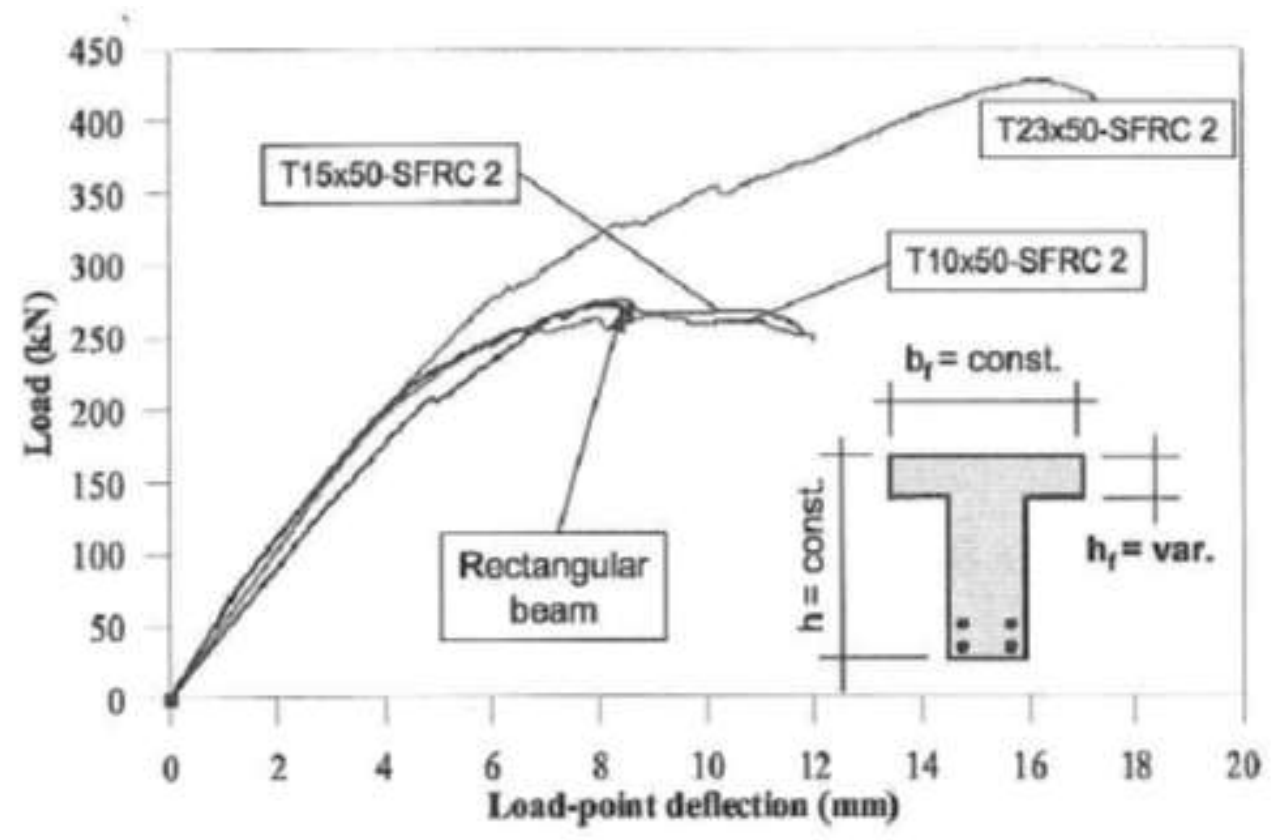

Fig.3. 15 Influence of the flange height on the load-deflection response (Series 3), [92]

\subsubsection{Effect of longitudinal ratio}

The primary effect of longitudinal reinforcement ratio was on beam ductility. Flexural yielding was observed in several beams with a longitudinal reinforcement ratio of approximately $2 \%$, whereas no yielding occurred in any of the beams with a $2.7 \%$ reinforcement ratio. For beams with a $2 \%$ longitudinal reinforcement ratio, the shear strength of beams with a $0.75 \%$ fiber volume fraction, prior to flexural yielding, was believed to be close to the shear demand associated with flexural yielding. Therefore, the occurrence and extend of flexural yielding in theses beams was primarily dictated by fiber content [6].

At lower values of $F$, very little difference in the ultimate shear strength was noticeable consequent upon an increase in main tensile reinforcement. However, when the fiber factor was increased from 0.5 to a little over 1.0, a steady increase in the shear stress was observed with the increase in main steel. In the case the presence of fibbers was seen to 
improve the effectiveness of dowel resistance by enhancing the tensile strength of the concrete in the splitting plane along the bars [30].

Longitudinal reinforcement affects beam shear strength by influencing the size of the compression zone and by providing shear resistance through dowel action. Depending on the amount of steel reinforcement used, flexural yielding might develop first, followed by shear failure of the beam. This is particularly important for cases in which a shear failure develops after limit the flexural yielding has occurred; and, thus, the beam ductility is not considered to be acceptable [6].

The limited experience after casting in this paper, suggests that minimum clear spacing between bars should not be less than the fiber length to prevent lumping of fibers along the longitudinal reinforcement [6].

The increase of $\rho$, results in increases of both the shear and the flexural resistances, but the increase of the latest one is higher [13].

\subsubsection{Influence of prestressing}

Prestressing decreases the slope of the compression struts and increases the extent of the non-cracked area. Prestressing also increases shear strength but in a more significant manner that the fiber addition [10].

\subsubsection{Influence of concrete strength}

For the same fiber factor, the shear strength is seen to increase with cube strength [30].

The concrete compressive strength was found to have no significant influence on the shear response of the fiber reinforced panels for the range of concrete strengths examined [44].

\subsection{Fibers influence on deflections}

Adding fibers, deflections are smaller ( [10], [20], [42]). On the other hand, for beams tested by Cuenca et Al. [32] did not find differences on deflections between beams with and without for their particular case.

Fibers make possible deflections visible before collapse ( [14], [15], [48]); these deflections are reduced because of increased stiffness ( [13], [29]) so deformation characteristics are improved ( [26], [35]).

On Shear Behavior of structural elements made of steel fiber reinforced concrete - PhD thesis 
On the other hand, if fibers acted compositely with stirrups, larger deflections are observed, thus:

Fiber concrete beams with web reinforcement greater ductility and the capacity for larger deformation while maintaining the concrete cover as an integral part of the beam [35]. Also, in T-beams with main steel of 2 to $4 \%, 0.8 \%$ fiber volume alone or in conjunction with a small amount of stirrups, produced steel yielding, extensive ductility, and large deflections [20].

\subsection{Fibers influence on dowel action}

The interaction between fiber contribution and the various resistant mechanisms is always favorable for strut-bending and dowel action and unfavorable for aggregate interlock. It involves a significant reduction in the role of aggregate interlock, and an increase in dowel action, especially in RC beams when the stirrup spacing is not altered even if fibers are added [103].

On the other hand, the dowel resistance of reinforced concrete beams depends on the tensile strength of the concrete and the bending resistance of tension steel. The presence of fiber reinforcement delays and controls dowel cracking, and thereby improves the stiffness ad deformation characteristics of the dowel crack zone. The load at which the first crack forms and ultimate dowel strength are both found to increase almost linearly with the flexural strength of the composite. There is an increase in the stiffness of the dowel zone as the fiber content, amount of tension steel, or amount of tension steel, or amount of web reinforcement is increased. The initial slope of the load-displacement curves at the dowel zone increased consistently with increase in fiber content. For a given loading, the concrete strain and dowel displacement at dowel crack decreased with increase in fiber content. The depth of the stressed zone due to dowel action is approximately twice the concrete cover plus bar diameter. The fiber reinforcement is very effective in containing the dowel crack growth and reducing the strain gradient along the dowel crack. The first crack and ultimate dowel strength increase almost linearly with the flexural strength of the composite. The first crack and ultimate dowel strength are very sensitive to the distribution of fiber in the dowel zone. They are affected by the spacing and concrete cover of the main reinforcement and the presence of stirrups which could lead to non-uniform fiber distribution. The main role of the fiber reinforcement is that of a crack arrester. Fibers control the propagation and widening of the dowel crack, and make failures very ductile. Beams with web reinforcement showed similar load capacity and ductility but suffered spalling and disintegration of the concrete cover [35]. 
So, fibers clearly controlled the cracking and displacement in the dowel zone, and enabled the beams to fully use the contribution to shear due to dowel action [20].

Finally, the addition of fibers reduced the severity of the failure mode and increased the spalling resistance. The effectiveness of dowel resistance increased with an increase in the fiber factor. This indicated that the presence of fibers improved the tensile strength of the concrete in the splitting plane along the reinforcement [30].

\subsection{Hollow Core Slabs (HCS) made with FRC}

\subsubsection{Introduction}

The HCS are manufactured by either long-line extrusion impose restrictions on the placing of secondary reinforcement. HCS are therefore exempt from the minimum shear reinforcement requirements found in design codes ( [104], [105]). Also, Angelakos et Al. [106] has raised concerns about the minimum shear reinforcement exception for deep, lightly reinforced, one-way slabs, particularly those made with high-strength concrete and high-strength steel. This lack of secondary and shear reinforcement leads to a number of potential problems in the use of HCS. In 1994, a study [107] suggested that the inclusion of steel fibers in HCS would be an economic solution to some of these problems [108].

\subsubsection{Manufacturing of HCS made with FRC}

In 1996, it had been found that collated steel fibers will disperse without balling in an unworkable, zero slump concrete as long as they are added to the mix before any free water. However to adequately compact this concrete using the HCS extrusion process it was necessary to make the mix slightly wetter and there was still a need to study fiber orientation [108]. ACl Committee 544 [109] and $\mathrm{JCl}$ [110] recommended that fibers should be added to the concrete mix as the final ingredient after all other components have been introduced. However, with this mixing procedure it was found that the majority of fibers did not separate and were still in the glued form. This suggested that the water was being absorbed by the aggregates and leaving too little free water to separate the fibers. On the other hand, adding finally the water adequately dispersed the fibers randomly within the mix and no balling of fibers occurred. The scouring action of aggregates on the fibers could have been responsible for the fiber separation observed when using the initial procedure. With the last procedure, fiber adequately dispersed randomly within the mix and no balling of fibers occurred [108]. 
Initially, in 1996, the extrusion machine could perform with FRC with no apparent difficulties, but the top surface of the slab (which was most obviously affected) had a honeycombed texture suggesting a lack of cement paste also, it was detected a lack of compaction ( [108], [111]).

In 1999, Paine [111] ensured that the manufacture of extruded HCS reinforced with steel fibers has been shown to be practicable.

The fibers distributed themselves consistently within the cross-section of the slabs providing reasonably homogeneous reinforcement. However, the orientation of the fibers was not random and was strongly influenced by the manufacturing process. Of particular interest was the tendency for the fibers to align vertically within the web [111]. This might be expected to improve the ultimate shear capacity of the slabs because web shear tension, which starts in the middle of the webs and propagates quickly in the vertical plane, leads to a brittle failure in plain mix slabs [111].

Recently, Cuenca \& Serna ( [112], [113]) has ensured that it is possible to produce fiberreinforced concrete hollow core slabs (HCS) without encountering technical problems.

\subsubsection{Advantages of adding fibers into concrete mix for HCS production}

In 1996, it appeared that fibers do considerably improve the shear strength of HCS and also helped to maintain strength after shear cracking. Fibers gave more ductile shear failures. Fibers may also improve the bond between strand and concrete resulting in greater dowel resistance to shear [108].

HCS with fibers reached higher shear capacities than those without fiber reinforcement, and obtain a more ductile behavior. This is a key advantage given the impossibility of placing transverse reinforcements on slabs ( [112], [113]). Also, the use of fibers is a possible solution to overcome shear failure since fibers are capable of increasing element strength to its full flexural capacity, thus attenuating Kani's valley ( [112], [113]).

\subsubsection{Shear behavior of HCS}

The shear failures were abrupt, brittle and occurred with little or no warning. As $a / d$ increased the explosiveness of the failure increased. Fig.3.16 compares the failure mechanisms of the slabs, showing how a tendency for flexural-type failures increased with $a / d$ and fiber volume [108]. 


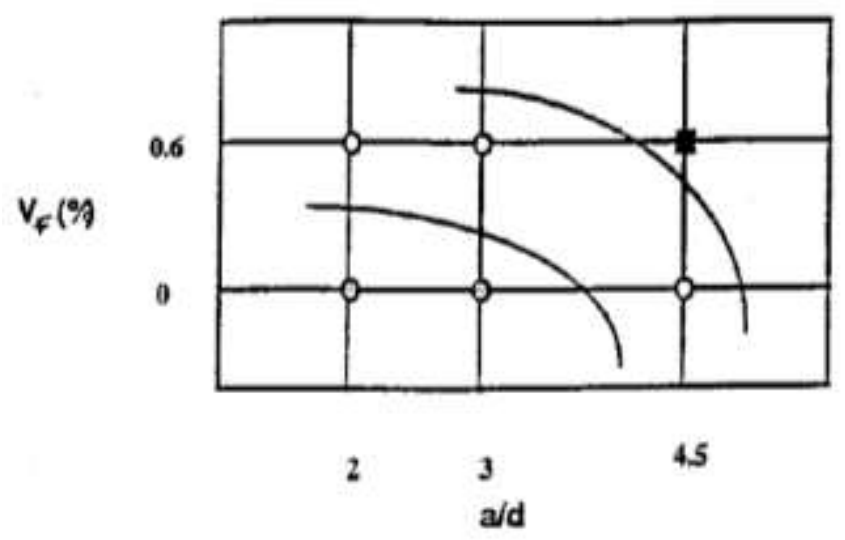

- shear failure

O shear failure preceded by flexural cracking

- flexural failure

Fig.3. 16 Observed failure modes for HCS [108]

This can be compared with Fig.3.17 which shows the failure modes for reinforced concrete and reinforced FRC beams [108].

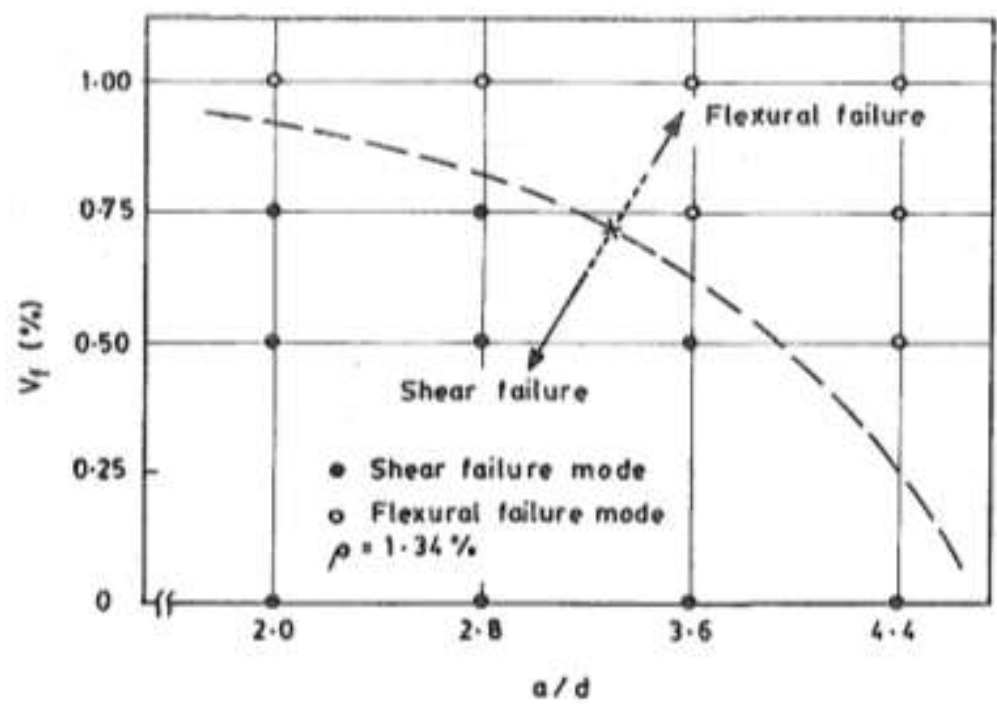

Fig.3. 17 Observed failure modes for FRC beams [25] 
At all $a / d$ ratios it can be seen that the FRC slabs had a much greater post-peak strength, and it was also observed that spalling was much reduced. At large deflections the fibers have pulled-out and are not bridging the majority of the crack. The increase in strength could therefore be due to the fibers in the compression zone. Swamy \& Al-Ta'an [114] and Bentur \& Mindess [115] have shown that fibers in the compression zone are important by performing tests with fibers only in the tension zone of reinforced beams. These tests found that the inclusion of fibers did not significantly enhance post-cracking strength [108].

Peaston et Al. [111] found that the addition of steel fiber to HCS increased the first crack and ultimate shear capacity. The exact nature of the improvement, however, was dependent on the $a / d$ ratio with different behavior being observed for the two $a / d$ ratio's investigated. Post-cracking ductility of fiber reinforced slabs was also substantially improved in comparison with plain slabs with safer, controlled failures being observed. Generally, the shear capacity increases with increased fiber content, fiber aspect ratio and with improved fiber-matrix interfacial bond. Fibers have a greater effect on the ultimate shear strength than the cracking shear strength. Increases in cracking shear strength are attributable to increases in the tensile strength of the composite which are likely to be small. The enhanced post-cracking performance with possible higher ultimate strength is associated with the energy that is required to pull the fibers out of the cracked matrix [111].

According to Peaston and coworkers [111], the slab tested on the shorter $a / d$ was expected to have a lower shear capacity because of its geometry. However, the predicted shear strength does not take into account either of the fact that the slabs at $a / d=2.8$ failed in a region where the prestress has been able to develop more than the slabs at $a / d=2.0$ or, more significantly, of the enhanced shear strength close to the support. Since the equation of BS 8110 [105] accurately estimates the shear strength of the plain HCS tested here, the $10 \%$ reduction in strength advocated by Pisanty [116] is inappropriate. This is probably because Pisanty tested over $a / d=3.5$ where the enhanced shear strength close to supports was not as significant [111].

The post-peak behavior of the plain slabs is characterized by a large reduction in load carrying capacity occurring simultaneously with a large deflection and wide diagonal shear cracks [111].

Elliott et Al. [117] tested beams under shear loadings. The beams represented a single web form a longitudinal section of a precast concrete hollow cored floor unit that does not contain shear links. The average ultimate shear capacity $V_{u l t}$ of the FRC beams was up 
to 1.52 times the capacity of the plain beam and, the maximum shear capacity at cracking was only 1.14 times the cracking capacity of the plain beams [117].

The use of short steel fibers in concrete is well established and, if dispersed correctly in adequate numbers, is known to increase the post-cracking tensile performance of plain concrete. One of the most successful types of fiber is the hooked end high tensile wire fiber of 30 to $50 \mathrm{~mm}$ in length and around $0.5 \mathrm{~mm}$ diameter. If such fibers could be successfully introduced into the hollow core extrusion and be properly distributed throughout the webs of the units, the fibers should improve both the shear resistance and ductility of these units in shear failure [117].

\subsubsection{Failure modes}

Two modes of shear failure can occur in HCS: flexural shear and web shear tension. Flexural shear occurs when a flexural crack develops into a shear crack and leads to a relatively ductile failure. Web shear tension is of greater concern because the failure is brittle and may not be preceded by any warning of impending failure. The shear tests performed by Girhammar in 1992 [118] were aimed to investigate the effects of fiber reinforcement on web shear tension failure in HCS. Web shear tension failure occurs when the principal tensile stress in the web, due to a vertical shear load, reaches the tensile strength of concrete. The resulting diagonal crack usually occurs in the middle of the web, where it is thinnest, and at a distance of $\boldsymbol{h} / \mathbf{2}$ from the inner face of the support [118] ( $\boldsymbol{h}$ being the depth of the slab). The crack propagates quickly at an angle of approximately 35 o to the direction of the slab causing almost immediate failure [111].

At a shear failure the webs are all highly stressed, and because the width of individual webs is unequal, varying by more than $15 \%$ in some cases, once a shear failure occurs in the critical web, it propagates rapidly throughout the unit. Thus, the shear capacity of the HCS is not the same as the shear capacity of its component X sections (HCS is compounded by $X$ webs) unless, of course, web widths are all exactly equal [117].

\subsubsection{Design of HCS}

\subsubsection{BS 8110 modified method}

To determine the fiber contribution to shear, Paine [108] used the Narayanan and Darwish's equation [119]. 
To account for FRC beams failing in web shear tension, Narayanan and Darwish altered the equation of BS 8110 [105] to:

$$
V_{R d}=0.67 b h \sqrt{f_{f c t, s p}^{2}+0.8 \sigma_{c p} f_{f c t, s p}}
$$

where the tensile split cylinder strength, $f_{f c t, s p}$, is found empirically from cube compression tests:

$$
f_{f c t, s p}=\frac{f_{f c, c u b}}{20-\sqrt{F}}+0.7+\sqrt{F}
$$

and:

$$
F=\eta_{b} \cdot V_{f} \cdot \lambda_{f}
$$

where $\boldsymbol{V}_{\boldsymbol{f}}$ is the fiber volume fraction, $\boldsymbol{\lambda}_{\boldsymbol{f}}$ is the fiber aspect ratio and $\boldsymbol{\eta}_{\boldsymbol{b}}$ is a bond efficiency factor to account for different fiber types.

The use of the split cylinder strength in plain HCS design has been shown to produce exaggeratingly high results [116]. Equations for shear strength of prestressed FRC, with the tensile strength derived indirectly from flexural strength or toughness may be more acceptable.

\subsubsection{Fiber supplement additive method}

$$
V_{u}=V_{c}+V_{b}
$$

Where $V_{c}$ is the concrete contribution to shear capacity, a combination of concrete compressive resistance $V_{c c}$, prestressing $V_{p}$, and dowel resistance $V_{d}$. The term $V_{b}$ is usually the sole measure of the improved shear resistance due to fibers [120].

$$
V_{u}=V_{c c}+V_{p}=\left[0.4 \sqrt{f_{c u}}+0.45 \sigma_{c p x}\right] b_{w} d
$$

3.14.6.2.1. $V_{b}$ according to Lim

$$
V_{b}=f_{t u} b_{w} d
$$

where $f_{t u}$ can be calculated theoretically as $\eta_{\theta} \cdot V_{f} \cdot \tau_{f} \cdot \lambda_{f}$ according to Lim [121], where $V_{f}$ is the fiber volume fraction, $\tau_{f}$ is the fiber matrix interfacial bond, $\lambda_{f}$ is the fiber aspect ratio, and $\eta_{\theta}$ is fiber orientation factor. 
3.14.6.2.2. $V_{b}$ according to Dramix guidelines

Dramix guidelines [122] defined $V_{b}$ as:

$$
V_{b}=0.54 f_{c t, a x} R_{t} b d
$$

where $\boldsymbol{R}_{\boldsymbol{t}}$ is the ratio of the tensile strength before and after cracking and is given by Nemegeer [123] as:

$$
R_{t}=\frac{1.1 W_{f} \lambda_{f}}{\left(180 C+W_{f} \lambda_{f}\right)}
$$

where $\boldsymbol{W}_{\boldsymbol{f}}$ is the fiber content (in $\mathrm{kg} / \mathrm{m}^{3}$ ) and $\boldsymbol{C}$ is a function of the anchorage effect of the fibers.

\subsection{Important note}

The author of this PhD thesis makes clear that to make the state-of-the-art of this chapter 3 , fragments of the literature studied have been collected. Many of the pieces have been reproduced verbatim from the original source to directly transmit the idea of the original author, it is not intended to explain the literature with other words to avoid doubts or reproduce a different idea that is not exactly transmitting the original author. The sentences used from papers from other authors are always accompanied by their citation number, so that the reader can know at all times where the fragment has been extracted. The author of the thesis has done a great deal of consultation, study and subsequent analysis of the literature, which has been collected in this chapter completely updated. Under no circumstances, the author of this PhD thesis has tried to appropriate material that does not belong to her, for that, each fragment has been properly cited.

\subsection{References}

[1] Fenwick and Paulay, "Mechanisms of shear resistance of concrete beams," Proceedings of the ASCE, vol. 94, no. 10, pp. 2325-2350, 1968.

[2] MC2010, fib Bulletin 55-56. Model Code - First complete draft, 2010.

[3] Di-Prisco, Plizzari and Vandewalle, "Fibre reinforced concrete: new design perspectives," Materials and Structures, vol. 42, pp. 1261-1281, 2009.

[4] Minelli and Plizzari, "Steel fibers as shear reinforcement for beams," in Proceedings 
of the Second fib Congress, Naples, Italy, 2006.

[5] Juárez, Valdez, Durán and Sobolev, "The diagonal tension behavior of fiber reinforced concrete beams," Cement and Concrete Composites, vol. 29, pp. 402-408, 2007.

[6] Dinh, Parra-Montesinos and Wight, "Shear behavior of steel fiber-reinforced concrete beams without stirrup reinforcement," ACl Structural Journal, vol. 107, no. 5, pp. 597-606, 2010.

[7] Padmarajaiah and Ramaswamy, "Behavior of fiber-reinforced prestressed and reinforced high-strength concrete beams subjected to shear," ACI Structural Journal, vol. 98, no. 5, pp. 752-761, 2001.

[8] Calixto, Filho and Gonçalvez, "Shear behavior of reinforced concrete beams with the addition of short steel fibers," ACI Special Publication, vol. 207, pp. 449-466, 2002.

[9] Schumacher, Walraven, Den-Uijl and Bigaj, "Rotation capacity of self-compacting steel fiber reinforced concrete beams," HERON, vol. 54, no. 2/3, pp. 127-161, 2009.

[10] Furlan and Bento-de-Hanai, "Prestressed fiber reinforced concrete beams with reduced ratios of shear reinforcement," Cement and Concrete Composites, vol. 21, pp. 213-221, 1999.

[11] Vandewalle, "Cracking behaviour of concrete beams reinforced with a combination of ordinary reinforcement and steel fibers," Materials and Structures, vol. 33, pp. 164-170, 2000.

[12] Narayanan and Darwish, "Fiber concrete deep beams in shear," ACl Structural Journal, vol. 85, no. 2, pp. 141-149, 1988.

[13] Imam, Vandewalle and Mortelmans, "Shear capacity of steel fiber high-strength concrete beams," ACI Special Publication, vol. 149, pp. 227-241, 1994.

[14] Conforti, Cuenca, Minelli and Plizzari, "Can we mitigate or eliminate size effect in shear by utilizing steel fibers?," in Proceedings of the fib Symposium "Concrete Engineering for Excellence and Efficiency", Prague, Czech Republic, 2011. 
[15] Conforti, Minelli, Cuenca and Plizzari, "Comportamento a taglio di travi alte in calcestruzzo armato fibrorinforzato," in Atti del 26o Convegno Nazionale Giornate AICAP, Padova, Italy, 2011.

[16] Imam, Vandewalle, Mortelmans and V. Gemert, "Shear domain of fibre-reinforced high-strength concrete beams," Engineering Structures, vol. 19, no. 9, pp. 738-747, 1997.

[17] Imam and Vandewalle, "Role of fibers in controlling failure modes of high-strength concrete beams," ACI Special Publication, vol. 193, pp. 503-515, 2000.

[18] Majdzadeh, Soleimani and Banthia, "Shear strength of reinforced concrete beams with a fiber concrete matrix," Canadian Journal of Civil Engineering, vol. 33, pp. 726734, 2006.

[19] Casanova, Rossi and Schaller, "Can steel fibers replace transverse reinforcements in reinforced concrete beams?," ACl Materials Journal, vol. 94, no. 5, pp. 341-354, 1997.

[20] Swamy and Bahia, "The effectiveness of steel fibers as shear reinforcement," Concrete International, pp. 35-40, 1985.

[21] Gustafsson and Noghabai, "Steel fibers as shear reinforcement in high strength concrete beams," International Journal of Nordic Concrete Research, no. 22, 1999.

[22] Lim and Oh, "Experimental and theoretical investigation on the shear of steel fibre reinforced concrete beams," Engineering Structures, vol. 21, pp. 937-944, 1999.

[23] Oh, Lim, Hong, Yoo and Chae, "Structural behavior of steel fiber reinforced concrete beams in shear," ACI Special Publication, vol. 182, pp. 9-27, 1999.

[24] Thomas and Ramaswamy, "Load-deflection performance of partially prestressed concrete T-beams with steel fibers in partial and full depth," Structural Concrete (Journal of the fib), vol. 7, no. 2, pp. 65-75, 2006.

[25] Mansur, Ong and Paramasivam, "Shear strength of fibrous concrete beams without stirrups," Journal of Structural Engineering, ASCE, vol. 112, no. 9, pp. 2066-2079, 1986. 
[26] Mansur and Ong, "Behavior of reinforced fiber concrete deep beams in shear," $\mathrm{ACl}$ Structural Journal, vol. 88, no. 1, pp. 98-105, 1991.

[27] Tan, Murugappan and Paramasivam, "Shear behavior of steel fiber reinforced concrete beams," ACl Structural Journal, vol. 89, no. 6, pp. 3-11, 1993.

[28] Tan, Paramasivam and Murugappan, "Steel fibers as shear reinforcement in partially prestressed beams," ACl Structural Journal, vol. 92, no. 6, pp. 643-652, 1995.

[29] Ashour, Hasanain and Wafa, "Shear behavior of high-strength fiber reinforced concrete beams," ACl Structural Journal, vol. 89, no. 2, pp. 176-184, 1992.

[30] Narayanan and Darwish, "Use of steel fibers as shear reinforcement," ACl Structural Journal, vol. 84, pp. 216-227, 1987.

[31] Cuenca and Serna, "Shear behavior of self-compacting concrete and fiber reinforced concrete beams," in Proceedings of 6th RILEM Symposium on Self-Compacting Concrete SCC, Montreal, Canada, 2010.

[32] Cuenca and Serna, "Shear behavior and Mode of Failures analysis of different structural elements made with fiber reinforced concrete," in 8th fib PhD Symposium, Lyngby, Denmark, 2010.

[33] Greenough and Nehdi, "Shear behavior of fiber reinforced self-consolidating concrete slender beams," ACI Materials Journal, vol. 105, no. 5, pp. 468-477, 2008.

[34] Thomas and Ramaswamy, "Shear strength of prestressed concrete T-beams with steel fibers over partial/full depth," ACl Structural Journal, vol. 103, no. 3, pp. 427435, 2006.

[35] Swamy and Bahia, "Influence of fiber reinforcement on the dowel resistance to shear," ACl Journal, vol. 76, no. 2, pp. 327-356, 1979.

[36] Minelli and Plizzari, "Progetto a taglio di travi in calcestruzzo fibrorinforzato prive di armatura trasversale (in Italian)," in Atti del 16 Congresso C.T.E., Parma, Italy, 2006.

[37] Minelli and Plizzari, "Un nuovo modello analitico per il progetto a taglio di elementi in calcestruzzo fibrorinforzato privi di armatura trasversale (in italian)," in Atti del 
24o Convegno Nazionale Giornate AICAP, Salerno, Italia, 2007.

[38] Rosenbusch and Teutsch, "Shear Design with sigma-epsilon method," in Test and design methods for steel fibre reinforced concrete -Background and Experiences-. Proceedings of the RILEM TC 162-TDF Workshop, Schnütgen and Vandewalle, Eds., RILEM Publications, 2003.

[39] Serna, Cuenca and Alves-de-Oliveira, "Self-compacting fiber reinforced in precast elements production for shear resistance," in Dedicated to Innovation: 50 YEARS MC-BAUCHEMIE, 2011.

[40] Cuenca and Serna, "Shear behavior of self-compacting concrete and fiber-reinforced concrete push-off specimens," in Design, Production and Placement of SelfConsolidating Concrete, RILEM Bookseries 1, Springer, 2010, pp. 429-438.

[41] Cuenca, Serna and Pelufo, "Structural behavior of self-compacting and fiber reinforced concrete under shear loading," in Proceedings of International Symposium of Shell and Spatial Structures IASS, Valencia, Spain, 2009.

[42] Balaguru and Ezeldin, "Behavior of partially prestressed beams made with high strength fiber reinforced concrete," ACl Special Publication, vol. 105, pp. 419-436, 1987.

[43] Khuntia, Stojadinovic and Goel, "Shear strength of normal and high-strength fiber reinforced concrete beams without stirrups," ACI Structural Journal, vol. 96, no. 2, pp. 282-290, 1999.

[44] Susetyo, Gauvreau and Vecchio, "Effectiveness of steel fiber as minimum shear reinforcement," ACl Structural Journal, vol. 108, no. 4, pp. 488-496, 2011.

[45] Meda, Minelli, Plizzari and Riva, "Shear behaviour of steel fibre reinforced concrete beams," Materials and Structures, vol. 38, pp. 343-351, 2005.

[46] Noghabai, "Beams of fibrous concrete in shear and bending: Experiment and model," Journal of Structural Engineering, ASCE, vol. 126, no. 2, pp. 243-251, 2000.

[47] Cuchiara, La-Mendola and Papia, "Effectiveness of stirrups and steel fibers as shear reinforcement," Cement and Concrete Composites, vol. 26, pp. 777-786, 2004.

On Shear Behavior of structural elements made of steel fiber reinforced concrete-PhD thesis 
[48] Minelli, Plizzari and Vecchio, "Influence of steel fibers on full-scale RC beams under shear loading," in Proceedings of the International Conference FramCoS - High Performance Concrete, Brick-Mansory and Environnmental Aspects, Catania, Italy, 2007.

[49] Pujadas, Blanco, De-La-Fuente and Aguado, "Cracking behavior of FRC slabs with traditional reinforcement," Materials and Structures, vol. 45, pp. 707-725, 2012.

[50] Sharma, "Shear strength of steel fiber reinforced concrete beams," ACl Journal, vol. 83, no. 4, pp. 624-628, 1986.

[51] Batson, Jenkins and Spatney, "Steel fibers as shear reinforcement in beams," $\mathrm{ACl}$ Journal, vol. 69, no. 10, pp. 640-644, 1972.

[52] Collins and Mitchell, Prestressed concrete structures, Prentice-Hall, 1991.

[53] Bischoff, "Tension stiffening and cracking of steel fiber-reinforced concrete," Journal of Materials in Civil Engineering, vol. 15, no. 2, pp. 174-182, 2003.

[54] Abrishami and Mitchell, "Influence of steel fibers on tension stiffening," $\mathrm{ACl}$ Structural Journal, vol. 94, no. 6, pp. 769-776, 1997.

[55] Samarrai and Elvery, "The influence of fibers upon crack development in reinforced concrete subject to uniaxial tension," Magazine of Concrete Research, vol. 26, no. 89, pp. 203-211, 1974.

[56] Massicotte, Belanger and Moffatt, "Analysis and design of SFRC bridge decks," in 5th RILEM Symp. on Fiber Reinforced Concrete, RILEM Publications, Cachan Cedex, France, 2000.

[57] Bischoff and Massicotte, "Structural design with fiber reinforced concrete: A North American perspective," in Proc., 2nd Asia-Pacific Specialty Conf. on Fiber Reinforced Concrete, Singapore, 1999.

[58] De-Montaignac, Massicotte and Charron, "Design of SFRC structural elements: flexural behaviour prediction," Materials and Structures, vol. 45, no. 4, pp. 623-636, 2012. 
[59] RILEM, "RILEM TC 162-TDF: Test and design methods for steel fibre reinforced concrete. Sigma-epsilon design method. Final Recommendation," Materials and Structures, vol. 36, pp. 560-567, 2003.

[60] Massicotte, "Implementing SFRC design into North American Codes: application to a building floor.," in International Workshop on the advanced in fibre reinforced concrete, Bergamo, Italia, 2004.

[61] Ultkjaer, Krenk and Brincker, "Analytical model for fictitious crack propagation in concrete beams," ASCE J Eng Mech, vol. 121, no. 1, pp. 7-15, 1995.

[62] Kooiman, Modelling SFRC for structural design. PhD thesis, Delft, Netherlands: University of Delft, 2000.

[63] Iyengar, Raviraj and Ravikumar, "Analysis study of fictitious crack propagation in concrete beams using a bilinear stress-crack width relation," in 3th International conference on fracture mechanics of concrete and strucutre (FRAMCOS III), Japan, 1998.

[64] Pedersen, New production processes, materials and calculation techniques for fiber reinforced concrete pipes. PhD thesis, Denmark: University of Denmark, 1996.

[65] AFGC-SETRA, Ultra high performance fibre-reinforced concretes, interim recommendations, France: AFGC Publication, 2002.

[66] CNR-DT-204, Guidelines for design, constructuion and production control of fiber reinforced concrete structures, Rome, Italy: National Research Council of Italy, 2006.

[67] Strack, "Modelling of crack opening of SFRC under tension and bending," in 7th International RILEM Symposium on FRC: Design and application, 2008.

[68] EC2, Eurocode 2. Design of concrete structures. Part 1: General rules and rules for buildings., Brussels, Belgium: European Committee for Standardization (CEN), 1992.

[69] Minelli and Plizzari, "Shear design of FRC members with little or no conventional shear reinforcement," in Proceedings of the fib Symposium "Tailor made concrete structures-New solutions for our society", Amsterdam, The Netherlands, 2008. 
[70] ACl.Committee.318, Building Code requirements for structural concrete ( $\mathrm{ACl} 318$ 11), American Concrete Institute, 2011.

[71] Minelli and Vecchio, "Compression Field Modeling of Fiber-Reinforced Concrete Members under shear loading," ACl Structural Journal, vol. 103, no. 2, pp. 244-252, 2006.

[72] Parra-Montesinos, "Shear strength of beams with deformed steel fibers. Evaluating an alternative to minimum transverse reinforcement," Concrete International, pp. 57-66, 2006.

[73] Imam, Vandewalle and Mortelmans, "Shear-moment analysis of reinforced highstrength concrete beams containing steel fibers," Canadian Journal of Civil Engineering, vol. 22, pp. 462-470, 1995.

[74] Williamson, «Steel fibers as web reinforcement in reinforced concrete,» de Proceedings, U.S. Army Service Conference, West Point, N.Y., 1978.

[75] De-Pauw, Taerwe, Van-den-Buverie and Moerman, "Replacement of shear reinforcement by steel fibers in pretensioned concrete beams," Taylor Made Concrete Structures, pp. 391-397, 2008.

[76] Campione, "Simplified flexural response of steel fiber-reinforced concrete beams," Journal of Materials in Civil Engineering, ASCE, vol. 20, no. 4, pp. 283-293, 2008.

[77] Cho and Kim, "Effects of steel fibers on short beams loaded in shear," ACI Structural Journal, vol. 100, no. 6, pp. 765-774, 2003.

[78] Sarhat and Abdul-Ahad, "The combined use of steel fibers and stirrups as shear reinforcement in reinforced concrete beams," ACl Special Publication, vol. 235, pp. 269-282, 2006.

[79] Furlan and Bento-de-Hanai, "Shear behavior of fiber reinforced concrete beams," Cement and Concrete Composites, vol. 19, pp. 359-366, 1997.

[80] Choi, Park and Wight, "Shear strength of steel fiber-reinforced concrete beams without web reinforcement," ACI Structural Journal, vol. 104, no. 1, pp. 12-21, 2007. 
[81] ACl-Committee-544, State of the Art Report on Fiber Reinforced Concrete. Report 544-1R-96 (Repproved 2002), 2002.

[82] Bencardino, Rizzuti, Spadea and Swamy, "Stress-Strain behavior of steel fiberreinforced concrete in compression," Journal of Materials in Civil Enginering, ASCE, vol. 20, no. 3, pp. 255-263, 2008.

[83] Cho, Lundy and Chao, "Shear strength of steel fiber reinforced prestressed concrete beams," in ASCE Structures Congress' 09, Austin, Texas, 2009.

[84] Kuchma, Végh, Simionopoulos, Stanik and Collins, "The influence of concrete strength, distribution of longitudinal reinforcement, and member size, on the shear strength of reinforced concrete beams," in Concrete Tension and Size Effect, CEB Bulletin 237, Lausanne, 1997, p. 258 pp..

[85] Bazant and Sun, "Size effect in diagonal shear failure: influence of aggregate size and stirrups," ACl Materials Journal, vol. 84, no. 4, pp. 259-272, 1987.

[86] Bazant and Kim, "Size effect in shear failure of longitudinally reinforced beams," $\mathrm{ACl}$ Journal, vol. 81, no. 5, 1984.

[87] Campione, Cucchiara and La-Mendola, "Role of fibers and stirrups on the experimental behavior of reinforced concrete beams and flexure and shear," in Proc., of Int. Conf. on Composites in Construction, Rende, Italy, 2003.

[88] Campione and Mindess, "Fibers as shear reinforcement for high strength reinforced concrete beams containing stirrups," in Proc., 3rd Int. RILEM Workshop on High Performance Fiber Reinforced Cement Composites, HPFRCC3, 1999.

[89] Dupont and Vandewalle, "Shear capacity of concrete beams containing longitudinal reinforcement and steel fibers," ACI Special Publication, vol. 216, pp. 79-94, 2003.

[90] RILEM, "Recommendations of RILEM TC 162-TDF: sigma-epsilon desing method," Materials and Structures, vol. 33, pp. 75-81, 2000.

[91] RILEM-TC-162-TDF, Test and design methods for Steel Fibre Reinforced Concrete Background and Experiences, Bagneux, France: RILEM Publications s.a.r.I., 2003. 
[92] Rosenbusch, Teutsch and et.Al, Trial Beams in Shear, Final Report Sub Task 4.2, Brite Euram project 97-4163: Test and design methods for steel fibre reinforced concrete, 2002.

[93] EHE-08, Instrucción de Hormigón Estructural EHE-08 (in spanish), Ministerio de Fomento, 2008.

[94] Minelli, Plain and Fiber Reinforced Concrete Beams under Shear Loading: Structural Behavior and Design Aspects, PhD thesis, Brescia, Italy: Starrylink Editrice, 2005.

[95] Li, Ward and Hamza, "Steel and Synthetic fibers as shear reinforcement," $\mathrm{ACl}$ Materials Journal, vol. 89, no. 5, pp. 499-508, 1992.

[96] Jansson, Flansbjer, Löfgren, Lundgren and Gylltoft, "Experimental investigation of surface crack initiation, propagation and tension stiffening in self-compacting steelfiber-reinforced concrete," Materials and Structures, 2012.

[97] El-Niema, "Reinforced concrete beams with steel fibers under shear," ACI Structural Journal, vol. 88, no. 2, pp. 178-183, 1991.

[98] Altun, Haktanir and Ari, "Effects of steel fiber addition on mechanical properties of concrete and RC beams," Construction and Building Materials, vol. 21, pp. 654-661, 2007.

[99] Akkaya, Peled and Shah, "Parameters related to fiber length and processing in cementitious composites," Materials and Structures, vol. 33, pp. 515-524, 2000.

[100] Holschemacher, Mueller and Ribakov, "Effect of steel fibers on mechanical properties of high-strength concrete," Materials and Design, vol. 31, pp. 2604-2615, 2010.

[101] Johnston and Skarendahl, "Comparative flexural performance evaluation of steel fiber-reinforced concretes according to ASTM C1018 shows importance of fiber parameters," Materials and Structures, vol. 25, no. 4, pp. 191-200, 1992.

[102] Barragán, Failure and toughness of steel fiber reinforced concrete under tension and shear, PhD thesis, Universitat Politècnica de Catalunya (UPC), 2002. 
[103] Di-Prisco and Romero, "Diagonal shear in thin-webbed reinforced concrete beams: fibre and stirrup roles at shear collapse," Magazine of Concrete Research, vol. 48, no. 174 , pp. 59-76, 1996.

[104] FIP-Recommendations, Precast Prestressed Hollow Core Floors, 1988.

[105] BS-8110, BS 8110: Part 1. Structural Use of Concrete, Code of Practice for Desgin and Construciton. Part 2: Code of Practice for Special Circumstances, British Standards Institution, 1985.

[106] Angelakos, Bentz and Collins, "Effect of concrete strength and minimum stirrups on shear strength of large members," Journal of Structural Engineering, vol. 98, no. 3, pp. 290-300, 2001.

[107] Glavind, Munch-Petersen and Pedersen, "Framework Programme 1989-92 Fibre Reinforced Concrete. Publication No. 14 1/94," Nordic Concrete Research, 1994.

[108] Paine, "Trial Production of Fibre Reinforced Hollow Core Slab. Research Report SR 96 007," Department of Civil Engineering, University of Nottingham, 1996.

[109] ACl-544, "Guide for Specifying, Proportioning, Mixing, Placing and Finishing Steel Fiber Reinforced Concrete. ACl 544.3R-93," ACl Materials Journal, vol. 90, no. 1, pp. 94-101, 1993.

[110] JCl, "Method of making Fiber Reinforced Concrete in the laboratory. JCl Standard SF1," JCI Standards for Test Methods of Fiber Reinforced Concrete, pp. 35-36, 1983.

[111] Peaston, Elliott and Paine, "Steel Fiber Reinforcement for extruded prestressed hollow core slabs," ACl Special Publication, vol. 182, pp. 87-107, 1999.

[112] Cuenca and Serna, "Failure modes and shear design of prestressed hollow core slabs made of fiber-reinforced concrete," Composites Part B: Engineering, vol. 45, no. 1, pp. 952-964, 2013.

[113] Cuenca and Serna, "Hormigón reforzado con fibras de acero para prefabricados estructurales. Contribución al esfuerzo cortante (in Spanish)," in V Congreso de ACHE, Barcelona, Spain, 2011. 
[114] Swamy and Al-Ta'an, "Deformation and ultimate strength in flexure of reinforced concrete beams made with steel fiber concrete," $\mathrm{ACl}$ Journal, vol. 78, no. 5, pp. 395405, 1981.

[115] Bentur and Mindess, Fibre Reinforced Cementitious Composites, Elsevier Applied Science, 1990, p. 449 pp..

[116] Pisanty, "The shear strength of extruded Hollow-Core Slabs," Materials and Structures, vol. 25, pp. 224-230, 1992.

[117] Elliott, Peaston and Paine, "Experimental and theoretical investigation of the shear resistance of steel fiber reinforced prestressed concrete X-beams-Part I: Experimental work," Materials and Structures, vol. 35, pp. 519-527, 2002.

[118] Girhammar, "Design principles for simply supported hollow core slabs," Structural Engineering Review, vol. 4, no. 4, pp. 301-316, 1992.

[119] Narayanan and Darwish, "Shear in prestressed concrete beams containing steel fibers," International Journal of Cement Composites and lightweight concrete, vol. 9, no. 2, pp. 81-87, 1987.

[120] Elliott, Peaston and Paine, "Experimental and theoretical investigation of the shear resistance of steel fiber reinforced prestressed concrete X-beams-Part II: Theoretical analysis and comparison with experiments," Materials and Structures, vol. 35, pp. 528-535, 2002.

[121] Lim, Paramasivam and Lee, "Analytical model for tensile behaivor of steel-fiber concrete," ACl Materials Journal, vol. 84, no. 4, pp. 286-298, 1987.

[122] Dramix-Guidelines, "Design of Concrete Structures. Steel Wire Fiber Reinforced Concrete Structures with or without ordinary reinforcement," 1995.

[123] Nemegeer and Tatnall, "Measuring toughness characteristics of SFRC-A critical view of ASTM C1018. Testing of Fiber Reinforced Concrete," ACl Special Publication, vol. 155, 1995. 


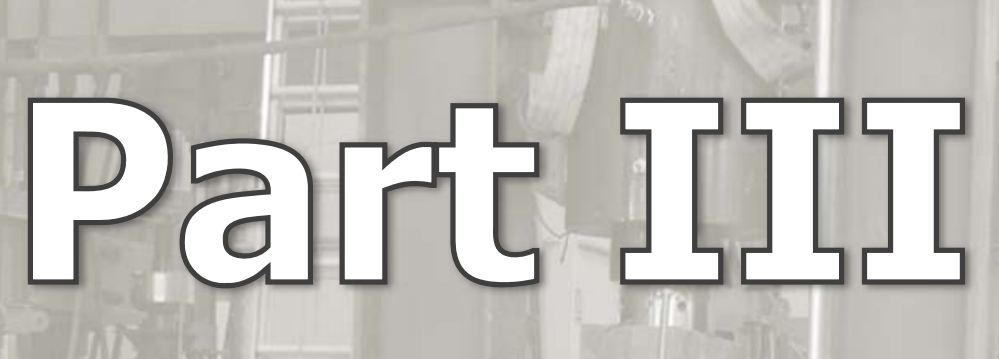

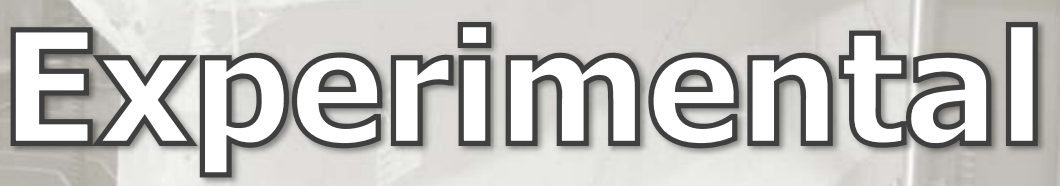




\section{PART III}

\section{EXPERIMENTAL TESTS}

\section{III.1 Contents of Part III}

After making a thorough study of the literature on the shear behavior of structural elements made of fiber reinforced concrete -FRC- (Chapter 3 ) and concrete without fibers (Annex $A$ ), it is possible to detect some possible aspects to take a step that allows to better understand the shear behavior of structural elements made with FRC:

In the literature is not entirely clear the contribution of the flange size of double-T beams to shear strength. In the current Codes, this effect does not appear for the determination of shear strength in concrete without fibers but it appears in the RILEM guidelines for FRC. It seems of practical interest to better understand whether or not the flange helps to resist shear. To this aim, it was carried out an experimental campaign consisting of 8 FRC prestressed beams and a concrete without fibers was used as reference. The beams had different top flange widths $(260,400$ and $600 \mathrm{~mm})$; two of the nine beams had both stirrups and fibers, one was reinforced only with stirrups and the other six beams were reinforced only with fibers for shear resistance. As additional variable, one of the beams was done with a larger flange (with an increase in height of $50 \mathrm{~mm}$ ). Chapter 4 explains in detail the experimental program: procedure, testing, data collection, analysis of results and conclusions.

On Shear Behavior of structural elements made of steel fiber reinforced concrete-PhD thesis 
Today it is well known that the size of the beam has a clear influence on the shear strength of the element. As the depth of the element increases, the lower is the shear strength achieved. This is due to the great influence that exists between the depth and the shear crack width. In large beams such opening is larger and this is detrimental to shear capacity. In Annex $A$ it was seen that Collins et al. came to the conclusion that longitudinal reinforcement distributed along the beam depth could eliminate the size effect, as the same happens if stirrups are added. The question that raised was if fibers could mitigate somewhat the size effect or even eliminate it as the stirrups can do. In order to give an answer to this question, it was carried out an experimental program for shear tests on 9 large beams, where 3 beams had a depth of $500 \mathrm{~mm}$, other 3 a depth of $1000 \mathrm{~mm}$ and the last 3 beams a depth of $1500 \mathrm{~mm}$. In turn, each depth was made from 3 types of concrete with the following amounts of fibers: 0,50 and $75 \mathrm{~kg} / \mathrm{m}^{3}$. This research is explained in detail in Chapter 5.

Another aspect that has attracted interest is to know the influence of fibers on shear behavior of beams. It is well known that fibers give rise to more ductile behavior with more dynamic failure modes in which, a priori, cannot be sure which of the shear cracks that were generated will provoke the beam failure. Furthermore, it is known that the presence of fibers results in a more distributed cracking pattern; in fact, in FRC beams, shear cracks appear more but thinner and closer. Another aspect to note is that Codes currently use $f_{R 3}$ to take into account the mechanical properties concerning FRC. This has been widely studied and justified, but it is not evident that the value of $f_{R 3}$ is the one that better represents the mechanical behavior of FRC for all combinations of compressive strength and fiber type. To this aim, in Chapter 6, a comprehensive experimental program consisting of 22 FRC beams has been carried out. In this program, three different compressive strength levels (low, medium and high; 30, 50 and 80MPa respectively) have been used. Also, five different types of fibers have been used, where three types of steel fibers had normal strength (45/50BN, 65/40BN, 80/50BN) and two types of fibers were made of high strength steel (80/30BP, 80/30BP).

After studying the literature, it was found that the addition of fibers can be very positive in structural elements where is very difficult to incorporate transverse reinforcement such as Hollow Core Slabs (HCS), manufactured by extrusion. The literature on HCS made with FRC is very scarce; also in addition, during manufacturing some problems raised up due to the addition of fibers. Therefore it was carried out an experimental program on HCS made with FRC, in which no manufacturing problems were detected, since the most interesting issue would be to take advantage of the fiber for industrial use. The experiments also seek to study different failure modes to analyze the contribution of the fibers, using different 
amounts of fibers and different $a / d$ ratio. This experimental program is presented in Chapter 7.

\section{III.2 Design Codes used in Part III}

For determining the shear strength, the most widely used international Design Codes have been used, such as the Eurocode 2 (EC2) and the first complete draft of the Model Code 2010 (MC2010). In this PhD thesis, when MC2010 is used, really it is going to be used its first complete draft. The first complete draft of the MC2010 proposes formulations to determine the shear value of elements with and without fibers. On the contrary, the EC2 does not have a formulation to determine the fiber contribution to shear; therefore, RILEM formulation is added to determine such contribution. Furthermore, as this thesis is mainly done in a spanish university, shear values have been also calculated according to the Spanish Code "EHE08". The latter is based on EC2 for the part of concrete without fibers and on RILEM to determine fiber contribution to shear.

Table III. 1 summarizes the formulations used in Part III, which includes Chapters 4 to 7. The limitations of the shear design formulas are reported in Table III. 2. Finally, a list with the notation of the main parameters used in Chapters 4 to 7 of Part III is presented (Table III. 3).

Table III. 1 Current Codes shear formulas

\begin{tabular}{|c|c|c|c|c|}
\hline \multirow[t]{2}{*}{ Code } & \multicolumn{2}{|l|}{ Theoretical Shear (V) } & \multicolumn{2}{|c|}{ Parameters } \\
\hline & $\begin{array}{l}\text { Concrete contribution } \mathrm{V}_{\mathrm{cu}} \\
\qquad \text { Fibers contribution } \mathrm{V}_{\mathrm{fu}}\end{array}$ & & $\begin{array}{l}\text { Without } \\
\text { stirrups }\end{array}$ & $\begin{array}{l}\text { With } \\
\text { stirrups }\end{array}$ \\
\hline EHE-08 & $\begin{array}{r}V_{c u}=\left[\left(C_{1} / \nu_{c}\right) \cdot \xi \cdot\left(100 \cdot \rho_{l} \cdot C_{2}\right)^{1 / 3}+0.15 \cdot \sigma_{c k}\right] \cdot \beta \cdot b_{o} \cdot d \\
V_{f u}=k_{f} \cdot 0.7 \cdot \xi \cdot 0.5 \cdot 0.33 \cdot\left(f_{R 3 k} / \nu_{c}\right) \cdot b_{o} \cdot d\end{array}$ & $C_{2}=f_{c v}$ & $\begin{array}{c}C_{1}=0.18 \\
\beta=1\end{array}$ & $\begin{array}{l}C_{1}=0.15 \\
\beta=\left(^{*}\right)\end{array}$ \\
\hline EC-2 + RILEM & $\begin{array}{r}V_{c u}=\left[\left(C_{1} / \gamma_{c}\right) \cdot \xi \cdot\left(100 \cdot \rho_{1} \cdot C_{2}\right)^{1 / 3}+0.15 \cdot \sigma_{c k}\right] \cdot \beta \cdot b_{o} \cdot d \\
V_{f u}=k_{f} \cdot 0.7 \cdot \xi \cdot 0.18 \cdot\left(f_{R 4 k} / \gamma_{c}\right) \cdot b_{o} \cdot d\end{array}$ & $C_{2}=f_{c k}$ & $\begin{array}{c}C_{1}=0.18 \\
\beta=1\end{array}$ & $\begin{array}{c}\beta=0 \\
V_{c u}=0\end{array}$ \\
\hline $\begin{array}{l}\text { MC2010 }\left(^{*}\right) \\
\text { Without fibers: }\end{array}$ & $\mathrm{V}_{\mathrm{cu}}=\mathrm{k}_{\mathrm{v}} \cdot\left(\mathrm{vf}_{\mathrm{ck}} / \mathrm{V}_{\mathrm{c}}\right) \cdot \mathrm{z} \cdot \mathrm{b}_{\mathrm{o}} \quad$ (Level III Approximation) & ----------- & & \\
\hline $\begin{array}{l}\text { MC2010 }(*) \\
\text { With fibers: }\end{array}$ & $\begin{array}{c}V_{c u}+V_{f u}=\left[\left(C_{1} / V_{c}\right) \cdot \xi \cdot\left(100 \cdot \rho_{l} \cdot C_{2}\right)^{1 / 3}+0.15 \cdot \sigma_{c k}\right] \cdot \beta \cdot \\
C_{2}=\left(1+7.5 \cdot\left(f_{\mathrm{ftuk}} / f_{c t k}\right)\right) \cdot f_{c k}\end{array}$ & & $\mathrm{C}_{1}=$ & \\
\hline
\end{tabular}

$\left(^{*}\right)$ First complete draft of the MC2010 
Table III. 2 Parameters for the determination of the shear strength and their limitations

\begin{tabular}{|c|c|}
\hline \multicolumn{2}{|l|}{ Common limitations for all Codes: } \\
\hline$\xi=1+V(200 / d) \leq 2.0$ & (1) \\
\hline$\rho_{l}=\left(A_{s}+A_{p}\right) /\left(b_{0} \cdot d\right) \leq 0.02$ & $(2)$ \\
\hline \multicolumn{2}{|l|}{ Particular limitations of each Code: } \\
\hline$\sigma_{c k}=\left[\left(N_{k}+P_{k}\right) /\left(b_{0} \cdot d\right)\right]<0.30 \cdot f_{c k} \leq 12 M p a(E H E-08)$ & (3) \\
\hline$\sigma_{c k}=\left[\left(N_{k}+P_{k}\right) /\left(b_{0} \cdot d\right)\right]<0.2 \cdot f_{c k}(E C 2$ and MC2010 for FRC) & (4) \\
\hline $\mathrm{k}_{\mathrm{f}}=1+\mathrm{n} \cdot\left(\mathrm{h}_{\mathrm{f}} / \mathrm{b}_{\mathrm{o}}\right) \cdot\left(\mathrm{h}_{\mathrm{f}} / \mathrm{d}\right) \leq 1.5($ EHE08 and RILEM $)$ & (5) \\
\hline$n=\left[\left(b_{f}-b_{o}\right) / h_{f}\right] \leq 3$ and $n \leq\left(3 \cdot b_{o} / h_{f}\right) \quad($ EHEO 8 and RILEM $)$ & (6) \\
\hline$V_{c u, \min }=\left[\left(0.075 / \gamma_{c}\right) \cdot \xi^{3 / 2} \cdot f c v^{1 / 2}+0.15 \cdot \sigma_{c k}\right] \cdot b_{o} \cdot d(E H E-08)$ & (7) \\
\hline$V_{c u, \min }=\left[0.035 \cdot \xi^{3 / 2} \cdot f c v^{1 / 2}+0.15 \cdot \sigma_{c k}\right] \cdot b_{o} \cdot d(E C 2 \& M C 2010$ for FRC) & (8) \\
\hline $0.5 \leq \operatorname{cotg} \theta \leq 2.0 \rightarrow 26.570 \leq \theta \leq 63.43 \circ$ (EHE-08) & (9) \\
\hline $1 \leq \operatorname{cotg} \theta \leq 2.5 \rightarrow 22^{\circ} \leq \theta \leq 45^{\circ}(E C 2)$ & (10) \\
\hline \multicolumn{2}{|l|}{$\beta$ determination (EHE-08): } \\
\hline$\beta=(2 \cdot \operatorname{cotg} \theta-1) /\left(2 \cdot \operatorname{cotg} \theta_{e}-1\right) ;$ if $0.5 \leq \operatorname{cotg} \theta<\operatorname{cotg} \theta_{e}$ & (11) \\
\hline$\beta=(\operatorname{cotg} \theta-2) /\left(\operatorname{cotg} \theta_{e}-2\right) ;$ if $\operatorname{cotg} \theta_{e} \leq \operatorname{cotg} \theta \leq 2.0$ & (12) \\
\hline \multicolumn{2}{|l|}{ Parameters influencing $V_{c u}(M C 2010):$} \\
\hline$\theta=290+7000 \cdot \varepsilon_{x}$ & $(13)$ \\
\hline$\varepsilon_{x}=\left[M_{E d} / z+V_{E d}+0.5 \cdot N_{E d}-A_{p} \cdot f_{p 0}\right] /\left[2 \cdot\left(E_{s} \cdot A_{s}+E_{p} \cdot A_{p}\right)\right]$ & (14) \\
\hline $\mathrm{k}_{\mathrm{v}}=0.4 \cdot 1300 /\left[\left(1+1500 \cdot \varepsilon_{\mathrm{x}}\right) \cdot\left(1000+0.7 \cdot \mathrm{k}_{\mathrm{dg}} \cdot z\right)\right] \quad$ if $\rho_{\mathrm{w}}=0$ & (15) \\
\hline $\mathrm{k}_{\mathrm{v}}=0.4 /\left(1+1500 \cdot \varepsilon_{\mathrm{x}}\right) \quad$ if $\rho_{\mathrm{w}} \geq 0.08 \cdot \mathrm{vf} \mathrm{f}_{\mathrm{ck}} / \mathrm{f}_{\mathrm{yk}}$ & (16) \\
\hline
\end{tabular}

\section{Table III. 3 Notation}

\begin{tabular}{|l|l|}
\hline$a$ & shear span \\
\hline$A_{p}$ & cross-sectional area of prestressed reinforcement \\
\hline$A_{s}$ & cross-sectional area of longitudinal tension reinforcement \\
\hline$A_{\alpha}$ & traditional shear reinforcement area \\
\hline$b_{f}$ & flange width \\
\hline$b_{o}$ & web width \\
\hline$d$ & effective depth \\
\hline$f_{b p t}$ & $\begin{array}{l}\text { constant bond stress at which the prestress is transferred to the concrete at } \\
\text { release of tendons }\end{array}$ \\
\hline$f_{c t d}(t)$ & $\begin{array}{l}\text { design tensile value of strength at time of release } \\
\text { characteristic tensile strength value for the concrete matrix }\end{array}$ \\
\hline$f_{c t k}$ & $\begin{array}{l}\text { characteristic ultimate residual tensile strength value for fiber-reinforced } \\
\text { concrete }\end{array}$ \\
\hline$f_{p 0}$ & stress in strands when the strain in the surrounding concrete is zero \\
\hline$f_{R 3 k}$ & $\begin{array}{l}\text { residual flexural tensile strength corresponding to CMOD=2.5mm (according to } \\
\text { EN 14645) }\end{array}$ \\
\hline$f_{R 4 k}$ & $\begin{array}{l}\text { residual flexural tensile strength corresponding to CMOD=3.5mm (according to } \\
\text { EN 14645) }\end{array}$ \\
\hline$f_{y \alpha, k}$ & yielding strength of shear reinforcement steel \\
\hline$I$ & second moment of area \\
\hline$k_{f}$ & factor to take into account the flanges contribution in the T-sections (EHE08 \\
\hline
\end{tabular}




\begin{tabular}{|c|c|}
\hline & and RILEM) \\
\hline$I_{\text {crit }}$ & critical length \\
\hline$I_{p t}$ & transfer length \\
\hline$I_{p t 2}$ & $\begin{array}{l}\text { upper bound value of the transmission length of the prestressing element: } \\
\mathrm{I}_{\mathrm{pt} 2}=1.2 \cdot \mathrm{I}_{\mathrm{pt}}\end{array}$ \\
\hline$I_{x}$ & distance of section considered from starting point of the transmission length \\
\hline$S$ & first moment of area above and about the centroidal axis \\
\hline$V_{c u}$ & design shear resistance attributed to concrete \\
\hline$V_{f u}$ & design shear resistance attributed to fibers \\
\hline$V_{\text {su }}$ & design shear resistance provided by shear reinforcement \\
\hline$V_{u 2}$ & design shear resistance \\
\hline$z$ & $\begin{array}{l}\text { internal lever arm corresponding to the maximum bending moment. In the } \\
\text { shear analysis, an approximate value } z=0.9 \cdot d \text { can be normally used }\end{array}$ \\
\hline$\alpha$ & inclination of stirrups in relation to the beam axis \\
\hline$\alpha_{1}$ & $=I_{x} / I_{p t 2} \leq 1$ for pretensioned tendons \\
\hline$\beta$ & reduction factor referred to the transmission length $(\beta=0.9)$ \\
\hline$\gamma_{c}$ & partial safety factor for concrete material properties \\
\hline$\gamma_{s}$ & $\begin{array}{l}\text { partial safety factor for the material properties of reinforcement and } \\
\text { prestressing steel }\end{array}$ \\
\hline$\varepsilon_{x}$ & longitudinal strain at the mid-depth of the member \\
\hline$\eta_{p 1}$ & $\begin{array}{l}\text { coefficient that takes into account the type of tendon and the bond situation } \\
\text { at release }\end{array}$ \\
\hline$\theta$ & inclination of the compression stresses \\
\hline$\theta_{\mathrm{e}}$ & reference angle of cracks inclination \\
\hline$\xi$ & factor that takes into account the size effect \\
\hline$\rho_{l}$ & reinforcement ratio for longitudinal reinforcement \\
\hline$\rho_{w}$ & percentage of shear reinforcement \\
\hline$\sigma_{c k}$ & $\begin{array}{l}\text { average stress acting on the concrete cross-section for an axial force due to } \\
\text { prestressing actions }\end{array}$ \\
\hline$\sigma_{p m 0}$ & tendon stress just after release \\
\hline$\varphi$ & reduction factor $(\varphi=0.8)$ \\
\hline$\phi$ & nominal diameter of the tendon \\
\hline
\end{tabular}




\title{
CHAPTER 4
}

\section{EXPERIMENTAL TESTS}

\author{
ON PARAMETERS
}

\section{INFLUENCING ON SHEAR}

\subsection{Introduction}

This chapter develops and explains the criteria for obtaining self-compacting fiber reinforced concrete (SCFRC) and the analysis of its production quality continuity in a precast industry and its ulterior application to produce prestressed concrete beams to minimize traditional transverse rebars.

An experimental program consisting in nine prestressed I-beams with unequal flange dimensions was developed to analyze fiber contribution to shear behavior.

The objective was to analyze shear behavior on real FRC prestressed beams, which are produced daily in a precast industry and are made with high-strength concretes. The main goals of this study were to:

On Shear Behavior of structural elements made of steel fiber reinforced concrete-PhD thesis 
- Propose a consistent SCFRC mix design adapted for continuous use in a precast industry.

- Evaluate the possibility of replacing all the transverse reinforcement and secondary rebars used for shear resistance in prestressed beams production.

- Analyze the current Codes that calculate shear strength capacity by means of their safety margins, which are obtained as the experimental to theoretical shear strength ratio.

- $\quad$ Check the possible influence of flange size on shear behavior.

\subsection{Concrete mix designs}

Reference SCC and a SCFRC with $60 \mathrm{~kg} / \mathrm{m}^{3}\left(\mathrm{~V}_{\mathrm{f}}=0.75 \%\right)$ of steel fibers were developed for this study. The aim of those concretes implied a nominal slump flow of $600 \mathrm{~mm}$ and an average compressive strength of about $60 \mathrm{MPa}$ at 28 days.

This objective was chosen to obtain self-compacting concretes with good compressive strength at early ages which can be placed, without vibration; this is in line with precast prestressed beam production demands.

The materials used were a CEM I 52.5R cement type and calcareous crushed aggregates: filler, sand and $7 / 12 \mathrm{~mm}$ size coarse aggregates. The fibers used were low carbon steel hooked-end steel: $40 \mathrm{~mm}$ length, $0.62 \mathrm{~mm}$ diameter, and a nominal aspect ratio (length/diameter) equal to 65 . These fibers are denominated by Bekaert@ as Dramix RC 65/40 BN.

The water/cement ratio and the superplasticizer dosage were respectively determined to reach the required strength and slump flow.

SCC mix design criteria [1], most of which were based on laboratory tests, suggest an increase in fine content. Naturally, a final application needs experimental verification under working conditions. When SCC has fibers, the quantity of fines has to be increased.

Based on the authors' previous research work [2], the concrete mix design was determined by adapting solid grading (including cement) to the theoretical Bolomey particle size distribution curve [3], defined as:

$$
p=a+(100-a)(d / D)^{1 / 2}
$$


where " $p$ " is the pass percentage through the " $d$ " sieve, " $D$ " is the concrete's maximum aggregate size and "a" is the Bolomey parameter [3], which depends on the desired workability of the concrete and aggregates properties.

For the concretes in this paper, the " $a$ " values used were: a=16 for SCC and a=20 for SCFRC. A relatively low "a" parameter was used because well graded sand was available.

Table 4.1 shows the mix design for both concretes. In Fig.4. 1, theoretical and actual particle size distribution curves are plotted.

Table 4. 1 Mix design adaptation $\left(\mathrm{kg} / \mathrm{m}^{3}\right)$

\begin{tabular}{|l|cc|}
\hline \multicolumn{1}{|c|}{$\left(\mathrm{kg} / \mathrm{m}^{\mathbf{3}}\right)$} & SCC & SCFRC \\
\hline 7/12 aggregate & 846 & 721 \\
\hline Sand & 924 & 985 \\
\hline Filler & 41 & 50 \\
\hline Cement & 440 & 460 \\
\hline Water & 198 & 205 \\
\hline Fibers (RC 65/40 BN) & 0 & 60 \\
\hline Superplasticizer & 11.1 & 12.8 \\
\hline W/C ratio & 0.45 & 0.45 \\
\hline
\end{tabular}

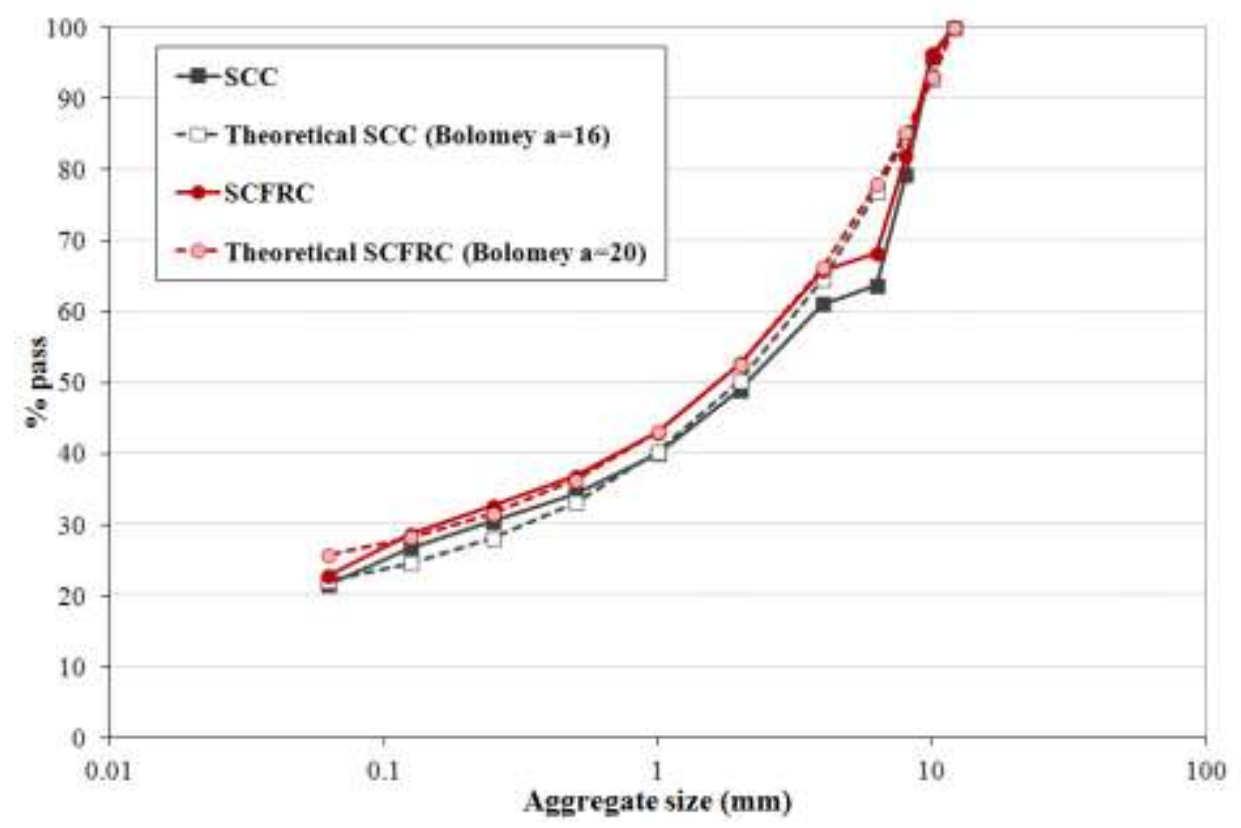

Fig.4. 1 Theoretical versus actual particle size distribution curves for selecting the mix design 


\subsection{Concrete properties and production control}

In Fig.4. 2, the pouring of SCFRC concrete into a beam formwork with no compacting process can be observed; a consistent mix design was obtained to be employed continuously in a precast industry.

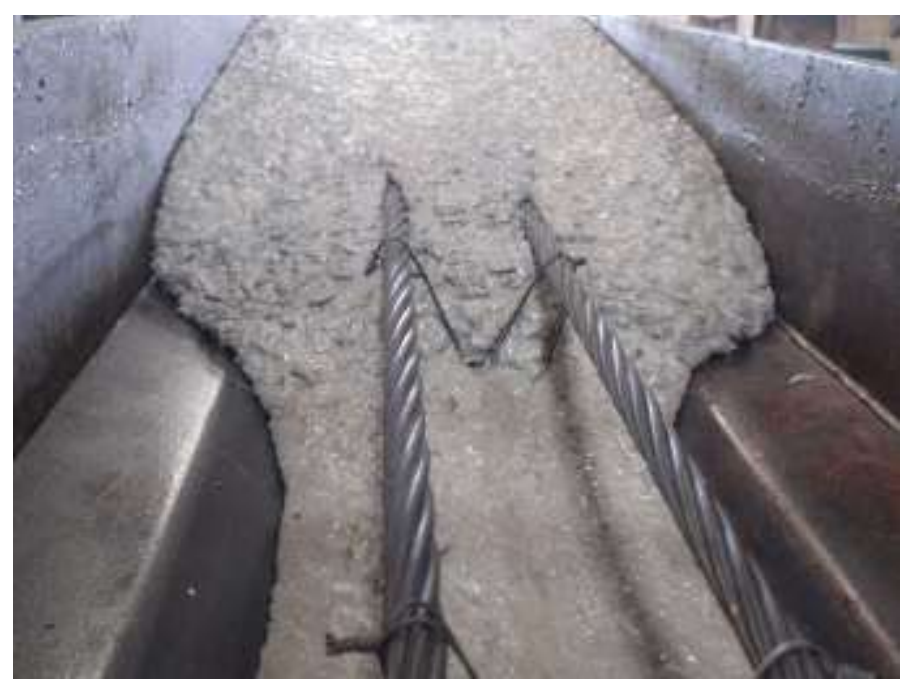

Fig.4. 2 Concrete pouring into the formwork

To analyze the mix design robustness, an exhaustive production quality control took place in the experimental program. To cast all nine programmed beams, a $2 \mathrm{~m}^{3}$ mix was used. Concrete was casted according to the utilities and conditions of a precast industry. The following tests were done with a sample from each mix: the slump-flow test (EN 12350-8), compressive strength test on $150 \times 300 \mathrm{~mm}$ cylinder specimens (EN 12390-3) and the flexural tensile strength test (EN 14651). The following was obtained from the flexural test: the limit of proportionality $\left(f_{c t t}\right)$ and the residual flexural tensile strength $\left(f_{R, j}\right)$ which corresponds to the crack mouth opening displacements (CMOD) linked to the crack openings (in $\mathrm{mm}$ ) of $0.5,1.5,2.5$ and 3.5 ( $\mathrm{j}=1,2,3,4$ respectively). All the mixes reached slump flow test values ranging between 550 and $710 \mathrm{~mm}$, which were sufficient to allow adequate concrete placing in the beams.

Table 4.2 shows the mechanical properties of the different concrete mixes for each beam. In order to facilitate the identification of the beams, each of them had a Specimen ID (Table 4.2). This identity took the following structure: 
\{Concrete: with fibers (HF) or without fibers $(H)\}$ - $\{$ Top flange width $(\mathrm{mm})\}-\{$ " $h$ " if depth $=800$, otherwise depth $=750 \mathrm{~mm}\}-\{$ "TR" if the beam has transverse reinforcement $\}$ \{number of the beam\}

For example, the beam HF600TR/1 is a beam made with fiber reinforced concrete transversally reinforced with stirrups with a top flange width equal to $600 \mathrm{~mm}$.

All the mechanical values (Table 4.2) were obtained as the average of three specimens 28 days after casting the beams. In order to analyze continuity on production, the averages, standard deviations (SD) and coefficients of variation (CoV) of the results are included.

Table 4. 2 Mechanical concrete properties (average values)

\begin{tabular}{|l|cccccc|}
\hline Specimen ID & $\mathbf{f}_{\mathrm{c}}[\mathrm{MPa}]$ & $\mathbf{f}_{\mathrm{ctl}}[\mathrm{MPa}]$ & $\mathbf{f}_{\mathrm{R} 1}[\mathrm{MPa}]$ & $\mathbf{f}_{\mathrm{R} 2}[\mathrm{MPa}]$ & $\mathbf{f}_{\mathrm{R} 3}[\mathrm{MPa}]$ & $\mathbf{f}_{\mathrm{R} 4}[\mathrm{MPa}]$ \\
\hline HF600TR/1 & 61.1 & 3.36 & 5.26 & 5.13 & -- & -- \\
\hline HF600TR/2 & 65.7 & 4.39 & 9.36 & 9.56 & 6.89 & 4.96 \\
\hline H600TR/3 & 52.4 & 3.64 & -- & -- & -- & -- \\
\hline HF600/4 & 65.4 & 4.70 & 10.46 & 7.99 & 6.24 & 5.12 \\
\hline HF600/5 & 65.9 & 4.20 & 8.55 & 8.43 & 5.55 & 3.92 \\
\hline HF400h/6 & 59.5 & 4.45 & 8.96 & 7.49 & 5.96 & 4.57 \\
\hline HF400/7 & 63.5 & 4.08 & 6.64 & 6.70 & 4.77 & 3.41 \\
\hline HF400/8 & 70.0 & 4.33 & 8.10 & 7.02 & 4.68 & 3.13 \\
\hline HF260/9 & 65.0 & 3.11 & 6.45 & 4.38 & -- & -- \\
\hline Average & 63.17 & 4.03 & 7.97 & 7.09 & 5.68 & 4.18 \\
\hline SD & 4.75 & 0.51 & 1.61 & 1.59 & 0.79 & 0.75 \\
\hline CoV (\%) & 8 & 13 & 20 & 22 & 14 & 18 \\
\hline
\end{tabular}

It is noteworthy that a brittle behavior of the fibers was observed during the flexural tensile strength tests, as deduced from the fact that $f_{R, 3}$ and $f_{R, 4}$ are clearly lower than $f_{R, 2}$. The $2 \mathrm{~mm}$ crack opening was often reached with the severance of several fibers without them sliding out of the concrete, and sometimes a brittle rupture was obtained before being able to determine the crack opening to $f_{R, 3}$ and $f_{R, 4}$. The values in Table 4.2 correspond to the results of at least two specimens. A possible reason of the brittle rupture of the fibers could be due to fact of combine a high-strength concrete matrix with steel fibers of low modulus, low carbon (65/40BN). To analyze properly this fact a complete experimental campaign have been developed in this $\mathrm{PhD}$ thesis to analyze the toughness properties of different types of concrete, made with several compressive strength levels and several types of steel fibers, for that see Chapter 6 of this PhD thesis.

The smallest variation was obtained for compressive strength with a CoV value of $8 \%$. Residual flexural strengths presented greater variability, with CoV values of between $13 \%$ and $22 \%$. This means than, even for residual flexural strength, dispersion can be controlled 
at levels only slightly higher than those obtained for compression strength in traditional concrete production when casting is performed under precast industry conditions.

Di Prisco [4] obtained a higher dispersion for the residual parameters, corresponding to an SCFRC used as a top slab (26.8\% to $34.6 \%$ ) when casting concrete with a small amount of fibers and under in situ production conditions.

\subsection{Experimental program and results analysis}

\subsubsection{Main variables and beams production}

Nine six meters long prestressed I-beams with unequal flange dimensions were cast. Fig.4. 3 shows the beams cross-section and reinforcement.
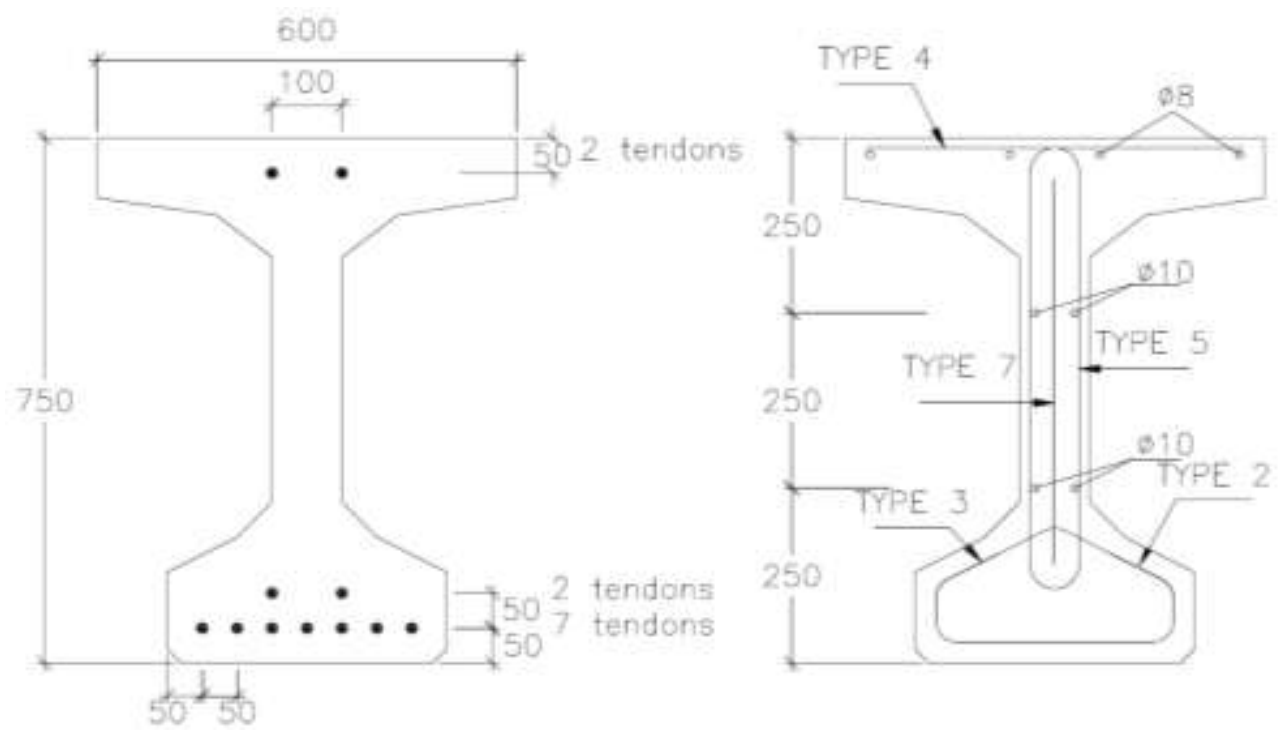

Fig.4. 3 Cross-section. Dimensions in $\mathrm{mm}$

Beams were prestressed over-reinforced longitudinally with 11 tendons (0.6" diameter with a nominal cross-section equal to $140 \mathrm{~mm}^{2}$ ) of 7 wires ( $\mathrm{Y} 1860 \mathrm{S7}$ ). Their initial tension was $1354 \mathrm{MPa}$ (before pre-stress losses, which can approximately account for $26.2 \%$ ). This reinforcement guaranties a beam failure by shear when tested. This longitudinal reinforcement implies a $\rho_{l}=1.83 \%$ for all the beams, except for specimen HF400h/6 with $\rho_{l}=1.71 \%$. All the rebars used for stirrups or additional reinforcement were made out of steel B 500 S type.

The experimental program variables were: 
- Top flange width (260 mm; $400 \mathrm{~mm} ; 600 \mathrm{~mm}$ )

- Concrete type (SCC or SCFRC)

- Presence or absence of traditional transverse reinforcement ( $\phi 8$ stirrups each 300 $\mathrm{mm}$, amount indicated in Table 4.3 as $\$ 8 @ 300 \mathrm{~mm}-2$ legs)

- Use of additional reinforcement, which is normally placed in beams made with SCC to control secondary failures (Fig.4. 3 and Fig.4. 4)

- The effect of a depth increase of the top flange was also analyzed, where the depth of the beam ( $h$ ) was either 750 or $800 \mathrm{~mm}$.

One additional reinforcement (type 7) was placed at both ends of all the beams to avoid longitudinal shear failures placed in the transition web-flange.

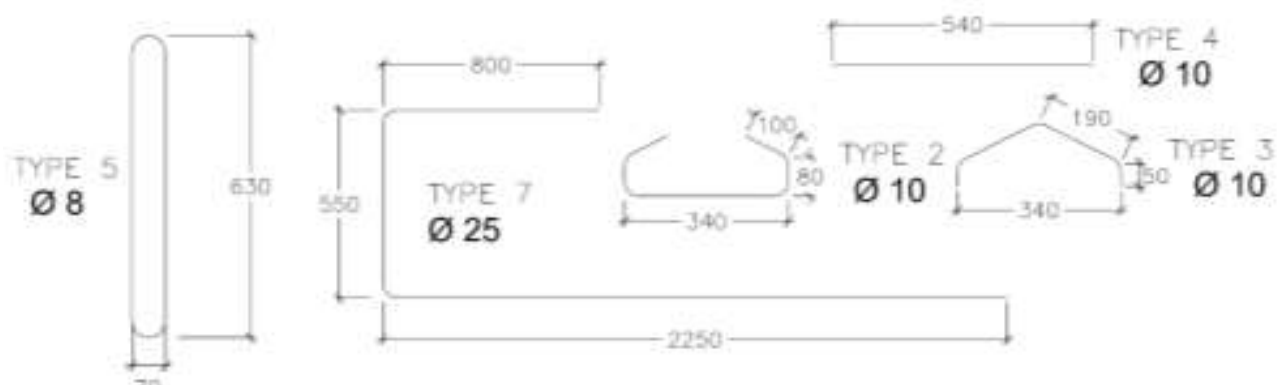

Fig.4. 4 Additional reinforcement typologies. Dimensions in $\mathrm{mm}$

Table 4. 3 shows the combination of variables for each tested beam.

Table 4. 3 Main study variables

\begin{tabular}{|c|ccccc|}
\hline Specimen ID & $\begin{array}{c}\text { Top flange } \\
\text { width }(\mathbf{m m})\end{array}$ & $\begin{array}{c}\text { Transverse } \\
\text { reinforcement }\end{array}$ & $\begin{array}{c}\text { Fibers } \\
\left(\mathbf{k g} / \mathbf{m}^{\mathbf{3}}\right)\end{array}$ & $\begin{array}{c}\text { Depth } \\
(\mathbf{m m})\end{array}$ & $\begin{array}{c}\text { Additional } \\
\text { reinforcements } \\
\text { (types) }\end{array}$ \\
\hline HF600TR/1 & 600 & $\phi 8 @ 300 \mathrm{~mm}-2$ legs & 60 & 750 & $2,3,4$ \\
\hline HF600TR/2 & 600 & $\phi 8 @ 300 \mathrm{~mm}-2$ legs & 60 & 750 & 2 \\
\hline H600TR/3 & 600 & $\phi 8 @ 300 \mathrm{~mm}-2$ legs & 0 & 750 & $2,3,4$ \\
\hline HF600/4 & 600 & 0 & 60 & 750 & $2,3,4$ \\
\hline HF600/5 & 600 & 0 & 60 & 750 & - \\
\hline HF400h/6 & 400 & 0 & 60 & 800 & - \\
\hline HF400/7 & 400 & 0 & 60 & 750 & - \\
\hline HF400/8 & 400 & 0 & 60 & 750 & $2,3,4$ \\
\hline HF260/9 & 260 & 0 & 60 & 750 & - \\
\hline
\end{tabular}




\subsubsection{Testing procedure}

Beams were tested as simple supported and were subjected to two load points. The distance between supports was $5.00 \mathrm{~m}$ and the shear span/depth ratio $(a / d)$ was 3.0 for all cases, except for beam HF400h/6 where was equal to 2.8 .

The two loads were applied to the beams by one $2500 \mathrm{kN}$ hydraulic jack. Loads were applied at a rate of $0.5-2.0 \mathrm{kN} / \mathrm{s}$. To monitor the behavior of the tested beams, the applied loads and vertical deflections were measured using a load cell and three displacement transducers placed on the middle span and over the middle of each shear span. All the variables were registered continuously by the data acquisition system. Photography and video equipment were also utilized in both the shear span zones on both sides of the beams. A synchronized recording system allowed us to report each photogram to the corresponding applied load. Later, the maximum shear crack opening versus the load curve was reported by means of a photo analysis. Fig. 4 . 5 shows the test set-up.

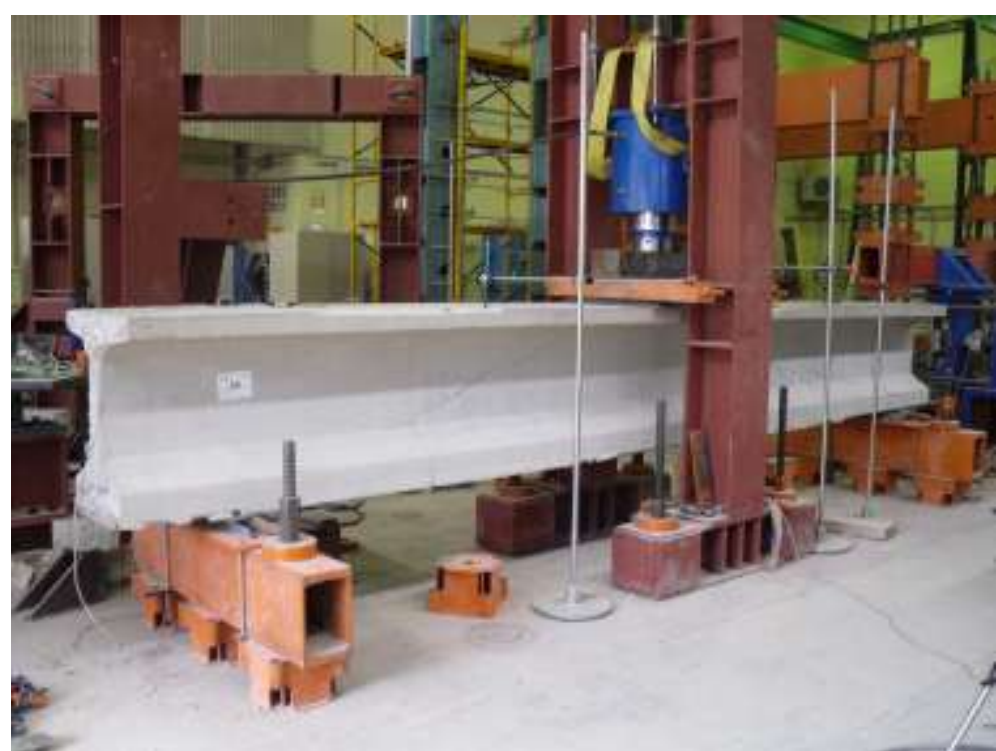

Fig.4. 5 Beam during shear test

\subsubsection{Results}

As expected, all the beams had a shear failure and presented diagonal cracks with flexural cracks of very little consequence. Table 4.4 offers the maximum load obtained for each beam. Greater shear capacity was obtained when stirrups and fiber acted simultaneously (Beams HF600TR/1 and HF600TR/2), reaching a value of $18.5 \%$ higher than that of the 
beam with only traditional stirrups (Beam H600TR/3). No significant difference was found between the two beams with both stirrups and fibers. The additional reinforcement types 3 and 4 in Beam HF600TR/2 did not imply any shear capacity improvement.

Table 4. 4 Experimental shear strength $(\mathrm{kN})$ for each tested beam

\begin{tabular}{|l|cc|}
\hline Specimen ID & $\begin{array}{c}\boldsymbol{V}_{\text {test }} \\
\text { (All beams) }\end{array}$ & $\begin{array}{c}\boldsymbol{V}_{\text {test }} \\
\text { (Beams only with fibers, not stirrups) }\end{array}$ \\
\hline HF600TR/1 & 571.61 & --- \\
\hline HF600TR/2 & 592.70 & --- \\
\hline H600TR/3 & 491.34 & --- \\
\hline HF600/4 & 392.44 & 392.44 \\
\hline HF600/5 & 347.17 & 347.17 \\
\hline HF400h/6 & 420.03 & --- \\
\hline HF400/7 & 389.95 & 389.95 \\
\hline HF400/8 & 428.31 & 428.31 \\
\hline HF260/9 & 325.58 & 325.58 \\
\hline Average & -- & 376.69 \\
\hline SD & -- & 36.26 \\
\hline CoV (\%) & -- & 9.62 \\
\hline
\end{tabular}

The beam with only stirrups also presented greater shear strength (an average of 30.4\%) than all the other beams with only fibers as shear reinforcement.

The differences among the beams with only fibers as shear reinforcement were clearly less significant. Although beam HF260/9 presented the lower shear strength, it is not possible to confirm any clear influence of the flange width as there is not a clear influence between flange widths of 400 or $600 \mathrm{~mm}$ (Fig.4.6). Table 4.4 provides the test values of the shear strength of only fiber reinforced beams of the same height. The low CoV value (9.62\%) was similar to the compressive strength dispersion found in this research and indicates lack of flange influence. It seems that these additional reinforcement (types 2, 3, and 4) could have some influence for beams with only fibers (and not stirrups), although there are not enough data to confirm it. If fibers contribution to shear depended on fibers efficiency, it would be possible to find a correlation between the shear strength of the beams and their concrete flexural residual strength. Nevertheless, no clear trend was obtained (Fig.4. 7), meaning that the flexural test method dispersions were greater than the effect on beam shear capacity. 


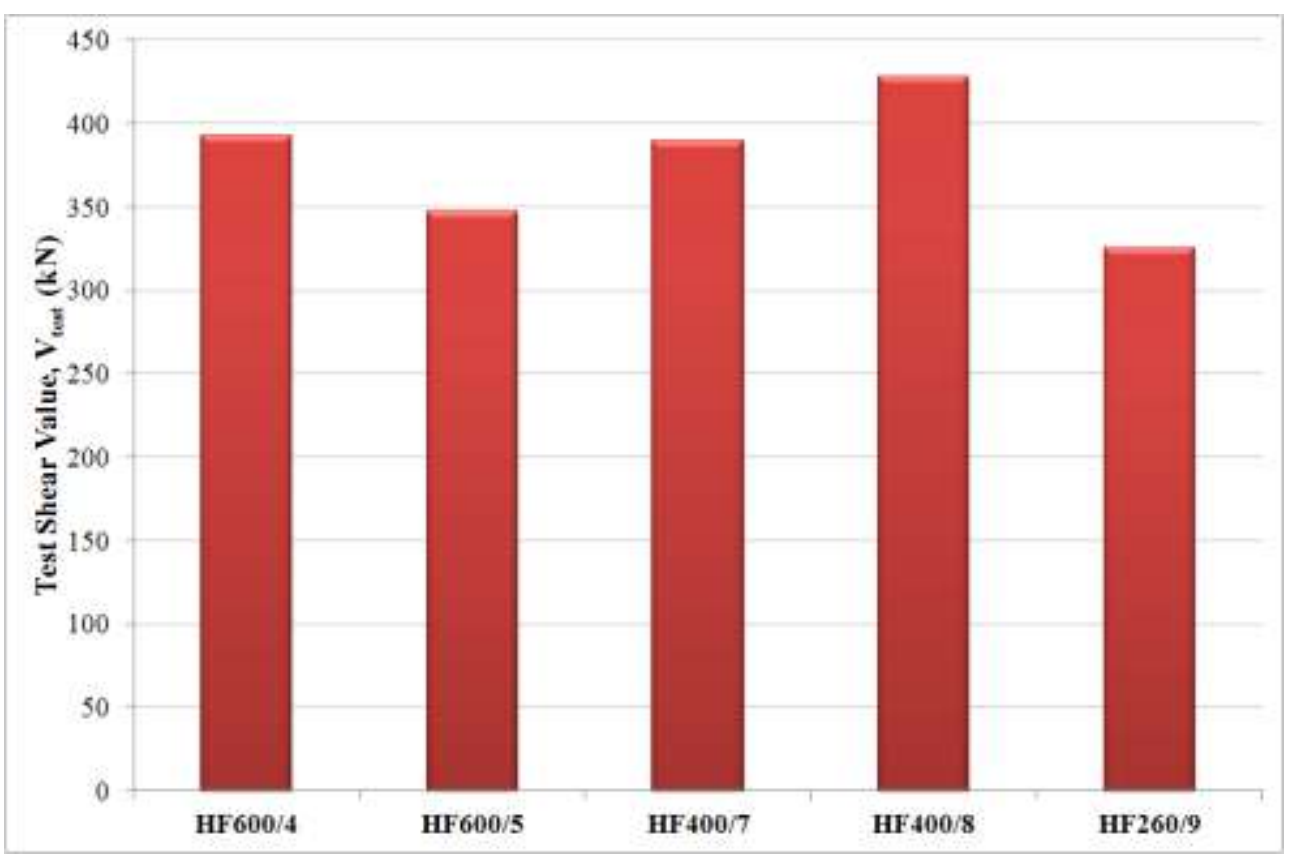

Fig.4. $6 \mathrm{~V}_{\text {test }}(\mathrm{kN})$ comparison of fiber-reinforced beams with a variable top flange width

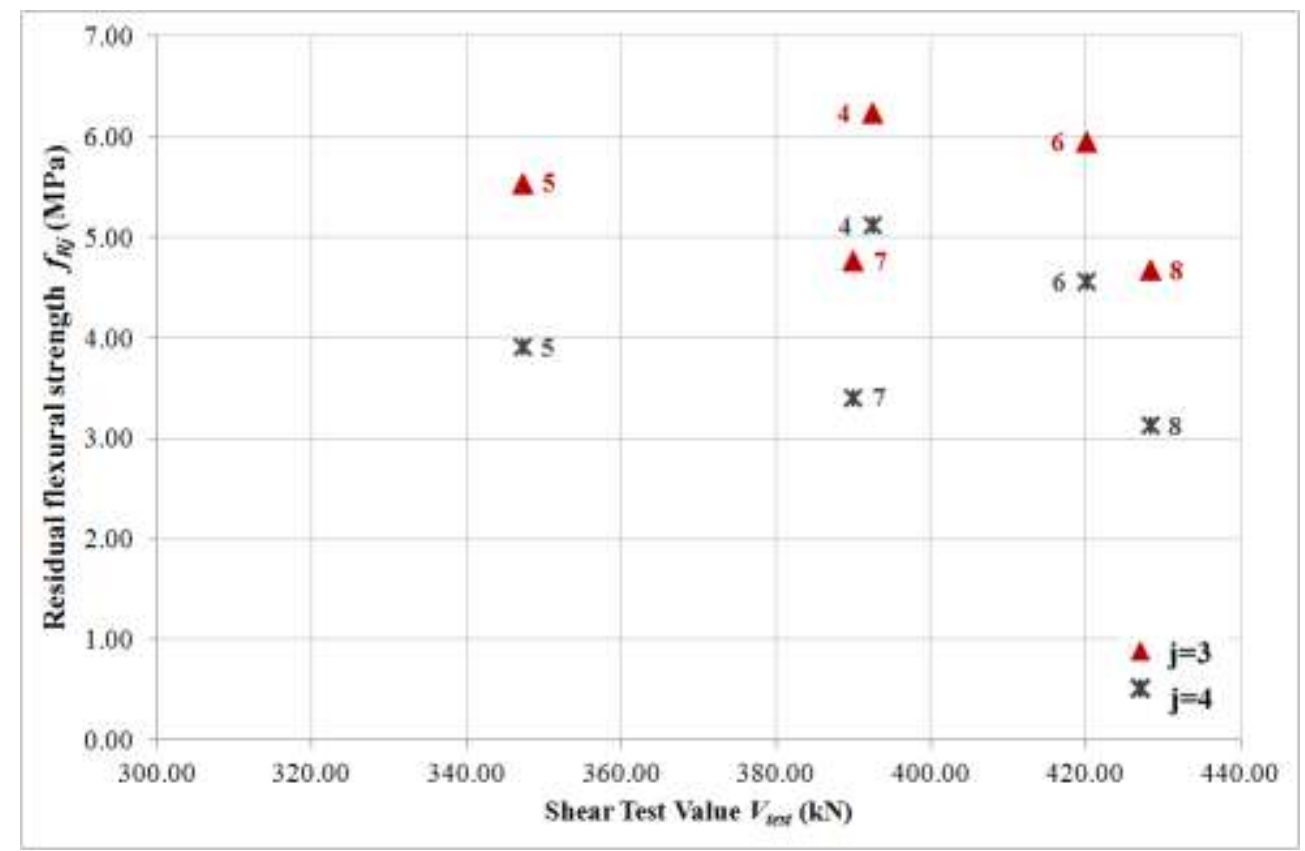

Fig.4. $7 \mathrm{~V}_{\text {test }}-\mathrm{f}_{\mathrm{Rj}}$ response for each beam (the number of the beam is next to each point) 
Based on this reflection, when analyzing the parameters influencing shear capacity (see 6.4.4), concrete residual flexural strength was considered a fix parameter, which was evaluated as the average of the residual strength obtained in the eight beams made with fibers. Identical criteria were applied for concrete compressive strength.

\subsubsection{Load-deflection response}

Fig.4. 8 shows the Load-mid span deflection response for one beam for each combination of top flange width and shear reinforcement conditions. In order to obtain a clearer graph, other beams were eliminated to provide no additional information. Compared with other tested beams, those with stirrups and fiber shear reinforcement showed a more ductile failure with controlled post-peak behavior. All the other beams, including this one with only stirrups and no fibers, revealed brittle failure with a sharp drop after the peak. No clear differences in ductility (post-peak behavior) were observed between the beams reinforced only with either fibers or stirrups.

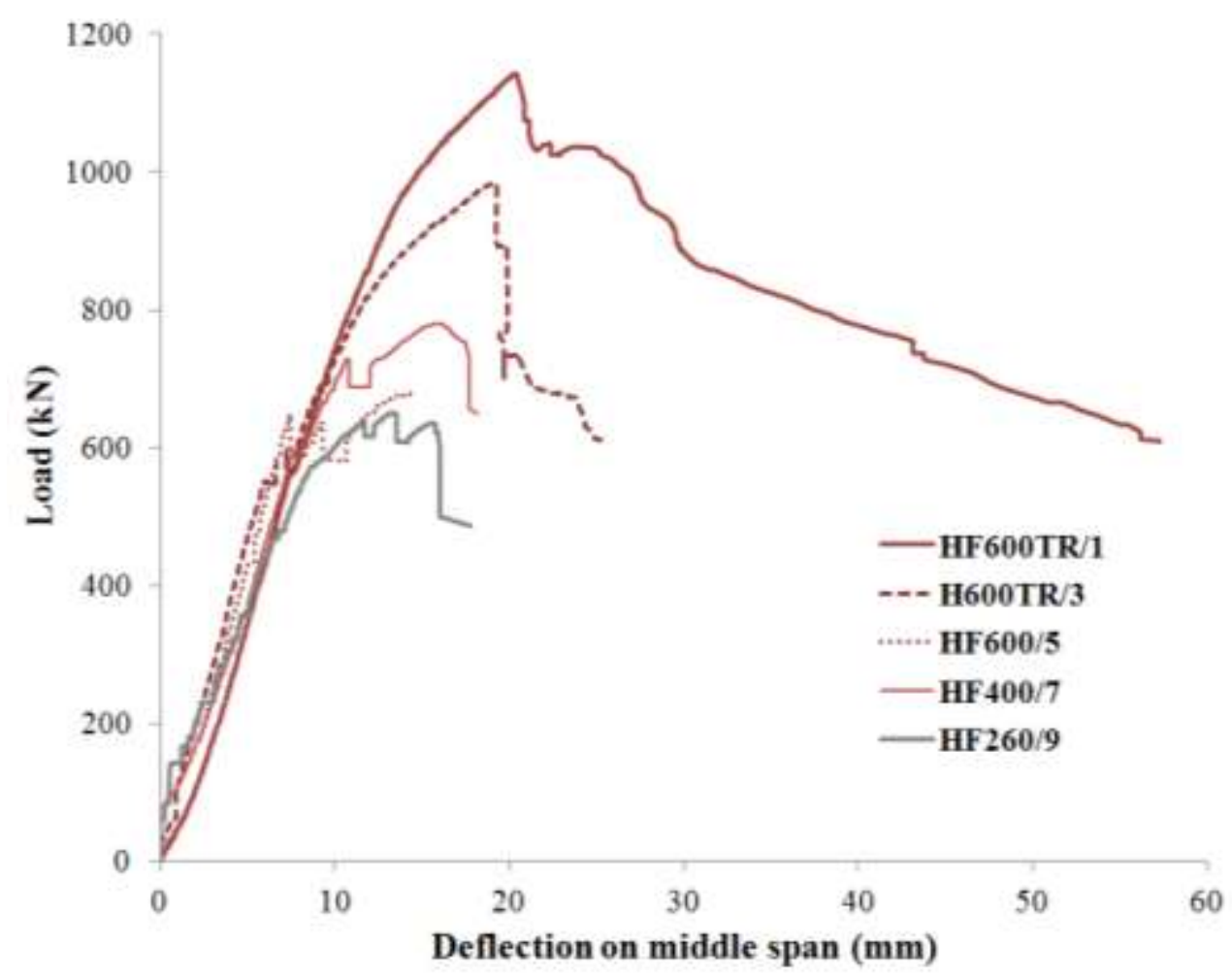

Fig.4. 8 Load-deflection responses on middle span

On Shear Behavior of structural elements made of steel fiber reinforced concrete-PhD thesis 


\subsubsection{Cracking pattern and Load-Crack width response}

The cracking pattern evolution on shear span at different loads is illustrated in Fig.4. 9 as a selection of the main types of beams with the same geometry.

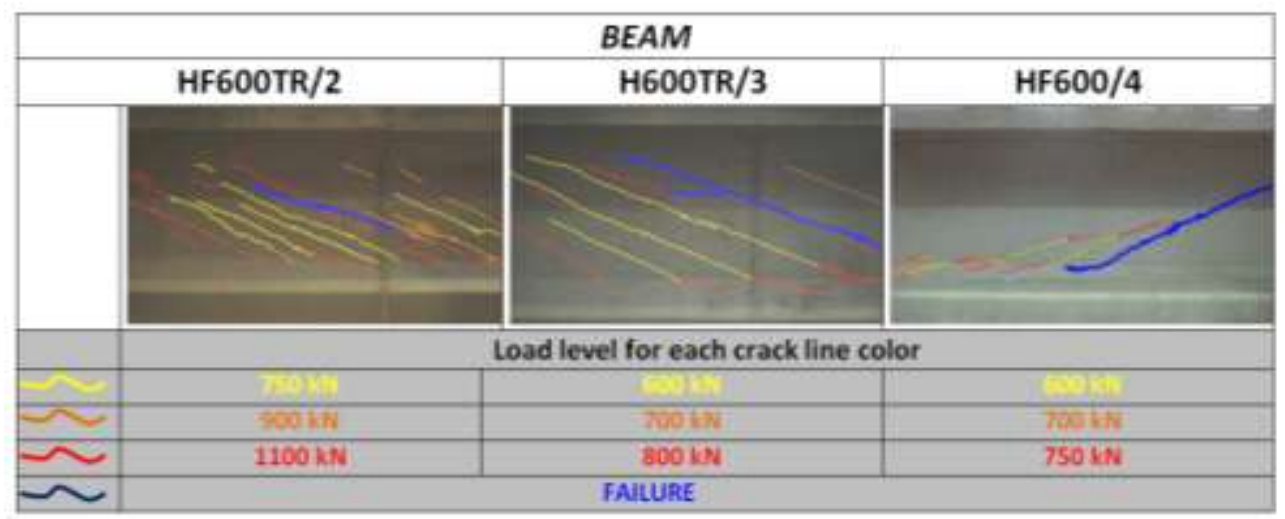

Fig.4. 9 Cracking patterns. Crack appearance and its corresponding load level

Fig.4. 10 represents the Load-Crack width response of these same beams. These figures allow us to analyze the influence of their shear reinforcement: transverse reinforcement (TR), fibers, or both. The other analyzed variables produced no remarkable difference in this behavior. These figures enable an assessment of the width, quantity and spacing among the cracks throughout the loading process.

The average crack inclination was very close to 22 의 all the beams.

For those beams reinforced to shear only with fibers (Beam HF600/4), only a few cracks developed upon low loads $(\approx 600 \mathrm{kN})$, and only one of them opened quickly. For Beam H600TR/3, which had only traditional reinforcement, cracks were more profuse, very straight and extremely parallel. Upon very low loads $(\approx 600 \mathrm{kN})$, some crack openings close to $0.3 \mathrm{~mm}$ were noted and rapidly progressed. For all the SCFRC beams, and for the beam with only stirrups, the crack which produced the failure either coincided with a previous crack or was generated from previous cracks. For Beam HF600TR/2 (which had traditional reinforcement and fibers), a larger number of cracks developed, with a narrower gap between them and a thin opening remained. It was necessary to reach a high load level to appreciate shear cracks, and shear cracks reached values of $0.2 \mathrm{~mm}$ only near ultimate loads. Cracks increased gradually, but in a way that was easy to control. The crack that finally produced the failure developed upon a very high load, involved two previous parallel cracks and produced a flatter final crack slope. 
In conclusion, clearly improved ductility was detected only when stirrups was placed on an SCFRC beam and when addition of fibers to the traditional transverse reinforcement led to a $35 \%$ increment in the maximum load for the same crack width. The crack width of the beam with traditional transverse reinforcement only (Beam H600TR/3) was $0.4 \mathrm{~mm}$ for a load of $750 \mathrm{kN}$. The same beam, but with fibers (Beam HF600TR/2), reached an ultimate, $35 \%$ higher load (1150kN) than without fibers.

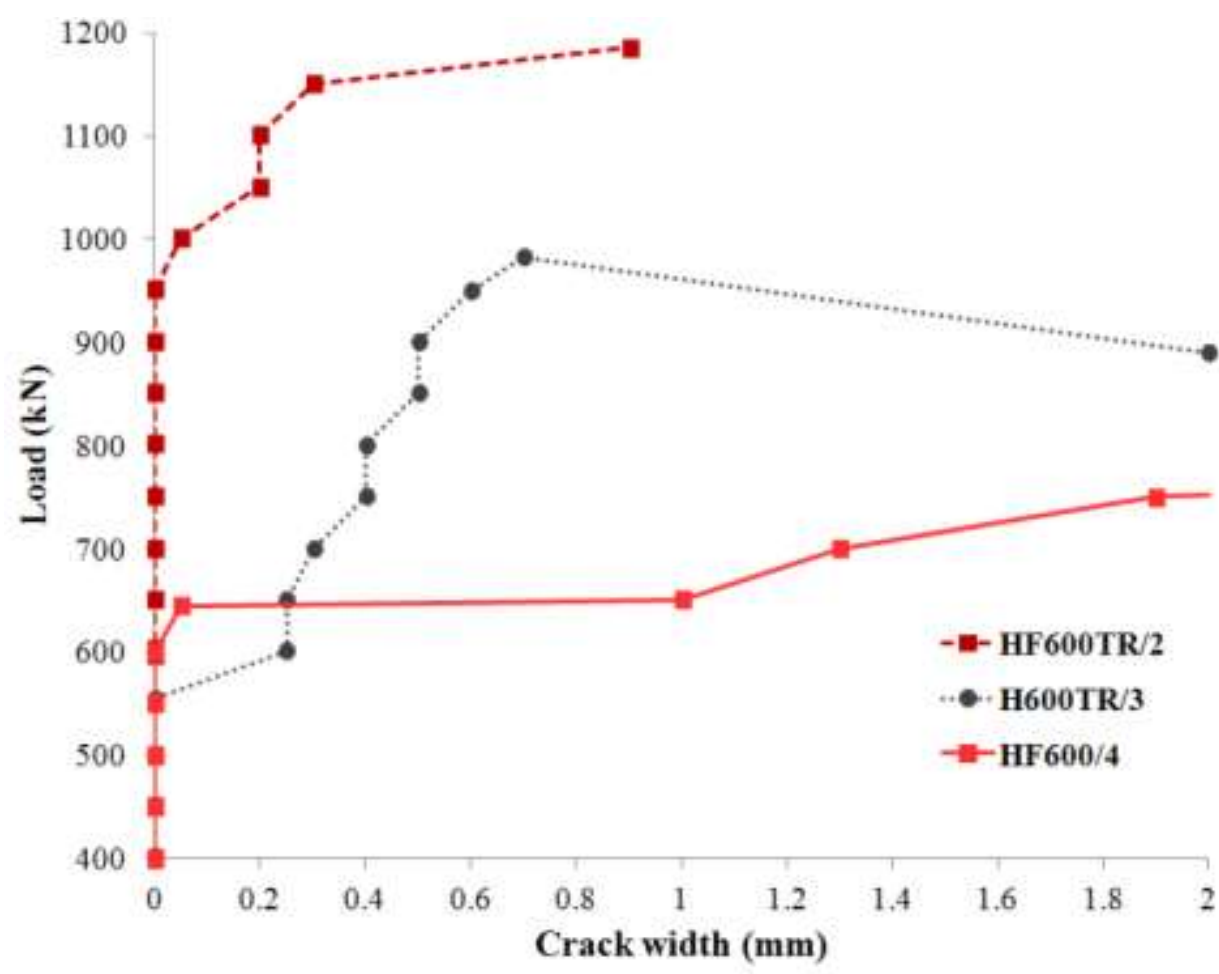

Fig.4. 10 Crack widths $(\mathrm{mm})$ on beams for different shear reinforcement combinations

\subsubsection{Shear values calculated with the current Design Codes}

Shear strength capacities were calculated by the formulation of current Codes EHE08 [5], EC2 [6] and MC2010 [7]. As EC2 has no formulation which takes into account fiber contribution, it was calculated by following the RILEM guidelines [8] (see Introduction to Part III). On the other hand, here in advance in this PhD thesis, when it is referred to the MC2010, this is the version of the first complete draft, because it was the version which was present during the development of this thesis.

On Shear Behavior of structural elements made of steel fiber reinforced concrete-PhD thesis 
No Code considers any explicit influence of cracks inclination on the fibers contribution evaluation or proposes any fibers effect on the $\theta$ value to be considered in the shear reinforcement contribution $\left(V_{s u}\right)$. Consequently, fibers are considered separately to stirrups.

In this way, the theoretical shear strength values were calculated by the following criteria for each Code:

- MC2010: Beam H600TR/3 (without fibers) was calculated by applying the most accurate form (Level III of Approximation), which permits the calculation of $\varepsilon_{x}$ and directly calculates the corresponding inclination of the compression stresses $(\theta)$. Level III of Approximation was based directly on the equations of the Modified Compression Field Theory (MCFT) [9]. Other beams (with fibers) were calculated by applying the formula proposed in MC 2010 (see subsection 4.7.7), which includes the effect of fibers inside the concrete matrix contribution.

- EHEO8: This reference angle of cracks inclination $\left(\theta_{\mathrm{e}}\right)$ was taken to be equal to the inclination of compression stresses $(\theta): \theta=\theta_{\mathrm{e}}$. And, $\theta$ value was calculated according to the "General method" of the EHEO8, analogous to the MCFT.

- EC2: When considering shear in beams with stirrups, EC2 neglects the concrete contribution to shear $\left(V_{c u}\right)$. Several authors, including the EC2 authors, have doubts about concrete contribution to shear when stirrups are needed. Cladera and Marí [ [10], [11]] concluded that the EC2 procedure is very easy to use but its results are very scattered. On the one hand, it may be too conservative for slightly shearreinforced beams or for prestressed beams; on the other hand, it may prove slightly underestimated for heavily reinforced members. For the EC2, $\theta$ value was determined equaling the ultimate capacity $\left(V_{u, 3}\right)$ for yielding stirrups with the ultimate capacity $\left(V_{u, 2}\right)$ for crushing of concrete struts, see Commentary to Eurocode [12] and Fig.4.11. For all beams, $\theta \approx 13$ o were obtained so, $\theta$ values were lower than the minimum bound value $21.8^{\circ}$, corresponding to $\operatorname{cotg} \theta=2.5$, therefore for calculations $\theta=21.8$ o was used. 


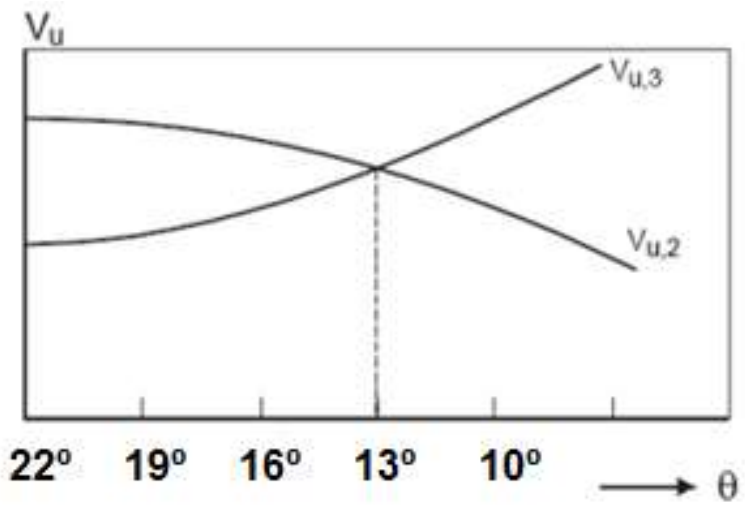

Fig.4. 11 Dependence of $\mathrm{V}_{\mathrm{u}, 2}$ and $\mathrm{V}_{\mathrm{u}, 3}$ on the strut inclination $\theta$ [12]

To obtain real predictable resistance concrete, partial safety factors for material properties were considered in the calculation as $\gamma_{c}=1$ and $\gamma_{s}=1$. Moreover, average values were utilized when a characteristic value appeared in a formula.

Code formulas include limitations on several parameters such as the $\rho_{\text {, reinforcement ratio }}$ for longitudinal reinforcement, the $\xi$ factor which takes into account the size effect, the $\sigma_{c k}$ average stress acting on the concrete cross-section for an axial force due to prestressing actions and minimum concrete contribution to shear $V_{c u}$, as presented in the Introduction to Part III. None of these limitations affected the values calculated in the beams tested for this experimental program.

Table 4.5 presents the theoretical shear strength values calculated with the current Codes for each beam.

Table 4. 5 Shear strength $(\mathrm{kN})$ calculated from the current Design Codes without safety factors

\begin{tabular}{l|cccc}
\hline Specimen ID & $\boldsymbol{V}_{\text {test }}$ & $\boldsymbol{V}_{\text {EHEO8 }}$ & $\boldsymbol{V}_{\text {EC2 }+ \text { RILEM }}$ & $\boldsymbol{V}_{\text {MC2010 }}$ \\
\hline HF600TR/1 & 571.61 & 491.21 & 423.76 & 474.40 \\
HF600TR/2 & 592.70 & 491.21 & 423.76 & 474.40 \\
H600TR/3 & 491.34 & 384.99 & 331.55 & 404.34 \\
\hline HF600/4 & 392.40 & 281.62 & 290.97 & 249.58 \\
HF600/5 & 347.20 & 281.62 & 290.97 & 249.58 \\
HF400h/6 & 420.00 & 298.81 & 308.86 & 261.58 \\
HF400/7 & 390.00 & 292.91 & 302.40 & 259.42 \\
HF400/8 & 428.30 & 292.91 & 302.40 & 259.42 \\
HF260/9 & 325.60 & 292.19 & 300.72 & 269.24 \\
\hline
\end{tabular}


Fig.4.12 and Fig.4.13 represent contributions to shear by means of concrete, stirrups and fibers for the current Codes: the Spanish Code EHE08, EC2 and MC2010 for all of the beams tested. In Fig.4.12, the results were evaluated by considering average values without applying safety factors. Fig.4.13 reproduces the values evaluated by considering design values. Design values were obtained by dividing the characteristic value by its corresponding material safety factor.

As all the formulas (except MC2010 for concrete without fibers) include an identical and explicit term after considering the favorable effect of prestressing reinforcement on concrete contribution, a line with the level of this effect has been represented in Fig.4.12 and Fig.4.13.

Fig.4.12 shows how the fibers effect is underestimated by the Codes, mostly by MC2010. Finally, Table 4.6 reports the shear contributions as a percentage due to stirrups, concrete and fibers.

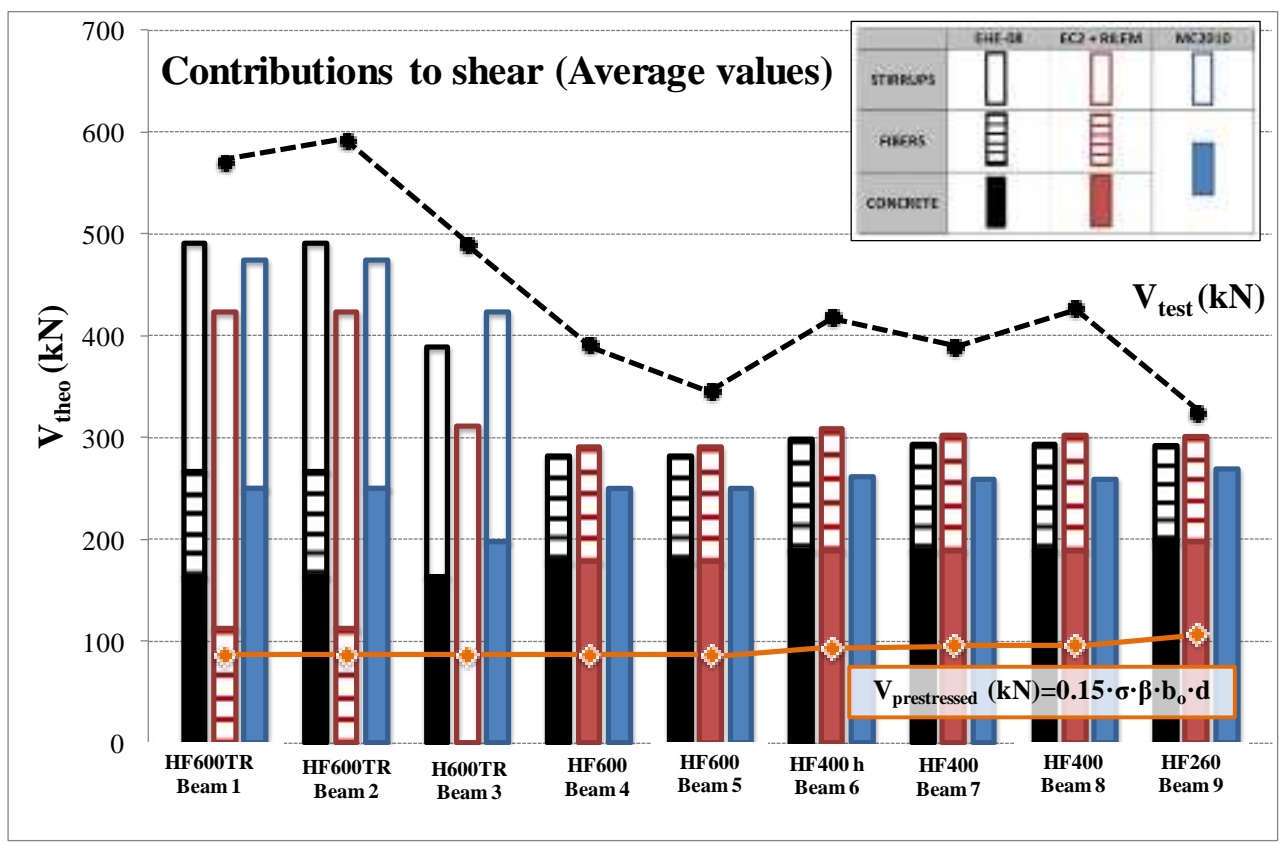

Fig. 4.12 Contributions of concrete, stirrups and fibers to the ultimate theoretical shear strength capacity (average values) 


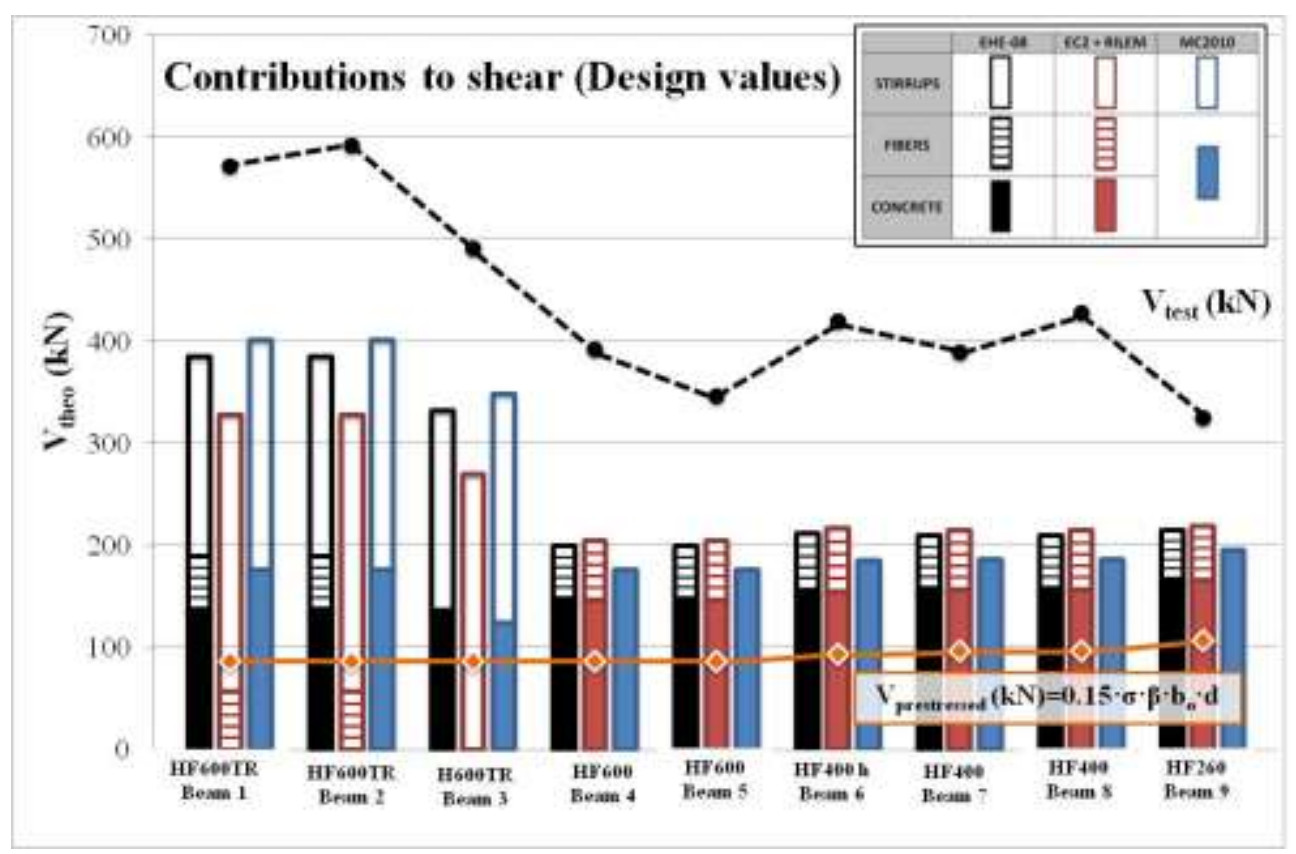

Fig. 4.13 Contributions of concrete, stirrups and fibers to the ultimate theoretical shear strength capacity (design values)

Table 4. 6 Shear contributions (\%) due to stirrups, concrete and fibers according to the current Design Codes (without safety factors)

\begin{tabular}{|c|c|c|c|c|c|c|c|c|c|}
\hline \multirow{2}{*}{$\begin{array}{l}\text { Specimen } \\
\text { ID }\end{array}$} & \multicolumn{3}{|c|}{ EHE08 } & \multicolumn{3}{|c|}{ EC2+RILEM } & \multicolumn{3}{|c|}{ MC2010 } \\
\hline & Stirrups & Concrete & Fibers & Stirrups & Concrete & Fibers & Stirrups & Concrete & Fibers \\
\hline HF600TR/1 & 46 & 33 & 21 & 74 & 0 & 26 & 47 & 5 & \\
\hline HF600TR/2 & 46 & 33 & 21 & 74 & 0 & 26 & 47 & 5 & \\
\hline H600TR/3 & 58 & 42 & 0 & 100 & 0 & 0 & 56 & 44 & 0 \\
\hline HF600/4 & 0 & 63 & 37 & 0 & 61 & 39 & 0 & 10 & \\
\hline HF600/5 & 0 & 63 & 37 & 0 & 61 & 39 & 0 & 10 & \\
\hline $\mathrm{HF} 400 \mathrm{~h} / 6$ & 0 & 63 & 37 & 0 & 61 & 39 & 0 & 10 & \\
\hline HF400/7 & 0 & 64 & 36 & 0 & 62 & 38 & 0 & 10 & \\
\hline HF400/8 & 0 & 64 & 36 & 0 & 62 & 38 & 0 & 10 & \\
\hline HF260/9 & 0 & 68 & 32 & 0 & 66 & 34 & 0 & 10 & \\
\hline
\end{tabular}

\subsubsection{Flange effect on shear strength.}

The $k_{f}$ factor in Codes EHE08 and RILEM, which takes into account flange contribution in the T-sections calculated by the formula reported in the Introduction to Part III, was assumed equal to 1 for rectangular sections, yet increased when there was a flange. For the cases presented herein, $k_{f}$ was equal to 1.5 for width flanges of up to $400 \mathrm{~mm}$, and $k_{f}$ equaled 1.35 for the smallest flange width tested $(260 \mathrm{~mm})$. In Fig.4.14, the EC2 safety 
margins (SM) were plotted for the beams only reinforced with steel fibers. In this graph, the theoretical values were obtained with the EC2 formulations, and the RILEM proposal was added to evaluate the shear contribution due to steel fibers. Four different options were calculated:

1. $k_{f}=1.5$ was applied to all the cases.

2. Without the $k_{f}$ application, then $k_{f}=1$.

3. $k_{f}$ was applied exactly as proposed in the RILEM approach.

4. $k_{f}$ was applied as proposed in the RILEM approach, but without its limitations.

When $k_{f}$ was not applied ( $2^{\text {nd }}$ option), highly conservative SM (safety margin) values were obtained. If we observe the 4th option ( $k_{f}$ without limitation), it is clear that SM lowered for $600 \mathrm{~mm}$ flange widths, meaning that the application of limitations was necessary. In subsection 4.4.3 it was concluded that, although the beam with the smallest flange width $\left(b_{f}=260 \mathrm{~mm}\right)$ presented the lowest shear strength, it was not possible to confirm any clear influence of the flange width as no clear differences in shear strength were observed for beams with flange widths up to $400 \mathrm{~mm}$. This idea corresponds directly with the results represented in Figure 4.14, in which the most balanced option (when comparing the theoretical and experimental results) may be obtained by applying the corresponding $k_{f}$ value ( $3^{\text {rd }}$ option) for the cases in which $h_{f}>400 \mathrm{~mm}$. Only the beam with a low $b_{f}$ value $\left(b_{f}=260 \mathrm{~mm}\right.$ ) was not conservative enough with this criterion. For this case, it cannot be considered that the width flange has an influence in shear strength and, therefore, $k_{f}=1$ should to be applied.

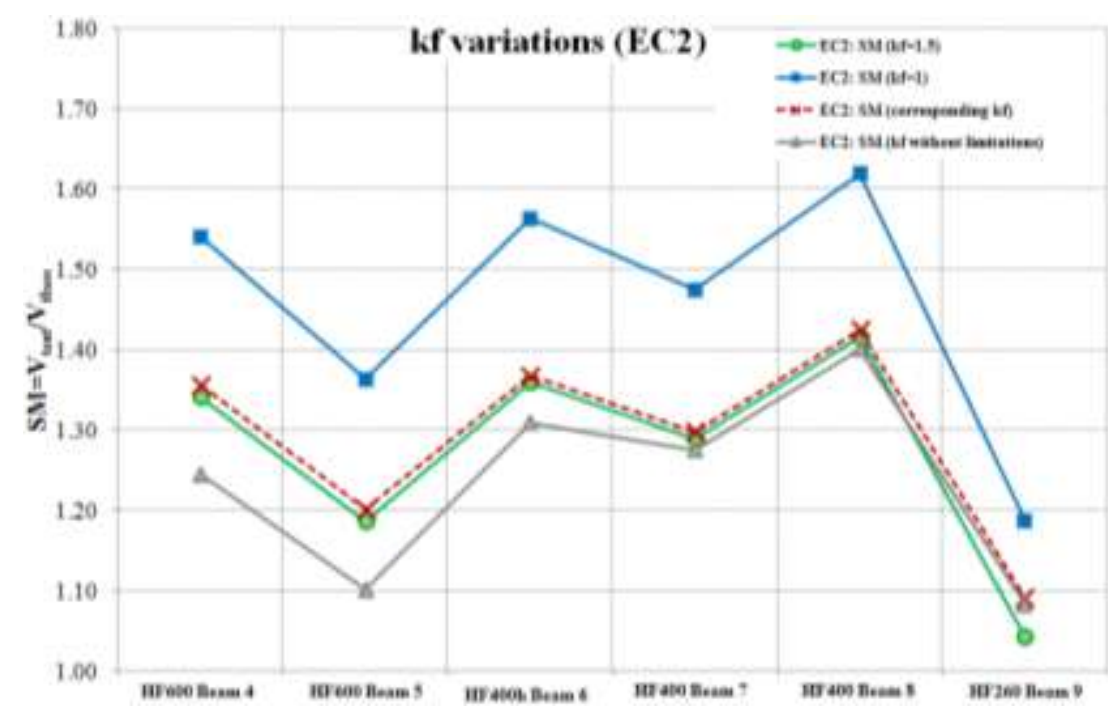

Fig. 4.14 SM variations when different flange factor values are applied 


\subsubsection{Assessment of shear formulations from current Design Codes.}

The safety margins (SM), obtained as $\mathrm{V}_{\text {test }} / \mathrm{V}_{\text {theo }}$ (the shear test value divided by the shear theoretical value), were used as a reference parameter to compare the results obtained from the different beams and Codes.

In order to achieve a more complete analysis of the SM of the current Design Codes, Fig.4.15 shows how the SM of the different analyzed Codes were plotted for the beams tested in the experimental program presented herein, along with six more beams corresponding to Minelli's PhD thesis [13]. Minelli's beams were similar to our HF600 series (prestressed, reinforced only with fibers, $700 \mathrm{~mm}$ depth and $600 \mathrm{~mm}$ flange width).

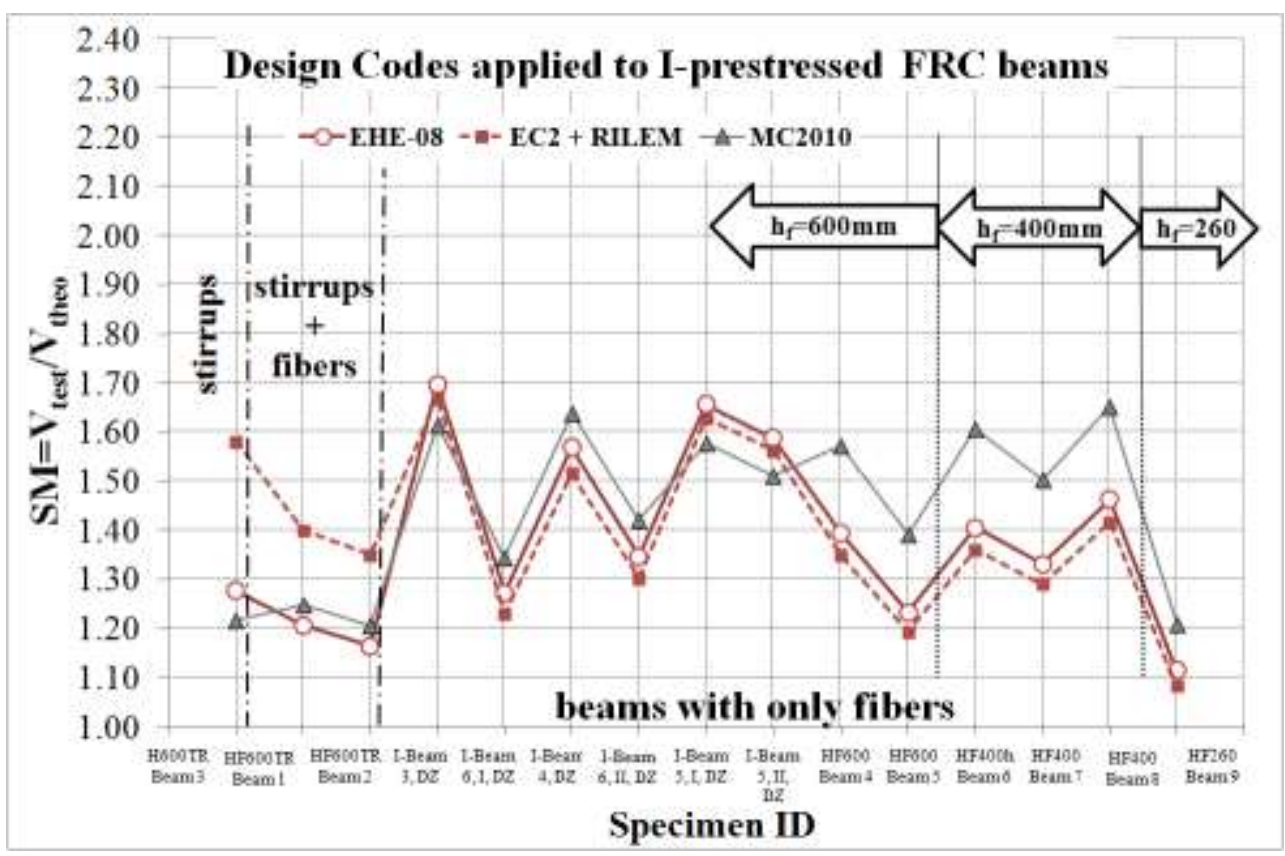

Fig. 4.15 Safety Margin $=V_{\text {test }} / V_{\text {theo }}$ without safety factors

The toughness properties of Minelli's concretes were obtained by means of four point bending tests to determine equivalent strengths such as $f_{\text {eq(0.6-3.0) }}$ usually, these values have been assumed to be $f_{R 3}$ in the literature.

The authors observed that if the limitation for the longitudinal reinforcement according to the EC2 and EHEO8 ( $\rho_{l, \text { max }}=0.02$, see Appendix B) is applied in beams with very high amounts of longitudinal reinforcement (which is the case of Minelli's database), the theoretical shear values are too conservative. This reasoning, coupled with the assertion 
of Cladera [14] which ensures that the limitation of longitudinal reinforcement could be extended from $2 \%$ to $4 \%$, led the authors to apply the real value of the longitudinal reinforcement ratio for the calculations although this ratio exceeded its limitation.

The graph represented in Figure 4.15 is divided into three parts: beams reinforced only with stirrups, stirrups with fibers and, finally, only reinforced fiber. Moreover, beams were arranged in descending order according to their flange width.

All the Codes presented safety margins greater than "1", which means a safe shear strength evaluation.

If the beams only reinforced with fibers are observed (Figure 4.15), MC2010 shows well balanced SM for a variable range of flange widths $\left(b_{f}\right)$. This formula (see Introduction to Part III) considered the whole effect of fibers as it multiplied the longitudinal reinforcement ratio by a parameter which included the compressive strength and toughness properties of the FRC. In this way, the fibers effect, that of improving the dowel action by increasing the bond between the rebar and concrete matrix, was implicit. The dowel action improvement due to fibers was too important for beams with very high longitudinal reinforcement ratios $\left(\rho_{l}>2 \%\right)$ to not be considered, as with EC2. Therefore, the application of EC2, with RILEM or EHE08's formulas, to Minelli's beams with large amounts of longitudinal reinforcement $\left(\rho_{l}\right)$ led to higher SM.

The current MC2010 formula for FRC offers a major advantage if compared with EC2 because MC2010 multiplies the longitudinal reinforcement ratio by the compressive strength and the toughness properties of the FRC. On the other hand, EC2 does not consider the toughness properties on the longitudinal reinforcement ratio. It is known that fibers improve the dowel action because they improve the bond between the rebar and the concrete matrix, as in Swamy [15], who ensured that fibers enable beams to fully use the shear contribution due to the dowel action; moreover, this fact must be included in the Design Codes as has been done with the MC2010 formulation for FRC elements.

MC2010 is highly conservative for all cases with FRC beams. It is important to remember that the limit of the longitudinal reinforcement ratios was equal to $2 \%$ and has not been applied in the values evaluation in Figure 4.15. Otherwise the SM obtained for the Minelli's beams should have been higher.

When stirrups were present, MC2010 with Level III of Approximation, or EHE08, were clearly better adjusted. In these cases, SM were close to 1.2, and were visibly narrower than those obtained for FRC (about 1.5). This may be justified by less confidence in the 
continuity of the FRC toughness properties. Obviously, additional studies must be done to reach and validate a more adjusted proposal.

\subsection{Conclusions}

An experimental program including shear tests on nine prestressed FRC I-beams with unequal flange dimensions has been developed. An SCFRC has been cast with good production continuity according to the slump flow test and its compressive strength and flexural behavior under industrial conditions, and with low levels of quality variability. The results indicate that inclusion of steel fibers in beams with stirrups provides a more ductile behavior. According to the analysis of failure modes, deflections and cracking patterns, the following conclusions can be drawn:

- Steel fibers control not only the appearance of cracks, but also their propagation.

- With steel fibers, more cracks are created, but these are narrower than without fibers, and the crack spacing is smaller as well.

- Steel fibers positively interact with traditional transverse reinforcement (additive effect).

- Fibers confer to concrete an important contribution to the tension stiffening mechanism.

- According to the flange width influence, the results obtained for tested beams indicate that the presence of a flange does not clearly produce a difference in the ultimate load capacity. These results are in agreement with the fact that the $k_{f}$ factor, which takes into account the contribution of flanges on shear according to RILEM, does not vary for $b_{f}>400 \mathrm{~mm}$.

- The RILEM approach does not model the positive effect of fibers on the dowel action, as fibers do not affect the term of longitudinal reinforcement and, therefore, in RILEM fibers and longitudinal reinforcement are completely independent. Thus, the application of RILEM leads to results which vary vastly as a function of the longitudinal reinforcement ratio.

- MC2010 bears in mind in its formulation the positive effect of fibers on the dowel action. In this way, fibers contribution increases when beams have high longitudinal reinforcement ratios. MC2010 shows well balanced SM for a variable range of flange widths $\left(b_{f}\right)$ and reinforcement ratios. However, these SM have highly very conservative values.

- Even though all the Codes underestimate the fiber effect on shear, a less conservative approach is needed in the MC2010 proposal.

On Shear Behavior of structural elements made of steel fiber reinforced concrete-PhD thesis 


\subsection{References}

[1] EFNARC, "The European Guidelines for Self-Compacting Concrete. Specification, Production and Use," 2005.

[2] Serna, Cuenca and Alves-de-Oliveira, "Self-compacting fiber reinforced in precast elements production for shear resistance," Dedicated to Innovation: 50 YEARS MCBAUCHEMIE, 2011.

[3] Bolomey, "The Grading of Aggregate and its influence on the characteristics of concrete," Revue des Matériaux de Construction et des Travaux Publiques, 1947.

[4] Di.Prisco, Plizzari and Vandewalle, "Fibre reinforced concrete: new design perspectives," Materials and Structures, vol. 42, pp. 1261-1281, 2009.

[5] EHE-08, Instrucción de Hormigón Estructural EHE-08 (in Spanish), Ministerio de Fomento, 2008, p. 702 pp..

[6] EC2, "Eurocode 2: Design of Concrete Structures - EN 1992-1-1," 2005.

[7] MC2010, "fib Bulletins 55-56. Model Code 2010. First Complete Draft," 2010.

[8] RILEM, «TC 162-TDF. Test and design methods for steel fibre reinforced concrete, stress-strain design method. Final Recommendation.," Materials and Structures, vol. 36, pp. 560-567, 2003.

[9] Vecchio and Collins, "The Modified Compression Field Theory for reinforced concrete elements subjected to shear," ACl Journal, vol. 83, no. 2, pp. 219-231, 1986.

[10] Cladera and Marí, "Shear strength in the new Eurocode 2. A step forward?," Structural Concrete, vol. 8, no. 2, pp. 57-66, 2007.

[11] Cladera and Marí, "Shear design procedure for reinforced normal and high-strength concrete beams using artificial neural networks. Part II: beams with stirrups," Engineering Structures, vol. 26, pp. 927-936, 2004.

[12] European-Concrete-Platform, "Eurocode 2 Commentary," Brussels, 2008. 
[13] Minelli, "Plain and Fiber Reinforced Concrete Beams under Shear Loading: Structural Behavior and Design Aspects," PhD thesis, University of Brescia, 2005.

[14] Cladera and Marí, "Shear design procedure for reinforced normal and high-strength concrete beams using artificial neural networks. Part I: beams without stirrups," Engineering Structures, vol. 26, no. 7, pp. 917-926, 2004.

[15] Swamy and Bahia, "The effectiveness of steel fibers as shear reinforcement.," Concrete International, vol. 7, no. 3, pp. 35-40, 1985. 


\title{
CHAPTER 5
}

\section{EXPERIMENTAL TESTS ON}

\author{
FIBERS INFLUENCE ON THE
}

\section{SIZE EFFECT ON SHEAR}

\subsection{Introduction}

In this chapter it will be discussed the possibility of steel fibers to mitigate the size effect in large beams. For that, an experimental program consisting in 9 beams with $h=500$, 1000 and $1500 \mathrm{~mm}$, made with three types of concretes with 0,50 and $75 \mathrm{~kg} / \mathrm{m}^{3}$ of fibers was done. The beams were tested with $\mathrm{a} / \mathrm{d}=3$ for all cases. The concrete was manufactured in a concrete plant of Italcementi Group, while the tests were carried entirely at the laboratory "Pietro Pisa" of the University of Brescia. 


\subsection{Materials}

The beams have been casted in different times using three different mix design. Specific concrete proportions have been used for mixing plain concrete (samples PC) and fiber reinforced concrete with an amount of fibers of $50 \mathrm{~kg} / \mathrm{m}^{3}$ (samples FRC50) and $75 \mathrm{~kg} / \mathrm{m}^{3}$ (samples FRC75). All mixtures have been mixed in a precast manufacturing plant of Italcementi Group ${ }^{\circ}$ (Fig.5.1) situated in Mompiano (Brescia) and concrete was provided to the university by mixing trucks.

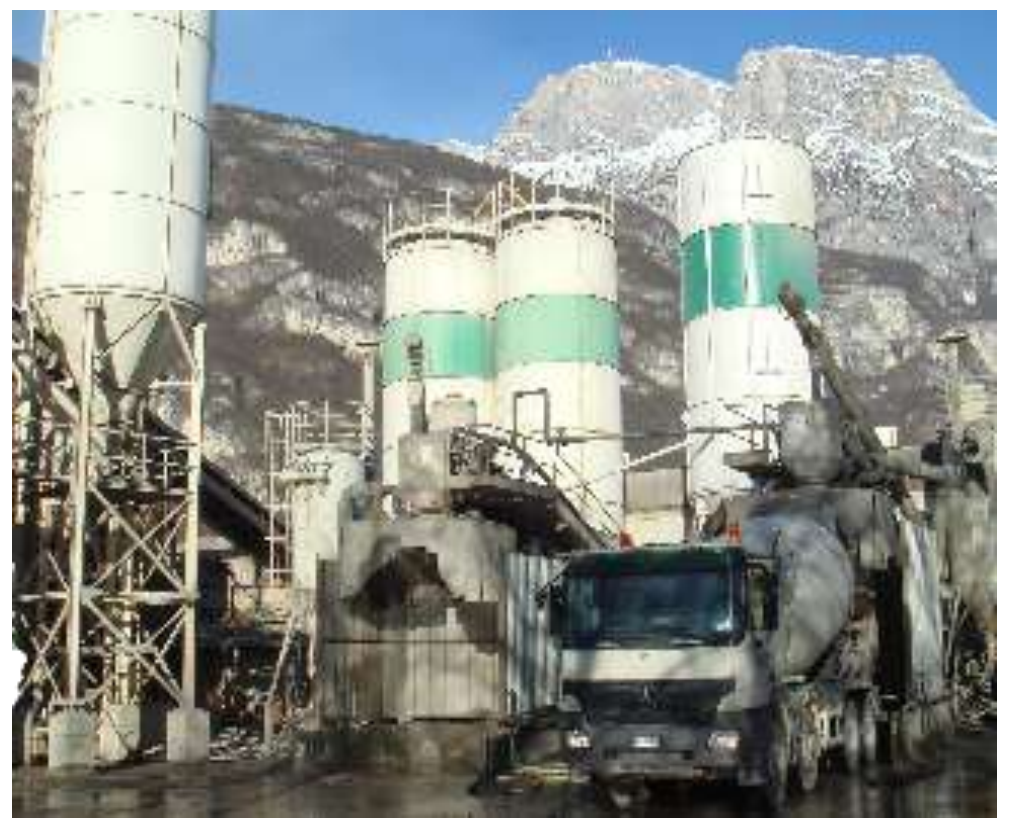

Fig.5.1 Concrete manufacturing plant

The materials used were a CEM I 42.5R cement type, sand 0/4mm and coarse aggregates with a maximum size of $16 \mathrm{~mm}$. The concretes had a water/cement ratio equal to 0.41 . As it can be seen in Table 5.1, mix designs only differ on the amounts of fibers and superplasticizer. The fibers used were low carbon steel with hooked-ends: $50 \mathrm{~mm}$ length, $0.8 \mathrm{~mm}$ diameter, and a nominal aspect ratio (length/diameter) equal to 62.5. Fibers were provided by La Matassina Group $^{\odot}$ and its product “La Gramigna ${ }^{\circledR ”}$ fibers was used.

Table 5.1 shows the three concrete compositions.

Table 5.2 show the fibers geometry and their characteristics. 
Table 5.1 Mix design of plain and fiber reinforced concretes

\begin{tabular}{|l|c|c|c|}
\hline Beams & PC & FRC50 & FRC75 \\
\hline Cement Type & CEM I-42.5R & CEM I-42.5R & CEM I-42.5R \\
\hline Cement Content $\left[\mathrm{kg} / \mathrm{m}^{3}\right]$ & 410 & 410 & 410 \\
\hline Sand 0/4 $\left[\mathrm{kg} / \mathrm{m}^{3}\right]$ & 1073 & 1073 & 1073 \\
\hline Coarse aggregate 4/16 $\left[\mathrm{kg} / \mathrm{m}^{3}\right]$ & 645 & 645 & 645 \\
\hline Maximum Aggregate Size $[\mathrm{mm}]$ & 16 & 16 & 16 \\
\hline Fibers $\left[\mathrm{kg} / \mathrm{m}^{3}\right]$ & 0 & 50 & 75 \\
\hline Water-Cement Ratio & 0.41 & 0.41 & 0.41 \\
\hline Super-Plasticizer $\left[\mathrm{I}^{\mathbf{3}} \mathbf{m}^{\mathbf{3}}\right]$ & 4.1 & 4.8 & 5.7 \\
\hline
\end{tabular}

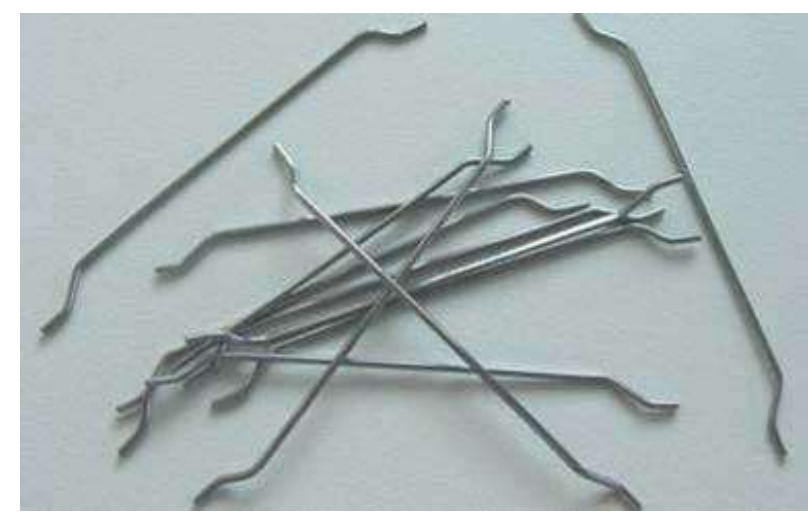

Fig.5.2 Fibers used

Table 5.2 Characteristics of the fibers adopted

\begin{tabular}{|l|c|}
\hline Designation & $\mathbf{5 0 / 0 . 8 0}$ \\
\hline Type of steel & Carbon \\
\hline Shape & Hooked \\
\hline Minimum Tensile Strength $[\mathbf{M P a}]$ & 1100 \\
\hline Length $[\mathrm{mm}]$ & 50 \\
\hline Diameter $[\mathrm{mm}]$ & 0.8 \\
\hline Aspect Ratio $\mathrm{I} / \boldsymbol{\phi}$ & 62.5 \\
\hline
\end{tabular}




\subsection{Concrete properties and production control}

For evaluating the mechanical properties of concrete, an exhaustive production quality control took place in the experimental program. Cylinders, cubes, round panels and prismatic specimens were produced, as shown Fig.5.3.

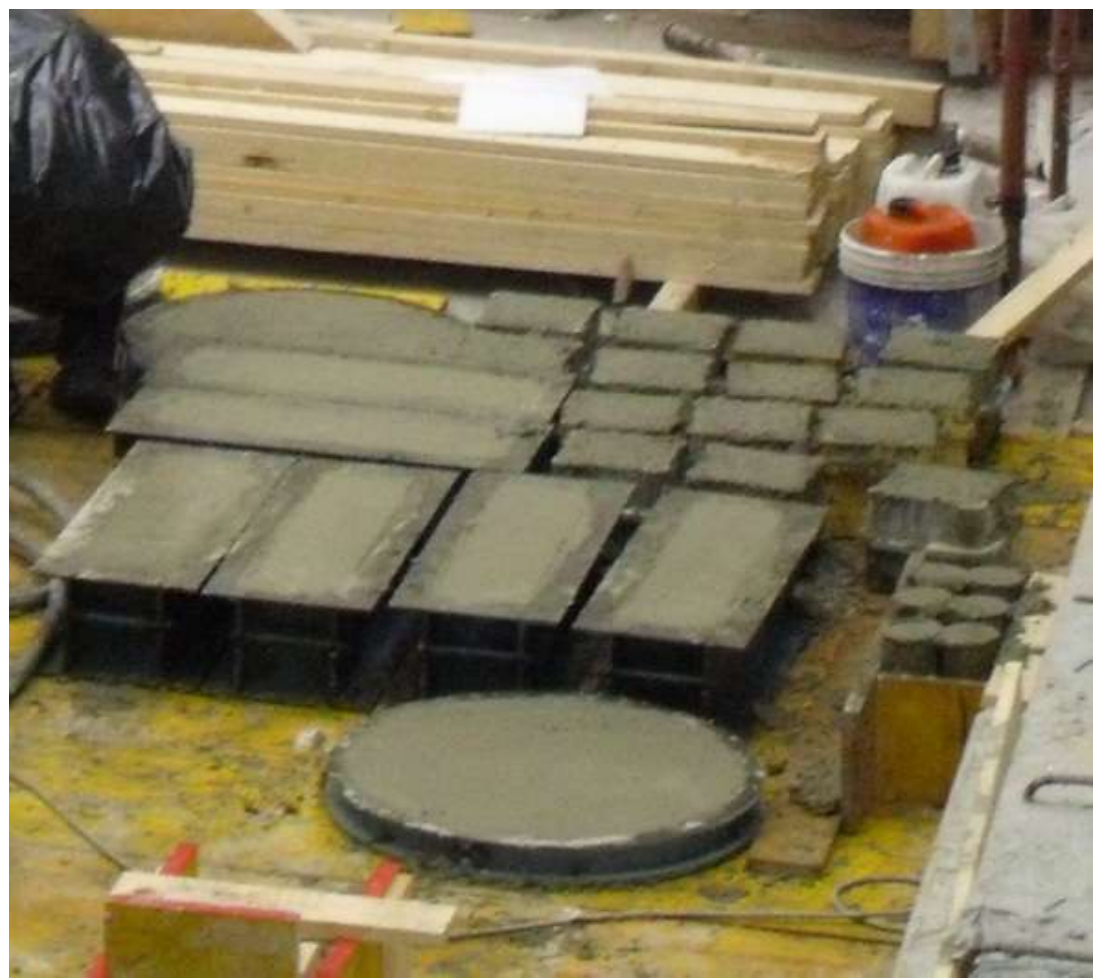

Fig.5.3 Round panel and cylinder, cubic and prismatic specimens just produced

The following tests were done: the slump-flow (EN 12350-8), compressive strength (EN 12390-3) and three point bending (EN 14651). The following was obtained from the flexural test: the limit of proportionality $\left(f_{c t l}\right)$ and the residual flexural tensile strength $\left(f_{R, j}\right)$ which corresponds to the crack mouth opening displacements (CMOD) linked to the crack openings (in $\mathrm{mm}$ ) of $0.5,1.5,2.5$ and 3.5 ( $\mathrm{j}=1,2,3,4$ respectively). Fig.5.4 exhibits the dimensions of the prismatic specimens according to the EN 14651, while Fig.5.5 shows a prismatic specimen during the three point bending test (EN 14651). 


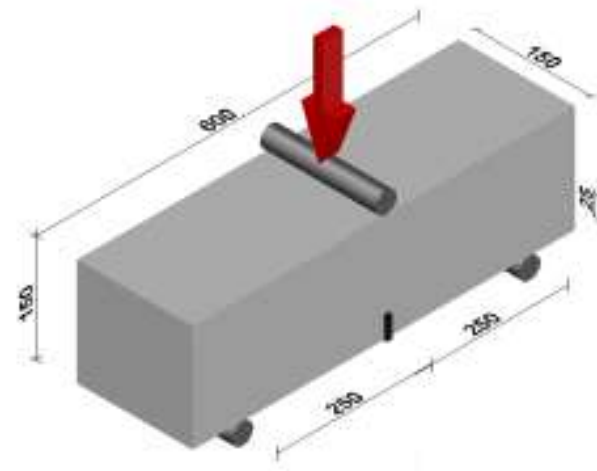

Fig.5.4 Flexural tensile strength test setup according to EN 14651

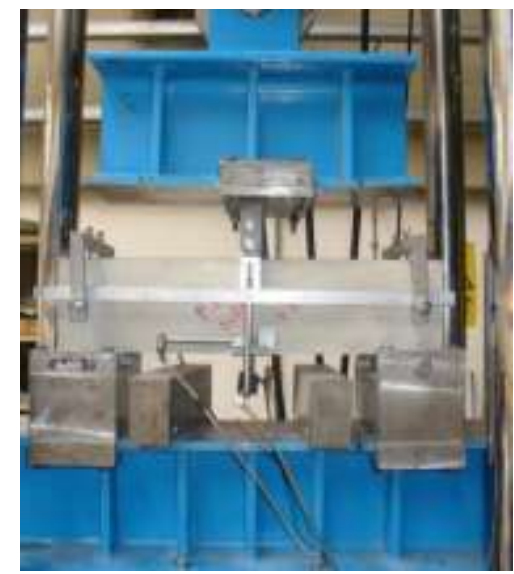

Fig.5.5 Prismatic specimen during the flexural tensile strength test according to EN 14651

Fig.5.6 exhibits the curves obtained by the three point bending tests. Beyond the peak load, it can be observed the clear differences between plain and fiber reinforced concrete. Plain concrete has a behavior totally brittle after the peak; namely, once the specimen cracks, immediately the specimen breaks in two blocks, dissipating a small energy. On the other hand, depending on the content, fibers enhance concrete toughness. Consequently, more energy is dissipated by cracks in fiber reinforced concrete.

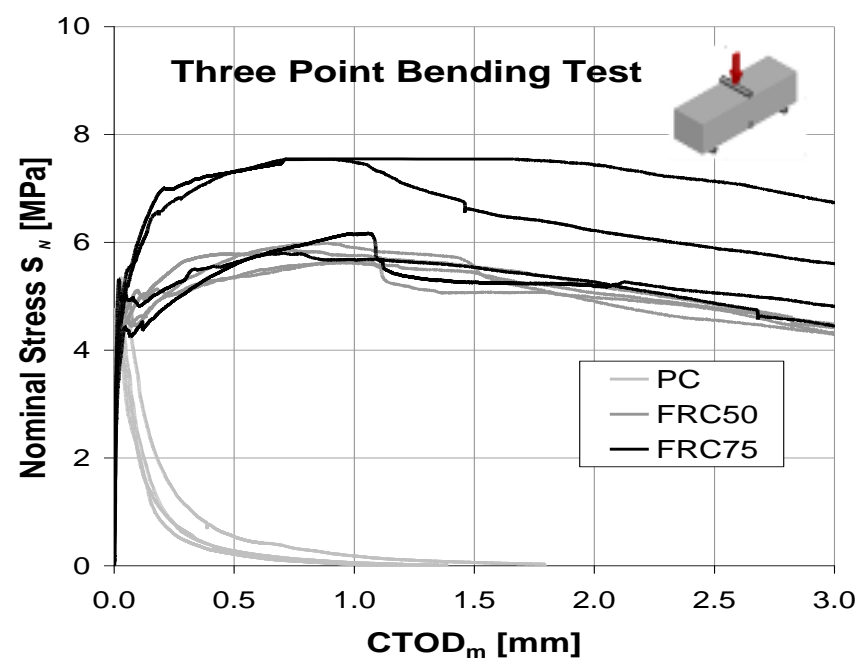

Fig.5.6 Nominal stress-CTOD curves according to EN 14651 
Table 5.3 shows the mechanical properties of the different types of concrete used: the average compressive strength $\left(f_{c m}\right)$; the average tensile strength $\left(f_{c t m}\right)$; the Young's modulus $\left(E_{c m}\right)$ and the average post-cracking residual strength $\left(f_{R 1}, f_{R 2}, f_{R 3}, f_{R 4}\right)$.

Table 5.3 Mechanical properties of concrete and post-cracking residual strengths according to EN 14651

\begin{tabular}{|l|c|c|c|}
\hline Beams & PC & FRC50 & FRC75 \\
\hline Fibres $\mathbf{V}_{\mathrm{f}}(\%)$ & 0.00 & 0.64 & 1.00 \\
\hline $\boldsymbol{f}_{\mathrm{cm}}[\mathrm{MPa}]$ & 38.7 & 32.1 & 33.1 \\
\hline $\mathbf{f}_{\mathrm{ctm}}[\mathrm{MPa}]$ & 3.0 & 2.4 & 2.5 \\
\hline $\mathbf{E}_{\mathrm{cm}}[\mathrm{MPa}]$ & 33500 & 30800 & 32100 \\
\hline $\boldsymbol{f}_{R, 1}[\mathrm{MPa}]$ & -- & 5.4 & 6.0 \\
\hline $\boldsymbol{f}_{R, 2}[\mathrm{MPa}]$ & -- & 5.6 & 6.1 \\
\hline $\boldsymbol{f}_{R, 3}[\mathrm{MPa}]$ & -- & 5.0 & 6.0 \\
\hline $\boldsymbol{f}_{R, 4}[\mathrm{MPa}]$ & -- & 4.5 & 5.5 \\
\hline
\end{tabular}

Also, round panel tests [1] were made using centrally loaded small round panels of 600 $\mathrm{mm}$ of diameter [2], see Fig.5.7. In these tests, energies of fracture after cracking were determined (Fig.5.8 and Table 5.4).

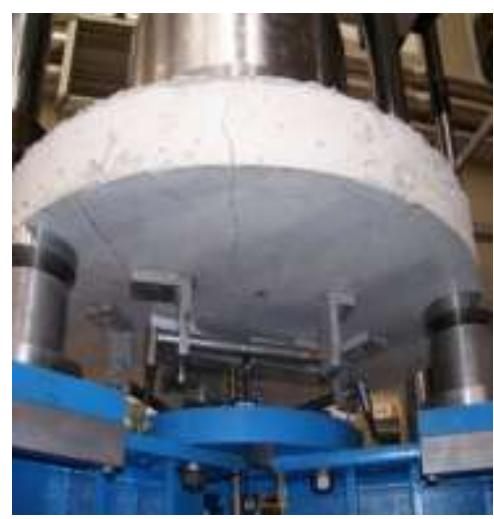

Fig.5.7 Round panel during the test 


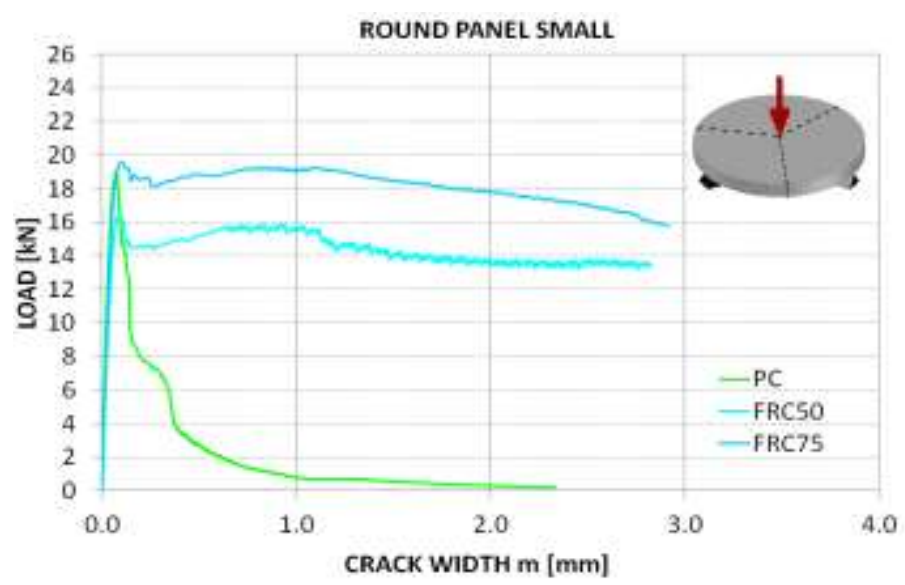

Fig.5.8 Load-crack width curve corresponding to the specimens made of PC, FRC50 and FRC75

Table 5.4 Energy absorbed corresponding to displacements $3.75 \mathrm{~mm}$ and $30 \mathrm{~mm}$ (Average values)

\begin{tabular}{|l|c|c|}
\hline Round panel & $\mathbf{G}_{3.75}[\mathbf{N} / \mathrm{mm}]$ & $\mathbf{G}_{\mathbf{3 0}}[\mathbf{N} / \mathrm{mm}]$ \\
\hline PC & 11.21 & 11.41 \\
\hline FRC50 & 53.92 & 93.11 \\
\hline FRC75 & 67.99 & 105.06 \\
\hline
\end{tabular}

The yielding and tensile ultimate strength of the longitudinal deformed reinforcing bars were, respectively: $506 \mathrm{MPa}$ and $599 \mathrm{MPa}$ for $\phi 14$ bars; $555 \mathrm{MPa}$ and $651 \mathrm{MPa}$ for $\phi 20$ bars and, $518 \mathrm{MPa}$ and $612 \mathrm{MPa}$ for $\$ 24$ bars. These are typical values for S500 steel, according to the current EC2 (2005).

\subsection{Experimental program}

\subsubsection{Main variables and beam production}

Nine large reinforced beams without stirrups with several depths (500, 1000 and 1500 $\mathrm{mm}$ ) with shear span 3 times their effective depth were casted. Fig. 5.9, Fig. 5.10 and Table 5 . 5 show the beam cross-section and reinforcement.

On Shear Behavior of structural elements made of steel fiber reinforced concrete-PhD thesis 


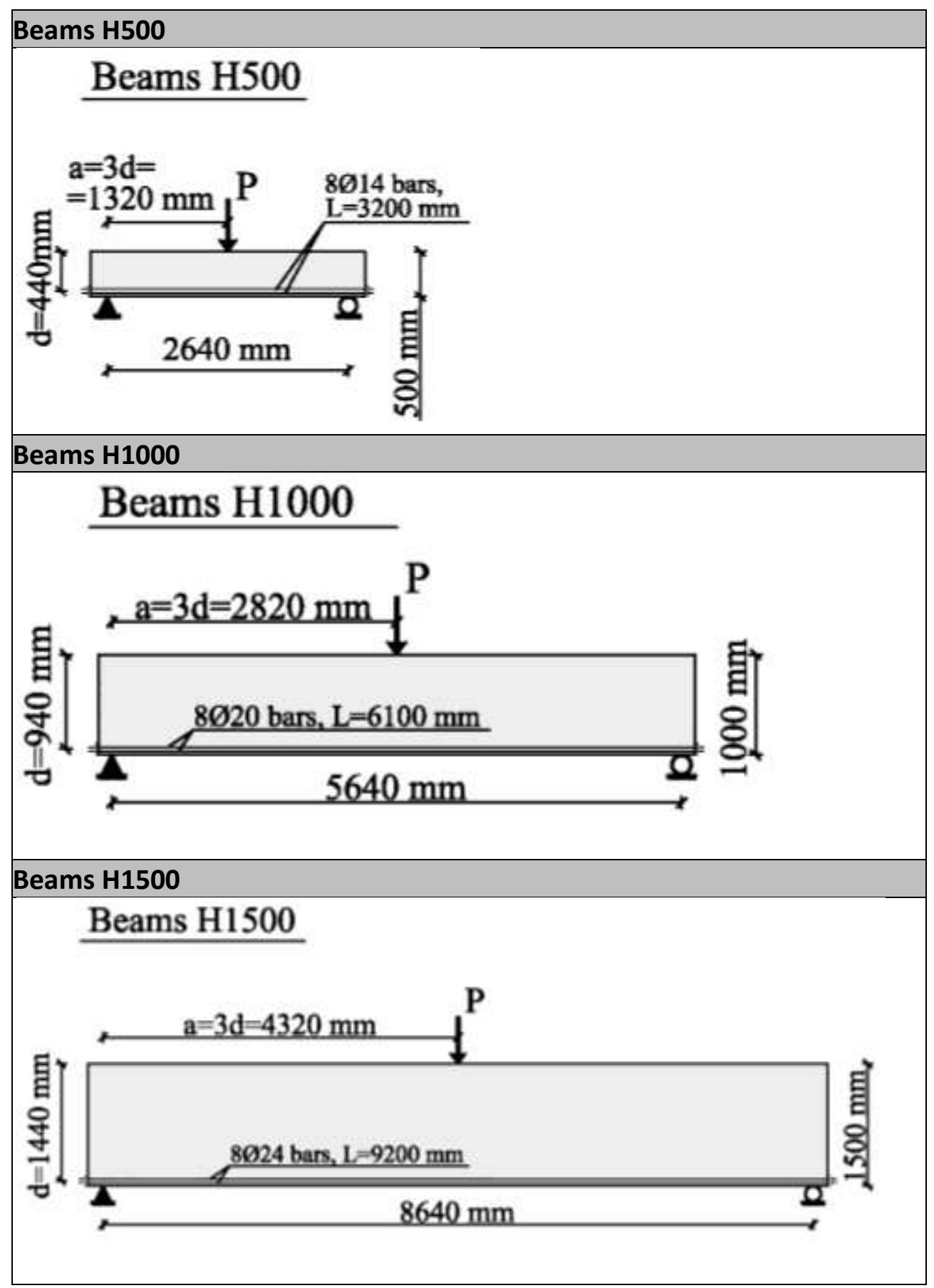

Fig.5. 9 Geometry and reinforcement details of beams (Frontal view) 


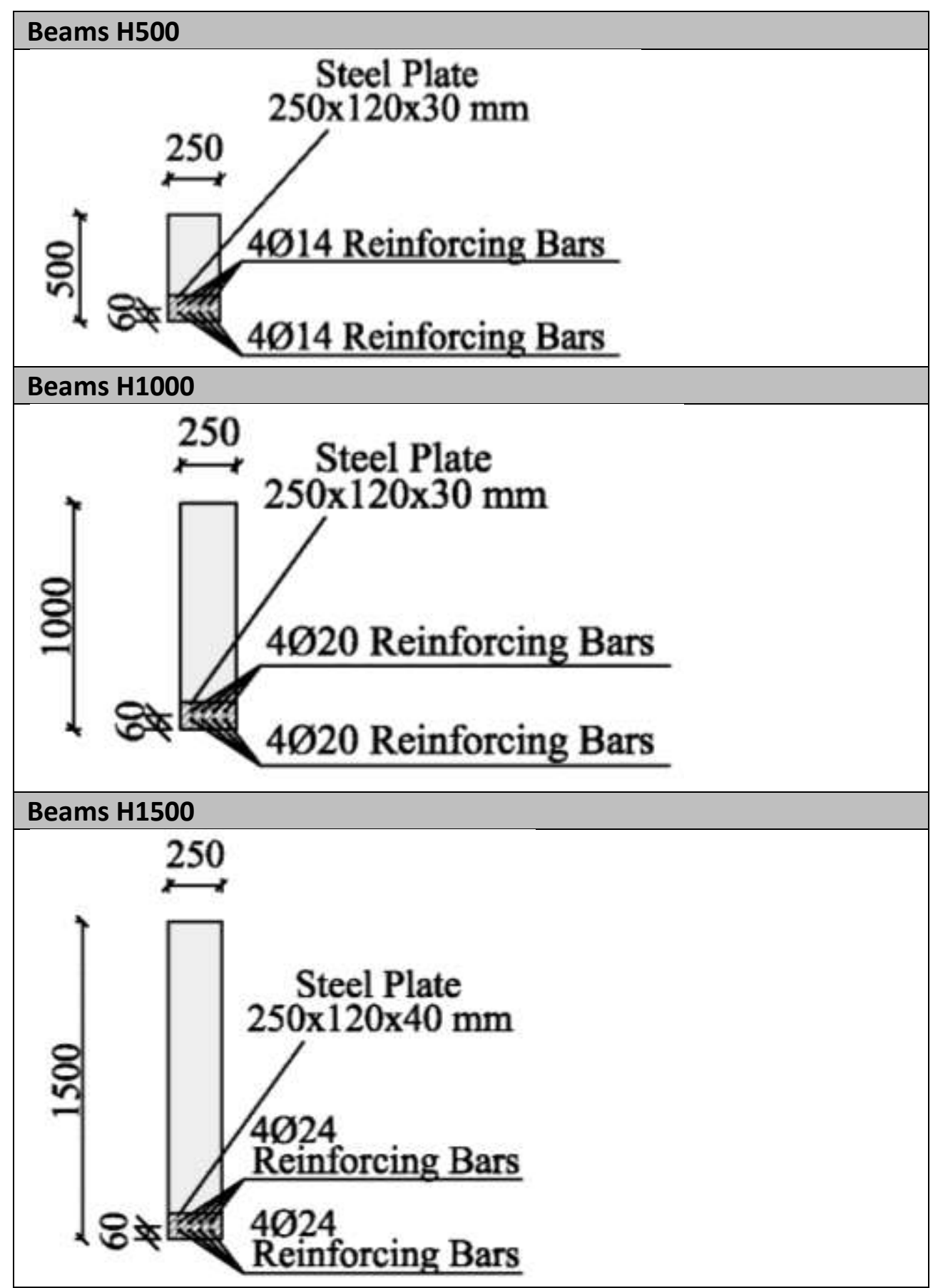

Fig.5. 10 Geometry and reinforcement details of beams (Cross-sections) 
Table 5.5 Geometry characteristics of specimens

\begin{tabular}{|l|c|c|c|}
\hline Beams & H500 & H1000 & H1500 \\
\hline Height (mm) & 500 & 1000 & 1500 \\
\hline Effective Depth $\boldsymbol{d}(\mathrm{mm})$ & 440 & 940 & 1440 \\
\hline Total Length (mm) & 3000 & 5900 & 9000 \\
\hline Span (mm) & 2640 & 5640 & 8640 \\
\hline Shear Span $\boldsymbol{a}(\mathbf{m m})$ & 1320 & 2820 & 4320 \\
\hline Width (mm) & 250 & 250 & 250 \\
\hline Gross Cover (mm) & 60 & 60 & 60 \\
\hline Reinforcement longitudinal bars & $8 \phi 14$ & $8 \phi 20$ & $8 \phi 24$ \\
\hline Reinforcement Area (mm $^{\mathbf{2}}$ ) & 1232 & 2513 & 3619 \\
\hline Reinforcement Ratio & $1.12 \%$ & $1.07 \%$ & $1.01 \%$ \\
\hline
\end{tabular}

The amount of longitudinal reinforcement has been designed to represent real cases. This longitudinal reinforcement implies a $\rho_{\text {, }}$ between 1.01 and $1.12 \%$ as shows Table 5.5 . All the rebars used were made out of steel B 500 S type.

The experimental program variables were:

- Height (500 mm; $1000 \mathrm{~mm} ; 1500 \mathrm{~mm}$ )

- Amount of fibers $\left(0,50\right.$ and $\left.75 \mathrm{~kg} / \mathrm{m}^{3}\right)$

All beams had the same width of $250 \mathrm{~mm}$ and gross cover of $60 \mathrm{~mm}$.

In Fig.5.11 it can be seen the formworks and their appearance just after pouring the concrete. 

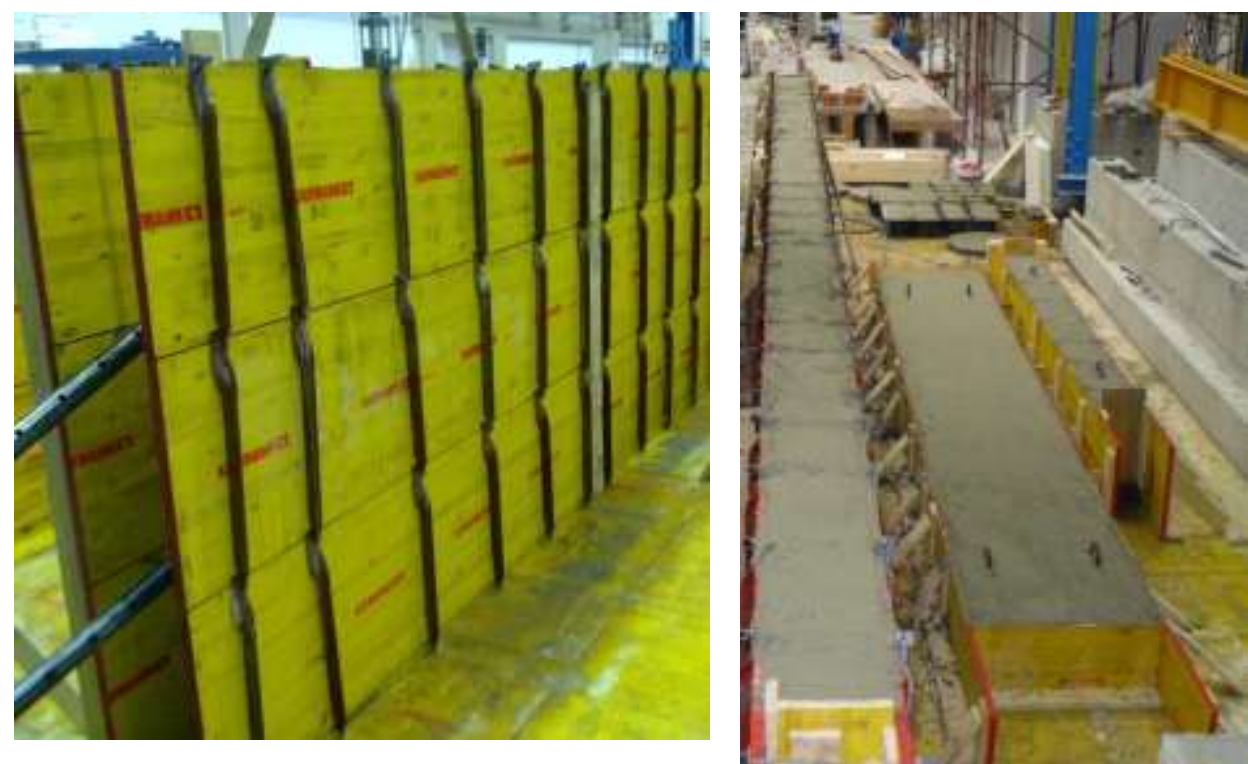

Fig.5. 11 Formworks and beams just casted

\subsubsection{Testing procedure}

Beams were tested under a three point loading system and a shear span-to-depth ratio $(a / d)$ of 3 . The load was applied to the beams by an electro-mechanical jack with displacement control. All tests began by imposing an initial displacement rate of $0.20 \mathrm{~mm} / \mathrm{min}$, decreased to $0.10 \mathrm{~mm} / \mathrm{min}$ after the appearance of some shear crack. For beams $\mathrm{H} 500$ was used a jack with a load capacity of $500 \mathrm{kN}$, whereas for beams $\mathrm{H} 1000$ and $\mathrm{H} 1500$, one of $1500 \mathrm{kN}$ was used. Load was measured with a load cell at load point. Before starting the test, preliminary elastic cycles were applied to verify the correct operation of the devices. Obviously, these cycles reached peak loads well below those of the first shear cracking, reaching 30,40 and $50 \mathrm{kN}$ for beams $\mathrm{H} 500, \mathrm{H} 1000$ and $\mathrm{H} 1500$, respectively.

Fig.5.12 shows the test arrangement of the beams. To prevent movement out of plane of the beams, $\mathrm{H} 1000$ and $\mathrm{H} 1500$ steel profiles were arranged around the beam ends. 


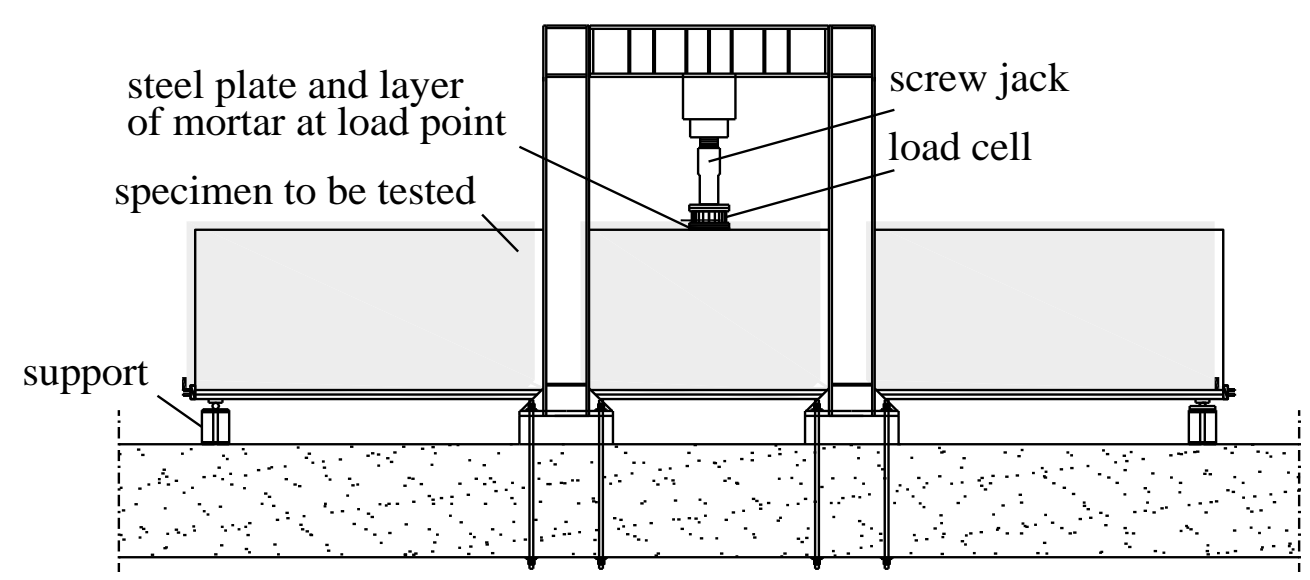

Fig.5.12 Three point test setup for the full-scaled beams

Instrumentation was available to measure: deflections, shear cracks widths, settlement of supports, shortening of top chord and elongation of bottom chord. Linear Variable Differential Transformers (LVDTs) were utilized for measuring deflections at midspan (front and back side) and support displacements. Potentiometric transducers were employed for measuring crack widths and strut shortenings. The latter were placed with an inclination of $40^{\circ}$ (struts) and 140 (crack widths) to the horizontal. This inclination was based on experimental observation of similar tests [3], in which the critical shear crack occurred at a distance of about the effective depth (d) from the support, directed towards the point of load application.

The instrumentation applied in the shear span for beams $\mathrm{H} 1000$ and $\mathrm{H} 1500$ (see Fig.5.13), was slightly different from the beams $\mathrm{H} 500$, due to their increased shear span area. Thus, in all beams were disposed 2 potentiometric transducers for measuring strut displacements on the front side of the beam and, also, transducers for measuring crack widths on the shear span. The latter on the following: 4 transducers ( 2 on the front and 2 on the back side) in $\mathrm{H} 500$ beams and 6 ( 4 on the front and 2 on the back side) in $\mathrm{H} 1000$ and $\mathrm{H} 1500$ beams.

Fig. 5.14 shows a front view of a $\mathrm{H} 1000$ beam before testing. 


\section{FRONT}

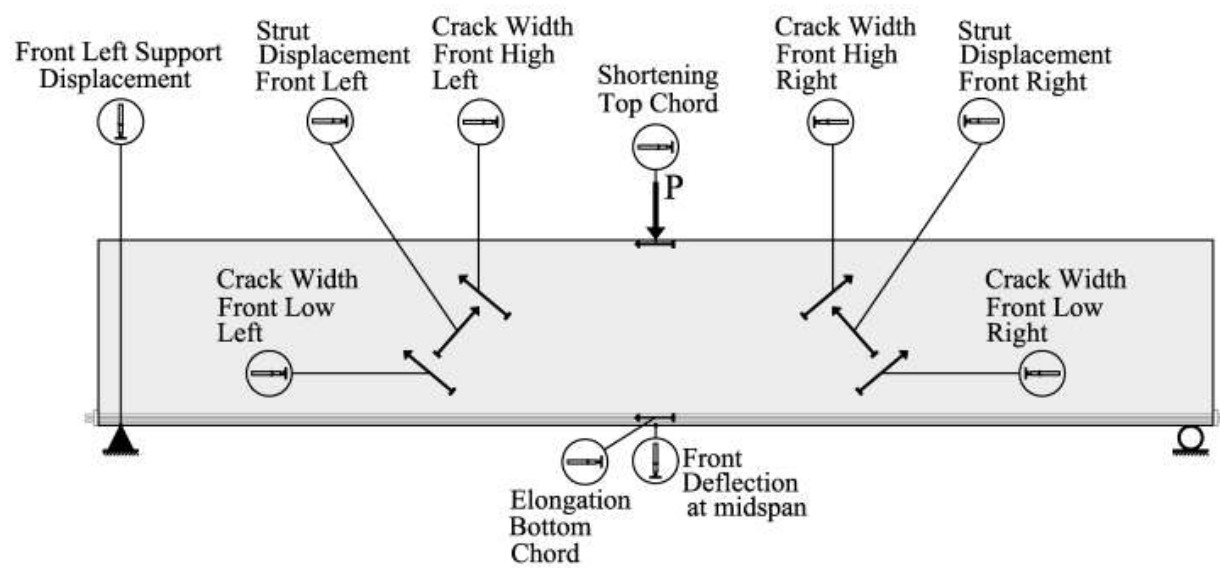

\section{BACK}

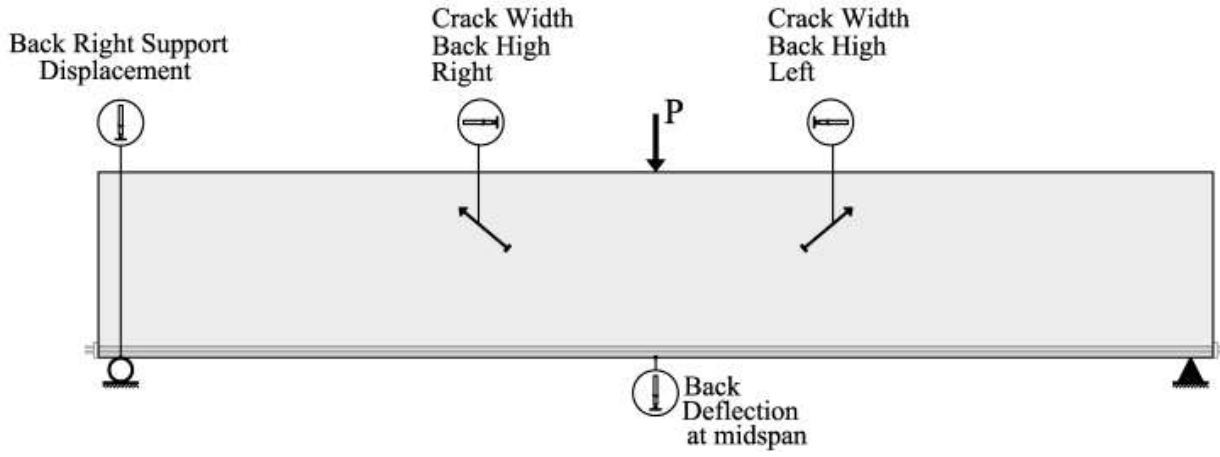

Fig.5.13 Instrumentation details for beams $\mathrm{H} 1000$ and $\mathrm{H} 1500$ 


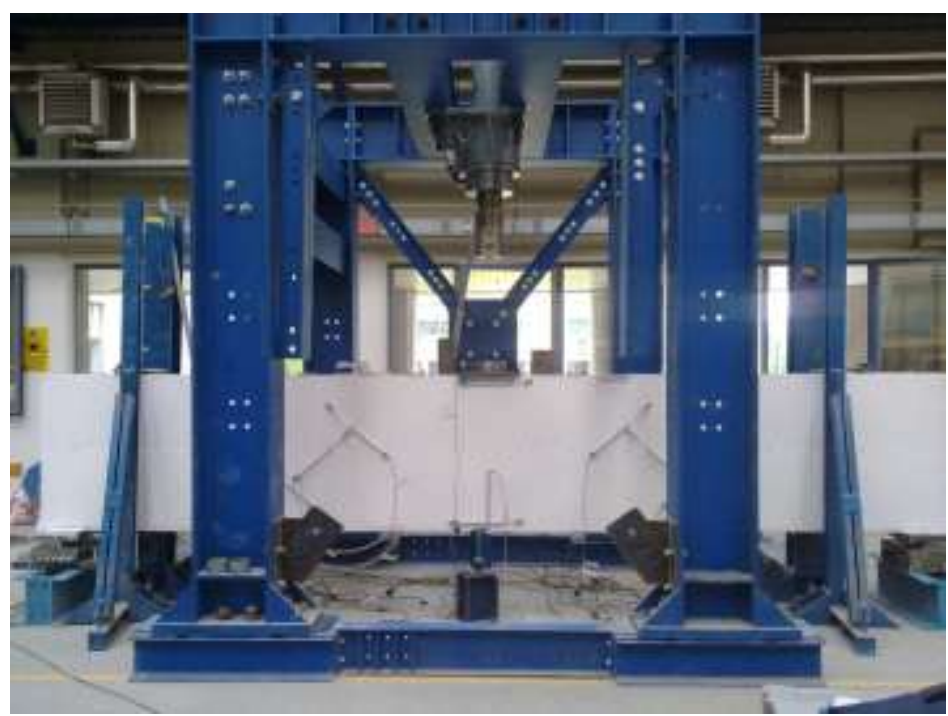

Fig.5.14 Front view of a beam $\mathrm{H} 1000$ under preparation for the test

\subsubsection{Results}

\subsubsection{Experimental results}

Fig.5.15 exhibits beam H1500-FRC75 ( $h=1500 \mathrm{~mm} ; 75 \mathrm{~kg} / \mathrm{m}^{3}$ of fibers) after failure testing.

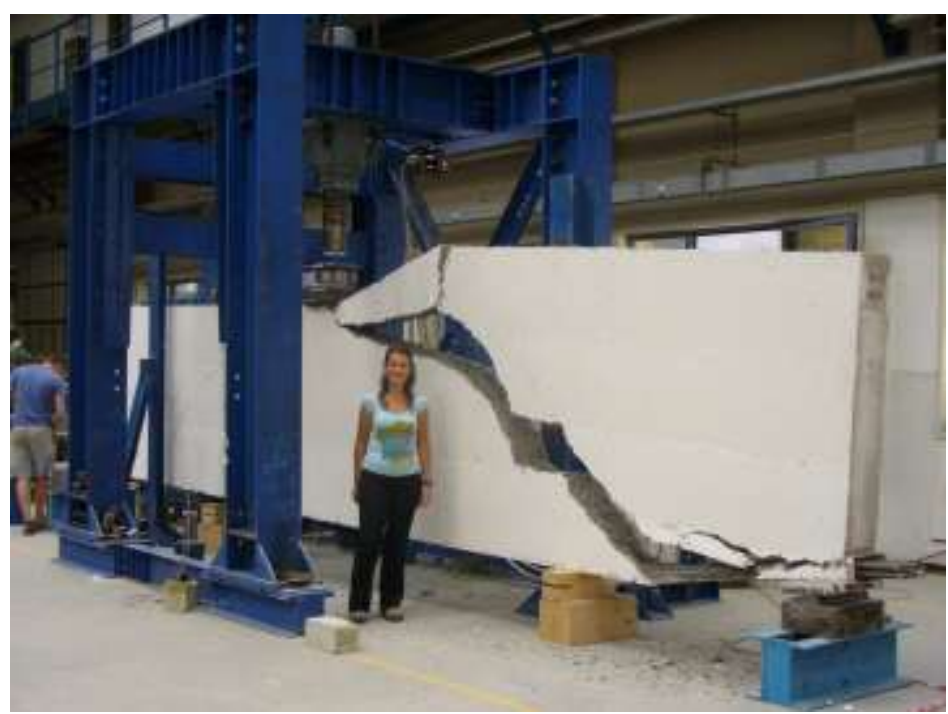

Fig.5.15 Beam H1500-FRC75 after its failure 
Table 5.6 reports the main experimental results: the failure mode, shear ultimate load $\left(V_{u}\right)$, shear stress $\left(v_{u}\right)$, ratio $v_{u} / f_{c m}{ }^{1 / 2}$, ultimate flexure moment $\left(M_{u, f l}\right)$, experimental ultimate moment $\left(M_{u}\right),\left(M_{u} / M_{u, f l}\right)$ ratio and the maximum deflection at midspan $\left(\delta_{u}\right)$.

The experimental ultimate moment $\left(M_{u}\right)$ was determined as $M_{u}=V_{u} \cdot a$ and the ultimate flexure moment $\left(M_{u, f l}\right)$ was calculated according to the EC2 for the RC beams while for the FRC beams it was calculated according to the MC2010, assuming a stress-block both in compression (according also to EC2) and in tension. The latter was characterized by a constant stress, in the whole tensile area, equal to $f_{F T u}$ (where $f_{F T u}=f_{R 3} / 3$ ). This formulation comes from the assumptions that the maximum compressive strain in the FRC, the maximum tensile strain in the steel and the maximum post-cracking tensile strain in the FRC are attained (Fig.5.16).

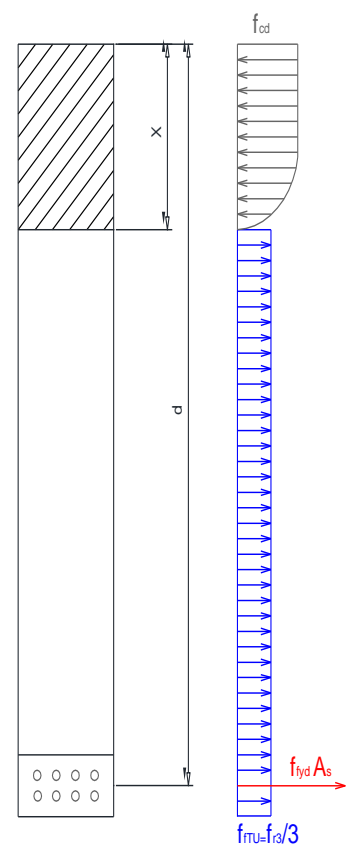

Fig.5.16 Stress distribution over the cross section of the beam

As can be seen in the Table 5.6, all beams failed in shear although beams H500FRC75 and H500FRC50 reached their flexure capacity with yielding of the longitudinal reinforcement. Beam H500-FRC50 behaved quite ductile. This is quite clear from the Table 5.6, where the $\left(M_{u} / M_{u, f l}\right)$ ratio exceeds unity in $\mathrm{H} 500$ beams made of FRC.

On Shear Behavior of structural elements made of steel fiber reinforced concrete - PhD thesis 
Table 5.6 Main experimental results

\begin{tabular}{|c|c|c|c|c|c|c|c|c|}
\hline \multirow[t]{2}{*}{ Specimen } & \multirow{2}{*}{$\begin{array}{c}\text { Failure } \\
\text { mode }\end{array}$} & $\mathbf{v}_{\mathrm{u}}$ & $\mathbf{v}_{\mathbf{u}}$ & $v_{u} /\left(f_{c m}\right)^{1 / 2}$ & $\mathbf{M}_{\mathrm{u}}$ & $\mathbf{M}_{\mathrm{u}, \mathrm{fl}}$ & $M_{u} / M_{u, f l}$ & $\begin{array}{l}\text { Midspan } \\
\text { Displ. } \delta_{u}\end{array}$ \\
\hline & & {$[\mathrm{kN}]$} & [MPa] & {$[-]$} & [kN m] & [kN m] & {$[-]$} & {$[\mathrm{mm}]$} \\
\hline H500 PC & Shear & 116 & 1.05 & 0.17 & 153 & 254 & 0.60 & 3.7 \\
\hline H500 FRC50 & Shear $\left({ }^{*}\right)$ & 240 & 2.18 & 0.38 & 316 & 285 & 1.11 & 35.0 \\
\hline H500 FRC75 & Shear $(*)$ & 235 & 2.13 & 0.37 & 310 & 293 & 1.06 & 9.1 \\
\hline H1000 PC & Shear & 188 & 0.80 & 0.13 & 529 & 1210 & 0.44 & 6.3 \\
\hline H1000 FRC50 & Shear & 272 & 1.16 & 0.20 & 767 & 1325 & 0.58 & 13.6 \\
\hline H1000 FRC75 & Shear & 351 & 1.49 & 0.26 & 989 & 1356 & 0.73 & 16.8 \\
\hline H1500 PC & Shear & 211 & 0.59 & 0.09 & 911 & 2511 & 0.36 & 7.0 \\
\hline H1500 FRC50 & Shear & 484 & 1.34 & 0.24 & 2089 & 2791 & 0.75 & 21.6 \\
\hline H1500 FRC75 & Shear & 554 & 1.54 & 0.27 & 2394 & 2864 & 0.84 & 23.5 \\
\hline
\end{tabular}

${ }^{(*)}$ Shear failure took place with yielding of longitudinal rebars.

Furthermore, the addition of fibers increases the shear ultimate capacity. In the case of $\mathrm{H} 500$ beams, the addition of fibers doubled the shear ultimate capacity of PC beams. For beams $\mathrm{H} 1000$, the addition of $50 \mathrm{~kg} / \mathrm{m}^{3}$ of fibers increases the shear capacity by almost $50 \%$ from the reference beam H1000PC; when added $75 \mathrm{~kg} / \mathrm{m}^{3}$, the increase was equal to $86 \%$. Also in beams $\mathrm{H} 1500$, fibers double shear ultimate capacity while, from 50 to 75 $\mathrm{kg} / \mathrm{m}^{3}$ of fibers ultimate capacity increased by $33 \%$.

\subsubsection{Load-deflection response}

Load-deflection curves (Fig.5.17 to 5.19) show that, in all the beams, greater amount of fibers, the greater the shear ultimate capacity reached and that, for the same load level, greater deflections are reached for cases of $50 \mathrm{~kg} / \mathrm{m}^{3}$ compared with those of $75 \mathrm{~kg} / \mathrm{m}^{3}$; although this effect is less evident in $\mathrm{H} 500$ beams, on higher beams ( $\mathrm{H} 1000$ and $\mathrm{H} 1500)$ it is more evident, especially in beams $\mathrm{H} 1000$ which reached a higher load of $75 \mathrm{~kg} / \mathrm{m}^{3}$ than in the $50 \mathrm{~kg} / \mathrm{m}^{3}$, as discussed above. 


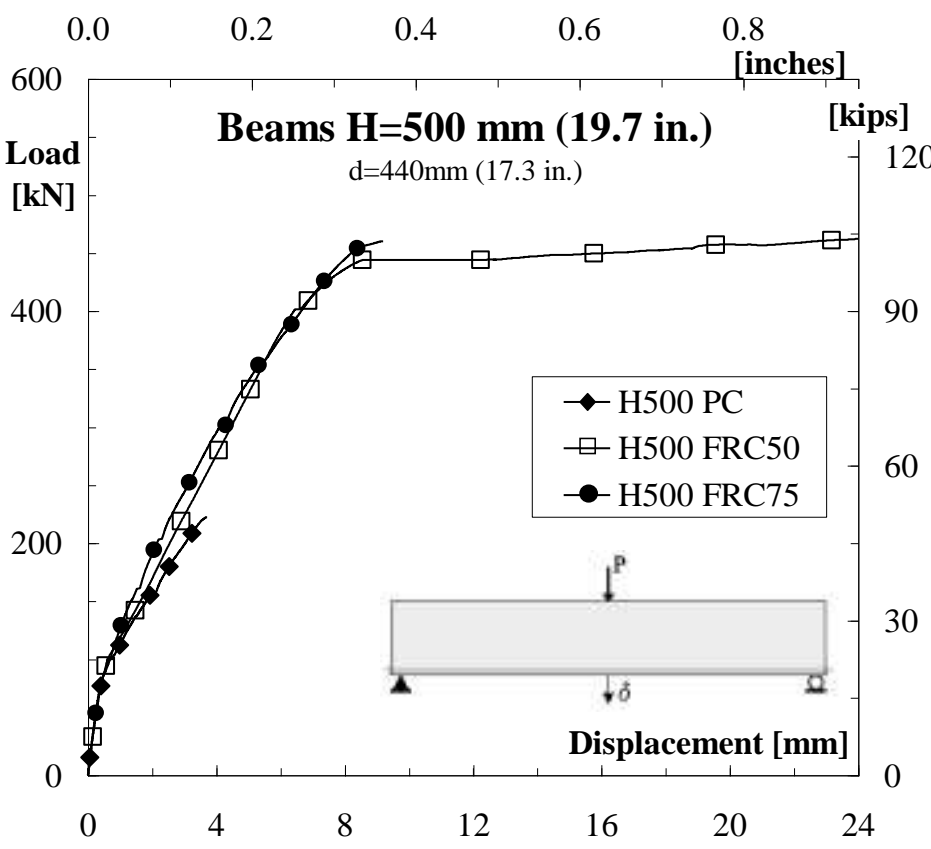

Fig.5.17 Experimental curve load vs. deflection of $\mathrm{H} 500$ beams

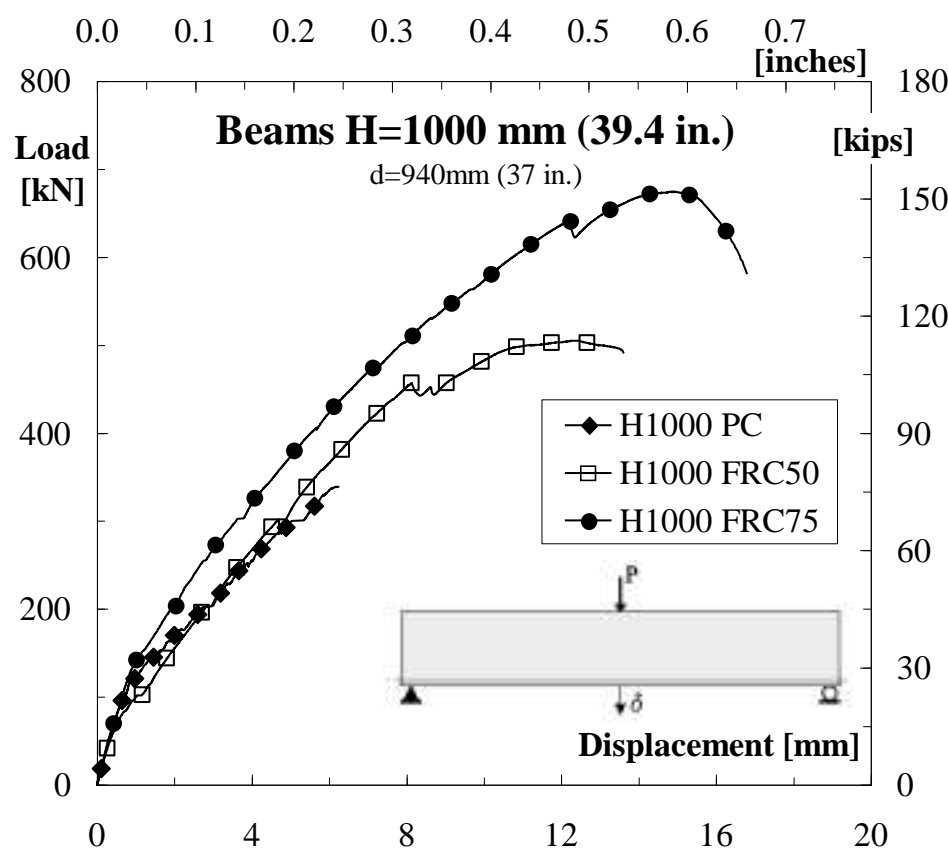

Fig.5.18 Experimental curve load vs. deflection of $\mathrm{H} 1000$ beams 


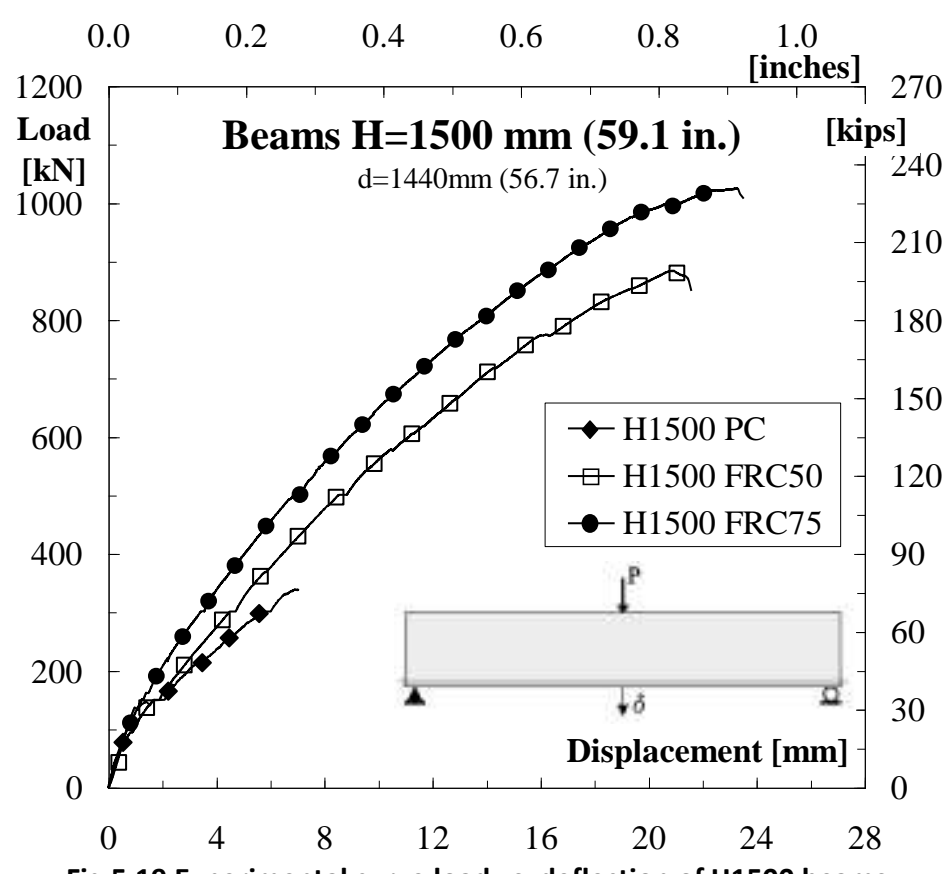

Fig.5.19 Experimental curve load vs. deflection of $\mathrm{H} 1500$ beams

\subsubsection{Cracking pattern and the Load-Crack width response}

Crack width-load curves (Fig.5.20, Fig.5.22, Fig.5.24) and crack patterns (Fig.5.21, Fig.5.23, Fig.5.25) show that the addition of fibers causes more smaller cracks giving to the beam a more ductile behavior.

Fibers determine an increase of the ultimate shear load and the load at which the shear crack becomes unstable. For instance, in $\mathrm{H} 1500$ series, an evident shear cracking began at $320 \mathrm{kN}$ for the reference sample, whereas it occurred at $570 \mathrm{kN}$ and $890 \mathrm{kN}$ for the FRC50 and FRC75 beams, respectively. The same trend can be seen for sample H1000: in the reference specimen, the shear crack first developed at a load of $240 \mathrm{kN}$, whereas $456 \mathrm{kN}$ and $482 \mathrm{kN}$ were the external loads necessary to initiate the shear cracking in the two elements cast with 50 and $75 \mathrm{~kg} / \mathrm{m}^{3}$ of steel fibers, respectively. While the plain concrete member fails early after the appearance of the first shear crack, with a maximum shear crack width of 0.25-0.50 mm, multi-cracking in shear was observed for the FRC samples, with single shear cracks wider than 1-3 $\mathrm{mm}$ and, even more important, steadily propagating. All flexure-shear cracks in the FRC specimens were $35-45$ o inclined to the horizontal. 
In all beams without fibers, as the test progresses, flexure cracks are formed at midspan, then an inclined crack develops causing the collapse of the beam. By contrast, in beams reinforced with fibers, after flexure cracks, inclined shear cracks appear, developing an unstable mechanism, which cannot be predicted which of all the inclined cracks end up causing final failure. In turn, it is observed that the addition of fibers causes shear cracks less inclined to the horizontal; the higher the amount of fibers, the smaller is the inclination of the cracks. An estimation of the inclination of the shear critical crack was also done by considering its inclination to the horizontal in a portion around the barycentric axis. As mentioned above, the experimentally determined angle $\theta$ diminished as the material toughness increased. In fact, the angle $\theta$ turned out to be equal to 44으, 41응 and $38^{\circ}$ to the horizontal, respectively for samples H1500 PC, H1500 FRC50 and H1500 FRC75. This trend was also found in the smaller series: for samples $\mathrm{H} 1000, \theta$ ranged from $42 \circ$ in the reference element, while it was equal to 370 and 340 respectively for beams FRC50 and FRC75; for beams H500, $\theta$ was 41으. 39을 and 32ㅇ, respectively for elements PC, FRC50 and FRC75.

In the case of sample $\mathrm{H} 1500$ FRC50, the main shear crack was not recorded as it developed much closer to the support than expected (i.e., it turned out to be external to the gauge length). 


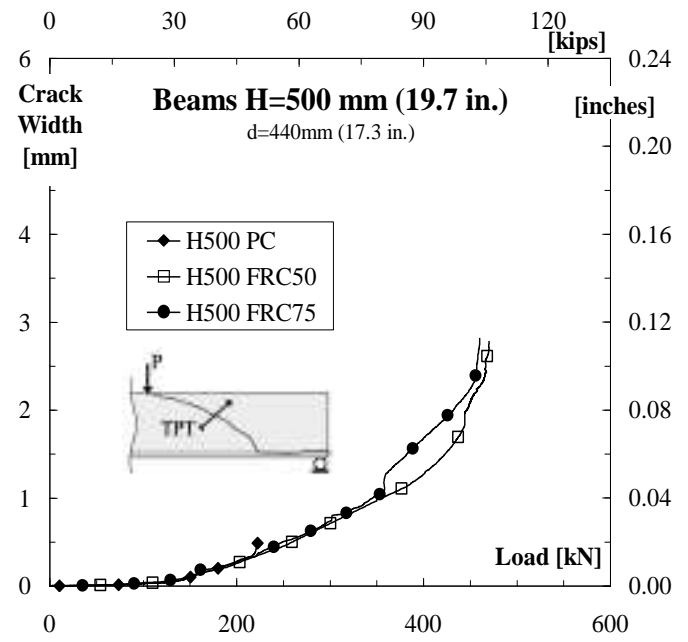

Fig.5. 20 Main shear crack width vs. load (kN) of H500 beams
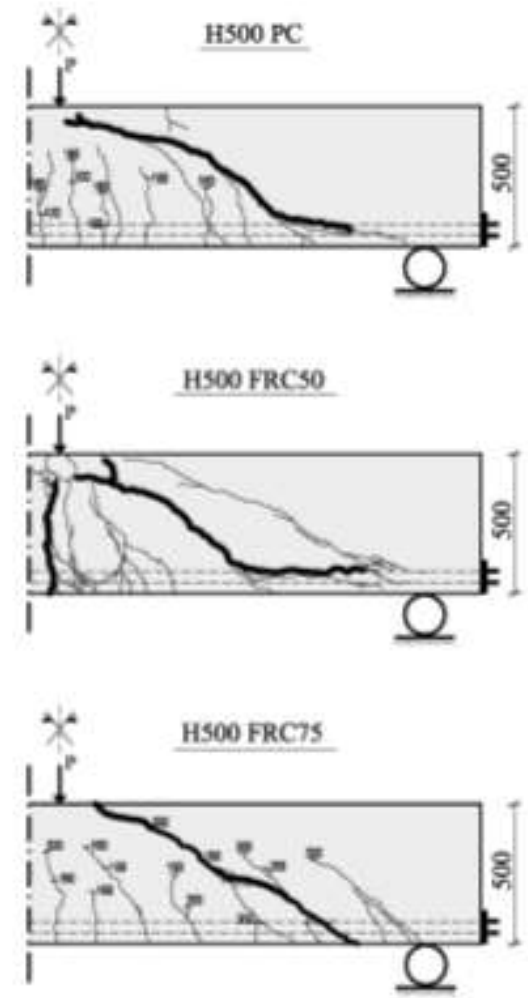

Fig.5. 21 Crack evolution for beams $\mathrm{H} 500$ (loads in $\mathrm{kN}$ ) 


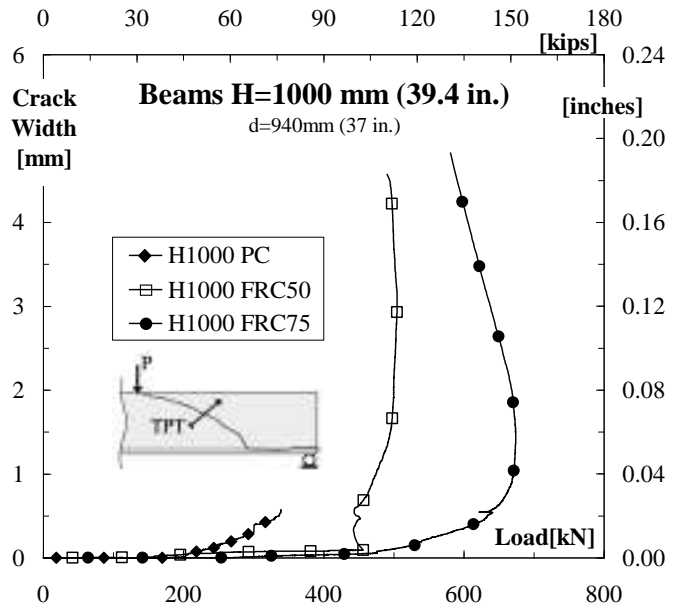

Fig.5.22 Main shear crack width vs. load (kN) of H1000 beams
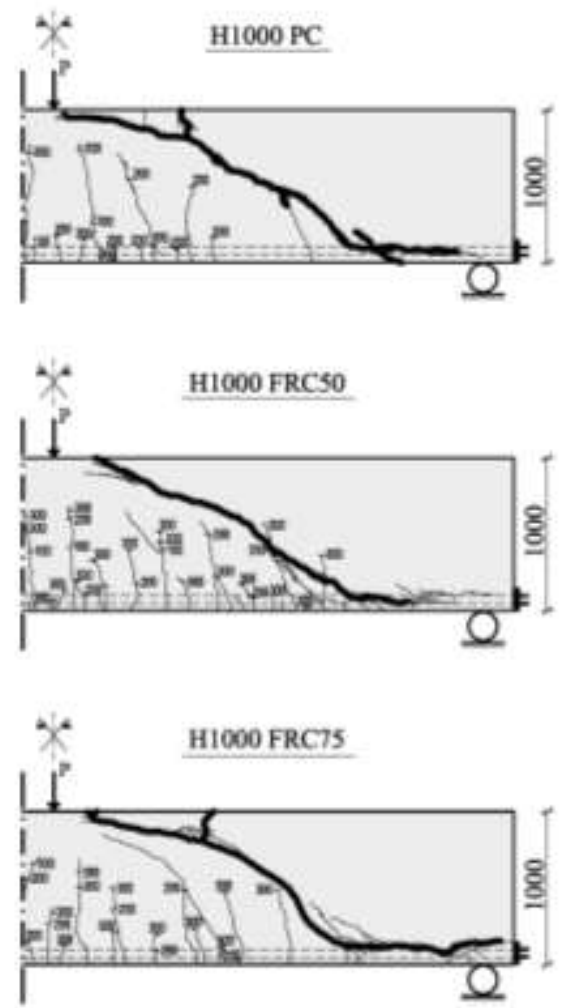

Fig.5.23 Crack evolution for beams $\mathrm{H} 1000$ (loads in kN) 


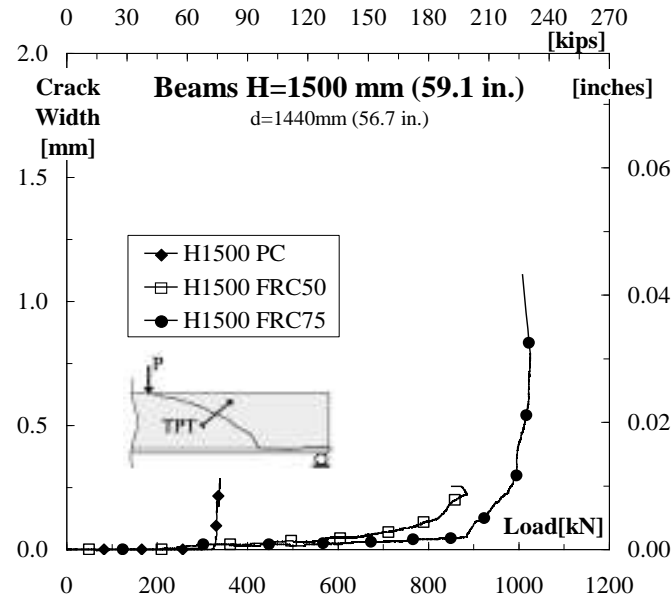

Fig.5.24 Main shear crack width vs. load (kN) of H1500 beams
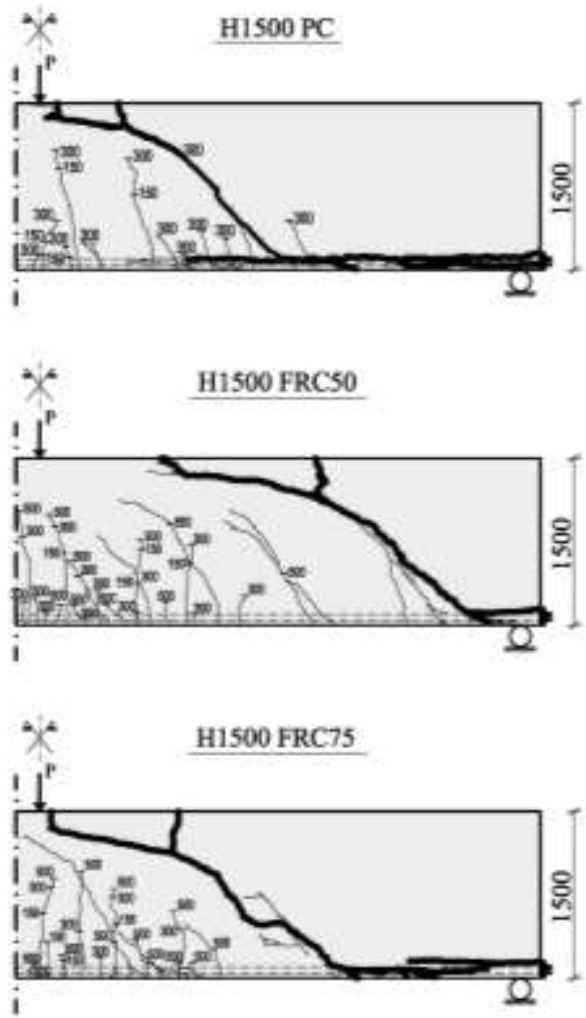

Fig.5.25 Crack evolution for beams $\mathrm{H} 1500$ (loads in kN) 
To analyze the formation and subsequent propagation of shear cracks in a beam of FRC, let's consider the beam FRC50 H1500. Fig.5.26 indicates the order of appearance of each of the cracks; as we see, fibers allow stress redistribution in the beam. Therefore, after the first crack forms, there is no collapse in FRC beam as occurs in PC beams; afterwards, different shear cracks appear from the center of the span to the beam ends (Fig.5.26), resulting in a non-cracked concrete arch (at the top of the beam) increasingly slim. Once a crack is formed, the following occurs when the latter offers a weaker path for the formation. This process is repeated until one of the cracks is not able of withstanding more stress and, eventually, causes the final failure of the beam.

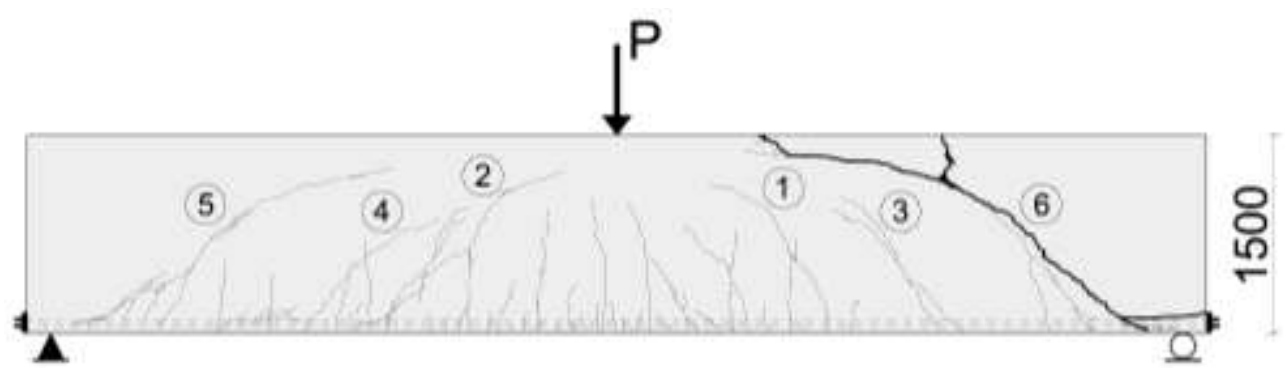

Fig.5.26 Crack evolution for beam H 1500 FRC 50

\subsubsection{Study of the size effect}

\subsubsection{Experimental study of the size effect}

Fig.5.27 reports the classical size effect graph representing the experimental ultimate shear strength over the square root of the compressive strength $\left(v_{u} / f_{c m}{ }^{1 / 2}\right)$ as a function of the effective depth $(d)$, whereas Fig.5.28 reports the ratio $v_{u} / v_{u, f l}$ (experimental shear strength over the maximum shear strength in the case of flexure collapse) versus the effective depth $(d)$, corresponding to the percentage of the maximum flexure capacity attained by the beams. In addition, the graph indicates the value of the residual tensile strength, $f_{R 3}$ for the beams tested, as it is a relevant parameter for the FRC in Design Codes.

Fig.5.27 evidences the rather good fitting between the experiments on plain concrete elements, presented herein. Fig.5.27 also shows how fibers can mitigate the size effect in high beams without stirrups. However, it seems that the results from $\mathrm{H} 1000$ beams are lower than expected. This suggests that, as ensured Bentz [4], after $1500 \mathrm{~mm}$ the decrease was very little by observing the results obtained herein, the FRC elements could also come

On Shear Behavior of structural elements made of steel fiber reinforced concrete - PhD thesis 
to an asymptote. In other words, given the results shown in the Fig.5.27, fibers could definitely mitigate the size effect for beams with effective depths higher than $1000 \mathrm{~mm}$, when the FRC is $75 \mathrm{~kg} / \mathrm{m}^{3}$; however, to confirm these findings, further tests would be needed.

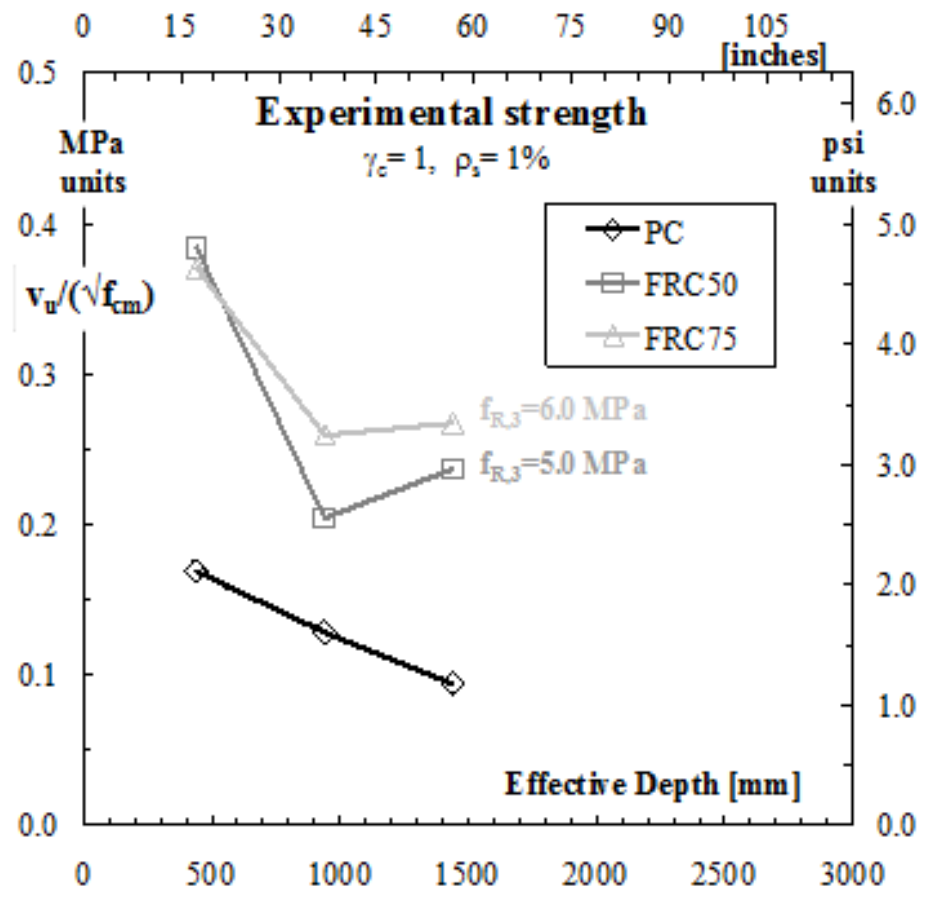

Fig.5.27 Ultimate shear strength vs. effective depth.

Fig.5.28 emphasizes that, with increasing $f_{R 3}$ it is possible to reach the full flexure capacity avoiding shear failure and, therefore, size effect. 


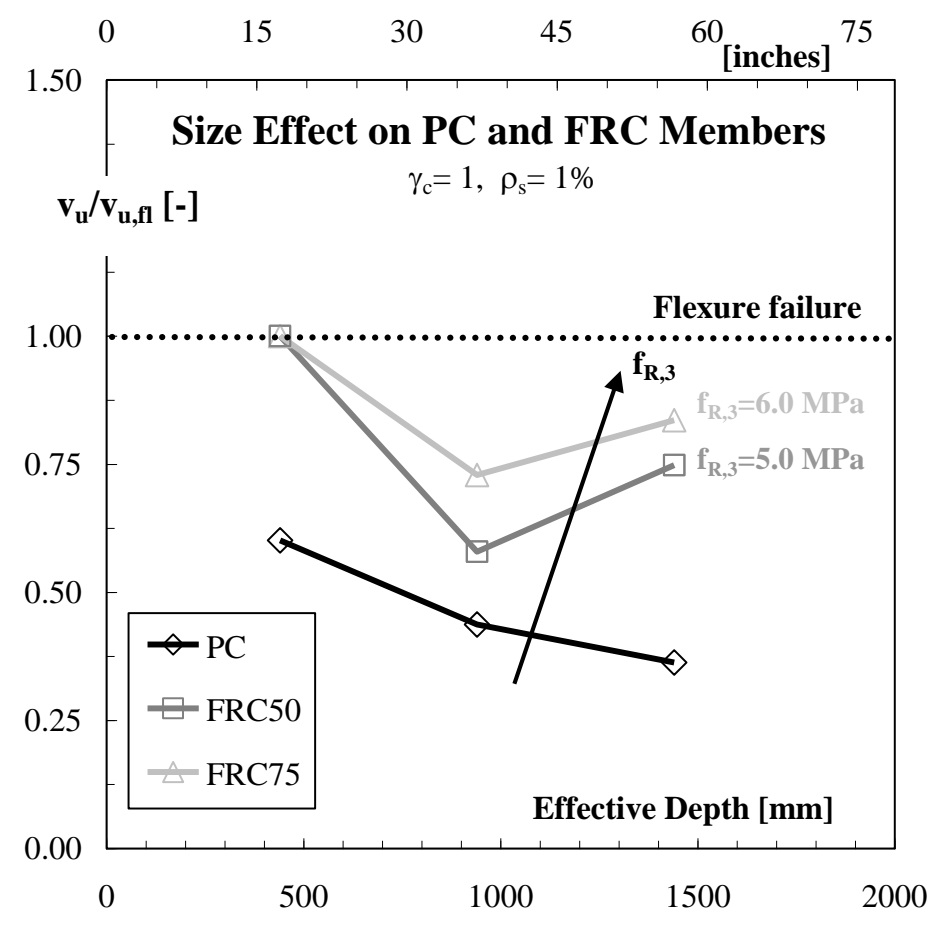

Fig.5.28 Trend of size effect for all beams (PC and FRC)

\subsubsection{Numerical analysis of the size effect}

The load-deflection behavior of beams was simulated numerically with the software VecTor 2 [5]. For modeling fiber reinforced concrete in VecTor 2, it should be introduced the constitutive law of the material in tension. To get that, specifies back analyses have been done on the prismatic specimens used for the three point bending tests. Then, the stress- strain curves in tension for all concrete have been determinate by dividing the crack opening by the crack spacing [6]. Crack spacing was assumed as the distance between the bending cracks of the beam, since they are the closest to represent the behavior in tension of the material. However, from another conceptual point of view (expecting that final failure is by shear), it has been considered that it could be better to take as a crack spacing the separation between shear cracks. Therefore, numerical simulations were reprocessed with VecTor, with the shear crack spacing, obtaining a loaddeflection numerical curve closer to the experimental one.

Since the fibers allow redistribution of stresses, in the numerical models a great number of shear cracks could be observed, generating new paths of cracking, contrarily elements without fibers. Some of the shear cracks are stabilized, because new cracks appear at 
weaker paths. This process of crack spacing development in FRC beams is not entirely clear (see [7]); in fact, a more significant crack spacing could correspond to the distance between two active shear cracks (that are growing during crack development) and not to two consecutive shear cracks. To clarify this concept, additional tests are necessary and, in the present work, a numerical parametric study was performed to better understand the influence of different values of crack spacing; in doing so, the crack spacing was assumed as twice and four times the distance between two consecutive shear cracks. The results for beams $\mathrm{H} 1000$ and $\mathrm{H} 1500$ with 50 and $75 \mathrm{~kg} / \mathrm{m}^{3}$ of fibers are shown from Fig.5.29 to Fig.5.32.

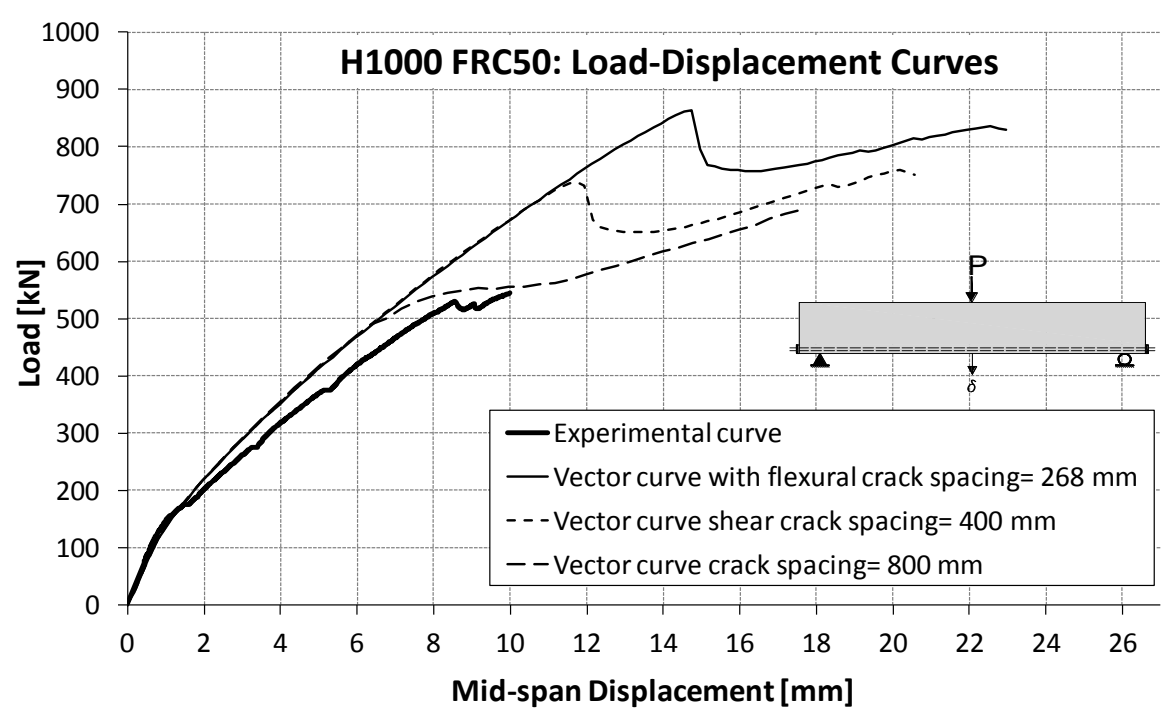

Fig.5.29 Numerical response against experimental results for load-deflection of H1000-FRC50 


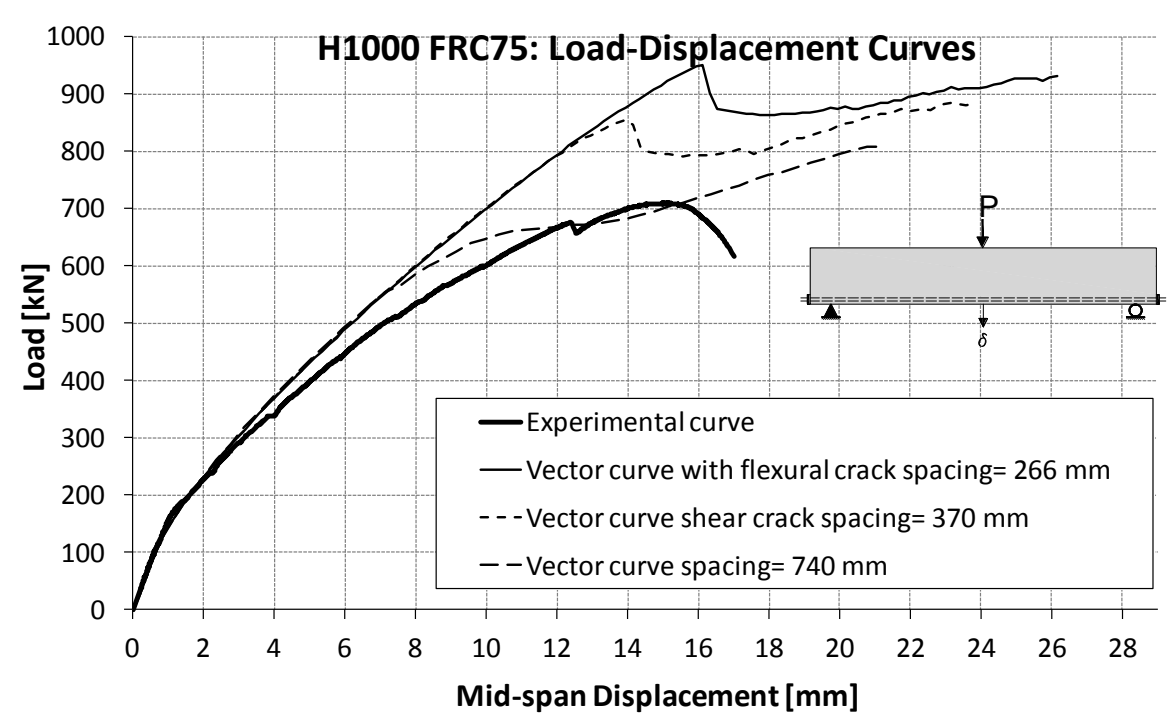

Fig.5. 30 Numerical response against experimental results for load-deflection of H1000-FRC75

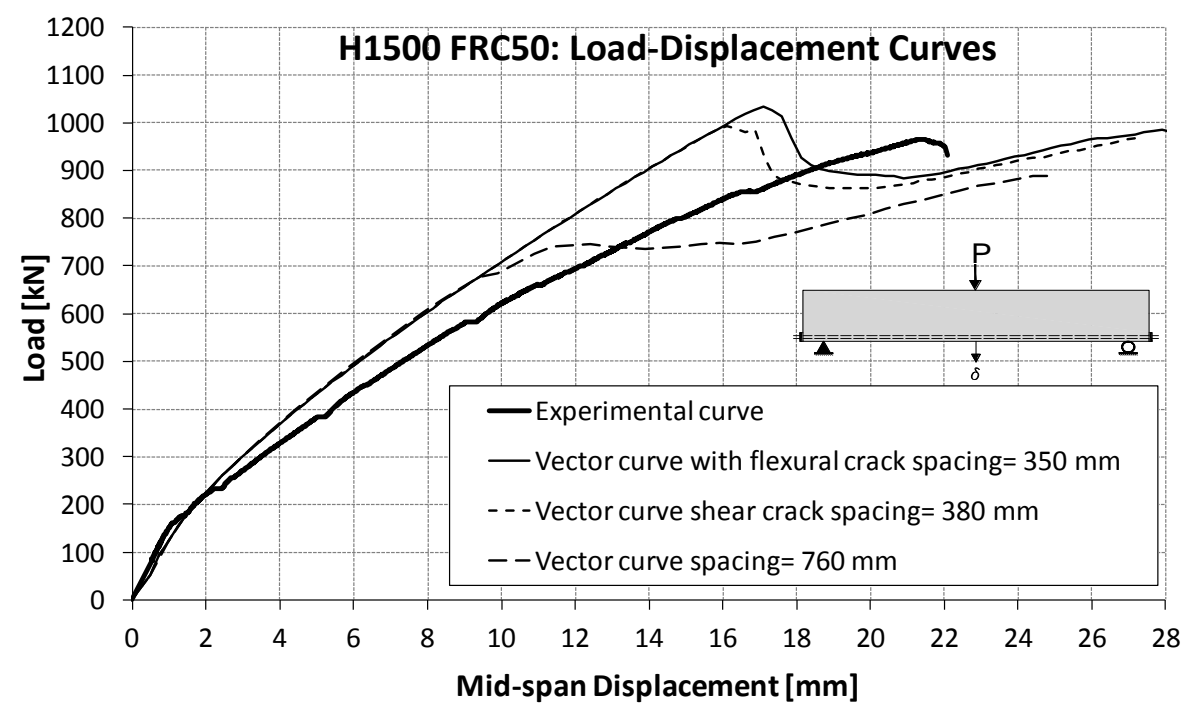

Fig.5. 31 Numerical response against experimental results for load-deflection of H1500-FRC50 


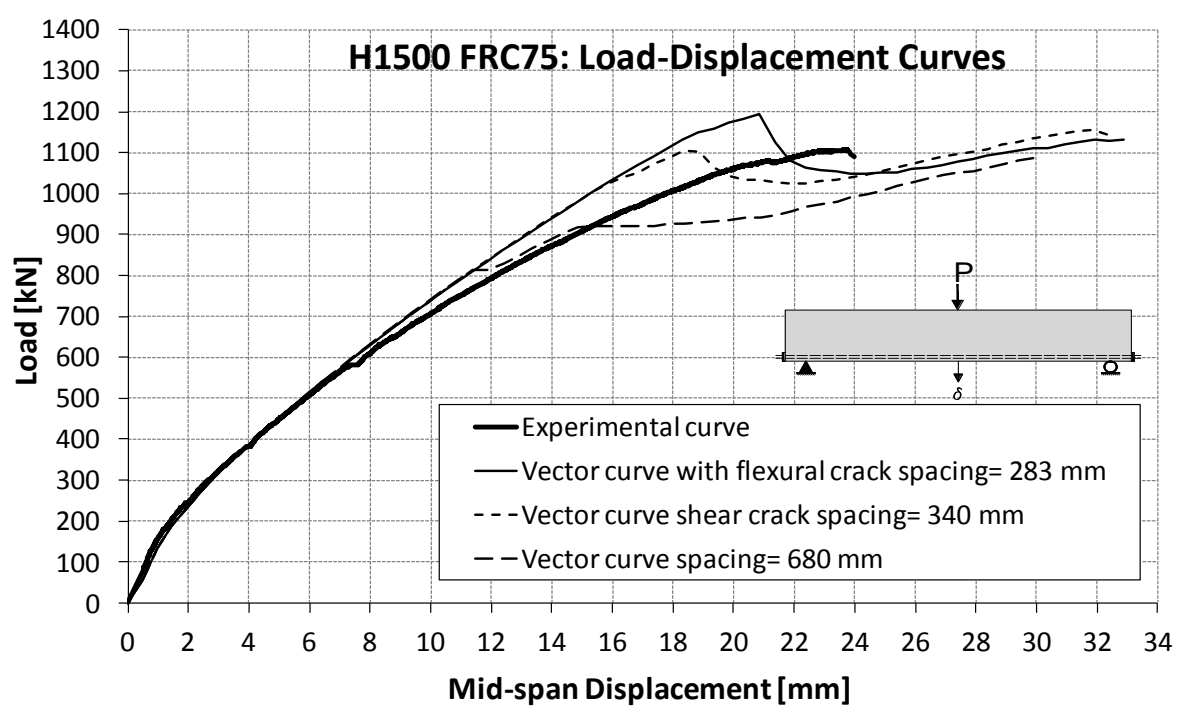

Fig.5.32 Numerical response against experimental results for load-deflection of H1500-FRC75

It can be observed a better comparison between experiments and numerical curves with a crack spacing larger than the measured one (twice or four times). This is confirmed by the plot in Fig.5.33 and Fig.5.34, referring to size effect. It can be therefore concluded that the proper crack spacing for the constitutive law should be referred to active shear cracks. Also, the smaller resistance of beams $\mathrm{H} 1000$ beams is not reproduced by the numerical analyses.

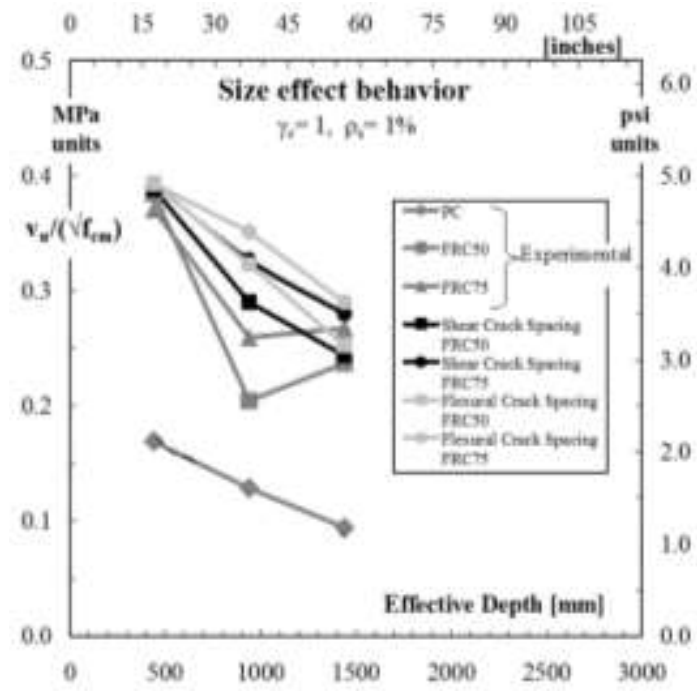

Fig.5.33 Size effect trend comparing experimental and numerical analysis with two different crack spacing: distance between bending cracks and distance between shear cracks 


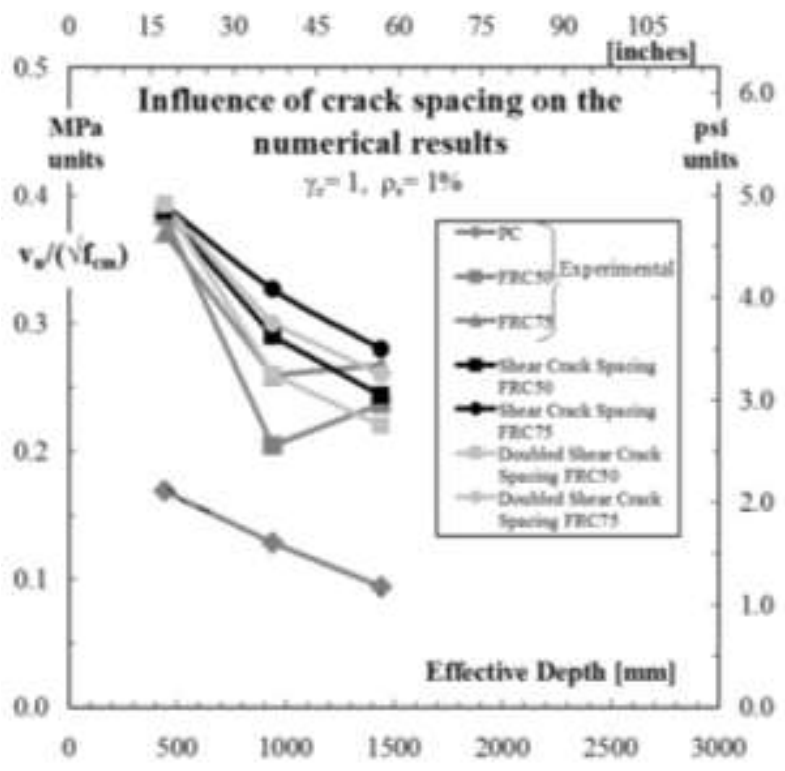

Fig.5.34 Size effect trend comparing experimental and numerical analysis with two different crack spacing: distance between shear cracks and the double of its distance

Once again, the size effect plots (Fig.5.33 and Fig.5.34) show that fibers can mitigate the size effect and that the resistance of larger beams approaches a horizontal asymptote.

\subsubsection{Shear values calculated with the current Design Codes}

The nine beams herein discussed were compared against the prediction of the models included in the following Codes: RILEM [8], Spanish EHE-08 [9] and MC2010 [6].

To better compare the resistance, partial safety factors for material properties were considered in the calculation as $\gamma_{c}=1$ and $\nu_{s}=1$. Moreover, average values of the material properties were utilized instead of the characteristic value present in the equations.

Table 5.7 reports the experimental and the shear theoretical values corresponding to the analyzed Design Codes.

On Shear Behavior of structural elements made of steel fiber reinforced concrete - PhD thesis 
Table 5.7 Shear strength $(\mathrm{kN})$ calculated from the current Design Codes without safety factors

\begin{tabular}{l|cccc}
\hline Specimen ID & $\boldsymbol{V}_{\text {test }}$ & $\boldsymbol{V}_{\text {EHE08 }}$ & $\boldsymbol{V}_{\text {RILEM }}$ & $\boldsymbol{V}_{\text {MC2010 }}$ \\
\hline H 500 PC & 115.68 & 116.38 & 116.38 & 109.15 \\
H 500 FRC50 & 239.53 & 215.93 & 225.61 & 188.68 \\
H 500 FRC75 & 234.53 & 238.76 & 250.42 & 199.39 \\
\hline H 1000 PC & 187.73 & 213.72 & 213.72 & 189.48 \\
H 1000 FRC50 & 272.14 & 399.54 & 417.60 & 346.50 \\
H 1000 FRC75 & 350.75 & 442.08 & 463.82 & 366.17 \\
\hline H 1500 PC & 210.98 & 301.27 & 301.27 & 244.34 \\
H 1500 FRC50 & 483.57 & 569.05 & 595.05 & 488.45 \\
H 1500 FRC75 & 554.13 & 630.21 & 661.50 & 516.18 \\
\hline
\end{tabular}

The safety margins (SM) obtained as $\mathrm{V}_{\text {test }} / \mathrm{V}_{\text {theo }}$ (the shear experimental value divided by the predicted shear value) were used as a reference parameter to compare the results obtained from the different beams and Codes. SM values are reported in Table 5.8.

Table 5.8 Safety margins calculated from the current Design Codes without safety factors

\begin{tabular}{l|ccc}
\hline Specimen ID & SM $_{\text {EHE08 }}$ & SM $_{\text {RILEM }}$ & SM $_{\text {MC2010 }}$ \\
\hline H 500 PC & 0.99 & 0.99 & 1.06 \\
H 500 FRC50 & 1.11 & 1.06 & 1.27 \\
H 500 FRC75 & 0.89 & 0.94 & 1.18 \\
\hline H 1000 PC & 0.88 & 0.88 & 0.99 \\
H 1000 FRC50 & 0.68 & 0.65 & 0.79 \\
H 1000 FRC75 & 0.79 & 0.76 & 0.96 \\
\hline H 1500 PC & 0.70 & 0.70 & 0.86 \\
H 1500 FRC50 & 0.85 & 0.81 & 0.99 \\
H 1500 FRC75 & 0.88 & 0.84 & 1.07 \\
\hline
\end{tabular}

The values presented in Table 5.8 are also plotted in Fig.5.35 for both PC and FRC beams. This permits to evaluate separately PC than FRC beams since these concretes have models and behaviors totally different. As showed Chapters 3 and 4, MC2010 for PC is based on the MCFT, and for FRC is based on variable truss analogy. Fig.5.35 shows that for $\mathrm{H} 500$ beams, Codes are safe, except for H500 FRC75 beam evaluated with RILEM and EHE08. Also, MC2010 evaluates properly the size effect on beams, giving safe values $(S M>1)$ for all beams, except for H1000 FRC50. From beams made with PC (without fibers), a decreasing line is observed and the SM decreases when effective depth increases; this line almost has safe values for all depths but, on the other hand, RILEM and EHE08 give unsafe values for H1000 PC and H1500 PC. 


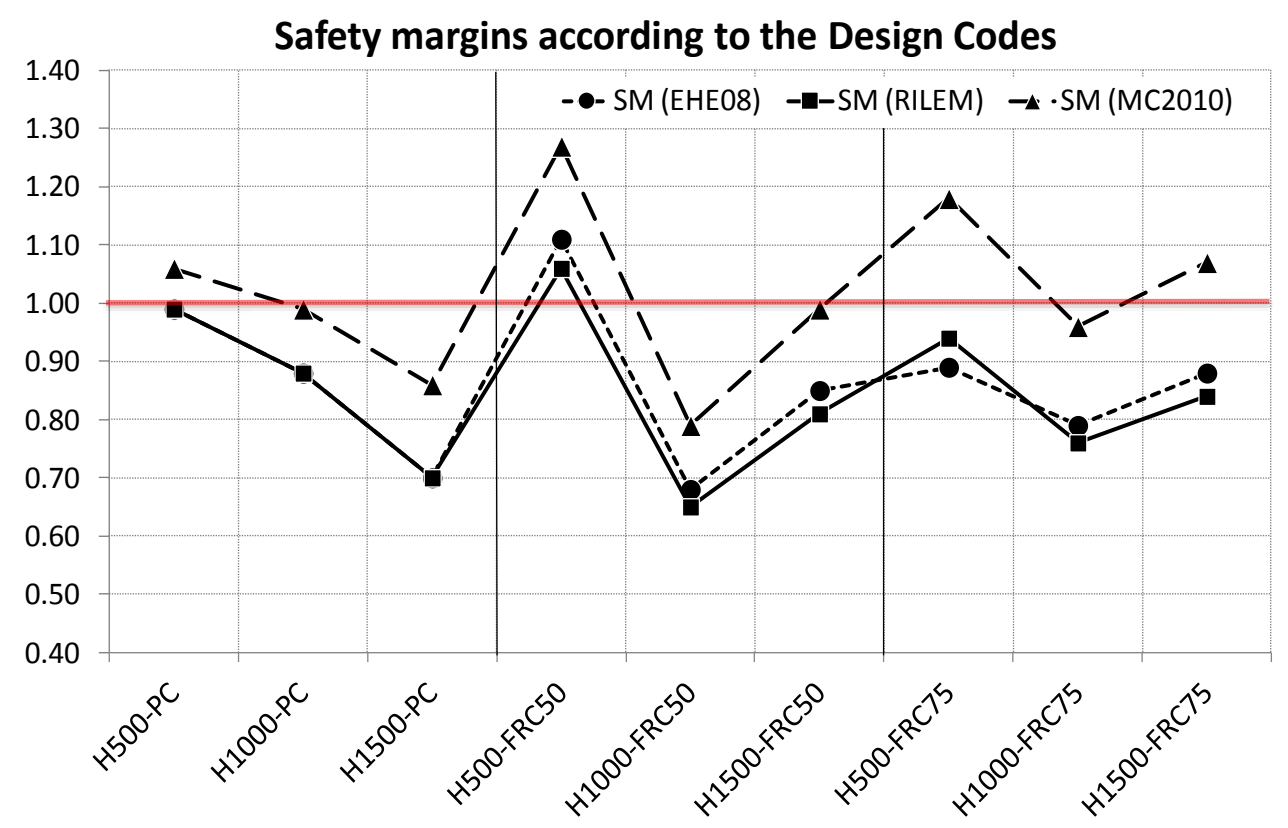

Fig.5.35 Safety Margin (SM) $=V_{\text {test }} / V_{\text {theo }}$ without safety factors

Finally, it can be observed that all the $\mathrm{H} 1000$ beams have a SM smaller than 1, indicating that something strange occurred during the tests.

\subsection{Conclusions}

Based on the experimental results, the following main conclusions can be drawn:

- $\quad$ Fibers substantially mitigate the size effect in shear that is increasingly reduced for increasing FRC toughness.

- $\quad$ FRC allows a multiple and stable shear crack development in the shear critical area, delaying (or even avoiding) the formation of the single critical shear crack.

- $\quad$ Fibers, even in relatively low amount, greatly influence the shear behavior of beams, basically by delaying the occurrence of the shear failure mechanism and, eventually, by altering the collapse from shear to flexure, with enhanced bearing capacity and ductility.

- It is essential to choose a proper value of the crack spacing for a good numerical simulation represented by the distance between active shear cracks; otherwise, simulations obtained will not represent well the actual behavior.

On Shear Behavior of structural elements made of steel fiber reinforced concrete - PhD thesis 
- A horizontal asymptote in the size effect law seems to be present (no further decrease of shear resistance with larger beam sizes); however, further studies are necessary to better understand the size effect in FRC and confirm this trend.

- MC2010 evaluates properly the shear behavior and the size effect on beams, having size significant for practice; RILEM and EHE08 give unsafe values for H 1000 PC and H 1500 PC.

- $\quad$ For PC beams a decreasing line on the graph SM versus increasing effective depth was observed.

\subsection{References}

[1] ASTM.C1550-10a, "Standard Test Method for flexural toughness of fiber reinforced concrete (using centrally loaded round panel)," ASTM International, West Conshohocken, 2002.

[2] Conti and Flelli, Caratterizzazione del calcestruzzo fibrorinforzato attraverso prove su piastre sottili (in italian), Brescia, Italy: Tesi di laurea, Università degli Studi di Brescia, 2008-09.

[3] F. Minelli, Plain and fiber reinforced concrete beams under shear loading: Structural behavior and design aspects, PhD thesis, University of Brescia, 2005.

[4] E. Bentz, "Empirical modeling of reinforced concrete shear strength size effect for members without stirrups," ACl Structural Journal, vol. 102, no. 2, pp. 232-241, 2005.

[5] Vecchio, "VecTor Analysis Group," [Online]. Available: www.civ.utoronto.ca/vector/software.html.

[6] MC2010, "fib Bulletins 55-56. Model Code 2010. First Complete Draft," 2010.

[7] Montaignac, Massicotte and Charron, "Design of SFRC structural elements: flexural behavior prediction," Materials and Structures, vol. 45, no. 4, pp. 623-636, 2012.

[8] RILEM, «TC 162-TDF. Test and design methods for steel fibre reinforced concrete, stress-strain design method. Final Recommendation.," Materials and Structures, vol. 36, pp. 560-567, 2003. 
[9] EHE-08, Instrucción de Hormigón Estructural EHE-08 (in Spanish), Ministerio de Fomento, 2008, p. 702 pp..

On Shear Behavior of structural elements made of steel fiber reinforced concrete-PhD thesis 


\title{
CHAPTER 6
}

\section{EXPERIMENTAL TESTS TO}

\author{
STUDY THE INFLUENCE ON THE
}

SHEAR BEHAVIOR OF FIBERS OF

\section{DIFFERENT CHARACTERISTICS}

\subsection{Introduction}

Steel fiber reinforced concrete (SFRC) is a composite material that is characterized by an enhanced post-cracking behavior due to the capacity of fibers to bridge the crack faces. The enhanced toughness is mainly provided by bond and high-modulus fibers in a suitable concrete matrix. Hooked fibers are more effective than straight and crimped ones in enhancing the post-peak energy absorption capacity. The effect of fibers on compressive strength is relatively small, and different fiber types seem to act similarly in this regard [1].

On Shear Behavior of structural elements made of steel fiber reinforced concrete - PhD thesis 
On the other hand, the inclusion of fibers decreases the concrete workability. This effect is more pronounced for fibers with higher aspect ratios.

Steel fibers in concrete can considerably influence shear behavior and shear capacity guarantying the minimum shear reinforcement required by the current Codes. SFRC makes possible a more distributed cracking pattern, where shear cracks are characterized by smaller crack spacing and widths [2].

Many studies have advanced the knowledge in shear behavior of FRC beams. Fiber content has a significant effect on shear behavior, but the fiber type was also found to be influential since both of them influence the FRC toughness. Fibers with a higher aspect ratio resulted in an increased shear strength due to the enhanced post-cracking behavior compared to fibers with a low aspect ratio [ [3]; [4]; [5]]. Hooked steel fibers with a length of $60 \mathrm{~mm}$ allowed a larger shear crack opening when compared to that observed in beams with $30 \mathrm{~mm}$ long fibers, but they were prone to problems associated with fiber lumping along the longitudinal reinforcement. In fact, horizontal clear spacing between reinforcing bars, no less than the fiber length, is recommended [6].

But there are more investigations analyzing the effect of amount of fibers on the shear behavior, than this one of the type of fibers, as can be observed from some databases [e.g. [3]; [7]].

To analyze the fiber contribution to shear capacity, Codes usually consider only the residual concrete strength at $2.5 \mathrm{~mm}$ crack opening in the flexural test $\left(f_{R 3}\right)$. However, it is possible to produce concretes with a similar $f_{R 3}$ but with very different post cracking behaviors. This is possible using fibers with different geometries and yielding capacity [8].

The aim of this Chapter is to obtain self-compacting fiber reinforced concrete (SCFRC) with a large variability of mechanical behaviors by using different fiber types, and to analyze its effect on the shear behavior, by considering the serviceability limit state (SLS), the ultimate limit state (ULS), and also analyzing the ductility on the load/deflection and load/shear crack opening behavior of these beams. To achieve the objectives, an experimental program consisting of SCFRC double-T beams was designed. Beams were $2400 \mathrm{~mm}$ long, with a double-T cross-section, a height of $350 \mathrm{~mm}$ and web width equal to $90 \mathrm{~mm}$.

The main parameters of study were: concrete compressive strength level (30,50, $80 \mathrm{MPa})$ and steel fibers quality (using fibers with different strength levels, lengths, and aspect ratios (length/diameter)). The amount of steel fibers $\left(50 \mathrm{~kg} / \mathrm{m}^{3}\right)$ was kept constant. Beams without fibers were produced as a reference. 


\subsection{Experimental program}

Three concrete matrixes, characterized by their compressive strength $(30,50$ and 80 $\mathrm{MPa}$ ), named as Low (L), Medium (M) or High (H) strength, were produced. With those concrete matrixes, 16 different self-compacting concretes were derived by only adding fibers. When used, the fiber content was always $50 \mathrm{~kg} / \mathrm{m}^{3}$. Each concrete is then defined by the compressive strength level and the fiber geometries (lengths and aspect ratio) as well as fiber strength levels. Table 6. 1 shows the nominal mix designs.

Table 6. 1 Mix designs $\left(\mathrm{kg} / \mathrm{m}^{3}\right)$

\begin{tabular}{|c|c|c|c|}
\hline & $\begin{array}{c}\text { Low strength } \\
\text { concrete (L) }\end{array}$ & $\begin{array}{c}\text { Medium strength } \\
\text { concrete (M) }\end{array}$ & $\begin{array}{c}\text { High strength } \\
\text { concrete (H) }\end{array}$ \\
\hline Cement 52.5R & 290 & 340 & 450 \\
\hline 7/12 aggregate & 658 & 731 & 610 \\
\hline Sand & 954 & 954 & 1075 \\
\hline Filler & 180 & 125 & 0 \\
\hline Silica fume & 0 & 0 & 50 \\
\hline Steel fibers & 50 & 50 & 50 \\
\hline Water & 210 & 210 & 175 \\
\hline Superplasticizer & 5.20 & 7.45 & 26.7 \\
\hline
\end{tabular}

Five different types of hooked-end steel fibers from Bekaert@ $\subseteq$ were used, both normal strength low carbon fibers (BN), with a tensile strength equal to $1225 \mathrm{MPa}$, or high strength high carbon (BP), with a tensile strength equal $3070 \mathrm{MPa}$.

To analyze the mix design, a characterization quality control took place in the experimental program. The following control tests were done: compressive strength test on $150 \times 300 \mathrm{~mm}$ cylinder specimens (EN 12390-3) and on cubic specimens $100 \times 100 \mathrm{~mm}$. Flexural tensile strength tests (EN 14651) was performed on notched beams to determine: the limit of proportionality $\left(f_{c t}\right)$ and the residual flexural tensile strength $\left(f_{R, j}\right)$ which corresponds to the crack mouth opening displacements (CMOD) linked to the crack openings (in $\mathrm{mm}$ ) of $0.5,1.5,2.5$ and 3.5 ( $\mathrm{j}=1,2,3,4$ respectively).

Each type of the fiber was referenced by its aspect ratio (length/diameter), its length (in $\mathrm{mm}$ ) and the steel strength level, according with the following structure:

\section{$\{$ Aspect ratio\} / \{Length $(\mathrm{mm})\} B N$ or BP}

Fig.6.1 shows the steel fibers used in the experimental program presented herein, 
consisting of twenty-two double-T beams. Beams were $2400 \mathrm{~mm}$ long, with a double-T cross section, $350 \mathrm{~mm}$ height and web width equal to $90 \mathrm{~mm}$ (Fig.6.2). All beams had a basic reinforcement, as shown in Fig.6.2 and Fig.6.3, without stirrups in one of the shear span (tested shear span), in order to localize the failure zone.

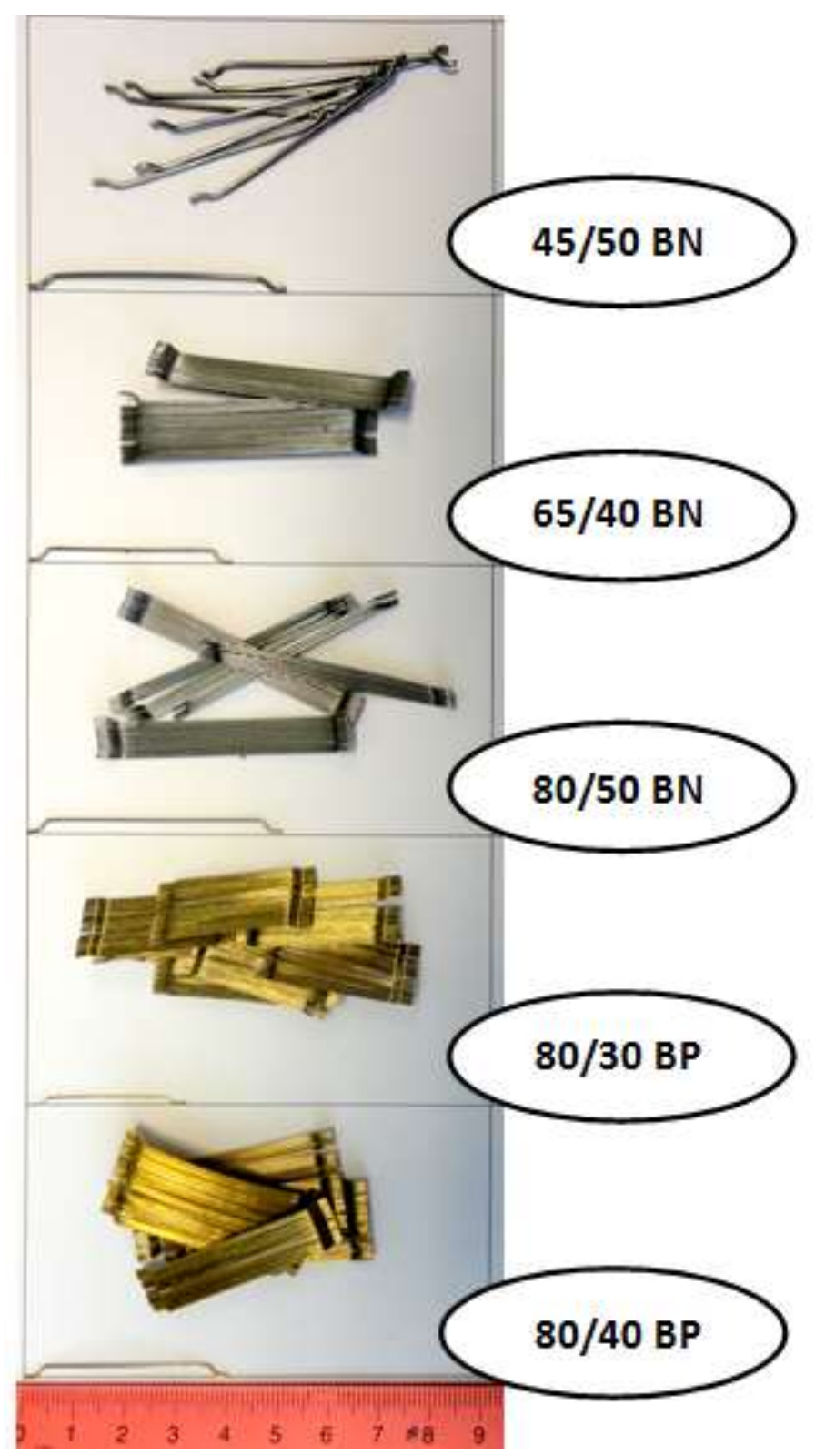

Fig.6. 1 Typology of steel fibers used in this experimental program (scale lines indicate millimeters) 

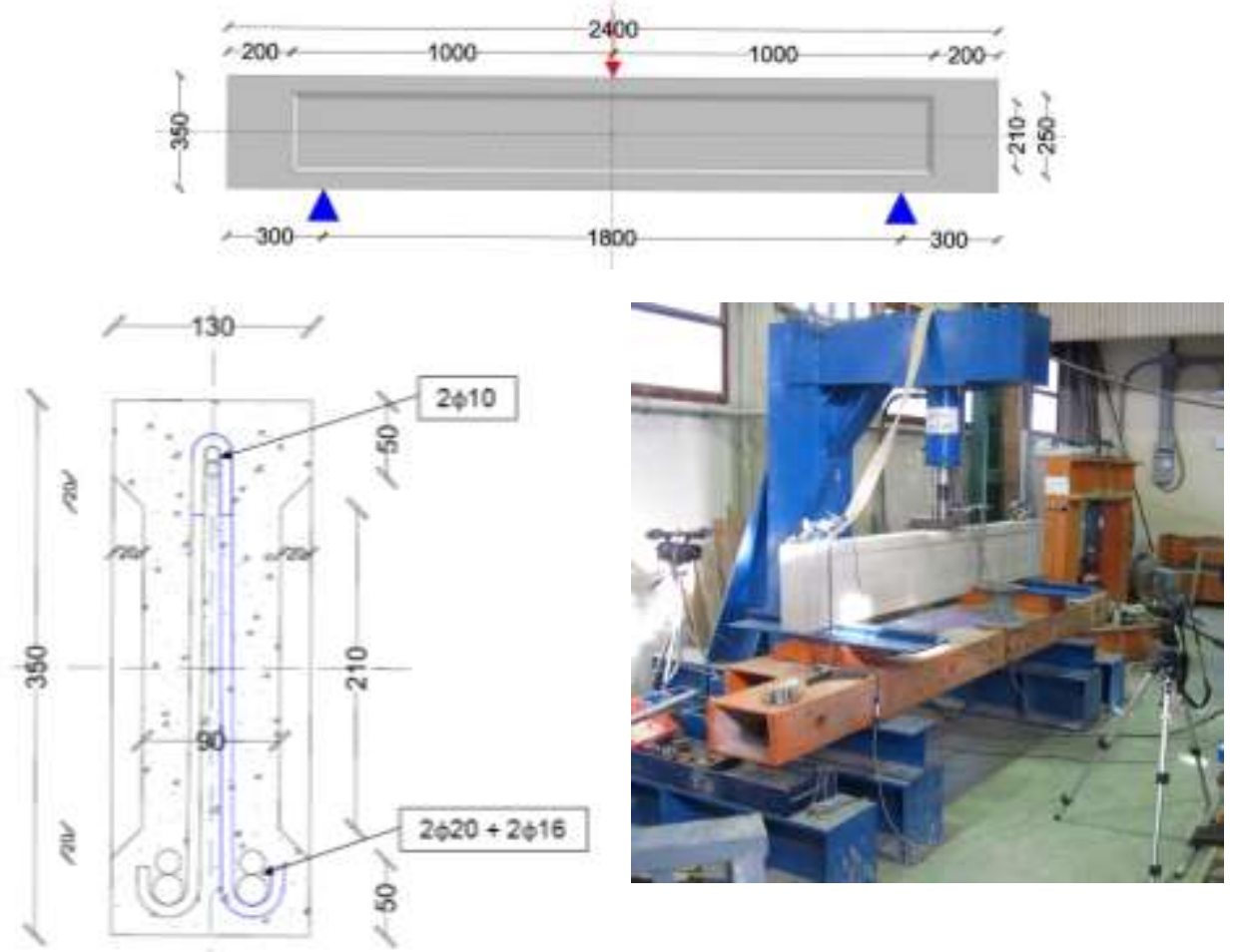

Fig.6. 2 Beams' geometry and test set-up. Dimensions in $\mathrm{mm}$

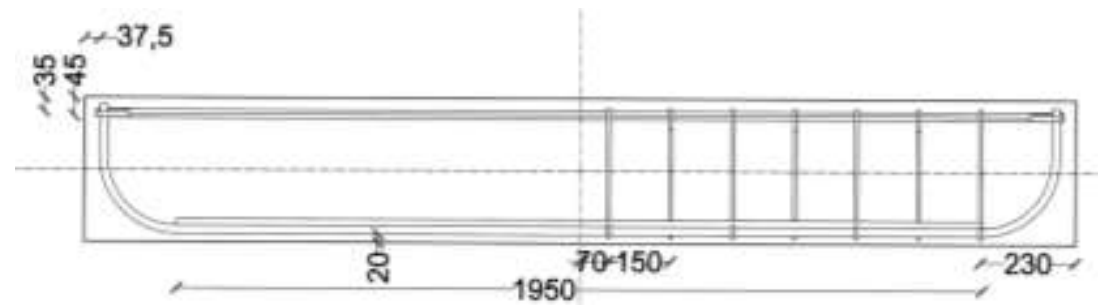

Fig.6. 3 Transverse reinforcement arrangement. Dimensions in $\mathrm{mm}$

Beams without fibers, including or not traditional shear reinforcement in the tested shear span, were produced to be utilized as a reference.

In order to facilitate their identification, the beam ID took the following structure:

$\{$ Concrete Compressive strength level: $(L)(M)$ or $(H)\}-\{$ Type of fibers $\}-\{a, b\}$ 
When traditional shear reinforcement in the tested shear span is provided, the type of fibers is substituted by the diameter o the employed rebar. When, there were two identical beams, their beam IDs were differentiated by placing: " $a$ " and " $b$ " at the end of the beam ID. The experimental program is shown in Table 6. 2.

Table 6. 2 Experimental program

\begin{tabular}{|c|c|c|c|}
\hline Reference & Beam ID & Fibers amount $\left(\mathrm{kg} / \mathrm{m}^{3}\right)$ & Transverse reinforcement \\
\hline V1 & M-65/40BN-a & 50 & --- \\
\hline V2 & $\mathrm{M}-80 / 40 \mathrm{BP}$ & 50 & --- \\
\hline V3 & $\mathrm{L}-80 / 50 \mathrm{BN}-\mathrm{a}$ & 50 & --- \\
\hline V4 & $\mathrm{L}-65 / 40 \mathrm{BN}$ & 50 & --- \\
\hline V5 & $\mathrm{M}-80 / 50 \mathrm{BN}$ & 50 & --- \\
\hline V6 & $\mathrm{H}-65 / 40 \mathrm{BN}$ & 50 & --- \\
\hline V7 & $\mathrm{H}-80 / 40 \mathrm{BP}$ & 50 & --- \\
\hline V8 & M-0 & 0 & --- \\
\hline V9 & $\mathrm{M}-45 / 50 \mathrm{BN}$ & 50 & --- \\
\hline V10 & L-80/40BP & 50 & --- \\
\hline V11 & $M-\phi 8$ & 0 & ф8@150mm-1 leg \\
\hline V12 & $\mathrm{M}-80 / 30 \mathrm{BP}$ & 50 & --- \\
\hline V13 & $\mathrm{H}-\mathrm{O}$ & 0 & --- \\
\hline V14 & $\mathrm{H}-80 / 50 \mathrm{BN}$ & 50 & --- \\
\hline V15 & $\mathrm{H}-45 / 50 \mathrm{BN}$ & 50 & --- \\
\hline V16 & $\mathrm{H}-80 / 30 \mathrm{BP}$ & 50 & --- \\
\hline V17 & $\mathrm{H}-\phi 8$ & 0 & ф8@150mm-1 leg \\
\hline V18 & $M-\phi 6$ & 0 & ф6@200mm-1 leg \\
\hline V19 & $\mathrm{H}-\phi 6$ & 0 & ф6@200mm-1 leg \\
\hline V20 & L- $\phi 6$ & 0 & \$6@200mm-1 leg \\
\hline V21 & M-65/40BN-b & 50 & --- \\
\hline V22 & L-80/50BN-b & 50 & --- \\
\hline
\end{tabular}

Beams were subjected to a three-point test (Fig.6.2) with an $a / d$ ratio equal to 2.92 for all beams, except for the beams V19 $(\mathrm{H}-\phi 6)$ and V20 (L-\$6), characterized by a ratio $a / d=3.02$, since the longitudinal reinforcement was placed $10 \mathrm{~mm}$ higher than the other beams (therefore, a lower effective depth $(d)$ was present). 


\subsection{Result of the concretes characterization}

Very different flexural strength and post-peak behavior were obtained even when comparing concretes made with the same matrix (Fig.6.4 and 6.5). Concretes with a clear ductile behavior, like those made with medium strength matrix and high strength fibers, and others with a brittle response as those made with high strength concretes and normal strength fibers, have been obtained. Fig. 6.4 and 6.5 shows that the most ductile behaviors corresponds to BP fibers, as expected, maintaining high loads at great CMOD values. On the other hand, concretes type $\mathrm{H}$ or $\mathrm{M}$ with $80 / 50 \mathrm{BN}$ or $65 / 40 \mathrm{BN}$ show a big difference between the residual $f_{R 3}$ and $f_{R 1}$ strength values and, as consequence, a brittle behavior.

Table 6.3 shows the mechanical properties of the different mixes of each beam. All the mechanical values were obtained as the average of at least three specimens, 28 days after casting the beams. The $\left(f_{R 3, m} / f_{R 1, m}\right)$ ratio is included to compare with the fiber classification proposed by the Model Code [8]. The obtained values, ranging from 0.21 to 1.16 , cover all the possibilities considered by this classification, except the highest hardening behavior $\left(f_{R 3, m} / f_{R 1, m}\right.$ ratio $\left.>1.3\right)$. A column with the average residual strength $f_{R m}=\left(f_{R 1}+f_{R 3}\right) / 2$ is also included.

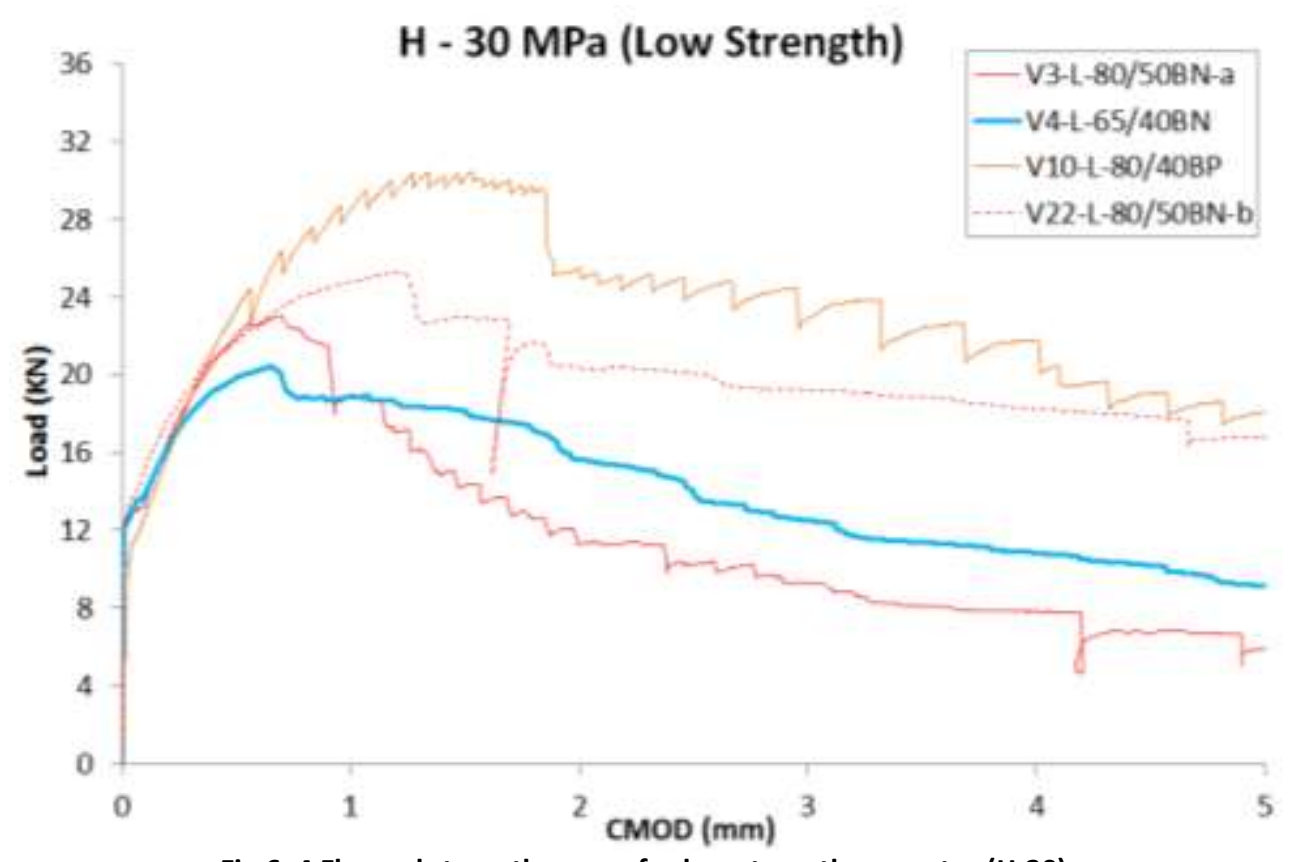

Fig.6. 4 Flexural strength curves for low strength concretes (H-30) 

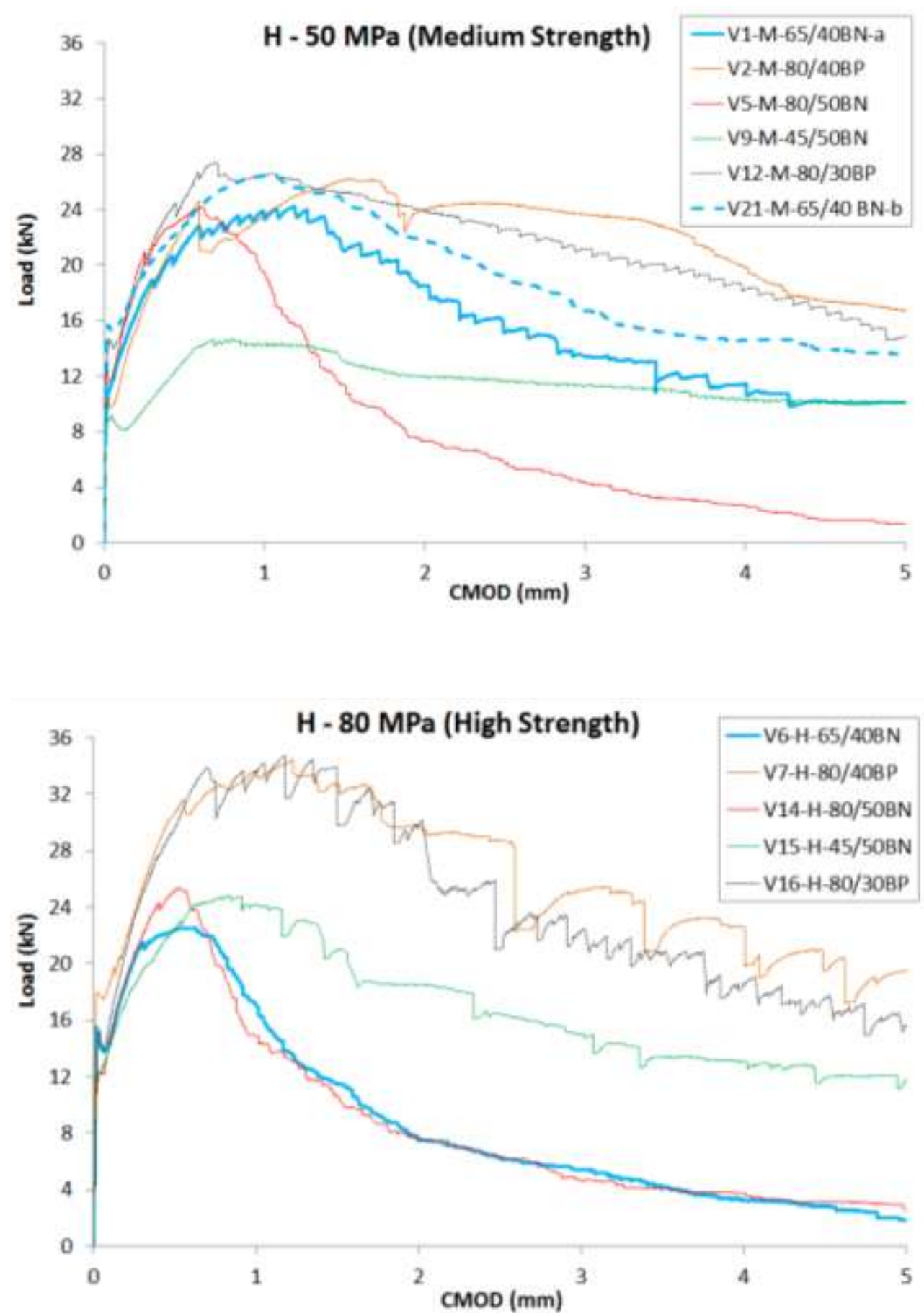

Fig.6. 5 Flexural strength curves for medium and high strength concretes (H-50 and H-80) 
Table 6. 3 Concrete mechanical properties (Average values)

\begin{tabular}{|c|c|c|c|c|c|c|c|}
\hline Ref. & Beam ID & $f_{\mathrm{cm}}(\mathrm{MPa})$ & $\begin{array}{c}\mathbf{f}_{\mathrm{R} 1, \mathrm{~m}} \\
(\mathrm{MPa})\end{array}$ & $\begin{array}{c}f_{\mathrm{R} 3, \mathrm{~m}} \\
(\mathrm{MPa})\end{array}$ & $\begin{array}{c}\mathbf{f}_{\mathrm{Rm}} \\
(\mathrm{MPa})\end{array}$ & $f_{R 3, m} / f_{R 1, m}$ & $\mathrm{~V}_{\text {test }}(\mathrm{kN})$ \\
\hline V1 & M-65/40BN-a & 66.58 & 6.48 & 4.50 & 5.49 & 0.69 & 74.8 \\
\hline V2 & M-80/40BP & 71.09 & 8.16 & 9.44 & 8.80 & 1.16 & 100.7 \\
\hline V3 & L-80/50BN-a & 34.29 & 5.29 & 3.55 & 4.42 & 0.67 & 59.5 \\
\hline V4 & L-65/40BN & 33.82 & 5.45 & 3.69 & 4.57 & 0.68 & 56.6 \\
\hline V5 & M-80/50BN & 61.87 & 7.50 & 1.83 & 4.67 & 0.24 & 72.2 \\
\hline V6 & $\mathrm{H}-65 / 40 \mathrm{BN}$ & 95.95 & 6.34 & 1.30 & 3.82 & 0.21 & 65.7 \\
\hline V7 & $\mathrm{H}-80 / 40 \mathrm{BP}$ & 88.10 & 12.20 & 10.60 & 11.40 & 0.87 & 111.6 \\
\hline V8 & $M-0$ & 50.48 & --- & --- & --- & & 37.5 \\
\hline V9 & M-45/50BN & 51.03 & 4.18 & 4.43 & 4.31 & 1.06 & 66.8 \\
\hline V10 & L-80/40BP & 40.74 & 7.71 & 8.18 & 7.95 & 1.06 & 81.2 \\
\hline V11 & $M-\phi 8$ & 50.48 & --- & --- & --- & & 80.9 \\
\hline V12 & M-80/30BP & 49.67 & 6.93 & 7.13 & 7.03 & 1.03 & 92.7 \\
\hline V13 & $\mathrm{H}-\mathrm{O}$ & 85.57 & --- & --- & --- & & 40.4 \\
\hline V14 & $\mathrm{H}-80 / 50 \mathrm{BN}$ & 96.34 & 6.70 & 1.91 & 4.31 & 0.29 & 62.9 \\
\hline V15 & $\mathrm{H}-45 / 50 \mathrm{BN}$ & 84.88 & 7.28 & 5.94 & 6.61 & 0.82 & 68.9 \\
\hline V16 & H-80/30ВР & 83.60 & 8.84 & 7.38 & 8.11 & 0.83 & 94.7 \\
\hline V17 & $\mathrm{H}-\phi 8$ & 85.57 & --- & --- & --- & & 94.3 \\
\hline V18 & M- $\phi 6$ & 48.25 & --- & --- & --- & & 74.1 \\
\hline V19 & $\mathrm{H}-\phi 6$ & 74.50 & --- & --- & --- & & 79.1 \\
\hline V20 & L- $\phi 6$ & 41.90 & --- & --- & --- & & 85.7 \\
\hline V21 & $M-65 / 40 B N-b$ & 45.30 & 6.20 & 5.55 & 5.88 & 0.90 & 55.7 \\
\hline V22 & L-80/50BN-b & 39.58 & 7.35 & 6.67 & 7.01 & 0.91 & 50.6 \\
\hline
\end{tabular}

Note: Yellow shaded rows and bold values indicate beams with BP fibers.

\subsection{Results of the shear tests on beams}

All failures were produced by shear with three different failure modes:

-FAILURE MODE (I): First crack appeared in the middle of the web with an inclination of 45 and a second crack forms close to the initial. The first crack is expanding, spreading all over the web and has a bigger width compared to the cracks created after it. An instantaneous increase is observed in all crack widths, as the bottom flange cracks, followed by a continuously increasing crack opening. In the end, new cracks are created connecting the other cracks to achieve the final failure (e.g. unreinforced beams: $M-0$ and 
$\mathrm{H}-0)$. Shear cracks development is shown in Fig.6.6.

-FAILURE MODE (II): The first crack appeared next to the point of loading and shortly after that, a second one is created, which propagates rapidly through the whole flange. The cracks spread to the support to the whole web and their width increased until the top flange was cracked. Afterwards, crack openings grow very fast and produce the failure (e.g. beams L-80/50BN-a, L-65/40BN, M-80/50BN, H-65/40BN, M-45/50BN, L-80/40BP, H80/50BN, H-80/30BP and L-80/50BN-b). Shear cracks development is shown in Fig.6.7.

-FAILURE MODE (III): First crack appeared in the web close to the loading point, with an inclination of about 45․ A second crack develops, with a larger inclination, closer to the support. Cracks develop slowly during the test, but cracked zones are created, where the concrete is significantly damaged, especially where cracks were clustering together. Finally, the failure occurs after the development of a crack in the top flange (e.g. beams with stirrups $\phi 8$ or BP fibers: $M-80 / 40 B P, M-\phi 8, M-80 / 30 B P$ and $H-\phi 8)$. Shear cracks evolution is shown in Fig.6.8.

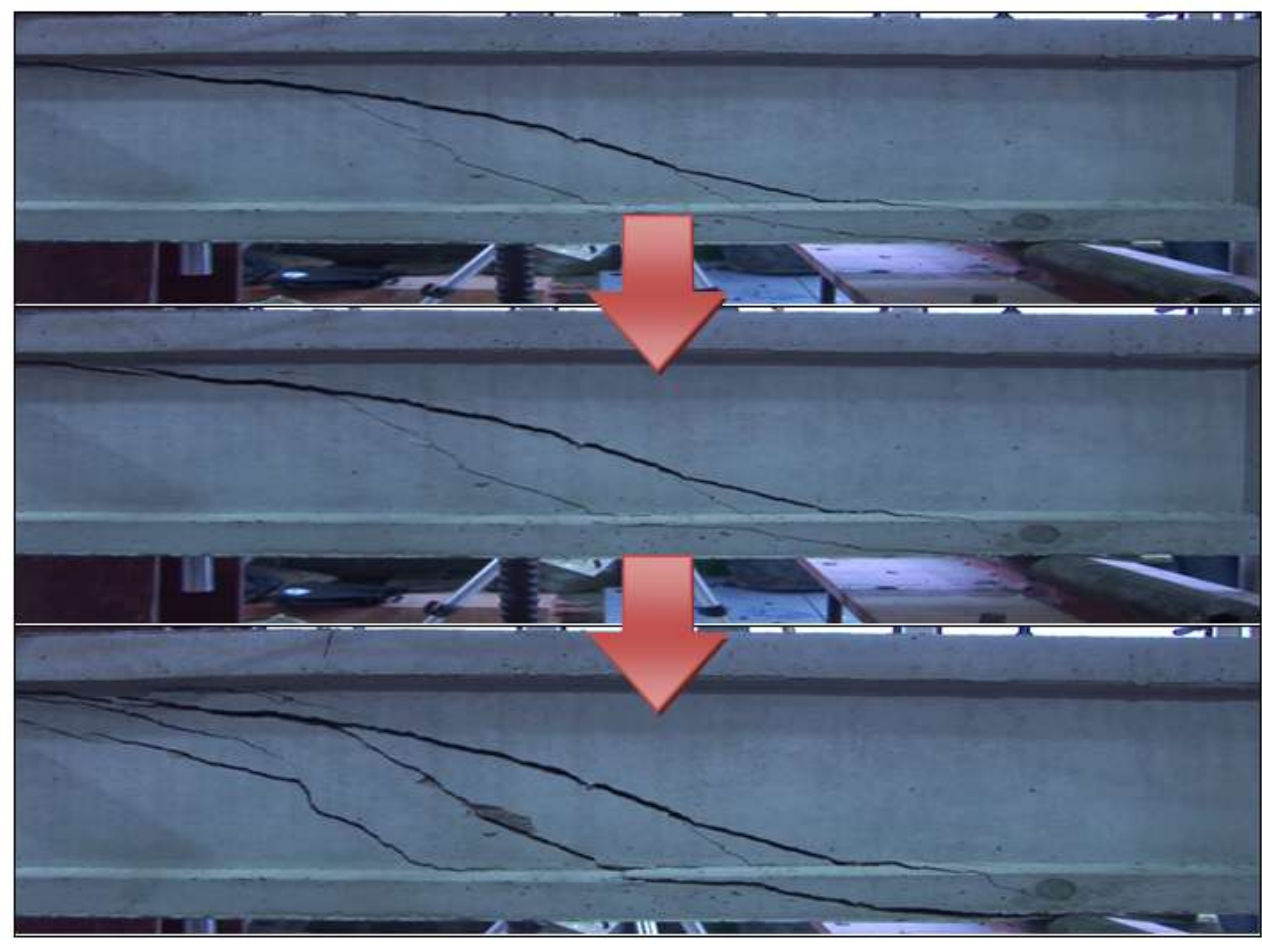

Fig.6. 6 Shear crack evolution (Failure mode I) 


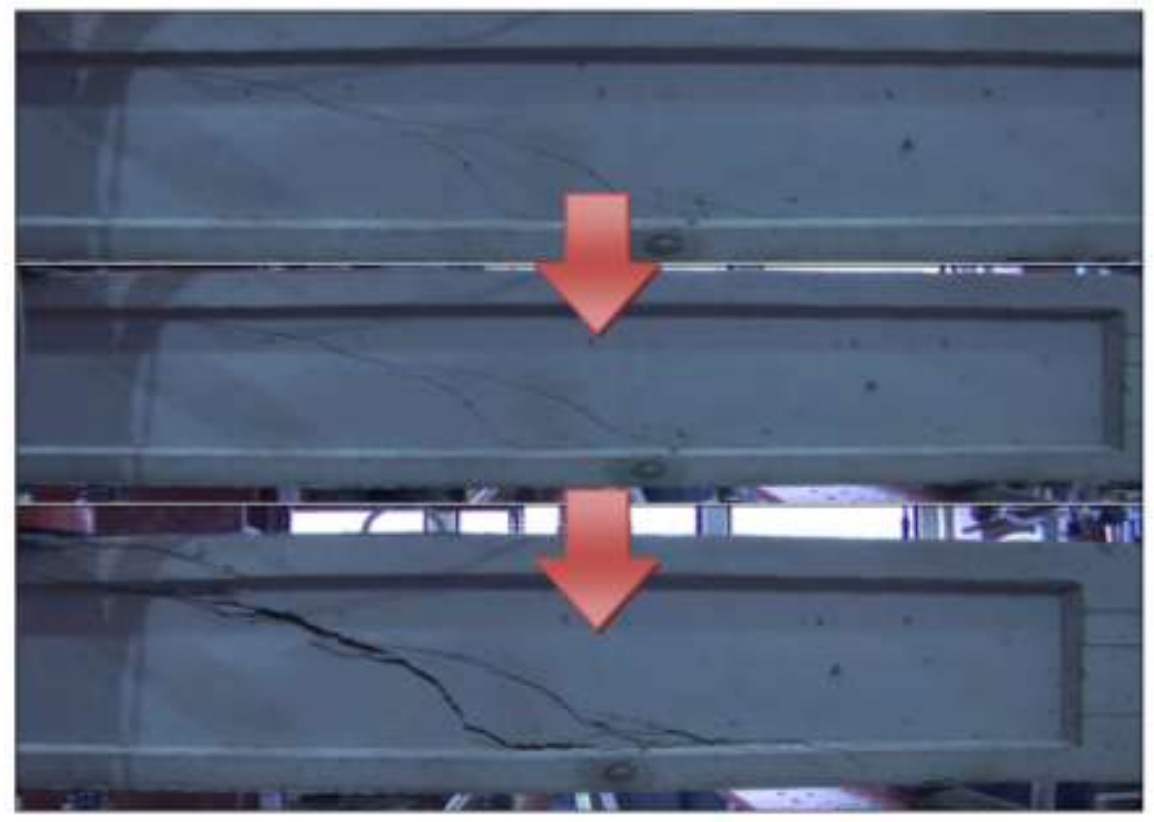

Fig.6. 7 Shear crack evolution (Failure mode II)

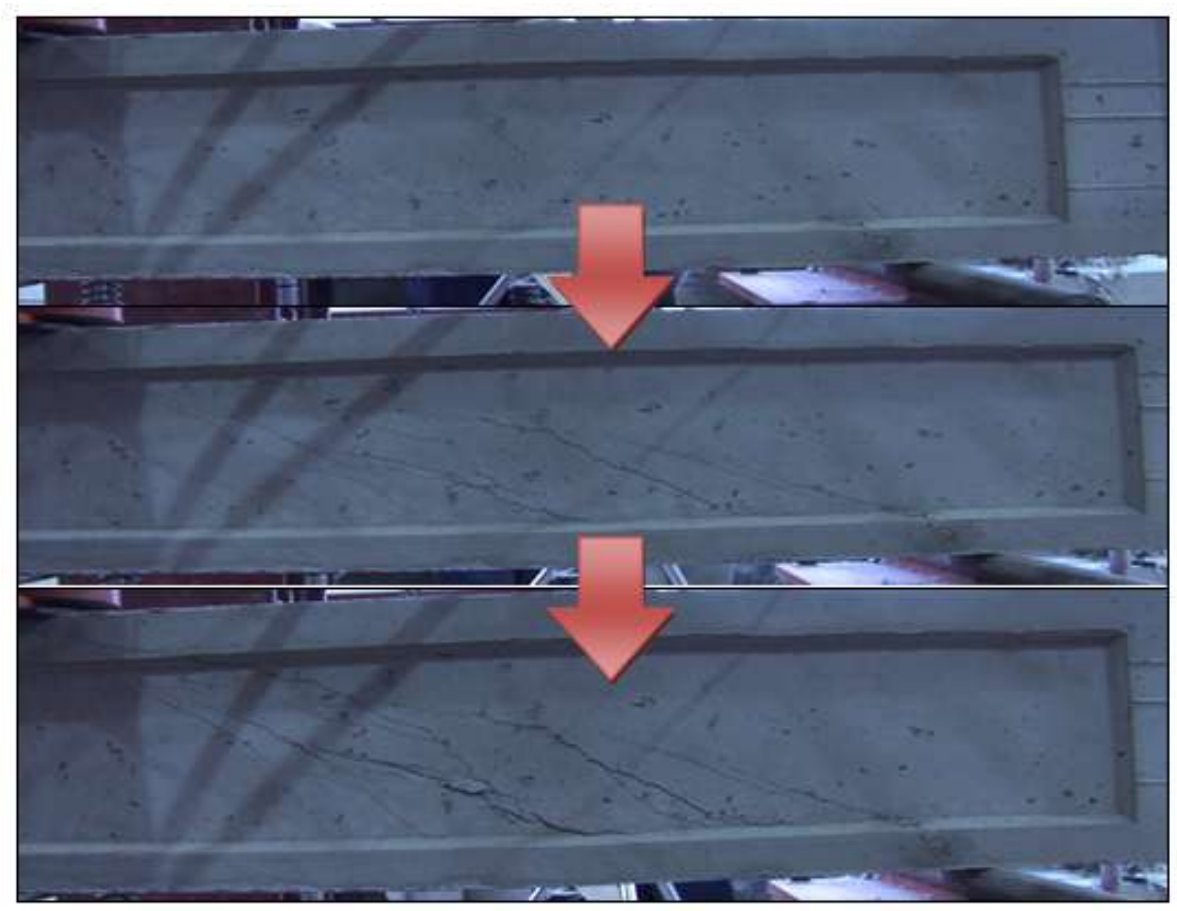

Fig.6. 8 Shear crack evolution (Failure mode III)

On Shear Behavior of structural elements made of steel fiber reinforced concrete - PhD thesis 
Shear strength behavior is significantly influenced by the fiber type, ranging from a low shear strength improvement (compared with unreinforced concrete) to a behavior even more ductile than that of a beam with stirrups. Low strength concretes with $\phi 6$ stirrups showed a very brittle post-crack behavior, while beams with BN fibers were the most ductile. For all strength levels, beams with BP fibers and reinforced beams reached the highest loads. Beams with traditional shear reinforcement show an important deflection increase just after the first crack and a greater load reduction after peak.

From those shear tests: load, deflection and crack widths were measured. Also, cracking pattern was observed by means of pictures and video recording.

Fig.6.9 shows the load-deflection response of all tested beams. The maximum loads are reported in Table 6.3.

Shear cracks widths development during the test was analyzed by analysis of pictures coordinated with loading process through the time (Fig.6.10). In the load-deflection curves, the point markers indicate the maximum shear crack width for its corresponding load-deflection value. It can be noticed that at shear peak load, the shear crack opening was about $0.2 \mathrm{~mm}$.

Observing Fig.6.10, the beam with stirrups ( $\mathrm{H} \phi 6)$ achieved the greatest deflection (at midspan) at the peak load and reached higher deflection, if compared with SFRC. The beam with BN fibers obtained crack widths slightly smaller for the same deflection, as compared to the beam with BP fibers. Obviously, the beam without any reinforcement had a completely brittle behavior.

In the subsection 6.3 of this Chapter 6, it was obtained that toughness properties of the FRC depended not only of the type of fibers, but also with the compressive strength of the concrete. For that, it was determined a new parameter $f_{R m}=\left(f_{R 1}+f_{R 3}\right) / 2$. After having the test results of the beams, it is intended to know if there is a relationship between the toughness properties (using shear stress $\tau$, determined with $f_{R 3}$ and $f_{R m}$ ) and the experimental shear value $\left(V_{\text {test }}\right.$ in $\left.\mathrm{kN}\right)$ and, which toughness value $\left(f_{R 3}\right.$ or $\left.f_{R m}\right)$ represents better the shear behavior to be included in the design Codes. Therefore, Fig.6.11 shows the experimental shear strength versus the " $\tau$ " factor proposed by RILEM [9] $\left(\tau=k_{f} \cdot 0.7 \cdot \xi \cdot 0.18 \cdot f_{R 3}\right)$ and, in Fig.6.12, the same tendency was analyzed but using an average residual flexure tensile strength $f_{R m}=\left(f_{R 1}+f_{R 3}\right) / 2$ instead of $f_{R 3}$. In order to analyze these same graphs (Fig.6.11 and Fig.6.12), the " $\tau$ " value for the beams with stirrups was determined through an analogy which consist on assume the $V_{s u}$ (corresponding to the stirrups contribution to shear) equal to $V_{f u}$ (corresponding to the fibers contribution to 
shear) obtaining, in this way, an equivalent $\tau$ value for the shear reinforcement $\left(\tau=V_{s u} / b \cdot d\right)$ which obviously have the same value for both graphs (Fig.6.11 and Fig.6.12) corresponding to $f_{R 3}$ and the $f_{R m}$, respectively. This is:

$$
V_{f u}=k_{f} \cdot 0.7 \cdot \xi \cdot 0.18 \cdot f_{R 3} \cdot b \cdot d \equiv V_{s u}
$$

with: $k_{f}=1.13 ; \xi=1.81 ; b=90 \mathrm{~mm}$ for all beams

$$
k_{f} \cdot 0.7 \cdot \xi \cdot 0.18 \cdot f_{R 3}=\tau=0.26 \cdot f_{R 3}
$$

For the particular case of beam V18 (M- $\phi 6)$, with $\$ 6 @ 200 m m-1$ leg:

$$
\begin{gathered}
0.26 \cdot f_{R 3} \cdot b \cdot d \equiv V_{s u}=23511(\mathrm{~N}) \\
0.26 \cdot f_{R 3}=\frac{23511}{b \cdot d}=\frac{23511 \mathrm{~N}}{90 \mathrm{~mm} \cdot 307.98 \mathrm{~mm}}=0.85
\end{gathered}
$$

Equivalent $\tau$ values for all the beams with stirrups are reported in Table 6.4.

Table 6. 4 Equivalent $\tau$-values for all the beams with stirrups

\begin{tabular}{|c|c|c|c|c|c|}
\hline Reference & Beam ID & $\mathbf{d}(\mathbf{m m})$ & Transverse reinforcement & $\mathbf{V}_{\text {su }}(\mathbf{N})$ & $\boldsymbol{\tau}=\mathbf{V}_{\text {su }} / \mathbf{b} \cdot \mathbf{d}$ \\
\hline V11 & M- $\phi 8$ & 307.98 & $\phi 8 @ 150 \mathrm{~mm}-1$ leg & 55730 & 2.010592 \\
\hline V17 & H- $\phi 8$ & 307.98 & $\phi 8 @ 150 m m-1$ leg & 55730 & 2.010592 \\
\hline V18 & M- $\phi 6$ & 307.98 & $\phi 6 @ 200 m m-1$ leg & 23511 & 0.848215 \\
\hline V19 & H- $\phi 6$ & 297.98 & $\phi 6 @ 200 m m-1$ leg & 22748 & 0.848230 \\
\hline V20 & L- $\phi 6$ & 297.98 & $\phi 6 @ 200 m m-1$ leg & 22748 & 0.848230 \\
\hline
\end{tabular}



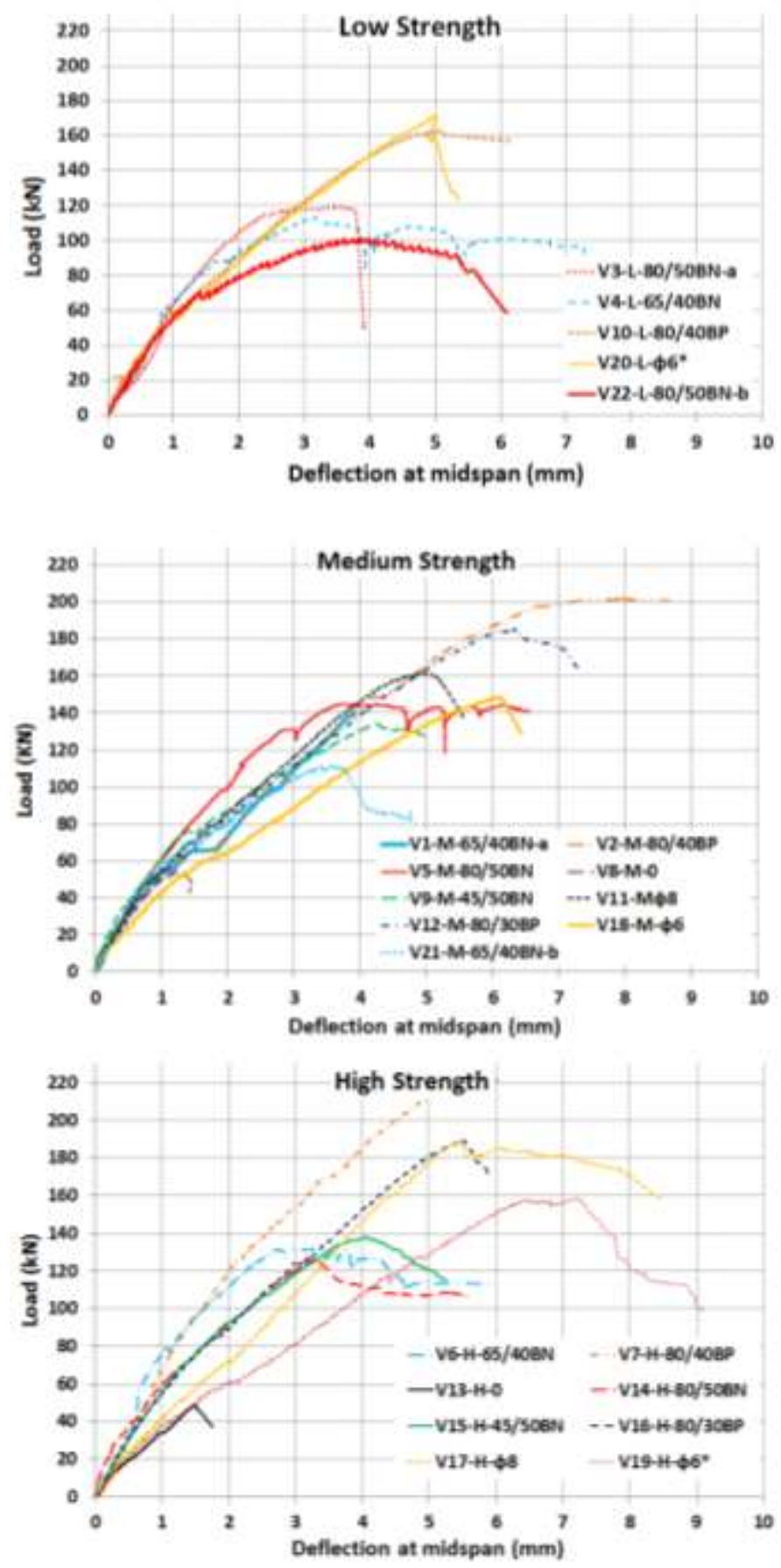

Fig.6. 9 Load-deflection at mid-span curves 


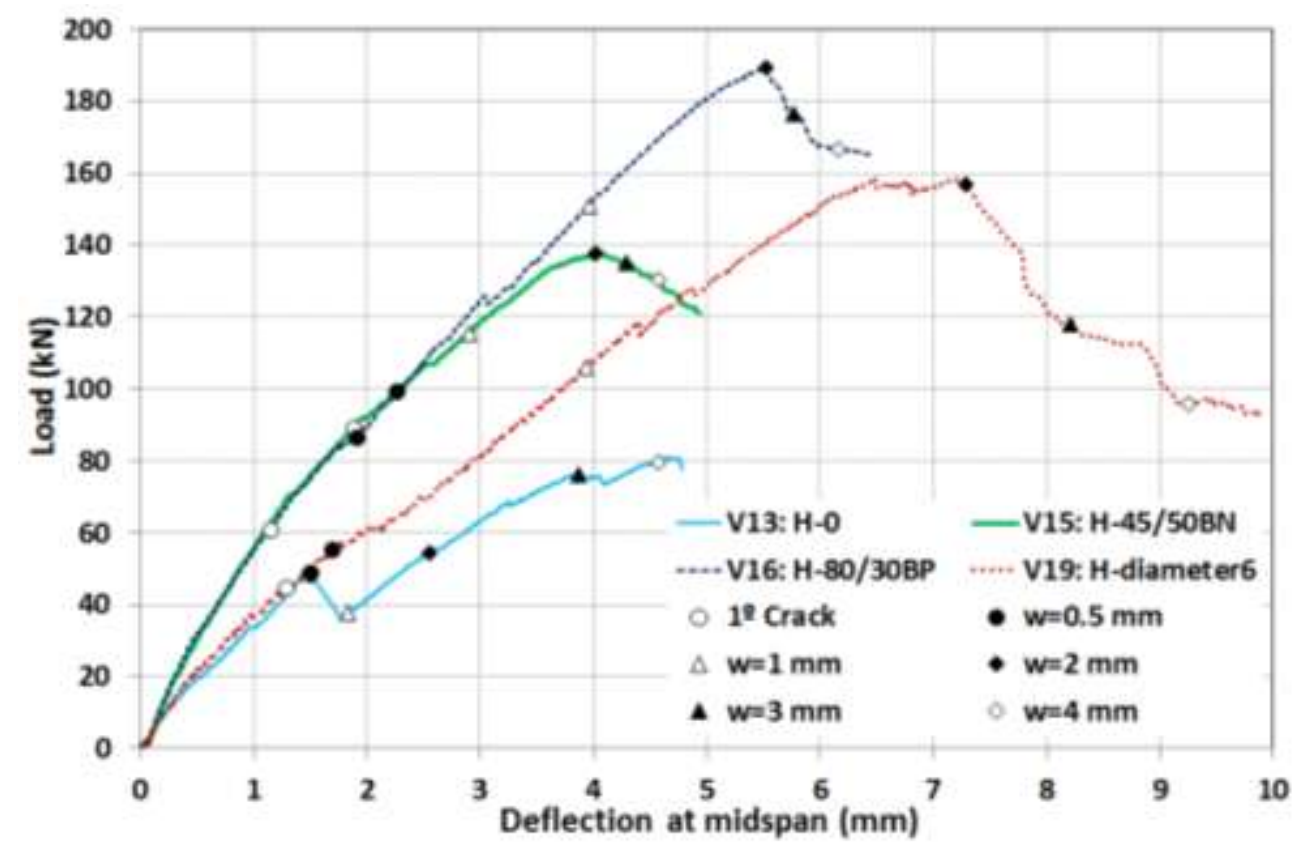

Fig.6. 10 Crack width evolution indicated over the load-deflection curve

In Fig.6.11 a linear tendency was observed. In Fig.6.12, the same tendency was analyzed but using an average residual flexure tensile strength $f_{R m}=\left(f_{R 1}+f_{R 3}\right) / 2$ instead of $f_{R 3}$, and a better correlation was obtained for medium strength concretes (see continuous green line). This linear dependency was found with no influence of concrete strength when varying from 55 to $90 \mathrm{MPa}$. The linear dependency for high strength concretes is very high (see dashed red line), with a value $r^{2} \approx 0.85$ for both cases, using $f_{R 3}$ and using $f_{R m}$. For medium strength concretes the approximation to a straight line is worse than for high strength concretes, but the correlation is slightly better when $f_{R m}\left(r^{2}=0.71\right)$ is used instead of $f_{R 3}\left(r^{2}=0.64\right)$. In a few words, after seeing Fig.6.11 and Fig.6.12, it seems that parameter represent much better the tendency of the experimental shear value (with a coefficient of correlation, $r^{2}$, close to the unit, thus, points follow approximately a straight line) for different levels of compressive strength, when $f_{R m}$ is used instead of $f_{R 3}$. Therefore, $f_{R 3}$ residual strength may not be the most adequate parameter to define the shear capacity, as the average crack width along the failure crack will be smaller.

For low strength concretes shear capacity is reduced, so is reasonable the compression strength limitation $\left(f_{c k} \leq 60 \mathrm{MPa}\right)$ according to the EHE-08 [10]. Only some points are out of this tendency. 
13

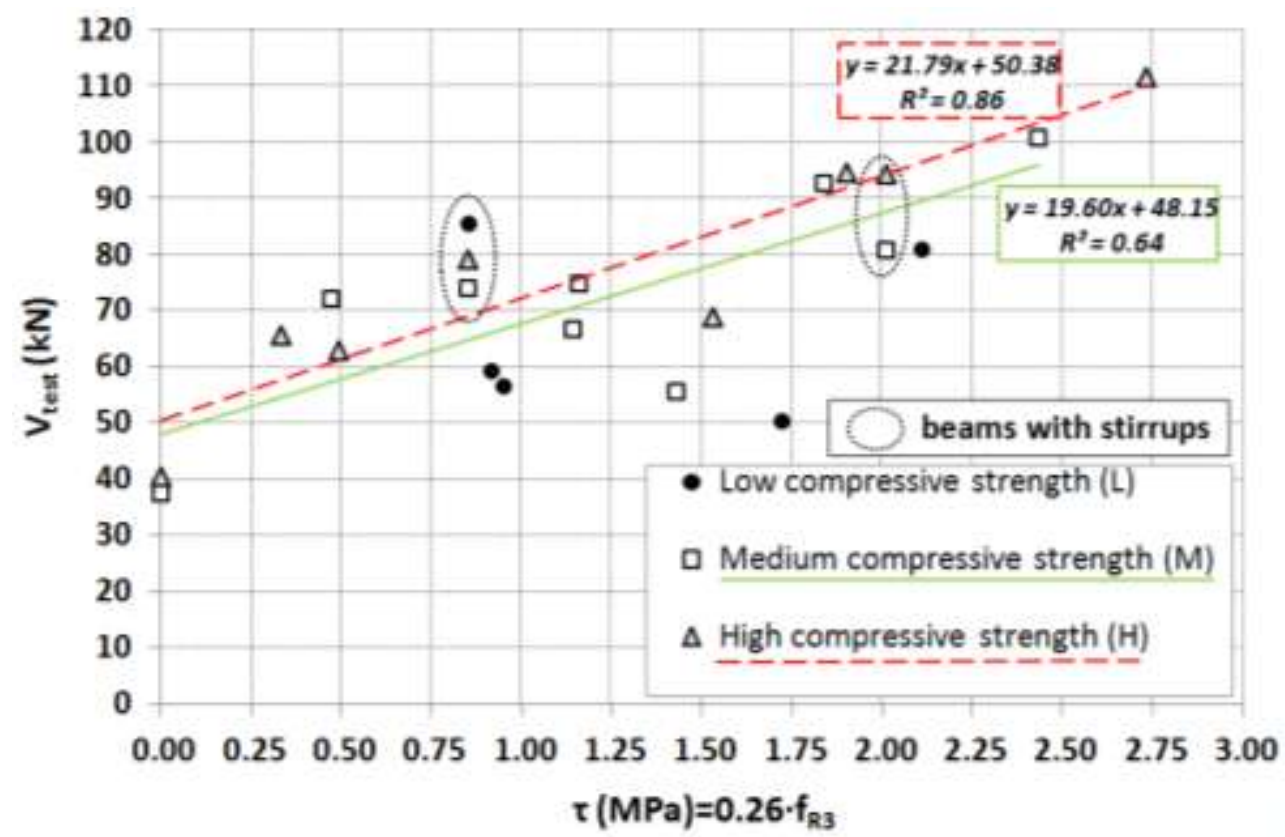

Fig.6. $11 V_{\text {test }}-f_{R 3}$ response

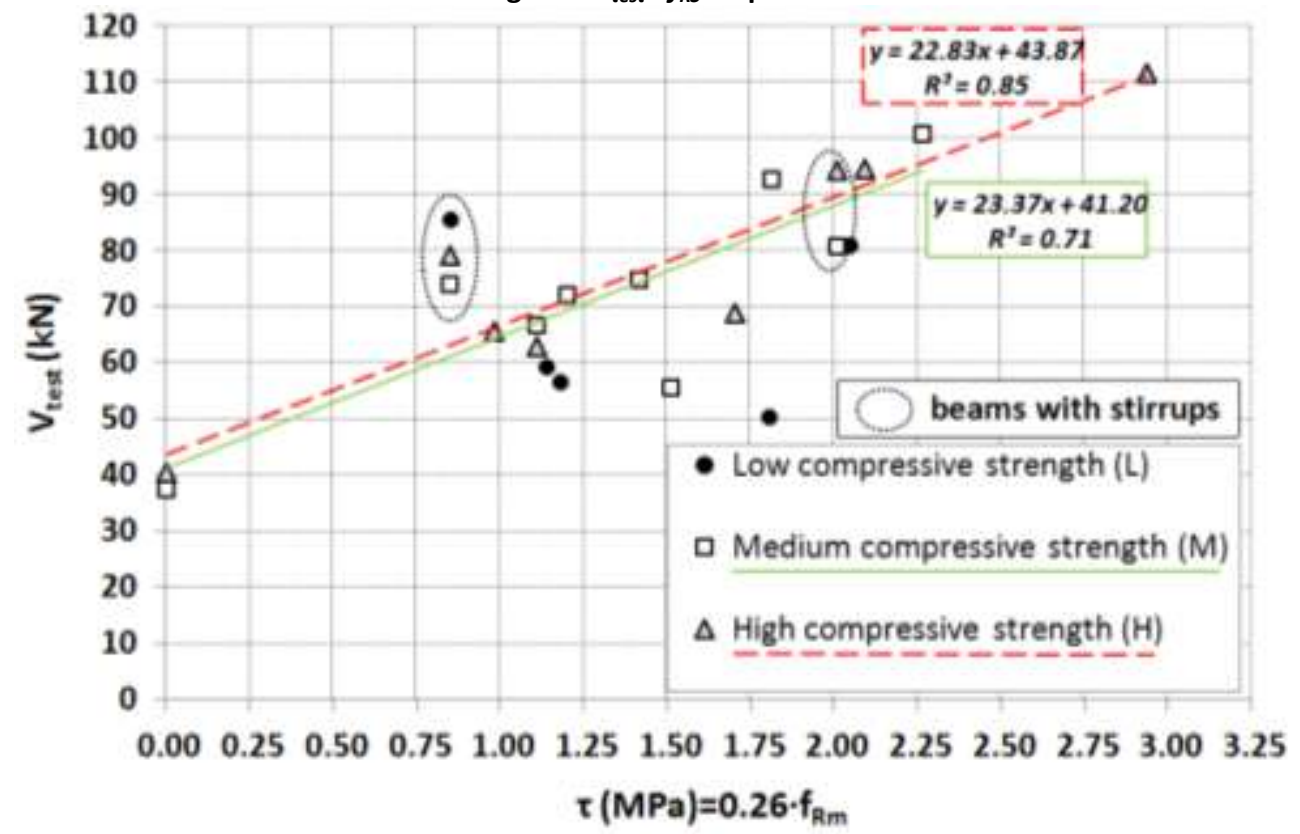

Fig.6. $12 v_{\text {test }}-f_{R m}$ response; $f_{R m}=\left(f_{R 1}+f_{R 3}\right) / 2$ 
The shear safety margin (SM) obtained as $V_{\text {test }} / V_{\text {theo }}$ (the shear test value divided by the shear theoretical value) was used as a reference parameter to compare the results obtained from the analyzed beams (see plot in Fig.6.13). Theoretical shear values were calculated by means of the formulation of the first complete draft of Model Code 2010 [8]. Beams without fibers were calculated by applying the most accurate form (Level III of Approximation), which permits the calculation of $\varepsilon_{x}$ and directly calculates the corresponding inclination of the compression stresses $(\theta)$. Level III of approximation was based directly in the equations of the Modified Compression Field Theory (MCFT) [11]. The beams with fibers were calculated by applying the formula proposed in MC2010, which includes the effect of fibers inside the concrete matrix contribution (see Table 6.5).

The reinforcement ratio for longitudinal reinforcement $\left(\rho_{l}=A_{s} /\left(b_{0} \cdot d\right)\right)$ was equal to $3.72 \%$ for all beams, except for beams V19 (H\$6) and V20 (L\$6) because of their lower effective depth $(d)\left(\rho_{l}=3.84 \%\right)$. It should be observed that MC2010 formula limits to a maximum $2 \%$ the $\rho_{l}$ value. Fig.6.13 shows SMs obtained in four cases: using the formula with and without the $\rho_{l}$ limitation $\left(\rho_{l, \max } \leq 2 \%\right.$ ), and also these combinations using $f_{R 3}$ or $f_{R m}$. As can be observed, in the formulations (see Table 6.5), the limitation of $\rho_{l}$ in MC2010 only affects beams reinforced with fibers. The results were arranged attending to their shear reinforcement type. Firstly, results for beams without fibers and stirrups are shown followed by the beams reinforced only with fibers (firstly low carbon fibers -BN- and then, high carbon fibers -BP- being both groups ordered by increasing length of fibers). Finally, results for beams with stirrups are represented.

It can be observed that SMs were more balanced for the same type of fiber (BN or BP), when SM values where calculated using $f_{R m}$ instead $f_{R 3}$; this underlines the important role of $f_{R 1}$ on shear strength.

Table 6. 5 Model Code 2010 (First Complete Draft) shear formulas

\begin{tabular}{|c|c|}
\hline Code & Theoretical Shear (V) \\
\hline \multicolumn{2}{|c|}{$V_{c u}$ : Concrete contribution to shear; $V_{f u}$ : Fibers contribution to shear } \\
\hline $\begin{array}{c}\text { MC2010 } \\
\text { Without fibers: }\end{array}$ & $\mathrm{V}_{\mathrm{cu}}=\mathrm{k}_{\mathrm{v}} \cdot\left(\mathrm{Vf}_{\mathrm{ck}} / \mathrm{V}_{\mathrm{c}}\right) \cdot \mathrm{z} \cdot \mathrm{b}_{\mathrm{o}} \quad($ Level III Approximation) \\
\hline MC2010 & $\mathrm{V}_{\mathrm{cu}}+\mathrm{V}_{\mathrm{fu}}=\left[\left(0.18 / \mathrm{V}_{\mathrm{c}}\right) \cdot \xi \cdot\left(100 \cdot \rho_{\mathrm{l}} \cdot \mathrm{C}_{2}\right)^{1 / 3}+0.15 \cdot \sigma_{\mathrm{ck}}\right] \cdot \mathrm{b}_{\mathrm{o}} \cdot \mathrm{d}$ \\
With fibers: & $\mathrm{C}_{2}=\left(1+7.5 \cdot\left(\mathrm{f}_{\mathrm{Ftuk}} / \mathrm{f}_{\mathrm{ctk}}\right)\right) \cdot \mathrm{f}_{\mathrm{ck}}$ \\
\hline
\end{tabular}

Contrarily to the results on previous papers [ [12]; [13]; [14]; [15]], in this program SM were lower than 1 , so unsafe, when real $\rho_{l}$ (without $2 \%$ limitation) is used. In other paper [15], it was observed that, when the longitudinal reinforcement was much higher to $2 \%$, shear strength estimations according to MC2010 were too conservative. In the experimental program developed in Chapter 6, this tendency was not observed, and a low 
SM (lower than 1 and then unsafe) is obtained when the actual $\rho$ value is applied. This fact may be explained as a consequence of a too small concrete cover over of the longitudinal reinforcement.

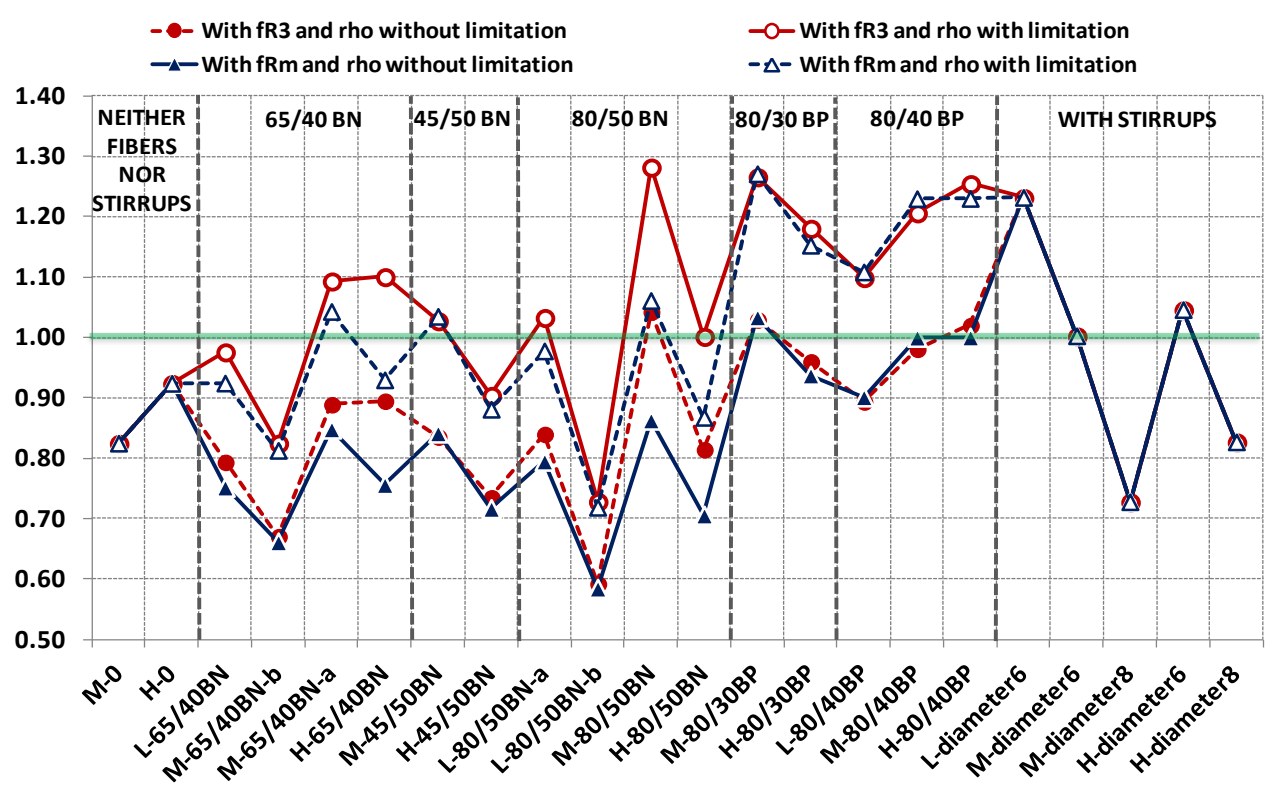

Fig.6. 13 Shear safety margins according to MC2010

Note: rho $(\rho)=$ longitudinal reinforcement ratio; where $\rho_{\max }=2 \%$

In Fig.6.13 it can be also observed that the beams with the best fibers (fibers BP) achieved safe $S M(S M \approx 1)$, this is because fibers BP make the cover more effective than with normal fibers (BN fibers). Fig.6.14 shows the beam M-0; it can be observed that failure was influenced by the small cover of the longitudinal reinforcement (see crack at the level of this reinforcement); triggering an earlier failure. Therefore, a lower SM (lower than the unit) was obtained (as can be seen in Fig.6.14).

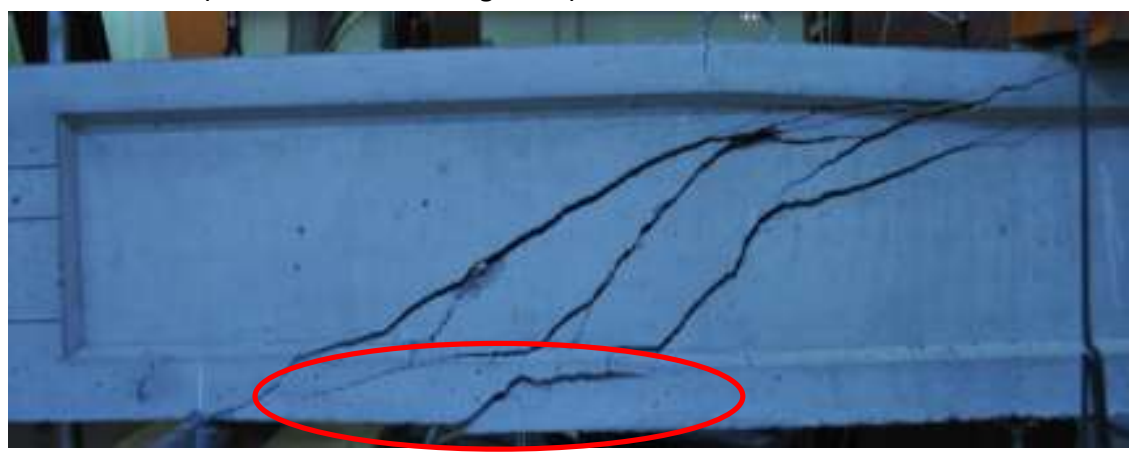

Fig. 6. 14 Small cover of beam M-0. 


\subsection{Conclusions}

An experimental program including shear tests on twenty-two reinforced FRC beams has been developed to investigate how the quality of the fibers can influence in shear behavior and the differences on behavior between reinforced beams with fibers a with stirrups. From the obtained, the following conclusions can be drawn:

- Shear strength and load deflection response shown an important dependence on the fiber type. Low strength concretes with $\$ 6$ stirrups shows a very brittle postcracking behavior while beams with BN fibers were the most ductile. For all strength levels, beams with BP fibers and stirrups reached the highest loads. Beams with stirrups show an important deflection increase just after the first crack and a greater load reduction after the peak. Beam with stirrups reached higher deflection and crack openings, if compared with SFRC.

- The parameter $f_{R 3}$, as a reference value for calculating shear strength, could be unsafe or overconservative. In these small beams (Chapter 6), the parameter $f_{R m}$ (average value between $f_{R 1}$ and $f_{R 3}$ ) may be more appropriate than $f_{R 3}$.

- $\quad$ Beside $f_{R 3}$, also $f_{R 1}$, plays a major role in shear behavior and shear strength of beams. This fact suggests using equivalent energy $\left(f_{e q}\right)$ to determine the shear strength of FRC beams in structural codes.

- In this program, safety margins obtained as $V_{\text {test }} / V_{\text {theo }}$ (the shear test value divided by the shear theoretical value) were lower than the unit, so unsafe, when real values of the longitudinal reinforcement ratio $\rho_{l}$ were used. The small cover of the main reinforcement may be the reason. Safety margins were low also for traditional reinforcements, even if stirrups yielded at failure.

\subsection{References}

[1] S. Soroushian and Z. Bayasi, "Fiber-type effects on the performance of steel fiber reinforced concrete," ACl Materials Journal, vol. 88, no. 2, pp. 129-134, 1991.

[2] fib, fib Bulletin 57, Shear and punching shear in RC and FRC elements, Salò, Italy: Workshop proceedings 2010, 2010.

[3] B. Adhikary and H. Mutsuyoshi, "Prediction of shear stregth of steel fiber RC beams using neural networks," Construction and Building Materials, vol. 20, pp. 801-811, 
2006.

[4] E. El-Niema, "Reinforced concrete beams with steel fibers under shear," $\mathrm{ACl}$ Structural Journal, vol. 88, no. 2, pp. 178-183, 1991.

[5] J. Susetyo, P. Gauvreau and F. Vecchio, "Effectiveness of steel fiber as minimum shear reinforcement," ACl Structural Journal, vol. 108, no. 4, pp. 488-496, 2011.

[6] H. Dinh, G. Parra-Montesinos and J. Wight, "Shear behavior of steel fiber-reinforced concrete beams without stirrup reinforcement," ACl Structural Journal, vol. 107, no. 5, pp. 597-606, 2010.

[7] G. Parra-Montesinos, "Shear strength of beams with deformed steel fibers," Concrete International, vol. 28, no. 11, pp. 57-66, 2006.

[8] MC2010, fib Bulletin 55, Model Code 2010 - First complete draft, Vol.1 and 2, 2010.

[9] RILEM, "RILEM TC 162-TDF: Test and design methods for steel fiber reinforced concrete," Materials and Structures, vol. 36, pp. 560-567, 2003.

[10] EHE08, Instrucción de hormigón estructural EHE-08 (in spanish)., Ministerio de Fomento, 2008.

[11] F. Vecchio and M. Collins, "The Modified Compression Field Theory for reinforced concrete elements subjected to shear," ACl Journal, vol. 83, no. 2, pp. 219-231, 1986.

[12] E. Cuenca, P. Serna and M. Pelufo, "Structural behavior of self-compacting and fiber reinforced concrete under shear loading," in Proceedings of the International Association for Shell and Spatial Structures (IASS) Symposium, Valencia, Spain, 2009.

[13] E. Cuenca and P. Serna, "Shear behavior of self-compacting concrete and fiber reinforced concrete beams," in 6th International RILEM Symposium on SelfCompacting Concrete (SCC2010), Montreal, Canada, 2010.

[14] P. Serna, E. Cuenca and M. Alves-de-Oliveira, "Self-compacting fiber reinforced in precast elements production for shear resistance," in Dedicated to Innovation: 50 years of MC-Bauchemie, 2011. 
[15] E. Cuenca and P. Serna, "Shear behavior of prestressed precast beams made of selfcompacting fiber reinforced concrete," 2012.

On Shear Behavior of structural elements made of steel fiber reinforced concrete - PhD thesis 


\title{
EXPERIMENTAL TESTS ON
}

\author{
HOLLOW CORE SLABS
}

MADE WITH FRC

\subsection{Introduction}

Hollow Core Slabs (HCS) are usually precast by extrusion and it is not easy to place stirrups; thus, it is difficult to guarantee shear resistance in some cases. This chapter describes an experience using fiber reinforced concrete (FRC) to produce HCS by extrusion to enhance shear resistance.

In this chapter, introduction of FRC as shear reinforcement in a continuous way has been conducted in a precast plant where 26 real-scale HCS were produced. Elements were produced and tested in shear according to the following variables: amount of steel fibers $\left(0,50\right.$ and $\left.70 \mathrm{~kg} / \mathrm{m}^{3}\right)$, two prestressing levels and a shear span/depth $(\mathrm{a} / \mathrm{d})$ ratio variable between 2.3 and 8.6 . 


\subsection{Experimental investigation}

Twenty-six HCS were tested and classified into two different series, mainly differenced by the tension in the prestressing strands and the different design failure modes expected in them.

In Series I, HCS and their test disposition were designed in order to have a shear-flexure failure. For Series II, a program with greater variability of predictable failure modes was developed and was based on a design for more heavily prestressed HCS which includes a wider range of fiber reinforcement contents.

\subsubsection{Hollow core slabs' geometry}

All the HCS presented the same geometry (Fig.7. 1) and a depth of $260 \mathrm{~mm}$. This geometry is within the scope of application of the European Standard EN 1168+A2 [1]. A different reinforcement, characterized by the number and diameter of wire or strand, its position and pretension (Fig.7. 1 and Table 7. 1), was tested in each Series. In Table 7. 1, "Initial tensile" is the prestressing tension applied prior to discounting prestressing losses; $r_{\text {inf }}$ is the cover on the bottom reinforcement; $\rho_{l}$ is the longitudinal reinforcement ratio (wires or 7-wire strands in this case) and $\sigma_{c}$ is the average stress acting on the concrete crosssection due to the prestressing axial force, including prestressing losses.

As Table 7. 1 shows, Series I included wires (Y 1860 C 5.0) with a diameter of $5 \mathrm{~mm}$ and 7wire strands ( $Y 1860$ S7 9.3), thus conforming a strand with a nominal diameter equal to $9.3 \mathrm{~mm}$ (the notation is defined in UNE 36094-97 and EN 10027-1) with a yielding stress $f_{p k}$ equal to $1637 \mathrm{MPa}$ and a tensile strength of $1860 \mathrm{MPa}$ for the wires, a yielding stress $f_{p k}$ equal to $1581 \mathrm{MPa}$ and a tensile strength of $1860 \mathrm{MPa}$ for strands. In Series II, on the other hand, only those wires with the same characteristics as those in Series I were used. All these values were nominal.

Table 7. 1 Reinforcement characteristics

\begin{tabular}{|c|c|c|c|c|c|c|c|c|c|c|}
\hline \multirow{2}{*}{ Series } & \multirow{2}{*}{$\begin{array}{l}\text { Initial } \\
\text { tensile } \\
\text { [MPa] }\end{array}$} & \multirow{2}{*}{$\begin{array}{c}\text { Prestressed } \\
\text { losses (\%) }\end{array}$} & \multirow{2}{*}{$\begin{array}{c}r_{\text {inf }} \\
(\mathrm{mm})\end{array}$} & \multicolumn{5}{|c|}{ REINFORCEMENT POSITION } & \multirow{2}{*}{$\begin{array}{c}\rho_{1} \\
(\%)\end{array}$} & \multirow{2}{*}{$\begin{array}{r}\sigma_{\mathrm{c}} \\
\mathrm{MPa}\end{array}$} \\
\hline & & & & $\mathbf{U}$ & $\mathbf{U}^{\prime}$ & V & $x$ & $\mathbf{Z}$ & & \\
\hline 1 & 1255 & 19.7 & 30 & $2 \phi 5$ & $5 \phi 9.3$ & -- & -- & $4 \phi 5$ & 0.5 & 2.87 \\
\hline II & 1255 & 27.2 & 25 & $25 \phi 5$ & -- & $9 \phi 5$ & $4 \phi 5$ & $4 \phi 5$ & 1 & 5.69 \\
\hline
\end{tabular}



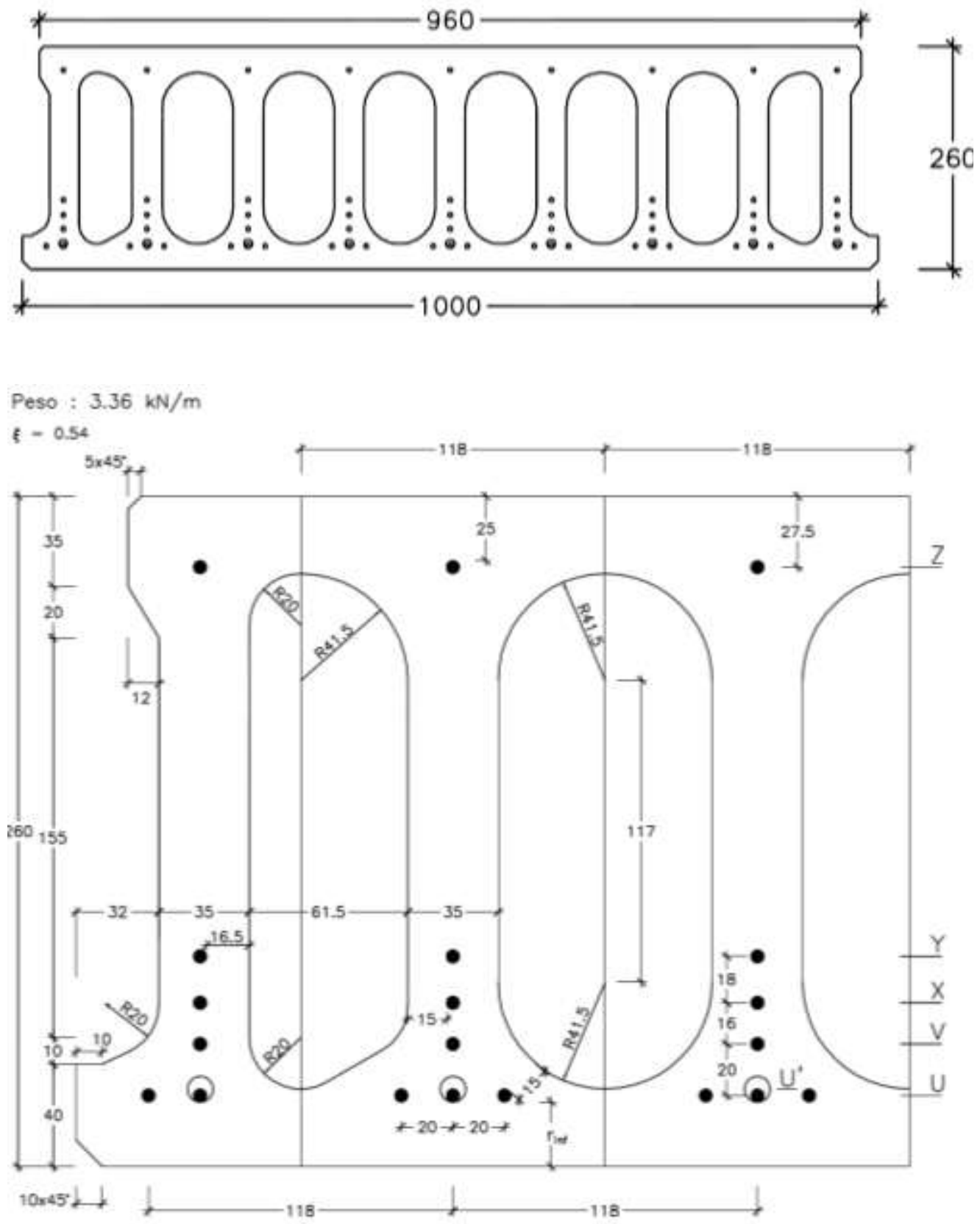

Fig.7. 1 Cross-section of HCS. Dimensions in millimeters 


\subsubsection{Concrete mix design}

One important goal was to produce HCS by extrusion with very dry concretes by adding different amounts of steel fibers $\left(0,50\right.$ and $\left.70 \mathrm{~kg} / \mathrm{m}^{3}\right)$. In order to optimize the material performance, several concrete compositions were tested.

The materials used in this study were a CEM I 52.5R cement type and calcareous crushed aggregates: $0 / 4 \mathrm{~mm}$-sized sand, $0 / 6 \mathrm{~mm}$-sized sand and $6 / 10 \mathrm{~mm}$-sized gravel. The steel fibers utilized were low carbon steel with hooked-end (RC 65/40 BN), 40mm in length, $0.62 \mathrm{~mm}$ in diameter, with an aspect ratio (length/diameter) equal to 65 .

Two concrete admixtures were used: an accelerating high range water reducer/superplasticizer and a specific admixture for extruded concretes.

Table 7. 2 presents the mix designs.

Table 7. 2 Mix design of the HCS tested

\begin{tabular}{|c|c|c|c|}
\hline$\left(\mathrm{kg} / \mathrm{m}^{3}\right)$ & TC & FRC-50 & FRC-70 \\
\hline Coarse aggregate $(6 / 10 \mathrm{~mm})$ & & 843 & \\
\hline Sand $(0 / 4 \mathrm{~mm})$ & & 690 & \\
\hline Sand $(0 / 6 \mathrm{~mm})$ & & 311 & \\
\hline Cement & & 411 & \\
\hline Water (liters) & & 198 & \\
\hline $\mathrm{W} / \mathrm{C}$ ratio & & 0.48 & \\
\hline Fibers & 0 & 50 & 70 \\
\hline Superplasticizer (liters) & 1.5 & 1.5 & 1.6 \\
\hline Admixture for extruded concretes (I) & 0.8 & 0.8 & 0.7 \\
\hline Mixing time (min) & 1.5 & 4.3 & 5.4 \\
\hline
\end{tabular}

Concrete without fibers was used in the daily HCS production in the precast industry that provided the FRC elements. Mechanical properties were controlled in one concrete sample by means of the compressive strength test on $150 \times 300 \mathrm{~mm}$ cylinders (EN 123903 ) and the flexural tensile strength test (EN 14651). The latter were obtained with the flexural test: the residual flexural tensile strength $\left(f_{R, j}\right)$, which corresponds to the crack mouth opening displacements (CMOD) linked to the crack openings of $0.5,1.5,2.5$ and $3.5 \mathrm{~mm}(\mathrm{j}=1,2,3,4$ respectively).

Table 7. 3 provides the mechanical properties of the different concrete mixes. All the values were obtained as an average of three specimens made with two different samples for each concrete type, 28 days after casting. As it can be observed in Table 7. 3 there is a big difference between the results of same types of concrete, probably because of 
different casting conditions and very different external temperatures as Series I and Series II were produced in different seasons. Also, it is very important to know that the concrete was made in a precast plant during its normal cycle of production and some little details could be changed to adapt the concretes of our Series to the needs of the company.

Table 7. 3 Concrete mechanical properties. Average values

\begin{tabular}{|c|c|ccccc|}
\hline Series & Concrete & $\mathbf{f}_{\mathrm{c}}[\mathrm{MPa}]$ & $\mathbf{f}_{\mathrm{R} 1}[\mathrm{MPa}]$ & $\mathbf{f}_{\mathrm{R} 2}[\mathrm{MPa}]$ & $\mathbf{f}_{\mathrm{R} 3}[\mathrm{MPa}]$ & $\mathbf{f}_{\mathrm{R} 4}[\mathrm{MPa}]$ \\
\hline \multirow{2}{*}{ I } & TC & 54.2 & -- & -- & -- & -- \\
& FRC-50 & 50.4 & 2.75 & 2.85 & 2.83 & 2.66 \\
\hline \multirow{3}{*}{ II } & TC & 43.8 & -- & -- & -- & -- \\
& FRC-50 & 38.2 & 4.25 & 4.66 & 4.70 & 4.37 \\
& FRC-70 & 35.9 & 5.74 & 6.03 & 5.80 & 5.47 \\
\hline
\end{tabular}

\subsubsection{HCS production}

A continuous slab was casted. It occupied a complete lane in which prestressed strands were positioned; the machine received the concrete and HCS were formed by extrusion (Fig.7. 2).

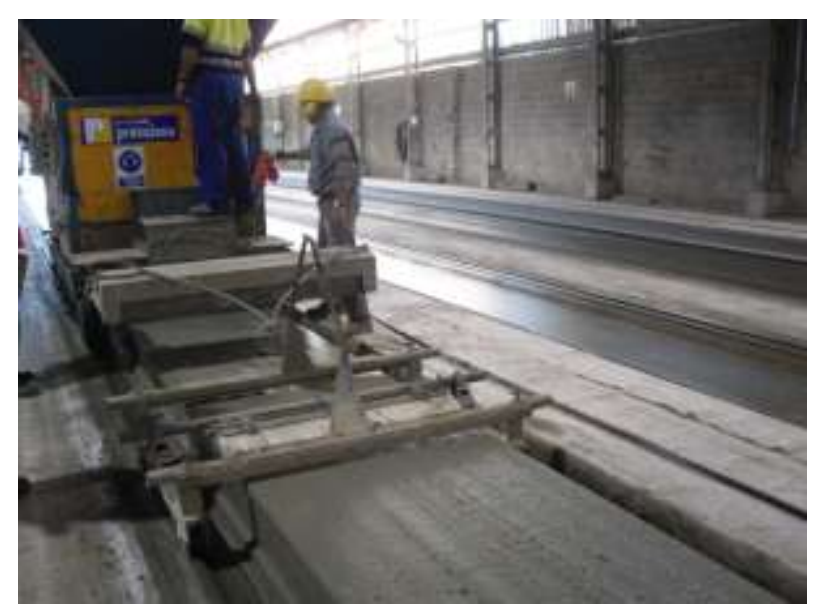

Fig.7. 2 Extrusion process

As expected [2], some problems initially occurred when a new concrete type was produced. The initial problems were related with the introduction of fibers into a very dry concrete mix to obtain an optimum concrete ready to use in the extrusion process. Yet after the preliminary adjustments in the process, these problems no longer appeared and a good surface aspect was achieved (Fig.7. 3). This fact demonstrates that it is possible to produce FRC Hollow Core Slabs in a normal daily production cycle of a precast plant. 


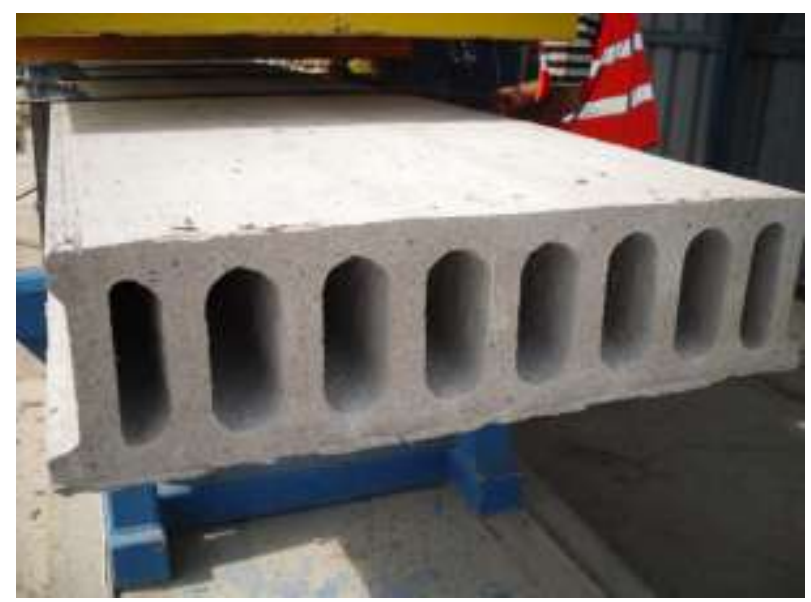

Fig.7. 3 How the surface of HCS looked

Only some slabs had an undulated surface, webs of different widths and defects on the slab surface, which were created in some zones where fibers blocked the extrusion machine. These stretches were thrown away.

\subsubsection{Test set-up}

HCS were subjected to a four-point test bending by adapting the loading scheme shown in Fig.7. 4.

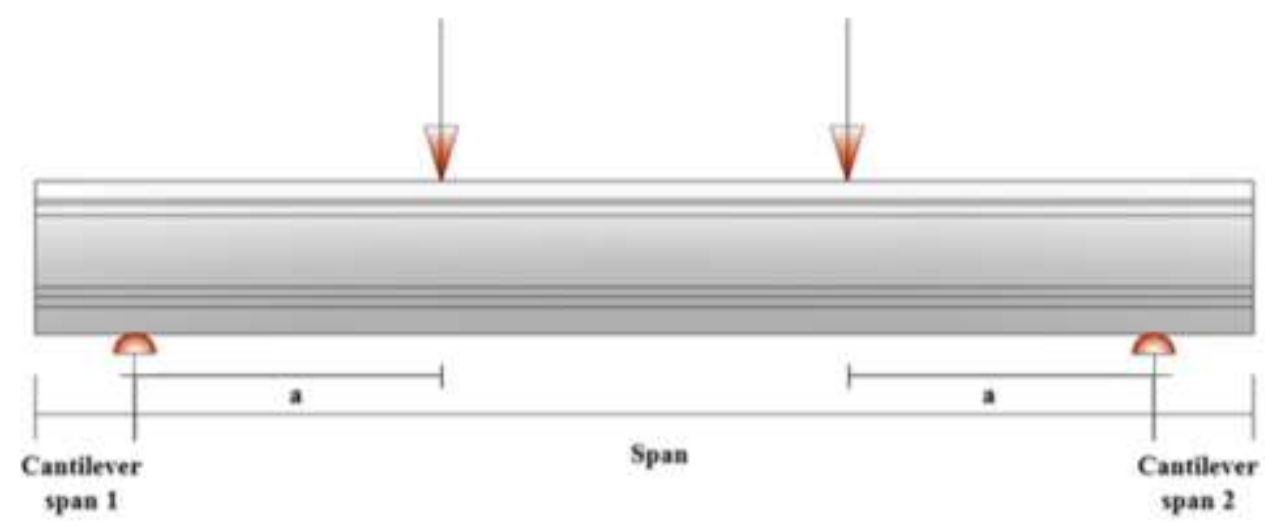

Fig.7. 4 Loading scheme adapted for the HCS test

Fig.7. 5 depicts the test set-up. Tests were done in the precast industry. 


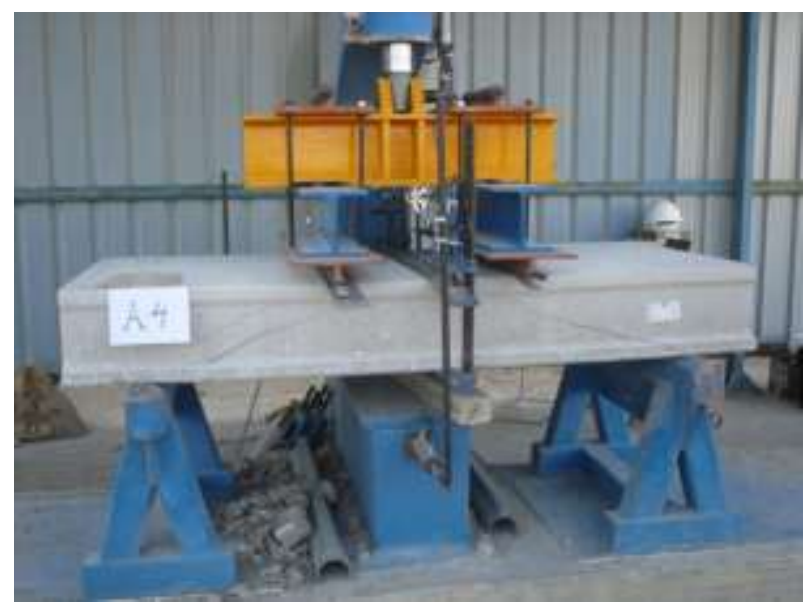

Fig.7. 5 Test set-up. Shear diagonal tension failure

Loads and supports were disposed into two cross lines. The shear span/depth $(\mathrm{a} / \mathrm{d})$ ratio varied between 3 and 4.4 in Series I. In Series II there were three different a/d ratios: 2.3, 3.4 and 8.6. Table 7. 4 indicates all these parameters. In order to facilitate their identification, the HCS "Specimen $I D$ " took the following structure:

\{Series: I or Ill - $\left\{\right.$ Amount of fibers $\left.\left(\mathrm{kg} / \mathrm{m}_{3}\right)\right\}-\{a / d$ ratio $\}\{a, b, c, \ldots\}$

If there were identical HCS, they were differentiated by placing: a, b, c, etc. So, an HCS from Series II with $50 \mathrm{~kg} / \mathrm{m}^{3}$ of fibers, and with $\mathrm{a} / \mathrm{d}=3.4$, which had other identical HCS, would be: II-50-3.4b.

In order to analyze the previous precrack effect, three HCS [II-0-3.4(P), II-50-3.4(P) and II-70-3.4(P)] were precracked before the shear test by loading the HCS with a longer span length $(\mathrm{a} / \mathrm{d}=4.9)$ until the maximum flexure crack width in the span reached $0.2 \mathrm{~mm}$. In these precrack steps, a shear of $161 \mathrm{kN}$ was accomplished. After the flexure precracking tests, supports were moved to adapt them to shear tests conditions in order to have shear failure on the flexure precracked zone.

Table 7. 4 shows the variables analyzed for each test, as well as the maximum load reached and the main failure mode. Fig.7. 6 shows the section for web shear tension failures that was adopted; it is given by the intersection between the centroidal axis of the $\mathrm{HCS}$ and the failure line that emerges from the edge of the support with an angle of $35^{\circ}$ to the horizontal axis, as indicated EN 1168+A2 [1], which delimitates the zone affected by the support reaction. 
Table 7. 4 Shear tests description and Specimen ID to each HCS

\begin{tabular}{|c|c|c|c|c|c|c|c|c|c|}
\hline & $\begin{array}{l}\text { Specimen } \\
\text { ID }\end{array}$ & $F^{*}$ & $\begin{array}{l}\text { a/d } \\
\text { ratio }\end{array}$ & $\begin{array}{l}\text { Cantilever } \\
\text { span } \\
(\mathrm{mm})^{* *}\end{array}$ & $\begin{array}{l}\mathrm{l}_{\mathrm{pt}} \\
\mathrm{mm}\end{array}$ & $\begin{array}{c}I_{\text {crit }} \\
(\mathrm{mm})\end{array}$ & $\begin{array}{l}V_{\text {test }} \\
(\mathbf{k N})\end{array}$ & F.M. & $\begin{array}{c}\text { HCS } \\
\text { length } \\
(\mathrm{mm}) \\
\end{array}$ \\
\hline \multirow{11}{*}{$\frac{\bar{y}}{\frac{\grave{\nu}}{\nu}}$} & $\mathrm{I}-0-4.1$ & \multirow{3}{*}{0} & 4.1 & 600 & \multirow{3}{*}{400.2} & 785.66 & 131.15 & SF & 3990 \\
\hline & $\mathrm{I}-0-4.3 \mathrm{a}$ & & 4.3 & 630 & & 815.66 & 131.11 & SF & 3980 \\
\hline & $\mathrm{I}-0-4.3 \mathrm{~b}$ & & 4.3 & 630 & & 815.66 & 134.90 & SF & 4000 \\
\hline & I-50-3.1 & \multirow{8}{*}{50} & 3.1 & 120 & \multirow{8}{*}{420.1} & 305.66 & 160.19 & $A$ & 2975 \\
\hline & I-50-3.9a & & 3.9 & 700 & & 885.66 & 162.10 & SF & 4000 \\
\hline & $\mathrm{I}-50-3.9 \mathrm{~b}$ & & 3.9 & 700 & & 885.66 & 162.10 & SF & 4000 \\
\hline & I-50-4.3 & & 4.3 & 860 & & 1045.66 & 152.61 & SF & 4500 \\
\hline & I-50-4.4 & & 4.4 & 870 & & 1055.66 & 158.62 & SF & 4500 \\
\hline & I-50-3.0a & & 3.0 & 120 & & 305.66 & 172.95 & SF & 2975 \\
\hline & $\mathrm{I}-50-3.0 \mathrm{~b}$ & & 3.0 & 2120 & & 2305.66 & 200.63 & SF & 4500 \\
\hline & $\mathrm{I}-50-3.1 \mathrm{c}$ & & 3.1 & 2035 & & 2220.66 & 189.43 & SF & 4500 \\
\hline \multirow{15}{*}{$\frac{\bar{y}}{\frac{u}{2}}$} & II-0-2.3 & \multirow{4}{*}{0} & 2.3 & 210 & \multirow{4}{*}{350.6} & 395.66 & 310.80 & $A$ & 1990 \\
\hline & II-0-3.4 & & 3.4 & 270 & & 455.66 & 213.10 & $S$ & 2600 \\
\hline & II-0-3.4 (P) & & 3.4 & 2105 & & 2290.66 & 266.20 & $S$ & 4500 \\
\hline & II-0-8.6 & & 8.6 & 250 & & 435.66 & 131.60 & SF & 4990 \\
\hline & II-50-2.3 & \multirow{5}{*}{50} & 2.3 & 500 & \multirow{5}{*}{384.1} & 685.66 & 410.00 & $\mathrm{~S}$ & 2600 \\
\hline & II-50-3.4a & & 3.4 & 225 & & 410.66 & 236.70 & $S$ & 2580 \\
\hline & II-50-3.4 (P) & & 3.4 & 260 & & 445.66 & 288.70 & $S$ & 4500 \\
\hline & II-50-3.4b & & 3.4 & 2500 & & 2685.66 & 202.00 & $S$ & 5000 \\
\hline & II-50-8.6 & & 8.6 & 270 & & 455.66 & 146.10 & $\mathrm{~F}$ & 4980 \\
\hline & II-70-2.3a & \multirow{6}{*}{70} & 2.3 & 225 & \multirow{6}{*}{400.3} & 410.66 & 310.70 & $S$ & 1990 \\
\hline & II-70-2.3b & & 2.3 & 215 & & 400.66 & 310.70 & $A$ & 2000 \\
\hline & II-70-3.4a & & 3.4 & 250 & & 435.66 & 266.70 & $S$ & 2570 \\
\hline & II-70-3.4 (P) & & 3.4 & 290 & & 475.66 & 315.00 & $S$ & 4500 \\
\hline & II-70-3.4b & & 3.4 & 290 & & 475.66 & 251.40 & $S$ & 4500 \\
\hline & II-70-8.6 & & 8.6 & 230 & & 415.66 & 135.20 & $\mathrm{~F}$ & 4980 \\
\hline
\end{tabular}

SF: Shear-flexure failure; S: Web shear tension failure; F: flexure failure; A: Anchorage failure of strands. $(P)=$ Hollow core slab precracked in flexure; ${ }^{*} \mathrm{~F}$ : Amount of steel fibers $\left(\mathrm{kg} / \mathrm{m}^{3}\right) ;{ }^{*}$ Values correspond to the cantilever span nearest the failure side; $I_{p t}$ : basic value of the transmission length; $I_{\text {crit }}$ : distance between the end of the slab and the critical section; F.M.: Failure mode.

Several HCS were tested with a critical length $\left(I_{c r i t}\right)$ below the transfer length $\left(I_{p t}\right)$, which was evaluated according to the European standard EN 1168+A2 [1] that, refers to Eurocode 2 [3] (see Table 7. 4). In some HCSs, this caused anchorage failure [I-50-3.1, II-02.3 and II-70-2.3b]. Nevertheless in HCS I-50-3.0a, which was also performed with a critical length below the required transfer length, there was no anchorage failure; the reason was that the crack which caused the failure was at a long distance from the cantilever. If there is not enough anchorage, prestressing contribution should not be considered but if, in this case, it is not considered in the calculations very high SM will be obtained. It is, therefore, evident that when the cantilever span is short, there is a partial transfer of prestressing. In 
Table 7.5, the parameters used in the basic value of the transmission length $\left(I_{p t}\right)$ calculation, according to the equation (8.16) of the EC2 (here (Eq. 7. 1)), are presented.

$$
I_{p t}=\alpha_{1} \cdot \alpha_{2} \cdot \phi \cdot \sigma_{p m 0} / f_{b p t}
$$

where: $\alpha_{1}=1.25$ for sudden release; $\alpha_{2}$ (Series I)=0.19 for 3 and 7-wire strands; $\alpha_{2}$ (Series II) $=0.25$ for tendons with circular cross section; $\phi$ is the nominal diameter of the tendon; $\sigma_{p m o}$ is the tendon stress just after release and $f_{b p t}$ is the constant bond stress at which the prestress is transferred to the concrete at release of tendons. $f_{b p t}$ is determinate with the equation (8.15) of EC2 (here (Eq. 7. 2):

$$
f_{b p t}=\eta_{p 1} \cdot \eta_{1} \cdot f_{c t d}(t)
$$

where: $\eta_{p 1}$ is a coefficient that takes into account the type of tendon and the bond situation at release $\left(\eta_{p 1}=2.7\right.$ for indented wires and $\eta_{p 1}=3.2$ for 3 and 7-wire strands); $\eta_{1}=1.0$ in this case (good bond conditions) and $f_{c t d}(t)$ is the design tensile value of strength at time of release. All these values are presented in Table 7. 5.

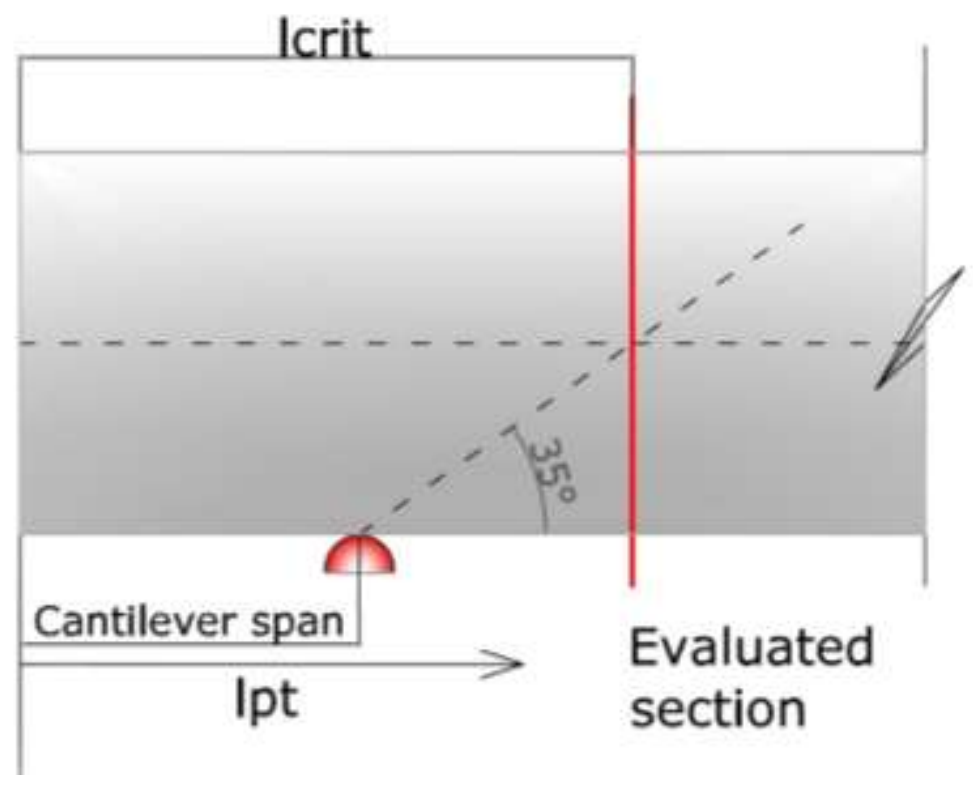

Fig.7. 6 Section taken in consideration in web shear tension failure calculations 
Table 7. 5 Parameters used in $I_{p t}$ calculation

\begin{tabular}{|c|c|c|c|c|c|c|c|}
\hline Series & Specimen ID & $\eta_{p 1}$ & $\begin{array}{l}f_{c t d}(t) \\
(M P a)\end{array}$ & $\begin{array}{c}f_{b p t} \\
(\mathrm{MPa})\end{array}$ & $\phi(m m)$ & $\begin{array}{c}\sigma_{p m 0} \\
(\mathrm{MPa})\end{array}$ & $\begin{array}{c}I_{p t} \\
(\mathrm{~mm})\end{array}$ \\
\hline \multirow{11}{*}{ I } & $\mid-0-4.1$ & 3.20 & 1.74 & 5.56 & 9.3 & 1007.77 & 400.20 \\
\hline & $\mathrm{I}-0-4.3 \mathrm{a}$ & 3.20 & 1.74 & 5.56 & 9.3 & 1007.77 & 400.20 \\
\hline & $\mathrm{I}-0-4.3 \mathrm{~b}$ & 3.20 & 1.74 & 5.56 & 9.3 & 1007.77 & 400.20 \\
\hline & $\mathrm{I}-50-3.1$ & 3.20 & 1.66 & 5.30 & 9.3 & 1007.77 & 420.07 \\
\hline & $1-50-3.9 a$ & 3.20 & 1.66 & 5.30 & 9.3 & 1007.77 & 420.07 \\
\hline & $l-50-3.9 b$ & 3.20 & 1.66 & 5.30 & 9.3 & 1007.77 & 420.07 \\
\hline & $\mathrm{I}-50-4.3$ & 3.20 & 1.66 & 5.30 & 9.3 & 1007.77 & 420.07 \\
\hline & I-50-4.4 & 3.20 & 1.66 & 5.30 & 9.3 & 1007.77 & 420.07 \\
\hline & $1-50-3.0 a$ & 3.20 & 1.66 & 5.30 & 9.3 & 1007.77 & 420.07 \\
\hline & $\mathrm{I}-50-3.0 \mathrm{~b}$ & 3.20 & 1.66 & 5.30 & 9.3 & 1007.77 & 420.07 \\
\hline & $1-50-3.1 c$ & 3.20 & 1.66 & 5.30 & 9.3 & 1007.77 & 420.07 \\
\hline \multirow{15}{*}{ II } & II-0-2.3 & 2.70 & 1.51 & 4.07 & 5 & 913.64 & 350.62 \\
\hline & II-0-3.4 & 2.70 & 1.51 & 4.07 & 5 & 913.64 & 350.62 \\
\hline & II-0-3.4 (P) & 2.70 & 1.51 & 4.07 & 5 & 913.64 & 350.62 \\
\hline & II-0-8.6 & 2.70 & 1.51 & 4.07 & 5 & 913.64 & 350.62 \\
\hline & II-50-2.3 & 2.70 & 1.38 & 3.72 & 5 & 913.64 & 384.10 \\
\hline & II-50-3.4a & 2.70 & 1.38 & 3.72 & 5 & 913.64 & 384.10 \\
\hline & II-50-3.4 (P) & 2.70 & 1.38 & 3.72 & 5 & 913.64 & 384.10 \\
\hline & II-50-3.4b & 2.70 & 1.38 & 3.72 & 5 & 913.64 & 384.10 \\
\hline & II-50-8.6 & 2.70 & 1.38 & 3.72 & 5 & 913.64 & 384.10 \\
\hline & II-70-2.3a & 2.70 & 1.32 & 3.57 & 5 & 913.64 & 400.33 \\
\hline & II-70-2.3b & 2.70 & 1.32 & 3.57 & 5 & 913.64 & 400.33 \\
\hline & II-70-3.4a & 2.70 & 1.32 & 3.57 & 5 & 913.64 & 400.33 \\
\hline & II-70-3.4 (P) & 2.70 & 1.32 & 3.57 & 5 & 913.64 & 400.33 \\
\hline & II-70-3.4b & 2.70 & 1.32 & 3.57 & 5 & 913.64 & 400.33 \\
\hline & II-70-8.6 & 2.70 & 1.32 & 3.57 & 5 & 913.64 & 400.33 \\
\hline
\end{tabular}

\subsection{Tests results and analysis}

\subsubsection{Failure modes}

Different failure modes were observed. 


\subsubsection{Shear failure modes}

7.3.1.1.1 Shear-flexure failure (SF)

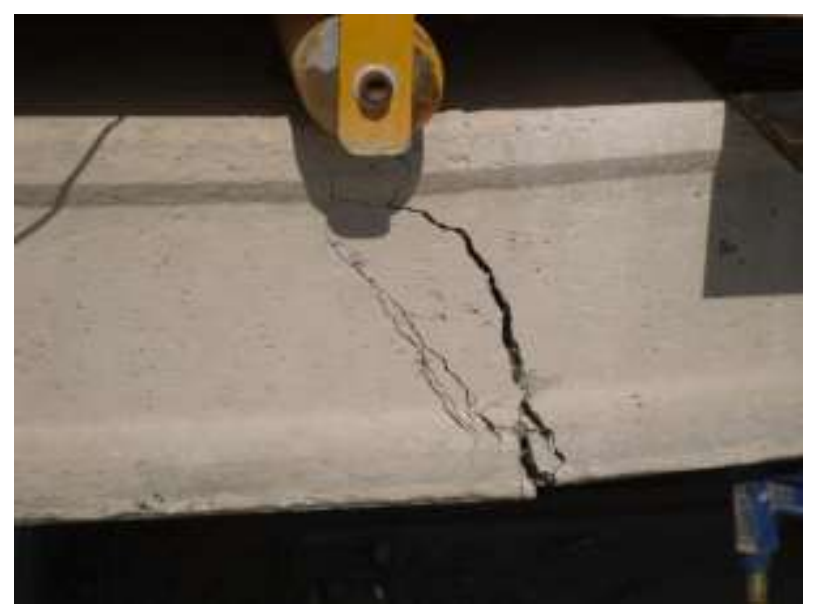

Fig.7. 7 Shear-flexure failure

On the shear-flexure failures (Fig.7. 7), flexure cracks initially developed but, eventually, one of them caused the failure. The failure crack was always situated in the shear span close to one of the load points. Firstly, the crack grew vertically to finally turn in direction by taking a shear slope near the top.

\subsection{Web shear tension failure of concrete (S)}

In most cases, failure was caused by diagonal shear tension (Fig.7. 5). Shear failure was produced by inclined cracks due to principal tensile stresses. On these slabs, a transverse reinforcement was not placed to resist shear, so fibers, prestressing strands and the concrete zone in compression had to resist shear stresses; if shear grew, the crack progressed upwardly to the HCS top.

\subsubsection{Flexure failure mode $(F)$}

For the higher $a / d$ ratio in Series II $(a / d=8.6)$, several flexure cracks developed vertically toward the top of the HCS, and one of these cracks continued to grow until a flexure failure (Fig.7. 8) took place. 


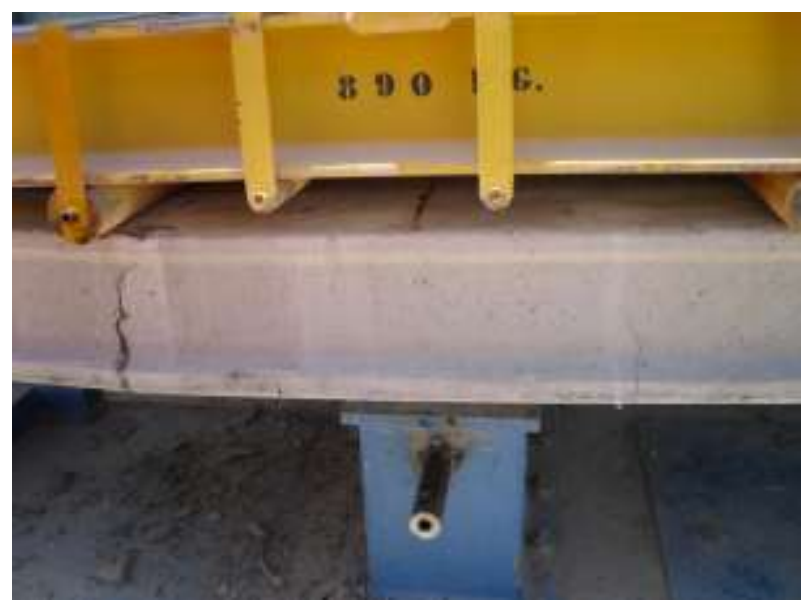

Fig.7. 8 Flexure failure

\subsubsection{Failure on anchorage of prestressing strands $(A)$}

During the tests, slippage on strands (Fig.7. 9 and Fig.7. 10) was also detected and, in most cases, this led to a diagonal crack.

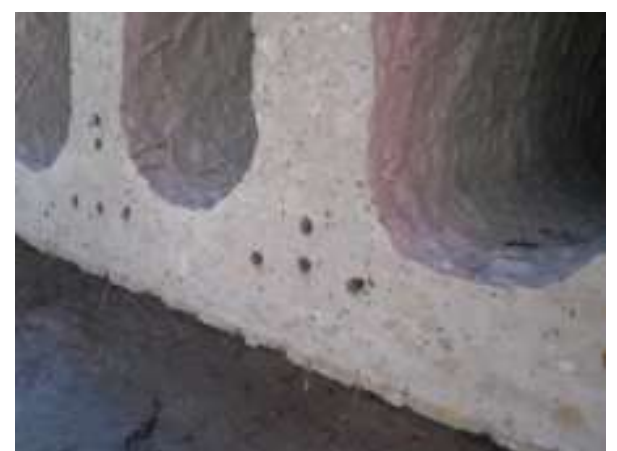

Fig.7. 9 Sliding of the strands in concrete

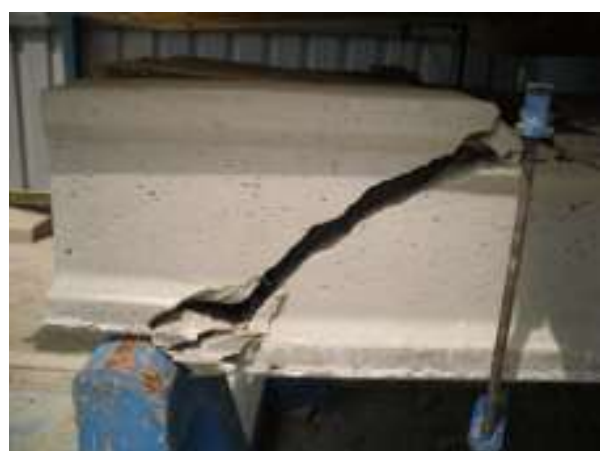

Fig.7. 10 Crack caused by tension shear and anchorage failure simultaneously

\subsubsection{Load-Deflection Response}

Fig.7. 11 plots the deflections on the mid-span for the most representative HCS of Series I. 


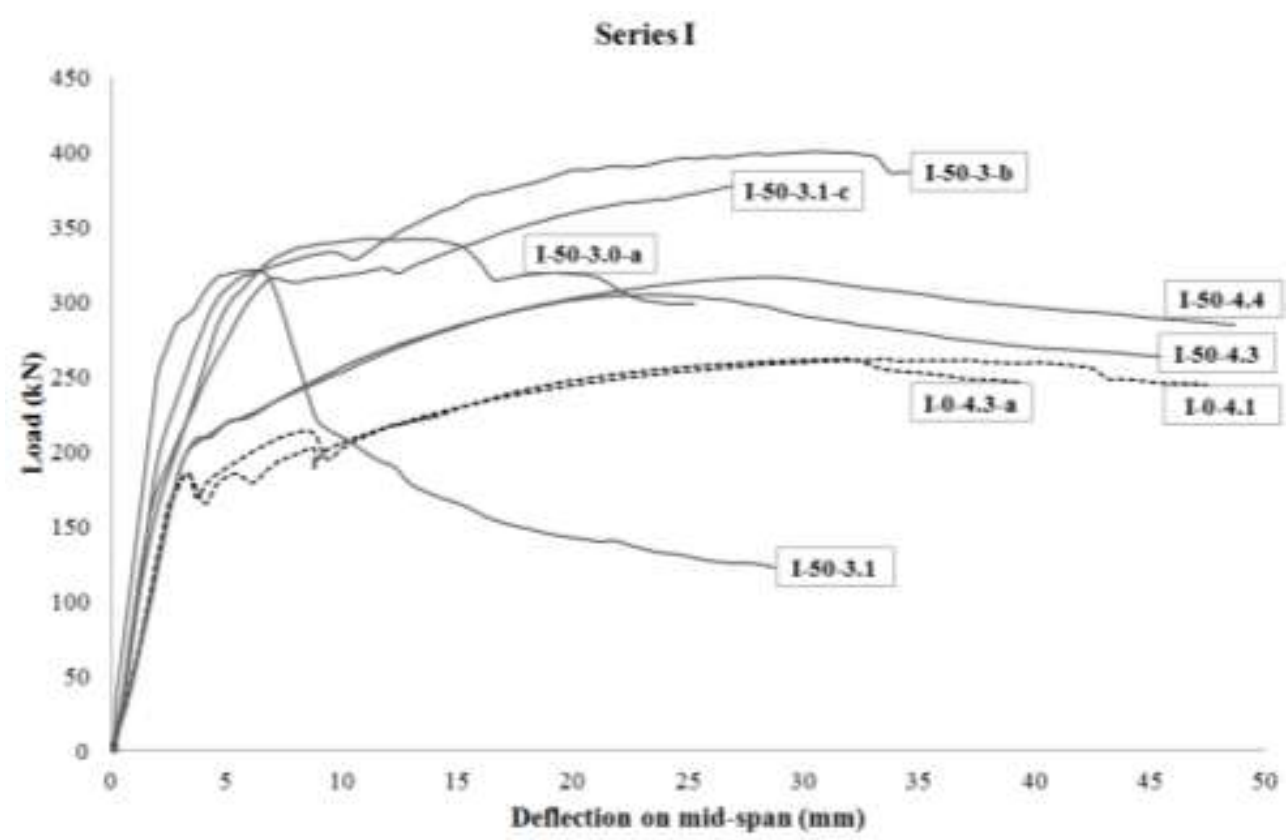

Fig.7. 11 Load-deflection response (Series I)

As expected, HCS 1-50-3.1 failed through anchorage and the failure was brittle. All the other HCS failed through shear-flexure and showed a ductile failure. The maximum load increased when shear span diminished. HCS with fibers exhibited greater shear capacities.

In Fig.7. 12, Fig.7. 13 and Fig.7. 14, the load-deflections curves of Series II are plotted and classified by fibers amount according to the shear span $(a / d)$ ratio. Three behaviors are distinguished. HCS with $\mathrm{a} / \mathrm{d}=2.3$ accomplished the greatest loads with brittle failure through a diagonal shear $(S)$.

In these cases, and especially when the critical length $I_{\text {crit }}$ was close to the transfer length $I_{t}$ (II-0-2.3 and II-70-2.3b), final failure was caused by anchorage. For HCS II-70-2.3a had a web shear tension failure occurred accompanied by anchorage failure, therefore, in situations like this, it is not entirely clear whether it is a shear tension failure or an anchorage failure (see Fig. 7. 10). The lowest ultimate loads corresponds to the HCS with $\mathrm{a} / \mathrm{d}=8.6$. In this supports-loads distribution, the highest deflections were achieved, showing clear ductile flexural failure (F) or shear-flexure (SF). In these cases, behavior was similar for the three types of concrete as the influence of fibers was only marginal, compared with the influence of the prestressing. 
The HCS with an a/d ratio=3.4 showed intermediate behavior by always cracking through web shear tension failure (S). The tendency of increasing shear capacity with an increasing amount of fibers is reported.

For the a/d ratio equal to 3.4, we can see (Fig.7. 15) that the HCS [II-0-3.4(P), II-50-3.4(P) and II-70-3.4(P)], accomplished a more ductile behavior with greater loads than their equivalent specimens non precracked. Moreover, dependence on fiber amount was clearly evident.

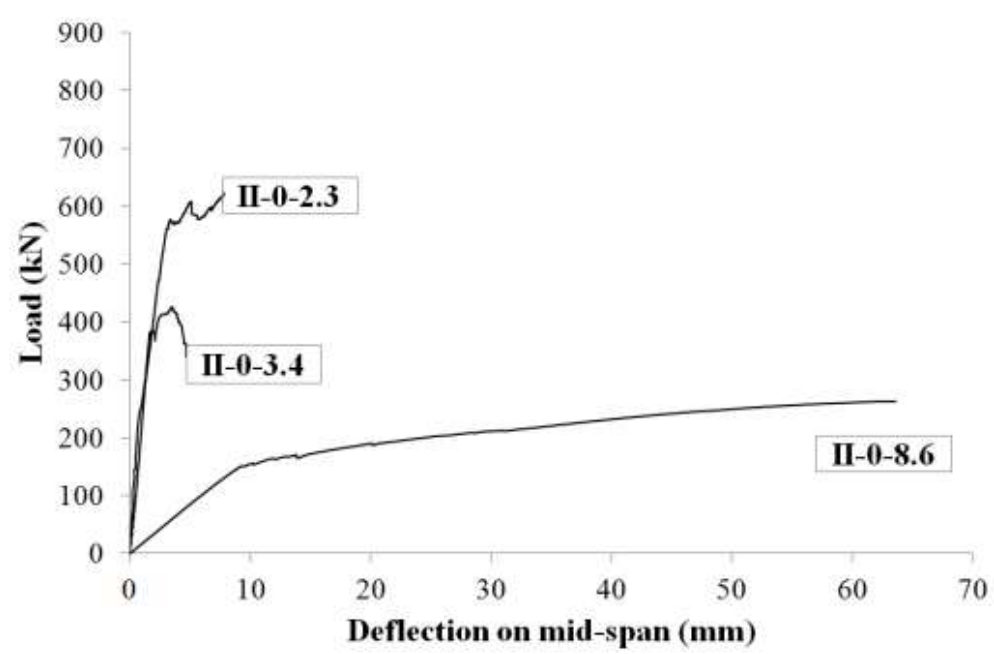

Fig.7. 12 Series II: HCS with $0 \mathrm{~kg} / \mathrm{m}^{3}$ of fibers

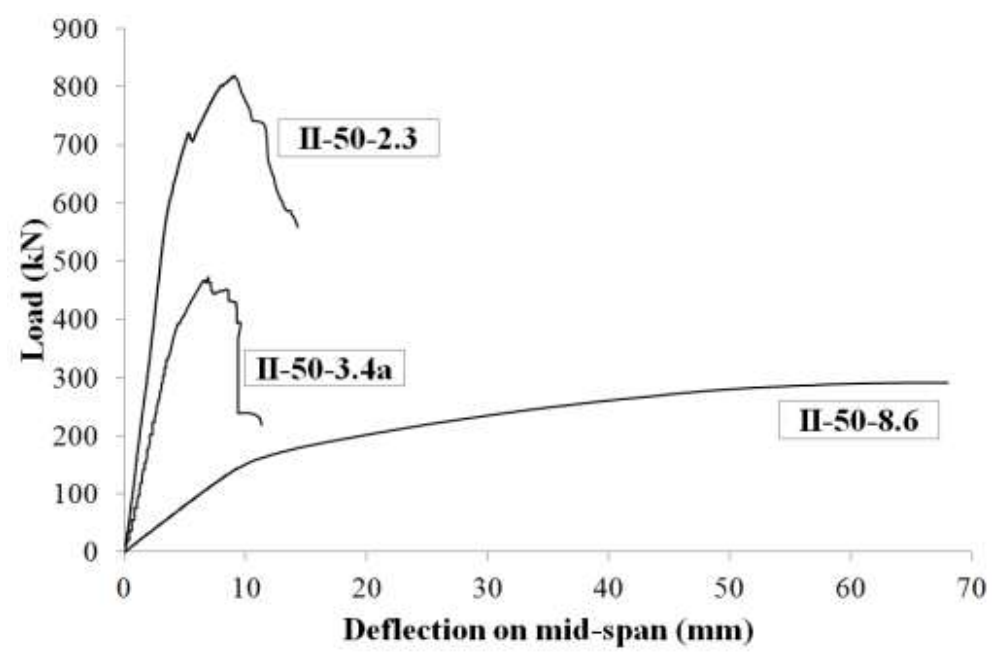

Fig.7. 13 Series II: HCS with $50 \mathrm{~kg} / \mathrm{m}^{3}$ of fibers 


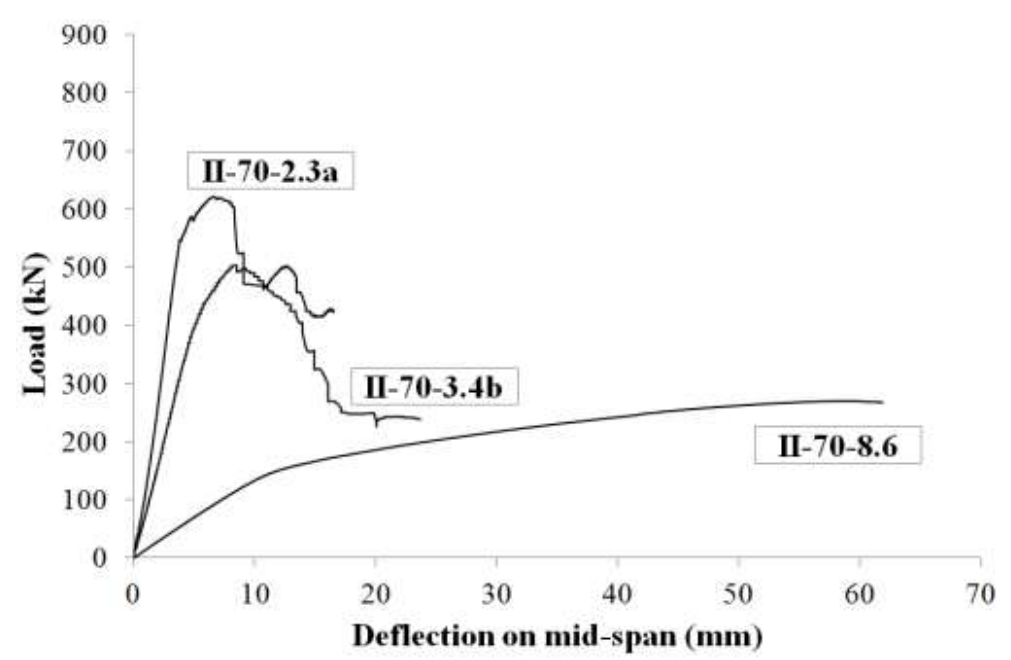

Fig.7. 14 Series II: HCS with $70 \mathrm{~kg} / \mathrm{m}^{3}$ of fibers

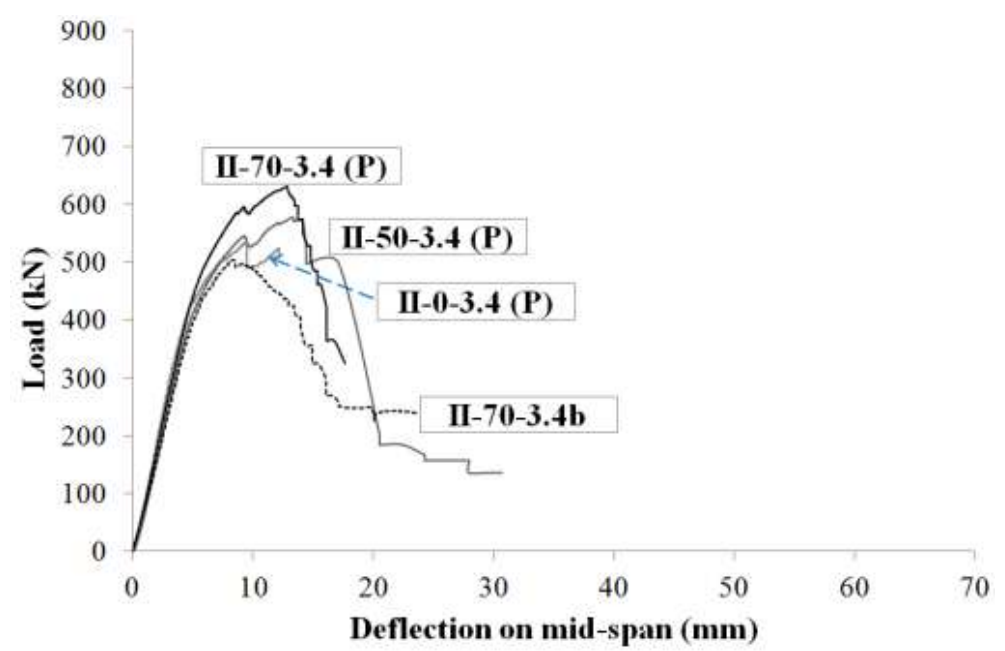

Fig.7. 15 Series II: HCS with $a / d=3.4$

\subsubsection{Shear values according to current Design Codes and failure modes discussion}

\subsubsection{Current Design Codes}

Some authors like Pisanty [4], among others, claimed that the model proposed in EC2 [3] to evaluate the uncracked shear capacity of prestressed elements overestimated the real ultimate strength. For this reason, the standard EN 1168+A2 [1] proposes a reduction of 
shear resistance proposed by the EC2 [3] for regions uncracked in bending by means of the reduction factor $\varphi=0.8$ (see Table III.3).

MC2010 [5] consider that shear tension failure can occur in regions uncracked in flexure (bending) when the principal tensile stress in the web reaches the tensile strength of concrete. MC2010 [5] ensures that this type of failure is relevant especially for precast elements like prestressed hollow core slabs. In other words, EC2 [3] considers a region as uncracked in bending when flexure stress is lower than tensile concrete strength.

Therefore, the shear capacity by diagonal shear tension was calculated for the critical section (Figure 7. 6) assuming the region as uncracked in bending using the formula of EN 1168+A2 [1] (Eq. 7. 3). As this standard has no formulation to take into account fiber contribution, it was calculated by following the RILEM proposal [6]; the values are indicated in Table 7. (see Notation in Table III.3). The safety margins (SM) were obtained as $V_{\text {test }} / \mathrm{V}_{\text {theo }}$ (the shear test value divided by the shear theoretical value).

$$
V_{R d c}=\varphi \cdot(I \cdot b / S) \cdot V\left(f_{c t}{ }^{2}+\beta \cdot \alpha_{1} \cdot \sigma_{c d} \cdot f_{c t}\right)
$$

To obtain real predictable resistance, the partial safety factors for material properties were considered in the calculation as $\gamma_{c}=1$ and $\gamma_{s}=1$ (Tables 7.6 and 7.8). Moreover, average values were utilized instead of characteristic values present in the formulas.

Table 7. 6 Shear resistance $(\mathrm{kN})$ of the regions uncracked in bending according to EN $1168+\mathrm{A2}$ $\left(V_{R d c}\right)$ and RILEM $\left(V_{f}\right)$

\begin{tabular}{|c|ccccccc|}
\hline $\begin{array}{c}\text { Specimen } \\
\text { ID }\end{array}$ & $\boldsymbol{V}_{\text {test }}$ & F.M. & $\boldsymbol{V}_{\boldsymbol{R} \text { dc }}$ & $\begin{array}{c}\boldsymbol{V}_{f} \\
\text { RILEM }\end{array}$ & $\boldsymbol{V}_{\text {Rdc }}+\boldsymbol{V}_{f}$ & $\boldsymbol{S} \boldsymbol{M}=\frac{\boldsymbol{V}_{\text {test }}}{\boldsymbol{V}_{\boldsymbol{R} d c}+\boldsymbol{V}_{\boldsymbol{f}}}$ & $\boldsymbol{S} \boldsymbol{M}=\frac{\boldsymbol{V}_{\text {test }}}{\boldsymbol{V}_{\text {Rdc }}}$ \\
\hline II-0-2.3 & 310.8 & $\mathrm{~A}$ & 191.58 & 0.00 & 191.58 & $\mathbf{1 . 6 2}$ & $\mathbf{1 . 6 2}$ \\
II-0-3.4 & 213.1 & $\mathrm{~S}$ & 207.30 & 0.00 & 207.30 & $\mathbf{1 . 0 3}$ & $\mathbf{1 . 0 3}$ \\
II-50-2.3 & 410.0 & $\mathrm{~S}$ & 230.04 & 78.77 & 308.81 & $\mathbf{1 . 3 3}$ & $\mathbf{1 . 7 8}$ \\
II-50-3.4a & 236.7 & $\mathrm{~S}$ & 170.22 & 78.77 & 248.99 & 0.95 & $\mathbf{1 . 3 9}$ \\
II-50-3.4b & 202.0 & $\mathrm{~S}$ & 258.44 & 78.77 & 337.21 & 0.60 & 0.78 \\
II-70-2.3a & 310.7 & $\mathrm{~S}$ & 159.29 & 98.83 & 258.12 & $\mathbf{1 . 2 0}$ & $\mathbf{1 . 9 5}$ \\
II-70-2.3b & 310.7 & $\mathrm{~A}$ & 156.75 & 98.83 & 255.58 & $\mathbf{1 . 2 2}$ & $\mathbf{1 . 9 8}$ \\
II-70-3.4a & 266.7 & $\mathrm{~S}$ & 165.45 & 98.83 & 264.28 & $\mathbf{1 . 0 1}$ & $\mathbf{1 . 6 1}$ \\
II-70-3.4b & 251.4 & $\mathrm{~S}$ & 174.87 & 98.83 & 273.70 & 0.92 & $\mathbf{1 . 4 4}$ \\
\hline
\end{tabular}

F.M.=Failure Mode.

On the other hand, when failure took place in a region cracked in bending, shear strength capacity was calculated by the formulation of standard EN 1168+A2 [1] under cracked conditions (based on EC2 [3]) and by adding fibers contribution according to RILEM [6] and MC2010 [5]. To obtain the elements' shear theoretical values, each HCS can be 
approximated to a single double T beam; when the web width $b_{o}$ was the sum of all the webs widths which composed the HCS. For the calculations, the fact that all the webs contributed in the same manner to resist shear was taken into account. However, some authors, like Elliott [7], suggested that the shear capacity of HCS is not the same as the shear capacity of each component section, unless web widths are exactly equal; since shear failure finally occurs in the critical web. Therefore, it seems reasonable to calculate shear by not taking into account all the webs of the HCS. As HCS were treated as a sum of the double $T$ beams, the contribution of the flange to the shear was considered in the calculations for the HCS made from fibers, by means of factor $k_{f}$ (Table III.2), proposed in the RILEM guidelines. This value $\left(k_{f}\right)$ was equal to 1.036 for all the cases. Neither EN 1168+A2 nor MC2010 considered flanges contribution to shear. For the HCS without fibers, MC2010 shear strength was calculated by applying the most accurate form (Level III of Approximation), which permitted the calculation of $\varepsilon_{x}$ (see Table III.1 in the introduction to Part III) and directly calculated the corresponding inclination of the compression stresses $(\theta)$. Level III of Approximation was based directly on the equations of the Modified Compression Field Theory (MCFT) [8]. The resistance of HCS with fibers were calculated by applying the formula proposed in MC2010 (see Table 7.7), which included the effect of fibers inside the concrete matrix contribution. All the formulas used to calculate shear strength are clearly summarized in Table 7. 7.

Table 7. 7 Current Codes shear formulas for elements without stirrups

\begin{tabular}{|c|c|c|}
\hline & Code & Theoretical Shear (V) \\
\hline & & $\mathrm{V}_{\mathrm{cu}}=$ Concrete contribution ; $\mathrm{V}_{\mathrm{fu}}=$ Fibers contribution \\
\hline \multirow{3}{*}{ 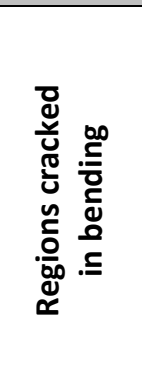 } & $\begin{array}{l}\text { EN } 1168+A 2[1]+ \\
\text { RILEM [6] }\end{array}$ & $\begin{array}{c}V_{c u}=\left[\left(0.18 / \gamma_{c}\right) \cdot \xi \cdot\left(100 \cdot \rho_{l} \cdot C_{2}\right)^{1 / 3}+0.15 \cdot \sigma_{c k}\right] \cdot b_{o} \cdot d ; \quad C_{2}=f_{c v} \\
V_{f u}=k_{f} \cdot 0.7 \cdot \xi \cdot 0.18 \cdot\left(f_{R 4 k} / \gamma_{c}\right) \cdot b_{o} \cdot d\end{array}$ \\
\hline & $\begin{array}{l}\text { MC2010 [5] } \\
\text { Without fibers: }\end{array}$ & $\mathrm{V}_{\mathrm{cu}}=\mathrm{k}_{\mathrm{v}} \cdot\left(\mathrm{vf}_{\mathrm{ck}} / \mathrm{\gamma}_{\mathrm{c}}\right) \cdot \mathrm{z} \cdot \mathrm{b}_{\mathrm{o}} \quad($ Level III Approximation $)$ \\
\hline & $\begin{array}{l}\text { MC2010 [5] } \\
\text { With fibers: }\end{array}$ & $\begin{array}{c}V_{c u}+V_{f u}=\left[\left(0.18 / \nu_{c}\right) \cdot \xi \cdot\left(100 \cdot \rho_{l} \cdot C_{2}\right)^{1 / 3}+0.15 \cdot \sigma_{c k}\right] \cdot b_{o} \cdot d \\
C_{2}=\left(1+7.5 \cdot\left(f_{\mathrm{Ftuk}} / f_{c t k}\right)\right) \cdot f_{c k}\end{array}$ \\
\hline 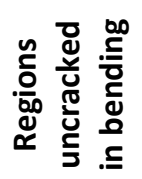 & $\begin{array}{l}\text { EN } 1168+A 2[1]+ \\
\text { RILEM [6] }\end{array}$ & $\begin{array}{l}v_{c u}=\phi \cdot(I \cdot b / S) \cdot v\left(f_{c t}^{2}+\beta \cdot \alpha_{l} \cdot \sigma_{c d} \cdot f_{c t}\right) \\
V_{f u}=k_{f} \cdot 0.7 \cdot \xi \cdot 0.18 \cdot\left(f_{R 4 k} / \gamma_{c}\right) \cdot b_{o} \cdot d\end{array}$ \\
\hline
\end{tabular}

Code formulae included limitations on several parameters, such as the $\rho_{l}$ reinforcement ratio for longitudinal reinforcement, the $\xi$ factor which considers size effect, the $\sigma_{c k}$ 
average stress acting on the concrete cross-section for an axial force due to prestressing actions, and the minimum concrete contribution due to shear $\mathrm{V}_{\mathrm{cu}}$, as presented in Table III.2 (see introduction to Part III). None of these limitations affected the values calculated in the beams tested in these Series. The safety margins $\left(S M=V_{\text {test }} / V_{\text {theo }}\right)$ were used as a reference parameter to compare the results obtained from the different beams and Codes. Table 7.8 shows the shear values (experimental and theoretical) and their SM; it also indicates the shear values corresponding to the flexure failure mode and their corresponding SM. The ultimate flexural moment was calculated by taking into account the fibers contribution, according to MC2010 [5]. In the SM columns (Table 7.8), the values exceeding the unit are shown in boldface.

Table 7.8 Shear values $(\mathrm{kN})$ calculated without safety factors using Codes and assuming regions cracked in bending (average values compression and residual flexural strength)

\begin{tabular}{|c|c|c|c|c|c|c|c|c|}
\hline Specimen ID & $V_{\text {test }}$ & F.M. & $V_{\text {FLEXURE }}$ & $\begin{array}{l}\text { SM } \\
\text { (F) }\end{array}$ & $V_{\text {EN1168+RILEM }}$ & $\begin{array}{c}S M(V) \\
\text { EN1168+RILEM }\end{array}$ & $V_{M C 2010}$ & $\begin{array}{c}S M \\
\text { (V) } \\
\text { MC2010 }\end{array}$ \\
\hline I-0-4.1 & 131.15 & SF & 133.86 & 0.98 & 100.55 & 1.30 & 104.16 & 1.26 \\
\hline I-0-4.3a & 131.11 & SF & 126.63 & 1.04 & 102.25 & 1.28 & 101.80 & 1.29 \\
\hline $\mathrm{I}-0-4.3 \mathrm{~b}$ & 134.90 & SF & 125.21 & 1.08 & 102.25 & 1.32 & 101.31 & 1.33 \\
\hline I-50-3.1 & 160.19 & $A$ & 196.42 & 0.82 & 149.18 & 1.07 & 128.10 & 1.25 \\
\hline $\mathrm{I}-50-3.9 \mathrm{a}$ & 162.10 & SF & 153.86 & 1.05 & 149.18 & 1.09 & 128.10 & 1.27 \\
\hline $\mathrm{I}-50-3.9 \mathrm{~b}$ & 162.10 & SF & 153.86 & 1.05 & 149.18 & 1.09 & 128.10 & 1.27 \\
\hline I-50-4.3 & 152.61 & SF & 139.87 & 1.09 & 149.18 & 1.02 & 128.10 & 1.19 \\
\hline I-50-4.4 & 158.62 & SF & 137.79 & 1.15 & 149.18 & 1.06 & 128.10 & 1.24 \\
\hline I-50-3.0a & 172.95 & SF & 199.25 & 0.87 & 149.18 & 1.16 & 128.10 & 1.35 \\
\hline $\mathrm{I}-50-3.0 \mathrm{~b}$ & 200.63 & SF & 197.82 & 1.01 & 149.18 & 1.34 & 128.10 & 1.57 \\
\hline $\mathrm{I}-50-3.1 \mathrm{c}$ & 189.43 & SF & 197.12 & 0.96 & 149.18 & 1.27 & 128.10 & 1.48 \\
\hline II-0-2.3 & 310.80 & $A$ & 560.58 & 0.55 & 150.10 & 2.07 & 182.42 & 1.70 \\
\hline II-0-3.4 & 213.10 & $S$ & 373.72 & 0.57 & 150.10 & 1.42 & 182.42 & 1.17 \\
\hline II-0-3.4 (P) & 266.20 & $S$ & 373.72 & 0.71 & 150.10 & 1.77 & 182.42 & 1.46 \\
\hline II-0-8.6 & 131.60 & SF & 149.49 & 0.88 & 150.10 & 0.88 & 115.25 & 1.14 \\
\hline II-50-2.3 & 410.00 & $S$ & 546.11 & 0.75 & 224.62 & 1.83 & 200.81 & 2.04 \\
\hline II-50-3.4a & 236.70 & $S$ & 364.07 & 0.65 & 224.62 & 1.05 & 200.81 & 1.18 \\
\hline II-50-3.4 (P) & 288.70 & $S$ & 364.07 & 0.79 & 224.62 & 1.29 & 200.81 & 1.44 \\
\hline II- $50-3.4 \mathrm{~b}$ & 202.00 & $S$ & 364.07 & 0.55 & 224.62 & 0.90 & 200.81 & 1.01 \\
\hline II-50-8.6 & 146.10 & $\mathrm{~F}$ & 144.13 & 1.01 & 224.62 & 0.65 & 200.81 & 0.73 \\
\hline II-70-2.3a & 310.70 & $S$ & 540.50 & 0.57 & 243.15 & 1.28 & 207.60 & 1.50 \\
\hline II-70-2.3b & 310.70 & A & 540.50 & 0.57 & 243.15 & 1.28 & 207.60 & 1.50 \\
\hline II-70-3.4a & 266.70 & $S$ & 360.34 & 0.74 & 243.15 & 1.10 & 207.60 & 1.28 \\
\hline II-70-3.4 (P) & 315.00 & $S$ & 360.34 & 0.87 & 243.15 & 1.30 & 207.60 & 1.52 \\
\hline II-70-3.4b & 251.40 & $S$ & 360.34 & 0.70 & 243.15 & 1.03 & 207.60 & 1.21 \\
\hline II-70-8.6 & 135.20 & $\mathrm{~F}$ & 144.13 & 0.94 & 243.15 & 0.56 & 207.60 & 0.65 \\
\hline
\end{tabular}

$P=$ Hollow core slab precracked in flexure; *Bond failure; Failures: SF: Shear-flexure failure; S: Web shear tension failure; F: flexure failure; A: Anchorage failure of strands; F.M.=Failure Mode. 


\subsubsection{Series I: Shear values according to current Design Codes}

By way of general conclusion, and as expected, all the slabs of Series I presented a failure mode through shear-flexure, therefore theoretical shear values were calculated in regions cracked in bending.

Fig.7. 16 plots the SM of all the HCS in Series I, except HCS (I-50-3.1), which had a failure through bonding. We can observe that the shear SM and the flexure SM are higher than the unit. These results demonstrate that exceeding both shear and flexural theoretical strengths at the same time it is possible. However, three HCS (I-50-3.0a, I-50-3.0 b and I50-3.1c) achieved higher SM values in shear due to the lower $a / d$ value. We can also notice how the MC2010 provisions are better balanced than those from EN1168+RILEM, and that EN1168+RILEM are less conservative than MC2010 when fibers are present.

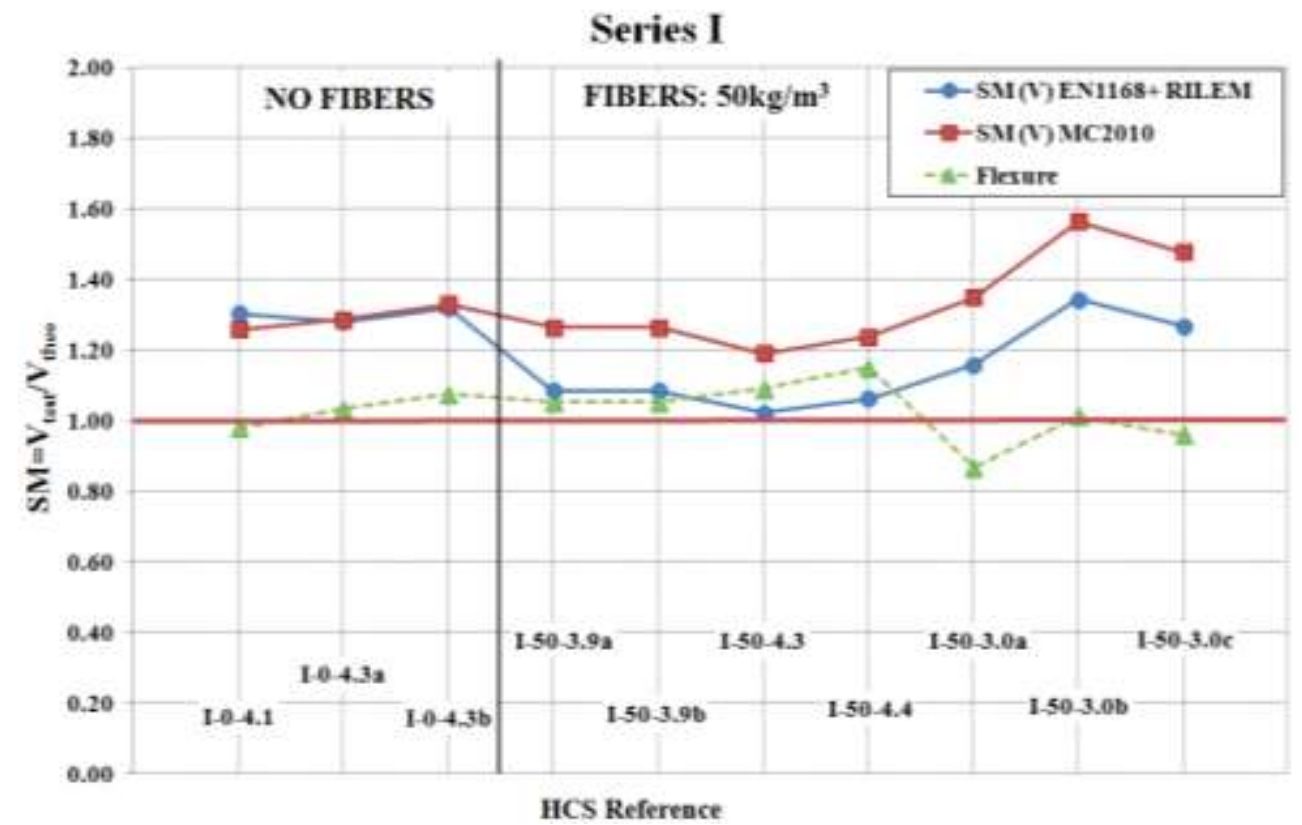

Fig.7. 16 Shear safety margins in regions cracked in bending (Series I)

\subsubsection{Series II: Shear values according to current Design Codes}

Series II had, in the majority, diagonal tensile failures, as it is shown in Table 7.8. Theoretically, pure diagonal tensile failures should be calculated using the formula for regions uncracked in bending; however, it is possible that a small flexure crack was produced prior to the diagonal tension failure. For this reason, it was decided to calculate 
the theoretical shear value also under the hypothesis of region cracked in bending (Figure 7. 17) to compare which of these two hypotheses is closer to the experimental value. Figure 7. 18 shows HCS from Series II which had web shear tension failures calculated according to both hypotheses: cracked or uncracked in bending.

Fig.7. 17 plots the shear and flexure SM for the tested Series II HCS, assuming regions cracked in bending according to EN1168. As with Series I, MC2010 was better balanced than EN1168 when comparing the elements with or without fibers for the same a/d. In any case, the results are very similar for both Code provisions. Nevertheless, a clear sensitivity to the a/d ratio was detected. Shear SM were greater for the HCS with a low $\mathrm{a} / \mathrm{d}$, and obtained values close to 2 . On the other hand, shear strength values were more balanced when a/d ratio was higher (3.4). Only HCS II-50-3.4b shows a shear SM lower than 1; it may be justified by a bad surface finishing. Evidently when flexural failure was observed (II-0-8.6, II-50-8.6, II-70-8.6), failure loads did not reach the theoretical shear strength (see rectangular boxes in Fig. 7. 17).

\section{Series II}

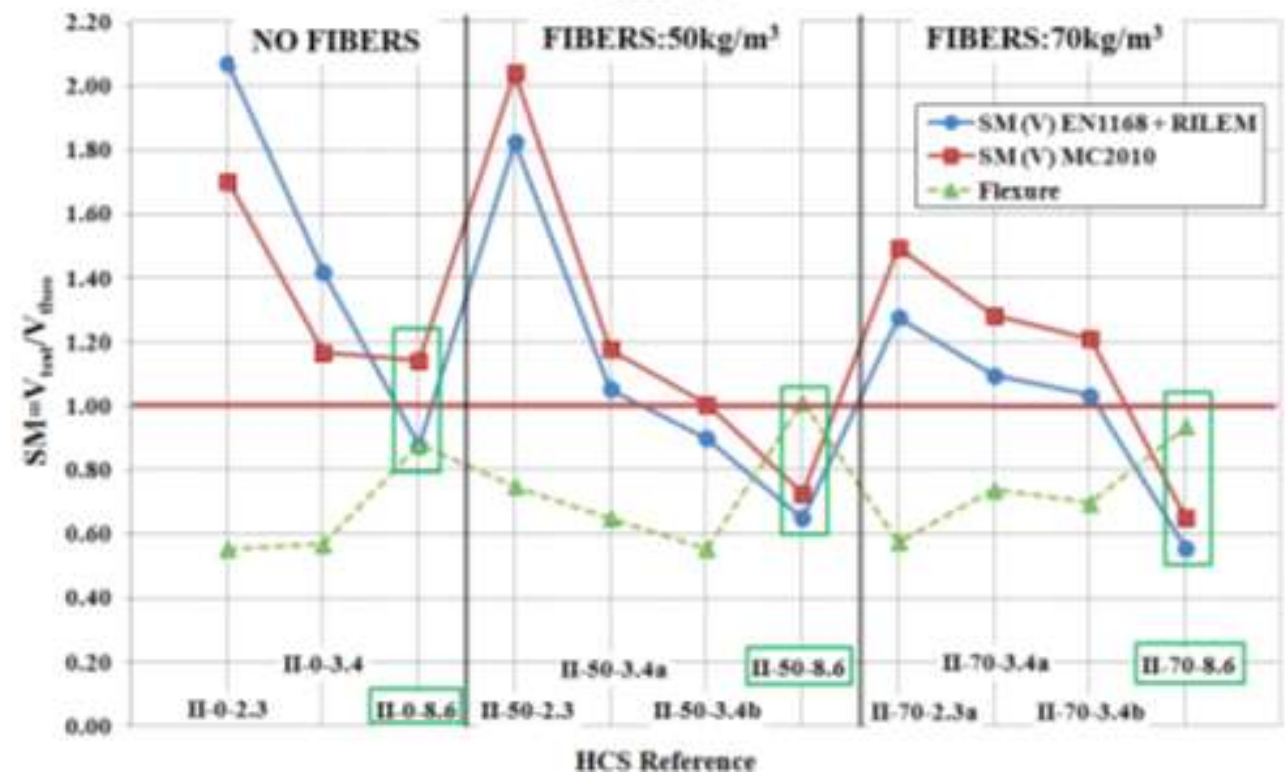

Fig.7. 17 Shear safety margins assuming regions cracked in bending (Series II)

In Fig.7. 18, only HCS with web shear tension failures have been represented, plotting together the SM values calculated with both hypotheses: regions cracked in bending (as were plotted in Fig.7. 17) and regions uncracked in bending (Table 7. 6), which means pure shear tension failures. As it can be seen in Fig.7. 18, for all HCS, except the II-50-3.4b (because of bad surface finishing), less SM were obtained assuming uncracked region. 


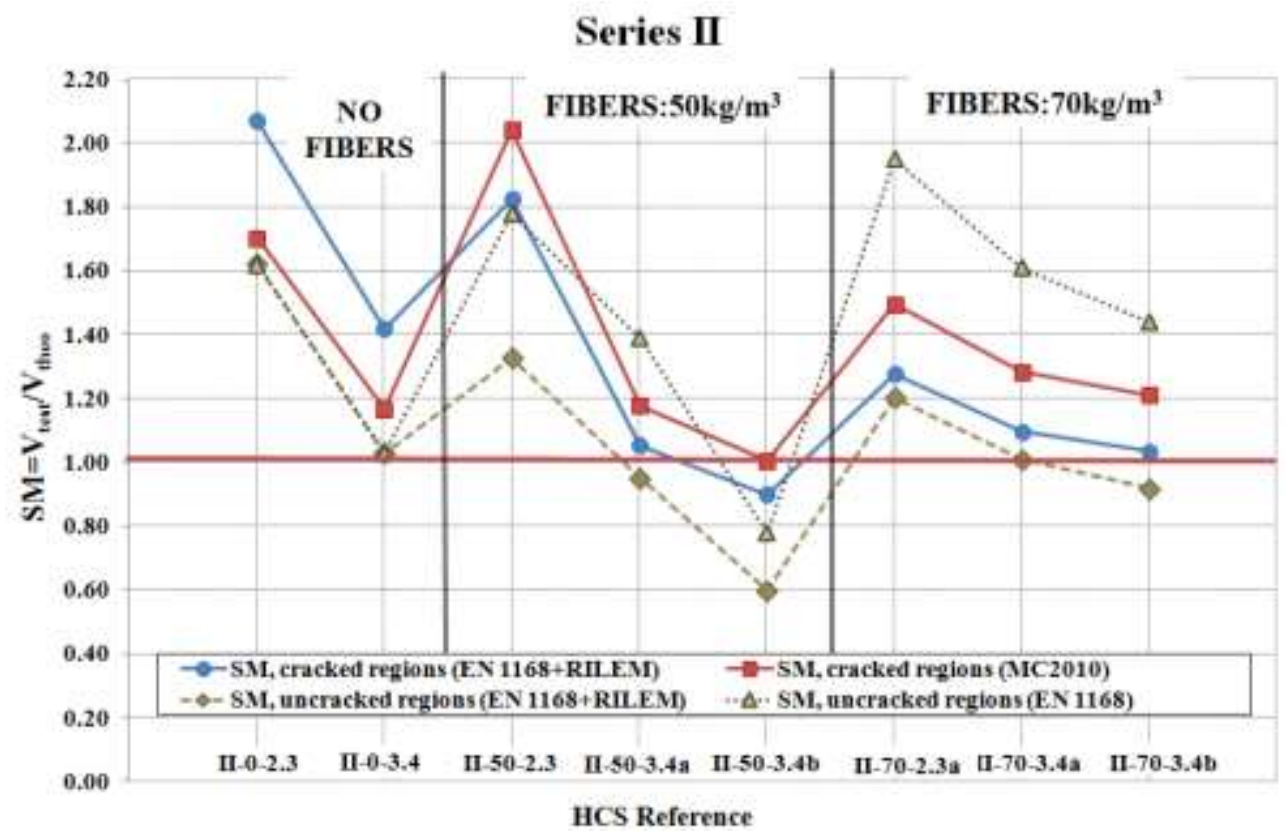

Fig.7. 18 Shear safety margins of HCS with web shear tension failure (Series II)

Precracking HCS before shear testing implied an increase in bearing load that was equal to 24.92\%, 31.62\% and $21.60 \%$ for HCS made with $0 \mathrm{~kg} / \mathrm{m}^{3}, 50 \mathrm{~kg} / \mathrm{m}^{3}$ and $70 \mathrm{~kg} / \mathrm{m}^{3}$ of fibers, respectively (Fig.7. 19). It is evident that flexural precracking makes diagonal tension crack propagation difficult and improves HCS behavior, observing that precracked HCS reached higher ultimate loads than their analogous non precracked (Table 7.8). This behavior occurs since, in regions previously precracked, the previous cracks intercept the stress fields and generate new cracks that do not correspond with the most unfavorable. From this Series, it can be observed that Codes are more conservative for the HCS without fibers, this is when brittle failures are expected; on the other hand, for ductile members, Codes give less SM [9], [10]. This fact, which the present work detects, agrees with the observations made by Peaston et al. [2]. In Fig.7.20 is represented the capacity achieved in flexure at the time of failure (in Fig.7.20 called SM in flexure) versus a/d ratio. It can be observed that the FRC slabs which had a shear-tension failure were over Kani's valley. Also, [11] those with shear-flexure failures had flexural capacities greater than expected, according to Kani's valley [11]. These results agree with Imam [12], who suggested that the region of diagonal failure disappears completely in Kani's valley when increasing fiber amount and efficiency.

In this way, use of fibers is a possible solution to overcome shear failure since fibers are capable of increasing element strength to its full flexural capacity. 


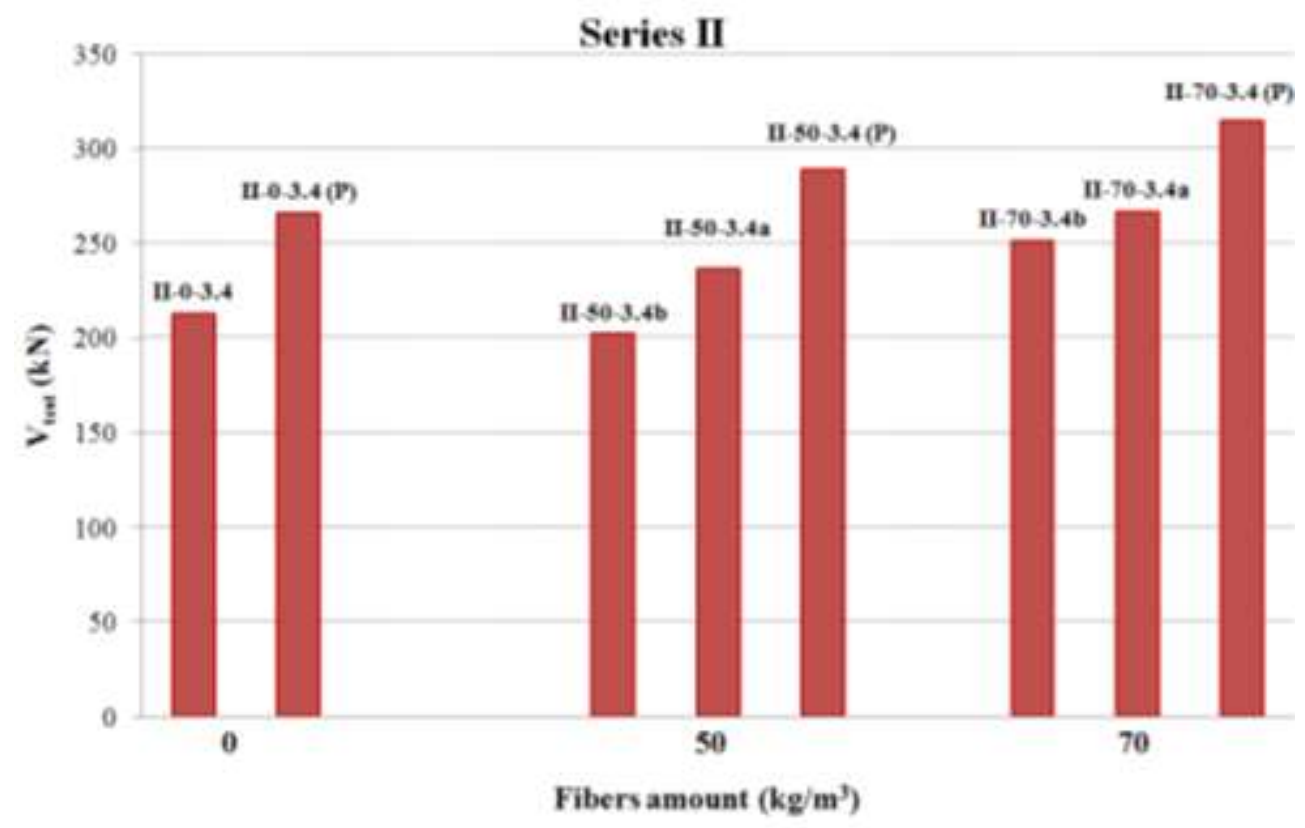

Fig.7. 19 Precrack influence on shear strength for HCS with $a / d=3.4$

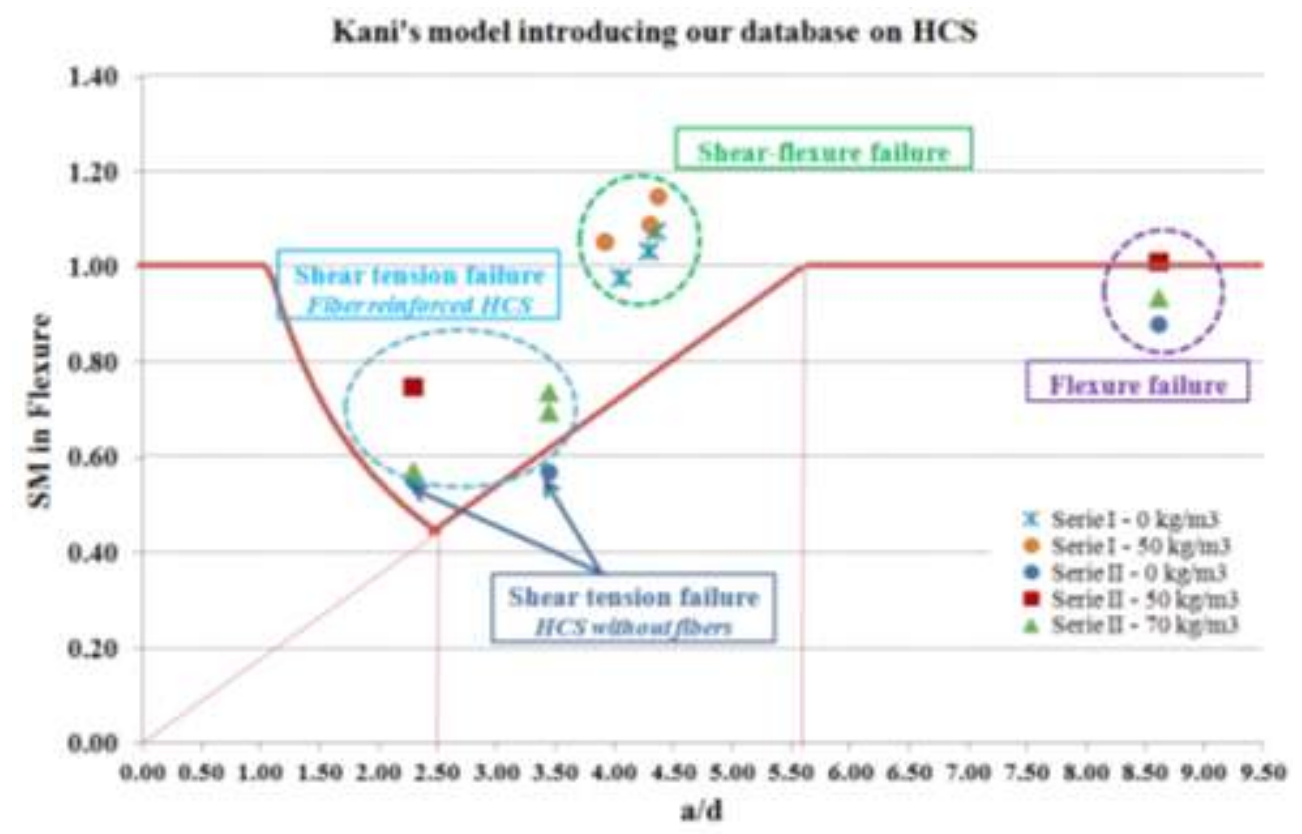

Fig.7. 20 Own database inside Kani's valley 


\subsection{Conclusions}

According to the tests, the following conclusions can be drawn:

- It is possible to produce fiber-reinforced concrete hollow core slabs (HCS) without encountering technical problems.

- An extensive experimental program has been developed to analyze the shear strength and failure behavior of HCS with different failure modes. The effect of fiber amount and shear span on behavior has been analyzed.

- HCS with fibers reached higher shear capacities than those without fiber reinforcement, and when characterized a more ductile behavior. This is a key advantage given the impossibility of placing transverse reinforcements in extruded HCS.

- A clear influence of the a/d ratio on shear strength and on shear behavior has also been detected.

- Model Code 2010 and European standard EN1168+A2 approaches were used to evaluate the HCS shear capacity for both traditional and FRC elements, assuming regions cracked in bending. In the EN1168 approach, the fibers effect was introduced as proposed by RILEM. Codes provisions are very similar and are very conservative when the HCS made with FRC shear strength are calculated for loads applied with low $\mathrm{a} / \mathrm{d}$ and brittle failures caused by web shear tension failure (S). However, they are well adjusted for high values of the a/d ratio and ductile failures caused by flexure (F) or shear-flexure (SF).

- The model proposed in EN1168 to evaluate the shear capacity in regions uncracked in bending provides a better approximation for HCS with web shear tension failures (S).

- The HCS previously precracked in flexure showed an enhanced shear behavior, and obtain higher safety margins (20-30\%) than those of uncracked HCS.

- Use of fibers is a possible solution to overcome shear failure since fibers are capable of increasing element strength to its full flexural capacity, thus attenuating Kani's valley. 


\subsection{Publication of these results}

The results of this paper were accepted in Composites Part B: Engineering Journal the $2^{\text {nd }}$ June 2012 and therefore will be published in this journal with the following reference:

[13] Cuenca E., Serna P., Failure modes and shear design of prestressed hollow core slabs made of fiber-reinforced concrete, Composites: Part B, vol.45, no.1, pp.952-964, 2013.

< doi: http://dx.doi.org/10.1016/j.compositesb.2012.06.005>

\subsection{References}

[1] UNE-EN1168+A2, "Precast concrete products. Hollow Core Slabs," 2006.

[2] Peaston, Elliott and Paine, "Steel fiber reinforcement for extruded prestressed Hollow Core Slabs," ACI Special Publication, vol. 182, pp. 87-107, 1999.

[3] EC2, "Eurocode 2: Design of Concrete Structures - EN 1992-1-1," 2004.

[4] Pisanty, "The shear strength of extruded hollow-core slabs," Materials and Structures, vol. 25, pp. 224-230, 1992.

[5] MC2010, "fib Bulletin 55-56. Model Code - First complete draft," 2010.

[6] RILEM, "RILEM TC 162-TDF: Test and design methods for steel fibre reinforced concrete. Final Recommendation," vol. 36, pp. 560-567, 2003.

[7] Elliott, Peaston and Paine, "Experimental and theoretical investigation of the shear resistance of steel fibre reinforced prestressed concrete X-beams. Part I: Experimental work," Materials and Structures, vol. 35, pp. 519-527, 2002.

[8] Vecchio and Collins, "The Modified Compression Field Theory for reinforced concrete elements subjected to shear," ACl Journal, vol. 83, no. 2, pp. 219-231, 1986.

[9] Cladera and Marí, "Shear design of reinforced and prestressed concrete beams: a proposal for code procedure," Hormigón y Acero, vol. 242, no. 4, pp. 51-63, 2006.

[10] Cladera and Marí, "Shear design procedure for reinforced normal and high-strength concrete beams using artificial neural networks. Part II: beams with stirrups," 
Engineering Structures, vol. 26, pp. 927-936, 2004.

[11] Kani, "The Riddle of Shear Failure and its solution," $A C l$ Journal, vol. 61, no 4, pp. 441467, 1964.

[12] Imam, Vandewalle, Mortelmans and V. Gemert, "Shear domain of fibre-reinforced high-strength concrete beams," Engineering Structures, vol. 19, no. 9, pp. 738-747, 1997.

[13] Cuenca and Serna, "Failure modes and shear design of prestressed hollow core slabs made of fiber-reinforced concrete," Composites: Part B, vol. 45, no. 1, pp. 952-964, 2013. 


$$
\text { Pant TrV }
$$

1. Sheân 1) $6 .(-\infty)$

@âabase 


\title{
CHAPTER 8
}

\author{
SHEAR DATABASE
}

\author{
AND STUDY OF THE
}

PARAMETERS INFLUENCING

\author{
SHEAR BEHAVIOR
}

\subsection{Introduction}

After thorough review of the literature on structural elements with shear failure, and after conducting several experimental programs whose values were compared later with the theoretical values obtained with the three selected Design Codes to calculate shear in elements reinforced with fibers, it was found that it would be useful and also necessary to build a large database of elements failing in shear in order to have a large number of cases 
that allow to better evaluate resisting phenomena and the validity of building Codes. For this reason, Chapter 8 shows the analysis of that database.

The structure of Chapter 8 is the following: Section 8.2 explains how the data have been selected. Data are analyzed separately in four cases: Case 1 encompasses the concrete beams with any shear reinforcement (neither fibers nor stirrups); Case 2 concerns beams with only stirrups (no fibers); Case 3 refers to beams with only fibers (no stirrups) and Case 4 concerns beams with fibers and stirrups. In each of these four cases the influence of the following parameters is analyzed: $d, a / d, f_{c m}, f_{R 3}, \rho, \sigma_{c}$, and amount of fibers and stirrups.

In Section 8.7 particular cases, that are subsets of the entire database, have been analyzed. The subsets have been organized to study the influence of single factors but also double interactions (interaction between 2 parameters). For each subset, an analysis of variance (ANOVA) has been performed and, to analyze the influence of each level of parameter in the SM, LSD have been determined. On the other hand, interaction graphs have been done to analyze the interaction between two different parameters into the SM.

Section 8.8 describes the conclusions of the influence of each parameter $(d, a / d$, etc) in the safety margin (SM).

Finally, in Section 8.9 are listed some suggestions or modifications to the selected Codes according to the results and trends observed in this Chapter 8.

\subsection{Data selection}

In total, 215 structural elements were used to prepare a complete database to analyze the shear behavior and the influence of each parameter on shear out of 363 elements of the experimental database. As can be seen, 148 elements were eliminated for various reasons. In particular, the following data were removed:

1. those with different failure modes to shear;

2. those beams which are not known in some detail;

3. the beams containing a mixture of more than one fiber type;

4. those which are not available any value of strength; and,

5. all those elements with ratios a/d smaller than 2.5 , in which arching action is dominant [1], [2], [3], [4].

The present database was made by using elements from other databases (as performed by the University of Brescia (Italy) and RILEM databases), plus all the elements tested in 
shear in the Brite/Euram project [5], beams tested by Dupont \& Vandewalle [6], other beams [7] as well as the elements tested within the present PhD thesis.

The input parameters used were: the shear span-to-depth ratio $(a / d)$; the effective depth $(d)$; the concrete cylinder compressive strength $\left(f_{c}\right)$; the residual flexural tensile strength $\left(f_{R 3}\right)$ corresponding to a crack mouth opening displacement CMOD $=2.5 \mathrm{~mm}$, according to the Standard EN 14651 [8]; the reinforcement ratio for longitudinal reinforcement $\left(\rho_{l}\right)$; the average stress acting on the concrete cross-section for an axial force due to prestressing actions $\left(\sigma_{c}\right)$; the amount of steel fibers $\left(\mathrm{kg} / \mathrm{m}^{3}\right)$ and transverse reinforcement area per unit length $\left(A_{s o} / s\right)$. The output value is the safety margin $(S M)$ obtained as $V_{\text {test }} / V_{\text {theo }}$ (the shear test value divided by the shear theoretical value).

A large shear database has been obtained, that covers a great interval of the main parameters influencing shear. Table 8. 1 summarizes the ranges of the different values used in this shear database.

Table 8. 1 Range of parameters in the complete database ( $\mathrm{N}=\mathbf{2 1 5}$ elements)

\begin{tabular}{|l|c|c|}
\hline Parameter & Minimum & Maximum \\
\hline $\mathrm{d}(\mathrm{mm})$ & 102 & 1440 \\
\hline $\mathrm{a} / \mathrm{d}$ & 2.50 & 4.69 \\
\hline $\mathrm{f}_{\mathrm{cm}}(\mathrm{MPa})$ & 17 & 96.34 \\
\hline $\mathrm{f}_{\mathrm{R} 3}(\mathrm{MPa})$ & 0 & 10.60 \\
\hline Amount of fibers $\left(\mathrm{kg} / \mathrm{m}^{3}\right)$ & 0 & 240 \\
\hline$\rho(\%)$ & 0.41 & 5.82 \\
\hline$\sigma_{\mathrm{c}}(\mathrm{MPa})$ & 0 & 12 \\
\hline $\mathrm{A}_{\mathrm{s} \alpha} / \mathrm{s}\left(\mathrm{cm}^{2} / \mathrm{m}\right)$ & 0 & 4.90 \\
\hline
\end{tabular}

The theoretical shear $\left(V_{\text {theo }}\right)$ was calculated for each of the beams according to three structural Codes: the Spanish Standard EHEO8 [9], the RILEM approach [10] and the first complete draft of Model Code 2010 [11]. In this Chapter 8, the limitations to the parameters according to the Codes (see Table III.2 in the introduction to Part III) were applied.

EHE-08 formulation considers fibers contribution separately from concrete, which is based in EC2 [12] while the contribution of the fibers is based on RILEM [10]. The MC2010 [11] considers fiber reinforced concrete (FRC) as a composite material when fibers represent a distributed reinforcement; contribution of fibers is modeled as a modifier of the longitudinal reinforcement ratio throughout a factor that includes the toughness 
properties of FRC [3]. The shear formulations of these Codes are summarized in Table III.1 (see Introduction to Part III).

\subsection{Case 1: Beams made without shear reinforcement (concrete neither fibers nor stirrups)}

Table 8. 2 and Table 8. 3 summarize the ranges of the different parameters used in this case, differencing between reinforced and prestressed beams respectively.

Table 8. 2 Range of parameters in the shear database of reinforced beams made without shear reinforcement ( $\mathrm{N}=37$ elements)

\begin{tabular}{|lcccc|}
\hline Parameter & Minimum & Maximum & Average & CoV (\%) \\
\hline$d(\mathrm{~mm})$ & 197 & 1440 & 395.38 & 65.59 \\
\hline $\mathrm{a} / \mathrm{d}$ & 2.50 & 4.69 & 3.19 & 21.61 \\
\hline $\mathrm{f}_{\mathrm{cm}}(\mathrm{MPa})$ & 20 & 85.57 & 36.90 & 34.50 \\
\hline $\mathrm{f}_{\mathrm{R} 3}(\mathrm{MPa})$ & -- & -- & -- & -- \\
\hline Amount of fibers $\left(\mathrm{kg} / \mathrm{m}^{3}\right)$ & -- & -- & -- & -- \\
\hline$\rho(\%)$ & 0.99 & 3.72 & 1.76 & 47.47 \\
\hline$\sigma_{\mathrm{c}}(\mathrm{MPa})$ & -- & -- & -- & -- \\
\hline $\mathrm{A}_{\mathrm{s} a} / \mathrm{s}\left(\mathrm{cm}^{2} / \mathrm{m}\right)$ & -- & -- & -- & -- \\
\hline
\end{tabular}

Table 8. 3 Range of parameters in the shear database of prestressed beams made without shear reinforcement ( $\mathrm{N}=\mathbf{6}$ elements)

\begin{tabular}{|lcccc|}
\hline Parameter & Minimum & Maximum & Average & CoV (\%) \\
\hline$d(\mathrm{~mm})$ & 226.47 & 550 & 282.16 & 42.46 \\
\hline $\mathrm{a} / \mathrm{d}$ & 3.27 & 4.30 & 380 & 11.72 \\
\hline $\mathrm{f}_{\mathrm{cm}}(\mathrm{MPa})$ & 43.80 & 54.20 & 50.25 & 9.30 \\
\hline $\mathrm{f}_{\mathrm{R} 3}(\mathrm{MPa})$ & -- & -- & -- & -- \\
\hline Amount of fibers $\left(\mathrm{kg} / \mathrm{m}^{3}\right)$ & -- & -- & -- & -- \\
\hline$\rho(\%)$ & 0.41 & 3.03 & 1.06 & 87.28 \\
\hline$\sigma_{\mathrm{c}}(\mathrm{MPa})$ & 2.87 & 10.18 & 4.77 & 54.24 \\
\hline $\mathrm{A}_{\mathrm{s} \alpha} / \mathrm{s}\left(\mathrm{cm}^{2} / \mathrm{m}\right)$ & -- & -- & -- & -- \\
\hline
\end{tabular}

\subsubsection{Influence of the $\mathrm{a} / \mathrm{d}$ ratio}

If safety margins ( $\left.S M=V_{\text {test }} / V_{\text {theo }}\right)$ are represented versus a/d for each Code: EHE08 [9], MC2010 [11] and RILEM [10] distinguishing elements without (filled squares) or with prestressing (empty squares), several tendencies are detected. It can be observed that EHEO8 is more conservative for prestressed elements (Fig. 8. 1). 


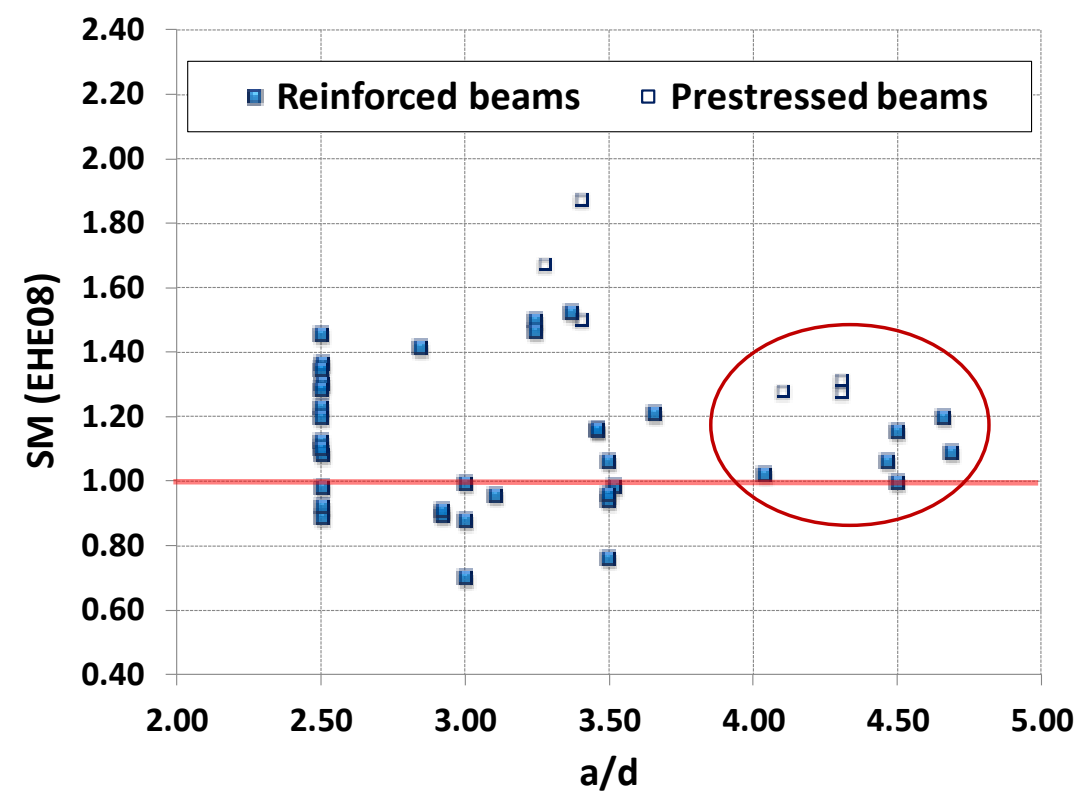

Fig. 8. 1 Beams without shear reinforcement (neither fibers nor stirrups). SM (EHE08) versus a/d

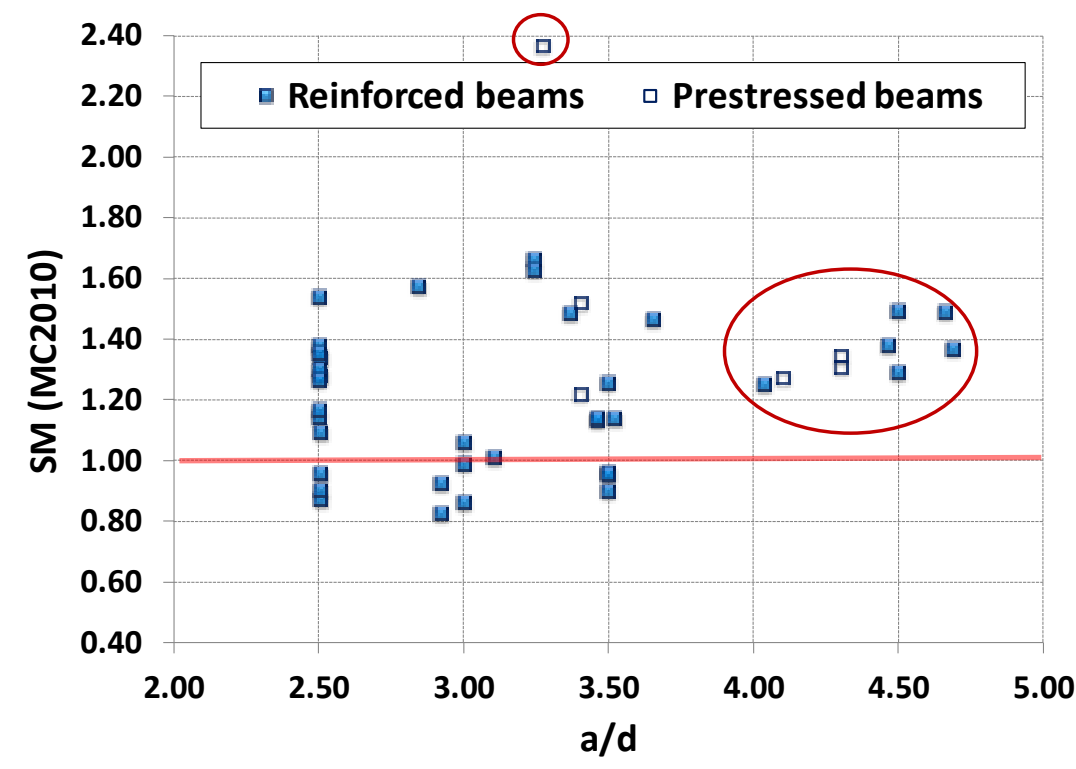

Fig. 8. 2 Beams without shear reinforcement (neither fibers nor stirrups). SM (MC2010) versus a/d 


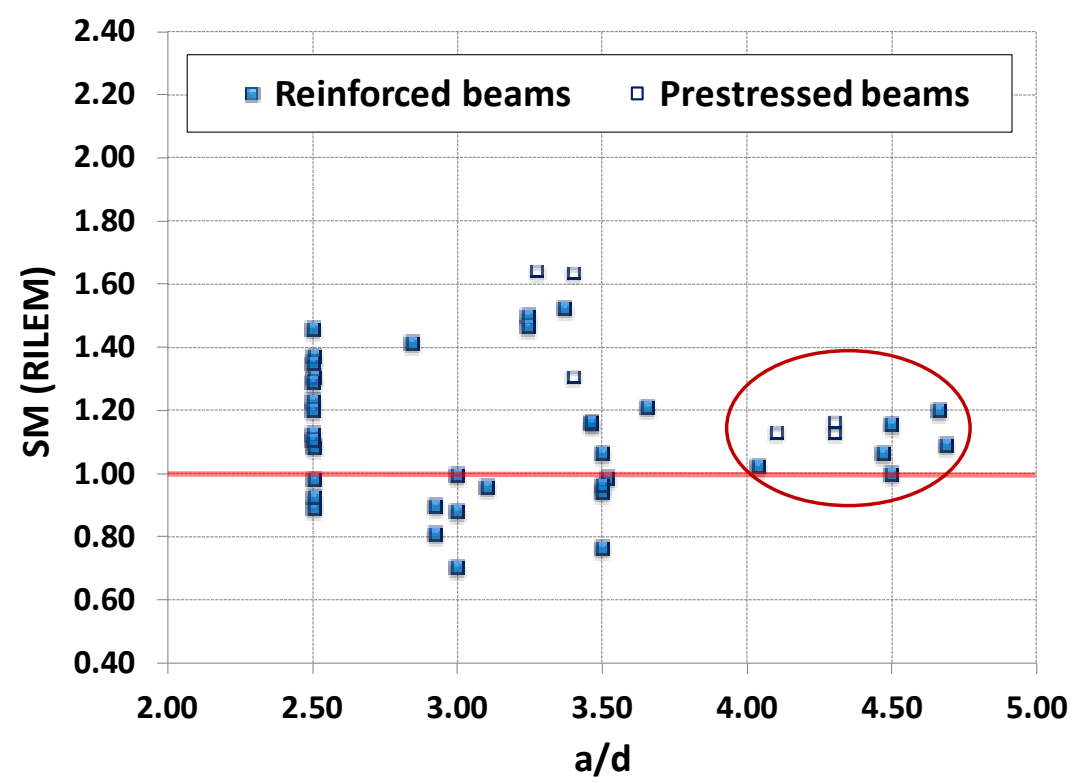

Fig. 8. 3 Beams without shear reinforcement (neither fibers nor stirrups). SM (RILEM) versus a/d

According to MC2010 (Fig. 8. 2) and RILEM (Fig. 8. 3), for the same a/d, when $a / d \geq 4$, reinforced and prestressed elements have similar SM. In Fig. 8. 2, it can be observed that in one case a great safety margin take place (SM close to 2.4 ). When a/d $\geq 4$, RILEM safety margins are very close to the unit (Fig. 8. 3).

In Fig. 8. 4, SMs are represented for each beam of this subset (Case 1: Beams without shear reinforcement). Each column represents one beam of this subset and on each column there are three points corresponding to its SM according to the Codes: EHE08, MC2010 and RILEM. Beams are sorted in ascending order according to their value of a/d (right vertical axis), so that the height of each column indicates the value of $a / d$ of each beam (as can be read on the right vertical axis). On the other hand, SM values of each beam can be obtained through the left vertical axis. Also, reinforced beams are represented by light grey columns (left side of the graph), while dark grey columns are prestressed beams (right side of the graph). Moreover, the upper side of the graph (green shaded), is the area in which Codes are conservative $(S M>1)$, whereas the lower side area (red shaded), when SM <1. For example, the first beam, starting from the left, it is a reinforced beam, because the column is in light grey; the height of the column indicates that, if one reads on the right vertical axis, the beam has an $a / d=2.5$. In turn, if one focus on the 3 points on the column, then SM values are obtained moving to the left vertical axis. 
With this graph it has been possible to observe that for $a / d>3.5$ the MC2010 was the most conservative (Fig. 8. 4).

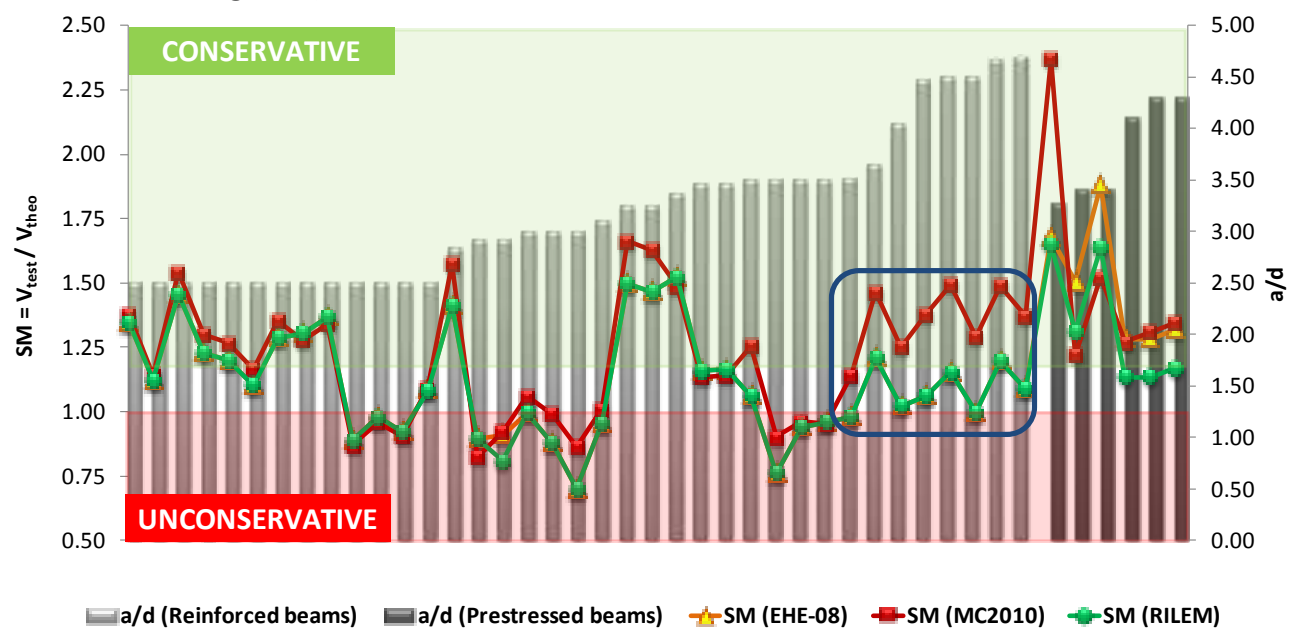

Fig. 8. 4 SM represented versus a/d for beams without any reinforcement (neither stirrups nor fibers)

\subsubsection{Influence of the effective depth, $d$. Size effect}

If experimental shear stress $\left(\mathrm{v}_{\mathrm{u}}=\mathrm{V}_{\text {test }} / \mathrm{b} \cdot \mathrm{d}\right)$ is represented versus effective depth (d), a clear tendency (size effect) is observed, as expected; in fact, shear stress decreased when effective depth increase (Fig. 8. 5).

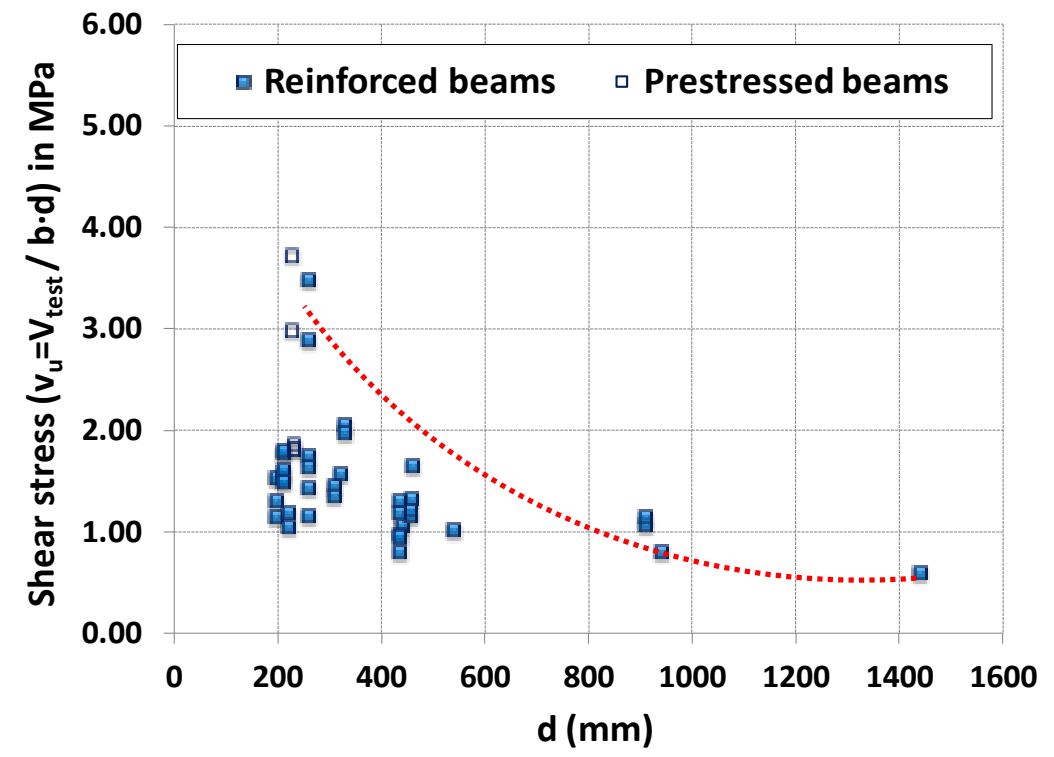

Fig. 8. 5 Beams without shear reinforcement (neither fibers nor stirrups). Size effect 
It can be observed that, when $d>900 \mathrm{~mm}$ (specifically $\mathrm{d}=1440 \mathrm{~mm}$ in this case), all Codes are unsafe (Fig. 8. 6). On the other hand, for $\mathrm{d}<900 \mathrm{~mm}$, all Codes give similar values.

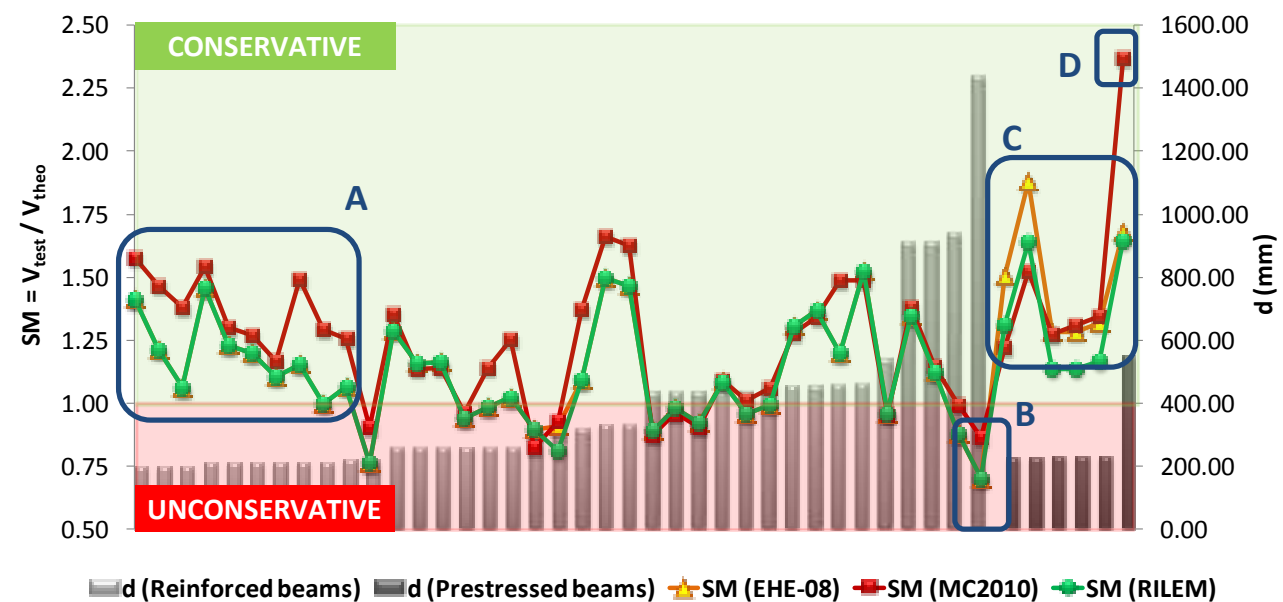

Fig. 8. 6 Beams without shear reinforcement (neither fibers nor stirrups). SM versus $d(\mathrm{~mm})$

Fig. 8. 6 also shows that all Codes are conservative for $d<200 \mathrm{~mm}$, although MC2010 underestimates the effect of the effective depth (d) in this range (see square $A$, in Fig. 8. 6). Codes are unconservative for reinforced beams with $d>900 \mathrm{~mm}$ (see square $B$, in Fig. 8. 6). Prestressed beams are always conservative for all Codes (see square $C$, in Fig. 8. 6). Finally it is noted that, for one of the prestressed beams, the MC2010 gives higher SM, it appears that the MC2010 underestimates the effect of prestressing, as discussed below (see square D, in Fig. 8. 6).

\subsubsection{Influence of the concrete compressive strength, $\boldsymbol{f}_{\boldsymbol{c}}$}

Trends on SM due to concrete compressive strength are not observed in beams without shear reinforcement.

\subsubsection{Influence of the amount of longitudinal reinforcement, $\rho_{I}$}

In prestressed beams without any shear reinforcement, SM increase when increase $\rho_{l}$ in the range $\rho_{l} \leq 2 \%$. When $\rho_{l} \gg 2 \%, \mathrm{SM}$ according to MC2010 in prestressed beams increases quickly (Fig. 8. 7).

\subsubsection{Influence of the prestressing stress, $\sigma_{c}$}

Prestressed beams are always safe according to all Codes (Fig. 8. 8). It can be observed that shear experimental stress and SM of all Codes increase linearly with $\sigma_{c}$ (Fig. 8. 9). 


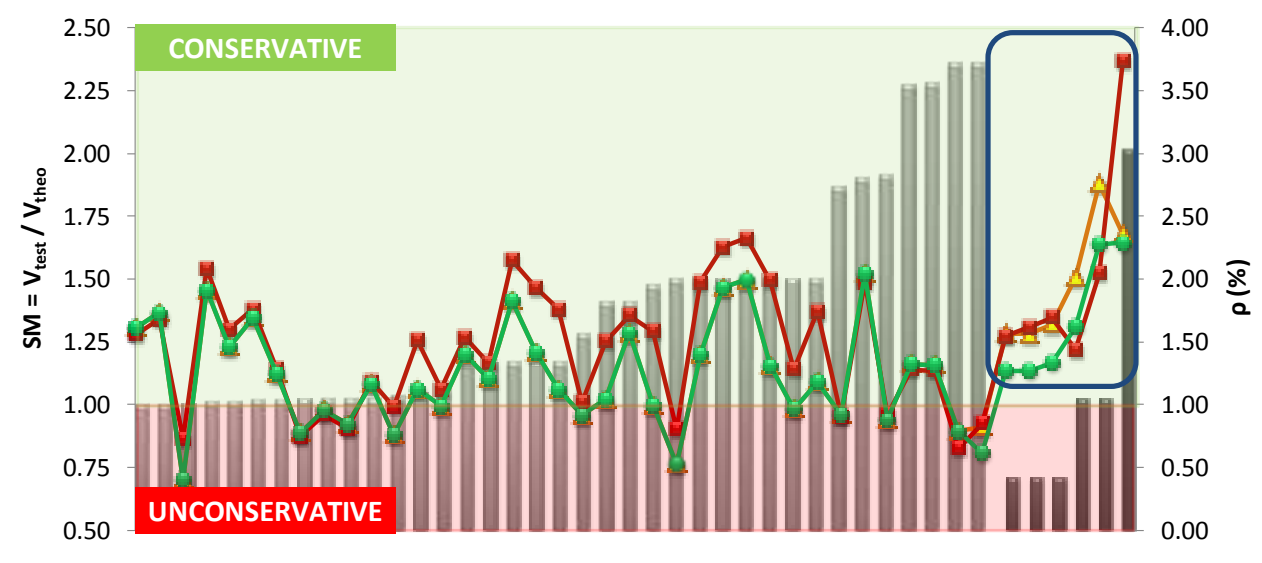

$\square$ rho (Reinforced beams) $\equiv$ rho (Prestressed beams) - SM (EHE-08) $=$ SM (MC2010) - SM (RILEM)

Fig. 8. 7 Beams without shear reinforcement. SM represented versus $\rho$ (\%)

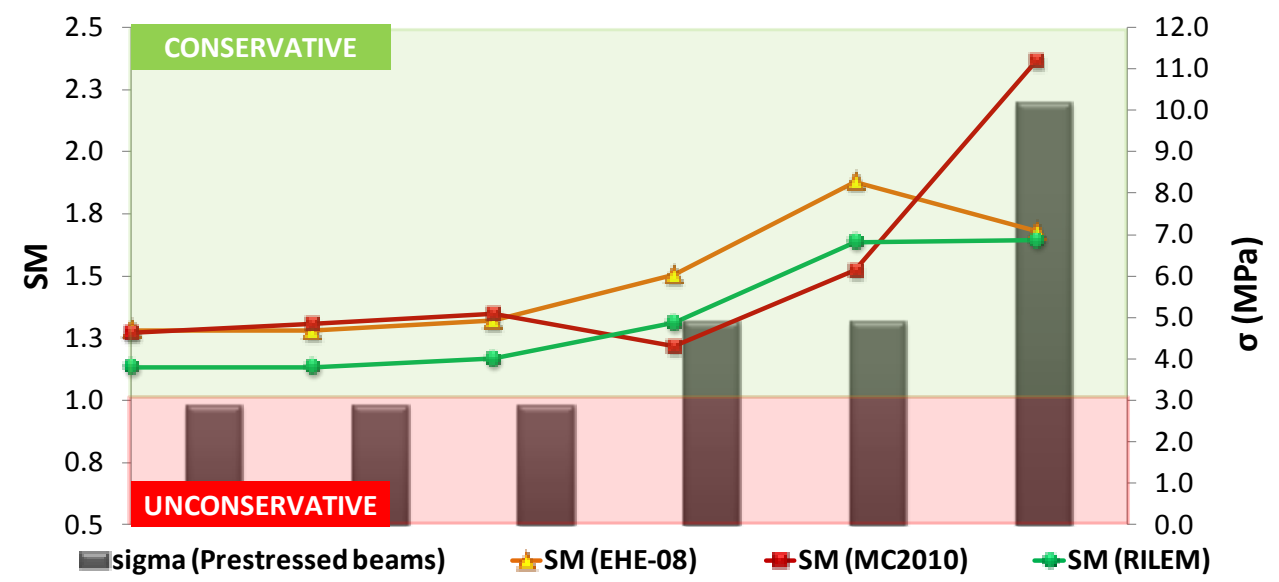

Fig. 8. $8 \mathrm{SMs}$ represented versus $\sigma_{c}(\mathrm{MPa})$ for beams without shear reinforcement

\subsubsection{General behavior of Codes for beams without shear reinforcement}

By determining the main statistics corresponding to the reinforced beams (Table 8. 4), it is observed that all Codes (EHE08, MC2010 and RILEM) have coefficients of variation (CoV) in the same order. The $5^{\text {th }}$ percentile values for all Codes are not very close to the unit, this fact makes not possible to ensure the designation of safe predictions. Analyzing

Table 8. 5, it is clear that all Codes are conservative for prestressed beams, EHE08 and RILEM present similar CoV, being the RILEM more adjusted for this subset. MC2010 have a 
great $\mathrm{CoV}$, but it is due to only one point with a very high SM which corresponds to a stress $\sigma_{c}$ with a value around $10 \mathrm{MPa}$ since, as stated, it appears that the MC2010 underestimates the effect of prestressed giving high values of SM when $\sigma_{c} \geq 10 \mathrm{MPa}$.
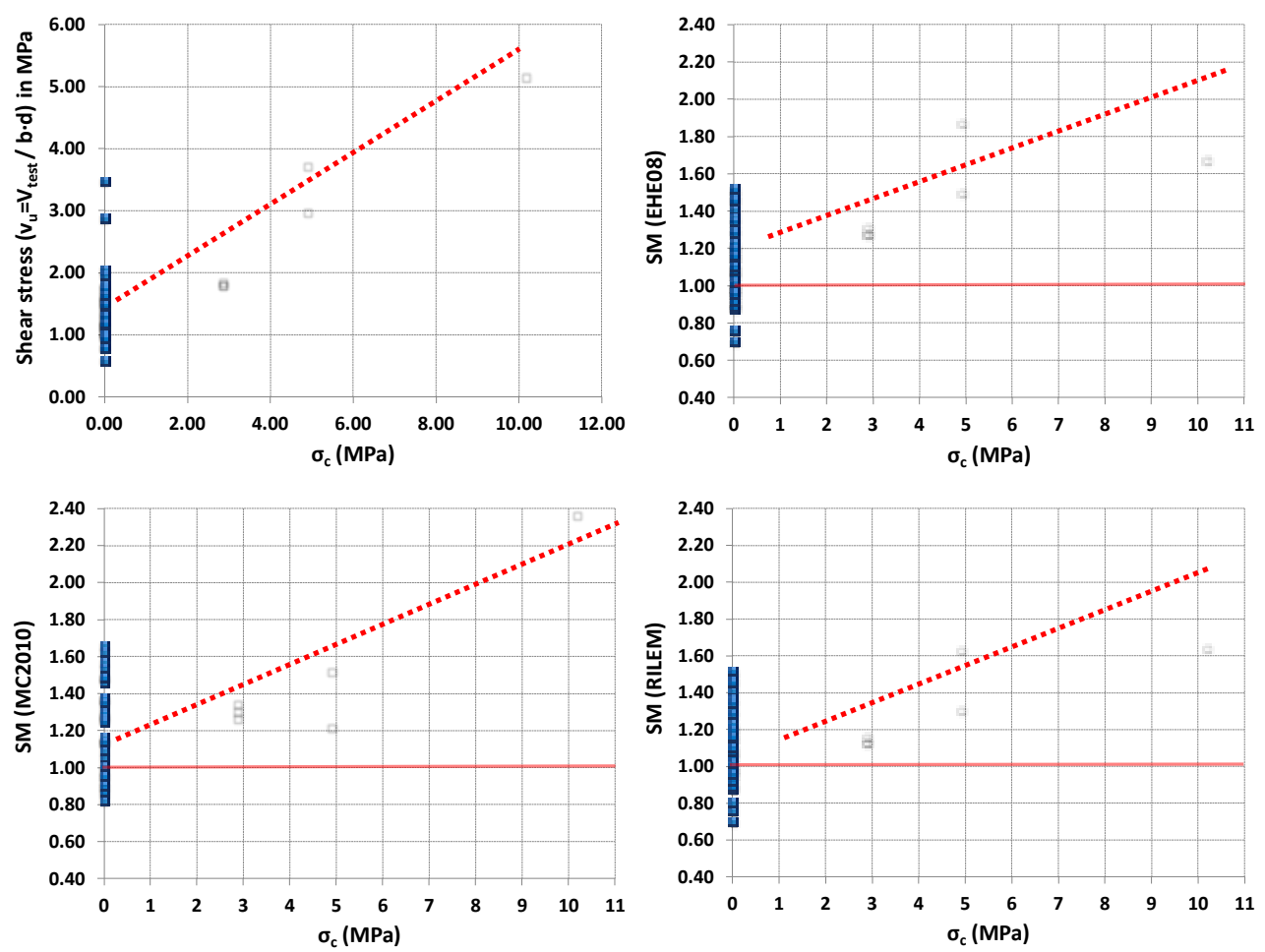

\section{- Reinforced beams a Prestressed beams}

Fig. 8. 9 Beams without shear reinforcement (neither fibers nor stirrups). Influence of $\sigma_{c}$

Table 8. 4 Summary of statistics of reinforced beams without shear reinforcement

\begin{tabular}{|lccc|}
\hline & \multicolumn{3}{c|}{ Reinforced beams (Plain concrete) } \\
\hline & EHE-08 & MC2010 & RILEM \\
\hline Minimum & 0.70 & 0.82 & 0.70 \\
\hline Maximum & 1.52 & 1.66 & 1.52 \\
\hline Average & 1.12 & 1.21 & 1.11 \\
\hline Standard deviation & 0.21 & 0.24 & 0.21 \\
\hline CoV (\%) & $\mathbf{1 8 . 3 8}$ & $\mathbf{1 9 . 4 5}$ & $\mathbf{1 8 . 7 4}$ \\
\hline $5^{\text {th }}$ percentile (\%) & $\mathbf{0 . 8 6}$ & $\mathbf{0 . 8 7}$ & $\mathbf{0 . 8 0}$ \\
\hline $95^{\text {th }}$ percentile (\%) & 1.47 & 1.59 & 1.47 \\
\hline
\end{tabular}


Table 8. 5 Summary of statistics of prestressed beams without shear reinforcement

\begin{tabular}{|lccc|}
\hline & \multicolumn{3}{c|}{ Prestressed beams (Plain concrete) } \\
\hline & EHE-08 & MC2010 & RILEM \\
\hline Minimum & 1.28 & 1.22 & 1.13 \\
\hline Maximum & 1.88 & 2.37 & 1.65 \\
\hline Average & 1.49 & 1.51 & 1.34 \\
\hline Standard deviation & 0.22 & 0.40 & 0.22 \\
\hline CoV (\%) & $\mathbf{1 5 . 0 7}$ & $\mathbf{2 6 . 3 8}$ & $\mathbf{1 6 . 6 3}$ \\
\hline $5^{\text {th }}$ percentile (\%) & $\mathbf{1 . 2 8}$ & $\mathbf{1 . 2 3}$ & $\mathbf{1 . 1 3}$ \\
\hline $9^{\text {th }}$ percentile (\%) & 1.83 & 2.16 & 1.64 \\
\hline
\end{tabular}

\subsection{Case 2: Beams with stirrups (no fibers)}

\subsubsection{Parameters influence on shear for beams with only stirrups}

Table 8. 6 summarizes the ranges of the different parameters used in this case: beams only reinforced transversally with stirrups, without fibers. In this subsection 9.4, only reinforced beams are analyzed since, in case 2 (beams with stirrups), there is only one prestressed beam and one element is not representative for the analysis.

Table 8. 6 Range of parameters in the shear database of reinforced beams with only stirrups $(\mathrm{N}=\mathbf{2 2}$ elements)

\begin{tabular}{|lcccc|}
\hline Parameter & Minimum & Maximum & Average & CoV (\%) \\
\hline$d(\mathrm{~mm})$ & 220 & 910 & 392.72 & 51.89 \\
\hline $\mathrm{a} / \mathrm{d}$ & 2.50 & 3.52 & 2.99 & 12.85 \\
\hline $\mathrm{f}_{\mathrm{cm}}(\mathrm{MPa})$ & 25.90 & 85.57 & 44.57 & 33.12 \\
\hline $\mathrm{f}_{\mathrm{R} 3}(\mathrm{MPa})$ & -- & -- & -- & -- \\
\hline Amount of fibers $\left(\mathrm{kg} / \mathrm{m}^{3}\right)$ & -- & -- & -- & -- \\
\hline$\rho(\%)$ & 0.99 & 3.84 & 2.46 & 44.97 \\
\hline$\sigma_{\mathrm{c}}(\mathrm{MPa})$ & -- & -- & -- & -- \\
\hline $\mathrm{A}_{\mathrm{s} \alpha} / \mathrm{s}\left(\mathrm{cm}^{2} / \mathrm{m}\right)$ & 1.40 & 4.90 & 2.51 & 42.98 \\
\hline
\end{tabular}

With respect to the a/d ratio, safety margins (SM) do not show any trend over the range studied $(2.5 \leq a / d \leq 3.5)$. In the range $(400<d<900 \mathrm{~mm})$ it is observed that SM increases with increasing values of the effective depth (d). For beams with $f_{c}>70 \mathrm{MPa}, \mathrm{SM}$ are unconservative; however, since there are two reinforced beams with $f_{c}>70 \mathrm{MPa}$, these values are not sufficient to ensure this tendency. Referring to the amount of longitudinal reinforcement $\left(\rho_{l}\right)$ and its influence on SM, no trends are detected; it is only observed an increasing trend in shear stresses with the increase of $\rho_{l}$. 
Also in this case, the only prestressed beam reinforced with stirrups is safe according all the Codes. No clear trends are obtained on the influence of the transverse reinforcement area $\left(A_{s \alpha} / s\right)$ on the shear stress or SM.

\subsubsection{General behavior of Codes for beams with only stirrups}

As shows Table 8. 7, EHE-08 presents the largest dispersion and also the lower $5^{\text {th }}$ percentile. MC2010 is the Code with less CoV. Anyway, all Codes present low values of $5^{\text {th }}$ percentile, and this could be indicate that Codes does not give very safe values for this particular subset, consisting in a sample of beams reinforced only with stirrups.

Table 8. 7 Summary of statistics of beams reinforced only with stirrups

\begin{tabular}{|lccc|}
\hline & \multicolumn{2}{c|}{ Reinforced beams (Beams with stirrups) } \\
\hline & EHE-08 & MC2010 & RILEM \\
\hline Minimum & 0.69 & 0.73 & 0.72 \\
\hline Maximum & 1.71 & 1.52 & 1.70 \\
\hline Average & 1.05 & 1.06 & 1.12 \\
\hline Standard deviation & 0.25 & 0.20 & 0.25 \\
\hline CoV (\%) & $\mathbf{2 4 . 1 6}$ & $\mathbf{1 8 . 4 0}$ & $\mathbf{2 2 . 4 1}$ \\
\hline $5^{\text {th }}$ percentile (\%) & $\mathbf{0 . 7 1}$ & $\mathbf{0 . 7 6}$ & $\mathbf{0 . 7 9}$ \\
\hline $95^{\text {th }}$ percentile (\%) & 1.41 & 1.38 & 1.47 \\
\hline
\end{tabular}

\subsection{Case 3: Beams with fibers (no stirrups)}

Table 8.8 and Table 8.9 summarize the ranges of the different parameters used in this case (beams only reinforced with fibers), differencing between reinforced and prestressed beams, respectively.

Table 8. 8 Range of parameters in the shear database of beams reinforced only with fibers $(\mathrm{N}=102)$

\begin{tabular}{|lcccc|}
\hline Parameter & Minimum & Maximum & Average & CoV (\%) \\
\hline$d(m m)$ & 102 & 1440 & 360.80 & 59.59 \\
\hline$a / d$ & 2.50 & 4.69 & 3.24 & 18.60 \\
\hline$f_{c m}(\mathrm{MPa})$ & 17.00 & 96.34 & 38.86 & 41.32 \\
\hline$f_{R 3}(\mathrm{MPa})$ & 1.22 & 10.60 & 3.65 & 49.24 \\
\hline Amount of fibers $\left(\mathrm{kg} / \mathrm{m}^{3}\right)$ & 15 & 240 & 63.31 & 66.33 \\
\hline$\rho(\%)$ & 0.99 & 3.72 & 2.23 & 39.80 \\
\hline$\sigma_{\mathrm{c}}(\mathrm{MPa})$ & -- & -- & -- & -- \\
\hline $\mathrm{A}_{\mathrm{s} a} / \mathrm{s}\left(\mathrm{cm}^{2} / \mathrm{m}\right)$ & -- & -- & -- & - \\
\hline
\end{tabular}


Table 8. 9 Range of parameters in shear database of prestressed beams with only fibers $(\mathrm{N}=\mathbf{2 6}$ )

\begin{tabular}{|lcccc|}
\hline Parameter & Minimum & Maximum & Average & CoV (\%) \\
\hline$d(\mathrm{~mm})$ & 226.47 & 738.89 & 440.93 & 48.79 \\
\hline $\mathrm{a} / \mathrm{d}$ & 2.84 & 4.40 & 3.40 & 11.15 \\
\hline $\mathrm{f}_{\mathrm{cm}}(\mathrm{MPa})$ & 35.90 & 77.00 & 55.38 & 22.78 \\
\hline $\mathrm{f}_{\mathrm{R} 3}(\mathrm{MPa})$ & 2.83 & 8.61 & 4.95 & 39.19 \\
\hline Amount of fibers $\left(\mathrm{kg} / \mathrm{m}^{3}\right)$ & 50 & 70 & 55 & 12.61 \\
\hline$\rho(\%)$ & 0.41 & 5.82 & 2.23 & 92.52 \\
\hline$\sigma_{\mathrm{c}}(\mathrm{MPa})$ & 2.87 & 12.00 & 7.16 & 50.05 \\
\hline $\mathrm{A}_{\mathrm{s} \alpha} / \mathrm{s}\left(\mathrm{cm}^{2} / \mathrm{m}\right)$ & -- & -- & -- & -- \\
\hline
\end{tabular}

\subsubsection{Influence of the $\mathrm{a} / \mathrm{d}$ ratio and the effective depth, $d$}

No trends are observed in the range studied for beams reinforced only with fibers.

\subsubsection{Influence of the concrete compressive strength, $f_{c}$}

Reinforced beams presented low SM for high compressive strength levels ( $\left.f_{c}>70 \mathrm{MPa}\right)$, of course, there are other beams with low SM, but the general trend is that with high strength, Codes tend to be less safe.

\subsubsection{Influence of the residual tensile strength (CMOD $=2.5 \mathrm{~mm}), f_{R 3}$}

Reinforced beams with $f_{R 3}>5 \mathrm{MPa}$ present low SM. Shear stresses increases when $f_{R 3}$ also increases for both, reinforced and prestressed beams. It can be observed that the slopes are different between reinforced and prestressed beams, due to the effect of prestressing which also produce higher shear stresses (Fig. 8. 10).

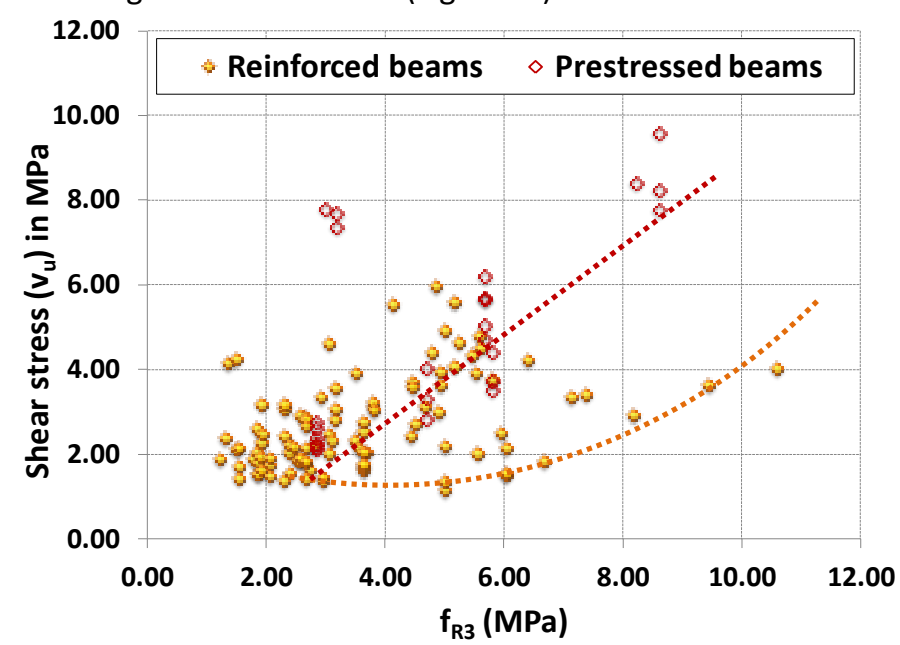

Fig. 8. 10 Experimental shear stress versus $f_{R 3}$ for beams reinforced only with fibers 


\subsubsection{Influence of the amount of longitudinal reinforcement, $\rho_{I}$}

In Fig. 8. 11, experimental shear stresses are represented versus the longitudinal reinforcement percentage. As it can be observed, no trend is detected in reinforced beams while, in prestressed beams, when $\rho_{l}$ increases also the shear stress increases.

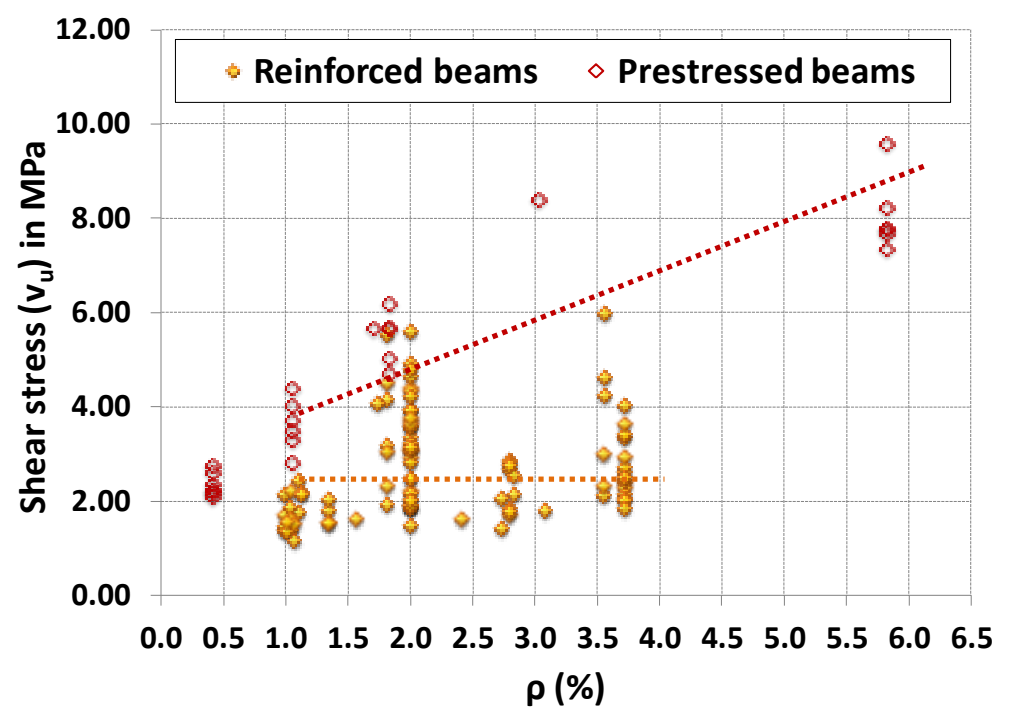

Fig. 8. 11 Experimental shear stress versus $\rho$ (\%) for beams reinforced only with fibers

In Fig. 8. 12, safety margins (SM) are represented versus $\rho_{l}$ according to Codes EHE08 and RILEM; in both Codes, the same trend is observed.

Fig. 8. 13 shows the SM determined according to the MC2010, versus $\rho_{l}$. For high $\rho_{l}$ (values that exceed the maximum limitation of $\rho_{l}\left(\rho_{l} \leq 2 \%\right)$ excessively high values of SM are obtained. In Fig. 8. 13, it can be also observed that the trends of prestressed beams are different between MC2010 and EHE \& RILEM. In the case of EHE \& RILEM, SM increases approximately linearly with $\rho_{l}$ but, on the other hand, SM of MC2010 initially increases more quickly than EHE \& RILEM, but for values higher than the limit value $\left(\rho_{l}\right.$ $=2 \%), \mathrm{SM}$ are very high and, therefore, very conservative.

In Fig. 8. 14, SM of all studied Codes (EHE, MC2010 and RILEM) are represented versus $\rho_{\text {I }}$ for all beams of this particular subset (only with fiber reinforcement).

Some reinforced beams (see square A in Fig. 8. 14) show high SMs; the reason is that these beams have a real value of $\rho_{l}$ greater than $2 \%$ (the exact value is unknown), but the data come from elements of the database of other authors. Therefore, the calculations are 
using a value lower than the actual $\rho_{l}$, resulting in a lower predicted value. In reinforced beams, when $\rho_{l} \geq 3 \%$, SMs of all Codes reduce (see square B in Fig. 8. 14), when $\rho_{l}$ increases. In prestressed beams, when $\rho_{l}$ increases, SM also increases; however, when $\rho_{l} \geq 5 \%$, it seems that MC2010 underestimates the effect of prestressed (see square C in Fig.8.14).
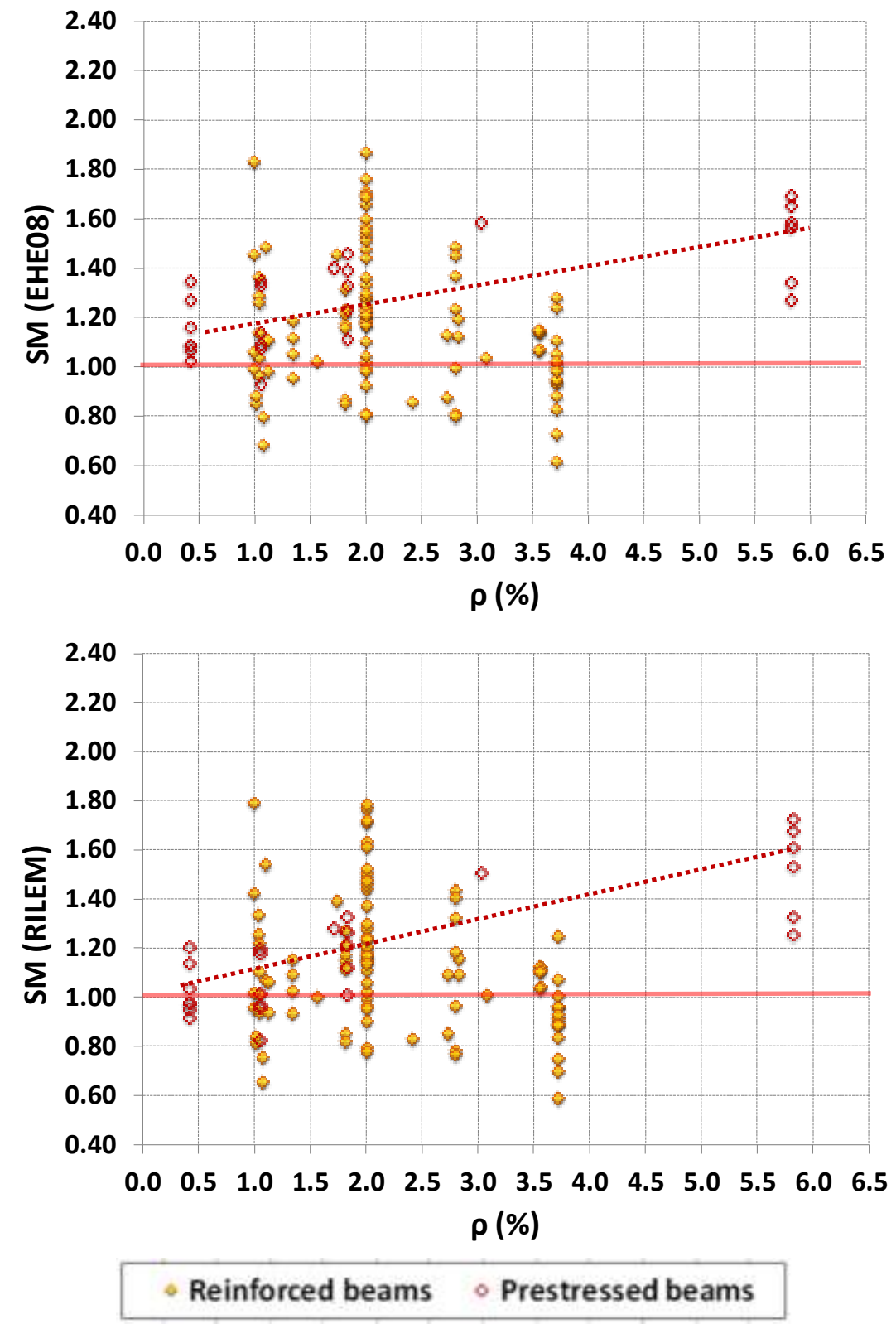

Fig. 8. 12 Safety margin $\left(V_{\text {test }} / V_{\text {theo }}\right)$ versus $\rho(\%)$ according to EHE08 and RILEM 


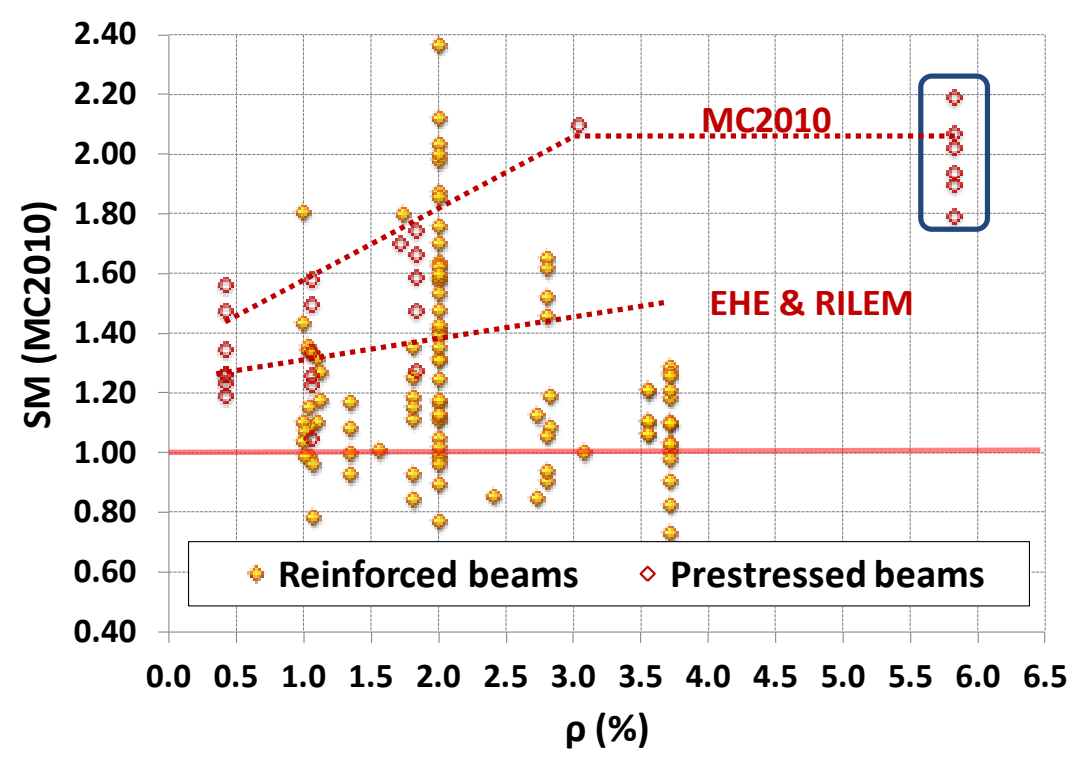

Fig. 8. 13 Safety margin $\left(\mathrm{V}_{\text {test }} / \mathrm{V}_{\mathrm{MC2010}}\right)$ versus $\rho(\%)$

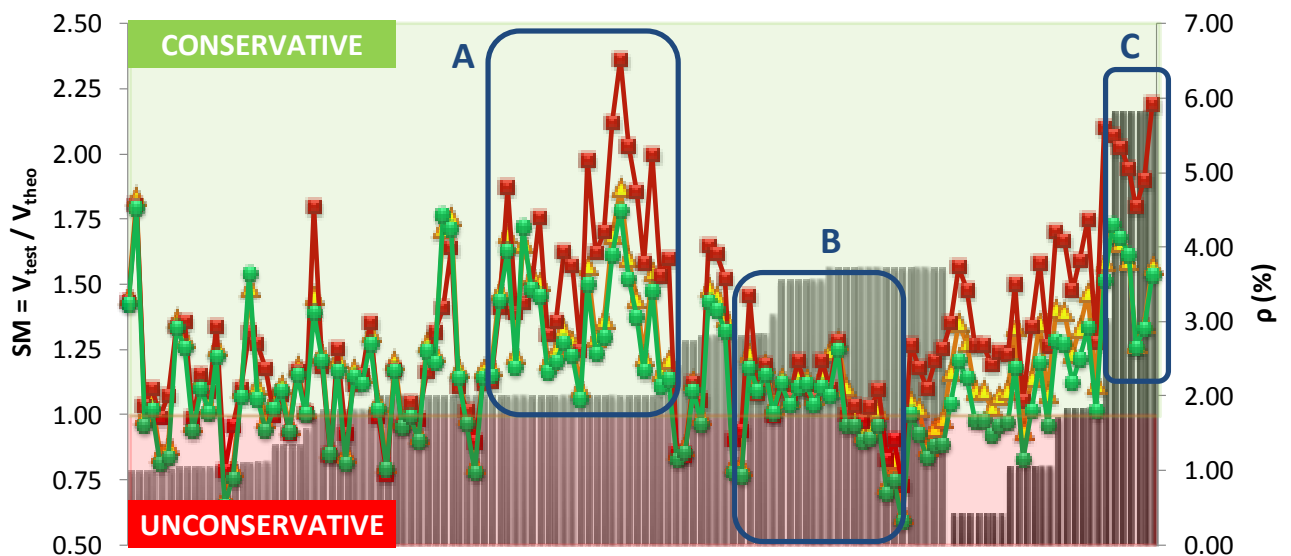

$\square$ rho (Reinforced beams) $\square$ rho (Prestressed beams) - SM (EHE-08)-

Fig. 8. 14 Beams transversally reinforced with fibers. SM represented versus $\rho$ (\%)

\subsubsection{Influence of the stress due to prestressing actions, $\sigma_{c}$}

In Fig. 8. 16 beams with fibers are ordered by increasing $\sigma_{c}$, SMs are represented with respect to $\sigma_{c}$ (Fig. 8. 16) and, to $f_{c}$ (Fig. 8. 16). In general, observing both graphs, it is observed that MC2010 is always the most conservative. RILEM \& EHE are most balanced for all levels of $f_{c}$ and $\sigma_{c}$ whereas MC2010 is more conservative for high levels of $f_{c}$ and $\sigma_{c}$. 
The first prestressed elements correspond to hollow core slabs (see square A in Fig. 8. 16). One beam (see dashed line square in Fig. 8. 16) has a clearly lower value of SM than its analogous beam (see square $B$ in Fig. 8. 16), this is because the beam has a flange width $\left(b_{f}\right.$ $=260 \mathrm{~mm}$ ) much lower than its analogous $\left(b_{\mathrm{f}}=400-600 \mathrm{~mm}\right)$. Therefore, RILEM \& EHE Codes, which take into account the contribution of the flange width in beams reinforced with fibers are overestimating the contribution of a flange which is very small. In beams with flanges of considerable size $\left(b_{f}>400 \mathrm{~mm}\right), \mathrm{MC} 2010$ gives higher SM than the other two codes (RILEM \& EHE), which means that determines a lower shear theoretical value since it neglects the contribution of flanges to shear (see Chapter 4).

\subsubsection{Influence of the amount of fibers, $\mathrm{kg} / \mathrm{m}^{3}$}

Reinforced and prestressed beams with fibers are always safe $(S M>1)$ for all Codes, according to this database, when the amount of fibers is greater than $125 \mathrm{~kg} / \mathrm{m}^{3}$ (Fig. 8. 17).

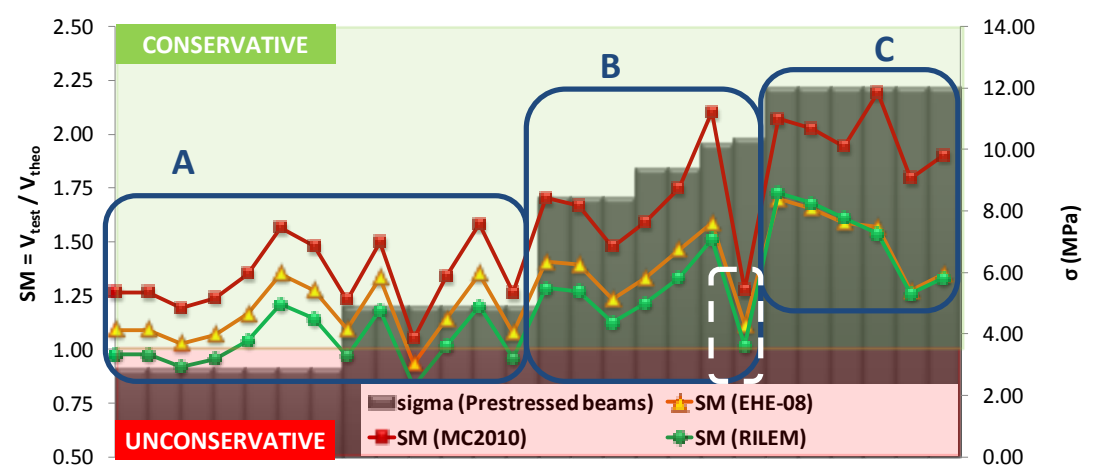

Fig. 8. 15 Beams transversally reinforced with fibers. SM represented versus $\sigma_{c}$ and $f_{c}(\mathrm{MPa})$

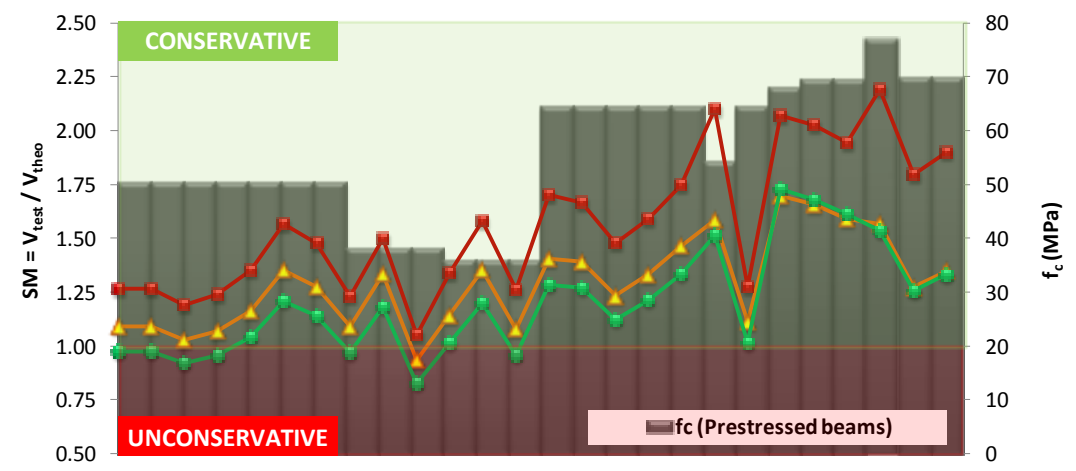

Fig. 8. 16 Beams transversally reinforced with fibers. SM represented versus $\sigma_{c}$ and $f_{c}(\mathrm{MPa})$ 


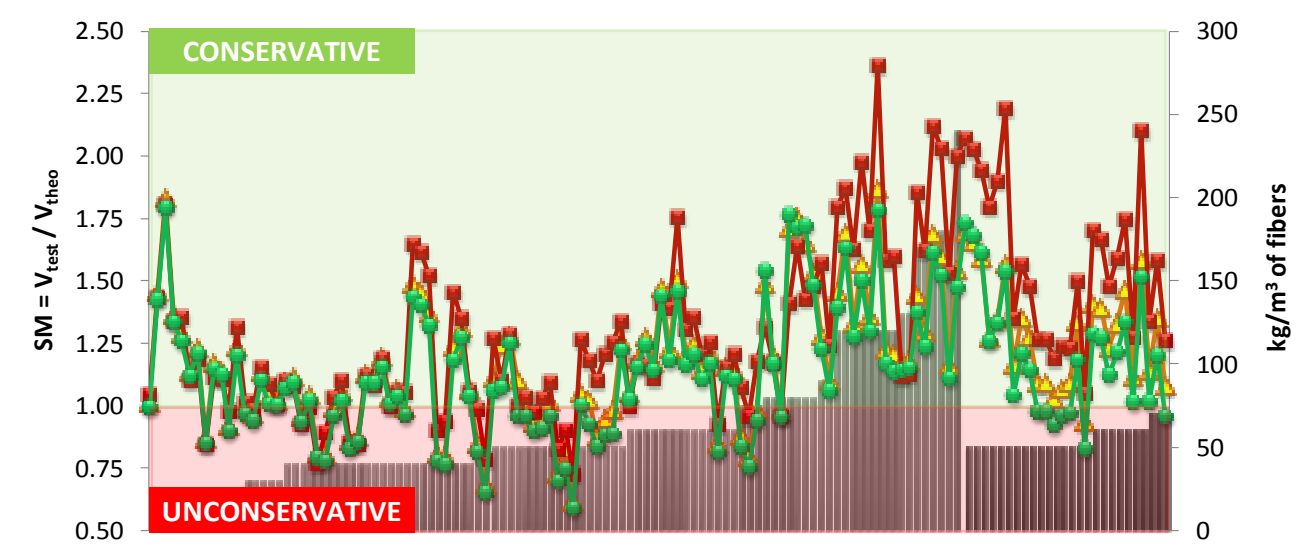

$\square \mathrm{kg} / \mathrm{m} 3$ (Reinforced beams) $\square \mathrm{kg} / \mathrm{m} 3$ (Prestressed beams) $\Rightarrow \mathrm{SM}$ (EHE-08) -SM (MC2010) -SM (RILEN

Fig. 8. 17 Beams transversally reinforced with fibers. SM represented versus $\mathrm{kg} / \mathrm{m}^{3}$ of fibers

\subsubsection{General behavior of Codes for beams with only fibers}

Table 8. 10 and Table 8. 11 show that, for the beams reinforced with fibers, MC2010 presents the greater $\operatorname{CoV}(\%)$ but, it is the safest Code, with the highest value of $5^{\text {th }}$ percentile (in reinforced and prestressed beams). Codes are safer for prestressed beams.

Table 8. 10 Summary of statistics of reinforced beams only with fibers

\begin{tabular}{|lccc|}
\hline & \multicolumn{3}{c|}{ Reinforced beams (Beams with fibers) } \\
\hline & EHE-08 & MC2010 & RILEM \\
\hline Minimum & 0.62 & 0.73 & 0.59 \\
\hline Maximum & 1.87 & 2.36 & 1.79 \\
\hline Average & 1.17 & 1.25 & 1.13 \\
\hline Standard deviation & 0.26 & 0.32 & 0.26 \\
\hline CoV (\%) & $\mathbf{2 2 . 3 2}$ & $\mathbf{2 5 . 8 1}$ & $\mathbf{2 3 . 0 7}$ \\
\hline $5^{\text {th }}$ percentile (\%) & $\mathbf{0 . 8 0}$ & $\mathbf{0 . 8 4}$ & $\mathbf{0 . 7 7}$ \\
\hline $95^{\text {th }}$ percentile (\%) & 1.69 & 1.87 & 1.63 \\
\hline
\end{tabular}

Table 8. 11 Summary of statistics of prestressed beams only with fibers

\begin{tabular}{|lccc|}
\hline & \multicolumn{3}{c|}{ Prestressed beams (Beams with fibers) } \\
\hline & EHE-08 & MC2010 & RILEM \\
\hline Minimum & 0.93 & 1.05 & 0.83 \\
\hline Maximum & 1.70 & 2.19 & 1.73 \\
\hline Average & 1.29 & 1.57 & 1.20 \\
\hline Standard deviation & 0.21 & 0.32 & 0.24 \\
\hline CoV (\%) & $\mathbf{1 5 . 9 2}$ & $\mathbf{2 0 . 2 3}$ & $\mathbf{2 0 . 2 0}$ \\
\hline $5^{\text {th }}$ percentile (\%) & $\mathbf{1 . 0 4}$ & $\mathbf{1 . 2 0}$ & $\mathbf{0 . 9 3}$ \\
\hline $95^{\text {th }}$ percentile (\%) & 1.64 & 2.10 & 1.66 \\
\hline
\end{tabular}




\subsection{Case 4: Beams with fibers and stirrups}

Table 8. 12 summarizes the ranges of the different parameters used in beams transversally reinforced with stirrups and fibers. A table for prestressed beams has no sense in this case, because only two prestressed beams are available in the database.

Table 8. 12 Range of parameters in the shear database of reinforced beams with only fibers ( $N=19)$

\begin{tabular}{|lcccc|}
\hline Parameter & Minimum & Maximum & Average & CoV (\%) \\
\hline$d(m m)$ & 210 & 650 & 293.68 & 34.65 \\
\hline $\mathrm{a} / \mathrm{d}$ & 3.10 & 4.50 & 3.53 & 10.06 \\
\hline $\mathrm{f}_{\mathrm{cm}}(\mathrm{MPa})$ & 38.00 & 50.67 & 45.33 & 9.91 \\
\hline $\mathrm{f}_{\mathrm{R} 3}(\mathrm{MPa})$ & 1.22 & 8.54 & 3.19 & 56.33 \\
\hline Amount of fibers $\left(\mathrm{kg} / \mathrm{m}^{3}\right)$ & 15 & 60 & 39.95 & 42.52 \\
\hline$\rho(\%)$ & 1.56 & 3.56 & 2.99 & 26.41 \\
\hline$\sigma_{\mathrm{c}}(\mathrm{MPa})$ & -- & -- & -- & -- \\
\hline $\mathrm{A}_{\mathrm{sa}} / \mathrm{s}\left(\mathrm{cm}^{2} / \mathrm{m}\right)$ & 1.40 & 3.53 & 2.18 & 34.50 \\
\hline
\end{tabular}

Influences in SM due to the parameters: $a / d, d, f_{c m}$ and $A_{s a} / s$ were not detected.

\subsubsection{Influence of the residual tensile strength, $\boldsymbol{f}_{R 3}$}

Fig. 8. 18 shows the SM of all Codes versus the residual tensile strength $f_{R 3}$, it can be observed that for reinforced beams the most conservative is the EHE while, for prestressed beams the RILEM is the safest, the MC2010 is the most balanced Code, as it maintains the same SM levels for reinforced and prestressed beams.

\subsubsection{Influence of the longitudinal reinforcement percentage, $\rho_{l}$}

In Fig. 8. 19 it can be observed that reinforced beams with $\rho_{l} \leq 2 \%$ and $f_{R 3}<1.5 \mathrm{MPa}$ are all in the side of unsafety $(S M<1)$. Reinforced beams with $\rho_{l}=3.5 \%$ have similar levels of SM for all Codes. The MC2010 is the most balanced in both: reinforced and prestressed.

\subsubsection{Influence of the stress due to prestressing actions, $\sigma_{c}$}

In this subset (beams reinforced with fibers and stirrups) there are only two prestressed beams, so they are not enough to formulate strong conclusions, but it seems that when both reinforcements are present (fibers + stirrups) SM for prestressed beams is higher.

\subsubsection{General behavior of Codes for beams with stirrups and fibers}

EHE08 has a CoV slightly greater than MC2010 and RILEM, but EHE08 also is the safer Code for this subset, presenting the greatest value of the $5^{\text {th }}$ percentile (Table 8.13 ). Table 8.14 summarizes the main conclusions obtained in sections 8.3 to 8.6 . 


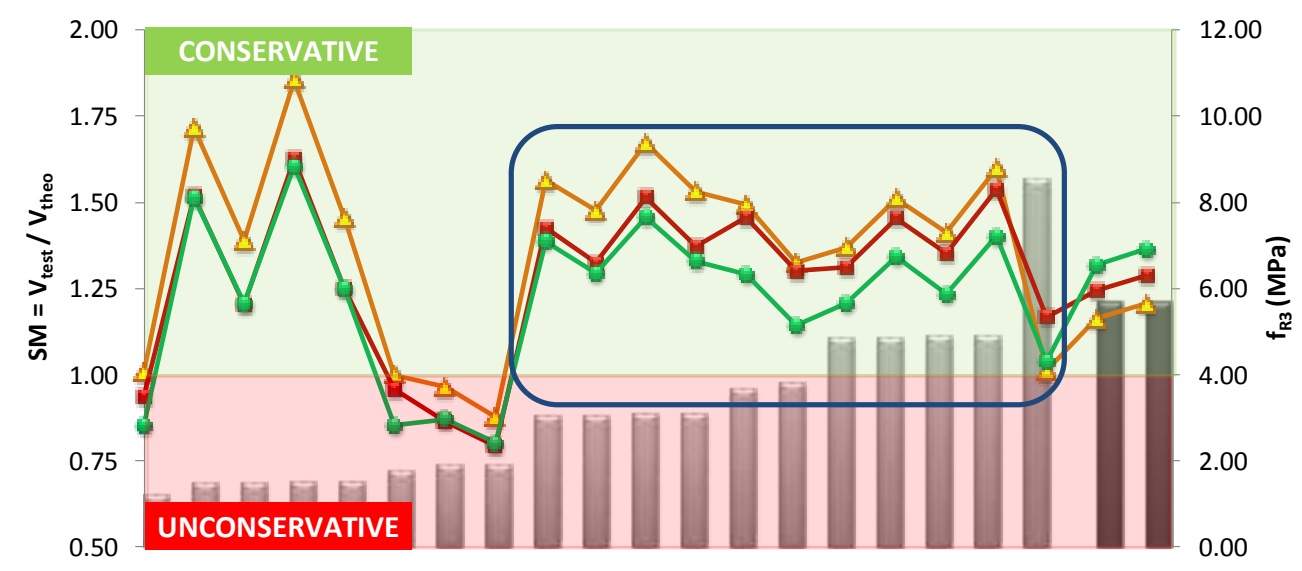

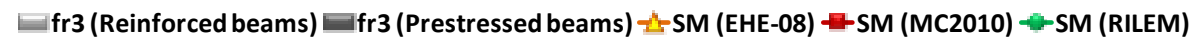

Fig. 8. 18 Beams transversally reinforced with fibers + stirrups. SM represented versus $f_{R 3}(M P a)$

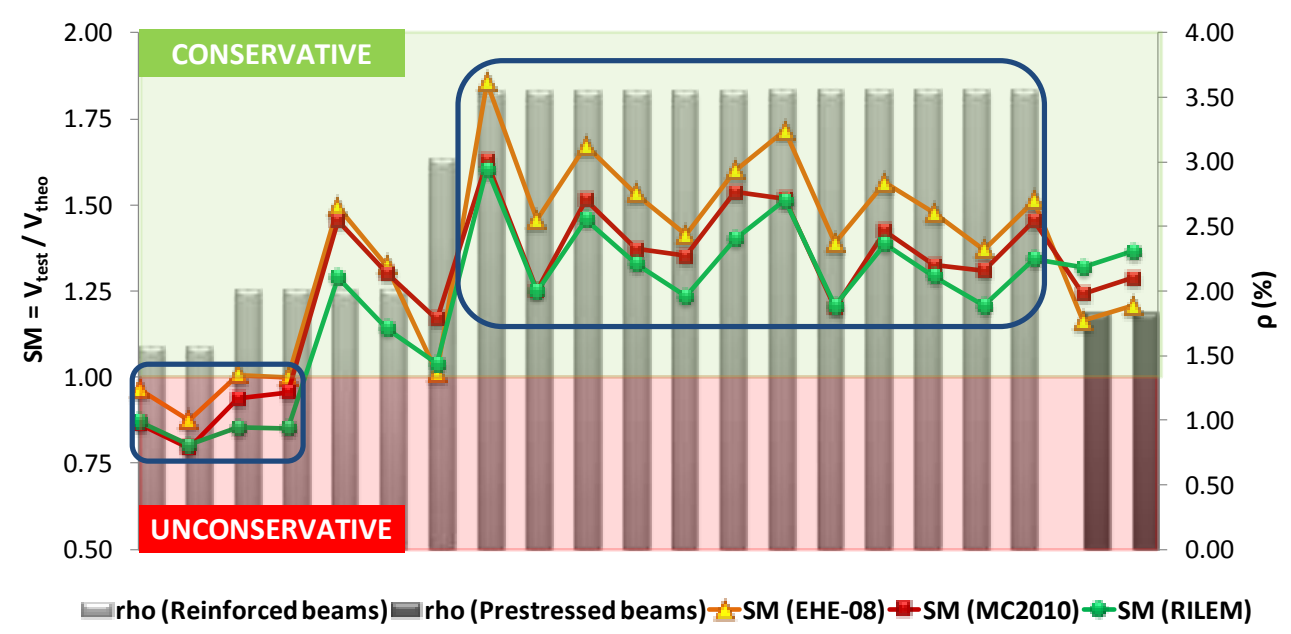

Fig. 8. 19 Beams transversally reinforced with fibers + stirrups. SM represented versus $\rho$ (\%)

Table 8. 13 Summary of statistics of reinforced beams only with fibers

\begin{tabular}{|lccc|}
\hline & \multicolumn{3}{c|}{ Reinforced beams (fibers and stirrups) } \\
\hline & EHE-08 & MC2010 & RILEM \\
\hline Minimum & 0.88 & 0.79 & 0.80 \\
\hline Maximum & 1.85 & 1.63 & 1.60 \\
\hline Average & 1.38 & 1.28 & 1.21 \\
\hline Standard deviation & 0.27 & 0.23 & 0.23 \\
\hline CoV (\%) & $\mathbf{1 9 . 8 2}$ & $\mathbf{1 8 . 2 9}$ & $\mathbf{1 8 . 8 2}$ \\
\hline $5^{\text {th }}$ percentile (\%) & $\mathbf{0 . 9 6}$ & $\mathbf{0 . 8 6}$ & $\mathbf{0 . 8 5}$ \\
\hline $95^{\text {th }}$ percentile (\%) & 1.73 & 1.55 & 1.52 \\
\hline
\end{tabular}




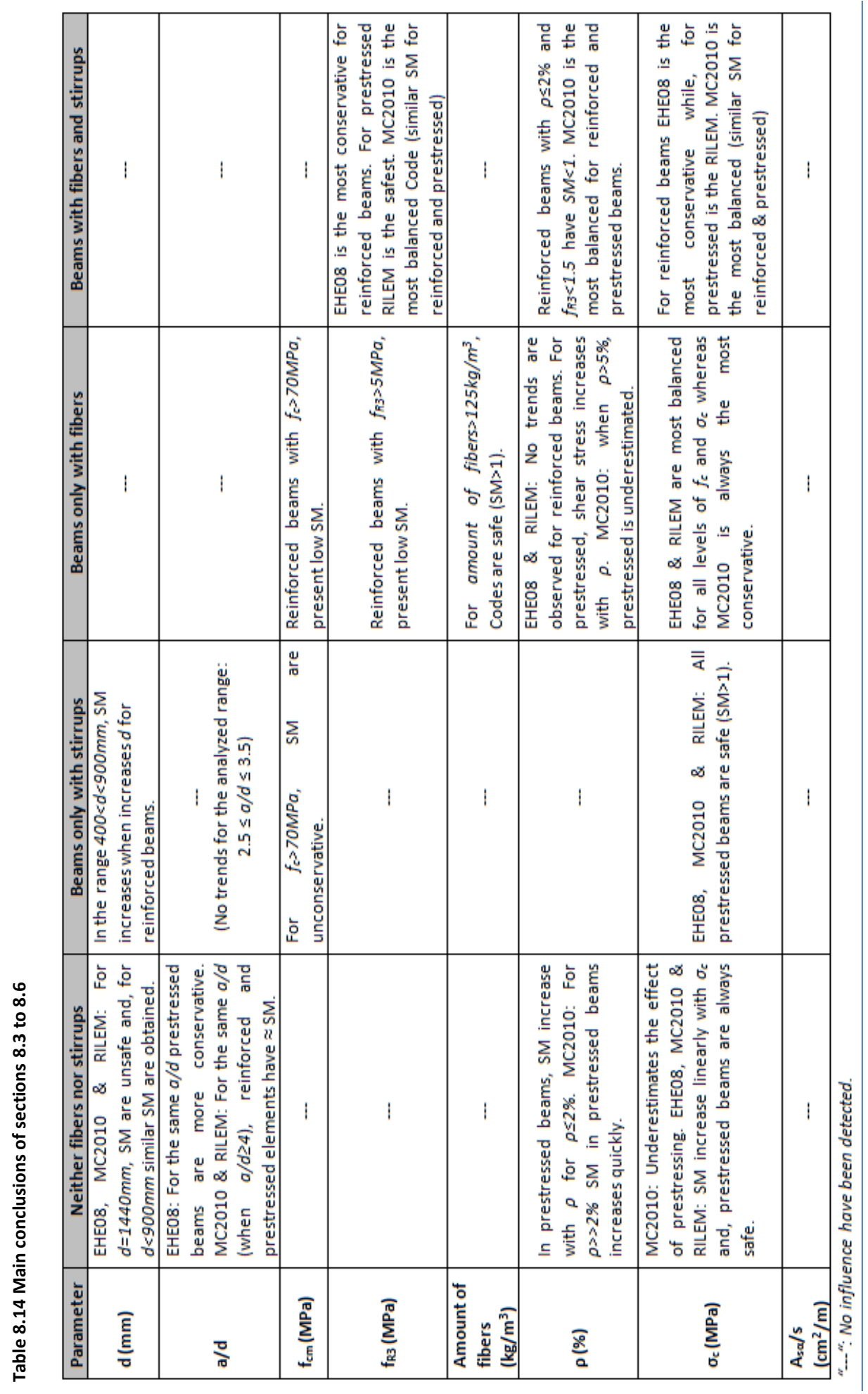




\subsection{Particular cases}

\subsubsection{Introduction}

Throughout this Chapter 8 , the role of the factors influencing shear strength in the safety margin (SM) in three design Codes (EHE, MC2010 and RILEM) have been analyzed in different cases: beams without any shear reinforcement, beams with only stirrups, beams with only steel fibers and finally, beams with stirrups and fibers.

At this point, in which the influence of the different factors on the SM is reported, it is presented the possible influence of the interactions of different factors on the SM. For this purpose, the analysis of variance "ANOVA" will be used.

ANOVA makes the following assumptions:

- Independence of cases. This is an assumption of the model that simplifies the statistical analysis.

- Normality. The distributions of the residuals are normal.

- Equality (or "homogeneity") of variances, called homoscedasticity. The variance of data in groups should be the same.

The one-way ANOVA examines the influence of an independent variable (factor) in the dependent variable, in this case, SM. The two-way analysis of variance is an extension to the one-way analysis since there are two independent variables (hence the name twoway).

Whenever possible, in two-way ANOVAs, interactions of simple factors and their possible influence on the dependent variable (SM in this case) will be studied.

The independent variables in a two-way ANOVA are called factors. The idea is that there are some variables, factors, which affect the dependent variable. Each factor will have two or more levels within it, and the degrees of freedom for each factor is one less than the number of levels.

ANOVA procedure will be described very briefly; herein further details of the fundamentals of ANOVA can be found in [13].

Below, the results obtained from several ANOVAs are summarized. The analyses were done for some experimental programs from the shear database analyzed in the previous 
sections. In this way, the ANOVA was done each time for series with the same geometry and cross-section and other constant variables, to have an ANOVA as robust as possible.

\subsubsection{Brite Series 1}

In this subsection, the beams from Series 1 of the Subtask 4.2- Trial Beams in Shear of Brite-Euram project [5] are going to be analyzed. This Serie 1 was carried out in the Technical University of Braunschweig (UBS) by Rosenbusch J. and Teutsch M. In Table 8.14 the constant variables within the same Series are indicated. In Table 8.15, the input data for the ANOVA analysis are presented, differencing the factors (independent variables) of the dependent variable (safety margin, SM) for all these subsections. In this case the three factors are: $f_{R 3}, A_{s w} / s$ and Code, having the factor $f_{R 3}$ four levels and, the other two factors, three levels. So, the number of complete cases is:

№ complete cases $=(\text { № of levels })^{\text {№ of factors }}=3^{2} \cdot 4^{1}=36$ complete cases

Table 8.14 Constant variables between the beams within the same Series (Brite Series 1)

\begin{tabular}{|l|}
\hline Constant variables: \\
\hline Cross-section $200 \times 300 \mathrm{~mm}$ : Rectangular reinforced (no prestressed) beams \\
\hline$\rho_{l}=3.56 \%$ \\
\hline $\mathrm{a} / \mathrm{d}=3.5$ \\
\hline 3 point test \\
\hline
\end{tabular}

Table 8.15 Factors and dependent variable analyzed in the ANOVA analysis of Brite Series 1

\begin{tabular}{|l|}
\hline Factors (independent variables): \\
\hline$f_{r 3}(\mathrm{MPa}): 0,1.49,3.05,4.85$. \\
\hline Transverse reinforcement, $A_{s w} / \mathrm{s}\left(\mathrm{cm}^{2} / \mathrm{m}\right): 0,1.4,2.8$. \\
\hline Codes: EHE08, MC2010, RILEM. \\
\hline Dependent variable: \\
\hline Shear safety margin (SM). \\
\hline
\end{tabular}

The ANOVA Table 8.16 decomposes the variability of safety margin on shear (SM) in contributions due to several factors. Since the sum of squares Type III has been chosen, the contribution of each factor is measured by removing the effects of other factors. Pvalues, test the statistical significance of each factor. Since six p-values are less than 0.05 , these factors have a statistically significant shear on SM on a $95.0 \%$ confidence level. 
Table 8.16 Analysis of Variance (ANOVA) for SM on shear - Type III Sums of Squares (Series 1)

\begin{tabular}{|c|c|c|c|c|c|}
\hline Source of variation & Sum of Squares & d.f & Mean square & F-ratio & p-value \\
\hline \multicolumn{6}{|l|}{ MAIN EFFECTS } \\
\hline $\mathrm{A}: f_{R 3}(\mathrm{MPa})$ & 0.0750528 & 3 & 0.0250176 & 22.99 & 0.0000 \\
\hline $\mathrm{B}: A_{s w} / \mathrm{s}\left(\mathrm{cm}^{2} / \mathrm{m}\right)$ & 0.631839 & 2 & 0.315919 & 290.25 & 0.0000 \\
\hline C: Code & 0.0546722 & 2 & 0.0273361 & 25.12 & 0.0001 \\
\hline \multicolumn{6}{|l|}{ INTERACTIONS } \\
\hline $\mathrm{AB}$ & 0.132739 & 6 & 0.0221231 & 20.33 & 0.0000 \\
\hline$A C$ & 0.0419722 & 6 & 0.00699537 & 6.43 & 0.0032 \\
\hline$B C$ & 0.0184944 & 4 & 0.00462361 & 4.25 & 0.0227 \\
\hline RESIDUAL & 0.0130611 & 12 & 0.00108843 & & \\
\hline TOTAL (CORRECTED) & 0.967831 & 35 & & & \\
\hline
\end{tabular}

In this case, Series 1 , have been possible to study double interactions, because there are enough residual degrees of freedom (d.f.), this is:
d.f. $($ effect $A)=3$; d.f. $($ effect $B)=2 ;$ d.f. $($ effect $C)=2$
d.f. $($ interaction $A B)=6$; d.f. (interaction $A C)=6$; d.f. $($ interaction $B C)=4$
d.f. $($ residual $)=$ d.f $($ total $)-$ d.f. $($ simple effects $)-$ d.f. $($ interactions $)=35-3-2-2-6-6-4=12$

As $d . f$. (residual) $=12$ then double interactions can be studied.

So in this case there are enough degrees of freedom to study interactions. Higher order interactions could be considered but, in general, not occur almost in practice, and is also difficult to interpret [14]. Henceforth, only double interactions will be studied. There is a double interaction between two factors, whether the effect of one of them is different according to the variant of the other factor considered. By means of ANOVA table, one knows what simple effects and what interactions are statistically significant, being those with $p$-value $<0.005$. But a significant value of $p$-value only would indicate that at least one of the levels of this factor differs from the others, but does not specify which ones differ. A simple way to clarify this issue is through the establishment of LSD (abbreviation of "Least Significative Difference") intervals for the mean for each level of each effect. The average difference between the two levels will be significant if the respective LSD intervals (Fig. 8. 20) do not overlap. As it can be observed, there are not significant differences between the several $f_{R 3}$ values. There are not differences in SM between MC2010 and RILEM but only significant differences between the EHE08 and the other two Codes. In this test Series, Codes are safer; in fact, as one increases the amount of transverse reinforcement, SM increases linearly. 

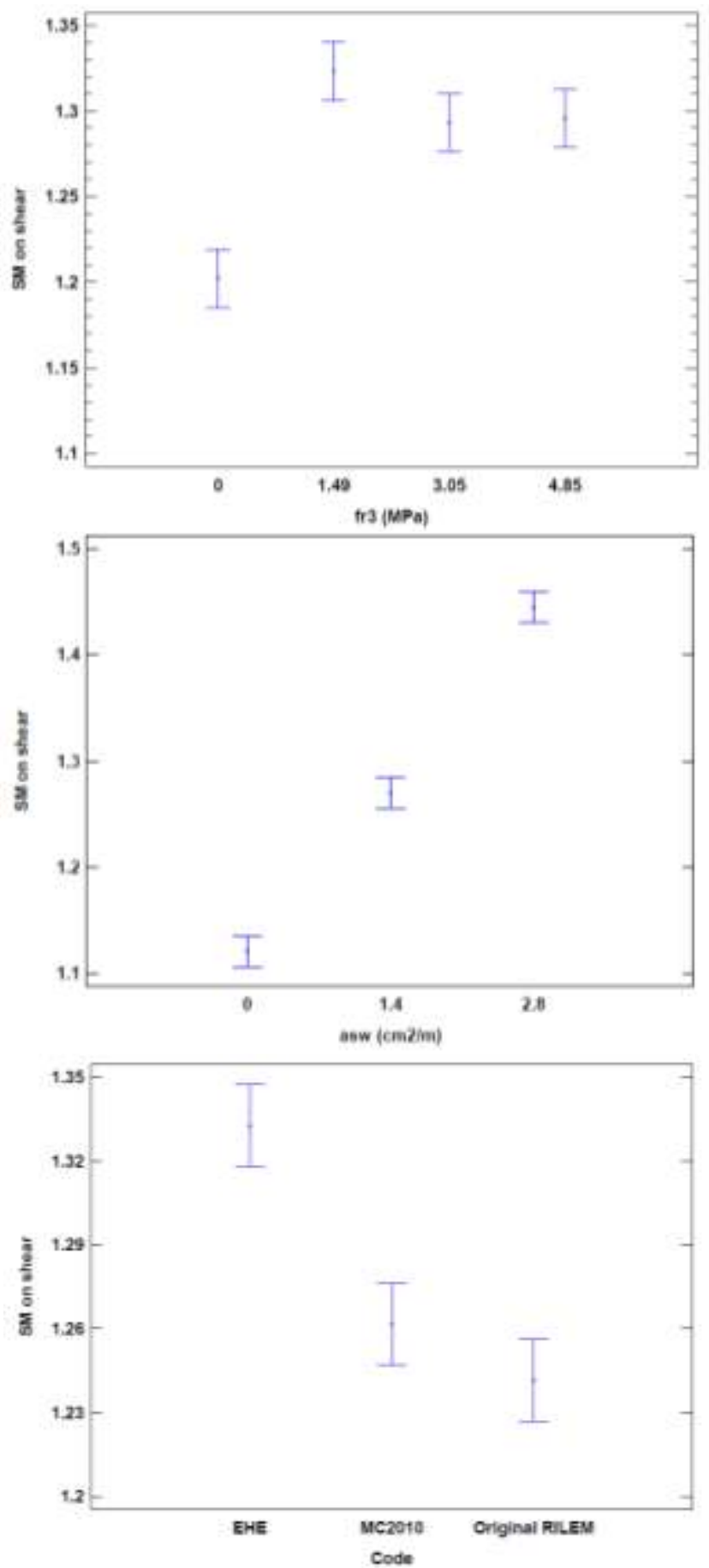

Fig. 8. 20 Means and 95.0 Percent LSD Intervals (Brite Series 1) 
LSD intervals are used when the effects are qualitative values, in this case, two of the three effects are quantitative; therefore, for a comprehensive statistical analysis, it would be suitable to decompose the quantitative effect in their linear and quadratic components but, the analysis just done is considered sufficient to study these particular cases.

As it can be observed in the ANOVA table, in this Series all interactions were statistically significant.

In Fig. 8. 21, Fig. 8. 22 and Fig. 8. 23 are shown the surface charts for this case; these graphs show how is affected the dependent variable (SM) for each combination among the various levels of two simple effects.
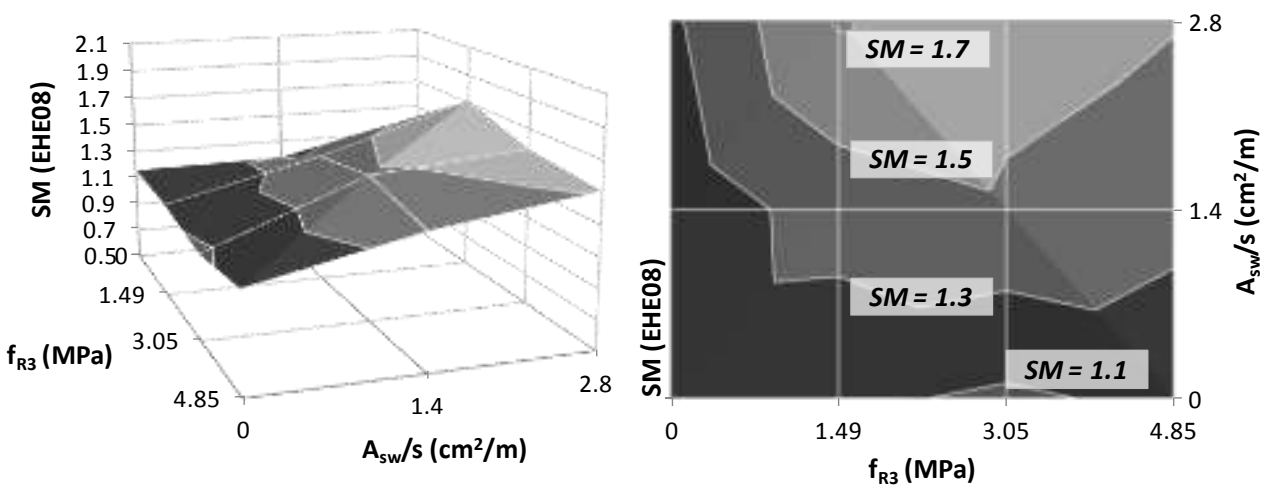

Fig. 8. 21 Influence of the interaction between $f_{R 3}$ and $A_{S w} / s$ in the SM according to EHE08
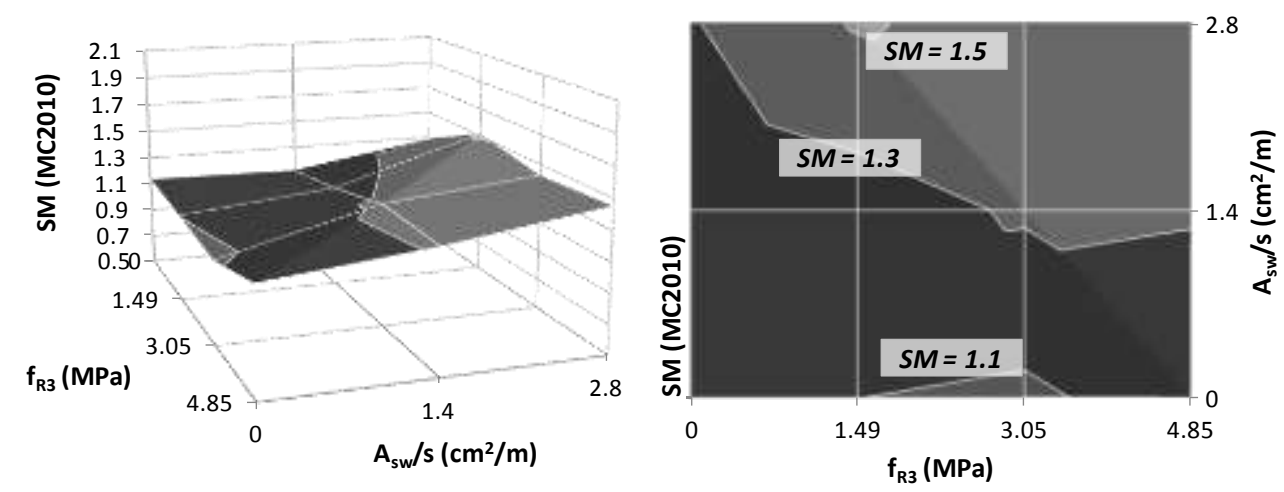

Fig. 8. 22 Influence of the interaction between $f_{R 3}$ and $A_{s w} / s$ in the SM according to MC2010 

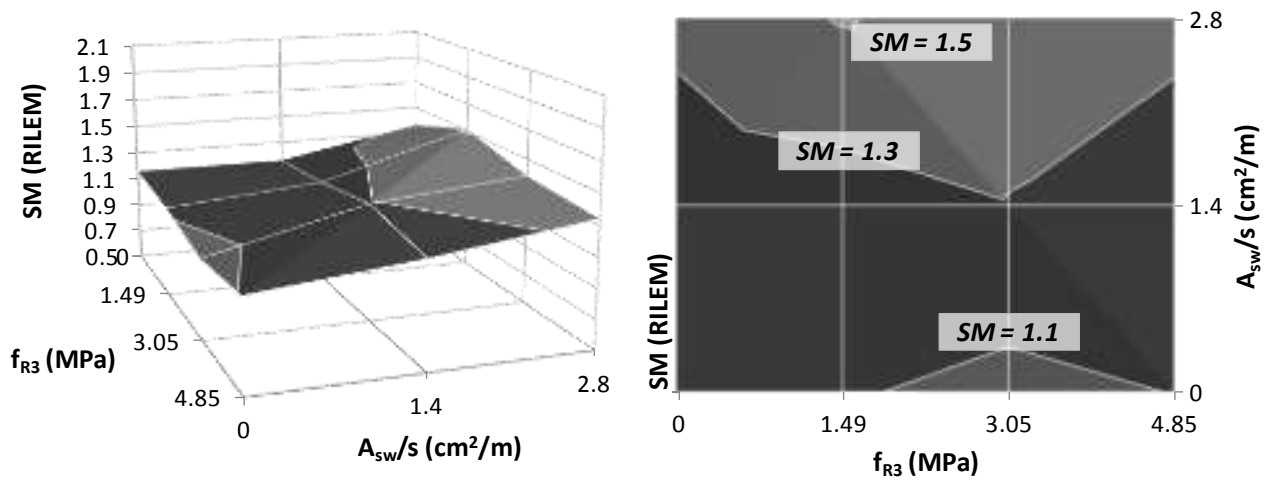

Fig. 8. 23 Influence of the interaction between $f_{R 3}$ and $A_{s w} / s$ in the SM according to RILEM

The influence of the interaction of $f_{R 3}$ and $A_{s w} / s$ on the safety margins (SM), according to the EHE08, MC2010 and RILEM, are plotted respectively in Fig. 8. 21, Fig. 8.22 and Fig. 8. 23. In each of these figures, two perspectives are represented. In the left picture a surface chart and, on the right, the same graph is represented as a topographic map indicating in each isoline (also called contour line) its corresponding SM value. In this Series, in particular, Codes are safer for greater amounts of transverse reinforcement; this trend is detected for all $f_{R 3}$ values. It is illogical that the Codes are more conservative with increasing the amount of transverse reinforcement. However, since results from this series do not provide a firm conclusion, more research is required on this topic.

\subsubsection{Brite Series 2}

In this subsection, the Series 2 of the Subtask 4.2- Trial Beams in Shear of Brite-Euram project [5] are going to be analyzed. This Serie 2 was carried out in the Katholieke Universiteit Leuven (KUL) by Dupont D. and Vandewalle L. In Table 8.17 the constant variables within the same Series are indicated.

In Table 8.18, the input data for the ANOVA analysis are presented, differencing the factors (independent variables) of the dependent variable (safety margin, SM) for all these subsections. In this case the three factors are: $f_{R 3}, \rho_{l}$ and Code, having the factor Codes three levels and, the other two factors, two levels. So, the number of complete cases is:

№ complete cases $=(\text { № of levels })^{\text {№ of factors }}=2^{2} \cdot 3^{1}=12$ complete cases 
Table 8.17 Constant variables between the beams within the same Series (Brite Series 2)

\begin{tabular}{|l|}
\hline Constant variables: \\
\hline Cross-section $200 \times 300 \mathrm{~mm}$ : Rectangular reinforced (no prestressed) beams \\
\hline No stirrups \\
\hline $\mathrm{a} / \mathrm{d}=2.5$ \\
\hline 4 point test \\
\hline
\end{tabular}

Table 8.18 Factors and dependent variable analyzed in the ANOVA analysis of Brite Series 2

Factors (independent variables):

$f_{r 3}(\mathrm{MPa}): 1.35,4.13$.

$\rho_{l}(\%): 1.16,1.81$.

Codes: EHE08, MC2010, RILEM.

Dependent variable: Shear safety margin (SM).

The ANOVA table (Table 8.19) decomposes the variability of safety margin on shear (SM) in contributions due to several factors. Since six p-values are less than 0.05 , these factors have a statistically significant shear on SM on a $95.0 \%$ confidence level.

Table 8. 19 Analysis of Variance (ANOVA) for SM on shear - Type III Sums of Squares (Series 2)

\begin{tabular}{|c|c|c|c|c|c|}
\hline Source of variation & Sum of Squares & d.f & Mean square & F-ratio & p-value \\
\hline \multicolumn{6}{|l|}{ MAIN EFFECTS } \\
\hline $\mathrm{A}: f_{R 3}(\mathrm{MPa})$ & 0.00100833 & 1 & 0.00100833 & 30.25 & 0.0315 \\
\hline $\mathrm{B}: \rho(\%)$ & 0.0954083 & 1 & 0.0954083 & 2862.25 & 0.0003 \\
\hline C: Code & 0.00506667 & 2 & 0.00253333 & 76.00 & 0.0130 \\
\hline \multicolumn{6}{|l|}{ INTERACTIONS } \\
\hline $\mathrm{AB}$ & 0.00140833 & 1 & 0.00140833 & 42.25 & 0.0229 \\
\hline$A C$ & 0.00826667 & 2 & 0.00413333 & 124.00 & 0.0080 \\
\hline$B C$ & 0.00166667 & 2 & 0.000833333 & 25.00 & 0.0385 \\
\hline RESIDUAL & 0.0000666667 & 2 & 0.0000333333 & & \\
\hline TOTAL (CORRECTED) & 0.112892 & 11 & & & \\
\hline
\end{tabular}

By means of LSD intervals (Fig. 8. 24), in this Series 2, it can be observed that there are significant differences in SM between both levels of $f_{R 3}$ and $\rho_{l}$. In this case, Codes are more conservative for small $f_{R 3}$ and when $\rho_{l}$ increases. There are also differences with different design Codes. In this case, the MC2010 is the safest while RILEM is the closest to the experimental results. 

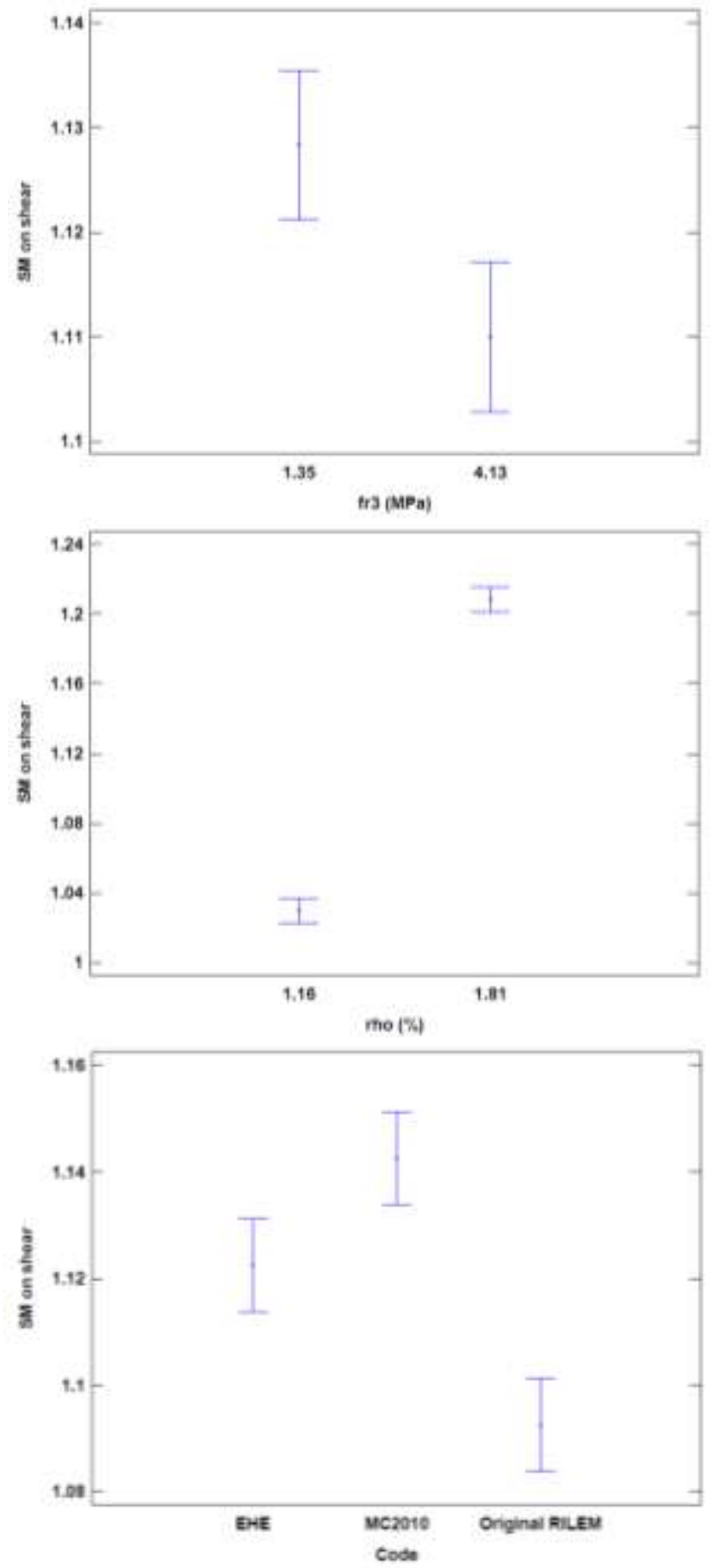

Fig. 8. 24 Means and 95.0 Percent LSD Intervals (Brite Series 2) 

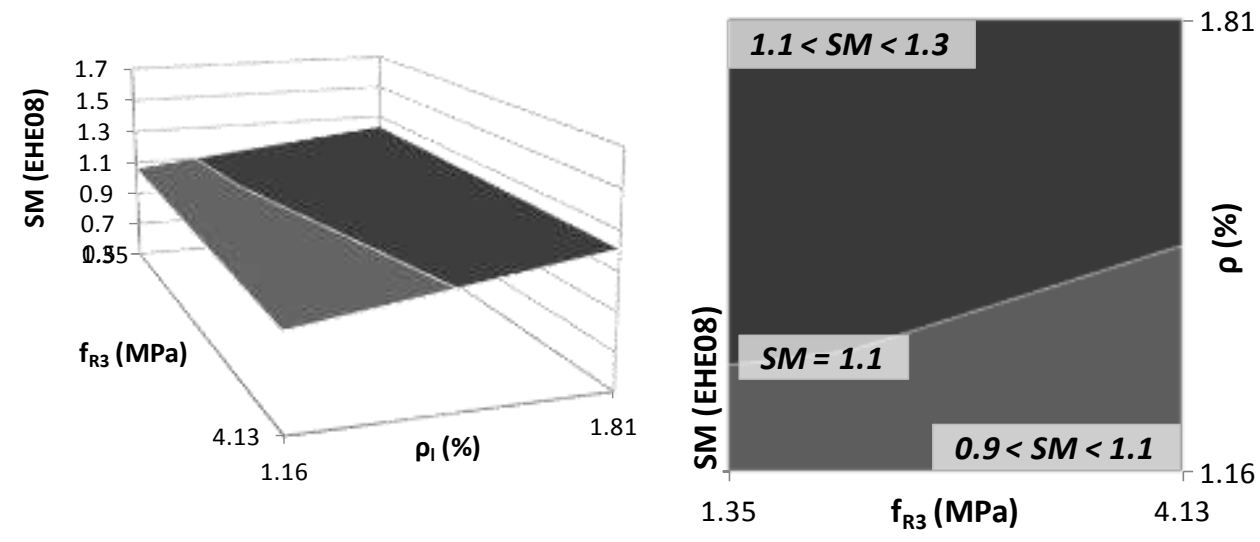

Fig. 8. 25 Influence of the interaction between $f_{R 3}$ and $\rho$ in the SM according to EHE08
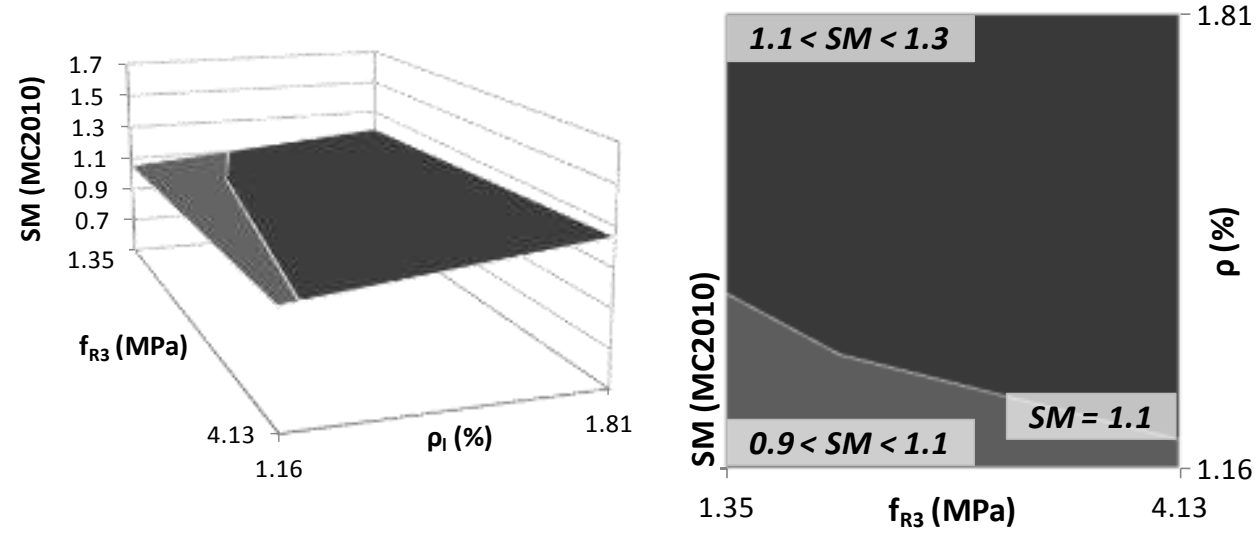

Fig. 8. 26 Influence of the interaction between $f_{R 3}$ and $\rho$ in the SM according to MC2010
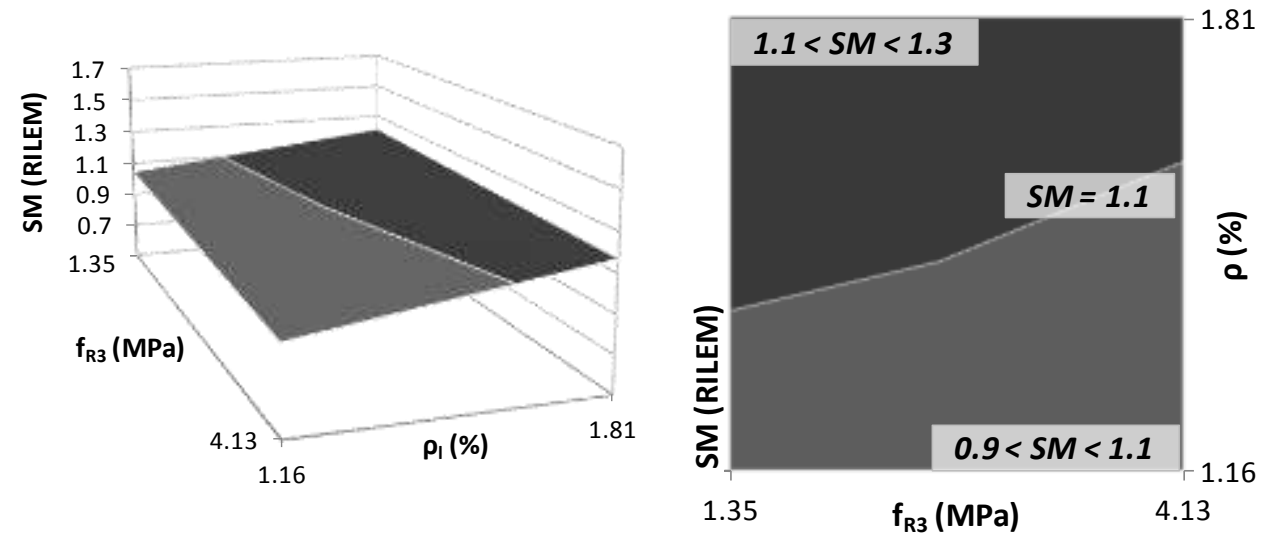

Fig. 8. 27 Influence of the interaction between $f_{R 3}$ and $\rho$ in the SM according to RILEM 
As it was seen in the ANOVA (Table 8.19), in this Series all interactions were statistically significant. By means of surface charts (Fig. 8.25 to Fig. 8. 27), it is possible to evaluate the influence of the interactions on the shear SM.

\subsubsection{Brite Series 3}

In this subsection, the Series 3 of the Subtask 4.2- Trial Beams in Shear of Brite-Euram project [5] are analyzed. This Serie 3 was carried out in the Universitat Politècnica de Catalunya (UPC) by Gettu R., Barragán B. E., Martín M.A., Ramos G. and Burnett I.

Two different analyses have been done related to this Series 3.

\subsubsection{Brite Series 3: Analysis I}

In Table 8.20 the constant variables within the same Series are indicated. In Table 8.21, the input data for the ANOVA analysis are presented, differencing the factors (independent variables) of the dependent variable (safety margin, SM). In this case the two factors are: $b_{f}$ and Code, having both factors three levels. So, the number of complete cases is: № complete cases $=(№ \text { of levels })^{\text {№ of factors }}=3^{2}=9$ complete cases

Table 8. 20 Constant variables between the beams within the same Series (Brite Series 3-I)

\begin{tabular}{|l|}
\hline Constant variables: \\
\hline Cross-section shape: Doble-T reinforced (no prestressed) beams \\
\hline No stirrups \\
\hline 3 point test \\
\hline $\mathrm{a} / \mathrm{d}=3.5$ \\
\hline $40 \mathrm{~kg} / \mathrm{m}^{3}$ of fibers RC $65 / 60 \mathrm{BN}$ \\
\hline $\mathrm{b}_{\mathrm{w}}=200 \mathrm{~mm}$ \\
\hline$\rho_{l}(\%)=2.8$ \\
\hline $\mathrm{h}=500 \mathrm{~mm}$ \\
\hline $\mathrm{hf}=150 \mathrm{~mm}$ \\
\hline
\end{tabular}

Table 8. 21 Factors and dependent variable analyzed in the ANOVA analysis of Brite Series 3-I

\begin{tabular}{|l|}
\hline Factors (independent variables): \\
\hline $\mathrm{b}_{\mathrm{f}}(\mathrm{mm}):$ 500, 750, 1000. \\
\hline Codes: $\mathrm{EHE08,} \mathrm{MC2010,} \mathrm{RILEM.}$ \\
\hline Dependent variable: \\
\hline Shear safety margin (SM). \\
\hline
\end{tabular}


The ANOVA table (Table 8.22) shows that both factors are significant. Since both p-values are less than 0.05 , these factors have a statistically significant shear on SM on a $95.0 \%$ confidence level.

Table 8. 22 Analysis of Variance (ANOVA) for SM on shear - Type III Sums of Squares (Series 3-I)

\begin{tabular}{|l|c|c|c|c|c|}
\hline \multicolumn{7}{|c|}{ Source of variation } & Sum of Squares & d.f & Mean square & F-ratio & p-value \\
\hline MAIN EFFECTS & 0.0230222 & 2 & 0.0115111 & 259.00 & $\mathbf{0 . 0 0 0 1}$ \\
\hline A: $b_{f}(\mathrm{~mm})$ & 0.0739556 & 2 & 0.0369778 & 832.00 & $\mathbf{0 . 0 0 0 0}$ \\
\hline B: Code & 0.000177778 & 4 & 0.0000444444 & & \\
\hline RESIDUAL & 0.0971556 & 8 & & & \\
\hline TOTAL (CORRECTED) & (C) F-ratios are based on the residual mean square error. \\
\hline
\end{tabular}

By means of LSD intervals (Fig. 8. 28), in this Series 3-I, it can be observed that there are significant differences in SM between both levels of $b_{f}$ and Code. In this case, Codes are more conservative for smaller flange widths $\left(b_{f}\right)$, SM decreases when $b_{f}$ increases. Also there are differences according to the design Codes used. In this case the MC2010, is the safest.

In this case, there are not enough degrees of freedom to study interactions so, only simple effects have been studied. 

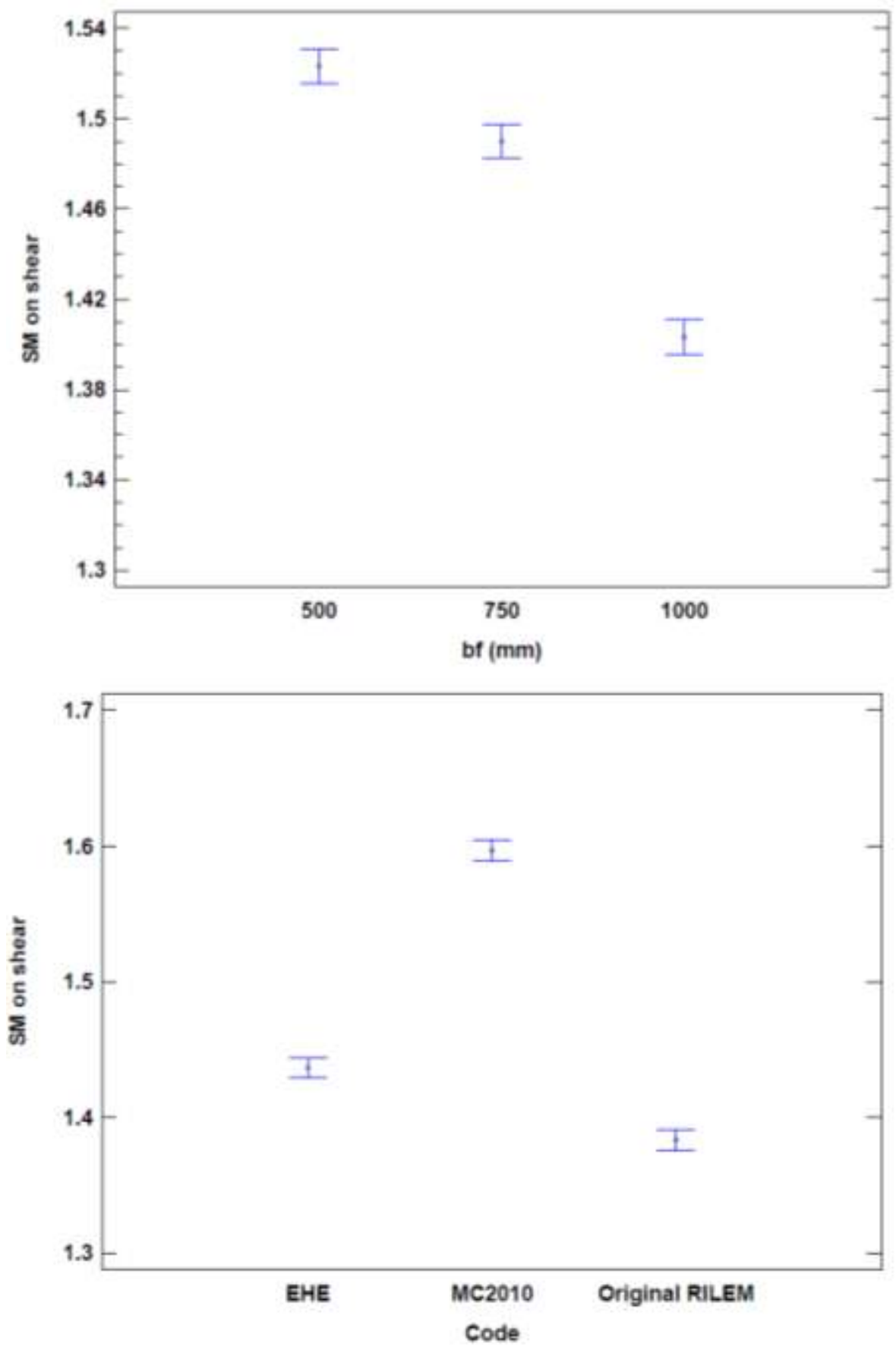

Fig. 8. 28 Means and 95.0 Percent LSD Intervals (Brite Series 3-I) 


\subsubsection{Brite Series 3: Analysis II}

In Table 8.23 the constant variables within the same Series are indicated. In Table 8.24, the input data for the ANOVA analysis are presented, differencing the factors (independent variables) of the dependent variable (safety margin, SM). In this case the two factors are: $h_{f}$ and Code, having both factors three levels. So, the number of complete cases is:

№ complete cases $=(\text { № of levels })^{\text {№ of factors }}=3^{2}=9$ complete cases

Table 8. 23 Constant variables between the beams within the same Series (Brite Series 3-II)

\begin{tabular}{|l|}
\hline Constant variables: \\
\hline Cross-section shape: Doble-T reinforced (no prestressed) beams \\
\hline No stirrups \\
\hline 3 point test \\
\hline $\mathrm{a} / \mathrm{d}=3.5$ \\
\hline $40 \mathrm{~kg} / \mathrm{m}^{3}$ of fibers RC $65 / 60 \mathrm{BN}$ \\
\hline $\mathrm{b}_{\mathrm{w}}=200 \mathrm{~mm}$ \\
\hline$\rho_{l}(\%)=2.8$ \\
\hline $\mathrm{h}=500 \mathrm{~mm}$ \\
\hline $\mathrm{b}_{\mathrm{f}}=500 \mathrm{~mm}$ \\
\hline
\end{tabular}

Table 8. 24 Factors and dependent variable analyzed in the ANOVA analysis of Brite Series 3-II

\begin{tabular}{|l|}
\hline Factors (independent variables): \\
\hline $\mathrm{h}_{\mathrm{f}}(\mathrm{mm}): 100,150,230$. \\
\hline Codes: EHE08, MC2010, RILEM. \\
\hline Dependent variable: \\
\hline Shear safety margin (SM). \\
\hline
\end{tabular}

The ANOVA table (Table 8.25) shows that both factors are significant. Since both $p$-values are less than 0.05 , these factors have a statistically significant shear on SM on a $95.0 \%$ confidence level.

Table 8.25 Analysis of Variance (ANOVA) for SM on shear - Type III Sums of Squares (Series 3-II)

\begin{tabular}{|l|c|c|c|c|c|}
\hline Source of variation & Sum of Squares & d.f & Mean square & F-ratio & p-value \\
\hline MAIN EFFECTS & 0.417156 & 2 & 0.208578 & 105.46 & $\mathbf{0 . 0 0 0 3}$ \\
\hline A: $h_{f}(\mathrm{~mm})$ & 0.0609556 & 2 & 0.0304778 & 15.41 & $\mathbf{0 . 0 1 3 2}$ \\
\hline B: Code & 0.00791111 & 4 & 0.00197778 & & \\
\hline RESIDUAL & 0.486022 & 8 & & & \\
\hline TOTAL (CORRECTED) & (II F-ratios are based on the residual mean square error. \\
\hline
\end{tabular}


By means of LSD intervals (Fig. 8. 29), in this Series 3-II, it can be observed that there are not significant differences in SM between the different levels inside the same factor. In this particular case, Series 3-II, there are not significant differences between flange depth of 100 and $150 \mathrm{~mm}$, being the Codes unconservative but, the SM corresponding to $h_{f}=230 \mathrm{~mm}$ is clearly different than the other two. There are not significant differences between EHE and RILEM; only MC2010 is different than the other two reaching the greatest SM in shear.
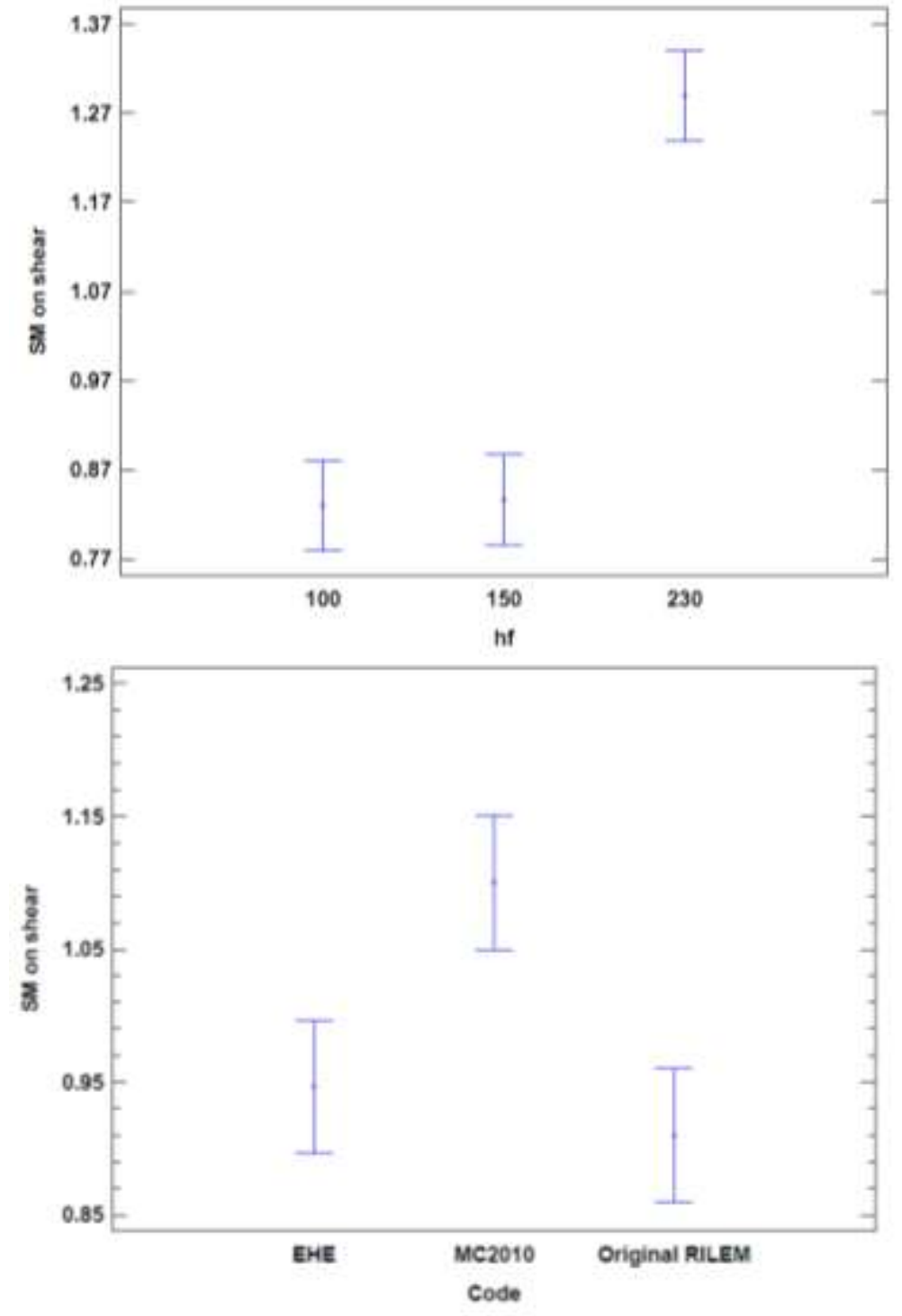

Fig. 8. 29 Means and 95.0 Percent LSD Intervals (Brite Series 3-II) 
In this case, there are not enough degrees of freedom to study interactions so, only simple effects have been studied.

\subsubsection{Study of size effect on shear}

In this subsection, the beams of Chapter 5, tested at the University of Brescia (Italy), are statistically analyzed. In Table 8.26, the constant variables within the same Series are indicated. In Table 8.27, the input data for the ANOVA analysis are presented, differencing the factors (independent variables) of the dependent variable (safety margin, SM) for all these subsections. In this case, the three factors are: $d, f_{R 3}$, and Code, having all factors three levels. So, the number of complete cases is:

№ complete cases $=(\text { № of levels })^{\text {№ of factors }}=3^{3}=27$ complete cases

Table 8.26 Constant variables between the beams within the same Series (Size Effect Beams)

\begin{tabular}{|c|}
\hline Constant variables: \\
\hline Cross-section shape: Rectangular reinforced (no prestressed) beams \\
\hline No stirrups \\
\hline 3 point test \\
\hline$a / d=3.0$ \\
\hline Type of fibers: La Gramigna (C) $l_{f} / d_{f}=62.5 ; l_{f}=50 \mathrm{~mm}$ \\
\hline $\mathrm{b}_{\mathrm{w}}=250 \mathrm{~mm}$ \\
\hline$\rho_{l}(\%)=1.12$ \\
\hline $\begin{array}{l}\text { Compressive strength level assumed constant: } \\
\text { 38.65MPa for PC; } 32.07 \mathrm{MPa} \text { for FRC50; } 33.08 \mathrm{MPa} \text { for } \mathrm{FRC75}\end{array}$ \\
\hline
\end{tabular}

Table 8.27 Factors and dependent variable analyzed in the ANOVA analysis of Size Effect Beams

\begin{tabular}{|l|}
\hline Factors (independent variables): \\
\hline $\mathrm{d}(\mathrm{mm}): 440,940,1440$. \\
\hline$f_{R 3}(\mathrm{MPa}): 0,5.00,6.00$. \\
\hline Codes: EHE08, MC2010, RILEM. \\
\hline Dependent variable: \\
\hline Shear safety margin (SM). \\
\hline
\end{tabular}

The ANOVA table (Table 8.28) shows that all main effects and two interactions have significant differences since their $p$-values are less than 0.05 . 
Table 8. 28 Analysis of Variance (ANOVA) for SM on shear -Type III S of Squares (Size Effect)

\begin{tabular}{|l|c|c|c|c|c|}
\hline $\begin{array}{c}\text { Source of } \\
\text { variation }\end{array}$ & $\begin{array}{c}\text { Sum of } \\
\text { Squares }\end{array}$ & d.f & $\begin{array}{c}\text { Mean } \\
\text { square }\end{array}$ & F-ratio & p-value \\
\hline MAIN EFFECTS & 0.313956 & 2 & 0.156978 & 409.51 & $\mathbf{0 . 0 0 0 0}$ \\
\hline A: $d(\mathrm{~mm})$ & 0.00682222 & 2 & 0.00341111 & 8.90 & $\mathbf{0 . 0 0 9 2}$ \\
\hline B: $f_{R 3}(\mathrm{MPa})$ & 0.153356 & 2 & 0.0766778 & 200.03 & $\mathbf{0 . 0 0 0 0}$ \\
\hline C: Code & 0.141889 & 4 & 0.0354722 & 92.54 & $\mathbf{0 . 0 0 0 0}$ \\
\hline INTERACTIONS & 0.00142222 & 4 & 0.000355556 & 0.93 & 0.4939 \\
\hline AB & 0.00988889 & 4 & 0.00247222 & 6.45 & $\mathbf{0 . 0 1 2 7}$ \\
\hline AC & 0.00306667 & 8 & 0.000383333 & & \\
\hline BC & 0.6304 & 26 & & & \\
\hline RESIDUAL & $\begin{array}{l}\text { TOTAL } \\
\text { (CORRECTED) }\end{array}$ \\
\hline All F-ratios are based on the residual mean square error. & \\
\hline
\end{tabular}

By means of LSD intervals (Fig. 8. 30), in this Series, it can be observed that, for the effect "effective depth (d)", there are significant differences between the three levels, being the SM corresponding to $d=440 \mathrm{~mm}$ clearly different from the other two. SM increases when increases the fiber content, but there are not significant differences between concrete without fibers and with $f_{R 3}=5 \mathrm{MPa}$. There are significant differences between the different, but MC2010 is, in this case, the safest Code. 

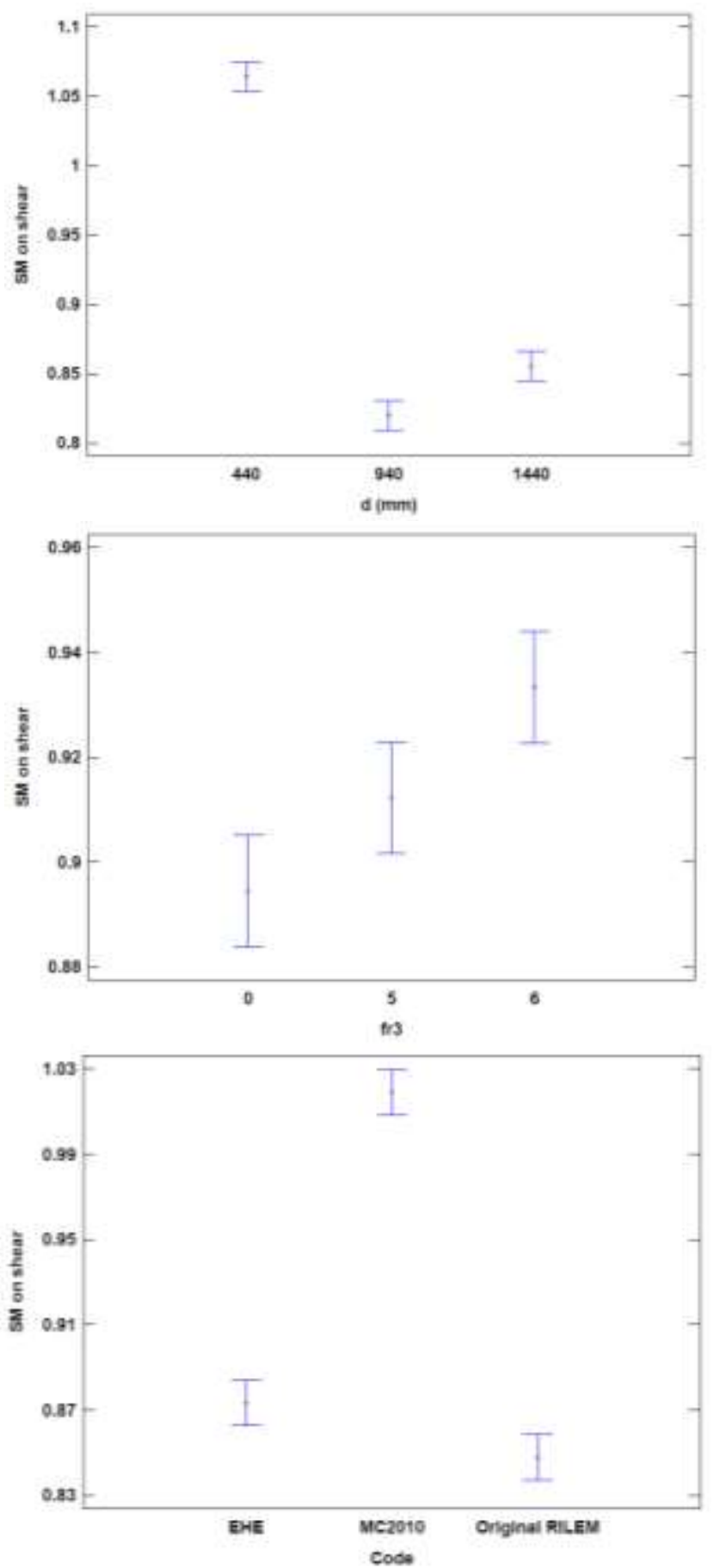

Fig. 8. 30 Means and 95.0 Percent LSD Intervals (Size Effect Beams) 
As was seen in the ANOVA table (Table 8.28), in this Series two interactions were statistically significant: $d$ with $f_{R 3}(\mathrm{AB})$, and $f_{R 3}$ with Code $(\mathrm{BC})$. By means of surface charts (Fig. 8. 31 to Fig. 8. 33), it is possible to evaluate the influence of the interactions on the shear SM.

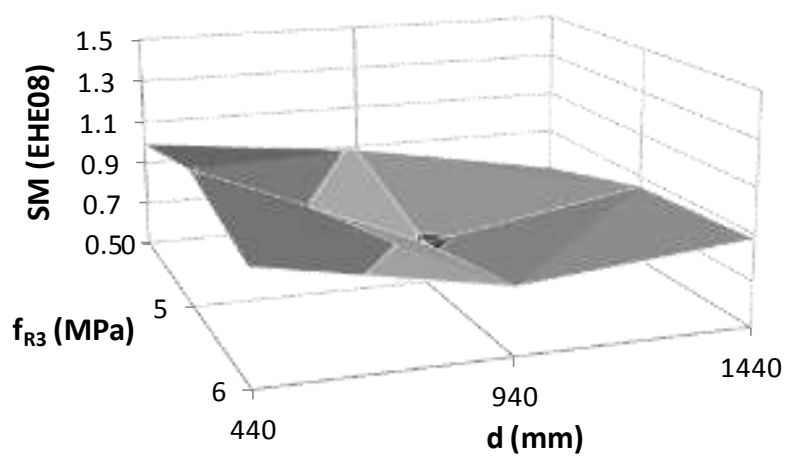

Fig. 8. 31 Influence of the interaction between $f_{R 3}$ and $d$ in the SM according to EHE08

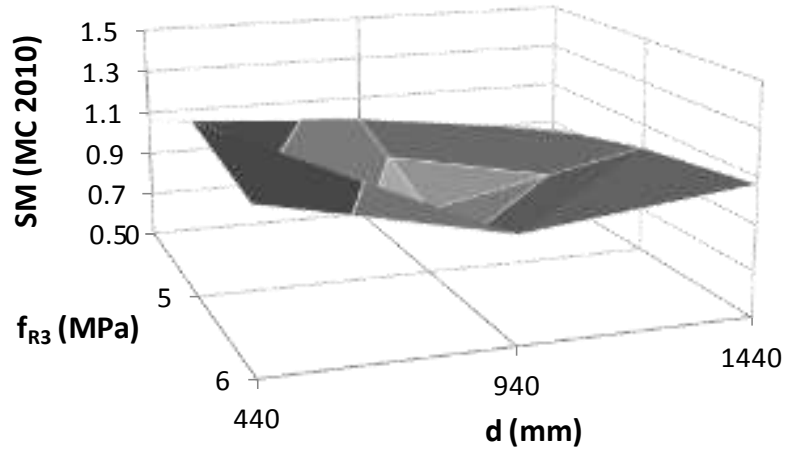

Fig. 8. 32 Influence of the interaction between $f_{R 3}$ and $d$ in the SM according to MC2010

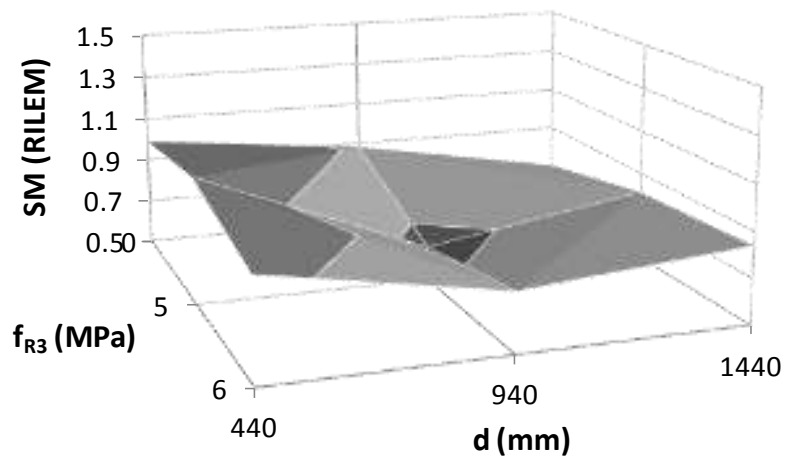

Fig. 8. 33 Influence of the interaction between $f_{R 3}$ and $d$ in the SM according to RILEM 
The surface charts shows clearly that the combination $f_{R 3}=5 \mathrm{MPa}$ with $\mathrm{d}=940 \mathrm{~mm}$ has a lower SM, according to the three Codes considered, and that fibers can mitigate size effect.

However, only one beam was tested for each combination so to obtain decisive conclusions further research in this topic will be needed.

\subsubsection{Beams with different types of fibers}

In this subsection, the beams of Chapter 6, tested at the Universitat Politécnica de València (Spain), are statistically analyzed by means of two different analysis, combining the compressive strength levels with several types of steel fibers with different lengths, aspect ratio and steel strength.

\subsubsection{Beams with different fibers types: Analysis I}

In Table 8.29, the constant variables within the same Series are indicated. In Table 8.30, the input data for the ANOVA analysis is presented, differencing the factors (independent variables) of the dependent variable (safety margin, SM). In this case, the three factors are: compressive strength level (Low, L; Medium, M; High, H), fibers type (65/40BN, $80 / 50 B N, 80 / 40 B P$ ) and Codes (EHE, MC2010, RILEM), having all factors three levels. So, the number of complete cases is:

№ complete cases $=(\text { № of levels })^{\text {№ of factors }}=3^{3}=27$ complete cases

Table 8. 29 Constant variables between the beams within the same Series $\left(f_{c} \& f_{R 3}\right.$ beams-l)

\begin{tabular}{|l|}
\hline Constant variables: \\
\hline Cross-section shape \\
\hline$\rho(\%)=3.72$ \\
\hline 3 point test \\
\hline $50 \mathrm{~kg} / \mathrm{m}^{3}$ of steel fibers \\
\hline
\end{tabular}

Table 8. 30 Factors and dependent variable analyzed in the ANOVA analysis of $f_{c} \& f_{R 3}$ beams-I

\begin{tabular}{|l|}
\hline Factors (independent variables): \\
\hline Compressive strength level: Low (L), Medium (M), High (H). \\
\hline Fibers type: 65/40BN, 80/50BN, 80/40BP. \\
\hline Codes: EHE08, MC2010, RILEM. \\
\hline Dependent variable: \\
\hline Shear safety margin (SM). \\
\hline
\end{tabular}


The ANOVA table (Table 8.31) shows that all main effects and two interactions have significant differences, since their $\mathrm{p}$-values are less than 0.05 .

Table 8. 31 ANOVA for SM on shear - Type III Sums of Squares $\left(f_{c} \& f_{R 3}\right.$ beams-I)

\begin{tabular}{|l|c|c|c|c|c|}
\hline \multicolumn{7}{|c|}{ Source of variation } & Sum of Squares & d.f & Mean square & F-ratio & p-value \\
\hline MAIN EFFECTS & 0.104674 & 2 & 0.052337 & 33.81 & $\mathbf{0 . 0 0 0 1}$ \\
\hline A: Compressive strength & 0.0444741 & 2 & 0.022237 & 14.36 & $\mathbf{0 . 0 0 2 3}$ \\
\hline B: Fiber type & 0.101252 & 2 & 0.0506259 & 32.70 & $\mathbf{0 . 0 0 0 1}$ \\
\hline C: Code & 0.112326 & 4 & 0.0280815 & 18.14 & $\mathbf{0 . 0 0 0 4}$ \\
\hline INTERACTIONS & 0.0126815 & 4 & 0.00317037 & 2.05 & 0.1802 \\
\hline AB & 0.0933481 & 4 & 0.023337 & 15.07 & $\mathbf{0 . 0 0 0 9}$ \\
\hline AC & 0.0123852 & 8 & 0.00154815 & & \\
\hline BC & 0.481141 & 26 & & & \\
\hline RESIDUAL & TOTAL (CORRECTED) & & & \\
\hline All F-ratios are based on the residual mean square error. \\
\hline
\end{tabular}

By means of LSD intervals (Fig. 8. 34), in this Series, it can be observed that, according to the compressive strength level only, there are significant differences between the low compressive level and the other two. In this particular case, only beams made with fibers $80 / 50 B N$ have SM significantly different than the other two types. Codes give SM values significantly different, being MC2010 the safest and the RILEM unconservative.

As it can be seen in Table 8.31, all main effects have a clear influence on the SM; furthermore, interactions between compressive strength and fiber type $(A B)$, and between fiber type and Code $(B C)$ present significant differences on SM. By means of surface charts (Fig. 8. 35 to Fig. 8. 37), it is possible to evaluate the influence of the interactions on the shear SM. 

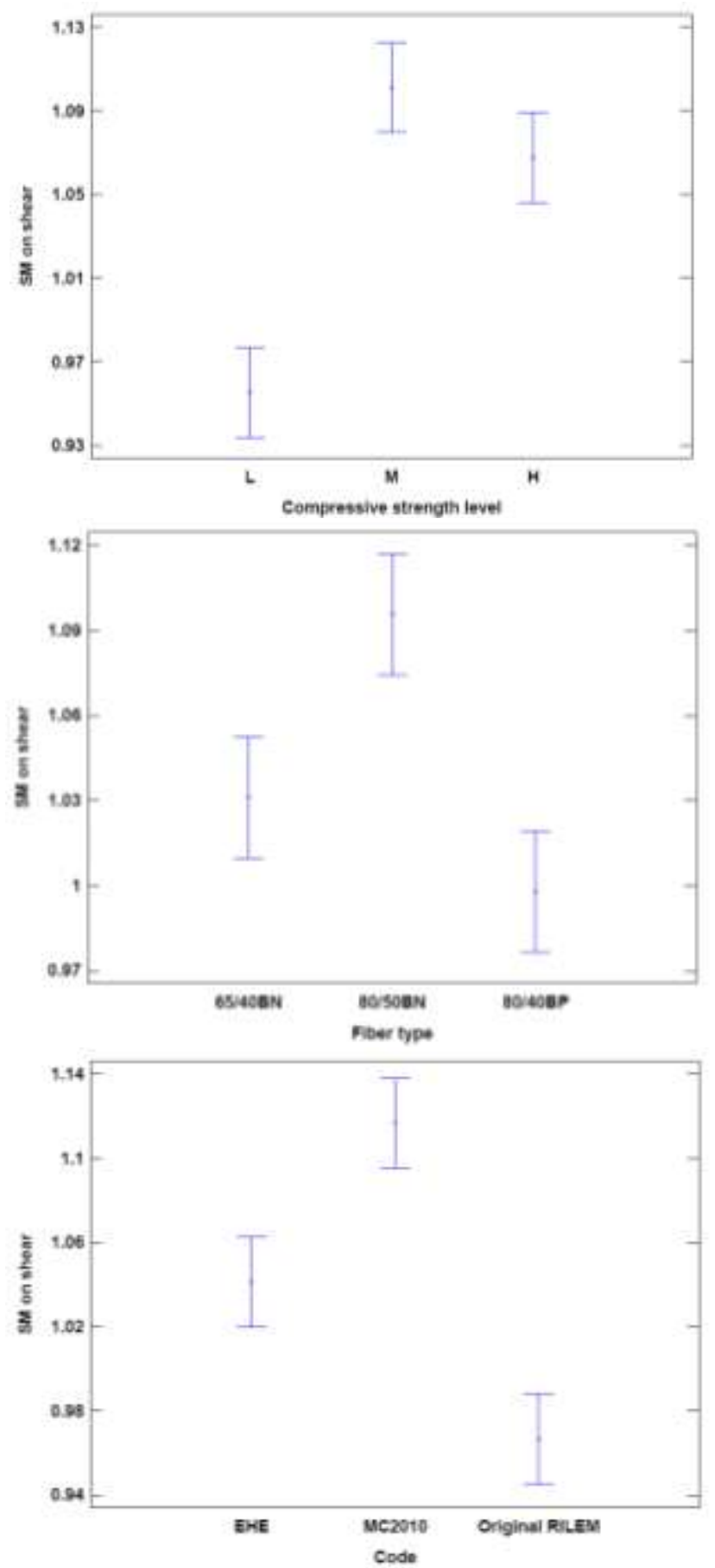

Fig. 8. 34 Means and 95.0 Percent LSD Intervals $\left(f_{c} \& f_{R 3}\right.$ beams-I) 

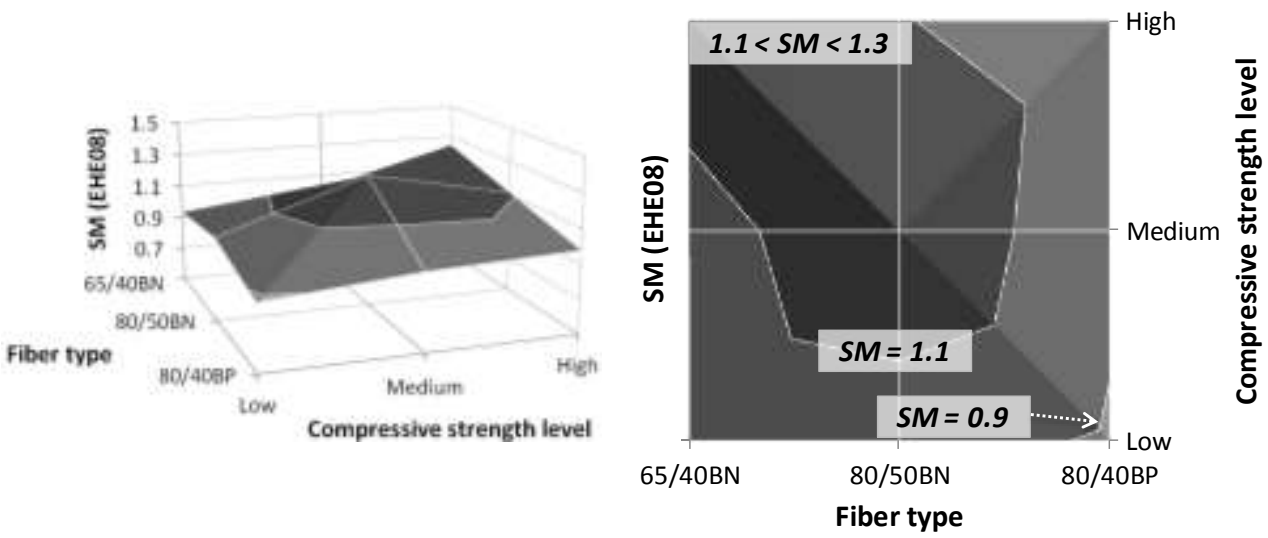

Fig. 8. 35 Influence of the interaction between fiber type and $f_{c}$ level in SM according to EHE08
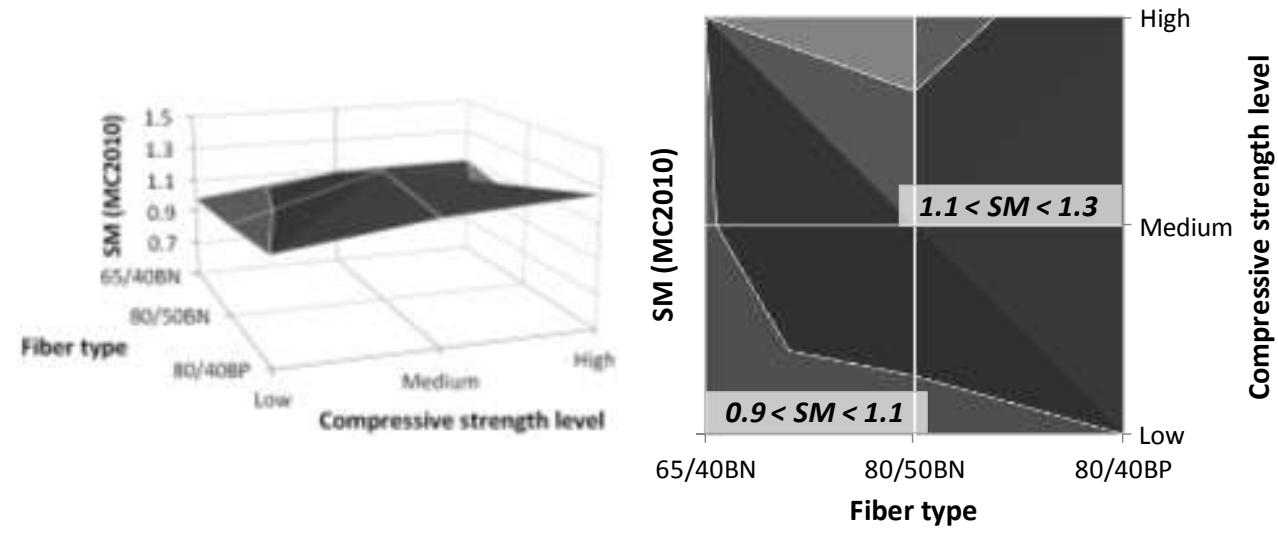

Fig. 8. 36 Influence of the interaction between fiber type and $f_{c}$ level in SM according to MC2010
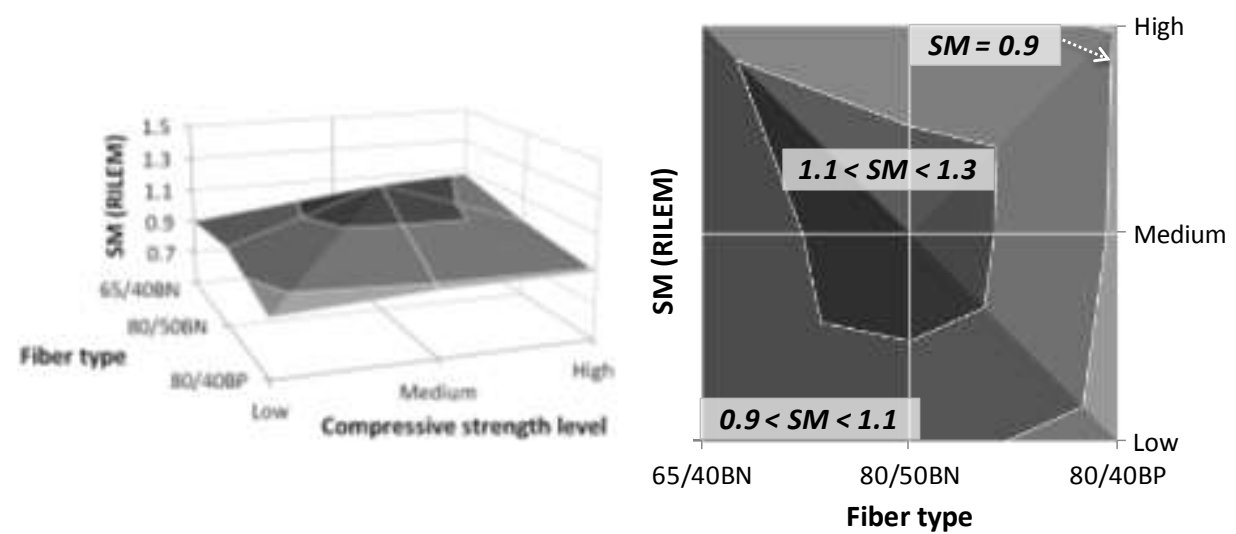

Fig. 8. 37 Influence of the interaction between fiber type and $f_{c}$ level in SM according to RILEM 
Analyzing the surface charts of this Series, it seems that all Codes give SM very close to the unit, so they are very safe for all the combinations. RILEM and EHE are unsafe when high strength fibers (80/40BP) are used. Of the three codes, in general, the MC2010 seems to be the safest. In general, Codes have low SM for concretes with low compressive strength and high strength fibers (80/40BP). On the other hand, Codes have greater SM for concretes with medium compressive strength and fibers $80 / 50 \mathrm{BN}$.

\subsubsection{Beams with different fibers types: Analysis II}

In Table 8.32, the constant variables within the same Series are indicated. In Table 8.33, the input data for the ANOVA analysis is presented, differencing the factors (independent variables) of the dependent variable (safety margin, SM). In this case, the three factors are: compressive strength level (Medium, $M$; High, $H$ ), fibers type $(45 / 50 B N, 65 / 40 B N$, $80 / 50 B N, 80 / 30 B P, 80 / 40 B P)$ and Codes (EHE, MC2010, RILEM), having all factors three levels. So, the number of complete cases is:

№ complete cases $=(\text { № of levels })^{\text {№ of factors }}=2^{1} \cdot 5^{1} \cdot 3^{1}=30$ complete cases

Table 8. 32 Constant variables between the beams within the same Series $\left(f_{c} \& f_{R 3}\right.$ beams-II)

\begin{tabular}{|l|}
\hline Constant variables: \\
\hline$\rho(\%)=3.72$ \\
\hline 3 point test \\
\hline $50 \mathrm{~kg} / \mathrm{m}^{3}$ of steel fibers \\
\hline
\end{tabular}

Table 8. 33 Factors and dependent variable analyzed in the ANOVA analysis of $f_{c} \& f_{R 3}$ beams-II Factors (independent variables):

Compressive strength level: Medium (M), High (H).

Fibers type: 45/50BN, 65/40BN, 80/50BN, 80/30BP, 80/40BP.

Codes: EHE08, MC2010, RILEM.

Dependent variable:

Shear safety margin (SM).

The ANOVA table (Table 8.34) shows that all main effects and two interactions have significant differences since their $p$-values are less than 0.05 . 
Table 8. 34 ANOVA for SM on shear - Type III Sums of Squares $\left(f_{c} \& f_{R 3}\right.$ beams-II)

\begin{tabular}{|l|c|c|c|c|c|}
\hline \multicolumn{7}{|c|}{ Source of variation } & Sum of Squares & d.f & Mean square & F-ratio & p-value \\
\hline MAIN EFFECTS & 0.0264033 & 1 & 0.0264033 & 22.65 & $\mathbf{0 . 0 0 1 4}$ \\
\hline A: Compressive strength & 0.213753 & 4 & 0.0534383 & 45.84 & $\mathbf{0 . 0 0 0 0}$ \\
\hline B: Fiber type & 0.148087 & 2 & 0.0740433 & 63.51 & $\mathbf{0 . 0 0 0 0}$ \\
\hline C: Code & 0.119313 & 4 & 0.0298283 & 25.59 & $\mathbf{0 . 0 0 0 1}$ \\
\hline INTERACTIONS & 0.00920667 & 2 & 0.00460333 & 3.95 & 0.0641 \\
\hline AB & 0.0984467 & 8 & 0.0123058 & 10.56 & $\mathbf{0 . 0 0 1 6}$ \\
\hline AC & 0.00932667 & 8 & 0.00116583 & & \\
\hline BC & 0.624537 & 29 & & & \\
\hline RESIDUAL & TOTAL (CORRECTED) & & \\
\hline All F-ratios are based on the residual mean square error.
\end{tabular}

By means of LSD intervals (Fig. 8. 38), in this Series, it can be observed that:

- Compressive strength level: there are significant differences. For high compressive strengths, Codes are more adjusted (less conservative).

- Fiber type: With fibers made with normal strength fibers (BN), Codes are more conservative when fibers are slenderer and longer. For high strength fibers (BP), the shorter are the more conservative for EHE and RILEM, as discussed in the interaction plots and surface charts.

- Code: There are significant differences between all Codes. MC2010 is the safest, and the mean value of SM for RILEM is below the unit. EHE gives SM very close to the unit.

As it can be seen in Table 8.34, all main effects have a clear influence on the SM; furthermore, interactions between compressive strength and fiber type (AB), and between fiber type and Code (BC) present significant differences on SM. By means of surface charts (Fig. 8. 39 to Fig. 8. 41), it is possible to evaluate the influence of the interactions on the shear SM. 

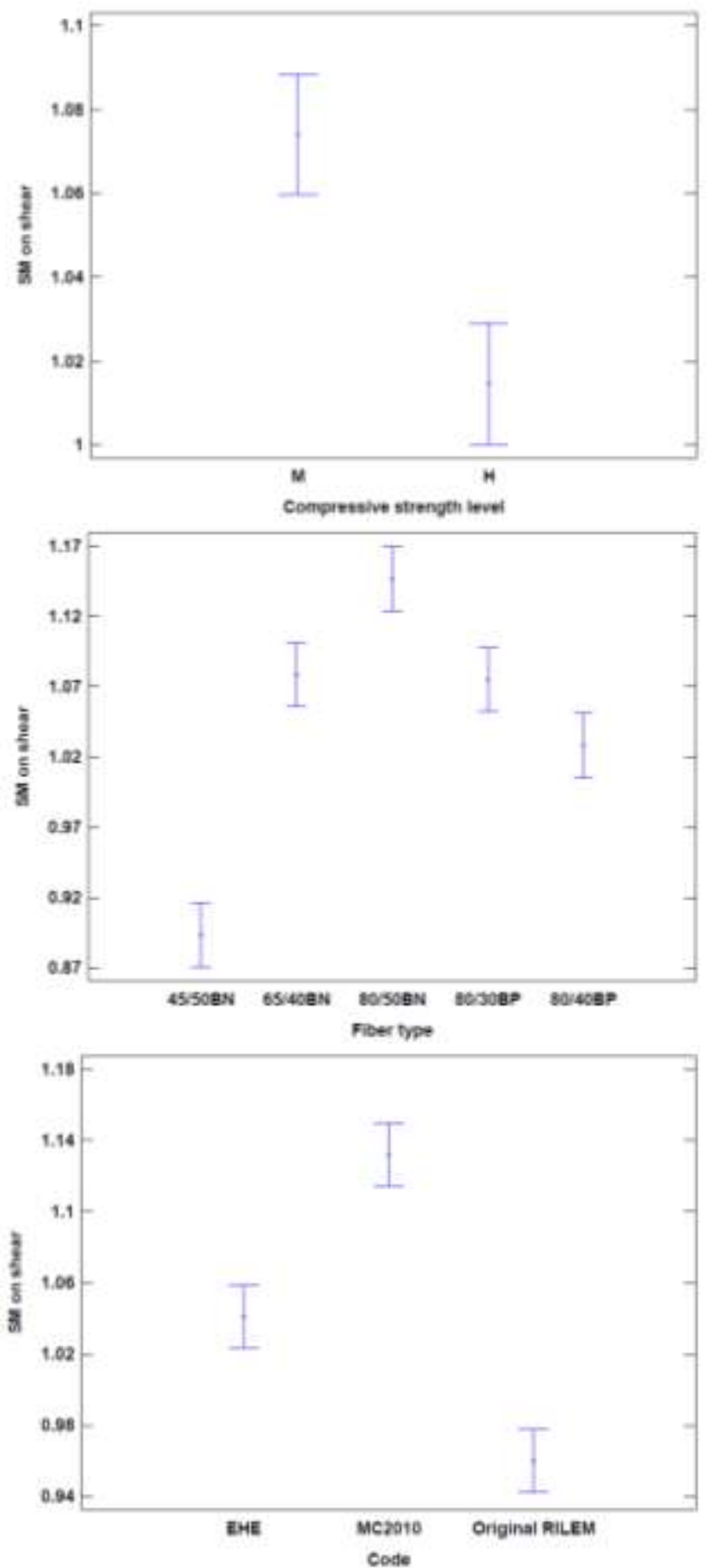

Fig. 8. 38 Means and 95.0 Percent LSD Intervals $\left(f_{c} \& f_{R 3}\right.$ beams-II) 


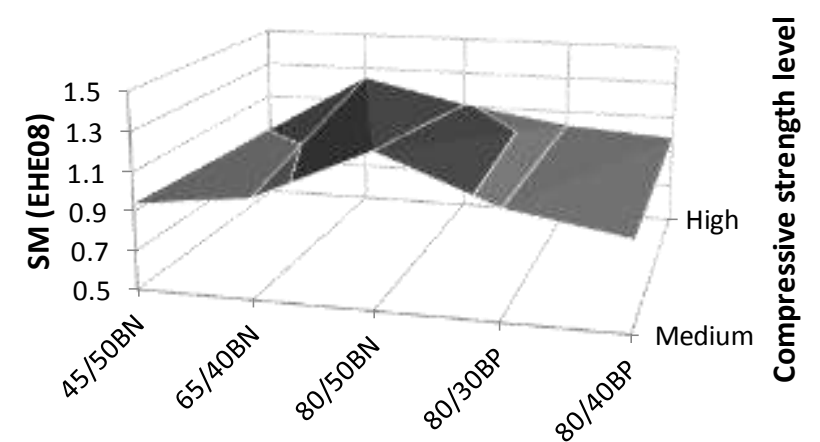

Fiber type

Fig. 8. 39 Influence of the interaction between fiber type and $f_{c}$ level in SM according to EHE08

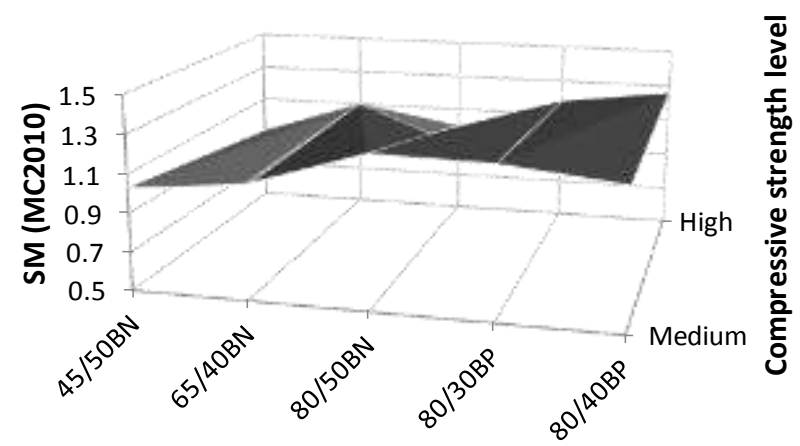

Fiber type

Fig. 8. 40 Influence of the interaction between fiber type and $f_{c}$ level in SM according to MC2010

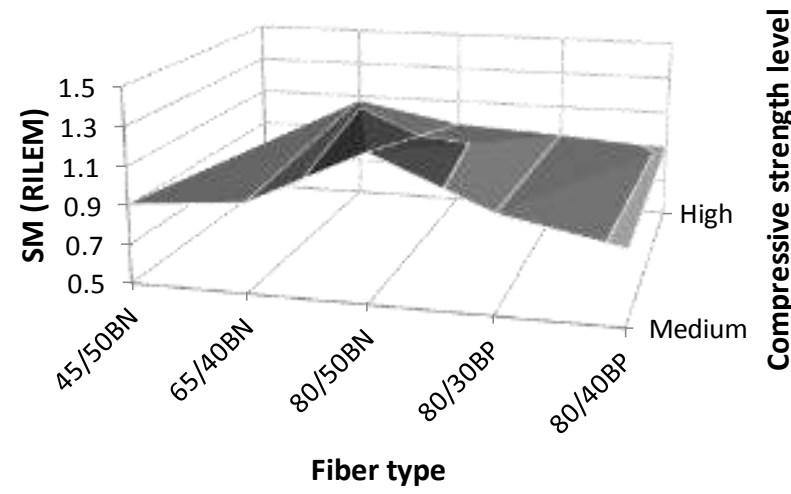

Fig. 8. 41 Influence of the interaction between fiber type and $f_{c}$ level in SM according to RILEM

By means of the surface charts, it can be observed that MC2010 is the safest; it only gives the lower results (SM around the unit) when using long fibers $(50 \mathrm{~mm})$. When fibers are 
long and shortly slender (45/50BN), MC2010 gives results slightly unsafe for both levels of compressive strength. When fibers are long and very slender (80/50BN), SM is low in high strength concrete.

RILEM is the most unconservative Code, followed by the EHE08. For this Series SM are always greater than the unit for beams of medium compressive strength and fibers $80 / 50 B N$.

When Codes gives $\mathrm{SM}<1$, it means that they estimate theoretical shear values too high; in this case, it seems that Codes are overestimating the effect of fibers. 45/50BN are fibers longer and less slender than the other types of fibers used; therefore, for the same amount of steel, less fibers are into the concrete. This fact, coupled with high compressive strength, results in a brittle matrix and, in this case, Codes should be more conservative.

\subsection{Conclusions according to the analyzed shear database}

After analyzing a shear database consisting of 215 structural elements, it was detected the influence of each parameter influencing shear.

In the following, Codes will be compared with the experimental results available in the considered database, under the assumption that the partial safety factors are equal to the unit; therefore, the comparisons will not refer to the safety because, in this case, this safety factor have to be considered.

\subsubsection{Influence of effective depth, $d$}

For effective depth (d) of about $200 \mathrm{~mm}$, Codes were always conservative for all cases except for beams with only stirrups (see square in solid line, Fig. 8. 42).

When $d \geq 900 \mathrm{~mm}$, in beams without any shear reinforcement (neither stirrups nor fibers), the analyzed Codes underestimate the shear strength; on the contrary, in beams with stirrups, Codes were too conservative. In beams with only fibers as shear reinforcement, Codes give intermediate results (see square in dashed line, Fig. 8. 42). So when stirrups are not present, Codes underestimate the shear strength for $d \geq 900 \mathrm{~mm}$.

It should be underlined that both, stirrups and fibers, can mitigate size effect in shear (Fig. 8. 43). 


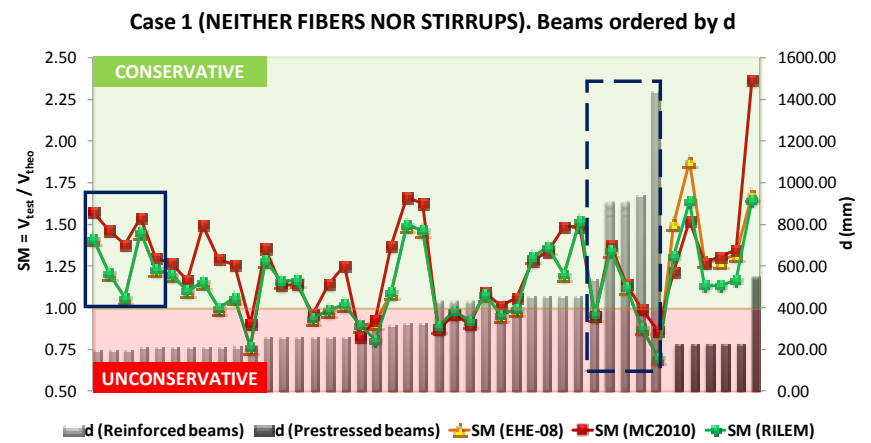

Case 2 (ONLY STIRRUPS). Beams ordered by $d$

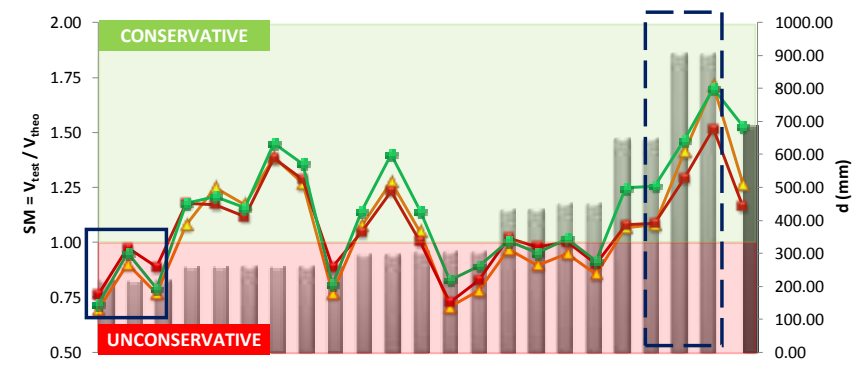

एd (Reinforced beams) $\rightleftharpoons \mathrm{d}$ (Prestressed beams)

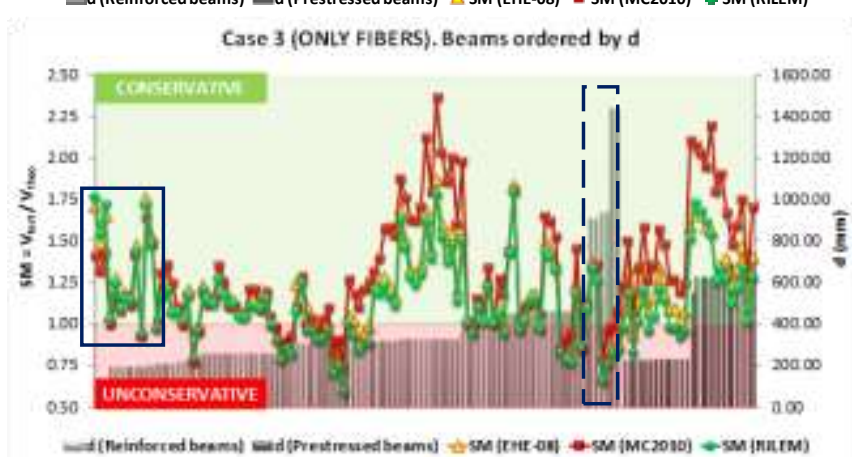

Case 4 (STIRRUPS + FIBERS). Beams ordered by d

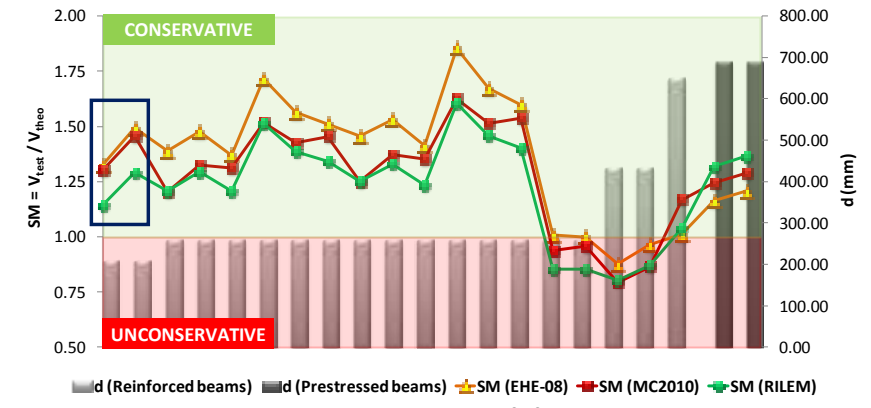

Fig. 8. 42 Influence of effective depth (d) on shear safety margins 

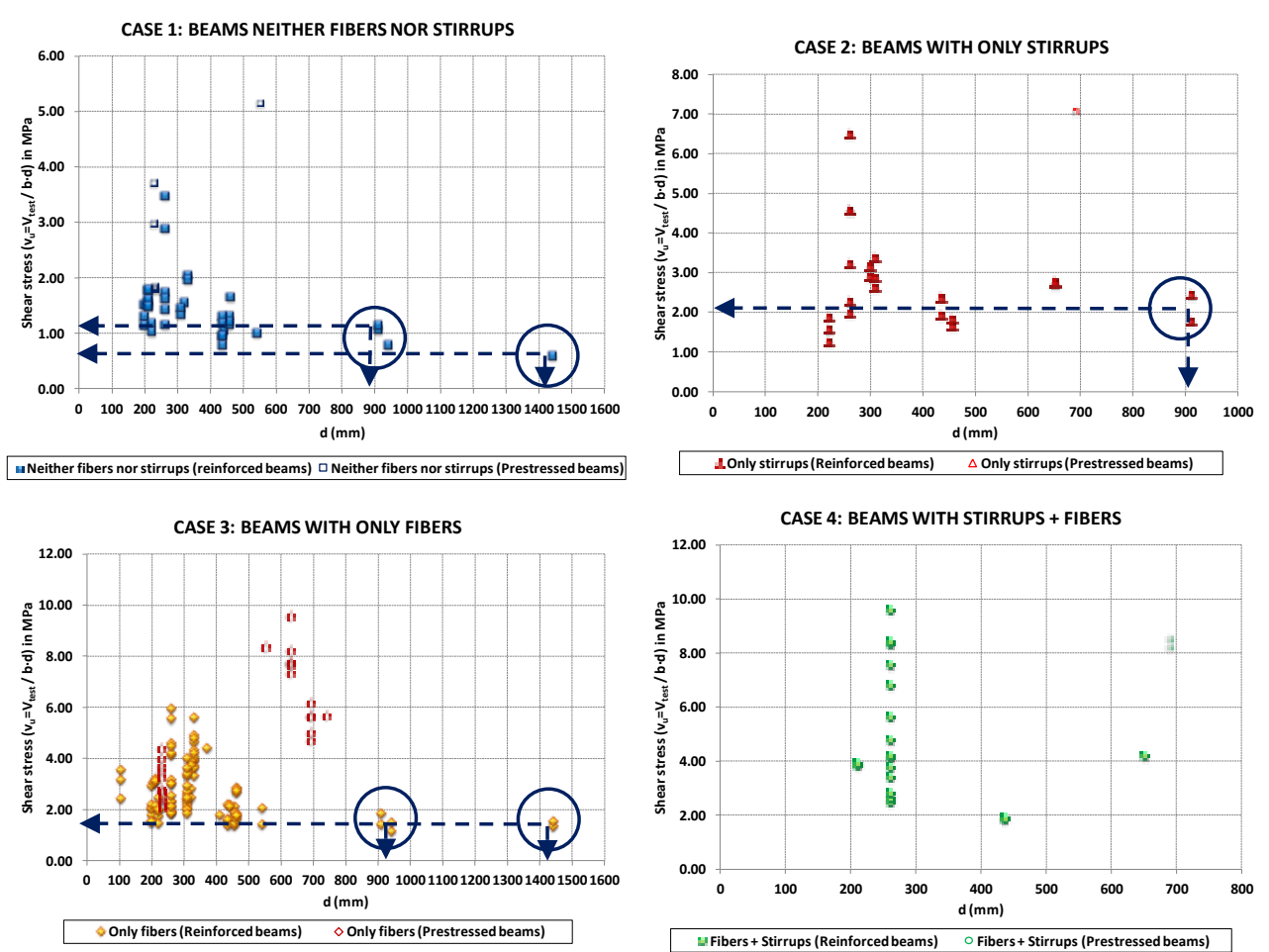

Fig. 8. 43 Influence of effective depth (d) on experimental shear stress

\subsubsection{Influence of the $\mathrm{a} / \mathrm{d}$ ratio}

For the range $2.5 \leq a / d \leq 3.5$, particular trends are not observed, independently of the reinforcement type (fibers and/or stirrups).

\subsubsection{Influence of the concrete compressive strength, $f_{c}$}

For all concrete beams, with different types of shear reinforcement, when concrete compressive strength $\left(f_{c}\right)$ was higher than 70MPa, Codes underestimate the shear strength (Fig. 8. 44). 


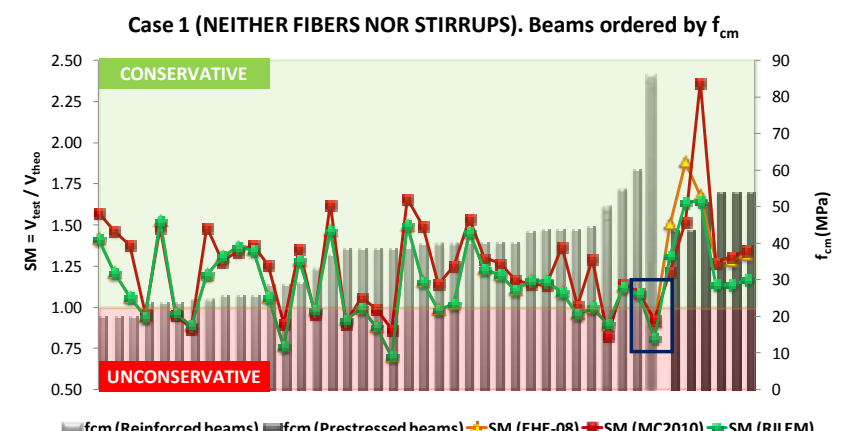

Case 2 (ONLY STIRRUPS). Beams ordered by $f_{c m}$

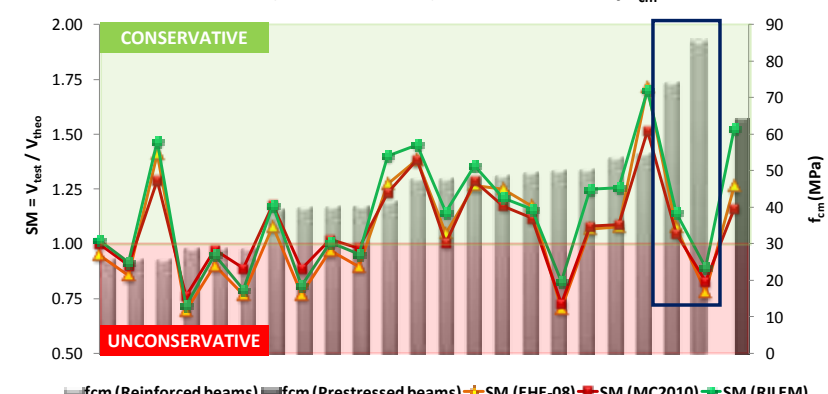

Case 3 (ONLY FIBERS). Beams ordered by $f_{c m}$

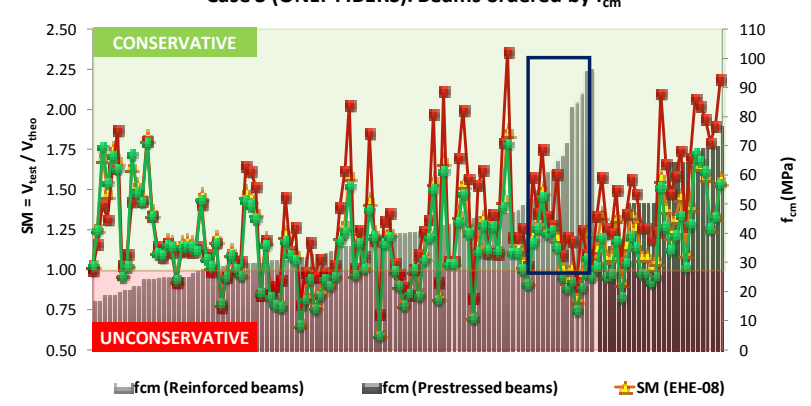

Case 4 (STIRRUPS + FIBERS). Beams ordered by $\mathrm{f}_{\mathrm{cm}}$

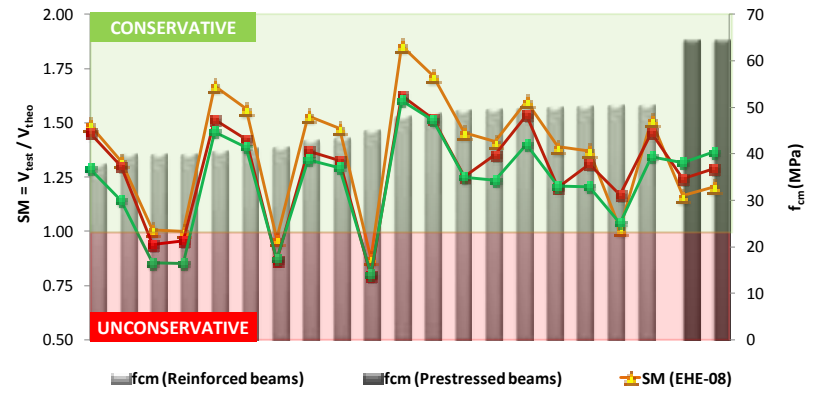

Fig. 8. 44 Influence of the concrete compressive strength $\left(f_{c}\right)$ on shear safety margins 


\subsubsection{Influence of the residual tensile strength, $f_{R 3}$}

For beams with only fibers as shear reinforcement, the SMs are generally higher than the unit, with a high scatter (Fig. 8. 45). The scatter is smaller in beams with both fibers and stirrups, but a lower number of results are available in the database (Fig. 8. 45).
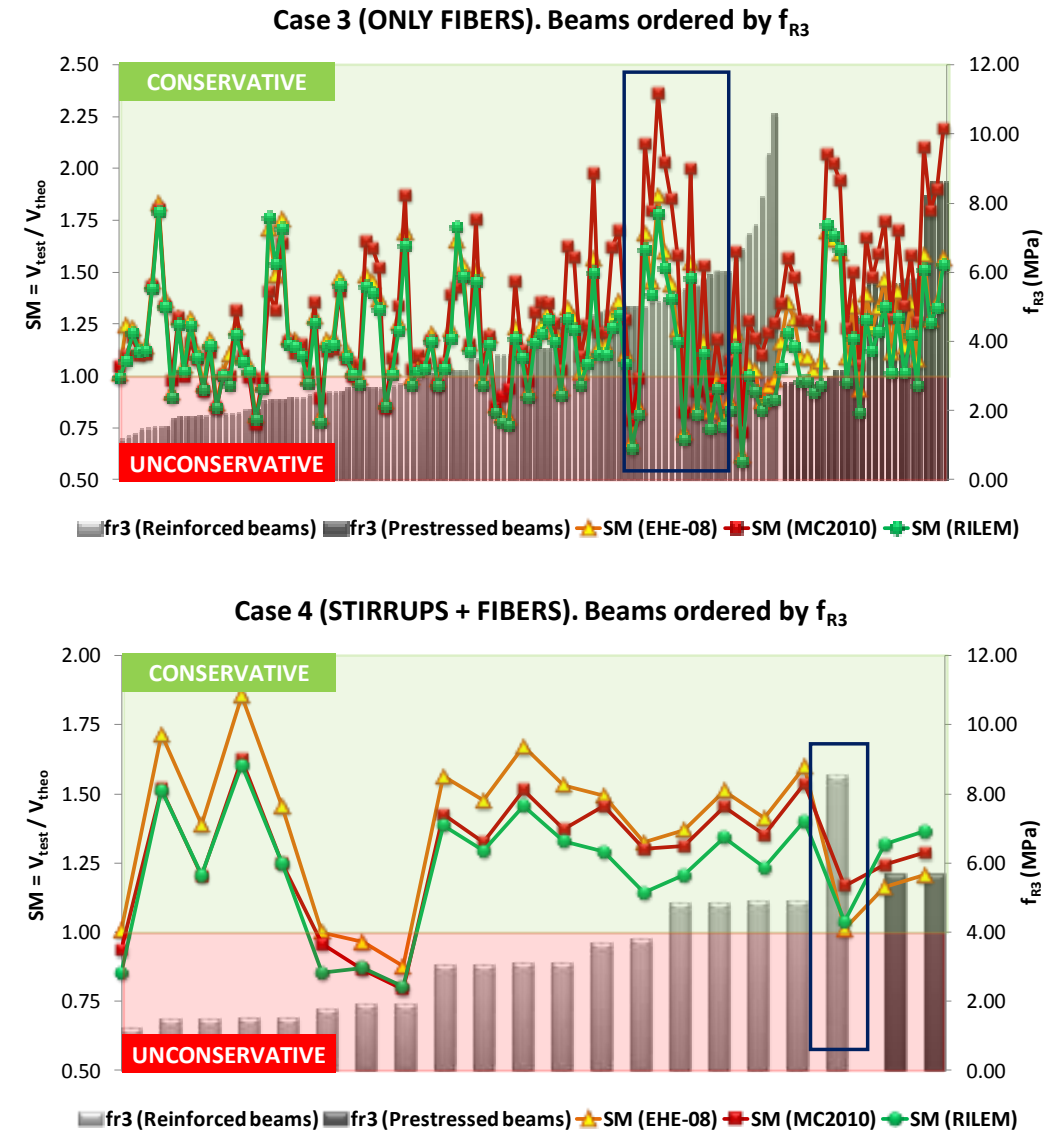

Fig. 8. 45 Influence of the residual tensile strength $\left(f_{R 3}\right)$ on shear safety margins

But fundamentally, it was evidenced that the shear should not rely solely on the value of $f_{R 3}$ for all types of FRC (with any type of fiber and any concrete compressive strength), since residual strength for smaller crack opening $\left(f_{R 1}\right)$ also influences the shear strength.

Hence parameters $f_{R 1}$ and $f_{R 3}$ should be linked to correctly estimate the theoretical shear value, as evidenced in Chapter 6 when an alternative parameter $f_{R m}=\left(f_{R 1}+f_{R 3}\right) / 2$ was proposed. 
Furthermore, in large beams, a crack opening corresponding to $f_{R 3}$, is not reached and a residual strength value related to $f_{R 1}$ should be considered. Reinforced beams with more than $125 \mathrm{~kg} / \mathrm{m}^{3}$ of fibers, evidenced $\mathrm{SM}>1$. In beams with combined reinforcement, for amounts of fibers greater than $40 \mathrm{~kg} / \mathrm{m}^{3}, \mathrm{SM}$ was always higher than 1 (Fig. 8. 46).

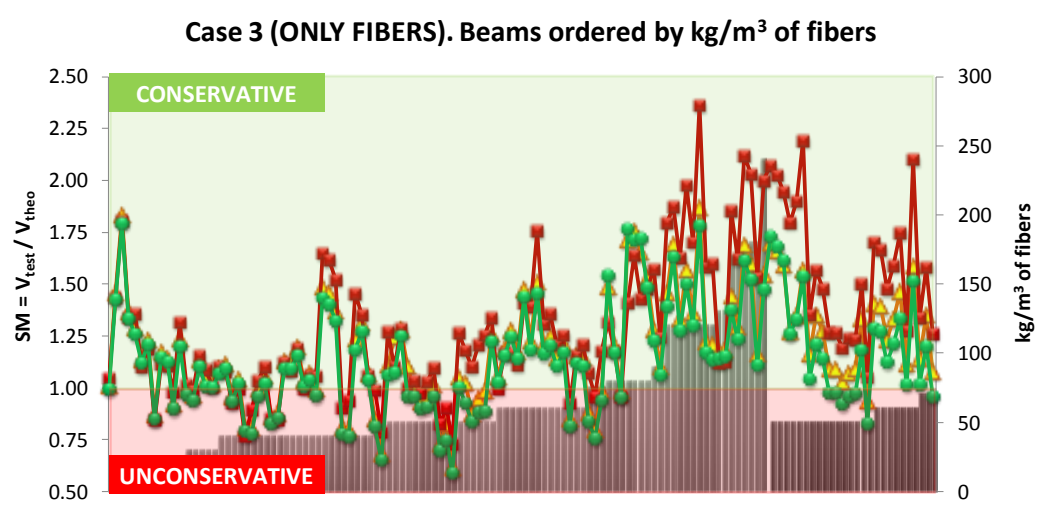

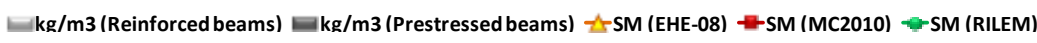

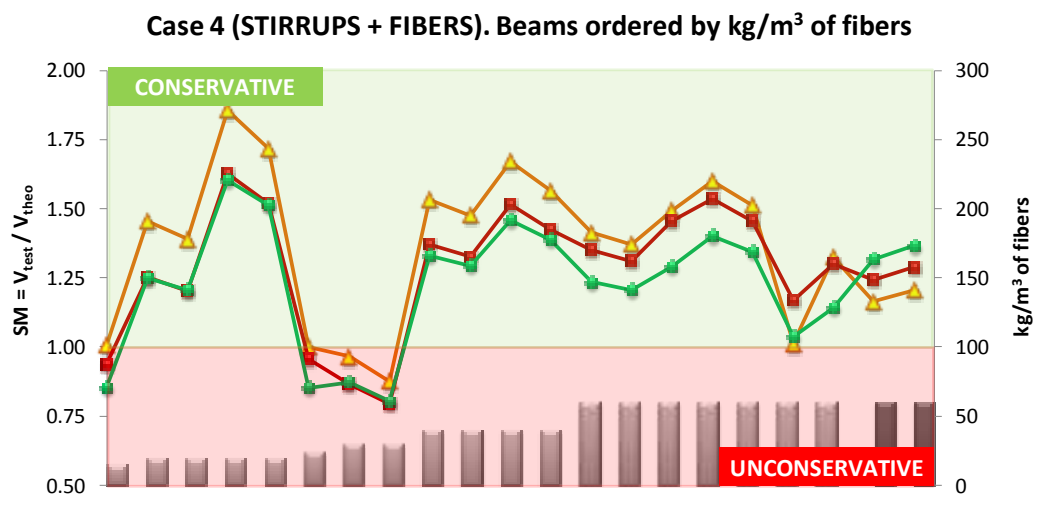

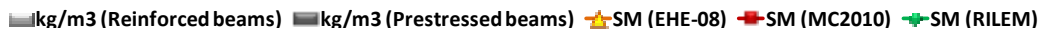

Fig. 8. 46 Influence of the amount of steel fibers $\left(\mathrm{kg} / \mathrm{m}^{3}\right)$ on shear safety margins

\subsubsection{Influence of the amount of longitudinal reinforcement, $\rho_{l}$}

Since $\rho>3.5 \%$ in reinforced beams, SM began a descent, to more $\rho$, less SM. This was observed in all cases, except when there were a combination of stirrups and fibers (Fig. 8. 47). For reinforced beams with stirrups and fibers, where $\rho<2 \%$ and $f_{R 3}<1.5 \mathrm{MPa}$, Codes were unsafe (Fig. 8. 48). In prestressed beams, for all cases and all Codes, more $\rho$, more SM (Fig. 8. 47). 

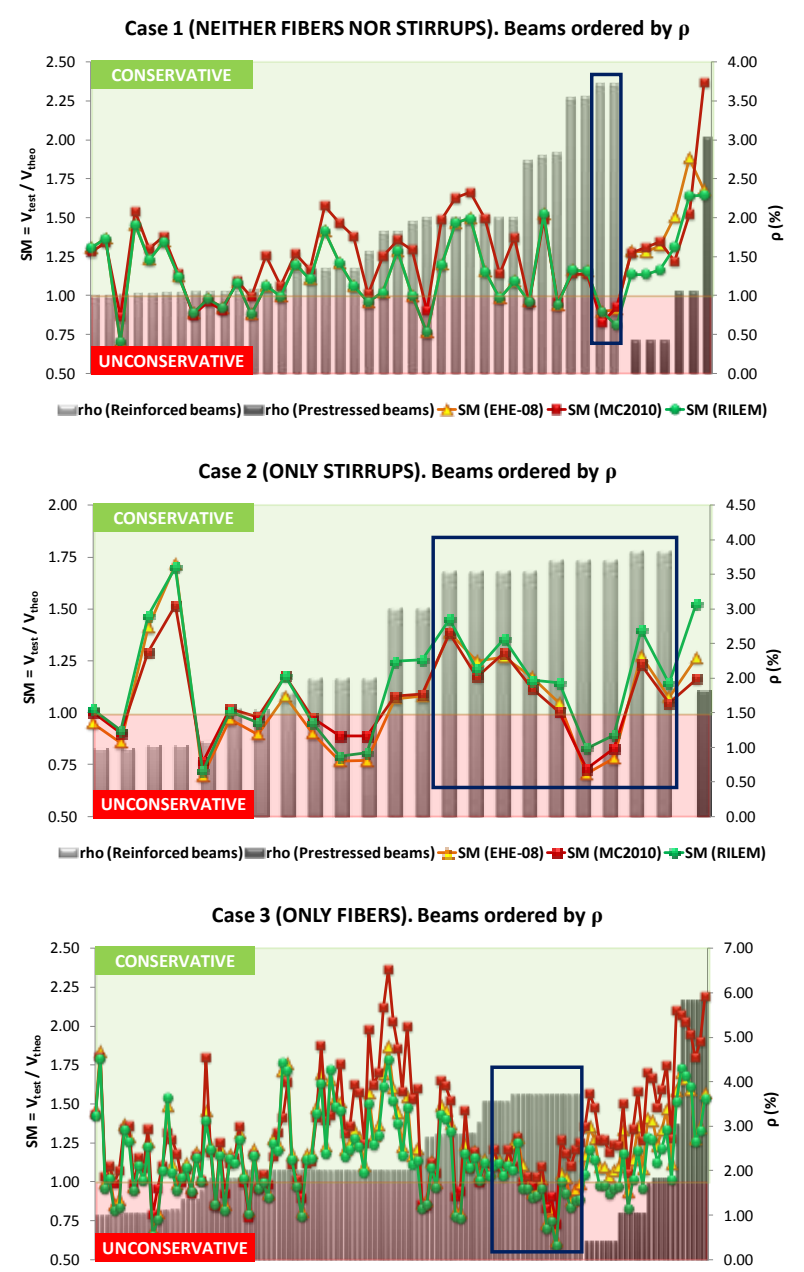

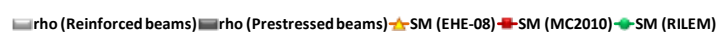

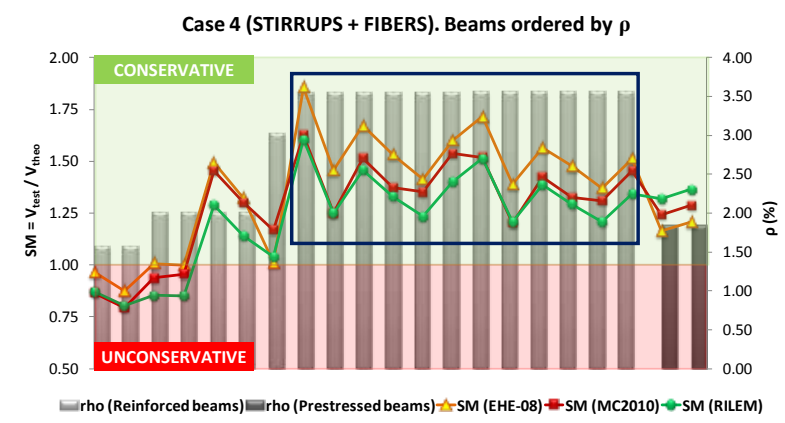

Fig. 8. 47 Influence of the amount of longitudinal reinforcement $\left(\rho_{l}\right)$ on shear safety margins 


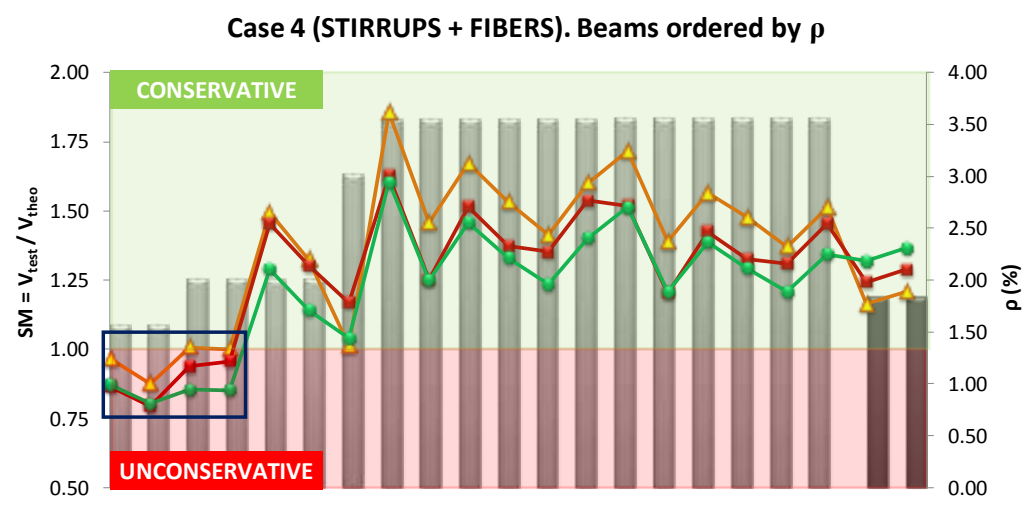

$\square$ rho (Reinforced beams) $\equiv$ rho (Prestressed beams) $\triangle-S M($ EHE-08) $-5 M$ (MC2010)- - SM (RILEM)

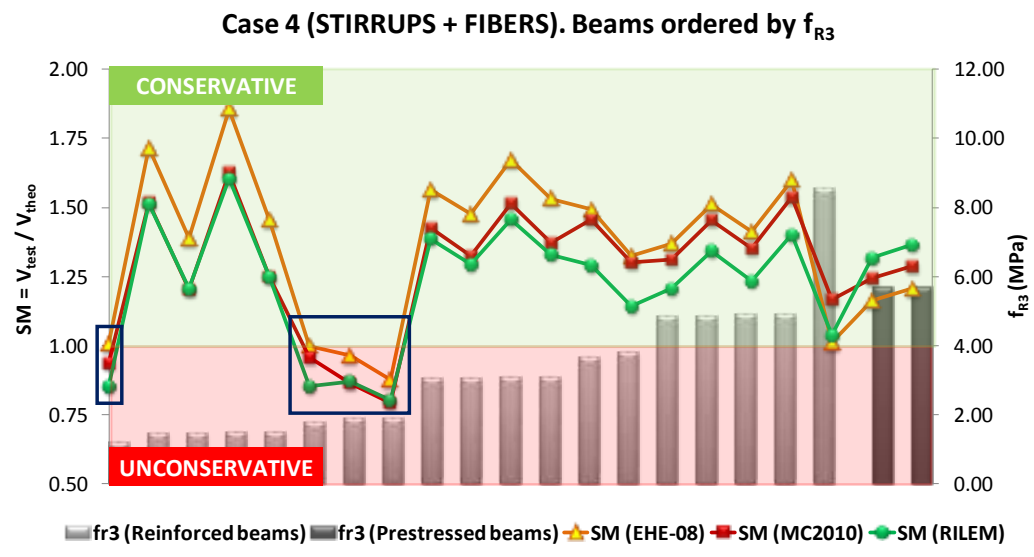

Fig. 8. 48 Influence of $\rho_{I}$ and $f_{R 3}$ on shear safety margins

\subsubsection{Influence of the stress due to the prestressing actions, $\sigma_{c}$}

Codes were always conservative for prestressed beams since they underestimate the effective shear strength experimentally determined. However, in beams with combined shear reinforcement (fibers and stirrups), prestressed beams had SM levels similar of those of beams without prestressing (Fig. 8. 49).

For beams without any shear reinforcement, SM of the prestressed beams had a clear dependence of prestressing, since the SM increased with the prestressing stress. In beams with shear reinforcement only, a larger scatter was observed (Fig. 8. 49). In these beams, MC2010 underestimated the effect of prestressing. In all Codes the SM decreased for prestressing stresses higher than $10 \mathrm{MPa}$ (Fig. 8. 49). 


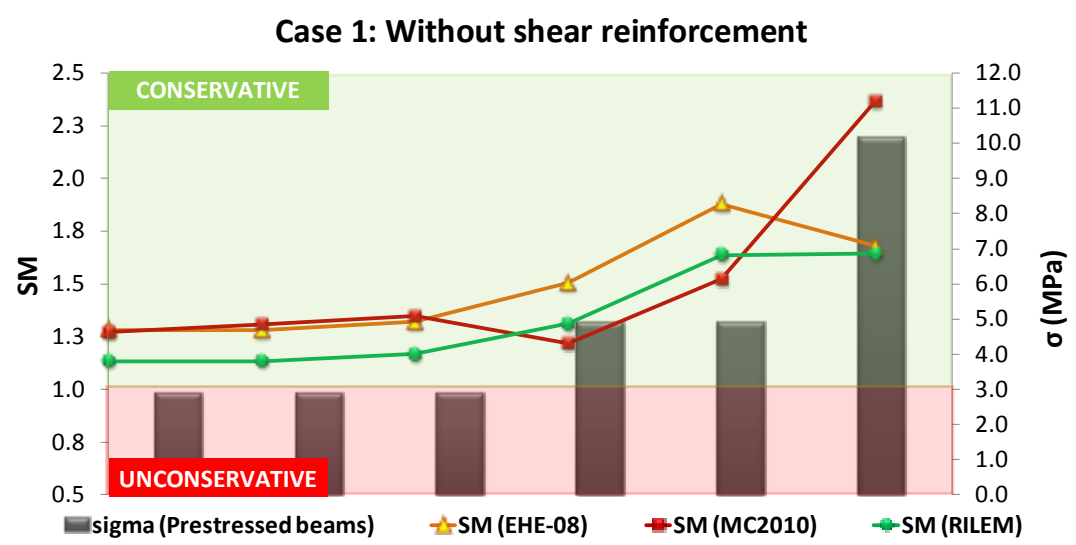

Case 3: Beams with only fibers

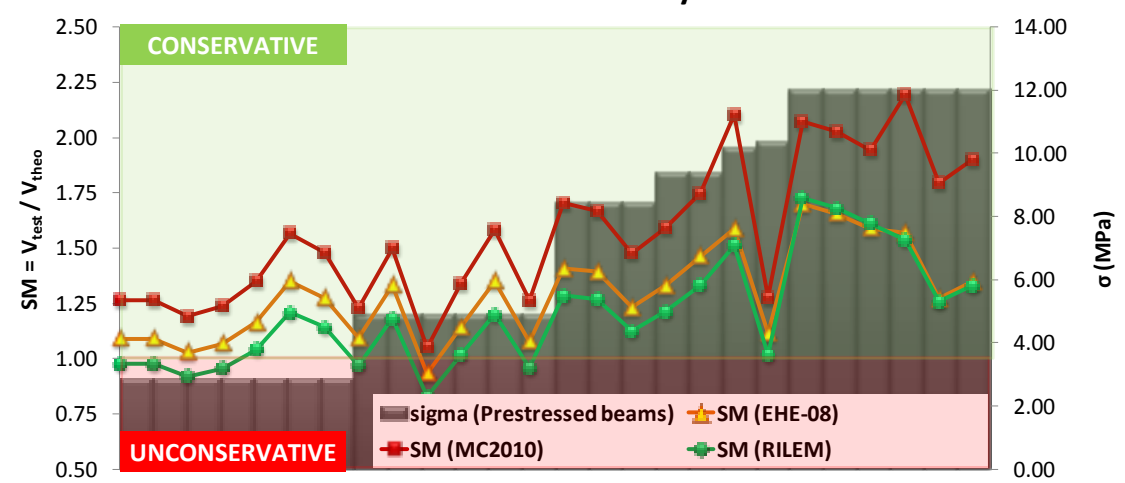

Fig. 8. 49 Influence of the stress due to prestressing actions $\left(\sigma_{c}\right)$ on shear safety margins

\subsection{Suggestions for Design Codes according to shear}

After analyze a large database consisting of 215 structural elements failing in shear, and determined the expected shear strength according to three different Design Codes, it was possible to evidence the role of the simple parameters and among these, the ones that could be better evaluated.

Unfortunately, although a lot of beams were included in the database, it was not possible to study the influence that each parameter has on the shear safety margin of each Code, but also the influence of some interactions between these parameters that seem to be particularly important.

The analyses performed on the database allowed observing that existing building Codes can be significantly improved and that every time new concrete matrices are developed with enhanced mechanical properties, the existing Codes may be no longer suitable. 
In the present work, some suggestions for improvements to existing Codes were made. In particular, the following suggestions are proposed:

- Codes are not reliable for calculating shear strength when $a / d<2.5$, since the arch action is very pronounced and shear strength provided by Codes is markedly conservative. For proper calculation of these cases, other methods should be used as the method of struts and ties.

- The larger the crack width at Ultimate Limit State becomes, the stronger the sizeeffect will be. Furthermore, it should be considered that the size factor is influence by the fiber length [15] and, therefore, by the FRC toughness. The latter is a mechanical property that better characterize the material behavior. Therefore, in fiber reinforced elements, the parameter governing the size effect should depend on the FRC toughness in addition to the element size.

- After analyzing the database, it was found that, for small elements without stirrups (eg. $d=200 \mathrm{~mm}$ ), Codes gave conservatives SM, and that, for larger elements, without stirrups, Codes overestimates the shear strength.

- For small depths will interest to decrease the SM by increasing the theoretical shear, for that, size effect factor $(\xi)$ must be increased. In contrast, for great depths, SM will be increased by reducing the theoretical shear by diminishing the size effect factor $(\xi)$. Therefore, the size effect rules proposed by Codes should be connected accordingly.

- It has been observed that Codes overestimate the shear strength of beams made of high strength concrete $\left(f_{c}>70 \mathrm{MPa}\right)$. Therefore, structural codes should provide rules that take into account the shear strength, when $f_{c}>70 \mathrm{MPa}$, as does the EHE when limits the compressive strength $\left(f_{c} \leq 60 \mathrm{MPa}\right)$ and the MC2010 for elements without fibers $\left(\left(f_{c k}\right)^{1 / 2} \leq 8 M P a\right)$. In fact, the Model Code [11] ensures that its limitation in $f_{c k}$ is provided due to the larger observed variability in shear strength of higher strength concrete, particularly for members without stirrups. However, concrete compressive strength also influences the FRC toughness.

- Beside fracture parameter $f_{R 3}$, parameter $f_{R 1}$ should be considered for shear strength, since it depends also on the smaller cracks. A parameter that better represents the shear strength in FRC could be represented by the average value $f_{R m}=\left(f_{R 1}+f_{R 3}\right) / 2$. 
- Codes are highly conservative for prestressed beams, better and more appropriate rules for considering the compressive stress in the beams should be proposed.

\subsection{References}

[1] Muttoni and Fernández-Ruiz, "Shear in slabs and beams: should they be treated in the same way?," fib Bulletin 57.Shear and punching shear in RC and FRC elements. Workshop Proceedings, p. 268 pp., 2010.

[2] Cladera and Marí, "Shear design of reinforced and prestressed concrete beams: a proposal for code procedure.," Hormigón y Acero, vol. 242, no. 4, pp. 51-63, 2006.

[3] Di-Prisco, Plizzari and Vandewalle, "MC2010: Overview on the shear provisions for FRC," fib Bulletin 57. Shear and punching shear in RC and FRC elements. Workshop proceedings., p. 268 pp., 2010.

[4] Bentz, "MC2010: Shear strength of beams and implications of the new approaches," fib Bulletin 57. Shear and punching shear in RC and FRC elements. Workshop proceedings, p. 268 pp., 2010.

[5] Rosenbusch, Teutsch, Dupont, Vandewalle, Gettu, Barragán, Martín, Ramos and Burnett, "Subtask 4.2: Trial Beams in Shear," in Brite-Euram Project: Test and design methods for steel fibre reinforced concrete, 2002.

[6] Dupont and Vandewalle, "Shear capacity of concrete beams containing longitudinal reinforcement and steel fibers," ACI Special Publication, vol. 216, pp. 79-94, 2003.

[7] Conforti, Cuenca, Minelli and Plizzari, "Can we mitigate or eliminate size effect in shear by utilizing steel fibers?," in Proceedings of fib Symposium PRAGUE 2011, 2011.

[8] EN14651:2005+A1, "Test method for metallic fibre concrete - Measuring the flexural tensile strength (limit of proportionality (LOP), residual)," 2005.

[9] EHE-08, Instrucción de Hormigón Estructural EHE-08 (in Spanish), Ministerio de Fomento, 2008, p. 702 pp..

[10] RILEM, «TC 162-TDF. Test and design methods for steel fibre reinforced concrete, stress-strain design method. Final Recommendation.," Materials and Structures, vol. 
36, pp. 560-567, 2003.

[11] MC2010, "fib Bulletins 55-56. Model Code 2010. First Complete Draft," 2010.

[12] EC2, "Eurocode 2: Design of Concrete Structures - EN 1992-1-1," 2005.

[13] Montgomery and Runger, Probabilidad y Estadística aplicadas a la Ingeniería, McGraw Hill, 1996.

[14] Romero and Zúnica, Métodos estadísiticos en Ingeniería, UPV, 2010.

[15] Vandewalle and Dupont, "Subtask 7.2. Final Report. Recommendations for the design of SFRC," Brite-Euram Project BRPR-CT98-0813: Test and design methods for steel fiber reinforced concrete, 2002. 


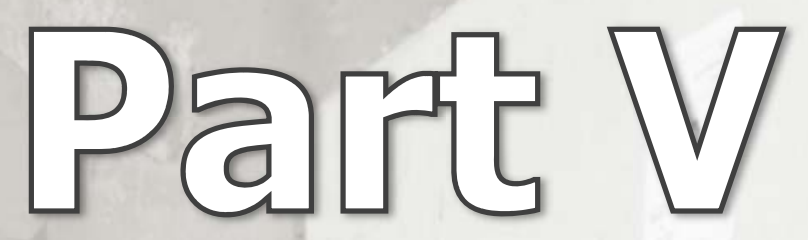

ConสIusions and

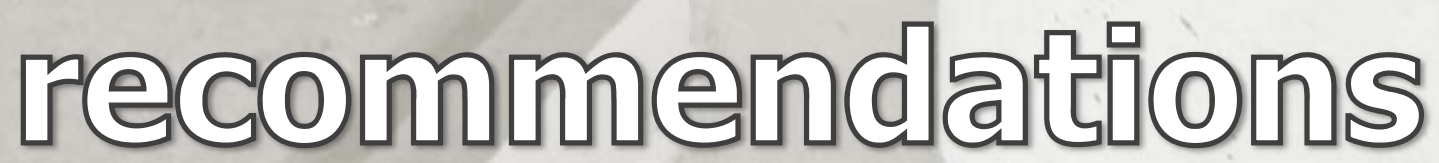




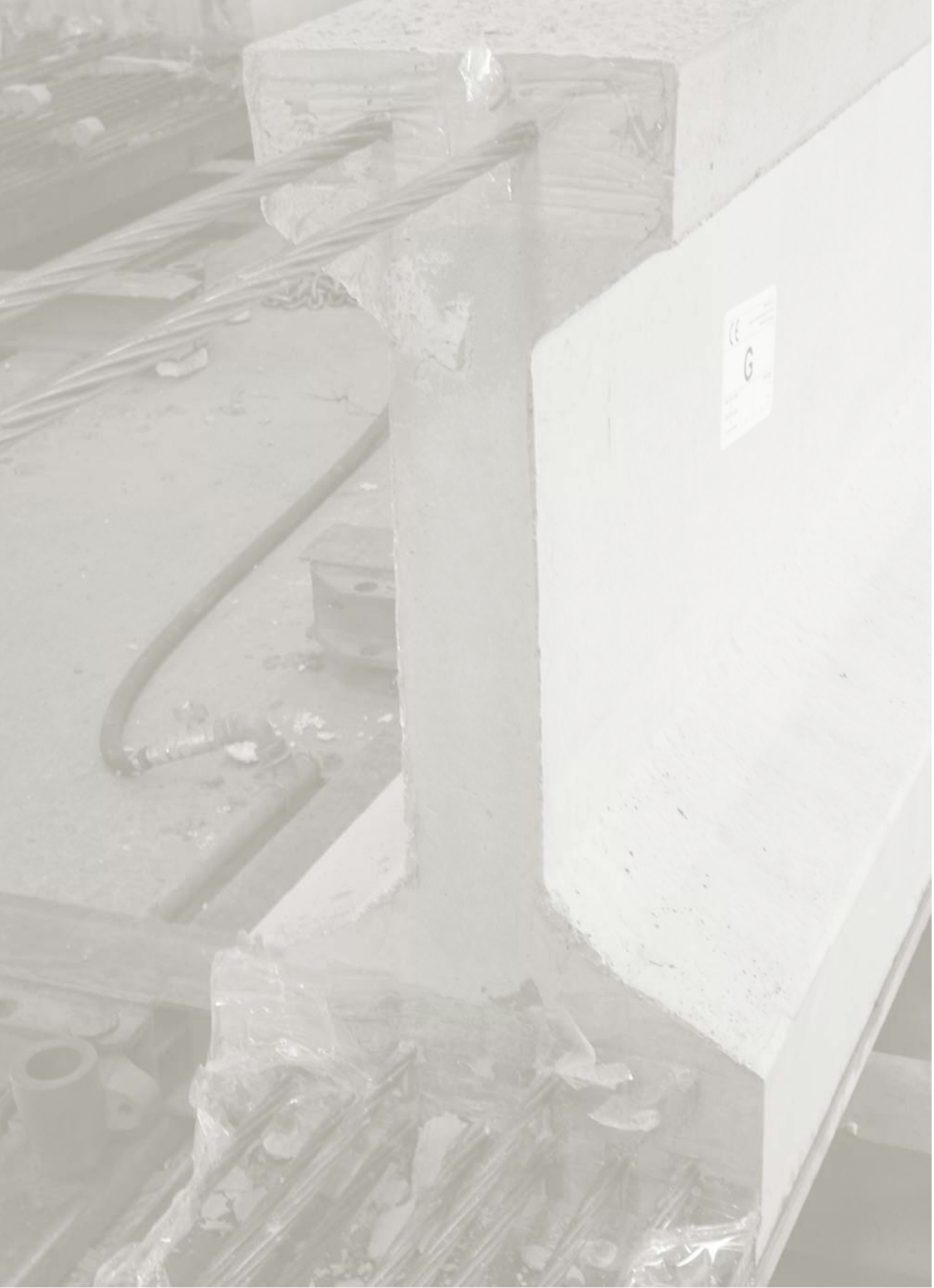




\section{CHAPTER 9} CONCLUSIONS

This thesis presents a comprehensive experimental program for analyzing the behavior of FRC beams with different dimensions, production processes and transverse reinforcement.

The analysis of the results confirms that steel fibers improve the shear behavior of beams and that their contribution may be highly beneficial in many cases and practically indispensable in others.

The main conclusions can be summarized as follows (subscript indicates the chapter referred to):

- A self-compacting fiber-reinforced concrete (SCFRC) of consistent quality can be cast in a continuous process, as shown by the slump flow test, compressive strength and flexural behavior under normal site conditions. ${ }^{\text {Chap. } 4}$

- Adding steel fibers to beams with stirrups improves ductility as steel fibers control cracking and help to prevent cracks from spreading. ${ }^{\text {Chap.4 }}$

- With steel fibers more cracks are created but they are smaller than in plain concrete and the crack spacing is also smaller. ${ }^{\text {Chap. } 4}$

- Beam flanges clearly improve shear behavior, as they prevent failure by compression in the top beam layer. This effect should be included in the Codes in the form of a flange coefficient $\left(k_{f}\right)$ for all types of concrete. An improvement in shear behavior 
with flange width was also observed, although there were two exceptional cases with no improvements: small flange widths (in relation to web width) and large flange widths (depending on the other dimensions of the cross section) in which shear improvement remains constant over a certain flange width. ${ }^{\text {Chap. } 4}$

- The RILEM approach does not model the positive effect of fibers on the dowel action, as fibers do not affect the longitudinal reinforcement term, so that RILEM considers fibers and longitudinal reinforcement to be completely independent. On the other hand, MC2010 considers the positive effect of fibers on the dowel action, so that the fibers' contribution increases with high longitudinal reinforcement ratios. ${ }^{\text {Chap.4 }}$

- Fibers substantially mitigate the size effect in shear: the effect of the descending trend in this factor becomes less steep with increasing FRC toughness and shear failure (and size effect) appears at higher effective depths in members. ${ }^{\text {Chap.5 }}$

- The constitutive law of FRC in tension is obtained from the prismatic specimen results (EN 14651). It is therefore necessary to consider an appropriate critical length $\left(L_{r}\right)$ for each specific case. ${ }^{\text {Chap. } 5}$

- Even small amounts of fibers greatly influence the shear behavior of beams, basically by delaying the occurrence of the shear failure mechanism and by altering the collapse from shear to flexure, with enhanced bearing capacity and ductility. ${ }^{\text {Chap. } 5}$

- - Fibers mitigate the size effect in shear, which declines with increased FRC toughness. ${ }^{\text {Chap.5 }}$

- $\quad$ Even though fibers have positive effects when added to stirrups, their contribution does not represent an optimized practical solution for at least two reasons. The first is mechanically-based, since fibers and stirrups do not come into action at the same time and their contributions cannot simply be added together. The second is practically-based, since the main advantage of using fibers consists of avoiding the use of stirrups and larger stirrup spacing. The only exception is that fibers control the formation and propagation of new cracks, but when they do show up the fiber mitigates their effects.

- A large amount of longitudinal reinforcement can be efficient for shear resistance, provided that it is well anchored and has sufficient cover. In these conditions the 
limitation on the amount of longitudinal reinforcement $\left(\rho_{l}\right)$ of $2 \%$, generally imposed by Design Codes should not be applied. ${ }^{\text {Chap.6 }}$

- Shear strength and load deflection response markedly depend on the fiber type (quality of steel and geometry of steel fiber) and its combination with the compressive strength of the concrete matrix. It is possible to have a brittle postcracking (high compressive concrete strength + low steel strength fibers) or a very ductile behavior (low or medium compressive concrete strength + high steel strength fibers). ${ }^{\text {Chap.6 }}$

- The combined effects of the structural system that comes into play in the structural member (position and amount of longitudinal reinforcement, section shape and dimensions), including the joint effects of stirrups and fibers, depend on the evolution of shear-crack width. Thus, for certain structural arrangements, the use of the fracture parameter $f_{R 3}$ as a reference value for calculating shear strength may be unsafe or over-conservative. In some circumstances, as in small beams, the average value between $f_{R 1}$ and $f_{R 3}$ may be more appropriate. ${ }^{\text {Chap. } 6 \text { and } 8}$

- Given the impossibility of placing stirrups in extruded Hollow Core Slabs (HCS), adding steel fibers to concrete certainly improves shear resistance, as it was demonstrated that it is possible to produce HCS without any technical problems. ${ }^{\text {Chap.7 }}$

- According to the database analyzed, it seems that Design Codes are always conservative for prestressed beams and they also seem to overestimate the shear strength of beams made with high strength concretes $\left(f_{c}>70 \mathrm{MPa}\right){ }^{\text {Chap.8 }}$

On Shear Behavior of structural elements made of steel fiber reinforced concrete - PhD thesis 


\section{CHAPTER 10}

\section{RECOMMENDATIONS}

\section{FOR FUTURE RESEARCH}

The following recommendations are based on the experimental and numerical results of the present study:

- A new push-off test should be performed subject to direct shear loads, with good control of crack width, in order to improve the response of the test in determining aggregate interlock in different concrete matrixes, at different levels of compressive strength and with different kinds of steel fibers.

- Improvements should be proposed for the current formulations in the Design Codes.

- FRC should be included in building codes for its toughness, but not only based on the $f_{R 3}$ parameter, as it is not representative for all types of FRC.

On Shear Behavior of structural elements made of steel fiber reinforced concrete-PhD thesis 


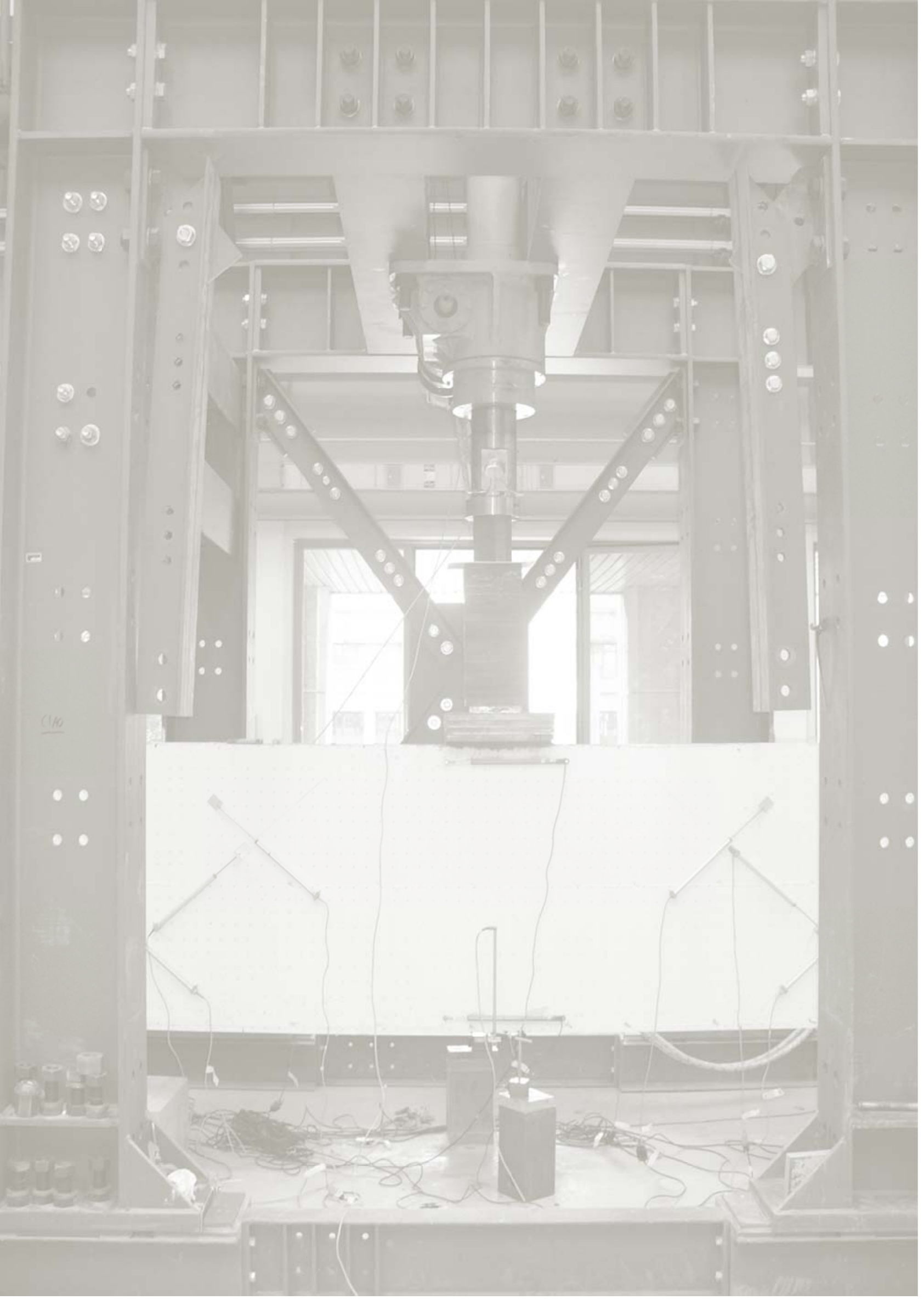




\section{APPENDIX A}

LITERATURE SURVEY ON SHEAR BEHAVIOR IN CONCRETE

\section{ELEMENTS WITHOUT FIBERS}

\section{A.1 Basic Theory}

\section{A.1.1 Stresses in an uncracked elastic beam}

From the free-body diagram (Fig.A.1), it can be seen that $d M / d x=V$. Thus shear forces and shear stresses will exist in those parts of a beam with gradient in the moment [1]. 


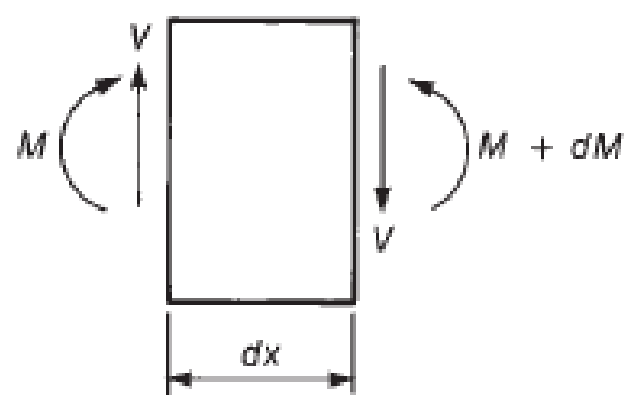

Fig.A.1 Internal forces on portion between sections in a beam [1]

By the traditional theory for homogeneous, elastic, uncracked beams, the shear stresses, $\boldsymbol{v}$, can be calculated, using the Eq. A.1 (Fig.A.2):

$$
v=\frac{V \cdot Q}{I \cdot b}
$$

where:

$V=$ shear force on the cross section;

$I=$ moment of inertia of the cross section about the neutral axis;

$Q=$ statical moment about the neutral axis of that portion of cross section lying between a line through the point where the shear stresses are being calculated, parallel to the neutral axis and nearest face, upper or lower, of the beam;

$b=$ width of the member at the section where the stresses are being calculated.
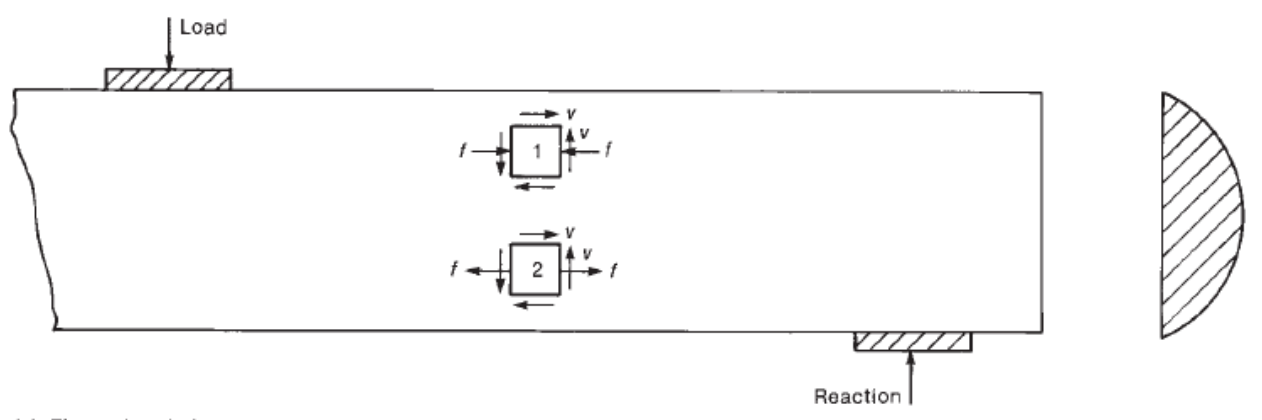

(a) Flexural and shear stresses acting on elements in the shear span.

(b) Distribution of shear stresses.

Fig.A.2 Normal, shear, and principal stresses in a homogeneous uncracked beam [1]

So, the distributions of shear stresses according to elastic theory for homogeneous beams are shown in Fig. A. 1. 


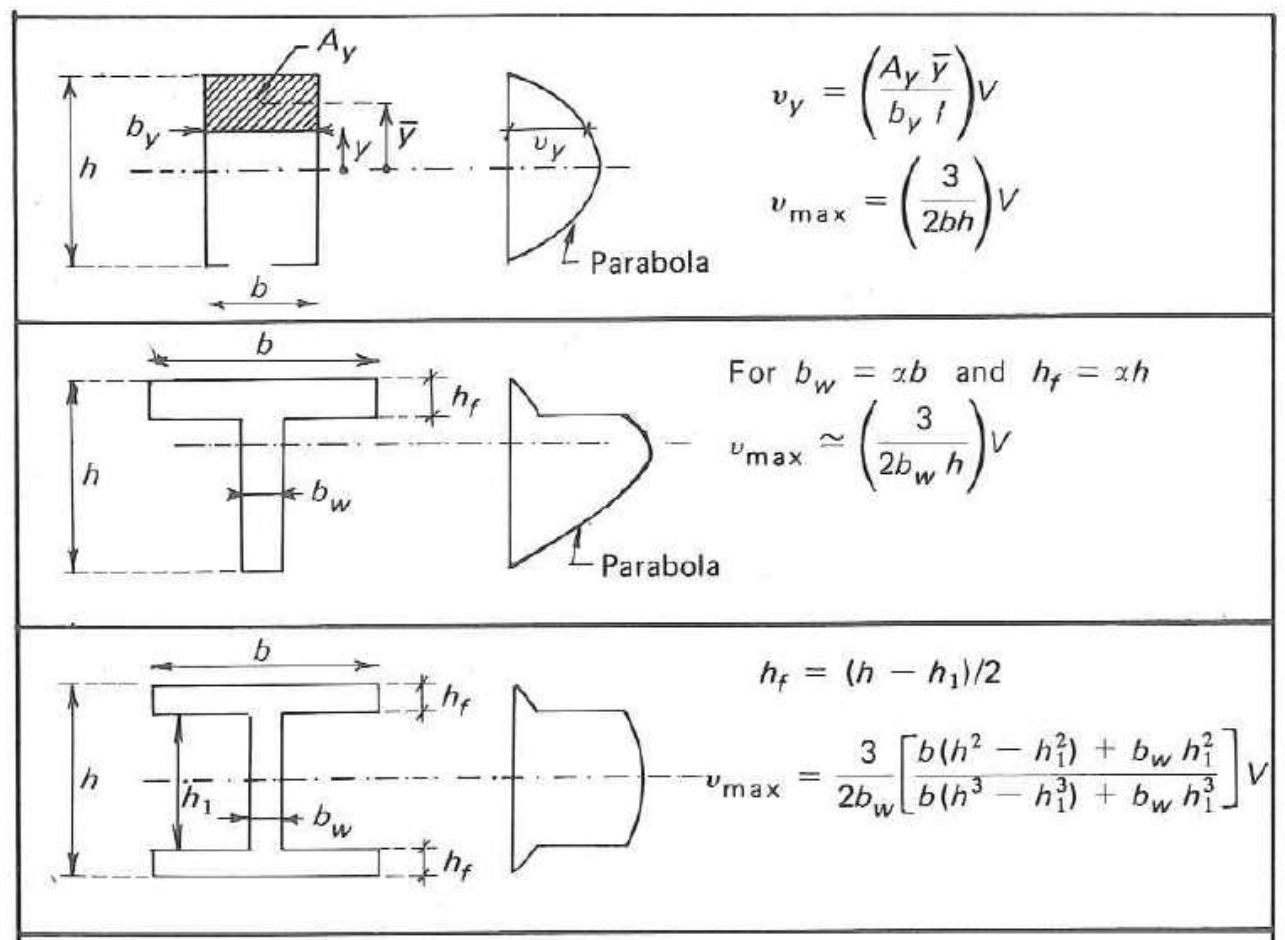

Fig. A. 1 Typical shear stress diagrams and maximum shear stresses for various sections [2]

It can be observed that almost all the shear force is resisted by the web, whereas the flange resists a very small percentage; as a consequence, in most practical problems, the shear capacity of the flange is neglected [3].

The surfaces on which principal tension stresses at the uncracked beam are plotted as curved lines in Fig.A. 2. These surfaces or stress trajectories are steep near the bottom of the beam and flatter near the top. Since concrete cracks when the principal tensile stresses exceed the tensile strength, the initial crack pattern should resemble the family of lines shown in Fig.A. 2 [1].

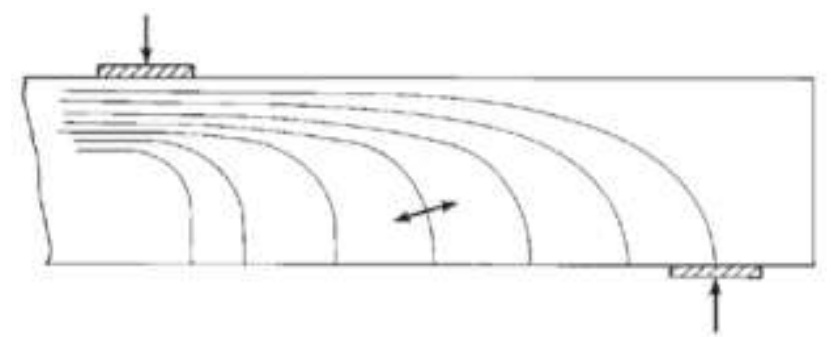

Fig.A. 2 Principal compressive stress trajectories in an uncracked beam [1] 
Fig. A. 3 shows the internal stresses acting on the infinitesimal elements $\boldsymbol{A}_{\boldsymbol{1}}$ and $\boldsymbol{A}_{\mathbf{2}}$. Using Mohr's circle, the principal stresses for element $\boldsymbol{A}_{\boldsymbol{1}}$ in the tensile zone below the neutral axis become:

$$
\begin{aligned}
& f_{t(\max )}=\frac{f_{t}}{2}+\sqrt{\left(\frac{f_{t}}{2}\right)^{2}}+v^{2} \rightarrow \text { Principal tension } \\
& f_{c(\max )}=\frac{f_{t}}{2}-\sqrt{\left(\frac{f_{t}}{2}\right)^{2}}+v^{2} \rightarrow \text { Principal compression } \\
& \tan 2 \theta_{\text {max }}=\frac{v}{f_{t} / 2}
\end{aligned}
$$
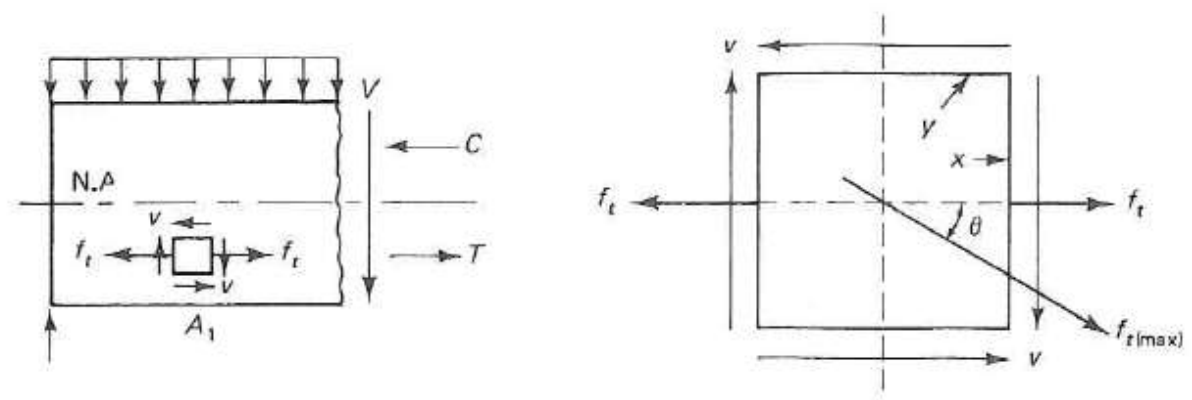

(a)

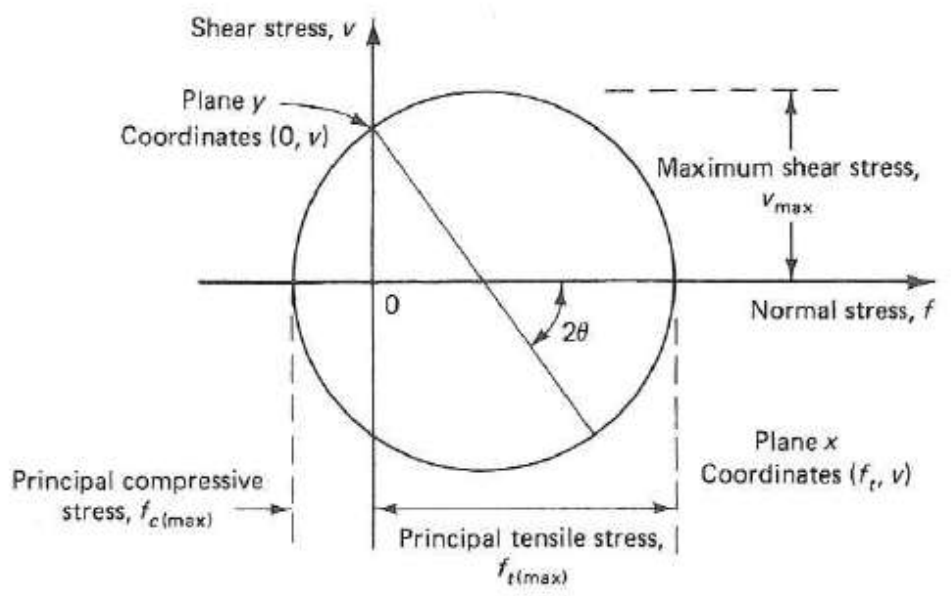

(b)

Fig. A. 3. Stress state in elements $A_{1}$ and $A_{2}$; (a) Stress state in element $A_{1}$; (b) Mohr's circle representation, element $A_{1}$. (c) Stress state in element $A_{2}$. (d) Mohr's circle representation, element $A_{2}$ [4] 


\section{A.1.2 Average shear stress between cracks}

The initial stage of cracking generally results in vertical cracks which eventually extend in a diagonal manner. The equilibrium of the section of beam between two adjacent cracks (Fig.A. 4-b) can be written as:

$$
T=\frac{M}{j d} \quad \rightarrow \quad T+\Delta T=\frac{M+\Delta M}{j d} \rightarrow \Delta T=\frac{\Delta M}{j d}
$$

where $j d$ is the lever arm, which is assumed to be constant. For the equilibrium of the element:

$$
\Delta M=V \Delta x \quad \text { and } \quad \Delta T=\frac{V \Delta x}{j d}
$$

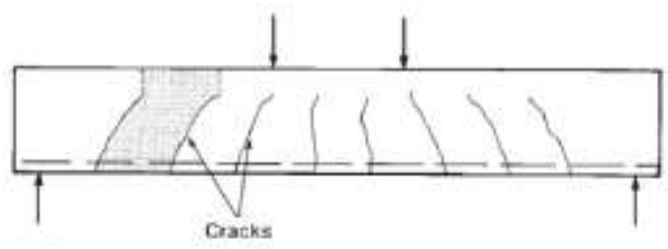

(a) Cracked beam

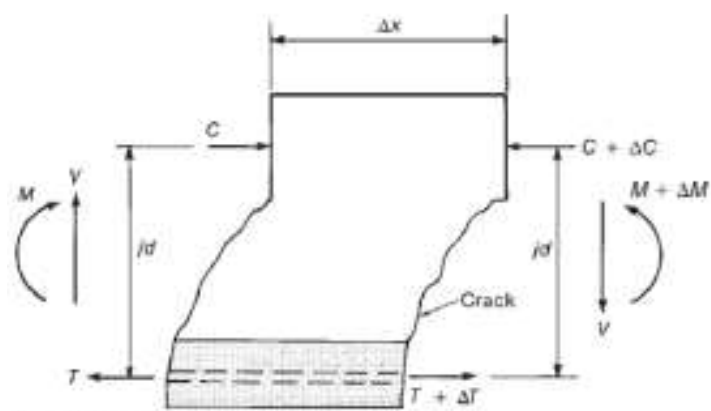

(b) Portion of beam between two eracks

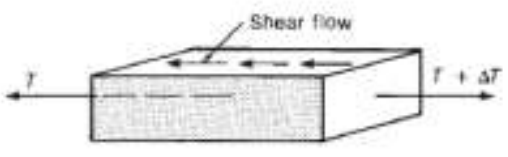

4c) Botiom part of beam.

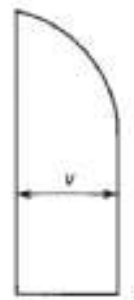

(d) Average shear stresses.

Fig.A. 4 Calculation of average shear stress between cracks [1]

If the shaded portion of Fig.A. 4-b is isolated as shown in Fig.A. 4-c, the force $\Delta T$ must be transferred by horizontal shear stresses on the top of the element. The average value of these stresses below the top of the crack is: 


$$
v=\frac{\Delta T}{b_{w} \Delta x} \quad \text { or } \quad v=\frac{V}{b_{w} j d}
$$

Where $j d \approx 0.875 d$ and $b_{w}$ is the thickness of the web. The distribution of average horizontal shear stresses is shown in Fig.A. 4-d. Since the vertical shear stresses on an element are equal to the horizontal shear stresses on the same element, the distribution of vertical shear stresses is the same of Fig.A. 4-d. This assumes that about $30 \%$ of the shear is transferred in the compression zone. The rest of the shear is transferred across the cracks. In 1970, Taylor [5] reported tests of beams without web reinforcement in which he found that about $25 \%$ of the shear was transferred by the compression zone, about $25 \%$ by doweling acting of the flexural reinforcement, and about $50 \%$ by aggregate interlock along the cracks [1].

\section{A.1.3 Beam action and arch action}

Shear forces acting on reinforced concrete beams are resisted either by beam action involving bond forces, or by arch action requiring the inclination of the internal compression force [6]. The essential structural component of the beam action is the concrete blocks, formed between flexural cracks of the shear span, which behave as cantilevers restrained by the compression zone of the beam [6]. In conventionally reinforced concrete, the arch action is confined to two localities of the beam. One is near load point and the other is in the vicinity of the support. Appreciable arch action over the whole shear span can only occur when these two localities merge. This takes place when an extensive diagonal crack extends through the shear span. When diagonal cracking occurs, the beam may either fail or it may sustain further sharing forces by means of arch action. This ability of the beam depends principally on the a/d ratio, the loading modalities and the size of the compression zone. Arch action can develop to an appreciable extent only after the breakdown of beam action. Therefore the ultimate strength of the two mechanisms is not additive [6].

The relationship between shear and bar force, assuming the beam as prismatic and the lever arm $j \boldsymbol{d}$ constant, can be rewritten as [7]:

$$
V=\frac{d}{d x}(T j d) \quad \rightarrow \quad V=\frac{d(T)}{d x} j d+\frac{d(j d)}{d x} T
$$


The first term of Eq.A.8, $j d \cdot d T / d x$, expresses the resisting contribution of the beam action, in which the tensile force in the bars is supposed to vary, and the internal lever arm, $j d$, is taken constant. The factor $d T / d x$ is the unit bond force in the longitudinal reinforcement [6]. The second term of Eq.A.8 expresses the resisting contribution of the arch action. This mechanism is characterized by the variation of the internal lever arm, $j d$, along the beam axis, while the tensile force $T$ is kept constant, so providing no bond force.

\section{Beam action:}

$$
\frac{d(j d)}{d x}=0 \quad \text { and } \quad V=\frac{d(T)}{d x} j d
$$

where $d(T) / d x$ is the shear flow across any horizontal plane between the reinforcement and the compression zone, as shown in (Fig.A. 4-c). For beam action to exist, this shear flow must exist.

\section{Arch action:}

The other extreme occurs if the shear flow, $d(T) / d x$, equals zero, giving:

$$
V=T \cdot \frac{d(d j)}{d x} \quad \text { or } \quad V=C \cdot \frac{d(j d)}{d x}
$$

This occurs if the shear flow cannot be transmitted, because the steel is unbounded, or if the transfer of shear flow is disrupted by an inclined crack extending from the load to the reactions. In such a case, the shear is transferred by arch action rather than beam action, as illustrated in (Fig.A. 5). In this member, the compression force $C$ in the inclined strut and the tension force $T$ in the reinforcement are constant over the length of the shear span.

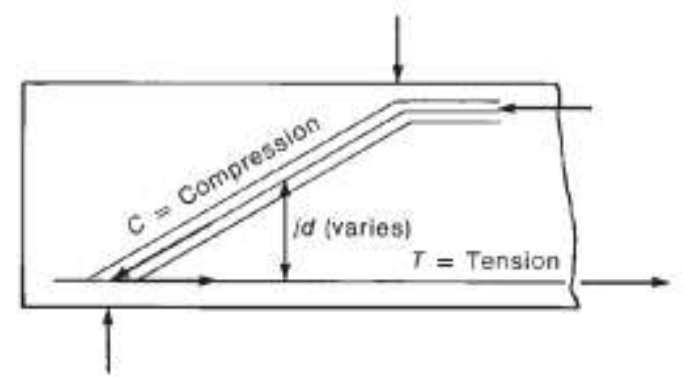

Fig.A. 5 Arch action in a beam [1] 
The compressed top turns near the support (maximum shear zone), so that the longitudinal compression in this top, $N_{c}$, has a vertical component $N_{c} \cdot \sin \theta$ that contributes to resist shear, transmitting it to the support. This forms in the beam a tied arch. This effect, which resists between 20 and $40 \%$ of $V_{c}$, depending on the relationship between the depth and the span of the beam, is strongly conditioned by the ability of the longitudinal reinforcement, reaching the support and acting as a tie of the arch [8].

Eurocode 2 presents two alternatives methods for accounting for arching action in beams. The simplest option is to reduce the component of shear force owing to loads applied within $2 d$ of the support by the multiple $a_{v} / 2 d$ (where $a_{v}$ is the clear shear span and $d$ is the effective depth). Eurocode 2 also allows short-span beams to be designed with the strut-and-tie method (STM), raising the question of which method to use. When $a_{v} / d$ is between 1 and 2, the diagonal crack forms independently of flexural cracks and the beam remains stable after the formation of the diagonal crack, which typically runs between the inner edges of the bearing plates (Fig.A. 6) [9].

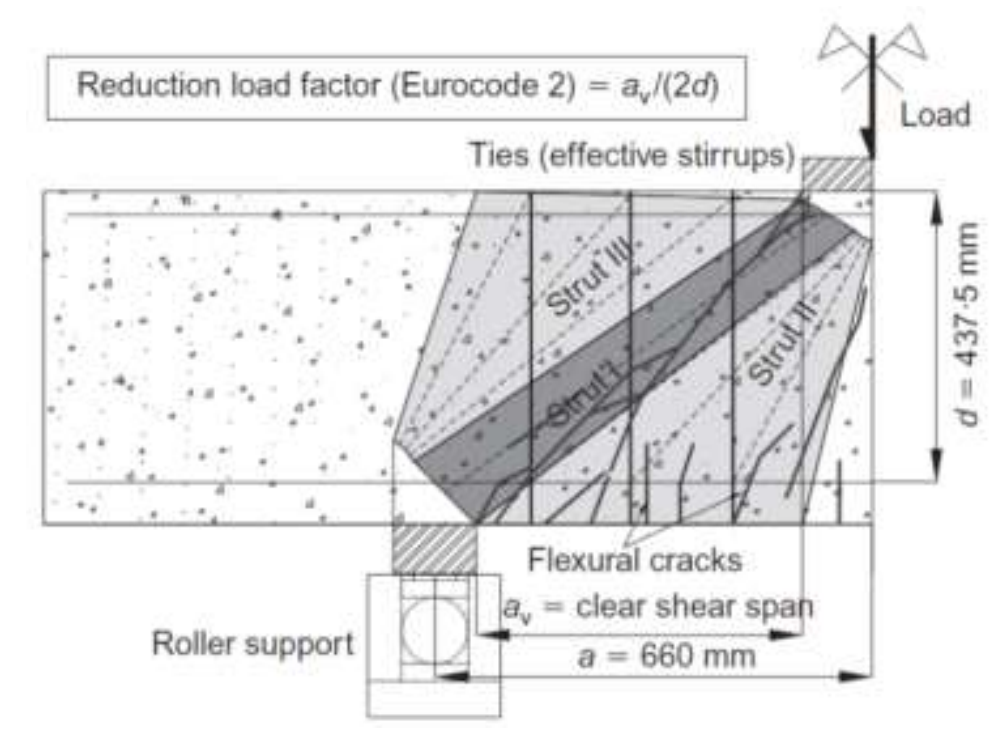

Fig.A. 6 Typical crack pattern and load paths in a short span beam $1<a_{v} / d<2$ with stirrups [9]

The shear strength and ductility of short-span beams can be enhanced by adding transverse reinforcement. Vertical stirrups increase shear strength if they cross the diagonal shear crack and they are considered effective for design purposes if placed within the central three quarters of the clear shear span $\boldsymbol{a}_{\boldsymbol{v}}$. It was shown [7] that the stirrup use positively affects the beam action by increasing: the dowel action for the support provided 
by stirrups to the longitudinal bars; the capacity of the concrete tooth for the diagonal compressive field relative to the truss mechanism; the aggregate interlock, for a lower crack opening due to the containment effect of stirrups [10].

Eurocode 2 uses Eq. A.11 to determine the shear strength of slender beams without shear reinforcement:

$$
V_{R d, c}=\frac{0.18}{\gamma_{c}}\left(100 \cdot \rho_{l} \cdot f_{c k}\right)^{1 / 3}(1+\sqrt{200 / d}) b d
$$

where $\gamma_{c}$ is the partial factor for concrete which equals $1.5 ; \rho_{l}=A_{s l} /(b d) ; f_{c k}$ is the concrete cylinder strength; $d$ is effective depth; and $b$ is member width.

Eq. A.11 accounts semi-rationally for size effects, dowel action, reinforcement ratio and concrete strength. Eurocode 2 reduces the design shear force by the multiple $a_{v} / 2 d$ to account for the increase in shear strength due to arch action in short-span beams. BS 8110 [11] adopts the alternative approach of multiplying the basic shear resistance $V_{c}$, which is calculated similarly to $\mathrm{V}_{\mathrm{Rd}, \mathrm{c}}$ in Eurocode 2, by an "enhancement" factor equal to $2 \mathrm{~d} / \mathrm{a}_{\mathrm{v}}$.

\section{A.2 Beams without shear reinforcement}

\section{A.2.1 Shear behavior in beams without shear reinforcement}

In 1902, Mörsch [12] used such an approach to derive the shear stress distribution for a reinforced concrete beam containing flexural cracks (see Fig. A. 7). Mörsch predicted that the shear stress would reach its maximum value at the neutral axis and would remain constant from the neutral axis down to the flexural steel. The value of this maximum shear stress would be:

$$
v=\frac{V}{b_{w} j d}
$$

Where $b_{w}$ is the web width and $j d$ is the flexural lever arm. Note that Mörsch's theory implies that high shear stresses are transmitted across the flexural cracks [13]. 

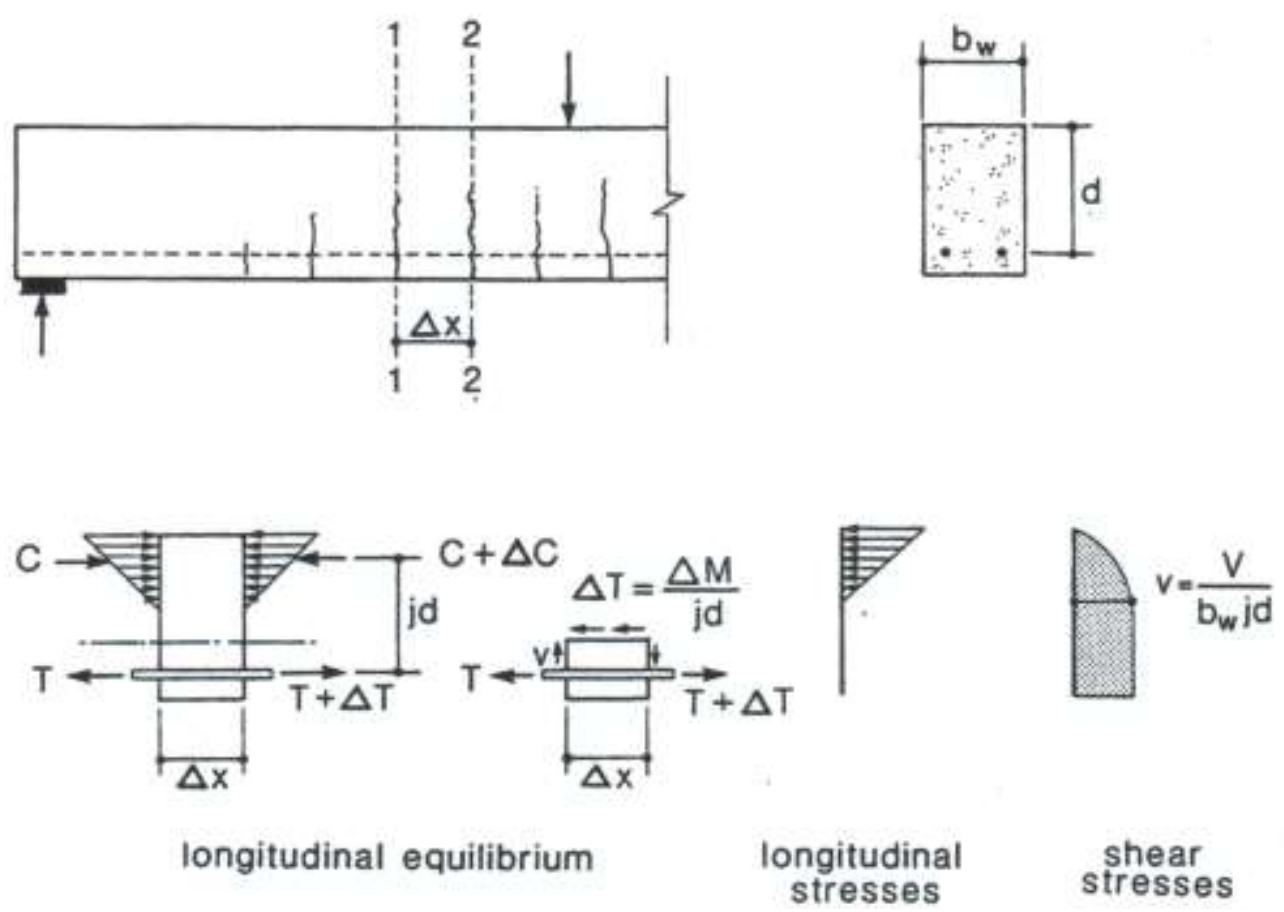

Fig. A. 7 Determining shear stress distribution in a reinforced concrete beam containing flexural cracks [12]

In the 1950s, researchers such as Zwoyer and Siess [14], Bresler and Pister [15], Guralnick [16] and Walther [17] studied the stress conditions in the concrete above flexural cracks in order to develop expressions for the shear capacity of members containing flexure-shear cracks. They typically assumed that all of the shear would be carried in the flexural compression zone and hence believed that the actual shear stress distribution was significantly different from that shown in Fig. A. 7. The uncertainty about the actual distribution of shear stresses over the section caused engineers to refer to the traditional shear stress of Eq. A.12 as the "nominal" shear stress [13].

Since Eq. A.12 was regarded as only a nominal indicator of shear intensity, the $1963 \mathrm{ACl}$ Code decided to simplify this shear stress equation to:

$$
v=\frac{V}{b_{w} d}
$$


where $d$ is the distance from the extreme compression fiber to the centroid of the tension reinforcement.

Kani [18] showed that shear failures are unlikely to occur for longitudinal reinforcement ratio's $\left(\rho_{l}\right)$ smaller than $0.6 \%$. However, his "shear valley" was based on beams with a cross-sectional effective depth of only $d=270 \mathrm{~mm}$. For larger depths, the critical value of $\rho_{l}$ decreases. In 1964, Kani [19] suggested a "comb" model for idealizing the load-carrying mechanisms of reinforced concrete beams, cracked in flexure and subjected to shear (see Fig.A. 8), [13].
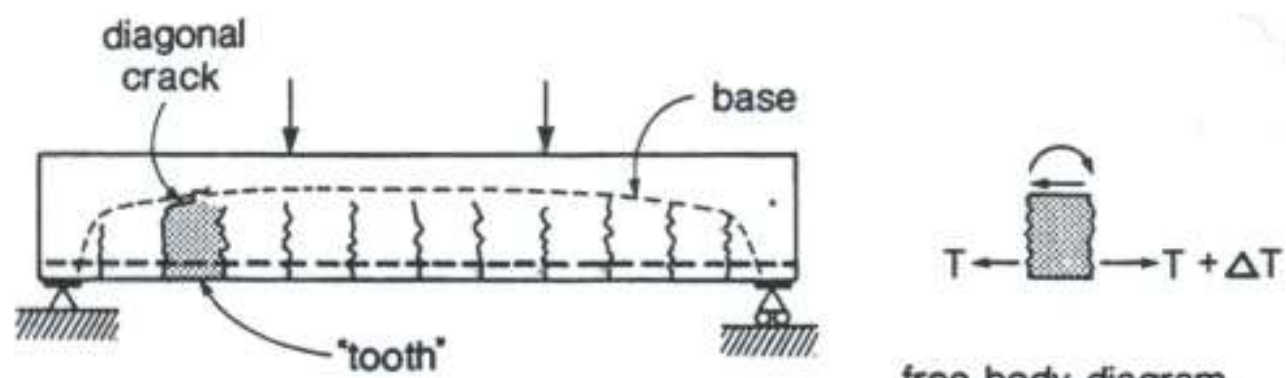

free-body diagram

of "tooth"

Fig.A. 8 Kani's comb model for cracked beams subjected to shear [18]

Fig.A. 9 illustrates the mechanism of comb-like concrete structure: the concrete teeth, separated by flexural cracks, are loaded by horizontal $\Delta T$ forces. The function of every concrete tooth can be compared to that of a short vertical cantilever anchored in the compressive zone of the beam and acted on by a horizontal $\Delta \mathrm{T}$ force. As long as the concrete teeth are capable of carrying the $\Delta T$ forces, the comb-like structure is essentially a beam with a distinctive compressive zone, with the highest compressive strain at the top fiber [19].

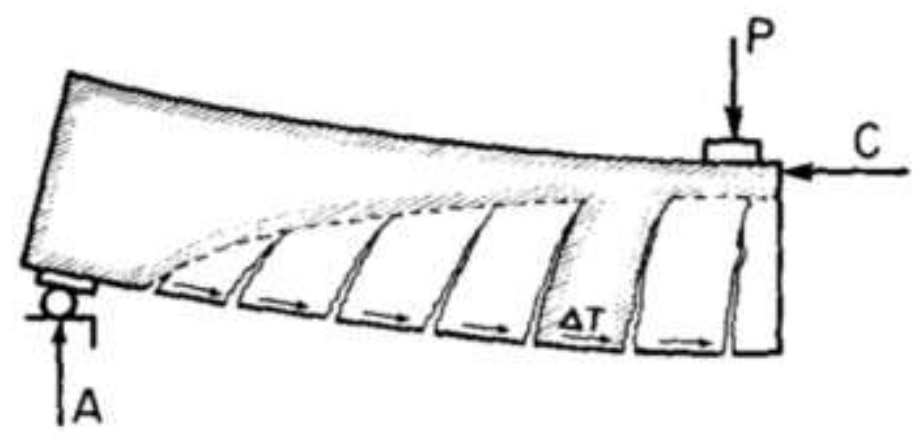

Fig.A. 9 The function of concrete teeth [19] 
After the resistance of the concrete teeth has disappeared the active cross-section is reduced and only a tied arch remains (Fig.A. 10). This transformation of a reinforced concrete beam into a tied arch may occur suddenly or may develop gradually [19]. The comb analogy also emphasizes the importance of bond on the shear transfer mechanisms. According to Kani's model, a beam reinforced only with an unbounded tendon will not develop flexure-shear cracks. Because larger beams have longer teeth, the comb model predicts that such beams will fail at lower shear stresses [20].

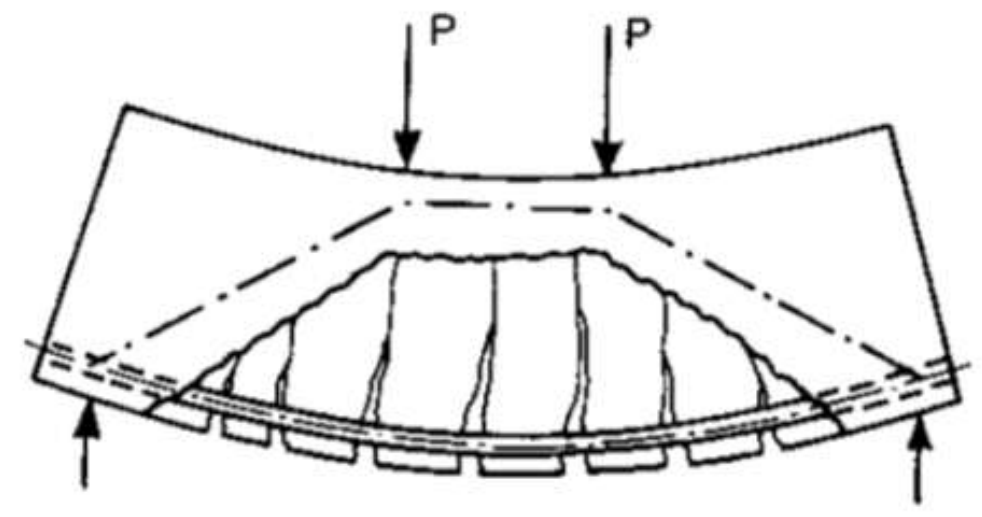

Fig.A. 10 Remaining concrete arch [19]

The three lines in Fig.A. 11 create three a/d regions, each with different characteristics [19]:

1. For small a/d ratios, the capacity of the concrete teeth is lower than the capacity of the arch. Therefore, under gradually increasing loads, the transformation of the beam into an arch occurs gradually and the structure fails when the capacity of the arch is exceeded.

2. In the medium region ( $\mathrm{a} / \mathrm{d}$ between $\alpha_{\min }$ and $\alpha_{\mathrm{TR}}$ ) the capacity of the arch is lower than the capacity of the concrete teeth but, failure does not occur until the capacity of the concrete teeth is exceeded. Since the arch capacity is lower than the applied load, a sudden collapse must follow.

3. In the region beyond the transition point $\alpha_{T R}$, no diagonal failure can be expected; only normal flexural failure is possible. 


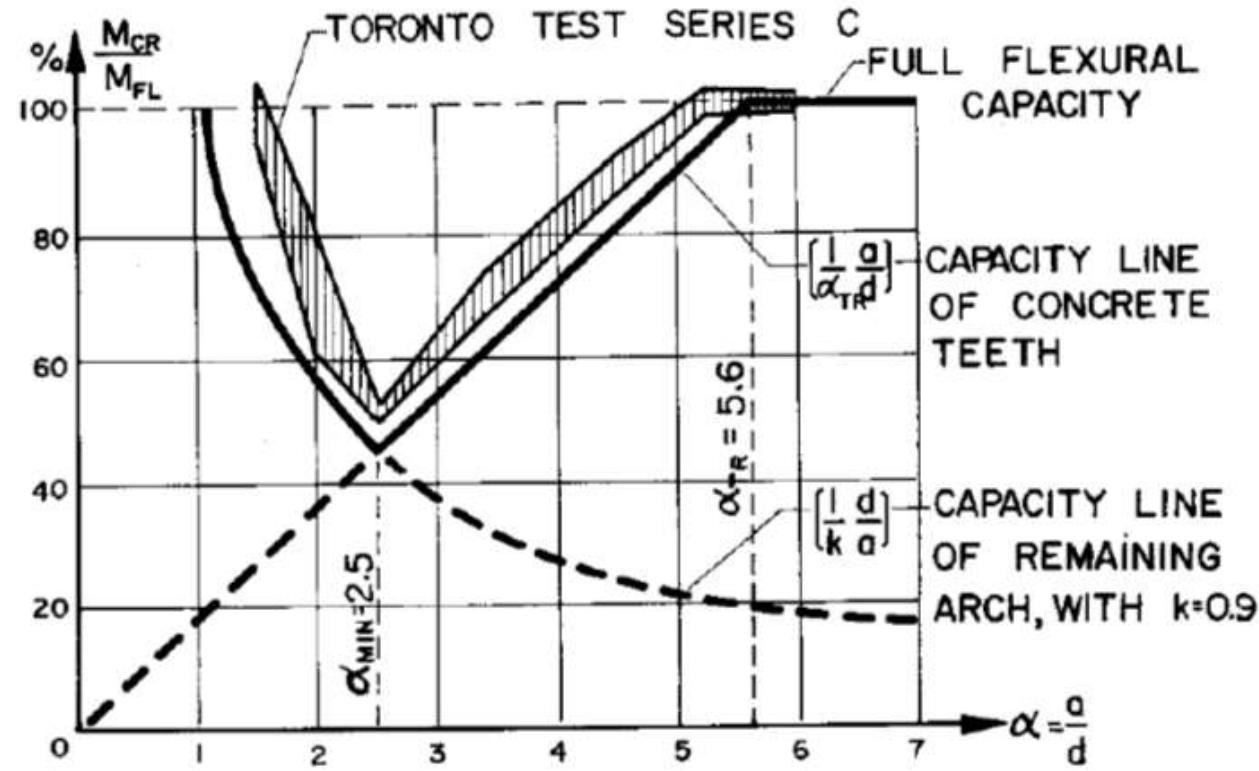

Fig.A. 11 Comparison of theoretical and test results [18]

\section{A.2.2 Mechanisms of shear resistance}

The shear resistance within normal reinforced concrete beams (steel percentage 1.0, concrete strength $45 \mathrm{MPa}$ and a/d between 2.3 and 4) concurs: the compression zone shear (20-40\%), the aggregate interlock (33-50\%) and the dowel action (15-25\%), [21]. For small beams (depth smaller than $0.3 \mathrm{~m}$ ), the crack bridging stresses, aggregate interlock and dowel action are important, contributing about $40 \%$ of $\mathrm{V}$ according to Bazant $\& \mathrm{Yu}$ [22].

The percentage of the shear force carried by the compression zone will be influenced by the size of the zone. The ultimate shear capacity of the zone will be affected by the concrete strength. Aggregate interlock shears will depend on the surface roughness of the cracks, aggregate type and the displacements across the cracks, whereas dowel action will depend on the layout of the tension steel the width of the dowel failure surface and the tensile strength of the concrete. Which one of these mechanisms break down first and causes beam failure, depends on the relative magnitudes of the forces carried in the three ways and, therefore, on the layout of the beam, [21]. 
Therefore, the contribution of the concrete is based on several effects (Fig.A. 12) that have been studied by testing beams without transverse reinforcement until failure, thus, are independent of the truss effect [8].

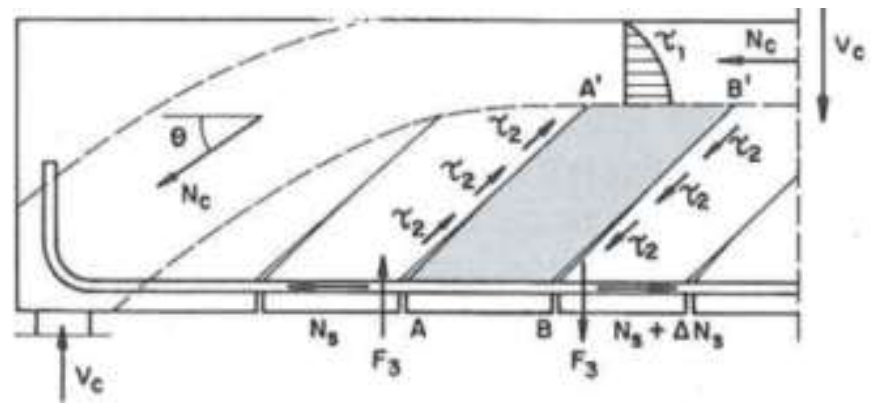

Fig.A. 12 Effect which contribute to shear resistance in a cracked section [8]

- $\quad$ Compression zone: In the members subjected to flexure, there is an upper area where the cracks do not reach and, in this area (compression zone), there are shear stresses which contribute to resist shear $\left(V_{c}\right)$. This resistance depends on the tensile strength of concrete $\left(f_{c t}\right)$ and also the characteristic compression strength $\left(f_{c k}\right)$, [8].

- $\quad$ Aggregate interlock: The struts, or areas of concrete between two flexure cracks, are capable to resist a certain shear stress. The strut AA'BB' (Fig.A. 12) can be regarded as a cantilever embedded in the compressed top (its section is recessed $A^{\prime} B^{\prime}$ ) and subjected to a force $\Delta N_{s}$ located at the level of the main reinforcement. The deformation of the cantilever requires a fiber elongation $A^{\prime} A$ and a shortening of the $B^{\prime} B$. Both the elongation and the shortening are constrained by the aggregate interlock which stitches together the two sides of the crack, causing tensions $\tau_{2}$. This effect, which covers 30 to $50 \%$ of $V_{c}$ depends on the fraction of coarse aggregate and the effective depth of the beam [8].

Walraven [23] developed a model that considered the probability that aggregate particles (idealized as spheres) will project from the crack interface. The aggregate interlock along the faces of the diagonal cracks gives a substantial contribution to the ultimate shear resistance of thin-webbed concrete beams. This contribution is larger in the sections where the shear cracks develop within the web, and smaller where the shear cracks develop from the flexural cracks in the bottom tensile flange. The percentage contribution to the nominal ultimate shear stress is larger for small and medium values of the ultimate shear stress, but is still remarkable at the largest values, when the interface displacements tend to become smaller (and so aggregate interlock effects) due to shear crack closeness, which is related to the large amount of the required shear reinforcement. Both small 
stirrup diameters and high concrete strengths promote aggregate interlock contribution [24].

- Dowel effect: The strut $\mathrm{AA}^{\prime} \mathrm{BB}^{\prime}$ is also stiffened by longitudinal reinforcement itself, that runs like a lock and sew it, opposing to deformation by longitudinal shear forces $F_{3}$ analogous to the tensions $\tau_{2}$. This effect covers between 15 and $25 \%$ of $V_{c}$ [8].

\section{A.2.3 Failure modes in beams without shear reinforcement}

The slenderness of the beam, that is, its shear span-to-depth $(a / d)$ ratio, determines the failure mode of the beam. Fig. A. 13 portrays the types of cracks expected in a reinforced concrete beam with or without adequate diagonal tension reinforcement [25].

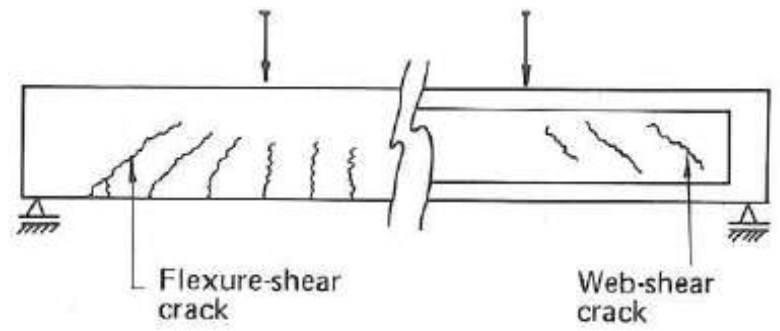

(a) Types of shear cracking

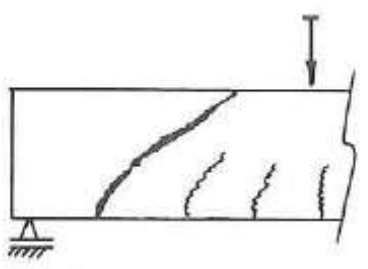

Diagonal tension failure

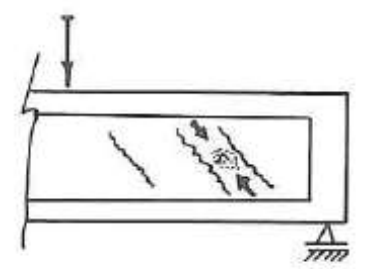

Web-crushing failure

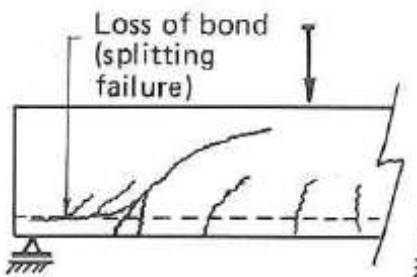

Shear tension failure

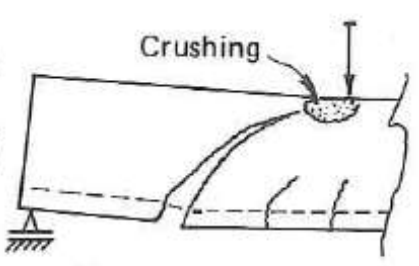

Shear compression failure

(b) Major types of shear failures

Fig. A. 13 Shear cracking and shear failures [2] 


\section{- $\quad$ Flexural failure:}

The more slender the beam, the stronger the tendency toward flexural behavior. In the region of flexural failure, cracks are mainly vertical in the middle third of the beam span and perpendicular to the lines of principal stress (Fig.A. 14). This type of behavior gives a clear warning of the imminence of collapse of the beam. The shear span-to-depth ratio for this behavior exceeds a value of 5.5 in the case of concentrated loading, and in excess of 16 for distributed loading [25].
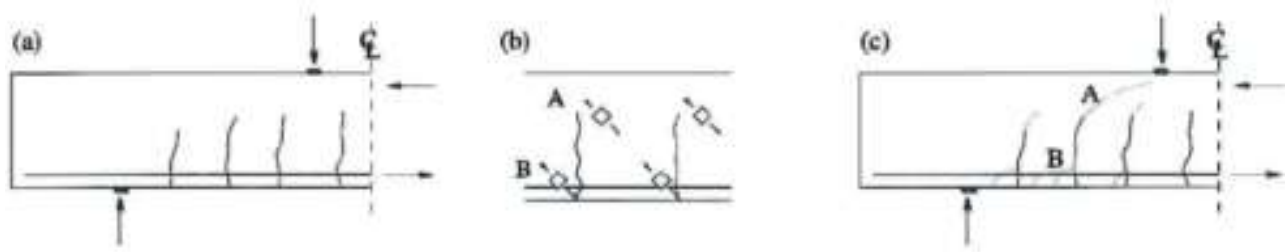

Fig.A. 14 Development of cracks according to beam shear-carrying mechanisms: (a) flexural cracks; (b) zones in tension; and (c) progression of flexural cracks; [26]

\section{- Diagonal tension failure:}

Diagonal tension failure occurs if the strength of the beam in diagonal tension is lower than its strength in flexure. The shear span-to-depth ratio is of intermediate magnitude, varying between 2.5 and 5.5 for the case of concentrated loading. The diagonal tension failure is the result of the combination of the flexural and shear stressed, taking into account the balancing contribution of the vertical component of the prestressing force, and noted by a combination of flexural and diagonal cracks. It is best termed flexure shear in the case of prestressed beams, and is more common to account for than web shear [25].

\section{- $\quad$ Shear compression failure:}

Beams that are most subject to shear compression failure have a small span-to-depth ratio of magnitude 2.5 for the case of concentrated loading and less than 5.0 for distributed loading. As in the diagonal tension case, a few fine flexural cracks start to develop at midspan and stop propagating as destruction of the bond occurs between the longitudinal bars and the surrounding concrete at the support region. Thereafter, and inclined crack steeper than in the diagonal tension case suddenly develops and proceeds to propagate toward the neutral axis. The rate of its progress is reduced with the crushing of the concrete in the top compression fibers and a redistribution of stresses within the top region. Sudden failure takes place as the principal inclined cracks dynamically joins the crushed concrete zone. This type of failure can be considered relatively less brittle than 
the diagonal tension failure due to the stress redistribution. Yet it is, in fact, a brittle type of failure with limited warning, and such a design should be avoided completely. Table A. 1 [4] summarizes the effect of the slenderness values on the mode of failure.

Table A. 1 Beam slenderness effect on mode of failure [4]

\begin{tabular}{|c|c|c|c|}
\hline & & \multicolumn{2}{|c|}{ a/d ratio as a measure of slenderness ${ }^{\mathrm{a}}$} \\
\hline Beam category & Failure mode & $\begin{array}{c}\text { Concentrated Load, } \\
\boldsymbol{a} / \boldsymbol{d}\end{array}$ & Distributed Load, $I_{\boldsymbol{d}} \boldsymbol{d}$ \\
\hline Slender & Flexure (F) & Exceeds 5.5 & Exceeds $16^{\mathrm{a}}$ \\
\hline Intermediate & Diagonal tension (DT) & $2.5-5.5$ & $11-16^{\mathrm{b}}$ \\
\hline Deep & Shear compression (SC) & $1-2.5$ & $1-5^{\mathrm{b}}$ \\
\hline
\end{tabular}

$I_{c}=$ shear span for distributed loads; $d=$ effective depth of beam; ${ }^{a} a=$ shear span for concentrated loads;

${ }^{b}$ For a uniformly distributed load, a transition develops from deep beam to intermediate beam effect

\section{A.3 Beams with shear reinforcement}

\section{A.3.1 Introduction}

The components of the internal shear resistance must equal the applied shear, indicated by the upper 45 o line (Fig. A. 15).

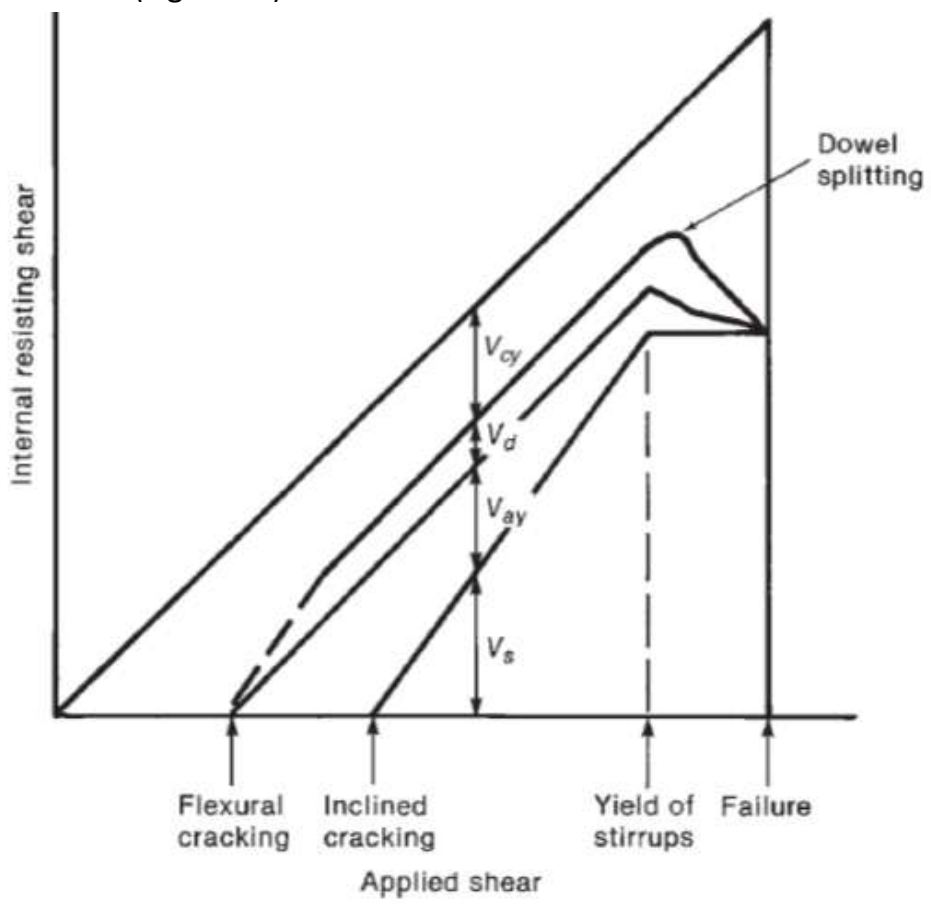

Fig. A. 15 Distribution of internal shears in a beam with web reinforcement [27] 
Prior to flexural cracking, the entire shear is carried by the uncracked concrete. Between flexural and inclined cracking, the external shear is resisted by $V_{c z}, V_{a y}$, and $V_{d}$. Eventually, the stirrups crossing the crack yield, and $V_{s}$ stays constant for higher applied shears. Once the stirrups yield, the inclined crack opens more rapidly. As the inclined crack widens, $V_{a y}$ decreases further, forcing $V_{d}$ and $V_{c z}$ to increase at an accelerated rate, until a splitting (dowel) failure occurs, the compression zone crushes due to combined shear and compression, or the web crushes (Fig. A. 15).

Each of the components of this process except Vs has a brittle load-deflection response. As a result, it is difficult to quantify the contributions of $V_{c z}, V_{d}$, and $V_{a y}$. In design, these are lumped together as $V_{c}$, referred to somewhat incorrectly as "the shear carried by the concrete". Thus, the nominal shear strength, $V_{n}$, is assumed to be:

$$
V_{n}=V_{c}+V_{s}
$$

Stirrups do not prevent inclined cracks from forming; they come into play only after the cracks have formed.

Shear failure is associated with the development of tensile stresses within the compressive zone and in particular the region of the compressive zone between the sections including: the load point, and a point lying at a distance of about twice the beam depth from the support. All this implied that the stirrups sustain tensile stresses developing within the compressive zone rather than transform the beam into a truss as widely considered [28].

For members with shear reinforcement, the equation developed for $\mathrm{V}_{\mathrm{c}}$ in provisions must account for the rules used for evaluating the angle of diagonal compression. For example, in current U.S. practice, where the angle $\theta$ is assumed to be 45 for prestressed concrete structures, the calculated contribution of the shear reinforcement is less and $V_{c}$ can afford to be larger than in other codes such as the LRFD Sectional Design Model where $\theta$ may be as low as 18 으. [29].

After the formation of the first shear crack, stirrups started to work and further shear cracks developed. The addition of web reinforcement improves the shear response of the specimen by increasing the failure shear strength and a higher ductile response. The size effect disappears when beams without stirrups contain well distributed longitudinal reinforcement [30]. Once shear cracking occurs in a member, transverse reinforcing steel (stirrups) will become significantly engaged in carrying the applied shear force. The 
increase in stirrup stress due to cracking depends on the amount of provided shear reinforcement and the tensile strength of the concrete. The larger the amount of shear reinforcement, the smaller is the increase in bar stress upon cracking and the better is shear cracking be controlled. In the case of light or even modest amounts of shear reinforcement, this reinforcement may yield after initial shear cracking and this could lead to fatigue concerns [31].

\section{A.3.2 The 45 truss model}

In 1899 Ritter explained the flow of forces in a cracked reinforced concrete beam in terms of a truss model. The diagonal compressive stresses in the concrete act as the diagonal members of the truss while the stirrups act as vertical tension members. The bottom chord of the truss consists of the longitudinal tension reinforcement while the flexural compression zone of the beam acts as the top chord [13].

In his classic 1902 text, Mörsch explained the truss model in more detail. He made it clear that the compression diagonals do not have to go from the top of one stirrup to the bottom of the next stirrup (see Fig. A. 16-a). Later editions of his text made it clear that rather than having discrete diagonal compressive struts there was a continuous field of diagonal compression resisting the shear (see Fig. A. 16-b).

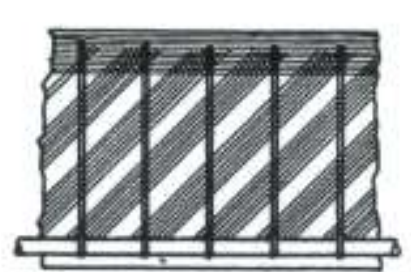

(a) Truss model

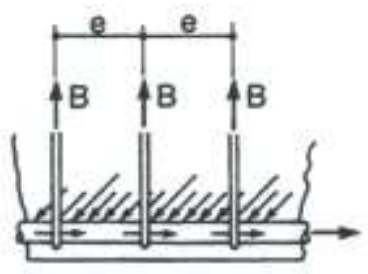

(b) Stirrup forces

Fig. A. 16 Morsch's truss model [12]

Both Ritter and Mörsch neglected the tensile stresses in the cracked concrete and assumed that after cracking the diagonal compression stresses would remain at 45 . The equilibrium conditions used by Ritter and Mörsch are summarized in Fig.A. 17 [13]. If the shear stresses are assumed to be uniformly distributed over an effective shear area $b_{w}$ wide and $j d$ deep (see Fig.A. 17-a), then the required magnitude of the principal compressive stresses can be found from the free-body diagram in Fig.A. 17-b. As the total diagonal compressive force $f_{2} \cdot b_{w} \cdot j d / V 2$ must equal $v 2 \cdot V$, the principal compressive stress is given by: 


$$
f_{2}=\frac{2 V}{b_{w} j d}
$$

The longitudinal component of the diagonal compressive force will equal V (see Fig.A. 17b). This force must be counteracted by an equal tensile force, $N_{v}$, in the longitudinal reinforcement. Hence the tensile force in the longitudinal reinforcement caused by the shear is given by:

$$
N_{v}=V
$$

From the free-body diagram shown in Fig.A. 17-c, it can be seen that the diagonal compressive force has a vertical component of $f_{2} \cdot b_{w} s / 2$, which must be balanced by the tensile force in the stirrup, $A_{v} f_{v}$. Substituting for $f_{2}$ from Eq.A.15 gives:

$$
\frac{A_{v} f_{v}}{S}=\frac{V}{j d}
$$

where $A_{v}$ is the cross-sectional area of the stirrup legs, $s$ is the stirrup spacing, $f_{v}$ is the tensile stress in the stirrups [13].

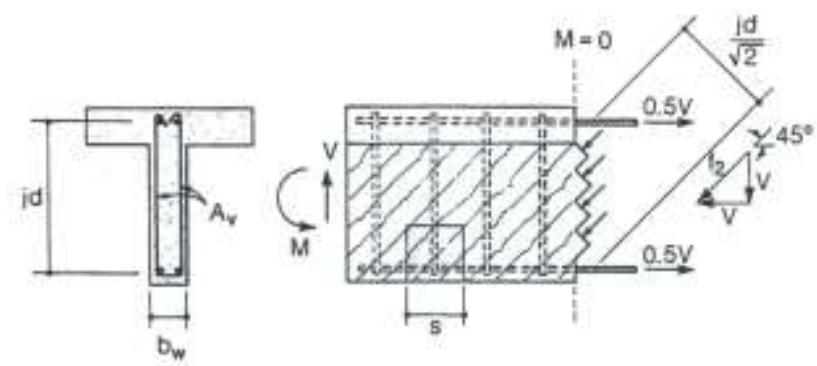

(a) Cross section

(b) Diagonal stresses and longitudinat equitibrium

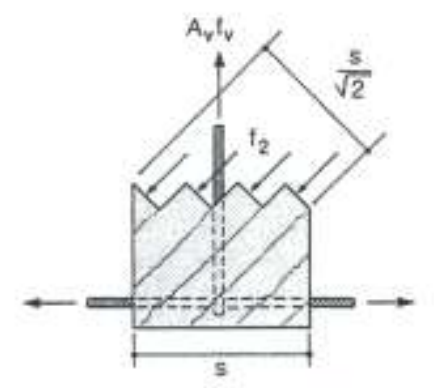

(c) Force in stirrups

Fig.A. 17 Equilibrium considerations for 450 truss [13] 
At the time that these equations were developed, design was based upon limiting the stresses at working loads. Stirrup areas and spacings were chosen so that the stirrups stresses given by Eq.A.17 remained below permissible values. The additional tensile stress in the longitudinal reinforcement caused by shear was checked using Eq.A.16 while the concrete compressive stress in the web was checked by Eq.A.15 [13].

The "secondary inclined cracks" mentioned by Mörsch are the flatter cracks which formed late in the life of the beam. If the stirrups were designed for this flatter slope, fewer stirrups could be used. While Mörsch obviously recognized that the choice of 45 was conservative, he could not see any practical way to determine the slope [13].

\section{A.3.3 The variable-angle truss model}

The ACl Code modified Mörsch's 45 truss model by adding a "concrete contribution" to compensate for the conservative nature of this model. Alternatively, Mörsch's model can be made more accurate by accounting for the fact that $\theta$ is typically less than 45ㅇ [13]. Leonhardt tests showed that the angle of inclination of the struts could fall below 45ㅇ to 30 o, thus improving the effectiveness of transverse shear reinforcement [8]. Fig.A. 18 summarizes the equilibrium conditions for the variable-angle truss model [13].

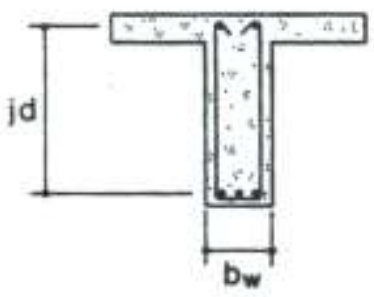

(a) Cross section

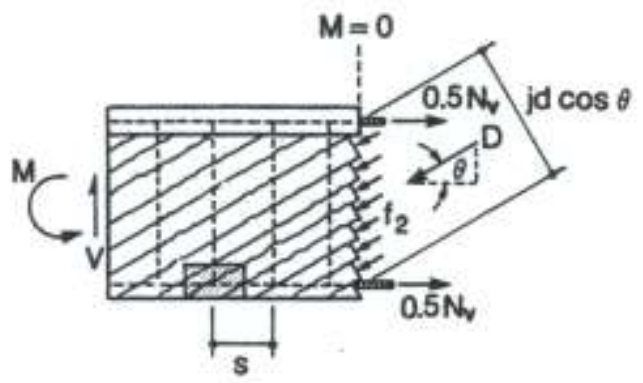

(b) Diagonal stresses and longitudinal equilibrium

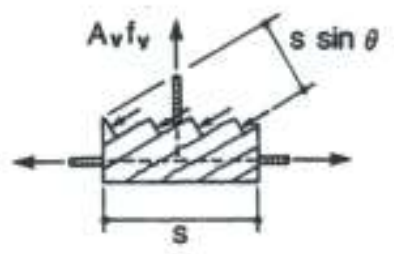

(c) Force in stirrups

Fig.A. 18 Equilibrium conditions for variable-angle truss [13] 
The required magnitude of the principal compressive stresses, $f_{2}$, can be found from the free-body diagram shown in Fig.A. 18-b. Equilibrium requires that the resultant, $D$, of the diagonal stresses must equal $V / \sin \theta$. As $D$ must equal $f_{2} \cdot b_{w} \cdot j \cdot d \cdot \cos \theta$, the principal compressive stress is:

$$
f_{2}=\frac{V}{b_{w} j d} \cdot \frac{1}{\sin \theta \cos \theta}=\frac{V}{b_{w} j d} \cdot(\tan \theta+\cot \theta)
$$

The longitudinal component of the diagonal compressive force will equal $V \cdot \cot \theta$ (see Fig.A. 18-b). This force must be counteracted by an equal tensile force, $N_{v}$, in the longitudinal reinforcement. Hence the tensile force in the longitudinal reinforcement due to shear is:

$$
N_{v}=V \cdot \cot \theta
$$

From the free-body diagram shown in Fig.A. 18-c it can be seen that the diagonal compressive force, $f_{2} \cdot b_{w} \cdot s \cdot \sin \theta$, has an outward thrust of $f_{2} \cdot b_{w} \cdot s \cdot \sin ^{2} \theta$, which must be counteracted by the tensile force, $A_{v} \cdot f_{v}$, in the stirrup. Substituting for $f_{2}$ from Eq. A.18 gives:

$$
\frac{A_{v} f_{v}}{s}=\frac{V}{j d} \tan \theta
$$

The equilibrium equations above are not sufficient to find the stresses in a beam caused by a fiber shear. There are four unknowns (i.e. the principal compressive stress, the tensile force in the longitudinal reinforcement, the stress in the stirrups, and the inclination, of the principal compressive stresses), but there are only three equilibrium equations. The fact that there are four unknowns and three equations caused Mörsch to believe that it was impossible to determine the slope $\theta$ mathematically [13].

In 1964, Kupfer [32] developed a procedure for determining the angle $\theta$ using minimum energy principles. In this derivation he assumed that the reinforcement and the concrete were linearly elastic and hence was able to predict the angle, $\theta$, for the cracked elastic range. To minimize the energy in a load-carrying system the stiffer elements must carry more load. For typical reinforced concrete beams the longitudinal reinforcement is much stiffer than the stirrups, and hence the value of $\theta$ for minimum energy is less than 45 은 [13]. 
In the traditional truss model the failure shear of a beam is determined form equilibrium (Eq.A.20) by assuming that at failure the stirrups yield (i.e. $f_{v}=f_{y}$ ) and by assuming that $\theta=45$ ․ Rather than assuming that $\theta=45$ ㅇ, we could assume a compressive stress, $f_{2}$, in the concrete at failure and then find $V$ and $\theta$ by solving the two simultaneous Eqs. 3.18 and 3.20. Alternatively, we could assume that at failure both the longitudinal reinforcement and the stirrups yield and the use Eqs. 3.19 and 3.20 to determine $V$ and $\theta$. These approaches which consider the mechanisms of failure are referred to as plasticity methods. Summaries of these methods are given by Nielsen [33] and by Thürlimann et al. [34].

In predicting the shear strength of beams using variable-angle truss models it is necessary to use an "effective" concrete compressive strength less than the cylinder crushing strength. A value of $0.6 \cdot \mathrm{fc}^{\prime}$ is frequently recommended ( [34], [35]). Additionally, it has been recommended that $\tan \theta$ not be taken less than 0.5 (i.e. $\theta \geq 27$ ) ). The variable-angle truss model was introduced into the 1978 CEB-FIP Code. In using this code, the designer can choose $\theta$ between 31 을 and 59. Additionally, for lightly loaded beams there is a small concrete contribution [13].

If the angle formed by the struts decreases, increases the shear force resisted by the stirrups and the oblique compression on the concrete $\sigma_{c}[8]$.

\section{A.3.4 Compression field theory}

Applying Wagner's approach to reinforced concrete and assuming that after cracking the concrete carries no tension and that the shear is carried by a field of diagonal compression, results in the following expression for the angle of inclination of the diagonal compression:

$$
\tan ^{2} \theta=\frac{\varepsilon_{x}-\varepsilon_{2}}{\varepsilon_{t}-\varepsilon_{2}}
$$

where:

$\varepsilon_{\mathrm{x}}=$ longitudinal strain of web, tension positive

$\varepsilon_{\mathrm{t}}=$ transverse strain, tension positive

$\varepsilon_{2}=$ principal compressive strain, negative quantity

For a given value of $\theta$, Eq. A.22 can be regarded as a compatibility condition relating the three strains, $\varepsilon_{2}, \varepsilon_{\mathrm{x}}, \varepsilon_{\mathrm{t}}$. 
The physical significance of Eq. A.21 can be appreciated if Fig.A. 19-a and Fig.A. 19-b are compared. For low crack inclinations (i.e. low $\theta$ ), the web reinforcement will be highly strained while for steep crack inclinations (i.e. high $\theta$ ), the longitudinal reinforcement will be highly strained [13].

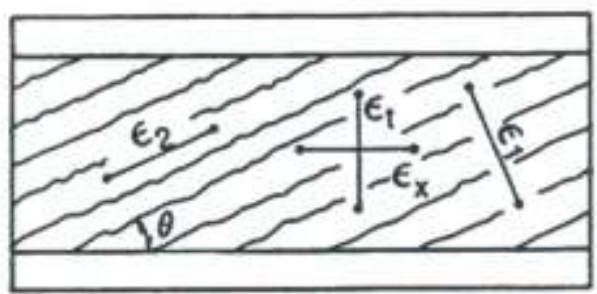

(a) Strains in beam-small $\theta$

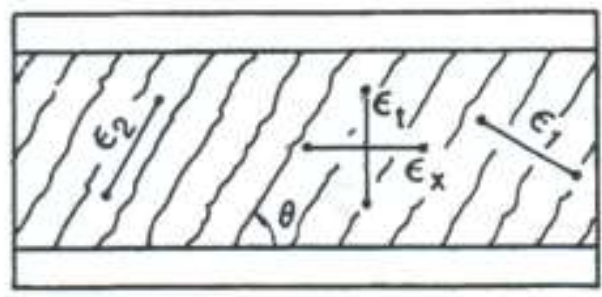

(b) Strains in beam-large $\theta$

Fig.A. 19 Relation between strains and $\theta$ [13]

By considering a symmetrically reinforced, longitudinally prestressed concrete beam subjected to shear, it can see that for a given level of shear, $V$, there are a total of fiber unknowns: the stress in the longitudinal bars, $f_{x}$; the stress in the longitudinal prestressing tendons, $f_{p}$; the stress in the stirrups, $f_{v}$; the diagonal compressive stress in the concrete, $f_{2}$; and the inclination, $\theta$, of these diagonal compressive stresses. By using the equilibrium, compatibility, and stress-strain relationships, the complete load-deformation response of a member subjected to shear can be determined. This approach has become known as the "compression field theory" ( [36]; [37]; [38]). To investigate the stress-strain characteristics of diagonally cracked concrete, Vecchio and Collins [39] tested reinforced concrete elements in pure shear [40]. Based on these tests, they found that the principal compressive stress in the concrete, $f_{2}$, is a function not only of the principal compressive strain, $\varepsilon_{2}$, but also of the coexisting principal tensile strain, $\varepsilon_{1}$. They suggested [41] the following stress-strain relationship:

$$
f_{2}=f_{2 \max } \cdot\left[2 \cdot\left(\frac{\varepsilon_{2}}{\varepsilon_{c}^{\prime}}\right)-\left(\frac{\varepsilon_{2}}{\varepsilon_{c}^{\prime}}\right)^{2}\right]
$$

where:

$$
\frac{f_{2 \max }}{f^{\prime}{ }_{c}}=\frac{1}{0.8+170 \cdot \varepsilon_{1}} \leq 1.0
$$


Note that increasing $\varepsilon_{1}$ will reduce $f_{2 \max } / f_{c}^{\prime}$. Because the compression field theory neglects the contribution of tensile stressed in the cracked concrete, it overestimates deformations and gives conservative estimates of strength. As a further development, the modified compression field theory, accounts for the influence of tension in concrete [13].

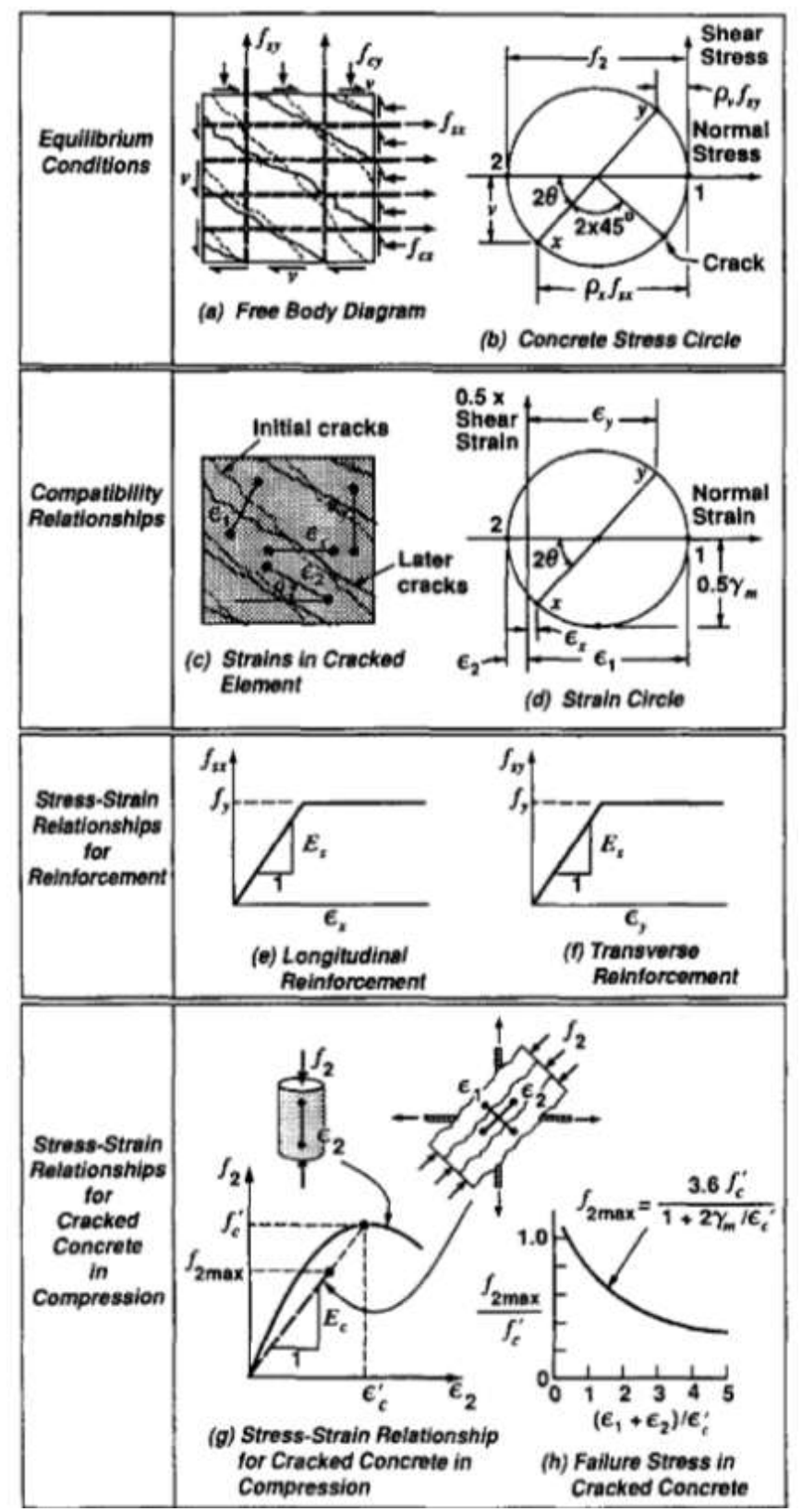

Fig. A. 20 Summary of Compression Field Theory [42] 


\section{A.3.5 The Modified Compression Field Theory (MCFT)}

In the 1980s, a relatively rational model based on the modified compression field theory (MCFT) was developed at the University of Toronto and now provides the basis of shear provisions in Canadian standards and American specifications for the design of concrete structures [43].

With the MCFT, the concrete contribution is assumed as carried by aggregate interlock. The ability of a crack to resist these stresses was observed by Walraven (1978) to decrease with decreasing concrete strength, decreasing maximum coarse aggregate size (representing crack roughness) and increasing absolute crack width (wider cracks resist lower shear stresses) [44].

In the compression field theory it is assumed that the principal tensile stress, $f_{1}$, becomes zero after concrete cracking. On the other hand, the modified compression field theory accounts for the contribution of the tensile stresses in concrete between cracks [13].

The experimental tests to verify the MCFT were done in panels tested in the jack-and-link assembly showed in Fig. A. 23 [45].
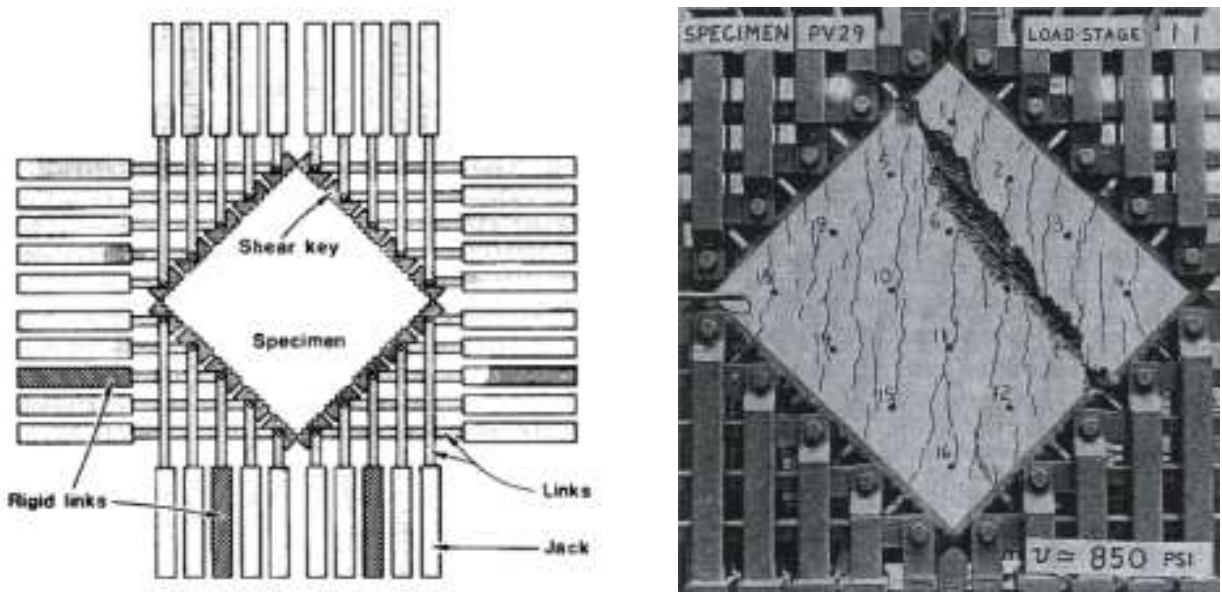

Fig. A. 21 Panel tests: (a) Jack-and-link assembly used to apply shear and tension to reinforced concrete elements; (b) Panel test after failure [45]

The equilibrium conditions for the modified compression field theory will be introduced by using the symmetrical cross section subjected to pure shear, shown in Fig. A. 22. The total area of longitudinal prestressing tendons in the section is $A_{p x}$ and the total area of nonprestressed reinforcement is $A_{s x}$. The shear on this section is resisted by the diagonal 
compressive stresses, $f_{2}$, together with the diagonal tensile stresses, $f_{1}$. It should be recognized that the tensile stresses in the diagonally cracked concrete vary in magnitude from zero at the crack locations to peak value between the cracks (see Fig. A. 22-b). Since the equilibrium equations are obtained by integrating the stresses over the cross section; it is appropriate to use the average values of the tensile stresses when formulating these equilibrium expressions [13]. From the Mohr's stress circle shown in Fig. A. 22-c, the following relationship for the principal compressive stress, $f_{2}$, can be derived:

$$
f_{2}=(\tan \theta+\cot \theta) \cdot v-f_{1}
$$

where:

$$
v=\frac{V}{b_{w} \cdot j d}
$$

The diagonal compressive stresses push apart the flanges of the beam while the diagonal tensile stresses pull them together (see Fig. A. 22). The unbalanced component must be carried by tension in the web reinforcement. This equilibrium requirement can be expressed as:

$$
A_{v} \cdot f_{v}=\left(f_{2} \cdot \sin ^{2} \theta-f_{1} \cdot \cos ^{2} \theta\right) \cdot b_{w} \cdot s
$$

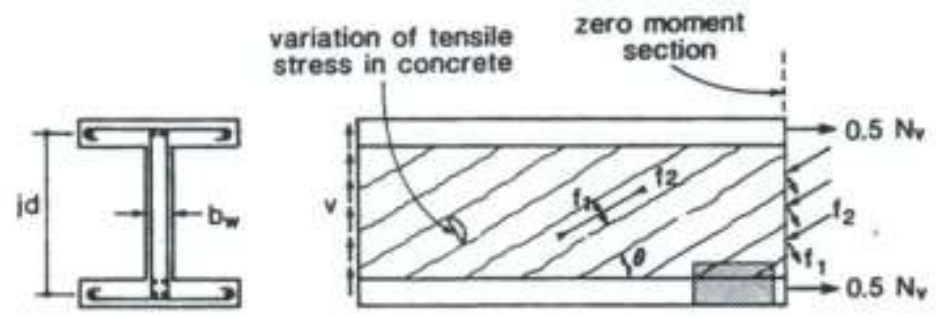

(a) Cross section

(b) Principal stresses in concrete

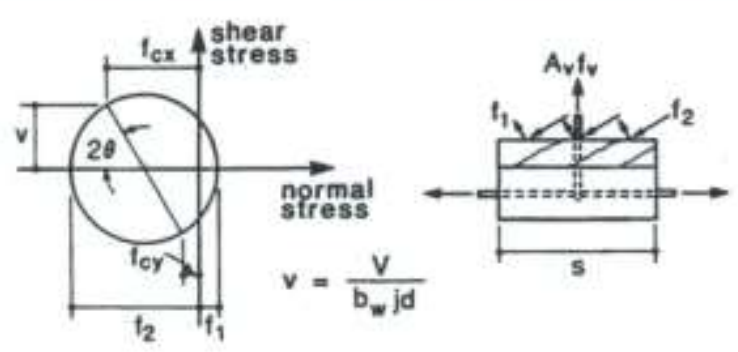

(c) Average concrete

(d) Tension in web reinforcement stresses

Fig. A. 22 Equilibrium conditions of modified compression field theory [13] 
where $f_{v}$ is the average stress in the stirrups. Substituting for $f_{2}$ from Eq. A.26 gives:

$$
V=f_{1} \cdot b_{w} \cdot j d \cdot \cot \theta+\frac{A_{v} \cdot f_{v}}{s} \cdot j d \cdot \cot \theta
$$

Eq. A.27 expresses the shear resistance of a member as the sum of a concrete contribution, which depends on tensile stresses in the concrete, and a steel contribution, which depends on tensile stresses in the stirrups (it has the same form as the $\mathrm{ACl}$ shear equation $V_{c}+V_{s}$ [13]). In the approach mentioned above we have considered the average stresses and average strains and have not dealt with local variations. The stresses that occur at a crack location will differ from the calculated average values (see Fig. A. 23). At a crack, the tensile stress in concrete goes to zero, while the tensile stresses in the reinforcement become larger. The shear capacity of the member may be limited by the ability of the member to transmit forces across the crack [13].

At low shear values, tension is transmitted across the crack by local increases in reinforcement stresses. At a certain shear force the stress in the web reinforcement will just reach yield at the crack locations. At higher shear forces transmitting tension across the crack will require local shear stresses, $v_{c r}$, on the crack surface (see Fig. A. 23-c), [13].

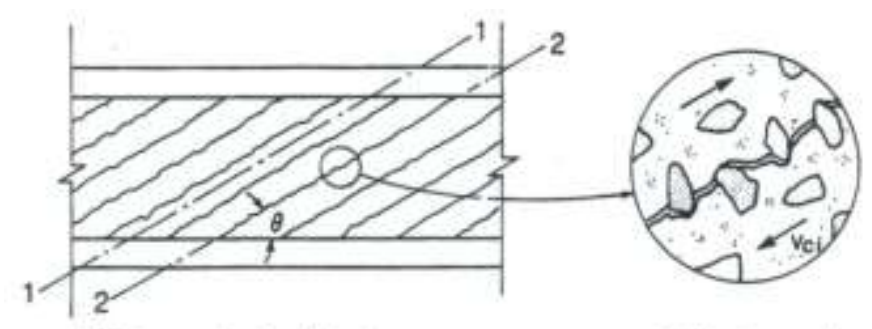

(a) Beam loaded in shear

detail at crack

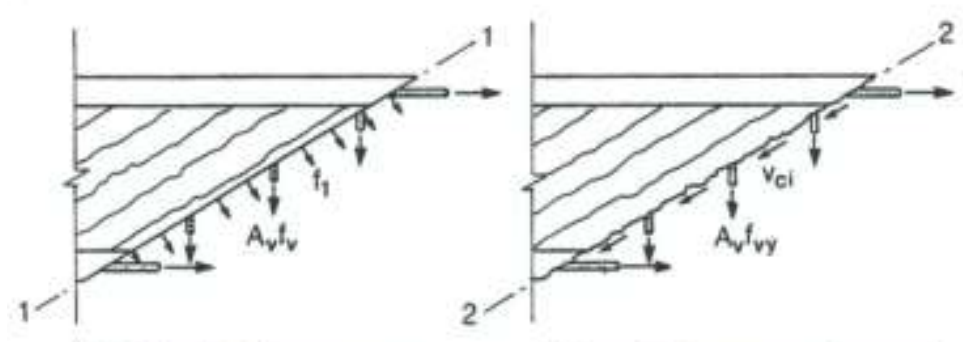

(b) Calculated average

(c) Local stresses at a crack

stresses

Fig. A. 23 Transmitting forces across cracks [13] 
The ability of the crack interface to transmit these shear stresses will depend on the crack width, $w$. It is suggested that the limiting value of $v_{c i}$ be taken as:

$$
\left.v_{c i}=\frac{0.18 \cdot \sqrt{f^{\prime}}}{0.3+\frac{24 \cdot w}{a+16}} \quad \text { [MPa and } \mathrm{mm}\right]
$$

where " $a$ " is the maximum aggregate size. The expression above has been simplified form the expressions developed by Vecchio and Collins [41] using the experimental data of Walraven [23] and the beneficial effects of local compressive stresses across the crack have been ignored [13].

The crack width, $w$, to be used in Eq.A.30 can be taken as the product of the principal tensile strain, $\varepsilon_{1}$, and the average spacing of the diagonal cracks. Thus:

$$
w=\varepsilon_{1} \cdot s_{m \theta}
$$

The spacing of the inclined cracks will depend upon the crack control characteristics of both the longitudinal and the transverse reinforcement. It is suggested that this spacing be taken as:

$$
s_{m \theta}=\frac{1}{\left(\frac{\sin \theta}{s_{m x}}+\frac{\cos \theta}{s_{m v}}\right)}
$$

where $s_{m x}$ and $s_{m v}$ are the crack spacings indicative of the crack control characteristics of the longitudinal and transverse reinforcement, respectively. Thus $s_{m x}$ is the average crack spacing that would result if the member was subjected to longitudinal tension while $s_{m v}$ is the average crack spacing that would result if the member was subjected to a transverse tension [13]. To account for the fact that crack spacings becomes larger as the distance from the reinforcement increases, the maximum distance from the reinforcement, instead of the cover distance " $c$ ", can be used [13]. A slightly increased degree of softening was found to develop in high-strength concrete. The compression-softening formulations and analysis procedures previously developed for normal strength concrete elements were found to apply equally well to high-strength concrete elements [46]. Fig.A.26 summarizes the main aspects of the Modified Compression Field Theory. 


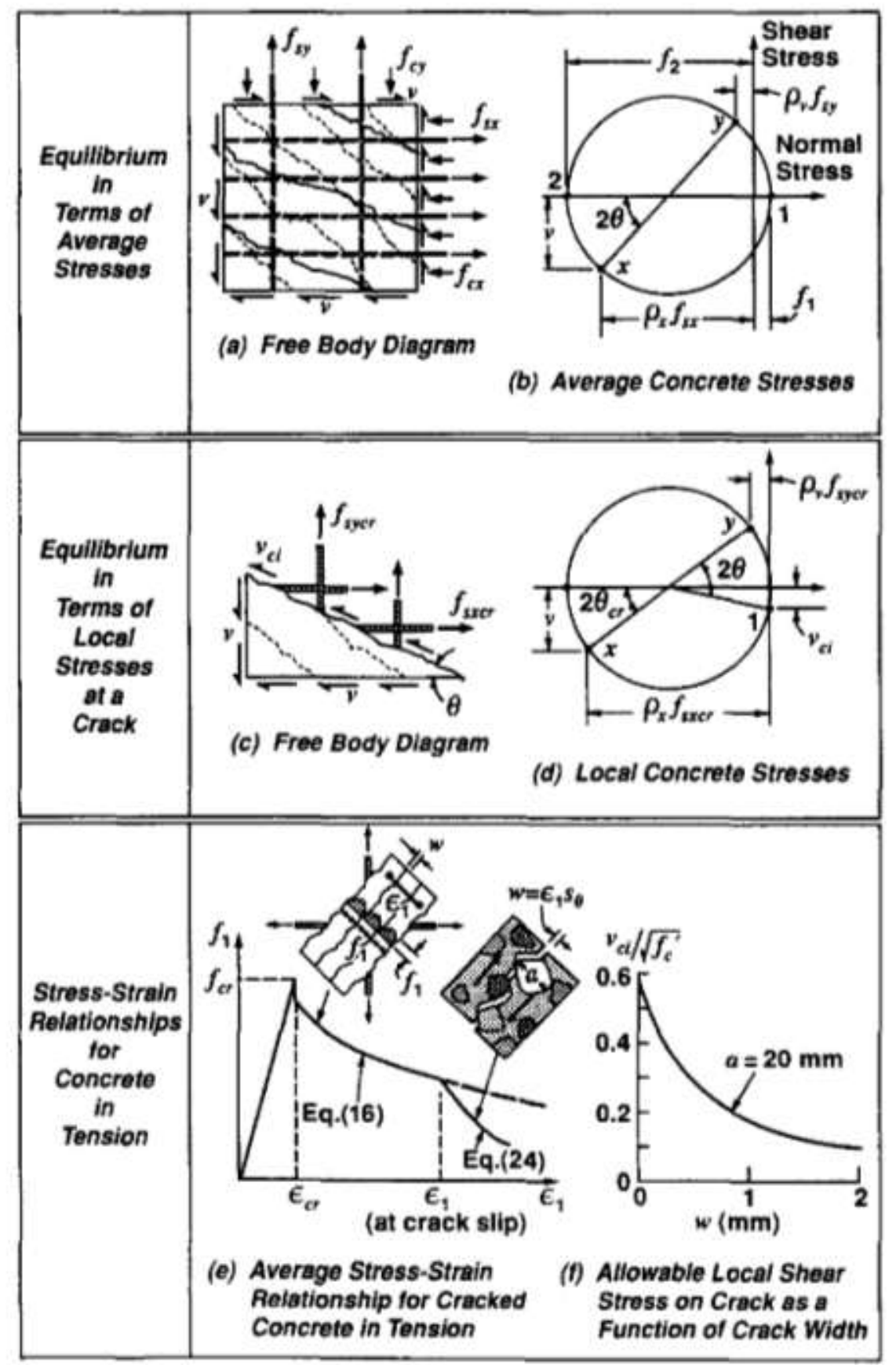

Fig. A. 24 Aspects of Modified Compression Field Theory, ACI-Committee445, 1998 [42] 


\section{A.4 Parameters influencing shear behavior}

\section{A.4.1 Concrete in tension}

For very small crack widths (or near the tip of cracks), concrete has a residual capacity to carry tensile stresses. The contribution of concrete in tension is thus only significant for members with small crack widths [26].

\section{A.4.2 Steel strength}

Taylor [47] claimed that the significant steel parameter in shear is the steel stress at the time of shear failure rather than the steel percentage. This is interesting, as beams using high-strength steel and carrying a given moment will have longer and wider cracks than beams with mild steel. Unfortunately, this variable interacts with steel percentage in such a way that it is difficult to separate the two effects [21].

\section{A.4.3 Longitudinal reinforcement ratio, $\rho_{l}$.}

The steel percentage is a significant parameter in the shear problem and influences the distribution of shear within a beam by controlling the height and width of cracks [21].

Fig. A. 25 presents the shear capacities of simply supported beams without stirups as a function of the steel ratio, $\rho_{l}=A_{s} / b_{w} \cdot d$. The practical range of $\rho_{l}$ for beams developing shear failures is about 0.0075 to 0.025 . In this range, the shear strength is approximately:

(Ib) $\rightarrow$ ACl equation 11-3

$V_{c}=2 \sqrt{f_{c}^{\prime} \cdot b_{w} \cdot d}$

(Eq. A. 31)

$V_{c}=\frac{\sqrt{f_{c}^{\prime} \cdot b_{w} \cdot d}}{6} \quad(N) \rightarrow$ ACl equation 11-3 in SI units

as indicated by the horizontal dashed line in Fig. A. 25. This equation tends to overestimate $V_{c}$ for beams with small steel percentages [48]. 


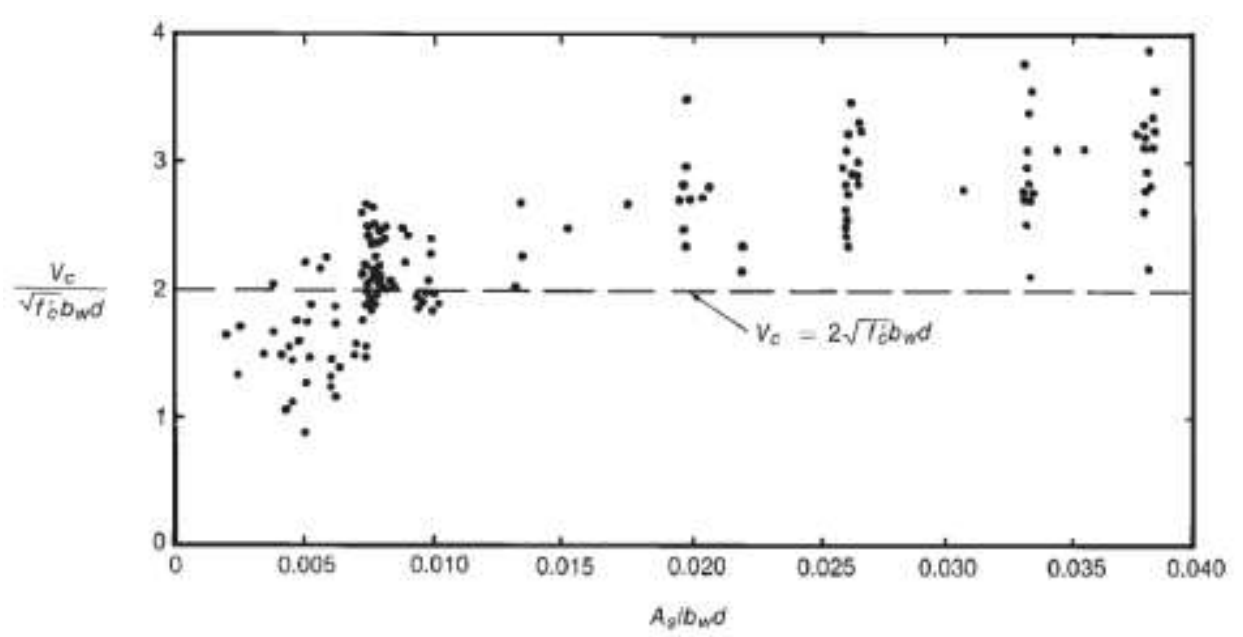

Fig. A. 25 Effect of reinforcement ratio, $\rho_{w}$, on shear capacity, $v_{c}$, of beams constructed with normal-weight concrete and without stirrups [1]

When the steel ratio, $\rho_{l}$, is small, flexural cracks extend into the beam and open more than would be with large values of $\rho_{l}$. An increase in crack width causes a decrease in the maximum values of the components of shear, $V_{d}$ and $V_{a y}$, that are transferred across the inclined cracks by dowel action or by shear stresses on the cracks surfaces. Eventually, the sliding resistance along the crack, $V_{c i}=V_{a y}+V_{d}$, decreases, and the beam fails in shear. In a beam without stirrups, a sudden failure occurs with inclined cracks [1].

The longitudinal reinforcement participates in resisting the external shear by a modified dowel action, with a significant contribution. The shear resistance of the longitudinal reinforcement action in conjunction with the embedding concrete depends on the size of the bars, spacing, concrete cover and strength [49].

Tests ( [18]; [50]; [51]) and analyses ( [50]; [52]) have shown that the shear strength of reinforced concrete beams drops significantly if the longitudinal reinforcement ratio decreases below $1.2 \%$ to $1.5 \%$, depending on the web thickness [27]. Also, beams with low steel percentages show a reduction in shear capacity that is due to an increase of crack width and length, resulting in lower interface shear transfer (lower interlock capacity) in a reduced size of the compression zone and in a reduced dowel action ( [21]; [42]).

On the other hand, if the steel percentage is increased, an increase in shear capacity will be expected [21]. The influence of the amount of longitudinal reinforcement is higher than that predicted by the Codes of practice. No limitation is necessary up to an amount of about 5\% [53]. In general, the total amount of reinforcement (prestressing steel and mild reinforcement) controls the behavior and strength of the member up to formation of the 
primary shear crack. For specimens containing equivalent amounts of reinforcement, essentially identical shear strengths $V_{c}$ were provided [54].

The beams without intermediate layers of crack control reinforcement failed with low values of shear, indicating the possibility of a serious safety concern for this type of member, Fig. A. 26 [55].

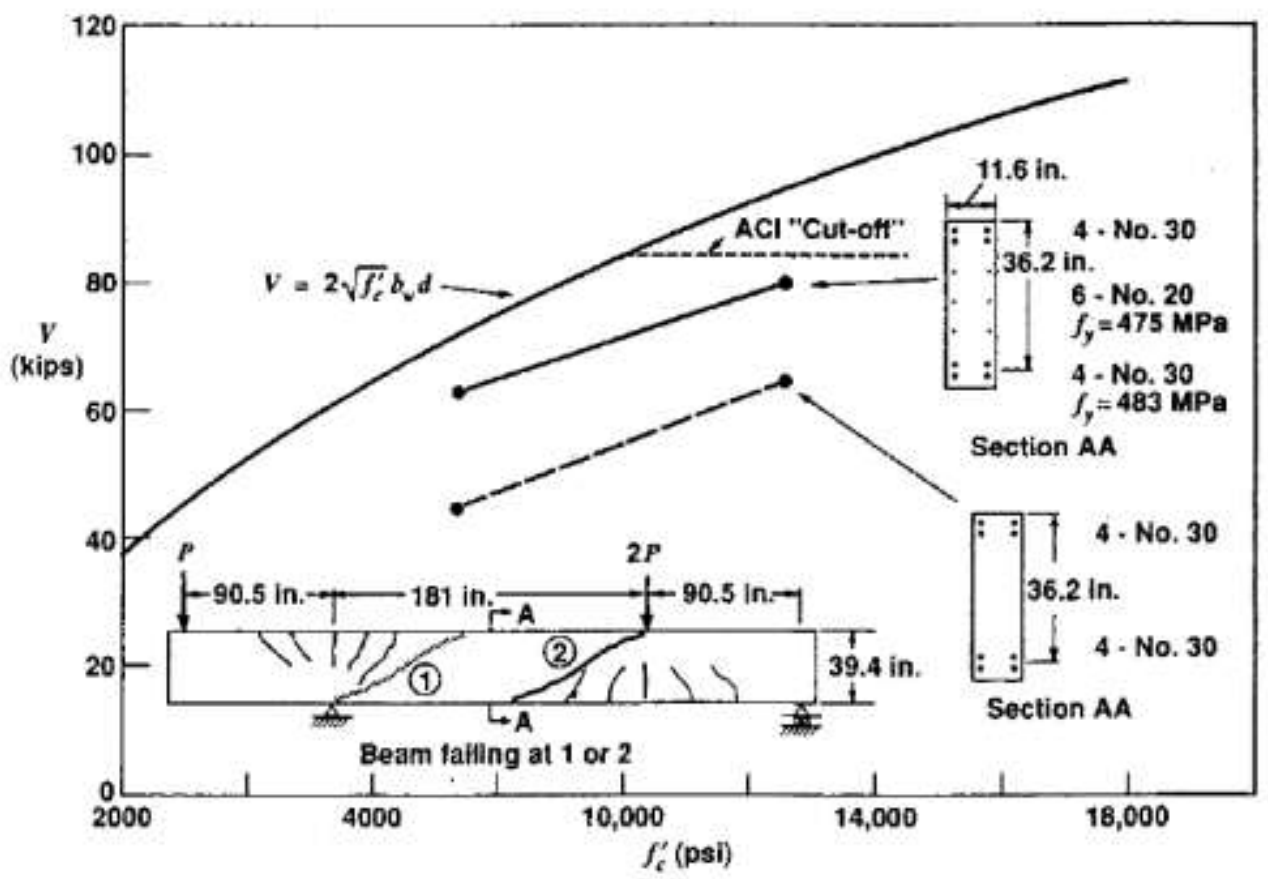

Fig. A. 26 Failure shears of four large high-strength concrete beams tested by Collins and Végh [55]

\section{A.4.4 Compressive strength of concrete, $f_{c}$.}

The concrete strength influences the dowel capacity and the aggregate interlock. Concrete strength is not a significant variable in shear and high strength concretes with weak aggregates may produce smooth-sided cracks that have low interlock capacity [21]. So, in high strength concrete (HSC) beams, the fracture planes are smoother than in normal strength concrete (NSC) beams, with consequent lower shear strength contribution of the aggregate interlock mechanism ( [56]; [57]; [58]). It was shown that the crack patterns and the failure modes of HSC and NSC beams are similar with shear-compression failure for beams with prevalent arch action and diagonal-tension failure for beams with prevalent beam action [10]. This supports the view that the nominal shear stresses in Codes should not increase indefinitely with concrete strength and the stress related to a concrete 
strength of $50 \mathrm{MPa}$ concrete, is probably a suitable maximum [21]. Therefore, generally, the higher the concrete compressive strength the higher the failure shear strength [53], [57] and [30].

However, the influence of the concrete compressive strength depends on the beam size and the amount of transverse reinforcement. For normal strength concrete beams, the greater the amount of transversal reinforcement, the higher the influence of the concrete compressive strength. The use of high-strength concrete tends to prevent shearcompression failure and to ensure a diagonal tension failure instead, thus increasing the effectiveness of the shear reinforcement [53].

If the influence of compressive strength level in the shear strength is evaluated according to the $\mathrm{ACl}$ approach, the following results can be observed:

- $\quad$ Fig. A. 28 summarizes the results of a series of beams containing only longitudinal reinforcement tested by Collins and Végh at the University of Toronto with the aim of studying the safety in shear of large beams made of high-strength concrete. It can be observed that the shear failure of these beams were less than those obtained by limiting the value of $\mathrm{Vf}^{\prime}{ }_{\mathrm{c}}$ to $100 \mathrm{psi}$, as required by the $1989 \mathrm{ACl}$ Code [51].

- In traditional U.S. design practice and in the LRFD Sectional Design Model, the contribution of concrete to shear resistance is taken as proportional to the square root of the cylinder compressive strength $f_{c}^{\prime}$. Fig. A. 26 presents some of the test data by Moody [59] from which the allowable design stress limit of $2 \mathrm{vf}_{\mathrm{c}}{ }^{\prime}$ was developed. The test beams were typically around 14 inches deep, overly reinforced in flexure, and contained large aggregates. Also shown in the figure are the results from a series of tests by Angelakos [60] carried out at the University of Toronto on larger and more lightly reinforced members cast using smaller size aggregates. As Fig. A. 27 shows, the apparent safety of the traditional equation for $2 v f_{c}{ }^{\prime}$, as used in U.S. practice for beams without shear reinforcement, is also dependent on the parameters of beam depth, concrete strength and maximum aggregate size, not considered in that expression [29]. 


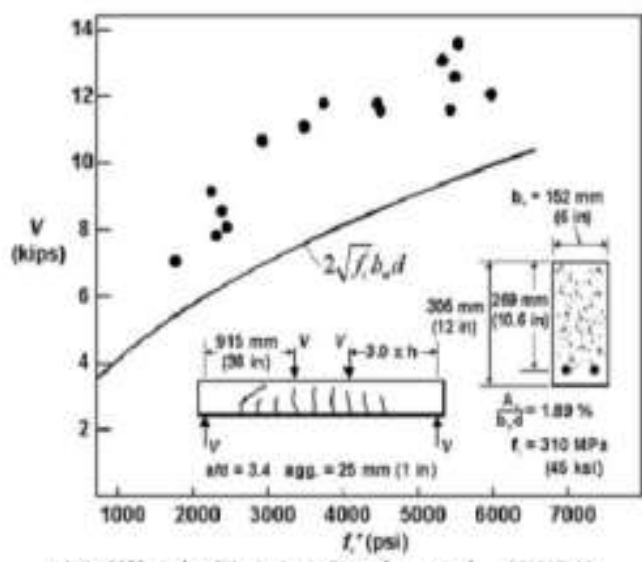

(a) Illinois Tests, Moody et al., (1954)

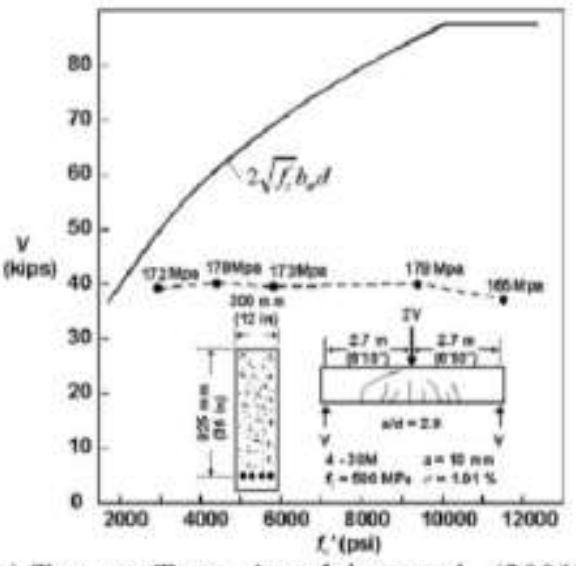

(b) Toronto Tests, Angelakos et al., (2001)

Fig. A. 27 Influence of concrete strength on shear capacity [59]

\section{A.4.5 Shear Span-to-Depth ratio, $a / d$}

All parameters being equal, an increase in $a / d$ gives a decrease in shear strength (Fig. A. $30-c)$. This is also expected, as flexural cracks in members with high $a / d$ ratios will be well developed, decreasing the interlock capacity [21].

The maximum moment and shear that can be developed correspond to the nominal moment capacity, $M_{n}$ (see horizontal line in Fig.A.30-b) The shaded areas show the reduction in strength due to shear. Web reinforcement is provided to ensure that the beam reaches the full flexural capacity, $M_{n}[27]$.

Fig.A.30-b shows the three types of shear spans:

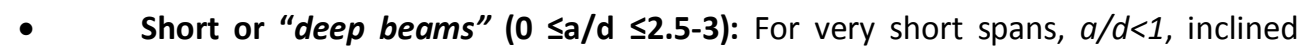
cracks joint load and support destroying the horizontal shear flow from the longitudinal steel to the compression zone, changing the behavior from beam action to arch action. The reinforcement works as a tension tie and the most common failure is an anchorage failure at the ends of the tension tie [1]. For $a / d<1$, the strength of the member is controlled by yielding of the flexural reinforcement, as cracks almost do not disturb the compression strut. For $1 \leq a / d \leq 2.5-3$, arching action is dominant. Shear cracking may progress in a stable manner. The load can thus be increased beyond the development of the first inclined shear crack. The position of the shear crack developing through the compression strut is governing for the strength, and large scatter in test results has traditionally been reported for such members [26]. 
- $\quad$ Slender (2.5-3 $\leq \mathrm{a} / \mathbf{d} \leq 6-13)$. Inclined cracks disrupt equilibrium and beam fails at the inclined cracking load (Fig.A. 30-b), [1]. Failure occurs due to strain localization in a shear crack which limits the strength of the inclined compression strut carrying shear (aggregate interlock), [26].

- Very slender shear spans $(a / d>6-13)$. Beams will fail in flexure prior to the formation of inclined cracks [1]. Yielding of the flexural reinforcement is again governing as beam shear-carrying mechanisms are capable of carrying loads larger than the one corresponding to the flexural strength [26].

For slender and very slender beams, Bernouilli (B)-region behavior dominates, a/d has little effect on the inclined cracking shear (Fig. A. 30-c) and can be neglected. The shaded area indicates the loss in capacity due to shear. Note that the inclined cracking loads of the short shear spans and slender shear spans are roughly constant (Fig. A.30-c). This is recognized in design by ignoring $a / d$ in the equations for the shear at inclined cracking. In the case of slender beams, inclined cracking causes immediate failure if no web reinforcement is provided. For very slender beams, the shear required to form an inclined crack exceeds the shear corresponding to flexural failure, and the beam will fail in flexure before inclined cracking occurs [1]. 


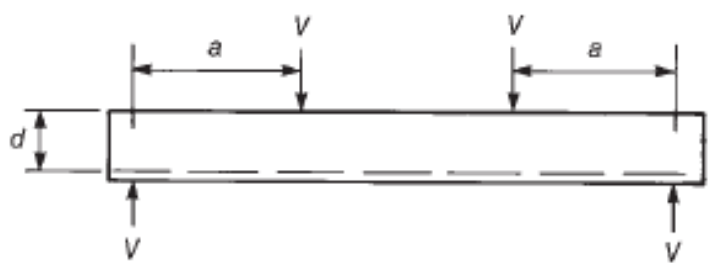

(a) Beam.

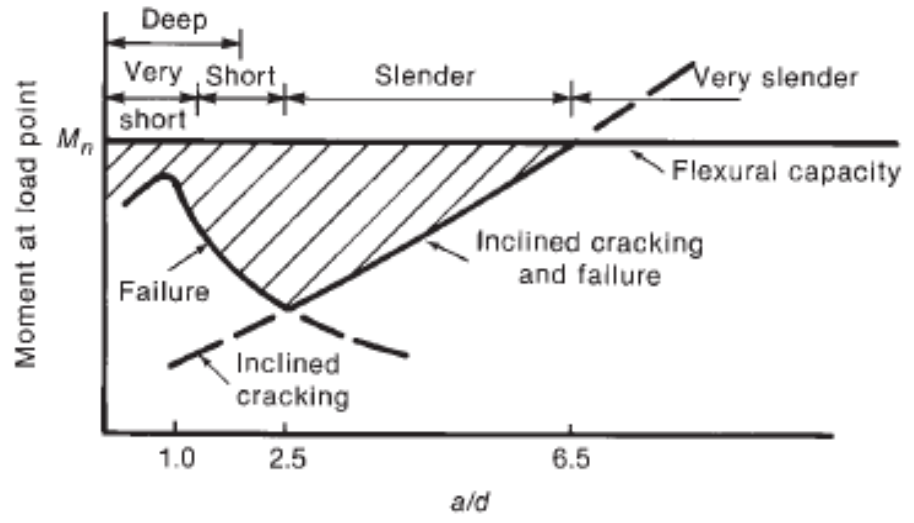

(b) Moments at cracking and fallure.

Fig. A. 28 Effect of $a / d$ ratio on shear strength of beams without stirrups [1]

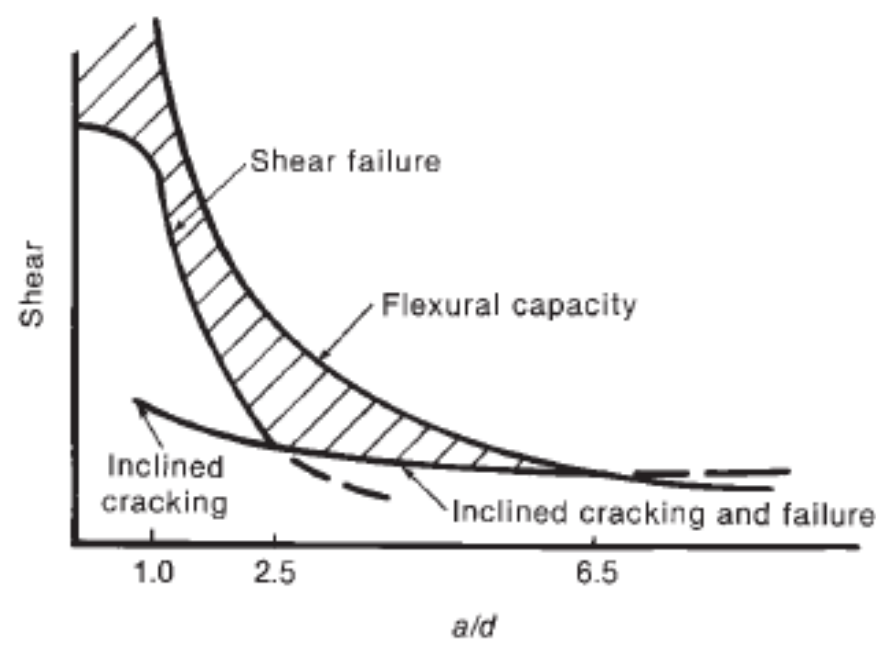

(c) Shear at cracking and failure.

Fig. A. 30 Effect of a/d ratio on shear strength of beams without stirrups [1] 
Therefore, there is a significant depth effect in shear for members without transverse reinforcement and little depth effect for members with shear reinforcement [29].

\section{A.4.6 Beam size (Size effect).}

Kani [20] indicated that shear stresses at failure decreased dramatically with increasing beam depth for a constant concrete strength and main steel ratio, thus the margin of safety against shear failure for beams without stirrups decreases as the size of the beams increases. After Kani, several experimental and theoretical studies during the past 40 years have further supported this relationship [61].

The assumption that the shear capacity is proportional to the depth of the member was investigated in a landmark study carried out by Shioya et al. [62] in which they tested reinforced concrete members that ranged in depth from 101.6 to $2997.2 \mathrm{~mm}$ (4 to 118 inches). All members were simply supported, did not contain shear reinforcement, were lightly reinforced in flexure $(0.4 \%)$, and subjected to a uniformly distributed load. In Fig. A. 31 , the normalized shear stress at failure is plotted versus the depth of the member. The horizontal line corresponds to the shear strength calculated using the traditional shear design expression of the ACl and AASHTO Standard Specifications ( [63]; [29]).

The dashed lines in (Fig. A. 31) show the variation in shear strength of beams without stirrups in tests. The beams were uniformly loaded and simply supported as shown in the inset. Each black circular dot in the figure corresponds to the strength of a beam having the section plotted directly below it. None of these beams had web reinforcement. The horizontal line at $V_{u} / V\left(f_{c}{ }^{\prime} b_{w} d\right)=2.0$ shows the shear $V_{c}$ that $A C l 318$ assumes to be carried by the concrete. Fig. A. 31 shows a very strong size dependency in uniformly loaded beams without web reinforcement [63].

The results show that the shear stress at failure decreases as the depth of the member increases. Of particular concern is that members greater than $914.4 \mathrm{~mm}$ ( 36 inches) deep failed under stresses approximately one-half of the strength calculated by these Codes of practice. However, although this depth effect is marked for beams without transverse reinforcement, available test data show little if any depth effect for beams with transverse reinforcement ( [63]; [29]). 


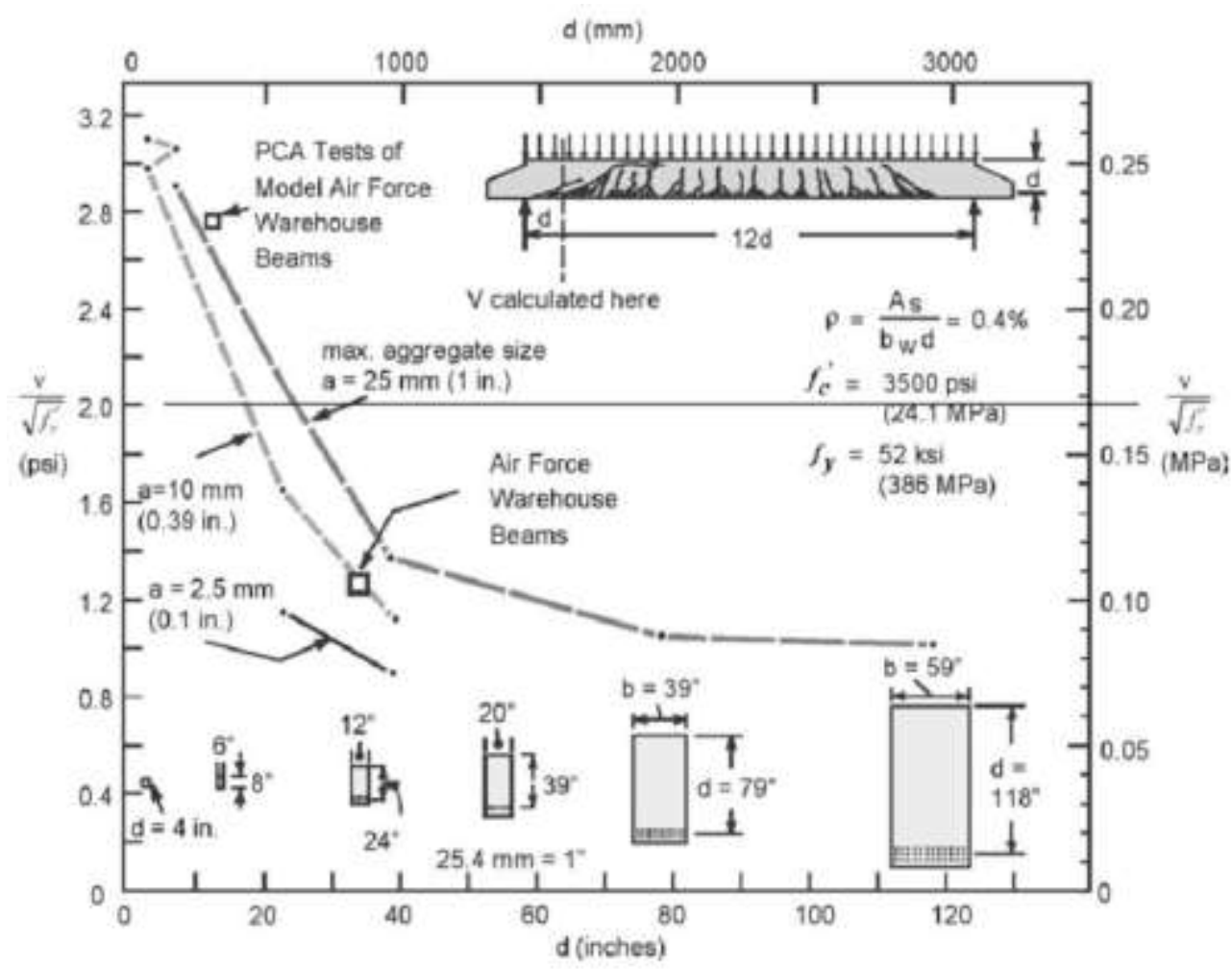

Fig. A. 31 Influence of depth on shear capacity ( [62]; [63])

The width of an inclined crack depends on the product of the strain in the reinforcement crossing the crack and the spacing of the cracks. With increasing beam depth, the crack spacings and the crack widths tend to increase. This leads to a reduction in the maximum shear stress, $v_{c i \text { max }}$, that can be transferred across the crack by aggregate interlock. An unstable situation develops when the shear stresses transferred across the crack exceed the shear strength, $v_{c i \max }$. When this occurs, the faces of the crack slip, one relative to the other.

It is possible that part of the loss of strength can be accounted for by the fact that although the cracks were wider in the deep beams than in the shallow beams, the surface of the cracks had the same roughness in both cases so that the contribution of aggregate interlock to their shear capacity was different [27].

There is general agreement that the main reason for this size effect is the larger width of diagonal cracks in larger beams; however, there is disagreement on how best to model this phenomenon. In 1984, Bazant [64] believed that the most important consequence of 
wider cracks is reduced residual tensile stresses and, as a result, propose using a size reduction factor:

$$
\lambda=\frac{1}{\sqrt{\left(1+\frac{d}{d_{0}}\right)}}
$$

based on nonlinear fracture mechanics, where do is an empirical parameter. Others believe that the most important consequence of wider cracks is a reduced ability to transmit cracks interface shear stresses.

On the other hand, the simplest explanation of the size effect in shear is that the larger crack widths that occur in larger members reduce aggregate interlock. Crack widths increase nearly linearly both with the tensile strain in the reinforcement and with the spacing between cracks. Shioya observed that the crack spacing at mid-depth of his beams was about equal to half the depth of the beams. To maintain beam action, a shear stress equal to about $\mathrm{V} /\left(\mathrm{b}_{\mathrm{w}} \cdot \mathrm{d}\right)$ must be transmitted across these cracks. The shear stress that can be transmitted across such cracks however, decreases as the crack width increases and as the maximum aggregate size decreases [65]. So, by increasing the beam depth, crack width at points on the longitudinal reinforcement tends to increase. Some authors believe that this leads to a reduction in aggregate interlock, resulting in an earlier diagonal cracking [66]. As wider cracks will be associated with lower aggregate interlock strength, anything that increases the value of $\boldsymbol{w}$ can be expected to result in decreased shear capacity [44].

Other authors [64], believe that the most important consequence of wider cracks is less residual tensile stress on the surface of the crack. Shioya et al. [62] observed the great influence of size effect and the maximum size aggregate [66].

Tests by Taylor [67] have shown much less size effect if the size of the coarse aggregate is changed in the same proportion as the beam size. For beams with $d / b>4$ Taylor has proposed that the design value of $v_{c}$, the shear stress carried by the concrete, should be reduced by $40 \%$ [27].

A number of workers have pointed out that large beams have less shear capacity than small ones and that this loss of strength is sufficiently serious to considered in design. Large members usually have concrete with normal sized aggregate so that the scale of the mix and therefore the roughness of the cracks do not increase to scale. It has been shown that this effect is indeed present [67] and that the interlock mechanism does not scale in these cases, so causing a decrease in shear strength [21].

Estefanía Cuenca Asensio - ICITECH - Universitat Politècnica de València 
Using fracture mechanics, Bazant [64] has explained the size effect on the basis of energy release on cracking. The amount of energy released increases with an increase in size, particularly in the depth. Although a portion of the size effect results from energy release, the author believes crack-width explanation of size effects fits the test data trends more closely.

Also, size effect is related to the concrete compressive strength. For deep beams, the benefit of a higher concrete compressive strength was outweighed by the loss caused by the size effect [68]. Some authors found out that high-strength concrete beam specimens showed a more significant size effect in shear than normal-strength concrete members. Thus, the influence of the size effect becomes bigger when the concrete compressive strength increases, to such an extent that, for deep beams, the benefit of having a higher concrete compressive strength is lower than the loss caused by the size effect [68], [53]. Because the cracks in high-strength concrete beams pass through the aggregate, beams made from such concrete are more sensitive to the size effect in shear [65].

Experimental tests carried out by Fujita in 2002 showed that shear fracture in high strength concrete (HSC) is characterized by a conspicuous localization of cracking in comparison with normal strength concrete (NSC), and that the propagation of these cracks was rapid, resulting in a more brittle fracture. A study leads to these relationships between size effect and concrete compressive strength:

$\frac{V}{b \cdot d} \propto\left(\frac{l_{c h}}{d}\right)^{1 / 4}$ for normal strength concrete (NSC)

$\frac{V}{b \cdot d} \propto\left(\frac{l_{c h}}{d}\right)^{1 / 2}$ for high strength concrete (HSC)

where the characteristic length $\left(I_{c h}\right)$ is equal to:

$$
l_{c h}(m m)=30700 \cdot f_{c}^{-1.1} \text { with } f_{c}(M P a)
$$

In the literature two ways to mitigate or eliminate size effect on shear strength have been found. That is:

\section{- Placing distributed longitudinal reinforcement along the depth of the beam.}

In 1993, Regan [69] affirmed that resistance to shear cracking was influenced by member size and the ratio of flexural reinforcement, as well as by concrete strength. 
In 1993, Collins, Mitchell, \& MacGregor [55] demonstrated that the size effect disappears when beams without stirrups contain well distributed longitudinal reinforcement and, in 1999, also Collins \& Kuchma [63] affirmed that the reduction in shear stress at failure was related more directly to the maximum spacing between the layers of longitudinal reinforcement rather than the overall member depth and therefore, the size effect was not only a function of the beam depth, but also of the distance between distributed longitudinal reinforcement $\left(s_{z}\right)$. Finally, they [63] concluded that size effect disappears in beams without shear reinforcement when they contain sufficient horizontal reinforcement distributed in the web. In 2004, Lubell et al. [65] pointed out that the addition of three layers of intermediate longitudinal bars (see Fig.A.32) greatly reduced the crack spacing near mid-depth and increased the shear capacity by more than $50 \%$ [65].

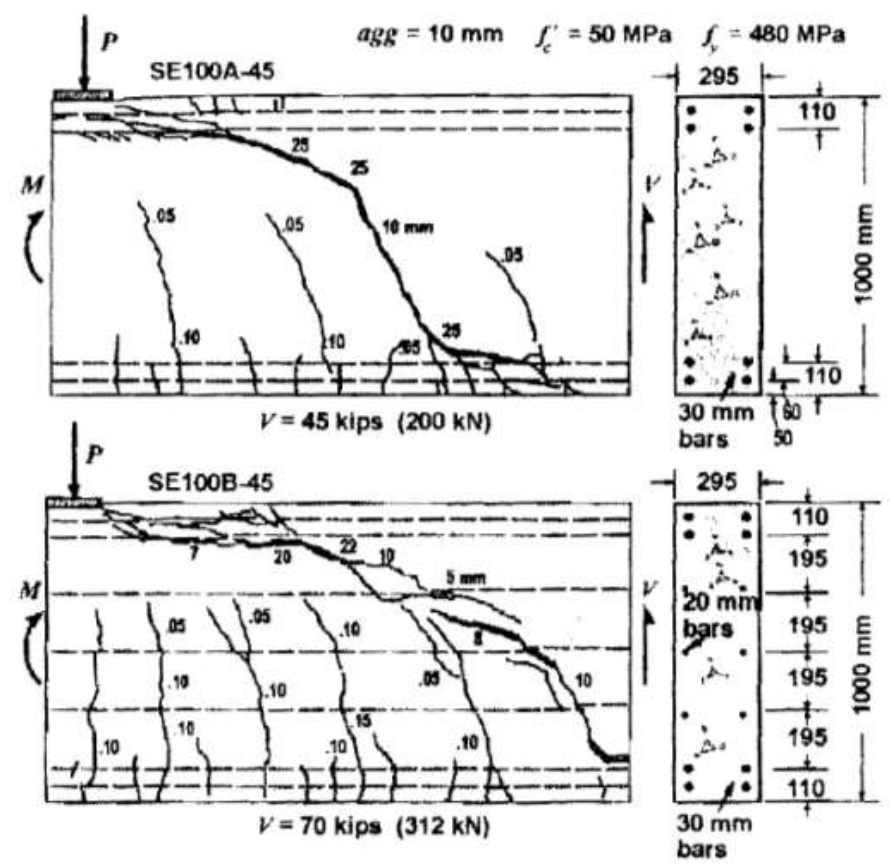

Fig.A.32 Influence of distribution of longitudinal reinforcement on cracking pattern and shear strength of two companion beams [65]

\section{- $\quad$ Adding stirrups:}

In beams with at least the minimum required web reinforcement, the web reinforcement holds the crack faces together so that the shear transfer across the cracks by aggregate interlock is not lost. As a result, the reduction in shear strength due to size is not observed in beams with web reinforcement [63]. 
In 1973, Committee 426 of ACl-ASCE [27], suggested that it appears reasonable to expect that while $V_{c}$ has a scale effect, $V_{s}$ has not, so that the effect of size on beams with web reinforcement is small.

In 2000, Frosch [70] affirmed that the effective stirrups were capable of developing, at minimum their yield strength after shear crack formation and, beam size did not affect the postcracking behavior or the shear strength provided by the stirrups.

In 2004, Lubell et al. [65] added that the provision of minimum stirrups controls the spacing of diagonal cracks, however, beams with such reinforcement do not display any significant size effect in shear. Hence, such reinforcement is even more beneficial for large beams than it is for small beams.

One traditional assumption is the independence of the contribution of concrete, $V_{c}$, and stirrups, $V_{s}$, to shear strength. Recent research shows that stirrups affect the concrete contribution and mitigate the size effect [63].

In 2004, Cladera \& Marí [53] pointed out that although members with a low amount of web reinforcement a reduction in failure shear stress was detected, this effect decreased when the amount of shear reinforcement increased and members with twice this amount of shear reinforcement did not show any reduction in shear strength due to the size effect in the Artificial Neural Networks analysis (ANN). It was detected that the size effect reduces the failure shear stress by about $25 \%$ as effective depth is increased from 250 to $700 \mathrm{~mm}[53]$.

The idea that stirrups cannot suppress completely size effect in large beams was also affirmed by other authors in this way: "Stirrups or other shear reinforcement are known to significantly enhance the shear strength of deep beam, thanks to strengthening of the so-called compression strut. However, this enhancement is not unlimited and the concrete compression strut eventually fails by compression-shear crouching, which has been shown to exhibit size effect" ( [71] to [72]).

Recently, in 2011, Yu \& Bazant [72] have concluded the same ideas:

- "Although stirrups mitigate the size effect on the shear strength of RC beams, they cannot suppress it completely, regardless of the stirrup ratio" [72].

- "The effect of shear reinforcement ratio on the shear strength is not linear. Large enough beams reach their maximum load before the stirrups yield, and then further strengthening of the shear reinforcement will not improve the shear strength of the beam" [72]. 
- "Although the spacing of stirrups significantly affects the inclination of the diagonal shear crack, it has a negligible effect on the shear strength of beam".

\section{A.4.7 Axial forces (Influence of Axial Loads).}

It is well known that axial tension decreases the shear strength of members without transverse reinforcement, and axial compression (due to an applied load or prestressing) increases the shear resistance. Axial tensile forces tend to decrease the inclined cracking load, while axial compressive forces tend to increase it (Fig.A.33). As the axial compressive force is increased, the onset of flexural cracking is delayed and the flexural cracks do not penetrate as far into the beam. Axial tension forces directly increase the stress, and hence the strain, $\varepsilon_{x}$, in the longitudinal reinforcement. This causes an increase in the inclined crack width, $w$, which, in turn, results in a decrease in the maximum shear stress, $v_{\text {ci max }}$ that can be transmitted across the crack. This reduces the shear failure load. The opposite is true for axial compressive forces. A similar increase is observed in prestressed concrete beams. The compression due to prestressing reduces the longitudinal strain, $\varepsilon_{x}$, leading to a higher failure load. Members without shear reinforcement subjected to large axial compression and shear may fail in a very brittle manner at the formation of first diagonal cracking [42].

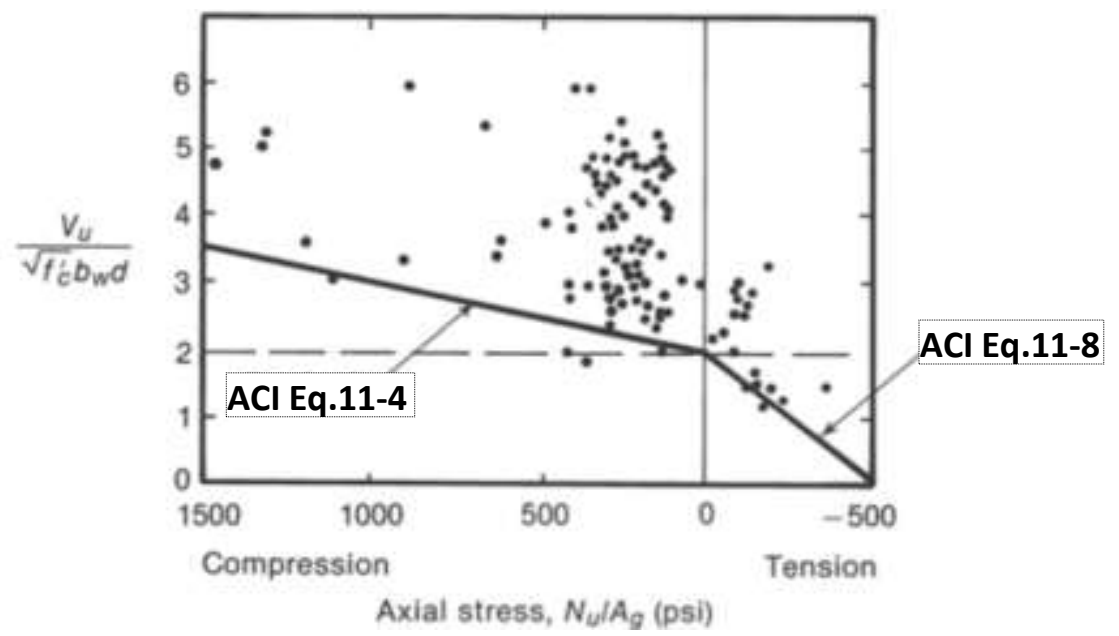

Fig.A.33 Effect of axial loads on inclined cracking shear [48]

Where in Fig.A.33, the represented equations are: 
Axial compression:

$$
V_{c}=2\left(1+\frac{N_{u}}{2000 A_{g}}\right) \sqrt{f_{c}^{\prime}} b_{w} d
$$

Axial tension:

$$
V_{c}=2\left(1+\frac{N_{u}}{500 A_{g}}\right) \sqrt{f_{c}^{\prime}} b_{w} d
$$

The influence of axial compression and tension on shear capacity is examined in Fig.A.34 [73].

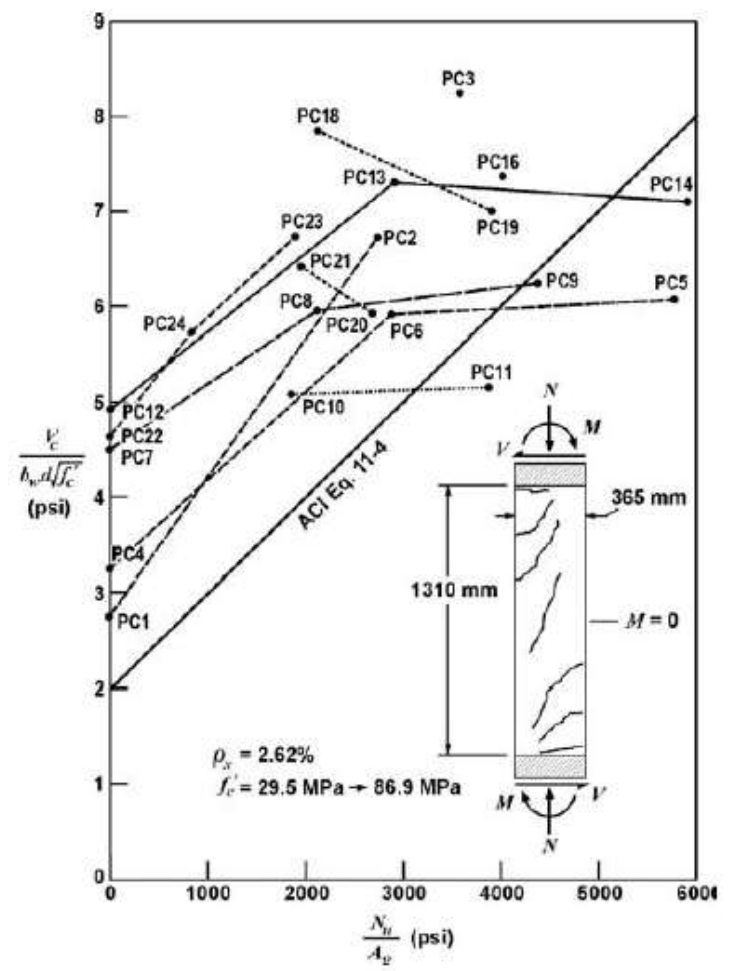

Fig.A.34 Influence of axial compression on shear capacity [73]

According with the effect of axial loads in beams with stirrups, it was detected that axial compression increases the number of stirrups that carry the shear across diagonal cracks while axial tension decreases the number of stirrups that are available to carry the shear across cracks [29]. On the other hand, referring to the influence of degree of prestressing 
in beams with stirrups, Thürlimann [74] experimentally showed that the positive influence of prestressing on the shear capacity depends on the level of prestressing. Contribution of prestressing to shear capacity increases by increasing the level of prestressing. Fig.A.35 indicates the stirrup forces versus the acting shear force including the cases of nonprestressed, partially prestressed and fully prestressed members. In this series of tests, the degree of prestressing varied between 0 and $100 \%$ [75].

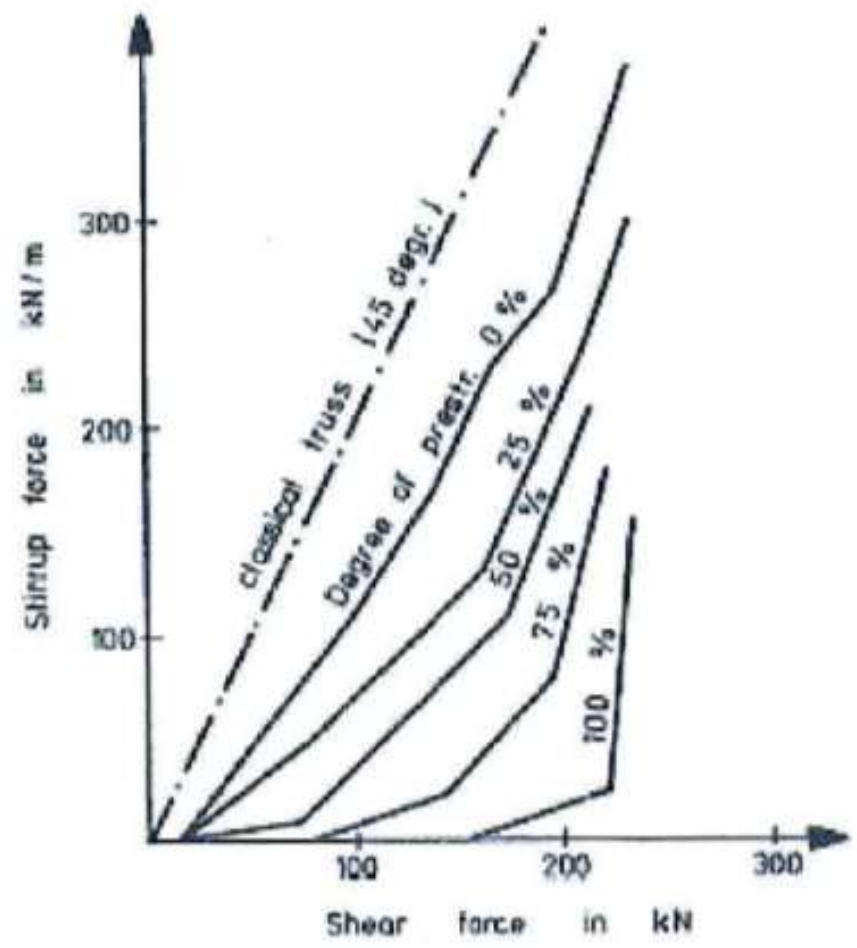

Fig.A.35 Influence of degree of prestressing on stirrup forces [74]

\section{A.4.8 Coarse aggregate size}

An important part of the shear capacity of a beam depends upon aggregate interlock. In high-strength concrete beams and some lightweight concrete beams, the crack goes right through the aggregate, resulting in a smoother surface and low shear strengths are obtained. In other cases, a rough cracked surface is obtained and shear test results much closer to those from dense concretes are obtained [21]; see Fig.A.36 [76].

As the size (diameter) of the coarse aggregate increases, the roughness of the crack surfaces increases, allowing higher shear stresses to be transferred across the cracks [63].

Estefanía Cuenca Asensio - ICITECH - Universitat Politècnica de València 


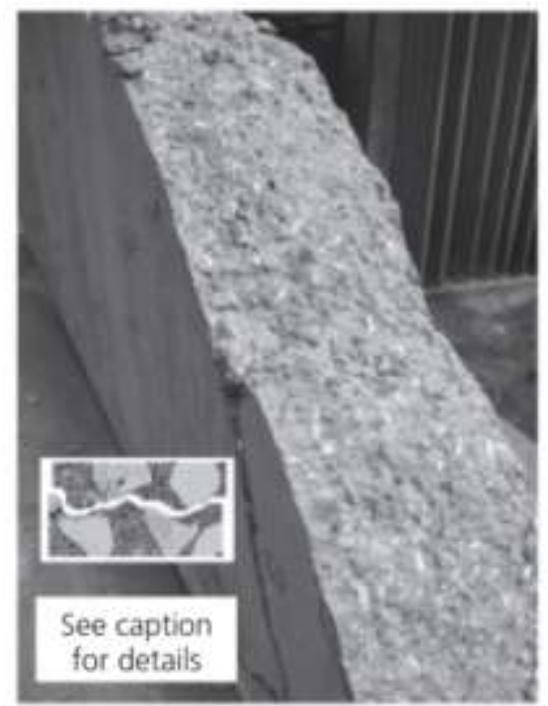

(a)

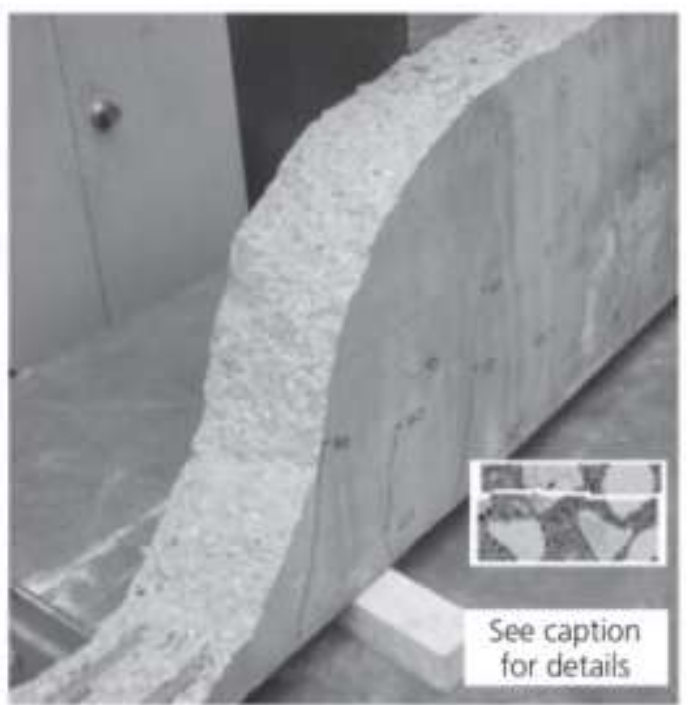

(b)

Fig.A.36 Failure surface at critical shear crack in beams without stirrups: (a) rough crack surface in beam $\left(f_{c}=80.2 \mathrm{MPa}\right)$ with gravel aggregate; and $(\mathrm{b})$ smooth crack surface due to aggregate fracture in beam $\left(f_{c}=68.4 \mathrm{MPa}\right)$ with limestone aggregate [76]

\section{A.4.9 Size of the top flange.}

Shear strength of T-beams is much higher than the shear strength of the rectangular beams of their web. This is solely due to the increase of the compression zone. An increase of stirrups does not give any advantage to T-beams over the rectangular beams [77]. Also, the ratio between the width of the compression flange $(b)$ and the thickness of the web $\left(b^{\prime}\right)$ is shown to have a considerable influence on the inclination of the top chord and of the diagonal struts of the truss and, consequently, on the tensile forces in the web [78].

If, in T beams, the compression and tension chords are kept equal and only the thickness of the web is reduced, then the tensile stresses of the equal stirrups increase almost in proportion to the ratio $b / b^{\prime}$ (Fig.A.37). This means that, even in beams with very thin webs, a part of the shear force must be carried by the chords and not by the web members [78]. 


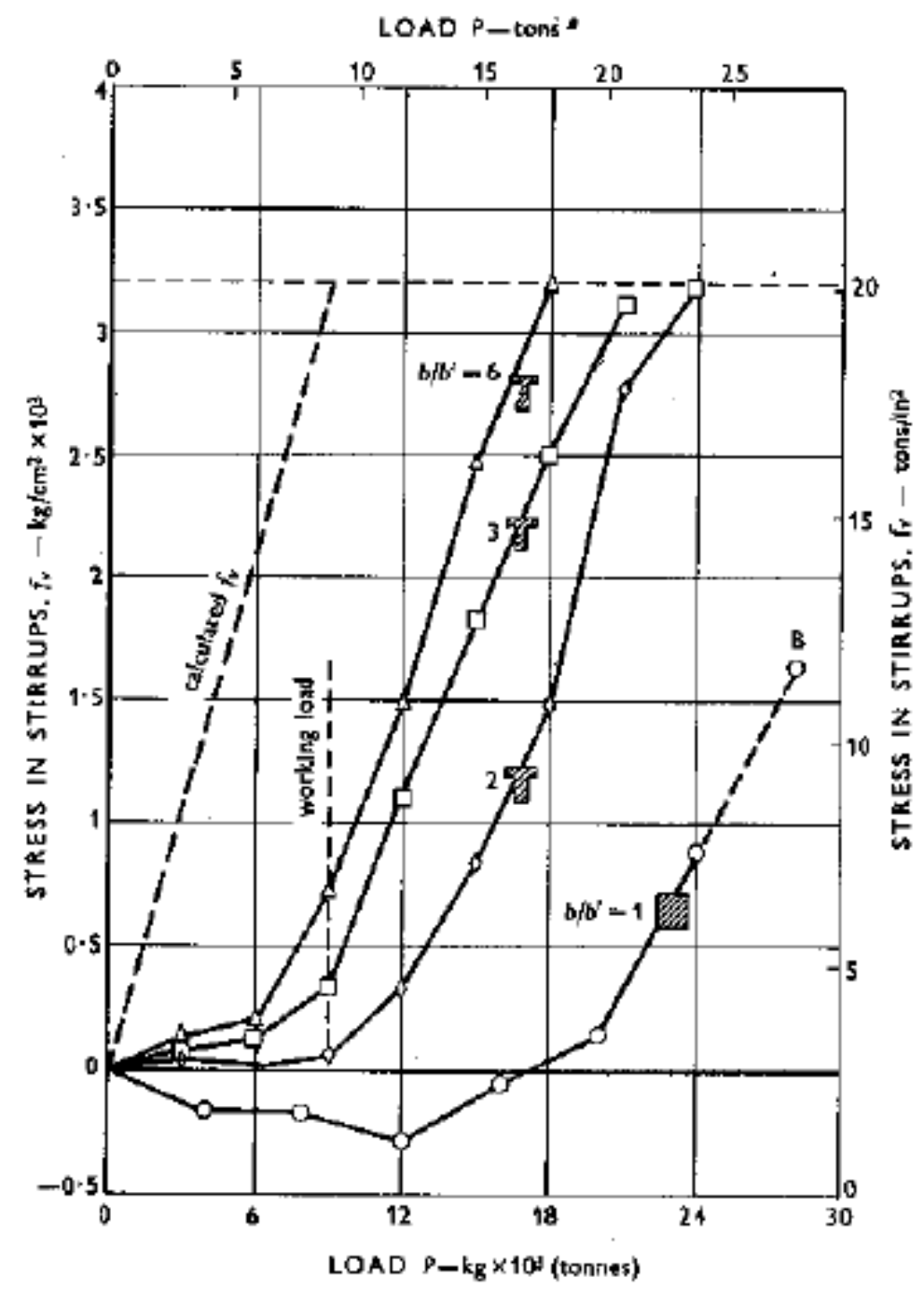

Fig.A.37 Average stresses in stirrups, measured in beams with the one variable $b / b^{\prime}$-width of compression zone to width of web, with equal and constant shear reinforcement $(\eta=0.38)$ compared to stresses calculated according to Mörsch [78]

The flange contribution to shear strength has been studied by several researchers:

In 1962-1963, Leonhardt \& Walther [79] (Fig.A.38) tested a series of beams with constant flange width but varying web thicknesses. The rectangular and thick web T-beams failed by shear compression and shearing of the compression flange while the thinnest web Tbeams failed by crushing of the web due to oblique compression stresses [27]. 


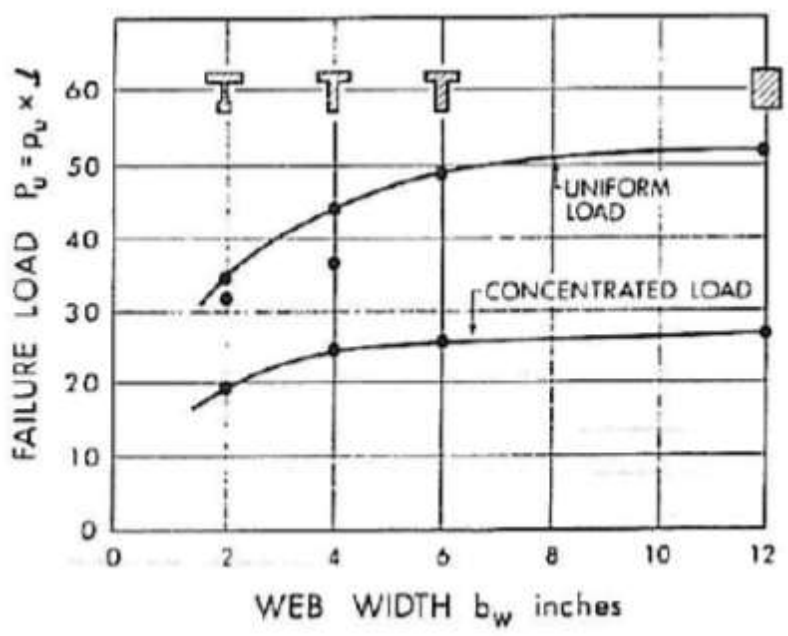

Fig.A.38 Effect of web thickness on shear strength, by [79]

In 1971, Placas \& Regan [52], and Leonhardt [80] (Fig.A.39) have suggested that only the portion of the flange immediately adjacent to the web can transmit a component of the shear in the compression zone. As a result, the compression is distributed over the width of the flange while the shear is concentrated above the web, leading to a critical state of stress in this area. Placas and co-workers [81] observed that the compression zone of that T-beam will frequently fail due to shearing in the region over the web rather than crushing [27].

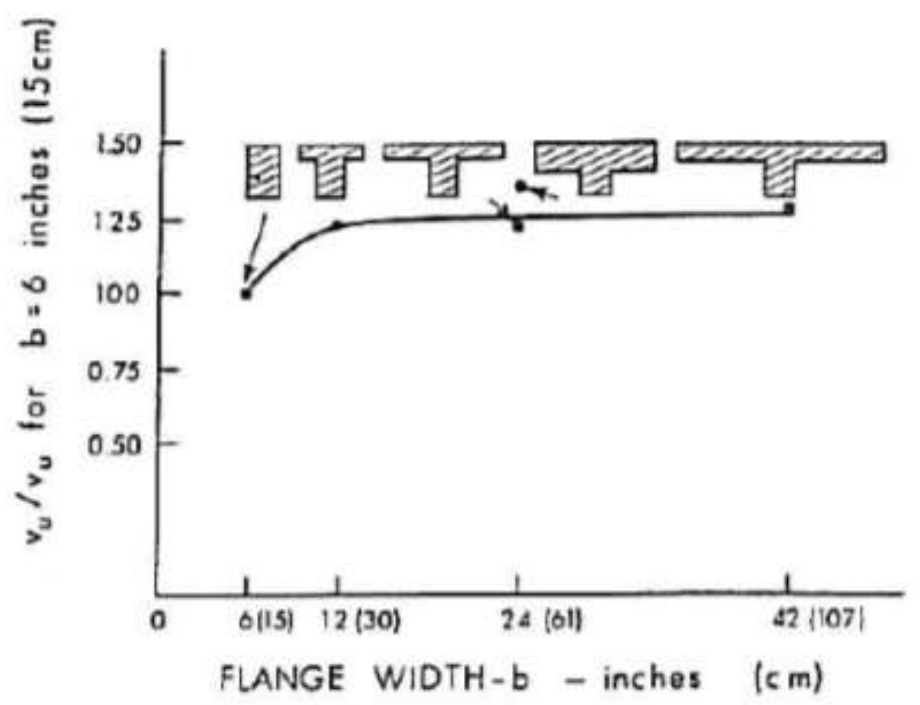

Fig. A. 39 Effect of flange width by Placas \& Regan [52] 
Several formulations are proposed to calculate flange contribution to shear:

- $\quad$ The increased shear strength of the " $\mathrm{T}$ " and "I" beams, relative to the rectangular beams, is attributed to the contribution of the compression flange which can be estimated as follows [82].

$$
V_{c z}=0.1 f_{c u}^{2 / 3}\left(b_{w}+1.5 \lambda h_{f}\right) h_{f}
$$

where:

$$
\lambda=1 \quad \text { if } \quad\left(b_{f}-b_{w}\right)>3 h_{f}
$$

and:

$$
\lambda=\frac{\left(b_{f}-b_{w}\right)}{3 h_{f}} \quad \text { if } \quad\left(b_{f}-b_{w}\right)<3 h_{f}
$$

- $\quad$ Zsutty proposed that Eq.3.39 for calculating the shear, $V_{c}$, carried by the concrete:

$$
V_{c}=v_{c}\left(b_{w} d+2 h_{f}^{2}\right)
$$

(Eq. A.39)

in which $h_{f}=$ the thickness of the flange.

For design purposes, however, it seems reasonable to ignore the strengthening effect of the flange and to continue to compute:

$$
V_{c}=v_{c} b_{w} d
$$

- $\quad$ The form factor approach provides a simple mathematical expression that can be used to estimate the contribution of the flange to the shear strength of a concrete section. This method provides consistent and accurate results for both rectangular sections and Tsections. Although it does not account for the thickness of the flange, it is expected that it should provide reasonable results for T-beam geometries commonly used in practice [83].

$$
\begin{gathered}
\text { Form factor: } \frac{A_{\text {req }}}{A_{\text {comp }}}=\frac{1}{\sqrt{b_{f} / b_{w}}}=\sqrt{b_{w} / b_{f}} \\
V_{c}=5 \sqrt{f_{c}^{\prime}}\left(b_{f} c \sqrt{b_{w} / b_{f}}\right) \text { when } c \leq t \text { (US units) }
\end{gathered}
$$




$$
V_{c}=5 \sqrt{f_{c}^{\prime}}\left(b_{f} t \sqrt{b_{w} / b_{f}}+b_{w}(c-t)\right) \text { when } c>t \text { (US units) }
$$

where: $\boldsymbol{b}_{\boldsymbol{f}}$ is the flange width (in.); $\boldsymbol{b}_{\boldsymbol{w}}$ is the web width (in.); $\boldsymbol{c}=\mathrm{k} \cdot \boldsymbol{d}$ is the neutral axis depth calculated using elastic cracked section analysis (in.) and $\boldsymbol{t}$ is the flange thickness (in.) [83]. Because the form factor yields a value of 1 when there are no flanges, the form factor approach unifies the calculation of the shear strength of both T-beams and rectangular beams [83].

- The shear-funnel method (Fig.A.40) provides a graphical means to account for the flange contribution to shear strength. $\theta$ was varied to determine the value of the angle that results in an area equal to the required flange shear area. Using an angle of 45은 results in a simple design tool for the computation of shear strength that produces results very similar but slightly more conservative than the form factor approach [83].

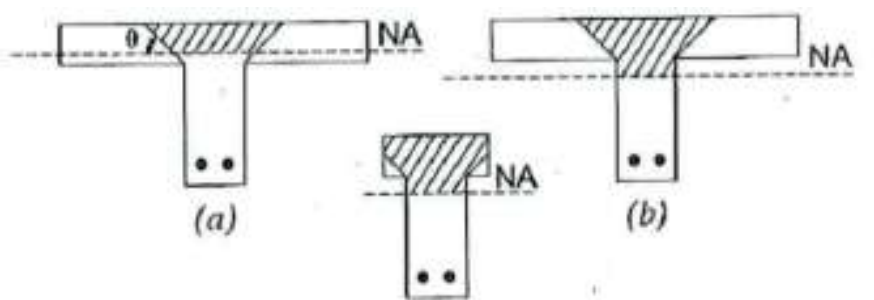

(c)

Fig. A. 40 Shear funnel; NA=neutral axis (by Tureyen, Wolf, \& Frosch [83])

Although both methods (form factor and shear funnel) performed well, their application may require more than the calculation time desired in design practice, as occurred with Zsutty's proposal. Therefore, the shear calculation provided by ignoring the flanges (Fig.A.41) is an extremely simple a conservative method for the calculation of shear strength. This method provides simplicity by considering that the flanged section is not required for the neutral axis calculation. The calculation of effective shear area using this method is illustrated in Fig.A.41 [83].

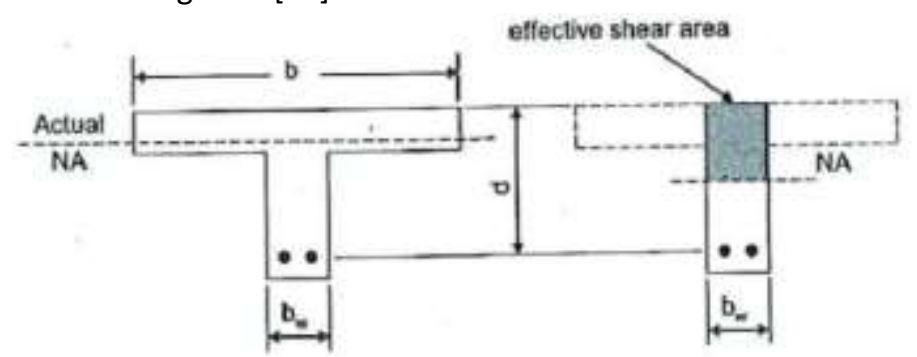

Fig. A. 41 Calculation of effective shear area by ignoring flanges (Tureyen, Wolf, \& Frosch [83]) 
On the other hand, EC2, BS 8110 and CSA A.23.3-04 assume that the shear force is entirely carried by the web in "I" and "T" sections and attribute the contribution of the compression flange to the web. Therefore, Sagaseta \& Vollum [76] suggest that it is "striking" that the variable strut inclination method in EC2 was validated with data from tests on highly stressed simply supported beams with "I" and " $T$ " sections [84] in which the compression flange contributed significantly, but indeterminately, to shear strength. The compression zone contributes less to shear strength in continuous than simply supported beams [76]. In Fig. A. 42 it can be seen that "I" and "T-sections" fail at significantly higher shear stresses than the rectangular sections shown [76].

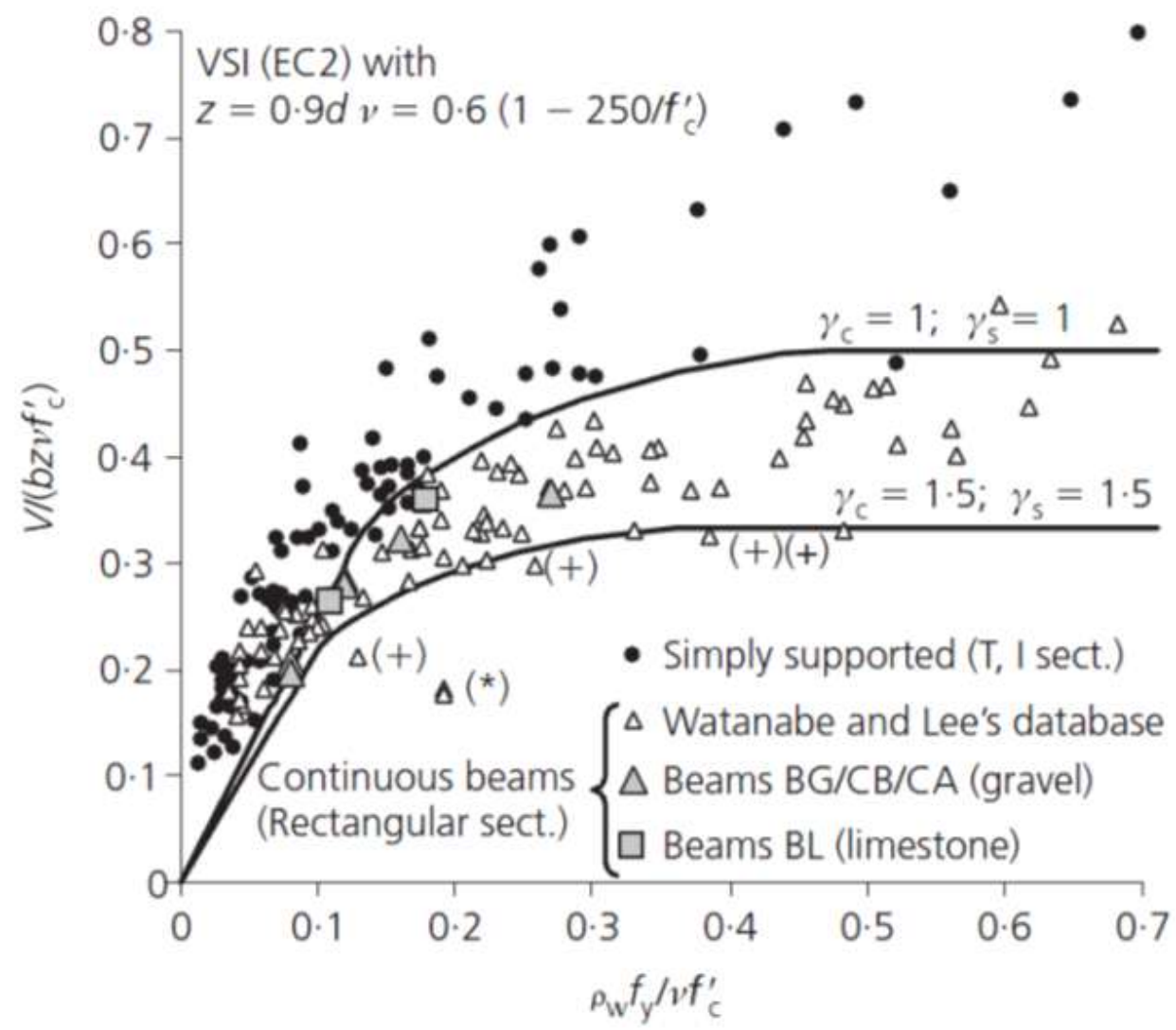

Fig. A. 42 Comparison of test data with shear strengths calculated with EC2 for simply supported beams with " $T$ " and "I" sections and continuous beams with rectangular section. Tests marked with $(*)$ failed prematurely due to bonding. Tests marked with $(+)$ had a very high concrete strength $f_{c}^{\prime}=140 \mathrm{MPa}$ [76]

Eq. A.42 implies that the compression flange increased the shear strength of the "I" and " $T$ " beams in Fig.A.42 between 10 and 20\%. This estimate is consistent with the findings of 
[79], [85], [86] and is of the same order as the difference between the shear strengths of comparable flanged and rectangular sections in Fig.A.42 [76].

\section{A.4.10 Stirrups.}

With large amounts of stirrups, the dowel and interlock contributions to shear capacity become much less important but they are nevertheless present and cannot be completely ignored in a theoretical approach [21]. Also, the greater the amount of shear reinforcement, the lesser crack width, and the larger the concrete contribution will be. The influence of the amount of web reinforcement is not linearly proportional to the failure shear strength. The more the stirrups, the less effective they are [53]. In addition, for members with large amounts of shear reinforcement, the compression field will remain at values of approximately 45ㅇ (crushing of the web prior to stirrup yielding). However, for low amounts of shear reinforcement, the compression field will significantly reorientate, leading to falter angles of the struts (and thus activating more shear reinforcement) [26].

On the other hand, in beams with the same relative amount of stirrups, the measured ultimate shear capacity is proportional to the beam width. The transverse distribution of stirrup legs across the web width does not have a significant effect on the shear capacity. With a uniform distribution of stirrups across the web, the interior legs carry a higher shear force than the exterior legs. The surface inclined cracks widths depend on the internal arrangement of stirrups but, at failure, all beams have about the same crack width. There was no significant variation in crack width through the web width in the widest beam with stirrup legs located only along the exterior edges [87].

The behavior after cracking of beams with sufficient transverse reinforcement is rather different of that of member without stirrups. This is due to the fact that a number of inclined cracks develop in the web and their width remains controlled by the transverse reinforcement. According to the theory of plasticity [88], shear will thus not be carried by a single concentrated strut, but a compression field will develop in the web [26].

Also, some authors pointed out that, for HSC beams, stirrups seemed to be more effective. The influence of the stirrups depends on the concrete compressive strength. For HSC beams that are not highly reinforced, this influence is higher than for normal strength concrete beams [53]. However, for beams with the same geometric amount of transverse reinforcement, the higher the concrete compressive strength, the more effective stirrups are [30]. 
Finally, to ensure that the shear capacity of all members with web reinforcement are adequate when designed according to $\mathrm{ACl}$ 318-11 [89], the transverse spacing of web reinforcement should be limited to the lesser of: a) the effective member depth $d$; and $b$ ) $600 \mathrm{~mm}$. These limits should be reduced by $1 / 2$ when the nominal shear stress exceeds $0.42 \mathrm{Vf}_{\mathrm{c}}{ }_{\mathrm{c}} \mathrm{MPa}[90]$.

\section{A.5 Current Design Codes}

In this subsection, the expressions for the calculation of shear strength on beams made with concretes without fibers according to the current Design Codes (EC2-2004 [91], EHE2008 [92], ACl-2011 [89] and Model Code-draft-2010 [93]) are briefly described.

Basically, current Design Codes can be classified in two groups: Codes based on plastic truss (EC2, EHEO8 and $\mathrm{ACl}$ ) and those based on equilibrium and compatibility equations (Model Code 2010) according to the MCFT [41]. These are models that respond to both serviceability and ultimate limit states and in which the cracked concrete is modeled with tensions in two directions. Furthermore, the crack is allowed to transmit friction efforts which cause tensile stresses in the concrete between cracks [94].

\section{A.5.1 Eurocode 2 (EC2)}

According to the previous version of EC2 of 1991, two alternative methods to calculate the ultimate shear capacity were proposed: the standard method and the variable inclination method. According to the standard method, the shear capacity is the sum of two terms: one is the shear reinforcement term, based on a truss mechanism with concrete struts inclined of $45^{\circ}$ to the member axis and the other one is the concrete term regarding the effects of the uncracked compression area, the dowel action of the longitudinal reinforcement and the aggregate interlock. In reality, macro-cracks that develop at failure don't necessarily coincide with the direction of the initial micro-cracks and non linear stress distribution takes place also before the formation of visible cracks. This phenomenon induces a transfer of shear force across the cracks that, consequently, influences the cracking angle which becomes important in the evaluation of the shear capacity [95], [96]. According to these considerations, only the variable inclination method is proposed in the current version of Eurocode 2 (2004) in which struts could have an inclination $\theta$ (to longitudinal beam axis) ranging from limit values $(1 \leq \cot \theta \leq 2.5)$ [97].

According to EC2, the shear resistance of a member with shear reinforcement and without inclined chords is equal to: 


$$
V_{R d}=V_{R d, c}+V_{R d, s}
$$

where:

$V_{R d, c}$ is the design shear resistance of the member without shear reinforcement; $V_{R d, s}$ is the design value of the shear force which can be sustained by the yielding shear reinforcement

\section{A.5.1.1. Members not requiring design shear reinforcement}

In regions cracked in bending the shear resistance is given by:

$$
V_{R d, c}=\left[\left(0.18 / \gamma_{c}\right) \cdot \xi \cdot\left(100 \cdot \rho_{l} \cdot f_{c k}\right)^{1 / 3}+0.15 \cdot \sigma_{c p}\right] \cdot b_{w} \cdot d
$$

$V_{R d, c}$ must be a minimum value of:

$$
V_{R d, c, \min }(\text { in } N)=\left[\left(0.035 \cdot \xi^{3 / 2} \cdot f_{c k}^{1 / 2}\right)+0.15 \cdot \sigma_{c p}\right] \cdot b_{w} \cdot d
$$

where:

$\gamma_{c}$ is the partial safety factor for concrete material properties; $f_{c k}$ is the compressive strength in $\mathrm{MPa} ; A_{s l}$ is the area of the tensile reinforcement, which extends $\geq\left(I_{b d}+d\right)$ beyond the section considered (see Fig.A.43); $b_{w}$ is the smallest width of the cross-section in the tensile area [mm]; $N_{E d}$ is the axial force in the cross-section due to loading or prestressing [in $\mathrm{N}$ ] ( $N_{E d}>0$ for compression), the influence of imposed deformations on $N_{E}$ may be ignored; $A_{c}$ is the area of concrete cross-section $\left[\mathrm{mm}^{2}\right]$. And:

$$
\sigma_{\mathrm{cp}}=\mathrm{N}_{\mathrm{Ed}} / \mathrm{A}_{\mathrm{c}}<0.2 \cdot \mathrm{fdd}_{\mathrm{cd}}[\mathrm{MPa}] ; \xi=1+\sqrt{\frac{200}{\mathrm{~d}}} \leq 2.0 \text {, with d in } \mathrm{mm} ; \rho_{l}=\frac{A_{S l}}{b_{w} d} \leq 0.02
$$
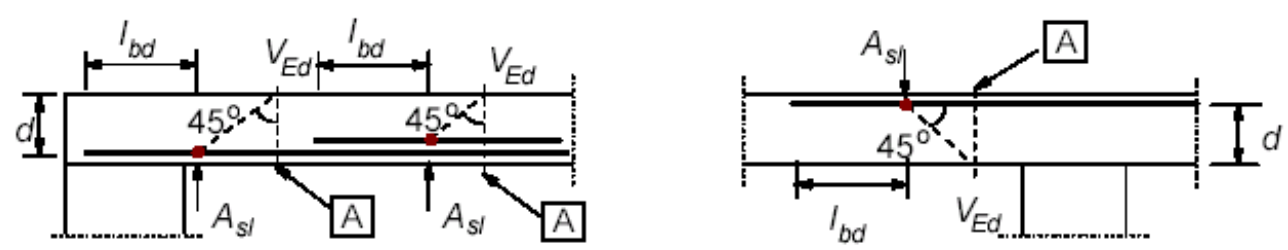

A - section considered

Fig.A. 43 Definition of $A_{s l}(\mathrm{EC2}, 2004$ [91]) 
In regions uncracked in bending (where the flexural tensile stress is smaller than $f_{c t k, 0.05} / \gamma_{c}$ ) the shear resistance should be limited by the tensile strength of the concrete. This condition is only fulfilled in compressed sections, or by the existence of prestressed or by the existence of a permanent compression [8]. In these regions the shear resistance is given by:

$$
V_{R d, c}=\frac{I \cdot b_{w}}{S} \sqrt{\left(f_{c t d}\right)^{2}+\alpha_{l} \sigma_{c p} f_{c t d}}
$$

where:

$I$ is the second moment of area; $b_{w}$ is the width of the cross-section at the centroidal axis; $S$ is the first moment of area above and about the centroidal axis; $\alpha_{1}=I_{x} / l_{p t 2} \leq 1.0$ for pretensioned tendons; $\alpha_{l}=1.0$ for other types of prestressing; $I_{x}$ is the distance of section considered from the starting point of the transmission length; $I_{p t 2}$ is the upper bound value of the transmission length of the prestressing element according to $I_{p t 2}=1.2 \cdot I_{p t} ; \sigma_{c p}$ is the concrete compressive stress at the centroidal axis due to axial loading and/or prestressing $\left(\sigma_{c p}=N_{E d} / A_{c}\right.$ in $\mathrm{MPa}, N_{E d}>0$ in compression).

For the determinations of the geometric characteristics $(I, S)$ of the cross-section homogenized characteristics should be used even though, without losing much accuracy, it can also be used characteristics of the gross section [8].

For members with loads applied on the upper side within a distance $0.5 d \leq a_{v} \leq 2 d$ from the edge of a support (or centre of bearing where flexible bearings are used), the contribution of this load to the shear force $V_{E d}$ may be multiplied by $\beta=a_{v} / 2 d$. This reduction may be applied for checking $V_{R d, c}$. This is only valid provided that the longitudinal reinforcement is fully anchored at the support.

The shear force $V_{E d}$, calculated without reduction by $\beta$, should however always satisfy the condition:

$V_{E d} \leq V_{R d, \max }=0.5 \cdot b_{w} \cdot d \cdot v \cdot f_{c d}$

where $\boldsymbol{v}$ is a strength reduction factor for concrete cracked in shear equal to:

$v=0.6 \cdot\left[1-\frac{f_{c k}}{250}\right]\left(f_{c k}\right.$ in $\left.M P a\right)$

and $V_{R d \text {, max }}$ is the design value of the maximum shear force which can be sustained by the member, limited by crushing of the compression struts 


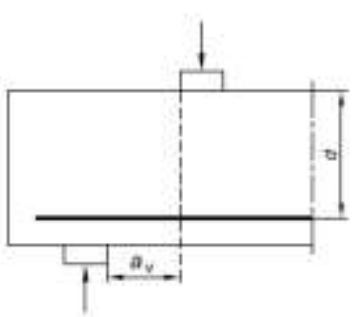

a)

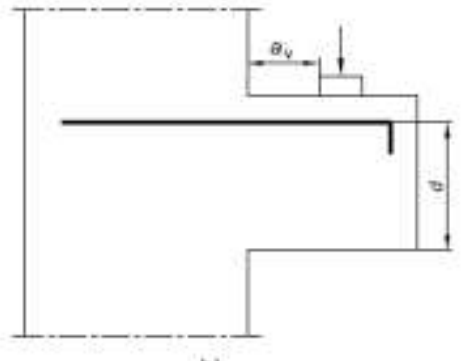

b)

Fig. A. 44 Loads near supports: (a) Beam with direct support; (b) Corbel (EC2, 2004 [91])

Beams with loads near to supports and corbels may alternatively be designed with strut and tie models.

\section{A.5.1.2. Members requiring design shear reinforcement}

The design of members with shear reinforcement is based on a truss model (Fig.A.45). Limiting values for the angle $\theta: 1 \leq \cot \theta \leq 2.5 \rightarrow 22^{\circ} \leq \theta \leq 45^{\circ}$.
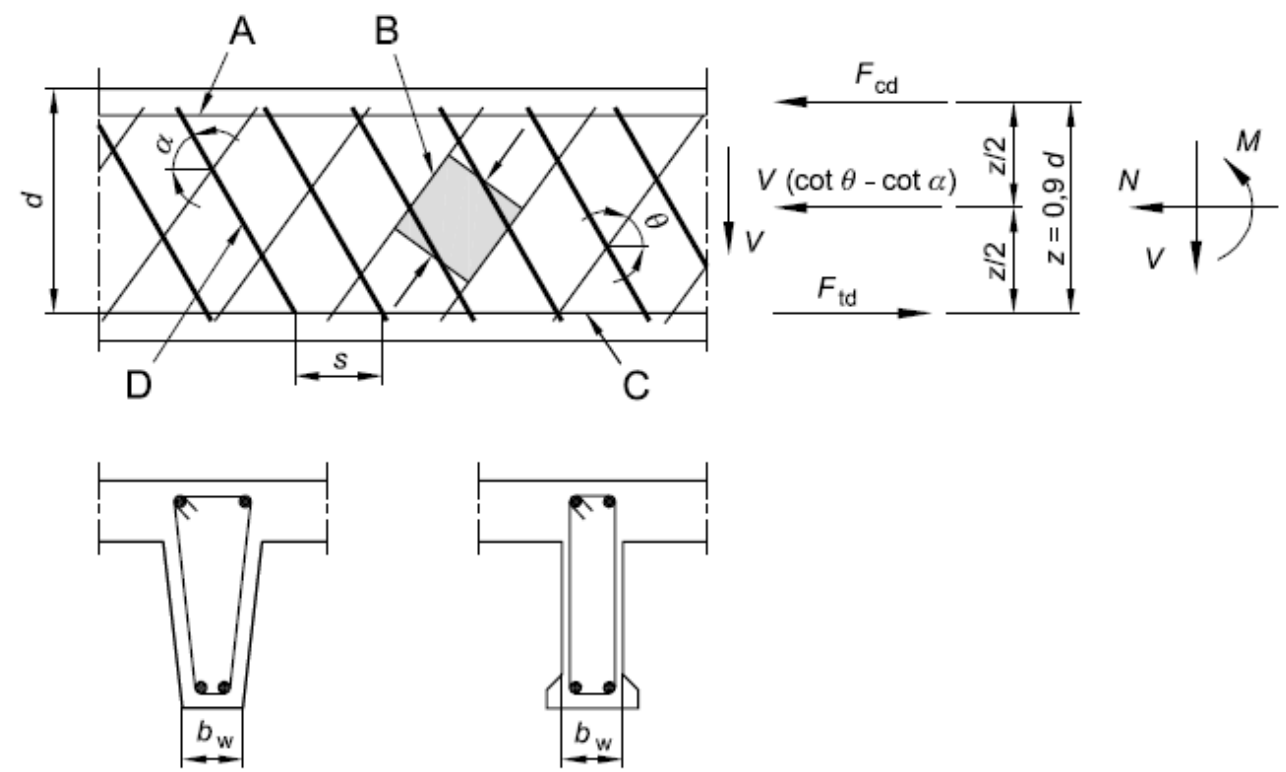

Fig.A.45 Truss model and notation for shear reinforced members (A: compression chord; B: struts; C: tensile chord; D: shear reinforcement), (EC2, 2004 [91])

In Fig.A.45 the following notations have been shown: $\alpha$ is the angle between shear reinforcement and the beam axis perpendicular to the shear force; $\theta$ is the angle between the concrete compression strut and the beam axis perpendicular to the shear force; $F_{t d}$ is 
the design value of the tensile force in the longitudinal reinforcement; $F_{c d}$ is the design value of the concrete compression force in the direction of the longitudinal member axis; $b_{w}$ is the minimum width between tension and compression chords; $z$ is the inner lever arm, for a member with constant depth, corresponding to the bending moment in the element under consideration. In the shear analysis of reinforced concrete without axial force, the approximate value $z=0.9 \mathrm{~d}$ may normally be used.

For members with vertical shear reinforcement, the ultimate shear value $\left(V_{R d}\right)$ according to the current Eurocode 2 is:

$V_{R d}=V_{R d, s}$

where:

$V_{R d, s}=\frac{A_{s w}}{s} \cdot z \cdot f_{y w d} \cdot \cot \theta$

and

$V_{R d, \max }=\frac{\alpha_{c w} \cdot b_{w} \cdot z \cdot v_{1} \cdot f_{c d}}{(\cot \theta+\tan \theta)}$

$A_{s w}$ is the cross-sectional area of the shear reinforcement; $s$ is the spacing between stirrups; $f_{y w d}$ is the design yield strength of the shear reinforcement; $v_{1}$ is a strength reduction factor for concrete cracked in shear:

$$
\begin{array}{ll}
v_{1}=0.6 & \text { for } f_{c k} \leq 60 \mathrm{MPa} \\
v_{1}=0.9-f_{c k} / 200>0.5 & \text { for } f_{c k} \geq 60 \mathrm{MPa}
\end{array}
$$

$\alpha_{c w}$ is a coefficient taking account of the state of the stress in the compression chord.

1

$$
\text { for } \sigma_{c p}=0
$$

$\left(1+\sigma_{c p} / f_{c d}\right)$

for $0<\sigma_{c p}<0.25 f_{c d}$

$$
\text { for } 0.25 f_{c d}<\sigma_{c p}<0.5 f_{c d}
$$


If the shear reinforcement yields the truss can, by rotation of the compression struts to a lower inclination, activate more reinforcement (Fig.A.46). Due to strut rotation, the stress in the concrete struts increases, consequently rotation can only continue until the crushing of the concrete occurs, Fig.A.47 [97].

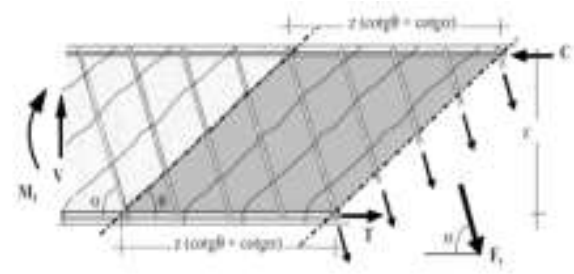

Fig. A.46 Variable inclination truss model: shear resistance provided by reinforcement [97]

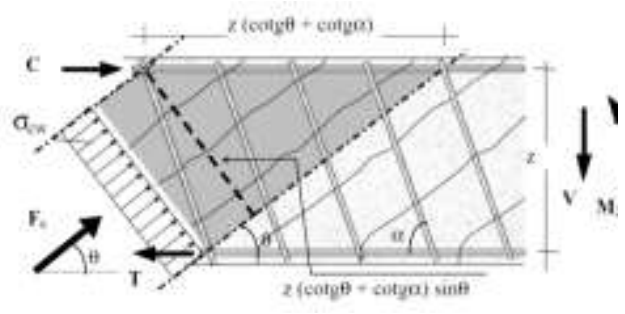

Fig. A.47 Variable inclination truss model: shear resistance provided by concrete struts [97]

The additional tensile force, $\Delta F_{t d}$, in the longitudinal reinforcement due to shear $V_{E d}$ may be calculated from:

$$
\Delta F_{t d}=0.5 V_{E d}(\cot \theta-\cot \alpha)
$$

Several authors, including EC2, have questioned the collaboration of concrete to shear when shear reinforcement is needed. Therefore, this collaboration has been deleted in the current EC2 [8].

\section{A.5.2 EHE 2008 (EHE08)}

The Spanish Standard (EHE08) is based on the EC2 due to the tendency of all standards of European countries to converge on a single European standard. Due to the great similarity between both standards, only the differences between EHE08 and EC2 will be discussed (Table A. 2). For further details of EHE08 formulation see [92]. 
Table A. 2 Differences between EHE08 and EC2

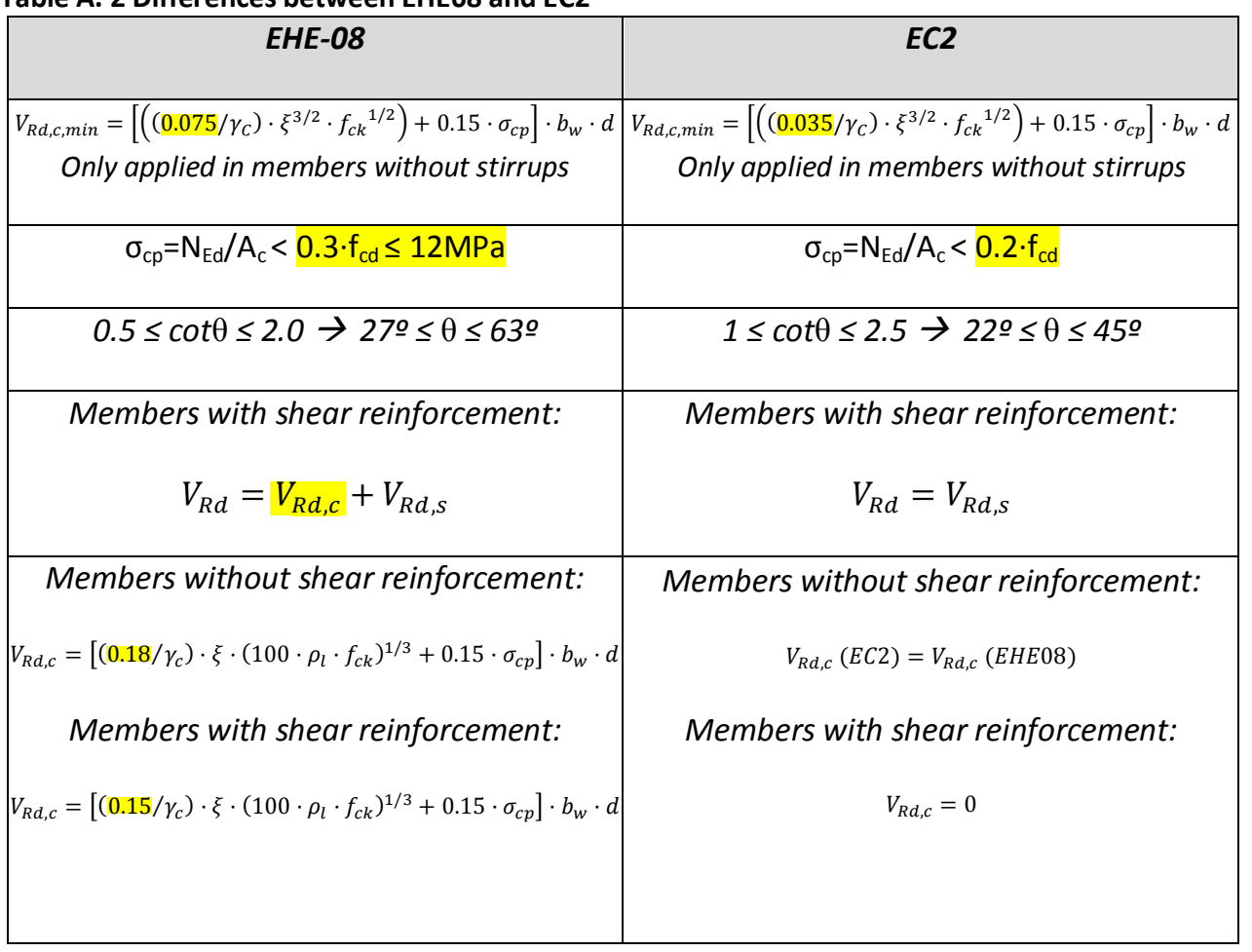

The minimum established in the EHEO8 throws great values equal to those offered by the general formula when the amount of longitudinal reinforcement is between 7 and $12 \%$ [8]. It can be seen that the factor contained in the shear strength expression of members with transverse reinforcement has been reduced from 0.18 to 0.15 compared with its analogous expression of members without shear reinforcement. This reduction is in line with the Model Code [98]. Some researchers defend the idea of taking even in this case a resistance equal to zero, relying on the stirrups the full shear strength (as proposed EC2). In this case, with transverse reinforcement, the EHE08 does not provide a lower limit for shear resistance as occurred for the case of members without transverse reinforcement [8]. The factor $\left(f_{c v}=0.035 \cdot \xi^{3 / 2} \cdot f_{c k}{ }^{1 / 2}\right)$ included in the expression of the minimum shear strength $\left(V_{R d, c, \min }\right)$ of EC2 is a $30 \%$ lower than that proposed by the EHE08. This minimum resistance yields values equal to those offered by the general formula where the amount of longitudinal reinforcement is between 2 and $4 \%$ for a concrete grade of $25 \mathrm{MPa}$ (the precise value depends on the concrete strength and depth) [8]. As stated earlier, several Authors question the contribution of concrete to shear in elements with transverse reinforcement. Thus, the EC2 despises this contribution in these cases. However, the 
EHE08 maintains the validity of such collaboration, so the Authors recommend taking into account, at least in reinforced concrete members [8].

\section{A.5.3 ACI 318-11 (ACI-11)}

The ACl318-11 [89] assumed that the angle of diagonal compression is 45을 and then limits the contribution of stirrups to guard against diagonal crushing occurring before yielding of the transverse reinforcement (stirrups). ACI318-11 also includes an expression for the concrete contribution to shear resistance, $V_{c}$, that is added to the contribution from transverse reinforcement $V_{s}$, in determining the nominal shear capacity, $V_{n}=V_{c}+V_{s}$. By contrast, plasticity base approaches have commonly been used in European design practice, EC2-2002, in which the capacity is taken to be when a mechanism forms of stirrup yielding and concrete reaching its diagonal compressive strength of $f_{2, \max }=\mathbf{0 . 6} \cdot f_{c}$. A lower limit to $\theta$ of $18^{\circ}$ in EC2 is used to evaluate the contribution of shear reinforcement $\left(V_{s}\right)[31]$.

\section{A.5.3.1. Shear strength}

In the $\mathrm{ACl}$ Code, the basic design equation for the shear capacity of slender concrete beams (beams with shear spans containing B-regions) is:

$$
\phi V_{n} \geq V_{u}
$$

where $V_{u}$ is the factored shear force at the section considered, $\phi$ is a strength-reduction factor, taken equal to 0.75 for shear, and $V_{n}$ is nominal shear strength computed by:

$$
V_{n}=V_{c}+V_{s}
$$

where $V_{c}$ is nominal shear strength provided by concrete and $V_{s}$ in nominal shear strength provided by shear reinforcement (stirrups).

The values of $V f_{c}^{\prime}$ used in the $\mathrm{ACl}$ formulas shall not exceed 100psi (8.3MPa).

The $\mathrm{ACl}$ Code utilizes units according to the US customary measurement system while the other Design Codes use the International System of Units (abbreviated "SI" form French: Système international d'unités). In all this subsection, equations will be expressed in its original format (the US customary measurement system) and also their adaptation to the International System (SI). Anyway, in Table A. 3 one can see the equivalence between both measurement systems. 
Table A. 3 Equivalence between US customary measurement system and International System

\begin{tabular}{|l|l|}
\hline US customary measurement system & International System of Units (SI) \\
\hline 1 in. & $0.0254 \mathrm{~m}$ \\
\hline $1 \mathrm{kip}$ & $4448.2216 \mathrm{~N}$ \\
\hline $1 \mathrm{psi}$ & $0.00689475728 \mathrm{MPa}$ \\
\hline
\end{tabular}

\section{A.5.3.2. Shear strength provided by concrete for nonprestressed members}

For members subject to shear and flexure only (shear at inclined cracking):

$$
\begin{aligned}
& V_{c}=\left(1.9 \sqrt{f_{c}^{\prime}}+2500 \rho_{w} \frac{V_{u} d}{M_{u}}\right) b_{w} d \leq 3.5 \sqrt{f_{c}^{\prime}} b_{w} d \quad \text { (US units) } \\
& V_{c}=\left(0.16 \sqrt{f_{c}^{\prime}}+17 \rho_{w} \frac{V_{u} d}{M_{u}}\right) b_{w} d \leq 0.29 \sqrt{f_{c}^{\prime}} b_{w} d \quad \text { (SI units) }
\end{aligned}
$$

When computing $V_{c}$ (Eq. A.62), $V_{u} d / M_{u}$ shall not be taken greater than 1.0 (in both measurement systems), where $M_{u}$ occurs simultaneously with $V_{u}$ at section considered.

For the normal range of variables, the second term in the parentheses in (Eq.A.61-US units) will be equal to about $0.1 V f_{c}^{\prime}\left(S I: 0.0083 V f_{c}^{\prime}\right)$. If this value is substituted into (Eq.A.61-US units), then the following equation results:

$$
\begin{gathered}
V_{c}=2 \sqrt{f_{c}^{\prime}} b_{w} d \quad \text { (US units) } \\
V_{c}=0.17 \sqrt{f_{c}^{\prime}} b_{w} d \text { (SI units) }
\end{gathered}
$$

For members subjected to axial compression, the $\mathrm{ACl}$ Code modifies (Eq. A.64) as follows:

$$
\begin{aligned}
& V_{c}=2\left(1+\frac{N_{u}}{2000 A_{g}}\right) \sqrt{f_{c}^{\prime}} b_{w} d \text { (US units) } \\
& V_{c}=0.17\left(1+\frac{N_{u}}{14 A_{g}}\right) \sqrt{f_{c}^{\prime}} b_{w} d \text { (SI units) }
\end{aligned}
$$

where $N_{u}$ is positive in compression and $N_{u} / A_{g}, v f_{c}{ }^{\prime}$ and 2000 shall be expressed in $p s i$ in (Eq.A.65-US units) and in MPa in (Eq.A.66-SI units). 


\section{A.5.3.3. Shear strength provided by concrete for prestressed members}

For the provisions of prestressed members, $\boldsymbol{d}$ shall be taken as the distance from extreme compression fiber to the centroid of prestressed and nonprestressed longitudinal tension reinforcement, if any, but need not be taken less than $\mathbf{0 . 8 0 h}$.

For members with effective prestress force not less than $40 \%$ of the tensile strength of flexural reinforcement (unless a more detailed calculation will be made in accordance with $V_{c i}$ and $V_{c w}$ which will be explained below):

$$
\begin{gathered}
V_{c}=\left(0.6 \sqrt{f_{c}^{\prime}}+700 \frac{V_{u} d_{p}}{M_{u}}\right) b_{w} d \text { (US units) } \\
2 \sqrt{f_{c}^{\prime}} b_{w} d \leq V_{c} \leq 5 \sqrt{f_{c}^{\prime}} b_{w} d \text { (US units) } \\
V_{c}=\left(0.05 \sqrt{f_{c}^{\prime}}+4.8 \frac{V_{u} d_{p}}{M_{u}}\right) b_{w} d \text { (SI units) } \\
0.17 \sqrt{f_{c}^{\prime}} b_{w} d \leq V_{c} \leq 0.42 \sqrt{f_{c}^{\prime}} b_{w} d \text { (SI units) }
\end{gathered}
$$

Two types of inclined cracking occur in concrete beams: web-shear cracking and flexureshear cracking. These two types of inclined cracking are illustrated in Fig.A.48.

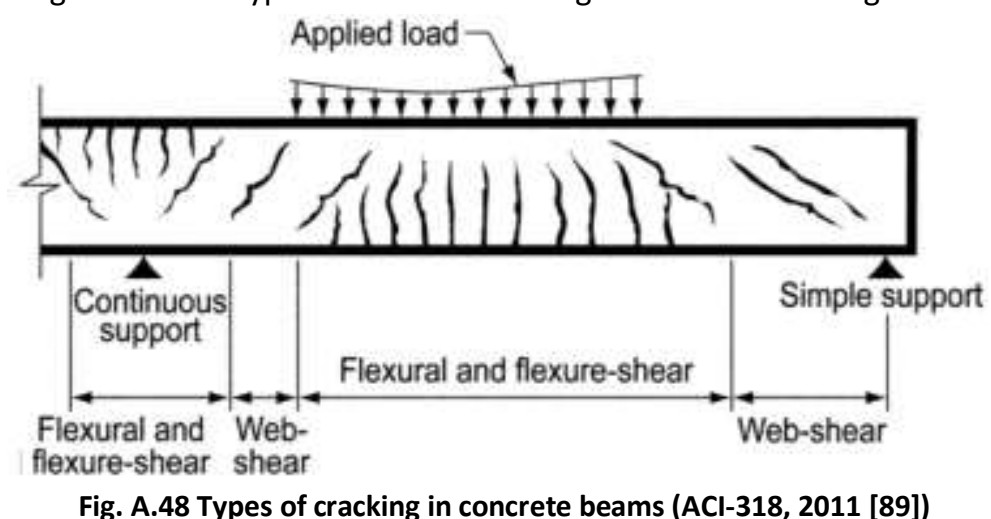

Fig. A.48 Types of cracking in concrete beams (ACl-318, 2011 [89]) 
Web-shear cracking begins form an interior point in a member when the principal tensile stresses exceed the tensile strength of the concrete. Flexure-shear cracking is initiated by flexural cracking. When flexural cracking occurs, the shear stresses in the concrete above the crack are increased. The flexure-shear crack develop when the combined shear and tensile stress exceeds the tensile strength of the concrete.

Eqs. (A.69) and (A.70) may be used to determine the shear forces causing flexure-shear and web-shear cracking, respectively. The nominal shear strength provided by the concrete $\boldsymbol{V}_{\boldsymbol{c}}$ shall be permitted to be computed in accordance with Eqs. (A.69) and (A.70), where $\boldsymbol{V}_{\boldsymbol{c}}$ is assumed equal to the lesser of $\boldsymbol{V}_{\boldsymbol{c} i}$ and $\boldsymbol{V}_{\boldsymbol{c} w}$.

$\boldsymbol{V}_{c i}$ (shear force that causes flexure-shear failure) shall be computed by:

$$
V_{c i}=\left(0.6 \sqrt{f_{c}^{\prime}} b_{w} d_{p}+V_{d}+\frac{V_{i} M_{c r e}}{M_{\max }}\right) \geq 1.7 \sqrt{f_{c}^{\prime}} b_{w} d \text { (US units) }
$$

where $\boldsymbol{d}_{p} \geq \mathbf{0 . 8 0} \cdot \boldsymbol{h}$ and values of $M_{\max }$ and $V_{i}$ shall be computed from the load combination causing maximum factored moment to occur at the section.

$$
\begin{gathered}
M_{c r e}=\left(\frac{l}{y_{t}}\right)\left(6 \sqrt{f_{c}^{\prime}}+f_{p e}-f_{d}\right) \text { (SI units) } \\
V_{c i}=\left(0.05 \sqrt{f_{c}^{\prime}} b_{w} d_{p}+V_{d}+\frac{V_{i} M_{c r e}}{M_{\text {max }}}\right) \geq 0.14 \sqrt{f_{c}^{\prime}} b_{w} d \text { (SI units) }
\end{gathered}
$$

where $\boldsymbol{d}_{p} \geq \mathbf{0 . 8 0} \cdot \boldsymbol{h}$ and values of $M_{\max }$ and $V_{i}$ shall be computed from the load combination causing maximum factored moment to occur at the section.

$$
M_{\text {cre }}=\left(\frac{l}{y_{t}}\right)\left(0.5 \sqrt{f_{c}^{\prime}}+f_{p e}-f_{d}\right)
$$

$\boldsymbol{V}_{c w}$ (shear force that causes web-shear failure) shall be computed by: 


$$
V_{c w}=\left(3.5 \sqrt{f_{c}^{\prime}}+0.3 f_{p c}\right) b_{w} d_{p}+V_{p} \quad \text { (US units) }
$$

where $d_{p} \geq 0.80 \cdot h$

(Eq. A. 71)

$$
V_{c w}=\left(0.29 \sqrt{f_{c}^{\prime}}+0.3 f_{p c}\right) b_{w} d_{p}+V_{p} \quad \text { (SI units) }
$$

$$
\text { where } d_{p} \geq 0.80 \cdot h
$$

(Eq. A.72)

\subsubsection{Shear strength provided by shear reinforcement}

Where shear reinforcement perpendicular to axis of member is used,

$$
V_{s}=\frac{A_{v} f_{y t} d}{S} \quad \text { (US units) }
$$

(Eq. A.73)

$$
\text { where } d_{p} \geq 0.80 \cdot h
$$

where $\boldsymbol{A}_{v}$ is the area of shear reinforcement within spacing $\boldsymbol{s}$.

\section{A.5.4 fib draft MODEL CODE 2010 (MC2010)}

The following equations of the fib draft Model Code 2010 [93] are provided for the shear resistance of the core webs of beams and slabs and do not include the effects of flanges.

\section{A.5.4.1. Design shear force and shear resistance}

The shear resistance of a web or slab (Fig. A. 49) shall be determined according to:

$$
V_{R d}=V_{R d, c}+V_{R d, s} \geq V_{E d}
$$

where: 
$V_{R d}$ is the design shear resistance; $V_{R d, c}$ is the design shear resistance attributed to the concrete; $V_{R d, s}$ is the design shear resistance provided by shear reinforcement; $V_{E d}$ is the design value of the shear force.

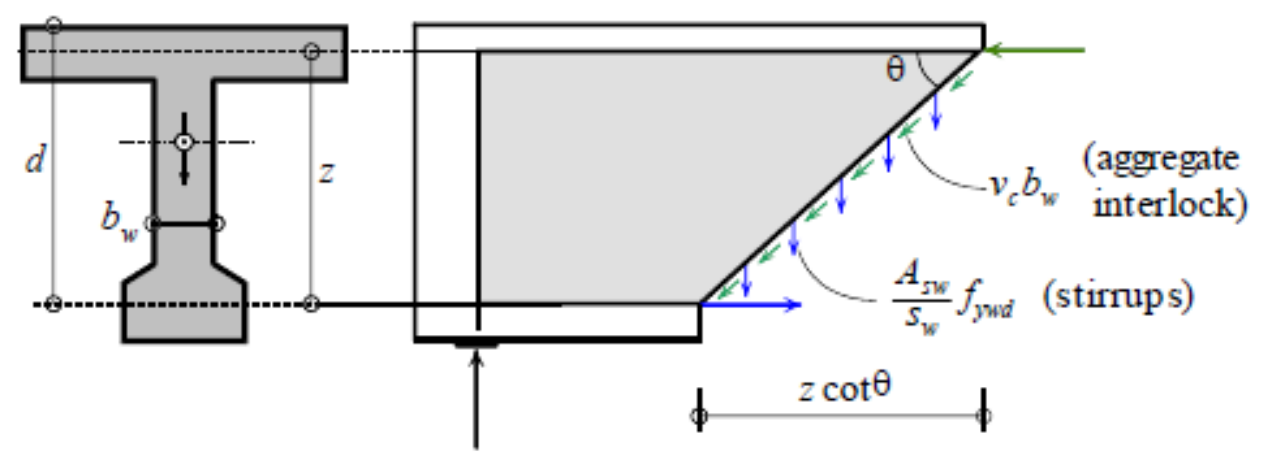

Fig. A. 49 Forces in the web of a beam (MC2010, 2010 [93])

For a cross sectional design, the design shear force shall in general be determined at control sections at a location $\boldsymbol{d}$ from the face of supports (see Fig.A.50) and from discontinuities of geometry or transverse applied forces. For the effective shear depth $\mathrm{z} a$ value of $0.9 \mathrm{~d}$ can be assumed.

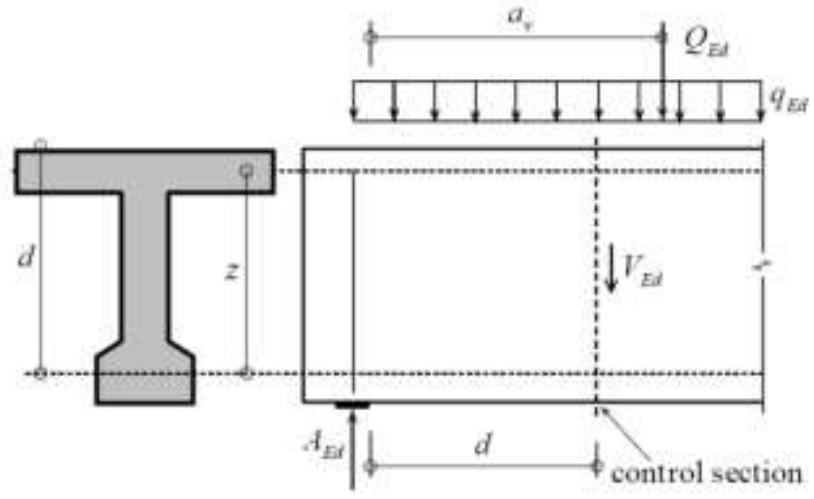

Fig. A. 50 Definition of control section for sectional design (MC2010, 2010 [93])

Unless more refined modelling techniques are used to consider loads taken directly to a support through strut or arch action (see Section 7.3.6), the following rules apply:

- the contribution of point loads applied within a distance of $d<a_{v} \leq 2 d$ from the face of the support to the design shear force $V_{E d}$ may be reduced by the factor: 
0 in the case of point loads applied as close as $a_{v}<d$ from the face of the support, the design shear force $V_{E d}$ shall be calculated with $\beta=0.5$ as if the load was applied at $a_{v}=d$.

\section{A.5.4.2. Levels of approximation}

In determining the shear or punching resistance of a member different levels of approximation may be used. The levels differ in their complexity and the accuracy of the results (Fig.A.51):

Level I Approximation: This level may be used for the conception or the design of a new structure. It requires no intermediate calculations by the engineer.

Level II Approximation: This level is appropriate for the design of a new structure as well as for a general or brief assessment of an existing member. The engineer must confirm that the angle $\theta$ is selected within a range that is a function of strain, and thus this strain must be calculated.

Level III (and higher) Approximation: It may be used for the design of a member in a complex loading state or where a more elaborate assessment of a member is required. The strain is required to produce any predictions, and thus this method requires the most computational effort to calculate.

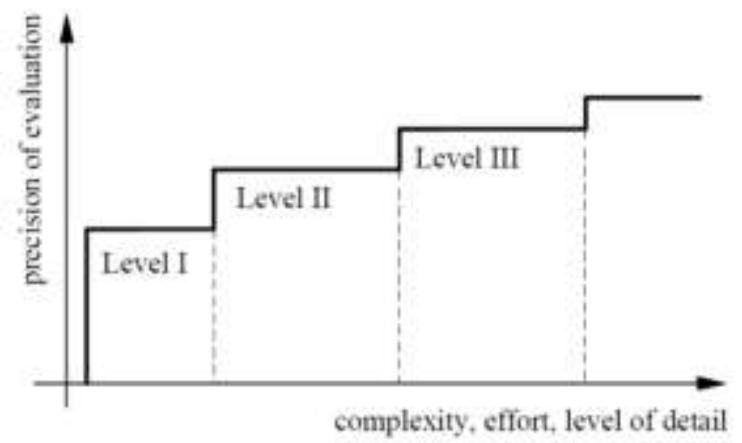

Fig. A. 51 Levels of approximation (MC2010, 2010 [93])

\section{A.5.4.3. Design equations}

The design shear resistance of a web or slab shall be determined as: 


$$
V_{R d}=V_{R d, c}+V_{R d, s}
$$

but is limited to:

$$
V_{R d, \max }=k_{c} \frac{f_{c k}}{\gamma_{c}} b_{w} z \frac{\cot \theta+\cot \alpha}{1+\cot ^{2} \theta}
$$

where:

$\theta$ denotes the selected inclination of the compression stresses; $\alpha$ is the inclination of the stirrups relative to the beam axis (Fig.A.52):
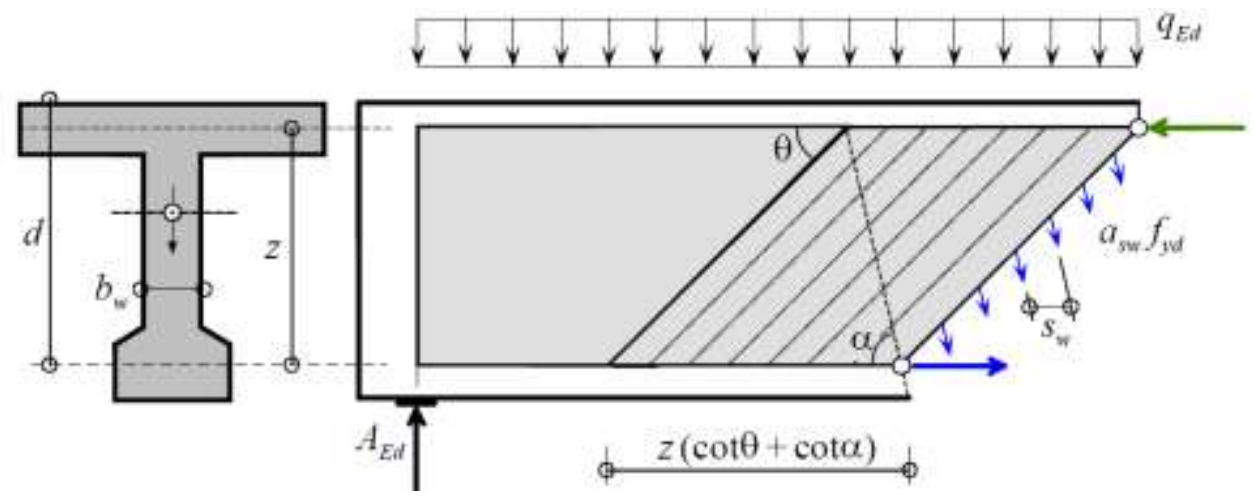

Fig. A. 52 Geometry and definitions (MC2010, 2010 [93])

In members that contain a percentage of shear reinforcement of:

$$
\rho_{w} \geq 0.08 \frac{\sqrt{f_{c k}}}{f_{y k}}
$$

The design shear resistance provided by the stirrups may be calculated as:

$$
V_{R d, s}=\frac{A_{s w}}{s_{w}} z f_{w y d}(\cot \theta+\cot \alpha) \sin \alpha
$$

The design shear resistance attributed to the concrete can be taken as:

$$
V_{R d, c}=k_{v} \frac{\sqrt{f_{c k}}}{\gamma_{c}} z b_{w} ; \sqrt{f_{c k}} \leq 8 M P a
$$

The longitudinal reinforcement at the section of interest must be able to resist the additional force due to shear of: 


$$
\Delta F_{t d}=\frac{V_{E d}}{2}(\cot \theta-\cot \alpha)+\frac{V_{R d, c}}{2}(\cot \theta+\cot \alpha)
$$

\section{A.5.4.3.1. Level I Approximation}

This level represents a variable angle truss model approach. The angle $\theta$ is taken as: $\theta=36$.

For members with no significant axial load, where $f_{c k} \leq 64 \mathrm{MPa}, f_{y k} \leq 500 \mathrm{MPa}$, cast with an aggregate size of at least $10 \mathrm{~mm}$ :

$$
\begin{array}{cl}
k_{c}=0.5\left(\frac{30}{f_{c k}}\right)^{1 / 3} \leq 0.5 & \left(f_{c k} \text { in } \mathrm{MPa}\right) \\
k_{v}=\frac{200}{(1000+1.3 z)} \leq 0.15 \quad \text { if } \rho_{w}=0 \\
k_{v}=0.15 & \text { if } \rho_{w} \geq 0.08 \sqrt{f_{c k}} / f_{y k}
\end{array}
$$

(Eq.A.83)

With a Level I approximation, the values $\boldsymbol{\theta}$ and $\boldsymbol{k}_{\boldsymbol{v}}$ are constants for members with stirrups, and are a function of the member size for members without stirrups to capture the size effect in shear.

\section{A.5.4.3.2. Level II Approximation}

This level comes from the variable angle stress field approach and it was developed by Sigrist as an extension of the conventional European plasticity-based methods, but with an additional strain restriction to prevent unconservative design being produced. The model is applicable to members with a minimum amount of stirrup reinforcement. It is based on an inclination of the compression stresses which can be chose within the following limits:

$$
20^{o}+10000 \varepsilon_{x} \leq \theta \leq 45^{\circ}
$$

(Eq.A.84)

where $\varepsilon_{x}$ represents the longitudinal strain at the mid-depth of the member as shown in Fig.A.53 and may be chosen as 0.001 for a preliminary design. If required, $\varepsilon_{x}$ shall be 
calculated with help of a plane section analysis (ignoring tension stiffening), but shall not be taken as less than -0.0002 .

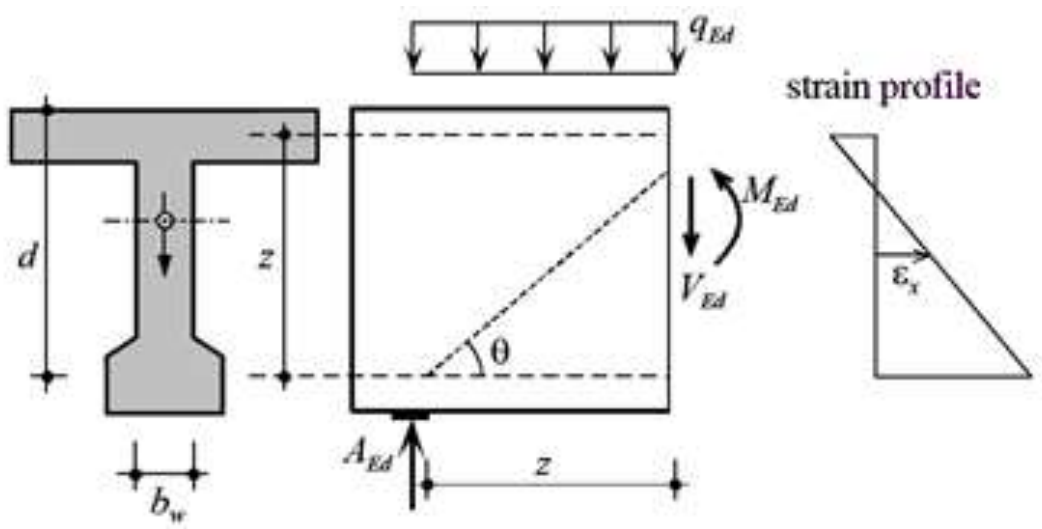

Fig.A. 53 MC2010 definitions [93]

The variable angle stress field approach allows a free choice of the strut inclination within certain limits. This is confirmed by experimental observations. Fig.A.54 shows an I-shaped beam on which the web deformations have been measured.
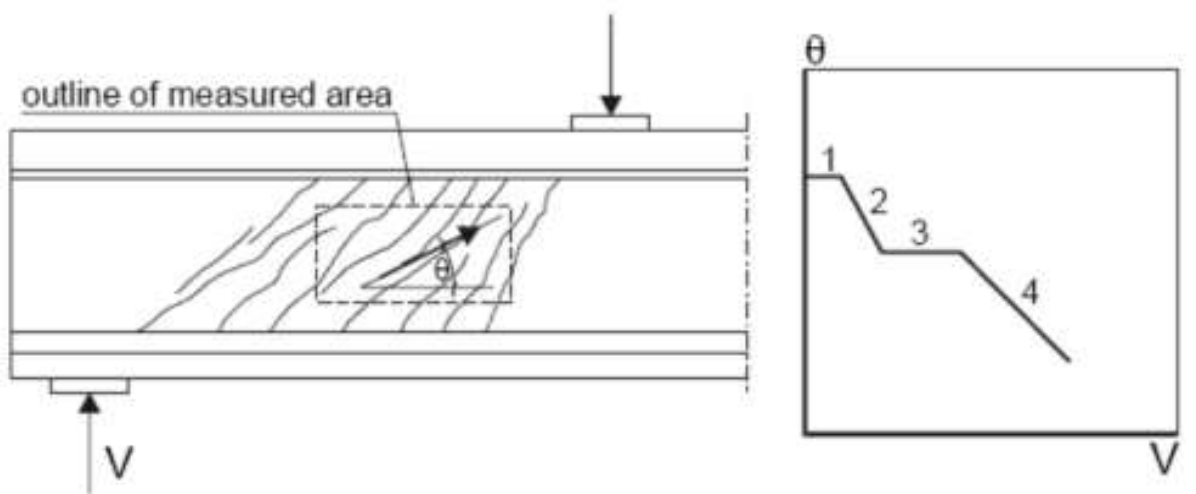

Fig.A. 54 Varying inclination of the compression stresses during loading [99]

In a level II Approximation the design shear resistance attributed to the concrete shall be neglected, i.e.:

$k_{v}=0$ and $V_{R d, c}=0$

(Eq.A.85)

The width of the beam or web shall be checked for the selected inclination of the compression stresses: 


$$
k_{c}=0.55\left(\frac{30}{f_{c k}}\right)^{1 / 3} \leq 0.55
$$

If plastic chord deformations have to be expected in the beam segment under consideration a Level IV Approximation shall be carried out. For Level II analyses, $\boldsymbol{k}_{\boldsymbol{v}}$ is taken as zero meaning that this method is only applicable to predict the strength of members with stirrups. The $\boldsymbol{\theta}$ value must fall within a range that depends on the longitudinal strain at mid-depth, $\boldsymbol{\varepsilon}_{\mathbf{x}}$ making this method a modified-plasticity approach [44].

\section{A.5.4.3.3. Level III Approximation}

This level represents a general form of sectional shear equations applicable to beams as well as slabs and any amount of shear reinforcement. The equations of the Level III Approximation were derived from the Modified Compression Field Theory (MCFT) and assume that the member contains well-detailed reinforcement in at least the longitudinal direction [41]. The angle $\theta$ may be assumed as:

$$
\theta=29^{\circ}+7000 \varepsilon_{x}
$$

where $\varepsilon_{x}$ represents the longitudinal strain at the mid-depth of the member (Fig.A.53) and shall be taken as:

$$
\varepsilon_{x}=\frac{M_{E d} / z+V_{E d}+0.5 N_{E d}-A_{p} f_{p 0}}{2\left(E_{s} A_{s}+E_{p} A_{p}\right)}
$$

where $f_{p o}$ is stress in the strands when the strain in the surrounding concrete is zero. If $\varepsilon_{x}$ was negative it shall be taken as zero or the value shall e recalculated with the denominator of the equation replaced by $2\left(E_{s} A_{s}+E_{p} A_{p}+E_{c} A_{c t}\right)$, however shall not be taken as less than -0.0002 . It is permissible to determine $\theta$ and $k_{v}$ using a value of $\varepsilon_{\mathrm{x}}$ which is greater than that calculated from the equation, however $\varepsilon_{\mathrm{x}}$ shall not be taken greater than 0.003 . 

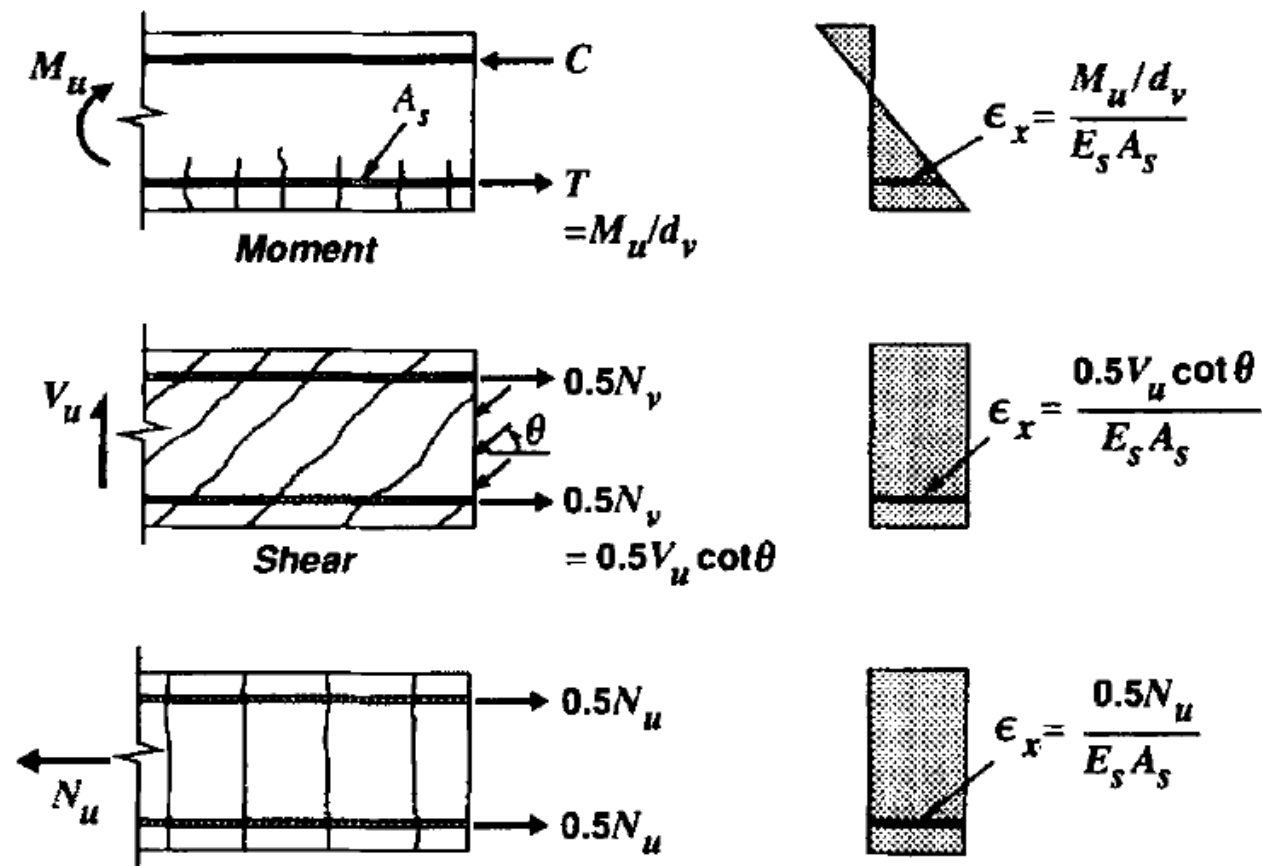

Axial Load

Fig.A. 55 Determination of strains, $\varepsilon_{x}$, for nonprestressed beam (ACI-Committee445, 1998 [42])

$$
\begin{array}{cc}
k_{c}=0.55\left(\frac{30}{f_{c k}}\right)^{1 / 3} \leq 0.55 & \left(f_{c k} \text { in } M P a\right) \\
k_{v}=\frac{0.4}{\left(1+1500 \varepsilon_{x}\right)} \cdot \frac{1300}{\left(1000+0.7 k_{d g} z\right)} & \text { if } \rho_{w}=0 \\
k_{v}=\frac{0.4}{\left(1+1500 \varepsilon_{x}\right)} & \text { if } \rho_{w} \geq 0.08 \sqrt{f_{c k}} / f_{y k}
\end{array}
$$

where: 


$$
k_{d g}=\frac{48}{16+d_{g}} \geq 1.15
$$

in which $d_{g}$ is aggregate diameter. For concrete strengths in excess of 70MPa, the aggregate size should be taken as zero as aggregate particles tend to fracture at cracking and are less able to contribute to crack roughness. To avoid a discontinuity, as concrete strengths vary from 64 to $70 \mathrm{MPa}$, the effective aggregate size can be linearly reduced to zero. For Level III, the strain $\varepsilon_{\mathbf{x}}$ is required to produce any predictions, such as $\theta$, and thus this method requires the most computational effort to calculate.

Fig.A.56 shows the limits on allowable angel of principal compression, $\theta$, based on the MCFT for members heavily loaded in shear and for different strains in the member at middepth $\left(\varepsilon_{\mathrm{x}}\right)$.

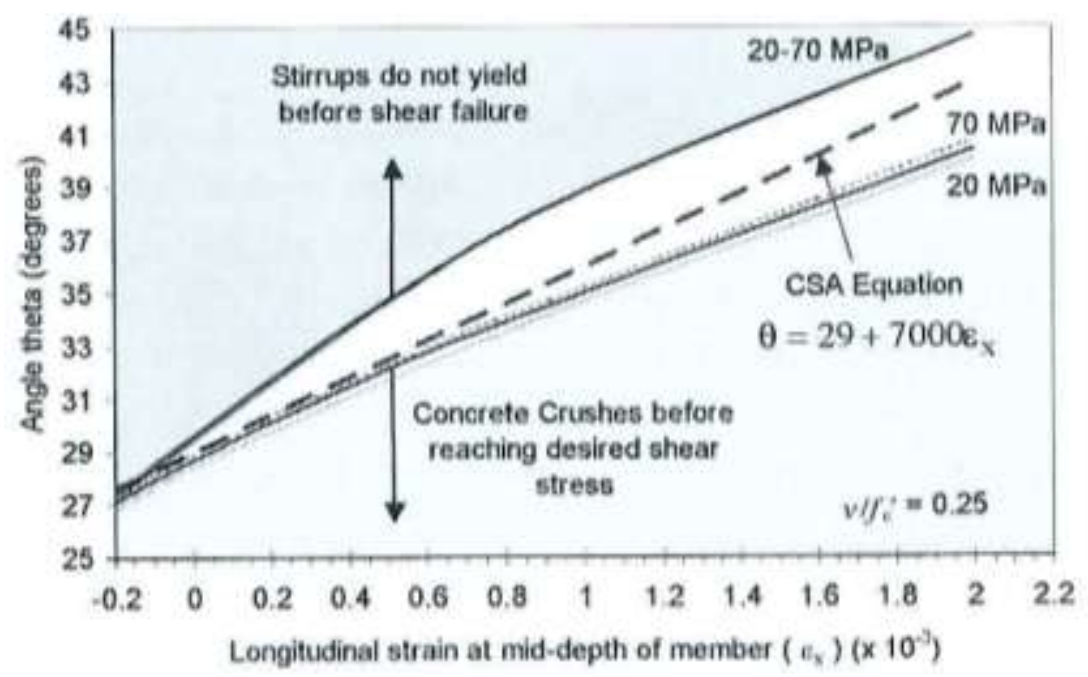

Fig.A. 56 Selection of theta equation for level III analysis [44]

\section{A.5.5 Last incorporations to the MC2010.}

In the previous subsection were presented the expressions corresponding to the first complete draft, published in April 2010 [93]. However, in late 2011, has submitted the revised draft after public comments which have modified some expressions and their limits. In the revised draft the expressions to determinate the shear value of concrete structural members are divided in three sections: members without shear reinforcement, members with shear reinforcement and hollow-core slabs. 


\section{A.5.5.1. Members without shear reinforcement}

There is evidence that the shear resistance of members without shear reinforcement is influenced by the maximum size of the aggregate $d_{g}$. If concrete with a maximum size of the aggregate different from $d_{g}=16 \mathrm{~mm}$ is used the value $k_{d g}$ may be calculated with:

$$
k_{d g}=\frac{32}{16+d_{g}} \geq 0.75
$$

\section{Level I of Approximation:}

For members with no significant axial load, with fyk $\leq 600 \mathrm{MPa}$, fck $\leq 70 \mathrm{MPa}$ and with a maximum aggregate size of not less than $10 \mathrm{~mm}$ :

$$
k_{v}=\frac{180}{1000+1.25 z}(z \text { in } m m)
$$

\section{Level II of Approximation:}

For this level, the design shear resistance is determined with:

$$
k_{v}=\frac{0.4}{1+1500 \varepsilon_{x}} \cdot \frac{1300}{1000+k_{d g} z}(z \text { in } \mathrm{mm})
$$

Provided that the size of the maximum aggregate particles, $d_{g}$, is not less than $16 \mathrm{~mm}, k_{d g}$ can be taken as $k_{d g}=1.0$.

\section{A.5.5.2. Members with shear reinforcement}

$$
V_{R d, \max }=k_{c} \frac{f_{c k}}{\gamma_{c}} b_{w} z \sin \theta \cos \theta
$$

where $\theta$ denotes the inclination of the compressive stress field.

The strength reduction factor is defined as:

$$
k_{c}=k_{\varepsilon} \eta_{f c}
$$

with: 


$$
\eta_{f c}=\left(\frac{30}{f_{c k}}\right)^{1 / 3} \leq 1.0 \quad\left(f_{c k} \text { in } \mathrm{MPa}\right)
$$

The limits of the angle compressive stress field, relative to the longitudinal axis of the member are:

$$
\theta_{\min } \leq \theta \leq 45^{\circ}
$$

where $\theta$ is the inclination of the compressive stress field and may be chosen freely between these limits.

\section{Level I of Approximation:}

In the level I approach, the design shear resistance is given by:

$$
V_{R d}=V_{R d, s} \leq V_{R d, \max }
$$

but need not to be taken less than the resistance of the same member without shear reinforcement.

The minimum inclination of the compressive stress field is:

$\theta_{\min }=25$ o for members with significant axial compression or prestress;

$\theta_{\min }=30$ - for reinforced concrete members;

$\theta_{\min }=40$ o for members with significant axial tension;

The width of the beam or web shall be checked for the selected inclinations of the compression stresses where $k_{\varepsilon}$ is taken as: $k_{\varepsilon}=0.55$

\section{Level II of Approximation:}

The inclination of the compression stresses can be freely selected for design, or analytically determined for assessment, within the limits. The minimum inclination of the compressive stress field shall be taken as:

$$
\theta_{\text {min }}=20+10000 \varepsilon_{x}
$$


where $\varepsilon_{x}$ represents the longitudinal strain at the mid-depth of the effective shear depth. The design shear resistance attributed to the concrete shall be neglected, i.e. $k_{v}=0$. The width of the beam or web shall be checked for the respective inclination of the compression stresses where $k_{\varepsilon}$ is taken as:

$$
k_{\varepsilon}=\frac{1}{1.2+55 \varepsilon_{1}} \leq 0.65
$$

where:

$$
\varepsilon_{1}=\varepsilon_{x}+\left(\varepsilon_{x}+0.002\right) \cot ^{2} \theta
$$

\section{Level III of Approximation:}

In the Level III approach, the design shear resistance in the range of $V_{R d}<V_{R d, \text { max }}\left(\theta_{\text {min }}\right)$ is given by:

$$
V_{R d}=V_{R d, s}+V_{R d, c}
$$

where $V_{R d, \max }\left(\theta_{\min }\right)$ is the calculated from (Eq.A.104) for $\theta=\theta_{\min }$.

$$
V_{R d, \max }=k_{c} \frac{f_{c k}}{\gamma_{c}} b_{w} z \sin \theta \cos \theta
$$

In the range of $V_{R d} \geq V_{R d, \text { max }}\left(\theta_{\text {min }}\right)$ the resistance is determined as in the Level II Approximation. The inclination $\theta_{\text {min }}$ is taken from:

$$
\theta_{\min }=20+10000 \varepsilon_{x}
$$

For determining the design shear resistance $V_{R d, c}$ attributed to the concrete the following expression shall be used:

$$
k_{v}=\frac{0.4}{1+1500 \varepsilon_{x}} \cdot\left(1-\frac{V_{E d}}{V_{R d, \max }\left(\theta_{\min }\right)}\right) \geq 0
$$




\section{A.5.5.3. Hollow-Core Slabs}

In this new Draft, there is a subsection on Hollow Core Slabs, which formulations are based in those for regions uncracked in bending. In single span prestressed hollow core slabs without shear reinforcement, shear failure occurs when the principal tension stress demand in the web exceeds the tensile strength of the concrete.

Level I Approximation:

$$
V_{R d, c t}=\frac{I_{c} \cdot b_{w}}{S_{c}} \sqrt{f_{c t d}^{2}+\alpha_{l} \cdot \sigma_{c p} \cdot f_{c t d}}
$$

where:

$I_{c}$ is second moment of area; $S_{c}$ is first moment of area above and about the centroidal axis; $b_{w}$ is width of the cross section at the centroidal axis; $\sigma_{c p}$ is concrete compressive stress at the centroidal axis due to prestressing, in the area where the prestressing force is fully introduced; $\alpha_{l}=I_{x} /\left(1.2 \cdot I_{b d, 0}\right)$. See Fig.A.57.

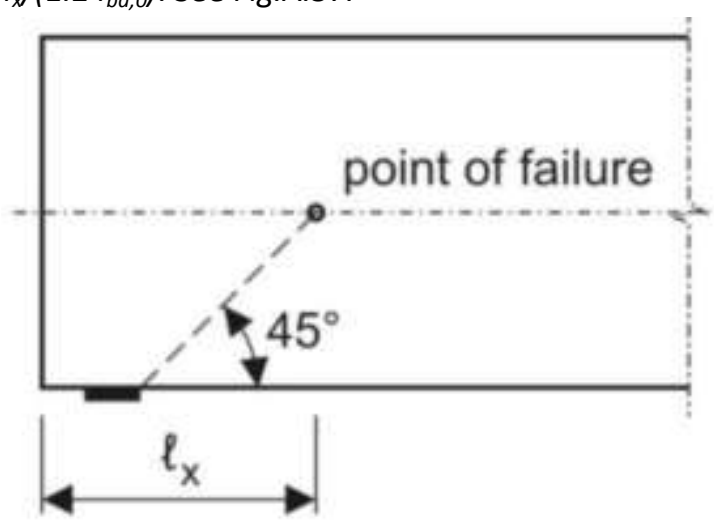

Fig.A. 57 Basis for derivation [93]

Level II Approximation:

In a Level II Approximation the design shear resistance is determined by:

$$
V_{R d, c t}=\frac{I_{c} \cdot b_{w}(y)}{S_{c}(y)}\left[\sqrt{f_{c t d}^{2}+\alpha_{l} \cdot \sigma_{c p}(y) \cdot f_{c t d}}-\tau_{c p}(y)\right]
$$


where $\tau_{c p}(y)$ is the shear stress in the concrete due to transmission of prestress at height $y$ and distance $I_{x}$.

The compressive stress at height $y$ and distance $I_{x}, \sigma_{c p}(y)$ is determined from:

$$
\sigma_{c p}(y)=\left[\frac{1}{A_{c}}+\frac{Y_{c}-y}{I}\right] \cdot F_{p}\left(l_{x}\right)
$$

And the shear stress in the concrete due to transmission of prestress:

$$
\tau_{c p}(y)=\frac{1}{b_{w}(y)}\left[\frac{A_{c}(y)}{A_{c}}-\frac{S_{c}(y)\left(Y_{c}-Y_{p t}\right)}{I}\right] \cdot \frac{d F_{p}\left(l_{x}\right)}{d x}
$$

where: $Y_{c}$ is height of concrete centroidal axis; $A_{c}$ is area of concrete cross-section; $A_{c}(y)$ is concrete area above height $y$; and $Y_{p t}$ is height of centroidal axis of prestressing steel.

\section{A.6 Comments and criticisms to the Design Codes}

\section{A.6.1 Comments and criticisms to Eurocode 2, EC2}

The "concrete term" $V_{c}$ has led to heavy discussions. Walraven [99] believes that the contribution of a concrete term especially applies to "laboratory beams" and hardly applies to large size box girder bridges, in which shear is an essential design criterion.

EC2 tends to overestimate the shear strength of the rectangular beams tested in if the lever arm for shear is taken as $0.9 \cdot d$ as recommended in the Code. Sagaseta and Vollum [76] propose that the safety factors $\left(V_{\text {test }} / V_{\text {calculated }}\right)$ for shear should be increased in sections without compression flanges by reducing the lever arm for shear form $z=0.9 \cdot d$ to $z=0.8 \cdot d$ for sections with a stirrup index $=\rho_{w} \cdot f_{y} / v \cdot f_{c}{ }^{\prime} \geq 0.05$ (where $\rho_{w}$ is the shear reinforcement ratio, $f_{y}$ the yield strength of reinforcement, $v$ is the strength reduction factor for concrete cracked in shear and $f_{c}{ }^{\prime}$ the concrete cylinder strength). This amendment makes the safety factors for shear in EC2 more comparable to that in CSA A.23.3-04 based on the MCFT [41].

Also, some questions may be raised with regard to the definition of $b_{w}$ being "the smallest width of the cross-section in the tensile area". Tests on tapered cross-sections showed that there is certainly an influence of the definition of the web widths, as shown in Fig.A.58, left (tests by Leung, Chew and Regan in 1976). Fig.A.58, right, shows that a definition of $b_{w}$ as the average widths of the beam would be appropriate for this case [100]. 

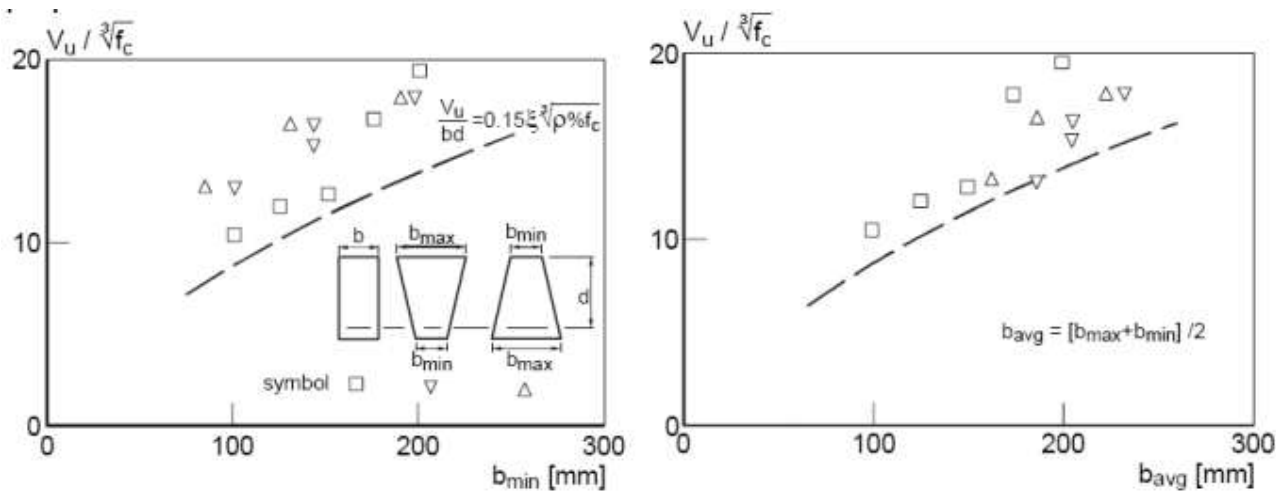

Fig.A. 58 Shear resistance of beams with tapered cross-section (Leung, Chew and Regan, 1976)

In 2000, Regan opted for a definition of $b_{w}=2 / 3 \cdot b_{\min }+1 / 3 \cdot b_{\max }$, but admits at the same time that the available evidence is rather scarce. A possible compromise could be to define $b_{w}$ as the average with of the part of the cross-section in tension, with a maximum of 1.25 of the minimum width [100].

An important question is whether the multiplication factor should be $(3 d / a, 2.5 d / a$ or $2 \mathrm{~d} / \mathrm{a}$ ) for loads near supports. For members not requiring design shear reinforcement, in 1998 , Regan concluded that: For simply supported beams subjected to concentrated loads a factor $(2.5 \mathrm{~d} / \mathrm{a})$ is appropriate; for continuous beams with concentrated loads even $(3 d / a)$ gives safe results and, for simply supported beams subjected to distributed loading only $(2 d / a)$ gives safe results [100].

In [68] it was suggested that the limit value for $\rho_{l}$ could be related to the concrete compressive strength, since for high-strength concrete beams the limit would be higher than for normal strength concrete beams. In addition, for the EC2 (and also the $A C I$ ), the safety was significantly reduced for larger members $(d \geq 900 \mathrm{~mm})$ and for elements with a low amount of longitudinal reinforcement $\left(\rho_{l} \leq 1 \%\right)$. In contrast, the average value of $V_{\text {fail }} V_{\text {pred }}$ was higher for members with more than $2 \%$ of longitudinal reinforcement, especially for high strength concrete beams, and for small members (d $\leq 100 \mathrm{~mm})$. In addition, it was found that truss models, like EC2, could be unconservative for highly transversally reinforced concrete members [53].

On the other hand, Cladera and Mari [94] propose to modify the size effect factor ( $\xi$ ) of the EC2 and EHE, because the size effect not only depends on the effective depth of the element but also the distance between layers of longitudinal reinforcement in the web $\left(s_{x}\right)$ [63]. This would need to consider: 


$$
\xi=1+\sqrt{\frac{200}{\mathrm{~s}_{\mathrm{x}}}}
$$

where $s_{x}$ would be the lesser of $z=0.9 \cdot d$ and the vertical distance between layers of horizontal reinforcement distributed in the web.

Moreover, for non prestressed members requiring shear reinforcement, in ENV 1992-1-1 the Standard Method and the Variable Inclination Method were offered as design alternatives. In the Standard Method, the "concrete term" is purely empirical and hides the physical reality. This reality is that a redistribution of forces occurs in the webs of shear reinforced concrete beams, resulting in strut inclinations smaller than 45 o, Fig.A.59.

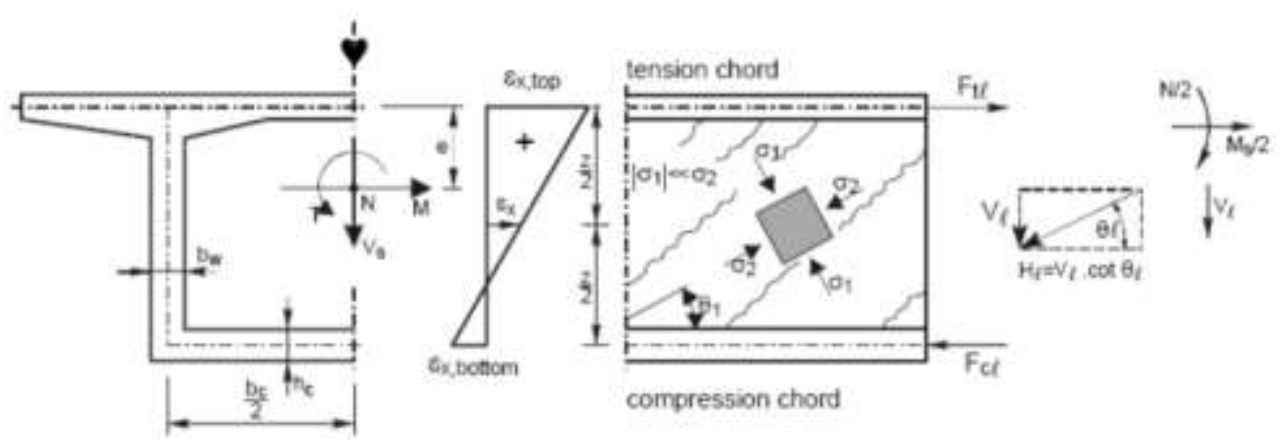

Fig.A. 59 Redistribution of forces in a shear-loaded web by strut rotation [100]

Because of a smaller strut inclination, a larger number of stirrups is activated, and the shear capacity is increased. A result of the smaller strut inclination is that the stresses in the concrete struts are larger, so that an appropriate upper limit to the shear capacity has to be defined. This method, with strut inclinations smaller than 45 may be assumed for design, and is known as the "variable strut inclination" method. This approach is not only attractive because it fits agreement with the physical reality, but also because it is a simple equilibrium method, giving a transparent view of the flow of forces in the structure [100].

In Eurocode 2 (ENV 1992-1-1), the designer is allowed to choose the strut inclination between $0.4<\cot \theta<2.5$ which means that $\theta$ may be chosen between $21.8^{\circ}$ and $68.2^{\circ}$. The choice of the lowest value mostly leads to the most economic design. In this case, the compression struts are supposed to rotate form an initial value of 450 to a lower value of about 22․ If the strut inclination is $\theta$ and the (vertical) shear reinforcement yields, a shear force $V_{u, 3}$ is transmitted, Fig.A. 60-a [100]. 


$$
V_{u, 3}=V_{s}=\frac{A_{s w}}{s} \cdot z \cdot f_{y w} \cdot \cot \theta
$$

If the shear reinforcement yields, the truss can, by rotation of the compression struts to a lower inclination, activate more stirrups for the transmission of the shear force and, as such, extend the zone of failure_[100].

Due to strut rotation, the stress in the concrete struts increases. Consequently, rotation can only continue until crushing of the concrete occurs. For an ultimate compression stress $f_{c 1}$ in the concrete struts, the corresponding shear force is $V_{u, 2}$ (Fig.A. 60-b):

$$
V_{u, 2}=V_{R d, \max }=\frac{b_{w} \cdot z \cdot f_{c 1}}{\cot \theta+\tan \theta}
$$

where: $f_{c 1}=v \cdot f_{c}$

In those equations: $b_{w}=$ web width; $z=$ =inner lever arm $\approx 0.9 \cdot d ; s=$ stirrup distance; $f_{y w}=y i e l d$ stress of stirrups; $\theta=$ inclination of concrete struts; $A_{s w}=$ cross-sectional area of one stirrup; $v=$ effectiveness factor, taking account of the fact that the beam web, which is transversally in tension, is not as well suited to resist the inclined compression as cylinders used to determinate $f_{c}$.
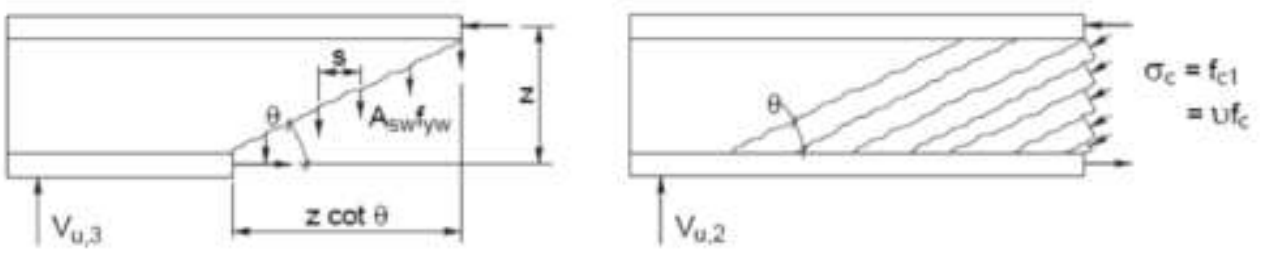

Fig.A. 60 (a): Ultimate capacity $v_{u, 3}$ for yielding stirrups; (b): Ultimate capacity $v_{u, 2}$ for crushing of concrete struts [100]

For $\boldsymbol{v}$ is used:

$$
v=0.6 \cdot\left(1-f_{c k} / 250\right)
$$

Fig.A. 61 shows the development of $V_{u, 2}$ and $V_{u, 3}$ for decreasing $\theta[100]$. 


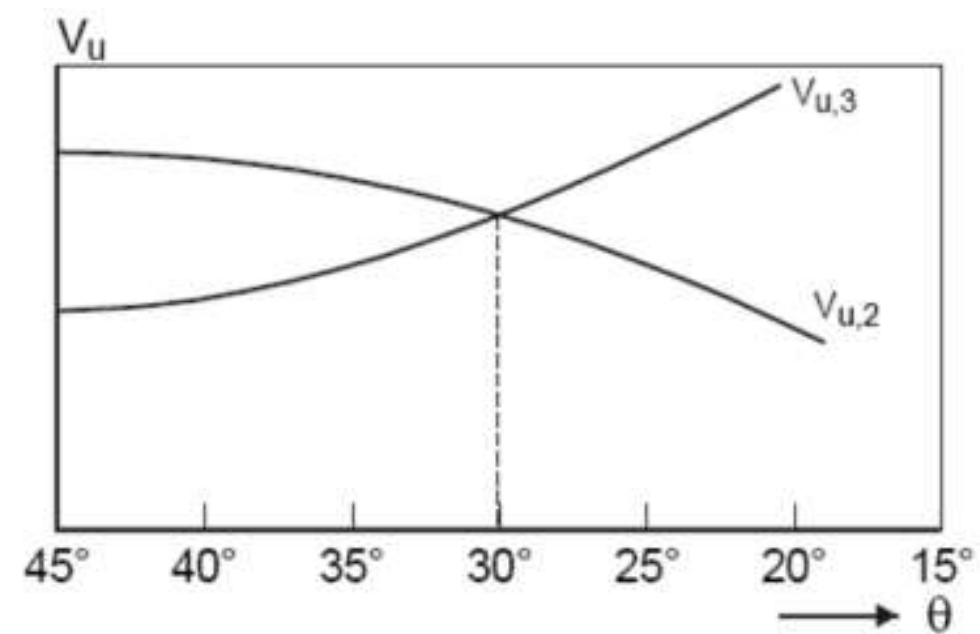

Fig.A. 61 Dependence of $\mathrm{V}_{\mathrm{u}, 2}$ and $\mathrm{V}_{\mathrm{u}, 3}$ on the strut inclination $\theta$ [100]

Also, measurements of the deformation of the web in shear loaded I-beams show typically a behavior as shown in Fig.A. 62. The diagram shows lines numbered form 1 to 4:
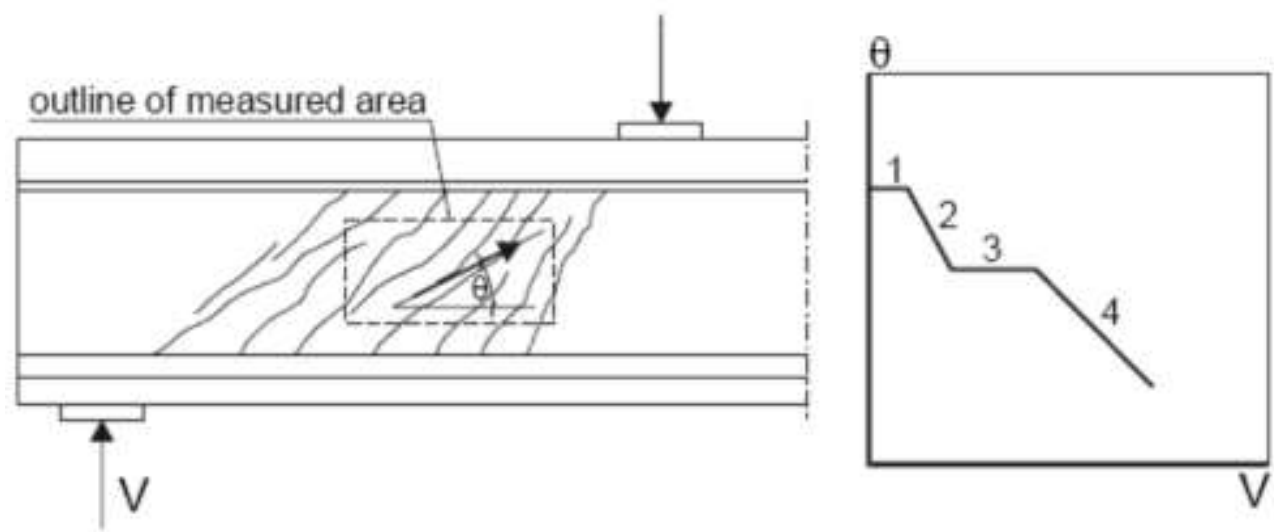

Fig.A. 62 Rotation of the concrete struts as measured on the web of beams with shear reinforcement, schematically represented (Walraven, [100])

Thus, in Fig.A.62, it can be observed that in the beginning of shear loading the beam is uncracked in shear so that the principal strain direction is 45o (Line 1); at the formation of inclined shear cracks the principal strain directions decreases (Line 2); after having reached the stabilized inclined crack pattern a new type of equilibrium is obtained. The behavior is elastic: the (constant) principal strain directions depend on the "stiffness ratio" in the cracked state (Line 3) and, when the stirrups start yielding the web searches for a new state of equilibrium. By rotating down to a lower inclination the beam activates more 
stirrups to carry the load. In the mean time the compressive stress in the concrete increases. When the crushing strength of the struts is reached the beam fails in shear (Line 4).

Cladera and Mari [101] concluded that the EC2 procedure is very easy to use by practicing engineers but it presents a great scatter of results. EC2 may be too conservative for slightly shear-reinforced beams (this is evident as the concrete contribution is neglected, a very important factor when the steel contribution is low) or for prestressed beams and it may be slightly unconservative for heavily reinforced members $\left(\rho_{w} \cdot f_{y}>2 \mathrm{MPa}\right.$, where $\rho_{w}$ is the reinforcement ratio for shear reinforcement). These unconservative results are due to the assumption of the EC2 procedure that the angle of the concrete struts can be as low as $\cot \theta=2.5$; meanwhile for highly reinforced beams $\cot \theta$ may only reach values around 1.10-1.30 according to models based on equilibrium and compatibility. In beams with stirrups, EC2 does not consider the concrete contribution and, therefore, in prestressed beams does not consider the influence of the prestressing force on the shear strength [101]. This makes that EC2 be very conservative, especially with increasing stress introduced by prestressing [94].

\section{A.6.2 Comments and criticisms to ACI}

Test results suggested that the amount of maximum shear reinforcement in $\mathrm{ACl} 318-11$ [89] needed to be increased for high-strength concrete beams because the test beams with a greater amount of $\rho_{\mathrm{t}} \cdot \mathrm{f}_{\mathrm{yt}}$ required by $\mathrm{ACl}$ 318-11 failed after the yield of the stirrups, Fig.A.63 [102].

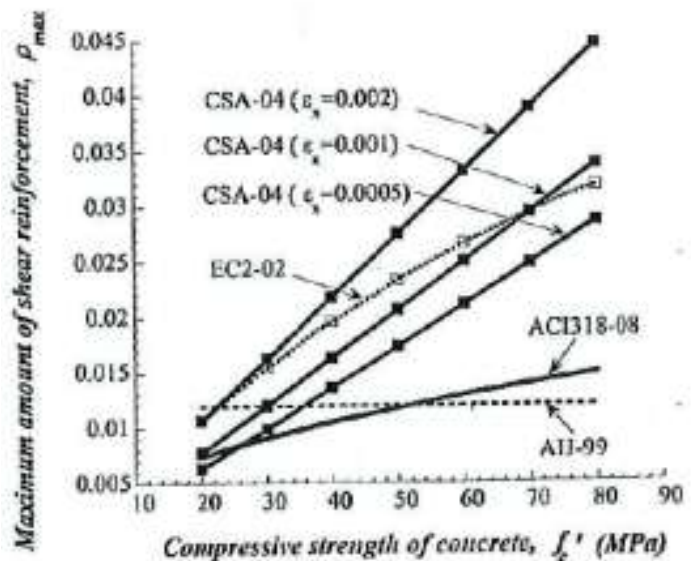

Fig.A. 63 Maximum amount of shear reinforcement versus compressive strength of concrete [102]

Richart [103] concluded that the assumption of 45 for the direction of principal compression might be the cause of the discrepancy between the predicted stirrup strains 
and the smaller measured stirrup strains. He pointed out that decreasing $\theta$ to 40 을 would decrease the predicted stirrup stresses by about $20 \%$. Also, the conservatism of the 45 ㅇ truss model is due to the neglect of tensile stresses in the concrete and the choice of 45 은 for the compressive strut inclination.

Because of concern that the $\mathrm{ACl}$ approach may be unconservative for beams with low amounts of longitudinal reinforcement, the ACI-ASCE Committee on shear and diagonal tension [27] recommended that $V_{c}$ should be taken as a function of the percentage of longitudinal reinforcement. However, this recommendation was not incorporated into the $\mathrm{ACl}$ Code because there was concern with complexity and it was believed that the minimum shear reinforcement requirements would prevent unconservative design.

The shear capacity of reinforced concrete members subjected to axial tension is influenced critically by the amount and distribution for the longitudinal reinforcement, factors which are ignored in the ACl Building Code expressions [45].

The $\mathrm{ACl}$ can be very unconservative if applied to large, lightly reinforced members because these procedures do not recognize that as the size of such members increases, the shear stress required to cause failure decreases, so until the $\mathrm{ACl}$ shear equations are improved [104], it would be prudent to be more conservative than the $\mathrm{ACl}$ Code when deciding where shear reinforcement is needed [105]. On the other hand, high-strength concrete members displayed a more significant size effect in shear than normal strength concrete members [63].

For members with stirrups, the $\mathrm{ACl}$ is conservative for high-strength concrete specimens [106], for T-beams, because ignores the flanges [83], [77] and, for members with shear reinforcement, in particular for members with the minimum amount of web reinforcement. It was detected that for high-strength concrete beams with stirrups, the limitation of the amount of longitudinal reinforcement to $2 \%$ is not experimentally justified [30]. On the other hand, $\mathrm{ACl}$ is slightly unconservative for members without stirrups [30].

So, $\mathrm{ACl}$ equations need to be modified to include the effect of concrete strength, critical shear span-depth ratio, tensile reinforcement ratio, and size effect in an appropriate manner [107]. 


\section{A.6.3 Comments and criticisms to MC2010 and MCFT}

The MCFT neglects the influence of previous cracks since it is a fully rotational crack approach in which shear stresses are checked along fictitious cracks which are assumed to be oriented parallels to the principal compressive stress field [76].

Of the many different theories and expressions related to the shear strength of RC beams that have been developed to date, only a few consider the size effect, like the modified compression field theory (MCFT) in which is based the Level III of Approximation of the MC2010. MCFT-based equations for shear take a simple account of crack opening and aggregate interlock across the dominant shear crack, which results in a size effect on the shear capacity of concrete members. According to simplified expressions derived from MCFT, the shear strength for very large beams is inversely proportional to the beam size [ [63]; [65]; [26]].

MCFT is one of the methods which take into account the contribution of shear friction across cracks in resisting shear [13], [41]. Another aspect of shear cracks is that they also weaken the concrete struts. The presence of transverse tensile stress and strain lowers the concrete compressive strength below its uniaxial strength (softening). The MCFT provides a means to evaluate the effect of this softening on the shear strength of RC beams [108].

Good results with MC2010 are obtained even for members with very high reinforcement ratios. Thus methods which take shear strength as a function only of the percentage of reinforcement and neglect the influence of the corresponding demand on the reinforcement often require cumbersome limits like the $2 \%$ limit on the EC2 shear strength equation for members without stirrups. Also, MC2010 predictions are equally good independently of the concrete strength and also independently of the strength of the reinforcement. The strain effect concept is well modeled by the MC2010 and the quality of the MC2010 prediction for members with stirrups is of similar quality across the range of the quantity of stirrups [44].

On the other hand, Chung and Ahmad [109] pointed out that MCFT is not applicable to lightly reinforced or unreinforced concrete member. These conclusions, however, were based on analyses that were an incomplete adaptation of the theory. Contrary to these conclusions, rotating crack analyses can provide an accurate representation of the strength, stiffness, and ductility of lightly reinforced shear-critical beams [109].

\section{A.6.4 Shear models from other authors}




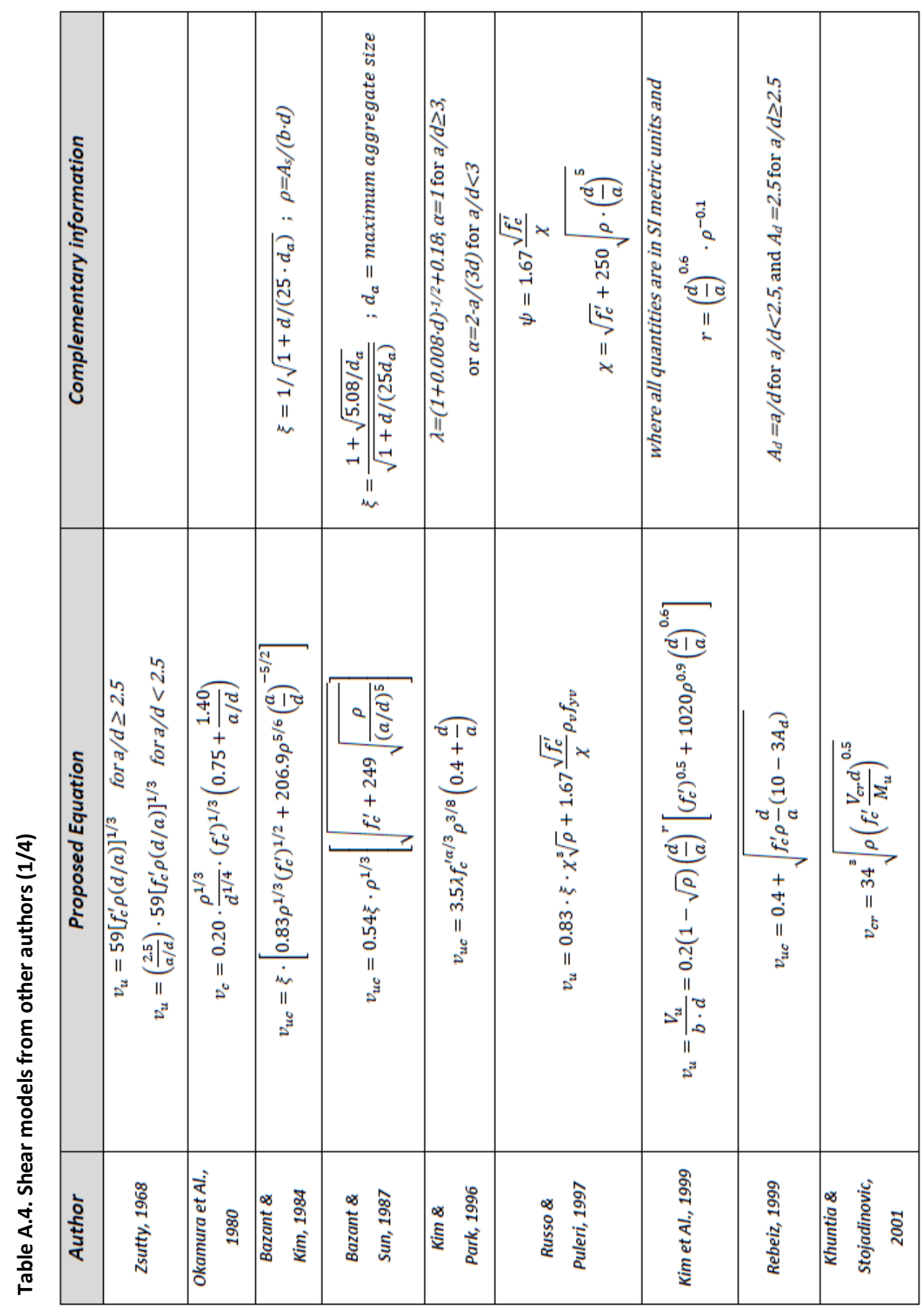

Estefanía Cuenca Asensio - ICITECH - Universitat Politècnica de València 


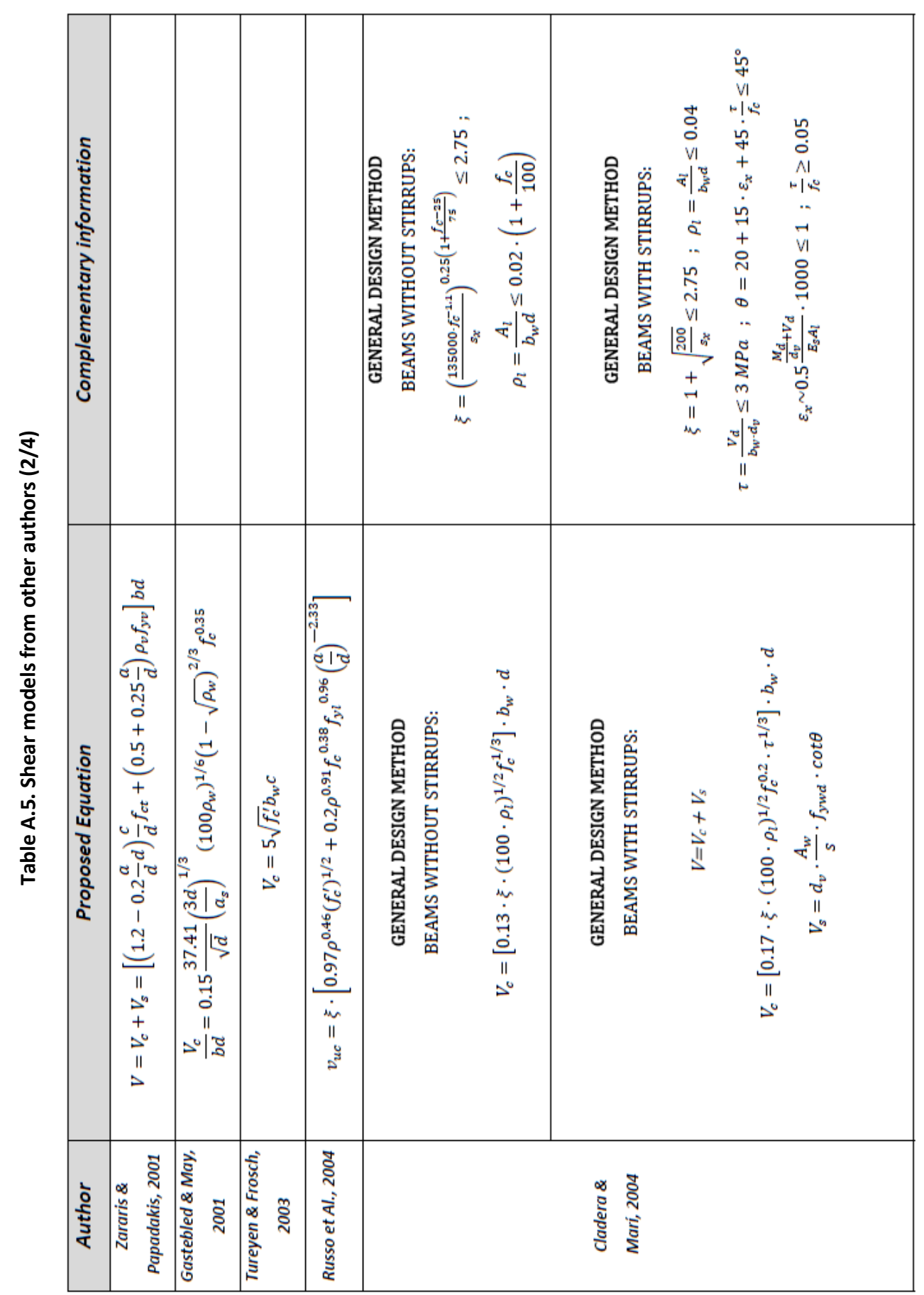




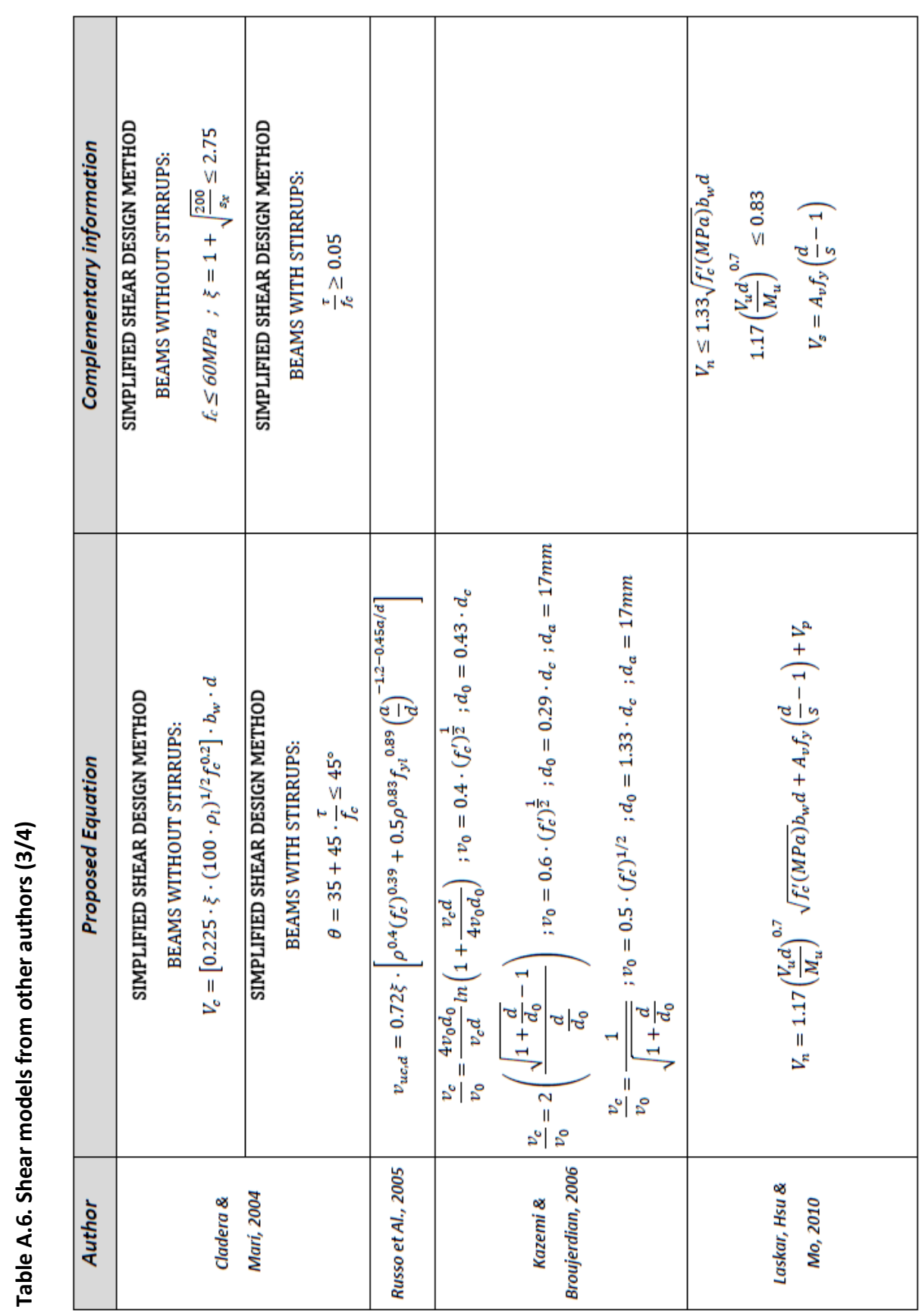

Estefanía Cuenca Asensio - ICITECH - Universitat Politècnica de València 


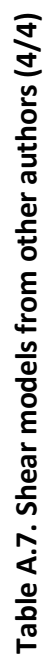

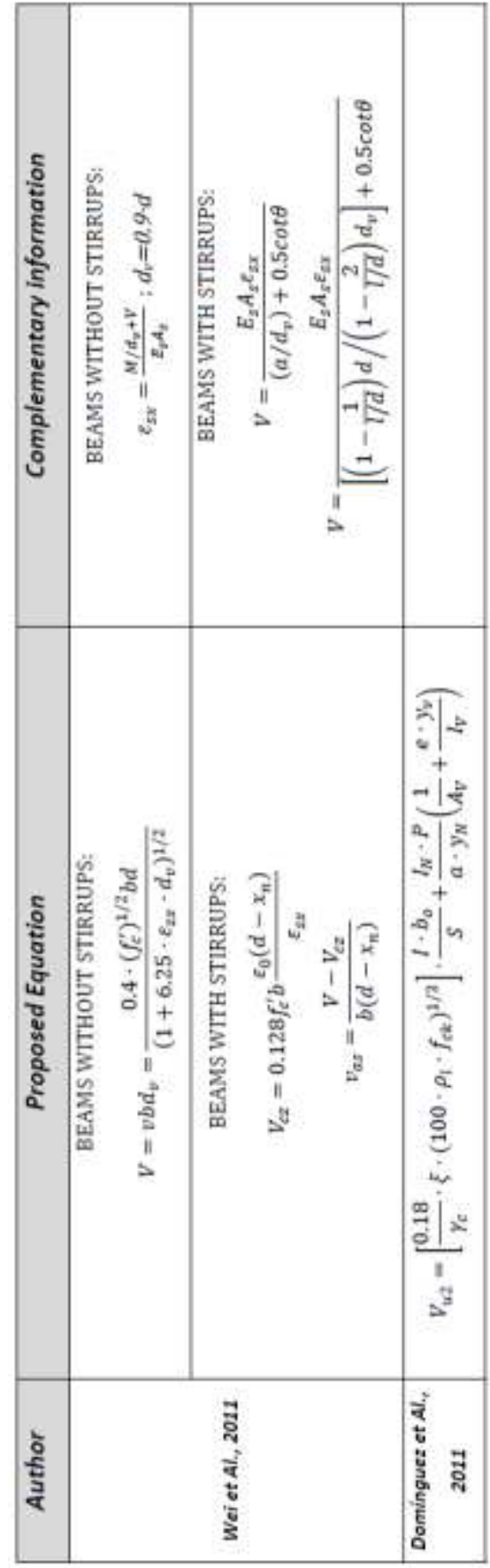




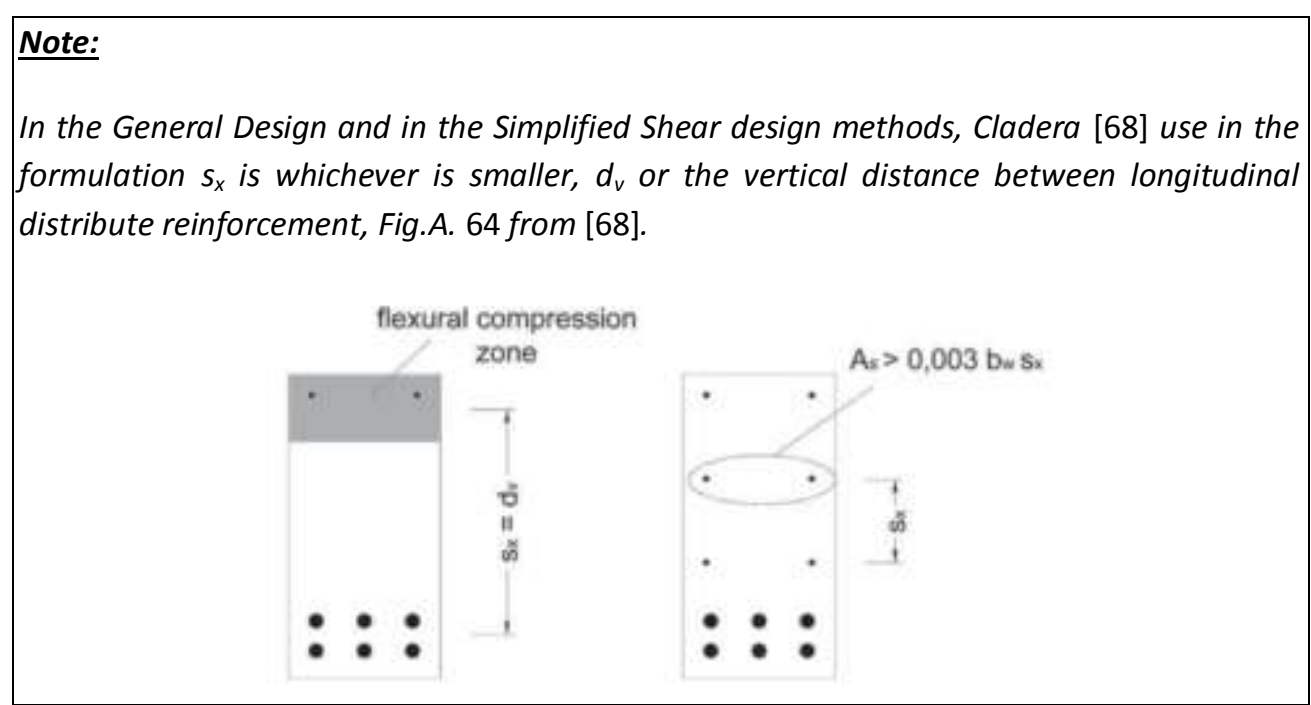

Fig.A. 64 Value of $s_{x}$ for members without web reinforcement [68]

Also, other models have been proposed:

- Dei Poli et Al. [110] proposed a model that is an improved version of the wellknown Mörsch's truss. The novelty is that the stiffening effects produced by stirrup-toconcrete bond and the bending and shear stiffness of the concrete struts between the cracks, are added to the effects of aggregate interlock and, at the joint with the compression flange, the strut section is assumed to be partially cracked and at the onset of failure in shear-compression. All three mechanisms produce a remarkable decrease in the inclination of the diagonal compression field in the web, accompanied by a great reduction of the stirrup role; moreover, the cracked field turns out to be more regular, with thinner and closer cracks. The proposed model allows the evaluation of the optimum stirrup ratio and of the web thickness in a thin-webbed beam failing in shear, taking into account many different aspects, provided that the material properties, the bond properties, the crack orientation, the section depth, and the ultimate shear stress are given [110].

- In 2005, Di Prisco and Gambarova [111] improved a model for reinforced concrete (RC) and prestressed concrete (PC) by introducing dowel action, no uniform distribution of crack opening and slip, and plastic-strain accumulation in the stirrups. The proposed approach was based on the truss analogy and on the diagonal-compression concept, within the context of limit analysis: the failure in shear was related to the simultaneous yielding of the stirrups and the collapse of the compressive struts in shear compression. The agreement between the predictions of the proposed model and the test 
results was quite good, both for normal and high-strength concretes. However, the model underestimates the shear capacity when the arch mechanism comes into play.

\section{A.7 Hollow Core Slabs (HCS) made with concrete without fibers}

\section{A.7.1 Introduction}

What is a "hollow core slab"?

The EN 1168 defines a Hollow core slab (HCS) as a "monolithic prestressed element or reinforced, with a constant total depth, divided into an upper and lower slab (also called flanges), joined by vertical webs, thus forming alveolus as longitudinal hollows in the crosssection, which is constant and has a symmetrical vertical axis".

HCS were developed in the 1950s when long-line prestressing techniques evolved [6]. HCS are advanced products in the prestressed precast concrete industry, especially in terms of efficient use of material (low self-weight) and due to the prestressing [112], and given their high quality due to the efficient production line manufacturing process [1], [2]. The hollow core components are pretensioned, which means that the tensions are tensioned in the casting beds before the casing and curing of the concrete and that they are anchored in the cured concrete $y$ bonding after the saw-cutting of the member (Girhammar, 1992). The concrete quality used in prestressed HCS results in a characteristic compressive strength of 35-50MPa [112].

The extrusion method has a very widespread use and has been utilized to produce inexpensive and easy-to-handle HCS ( [1] among others). Nevertheless, the extrusion method is not without its drawbacks because it does not allow shear reinforcement incorporation, and anchorage reinforcement by bond is produced. Shear on HCS and its failure modes have been studied by different authors ( [112], [113], [114], [115] among others), who analyzed various failure modes: flexure, anchorage and shear (by web shear tension or by shear-flexure).

The parameters which mainly affect the shear strength of prestressed precast HCS are amount of prestress force, concrete strength (compressive and tensile strengths), loading conditions, and interlocking forces in the shear crack.

Nowadays, the relevant method to calculate HCS is given in European Standard EN 1168:2005+A3:2012 [116] (this Standard has substituted the previous EN 1168:2005+A2:2009). This Standard deals with the requirements and the basic 
performance criteria and specifies minimum values where appropriate for precast hollow core slabs made of prestressed or reinforced normal weight concrete according to EN 1992-1-1:2004 (EC2). This European Standard covers terminology, performance criteria, tolerances, relevant physical properties, special test methods, and special aspects of transport and erection.

Anyway, HCS also could be calculated in the same way as beams. To obtain the elements' shear theoretical values, each HCS can be approximated to a single double T beam; so web width $\boldsymbol{b}_{\boldsymbol{0}}$ was the sum of all the webs widths which composed the HCS. For the calculations, the fact that all the webs contributed in the same manner to resist shear was taken into account. However, in this subsection 3.9 only the European Standard EN $1168+\mathrm{A} 2$ will be explained, because the Design Codes (EC2, EHE, ACl and MC2010) were explained in previous sections of this chapter 3 (see section 3.6).

The conformity assessment provided in the European standard EN 1168:2005+A3:2011 (here in advance: EN 1168) refers to the finished precast elements that are marketed and covers all production operations performed at the factory. This Standard refers to the Standard EN 1992-1-1 (Eurocode 2) for design rules. When necessary, provide additional supplemental rules. The Standard EN 1168 specifies requirements and basic behavior criteria, as well as minimum values where appropriate for precast HCS made of prestressed concrete or normal density reinforcement, according to the Standard EN 1992-1-1:2004. The application of EN 1168 is limited to prestressed elements with a maximum depth of $500 \mathrm{~mm}$ and a maximum width of $1200 \mathrm{~mm}$. For reinforced elements, the maximum depth is limited to $300 \mathrm{~mm}$ and the maximum width without transverse reinforcement to $1200 \mathrm{~mm}$, and with transverse reinforcement, to $2400 \mathrm{~mm}$. The diameter of the prestressing steel is limited to a maximum of $11 \mathrm{~mm}$ for wires and to $16 \mathrm{~mm}$ for tendons. Thermal prestressing bars are only allowed in the cases cited in Appendix $\mathrm{K}$ of the EN 1168.

The use of shear reinforcement is generally not feasible for HCS and, therefore, the shear strength, particularly of deep slabs, may be limited to the shear strength of the concrete [117].

\section{A.7.2 Methods of manufacturing}

Two basic manufacturing methods are currently in use for the production of HCS. One is a dry cast or extrusion system where a very low slump concrete is forced through the machine. The cores are formed with augers or tubers with the concrete being compacted around the cores (Fig.A.65). The second system uses a higher slump concrete. Sides are 
formed either with stationary, fixed forms or with forms attached to the machine with the sides being slip formed. From now on, this chapter will be focused only on the dry cast or extrusion system [118].

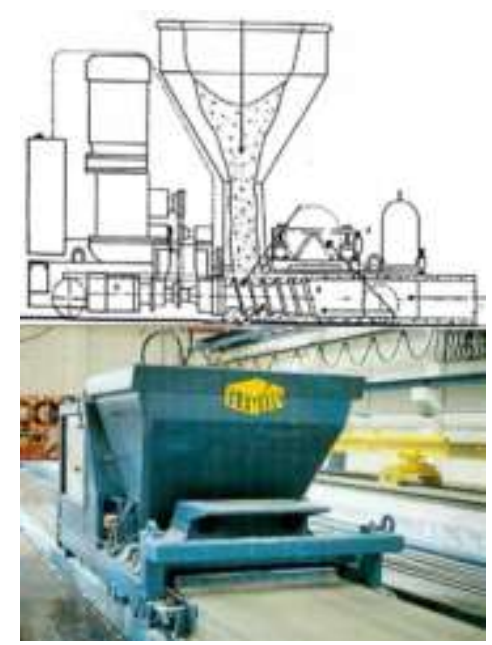

Fig.A. 65 Extrusion machine "Extruder" (Spiroll), [119]

Traditional vibrator concrete compacting systems have been replaced by extruders, which use the shear compacting principle. Shear compacting is more quiet and allows the use of low slump concrete, which can reduce curing time, save cement, an improve slab quality [120].

\section{A.7.3 Materials}

For the low slump concretes, water content is limited to slightly more than that required for cement hydration. Water-cement ratios are typically about 0.3. Mixing is critical because the limited water available must be well dispersed in the mix. Water reducing admixtures can be used to optimize a mix by reducing cement and water requirements while still retaining adequate workability for proper compaction of the concrete by the machine. Air entrainment admixtures are not effective in the dry mix concrete. With the low water-cement ratios and compaction placing method, air is difficult to disperse well and maintain [118].

\section{A.7.4 Advantages of HCS}

HCS are most widely known for providing economical, efficient floor and roof systems. When properly coordinated for alignment, the voids in a HCS may be used for electrical or 
mechanical runs. Structurally, a HCS provides the efficiency of a prestressed member for load capacity, span range, and deflection control. Excellent fire resistance is another attribute of the HCS. Depending on thickness and strand cover, ratings up to 4 hour endurance can be achieved. Used as floor-ceiling assemblies, HCS have excellent sound transmission characteristics associated with concrete [118].

The economy of the generalized hollow core system is in the quantity of slabs that can be produced at a given time with a minimum of labor required. Each slab on a given casting line will have the same number of prestressing strands. Therefore the greatest production efficiency is obtained by mixing slabs with the same reinforcing requirements from several projects on a single production line. This implies that best efficiency for a single project is obtained if slab requirements are repetitive [118].

The advantages of prestressed HCS compared to conventionally reinforced solid concrete slabs are primarily crack-free or controlled crack widths in the serviceability state; smaller deflection; lower dead load and smaller depth. The lower self-weight is due to both the holes and the use of high-strength strands with smaller cross-sectional area. It is essentially the behavior in the serviceability state and the shear capacity that can be improved by the prestressing. The gain in ultimate bending capacity due to prestressing is usually negligible [112].

\section{A.7.5 Shear behavior of HCS}

In 1991, Pisanty \& Regan [121] established that the shear strength of prestressed, precast, hollow-core slabs depends mainly on three factors: the tensile strength of the concrete in the webs, the prevailing compressive stress where shear strength is verified, and a shape factor depending on the geometry of the particular slab [121]. In 1992, also Pisanty [122] added that the shear capacity generally depends on the shear strength of the compression zone, on the interlocking forces in the shear crack, and on the dowel action in the strands; the shear strength varies with the prestressing force.

In addition, the shear strength of pretensioned slabs can also be affected by an increase in the prestress transfer length due to excess initial strand slip. The "strand slip theory" appears to adequately predict the reduced capacity and failure mode of slabs having such excess slip [123]. Also, below a minimum prestressing level the elements become vulnerable to a lower mode of shear failure due to earlier flexural cracking [122].

Moreover, Walraven \& Mercx [124] and FIP [125] assume a conservative position by claiming that the prestressing force to be taken into consideration for the compressive 
stress at distance $y_{b}$ form the edge of the support is that at the face of the support. The actual meaning of this concept is that force begins to spread form the inner face from the support towards the centroid in the direction of the span, which would leave the part of the element above the support (above the centroid and left of line a-a in Fig.A.66 below) virtually unstressed. It is, however known that this region is very vulnerable to cracking due to tensile stresses arising from the prestress closely above the support [126], which can only be due to the prestressing effectively taking place over the support as well. There are, on the other hand, reports on excessive slip of the strands [123], the consequence of which is a delay in the effect of the transfer of prestressing [122]. In all shear-tension mode failures the principal shear crack projects from the inner edge of the support, in the span direction at less than 45을 122$]$.

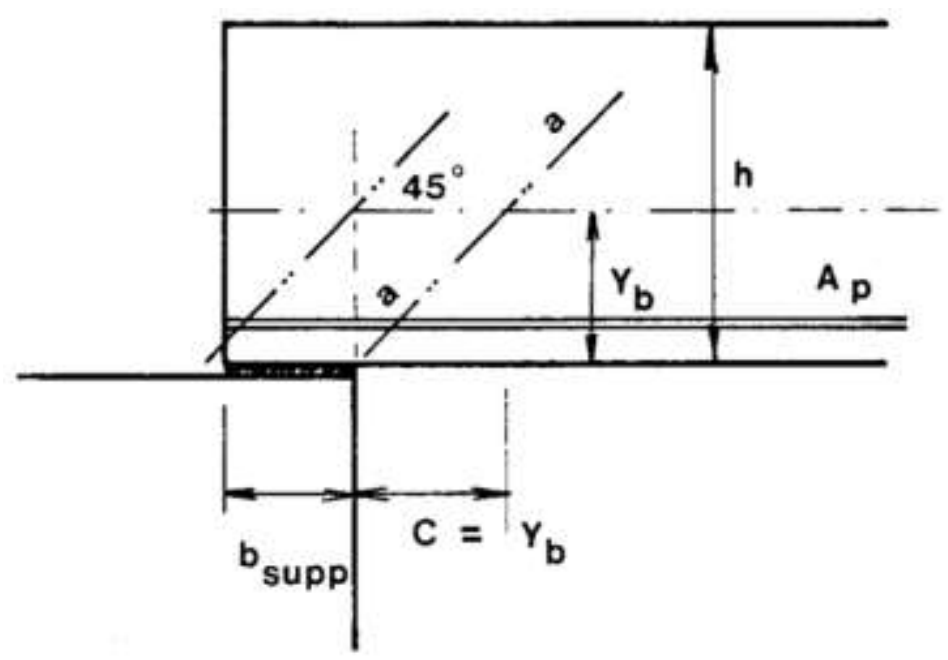

Fig.A. 66 Section for verification of shear capacity at distance $c$ from support edge [122]

Bertagnoli \& Mancini [113] did not find safety problems related to shear failure in uncracked regions so long as they are correctly designed according to EC2. Anyway, a general final design recommendation is to choose wider bearing support plates, relating them to the depth of the slab; the wider is the support plate, the bigger the amount of prestressing introduced to the slab before the loads giver rise to relevant shear actions [113]. 


\section{A.7.6 Failure modes}

\section{A.7.6.1 Behavior in bending}

\section{A.7.6.1.1 Pure flexural failure}

Due to the relatively small cross-section of the steel, the ductility of a slab after flexural cracking is considerable. Fork-shaped cracks develop, which reduce the compression area, but failure nevertheless generally occurs in consequence of rupture of the prestressing steel. So in pure flexure failures the bearing capacity is limited by the strength of the prestressing steel [124].

\section{A.7.6.1.2 Anchorage failure}

If the cracking pattern extends too far towards the support a situation may occur in which the length of the anchored strand is too small to develop sufficient anchorage capacity; the strands slip through the concrete [112], [127] causing considerable widening of the cracks and large rotations. The anchorage capacity depends mainly on the compaction of the concrete around the strands [124]. The ultimate failure mode corresponding to anchorage failure of strands or rupture (yielding) of strands can only occur if the flexural shear cracking capacity of the concrete has been exceeded. This failure mode is of the ductile type if the anchorage failure is due to loss of bond, and is of the brittle type if the failure is due to splitting or dowel action [112].

The support lengths of HCS are usually a few centimeters only, and the bond properties of prestressed strands are much weaker than those deformed bars. Because the prestress in strands needs a certain length to be transferred, additional shear stresses are produced in the transfer region. In addition, the large proportion of voids makes HCS susceptible to shear failure [120].

Any relative slip between the materials that is not accounted for in the design verification can lead to the collapse of a member due to the debonding of prestressing strands, or otherwise trigger another failure mode. In the case of hollow-core slabs without shear reinforcement, the application of highly concentrated loads within the transmission length should be avoided or, if that is not possible, special attention should be given to quality control during production and erection of the slabs to ensure that the hypotheses used in the project still apply [114]. 


\section{A.7.6.1.3 Flexural compression failure of concrete}

The ultimate failure mode corresponding to flexural compression failure of concrete can occur only if the yielding (or anchorage) failure capacity (or deformation capacity) of the strands is sufficiently high. This final failure mode is of the brittle type (almost of explosive type). The crushing of concrete is always preceded by high bond slip or elongation of the strands. Failure due to concrete crushing can be avoided by prescribing an upper limit for the tensile capacity of the strands [112].

\section{A.7.6.2 Behavior in shear}

The two types of shear failures (flexure-shear and web shear failure) can be shown to be generally related to the amount of prestressing force and the shear span. With low amounts of prestress and a longer shear span, flexural stresses are more dominant and the flexure-shear failure results. With heavy prestress and a short shear span, the flexural stresses do not have as great an effect, hence the web shear failure occurs [128].

Yang [120] found that the flexure-shear strengths were in reasonable agreement with Codes but that web-shear strengths showed considerable scatter compared with Code predictions. Yang also observed that the rate at which the prestressing force was transferred to the concrete within the transfer length could significantly affect the webshear strength. Web-shear cracking occurred when the principal tensile stress in the units (at the intersection of the narrowest web and the bottom flange) reached the tensile strength of the concrete for a location on a line drawn from the centerline of the support at an angle of $35^{\circ}$ to the axis of the unit [117].

\section{A.7.6.2.1 Shear tension failure}

If the tensile strength in the webs of the slab becomes too high in the region not cracked in bending, an inclined crack occurs when the principal tensile stress in the web reaches the tensile strength of the concrete [112], [120]. The diagonal crack normally appears in the middle of the web and propagates both in the upward and the downward direction, resulting in immediate failure. The crack is generally formed in the region where the favorable influence of the vertical support stresses is exhausted and the prestressing force, which needs some length to develop, is not yet fully introduced [124].

Theoretical analyses show that the crack appears in the middle of the web approximately at a distance $h / 2$ from the inner face of the bearing, when the cross-section of the voids is circular. For non-circular voids the situation is more complicated [112]. 


\section{A.7.6.2.2 Flexural shear failure}

This failure is assumed to be initiated by a (vertical) flexural crack at the bottom of the member, usually near the support, which grows to a (diagonal) shear crack through the web extending up to the compression area of the member. This leads to ultimate failure if the anchorage (or tensile) capacity of the strands, or the flexural shear compression failure capacity of the concrete, is lower than that corresponding to cracking failure. Since prestressed hollow core units do not have shear reinforcement, the shear capacity depends solely on the concrete and the longitudinal pretensioned strands. It is noted that near the support, neither the anchorage capacity of the strand is fully developed (within the development length), no is the prestressing force fully transferred. This leads to a greater tendency for the unit to fail in this flexural shear cracking mode. The cracking capacity depends on the prestressing force [112].

Tests on prestressed HCS [ [124]; [127]] show that flexural shear compression failure mode more or less never occurs as a primary failure mode.

\section{A.7.7 Design of HCS}

In U.S. the design of HCS is governed by the ACl 318 Code. Excellent references for HCS are: $P C l$ Design Handbook for prestressed member design and the PCl Standard Design Practice which reflects design practices in the industry [118].

Pajari [115] pointed out that the EC2 method overestimated the mean shear strength for all slab types. While the overestimation was only slight for slabs with circular voids, it was obvious for units with flat webs. So, the effect of the shape of the webs on the shear resistance is so strong that regarding all slabs as one population is not justified [115]. The EC2 should never be used without a reduction factor for slabs with flat webs, and its applicability to other slab types should always be verified either numerically or experimentally before it is used [115]. So, as the shear resistance predicted by the EC2 was conservative for some slab types and non conservative for some others, another design method proposed by Yang gave a much better fit with test results. For this reason it is proposed that the present design method in EC2 will be replaced by Yang's method [120], possibly modified with a calibration factor [115].

On the other hand, Bertagnoli and Mancini [113] have shown that EC2 gives satisfactory results when compared with a great number of shear test results. In EC2, the design model for shear compression failure, which is completely different from web shear failure, is overconservative. This model often predicts a lower resistance than the model for web 
shear failure. When this lower value is applied to cases in which the actual failure mode is web shear failure, a safe design is obtained [129]. Also, it was observed that the value assumed for prestressing losses has a very slight influence on the results in all cases, so turns out to be a marginal parameter for the interpretation of the phenomenon [113].

\section{A.7.7.1 Shear Design according to EN 1168}

\section{A.7.7.1.1 General procedure of verification}

The shear failure of the HCS without shear reinforcement can happen in regions cracked in bending and in regions uncracked in bending. If a flexural crack appears over the anchorage length of the reinforcement, may also take place a failure of the anchorage. All failure modes should be considered:

- The shear strength in cracked regions should be calculated using the expressions (6.2a) and (6.2.b) of EN 1992-1-1:2004 (EC2).

$$
\begin{gathered}
V_{R d, c}=\left[\frac{0.18}{\gamma} \cdot \xi \cdot\left(100 \cdot \rho_{l} \cdot f_{c k}\right)^{1 / 3}+0.15 \cdot \sigma_{c p}\right] \cdot b_{w} \cdot d \\
V_{R d, c}=\left[V_{\min }+0.15 \cdot \sigma_{c p}\right] \cdot b_{w} \cdot d
\end{gathered}
$$

- The shear strength in uncracked regions should be calculated using the expression (6.4) of EN 1992-1-1:2004 (EC2), taking into account, where relevant, the additional shear stresses due to the transfer of the prestressing force and referring to the most unfavorable position in the cross-section. In paragraphs 3.9.5.1.2 and 3.9.5.1.3 a method for applying this calculation is indicated.

$$
V_{R d, c}=\frac{I \cdot b_{w}}{S} \sqrt{\left(f_{c t d}\right)^{2}+\alpha_{l} \sigma_{c p} f_{c t d}}
$$

- The resistance against anchorage failure must be calculated in accordance with paragraph 9.2.1.4 of EN 1992-1-1:2004 (EC2).

\section{A.7.7.1.2 Shear resistance in uncracked sections}

Uncracked regions in bending are defined by a flexure tensile stress of less than $f_{c t k 0.05} / \gamma_{c}$. Here, the shear strength should be calculated according to the following equation: 


$$
V_{R d, c}=\frac{I \cdot b_{w}(y)}{S_{c}(y)} \sqrt{\left(f_{c t d}\right)^{2}+\alpha_{l} \sigma_{c p}(y) f_{c t d}}-\tau_{c p}(y)
$$

This equation should be applied with reference to the critical points of a straight line breaking arising from the edge of the support with an angle $\beta=35^{\circ}$ to the horizontal axis. The critical point is the point of that line where the result of the expression of $V_{R d, c}$ is the smallest.

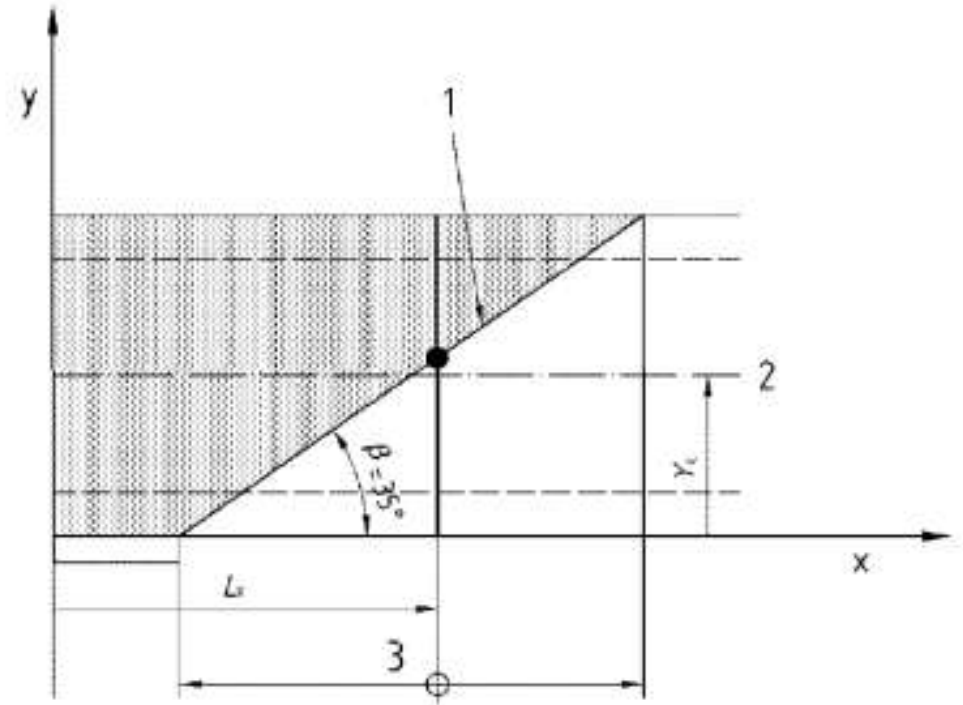

Fig.A. 67 Failure line in uncracked regions; 1: Failure line; 2: Central axis depth; 3: Transverse section [116]

where:

$I=$ second moment of area; $S=$ first moment of area above and about the centroidal axis; $b_{w}=$ web width; $\alpha_{1}=I_{x} / I_{p t 2}$, with $I_{x} / I_{p t 2} \leq 1$ for pretensioned tendons; $I_{x}$ : distance of section considered from starting point of the transmission length; $I_{p t 2}$ : upper bound value of the transmission length of the prestressing element: $I_{p t 2}=1.2 \cdot I_{p t} ; \sigma_{c p}=N_{E d} / A=$ average stress acting on the concrete cross-section for an axial force due to prestressing actions; $f_{c t d}=f_{c t k 0.05} / \gamma_{c}=$ design characteristic tensile strength.

\section{A.7.7.1.3 Simplified expression}

As an alternative to the previous expression, the following simplified equation can be applied: 


$$
V_{R d, c}=\varphi \cdot \frac{I \cdot b_{w}}{S} \sqrt{\left(f_{c t d}\right)^{2}+\beta \cdot \alpha_{l} \sigma_{c p} f_{c t d}}
$$

(6.4) of EC2

(Eq.A.119)

where:

$\varphi=0.8=$ reduction factor; $\beta=0.9=$ reduction factor referred to the transmission length.

\section{A.7.7.2 Shear Design according to formulas of other authors}

\section{A.7.7.2.1 Walraven and Mercx [124]}

A 5\% lower limit for the shear tension capacity was calculated from:

$$
V_{u k}=0.75 \cdot \frac{I \cdot b_{w}}{S} \sqrt{\left(f_{c t d}\right)^{2}+\alpha_{l} \sigma_{c p} f_{c t d}}
$$

where: $b_{w}=\sum_{i}^{n} b_{w_{i}}=$ Sum of web widths

To simplify the design, it is generally assumed that the HCS behave like simply supported beams. This simplification means that the mechanical model of a HCS is a number of parallel I-beams. A more accurate way would be to regard one slab unit as a beam, the width of which at a given depth being equal to the total width minus the sum of core widths [129], see Fig.A.68.

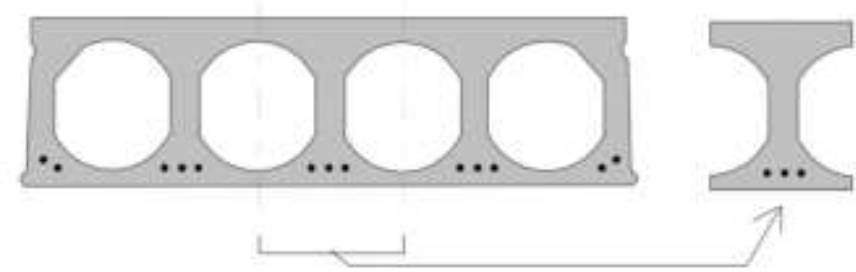

Fig.A. 68 A longitudinal cut representing the whole slab unit [129]

The coefficient of reduction " 0.75 " resulted in good agreement with an analysis of results of tests by other authors (see [130]), where also 0.75 was found.

Having taken into consideration that a reduction factor is found to be necessary, this brings the expression for shear capacity in shear tension mode to one of the following [122]: 


$$
V_{u k}=0.75 \cdot \frac{I \sum b_{w}}{S} \sqrt{\left(f_{c t k, \min }\right)^{2}+0.8 \cdot \alpha_{l} \cdot \sigma_{c p} f_{c t k, \min }}
$$

The need for an additional reduction factor exists, namely 0.75 . The need for an overall reduction factor may tend to diminish with growth of the web width, allowing an improved performance [122].

The assumption for the concrete tensile strength in the form of high splitting tensile strength was exaggerated, and reduction of this strength brings the calculations to a realistic value [122].

As a lower limit for shear compression failure the following expression can be used:

$$
V_{u k, x}=0.068 b_{w} d\left(1+0.5 \frac{100 A_{s}}{b_{w} d}\right) \sqrt{f_{c}}+\frac{M_{0}}{M_{x} / V_{x}}
$$

Walraven and Mercx [124] noticed that the observed shear resistance was lower than the predicted one when the voids were noncircular.

\section{A.7.7.2.2 Yang's method [120]}

A design procedure for HCS, Yang's method, which predicts the capacity against shear failure of web and the position of the critical point, has been proposed. The procedure can be applied to different loading cases, prestress levels, types of cross-section material and geometric parameters. The correction factors for different void shapes are not needed in the procedure [120], on the other hand, in the traditional design procedure, correction factors for different types of voids should have to be introduced [ [127]; [112]]; however, it was impossible to determine all the correction factors for different types of cross sections of HCS [120].

According to the Yang's method, the capacity against shear failure of web can be given as:

$$
\begin{aligned}
V=\frac{b I_{y}}{S_{c p}}\left\{\frac{b}{2 S_{c p}} f_{c t} x_{c p} z_{c p}+\frac{S_{c p}}{b}\left(\frac{e}{I_{y}}-\frac{A_{c p}}{A S_{c p}}\right) \frac{d N_{p}}{d x}\right. \\
\left.+\left[\left(\frac{b}{2 S_{c p}} f_{c t} x_{c p} z_{c p}\right)^{2}+\left(\frac{e}{I_{y}}-\frac{A_{c p}}{A S_{c p}}\right) f_{c t} x_{c p} z_{c p}+\left(\frac{1}{A}-\frac{z_{c p} e}{I_{y}}\right) N_{p} f_{c t}+f_{c t}^{2}\right]^{1 / 2}\right\}
\end{aligned}
$$


The coordinate of the point $\left(x_{c p}, z_{c p}\right)$, can simply be predicted as the intersection of the narrowest web width of HCS and the line form the centre of support at an angle $\beta=35$ o with the bottom surface of the HCS (Fig.A.69). The coordinate $x_{c p}$ can be expressed as:

$$
x_{c p}=\frac{h_{c p}}{\tan \beta} \approx \frac{h_{c p}}{0.7}
$$

where $h_{c p}=$ distance between the critical point and bottom surface of the HCS. For HCS with circular voids, the critical point is near to the centroid of the cross section, Fig.A.69. For HCS with noncircular voids, it is located at the intersection of the narrowest web width and the bottom flange, which is far away from the centroid of the cross section, Fig.A.69.

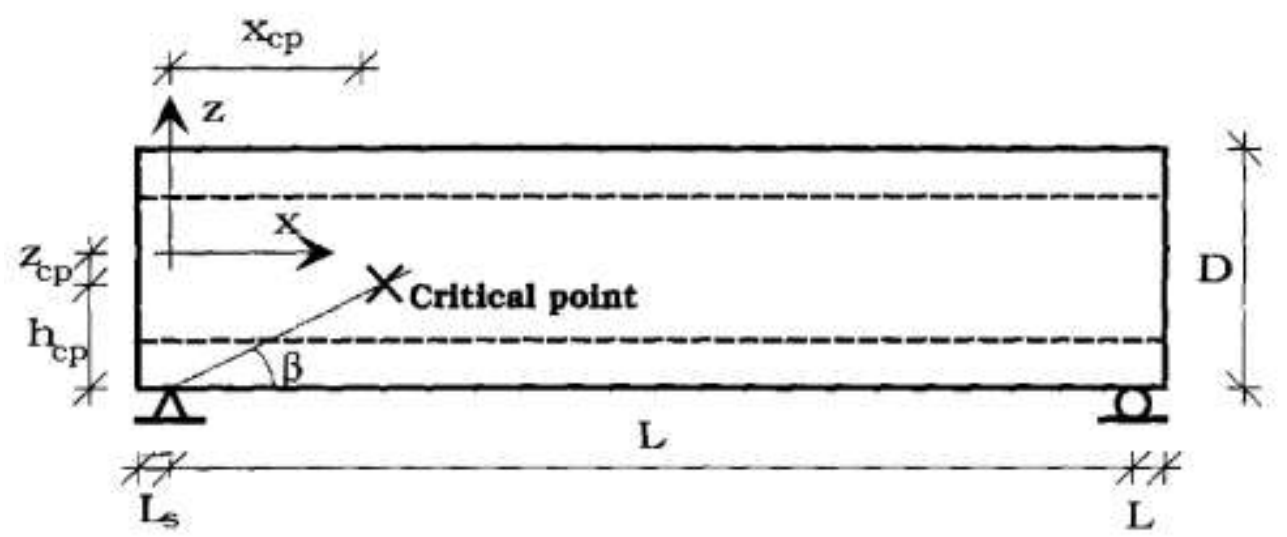

Fig.A. 69 Horizontal position of critical point [120]

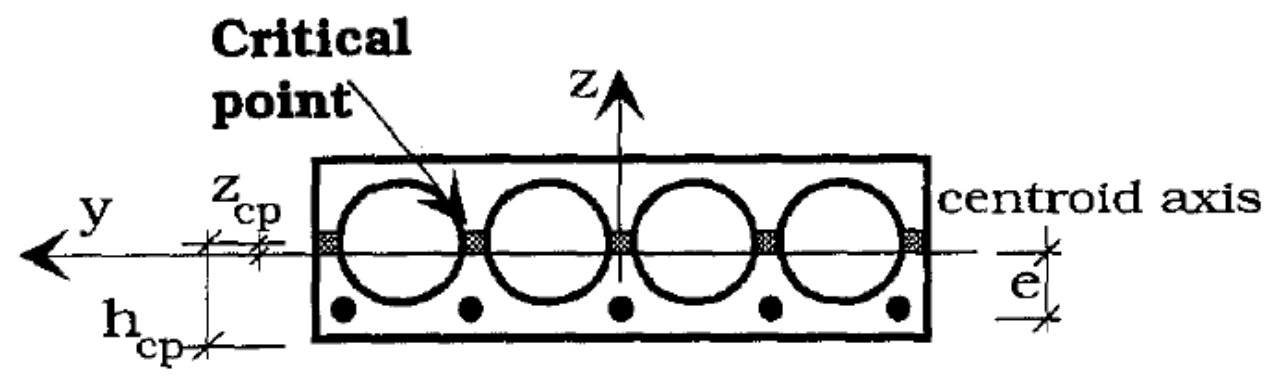

Fig.A. 70 Vertical position of critical point for HCS with circular voids [120] 


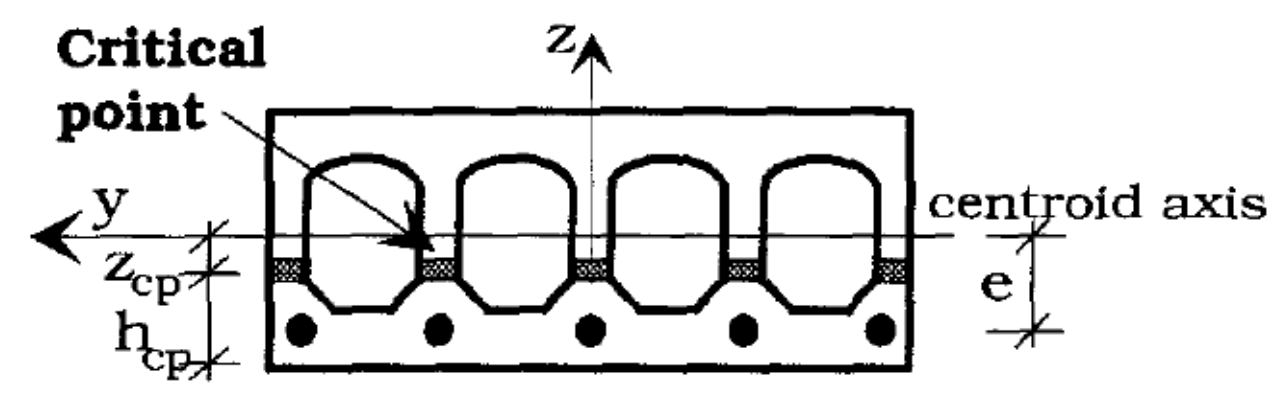

Fig.A. 71 Vertical position of critical point for HCS with noncircular voids [120]

The angle $\beta$ between the bottom of the HCS and the line from the center of the support to the critical point, Fig.A.72, can be approximately taken as 35․ It is also shown that the critical point is located at the intersection of the narrowest web width and the bottom flange of HCS (Fig.A.70 and Fig.A.71). Especially for HCS with noncircular voids, the critical point is far away from the centroid of the cross section.

Yang's method [120] takes the shear stresses due to the transfer of the prestressing force into account. Yang's method, in which the shear stresses are derived from Navier's bending theory, gave good correspondence with test results [115].

So, according to Yang, the vertical compressive stress due to the support reaction is taken into account as shown in Fig.A. 72. The critical point is located somewhere on a straight line $A^{\prime} B^{\prime}$ shown in Fig.A. 72-b (where: points to be considered = possible critical points). By choosing closely spaced points, hereafter called considered points, along the line and calculating the maximum principal stress in each of them, the critical point where the principal stress has its maximum value can be determined for each load case. By varying the load, the resistance against the web shear failure is determined [115].

Yang concluded that a web shear failure can only take place outside the zone affected by the support reaction, which is the grey-shaded zone in Fig.A. 72-a. 


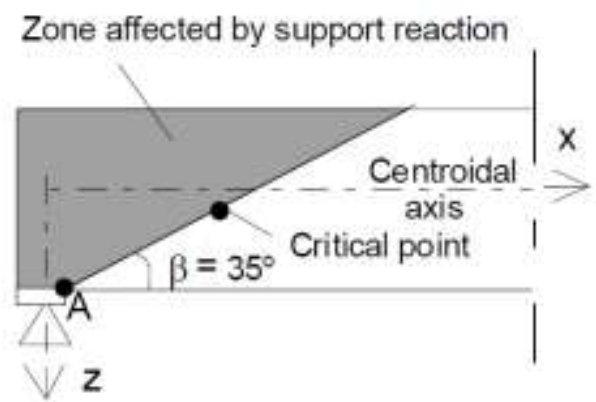

a)

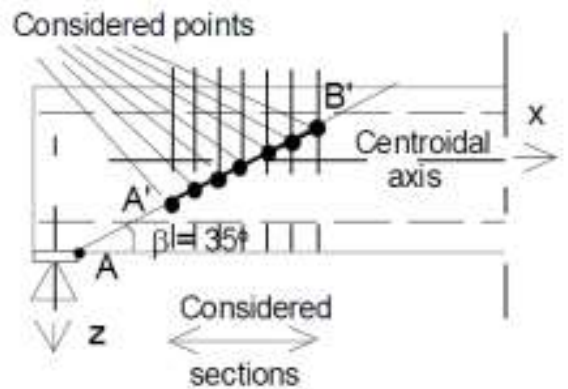

b)

Fig.A. 72 (a) Possible location of critical point next to the zone affected by support reaction; (b) Points and sections taken into consideration in calculations [115]

The geometric symbols are illustrated in Fig.A. 73. The web width depends on $z_{c p}$ and is obtained from:

$$
b_{w}=\sum_{i} b_{w i}\left(z_{c p}\right)
$$

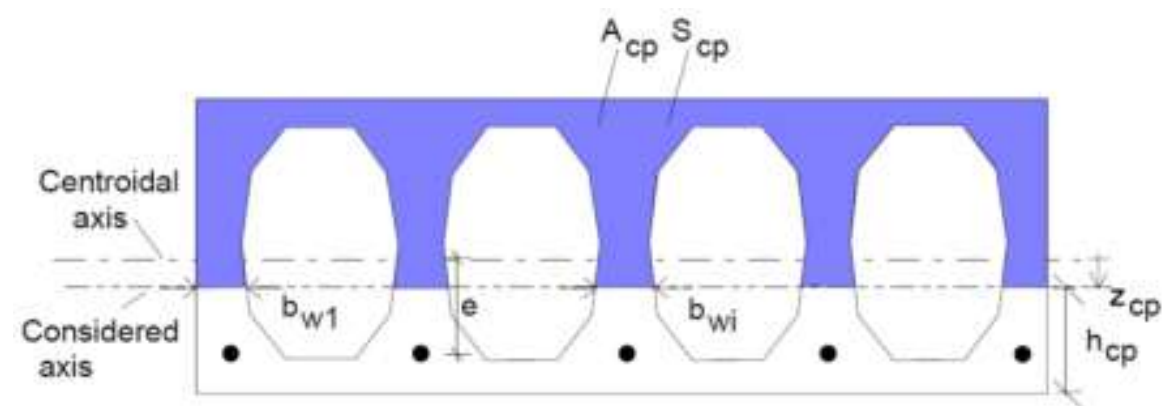

Fig.A. 73 Illustration of geometric parameters of considered cross-section [115]

If the webs are flat, a good guess for the critical position is the junction of the webs and the flange [115].

\section{A.7.7.2.3 Method proposed by Menegazzo et Al. [114]}

The methodology presented by Menegazzo et Al. [114] for the shear design of HCS is based on the Modified Compression Field Theory (MCFT), proposed by Collins et Al., together with the basis of the CSA A23.3 Code [131] and the safety concepts from EC2. This procedure has the following main benefits: it is based on a general theory of shear 
applied to reinforced and prestressed concrete elements; when compared to experimental results and Codes, the model gives good results; and, it is simple to use and is appropriate for design [114].

For elements without shear reinforcement it is assumed that shear will be resisted mainly by aggregate interlock. Therefore, the shear resistance in the proposed methodology is taken as:

$$
V_{R d}=\frac{2}{\gamma_{c}} \beta b_{w} d_{v} 2 f_{c t m}
$$

The term $v f_{c k}$ in the original equation of the MCFT has been replaced by $2 \cdot f_{c t m}$, which likewise should not be greater than 8MPa. The curves $v f_{c k}$ and $2 \cdot f_{c t m}$ are similar (Fig.A.74). However, the proposed modification allows the unequal increase between the compressive strength and tensile strength of concrete to be considered and allows the tensile strength of the concrete to be applied directly in the calculation of the shear resistance:

$$
\begin{array}{cc}
f_{c t m}=0.30 f_{c k}^{2 / 3} & \mathrm{C} \leq \mathrm{C} 50 / 60 \\
f_{c t m}=2.2 \ln \left(1+\frac{f_{c k}}{10}\right) & \mathrm{C}>\mathrm{C} 50 / 60
\end{array}
$$

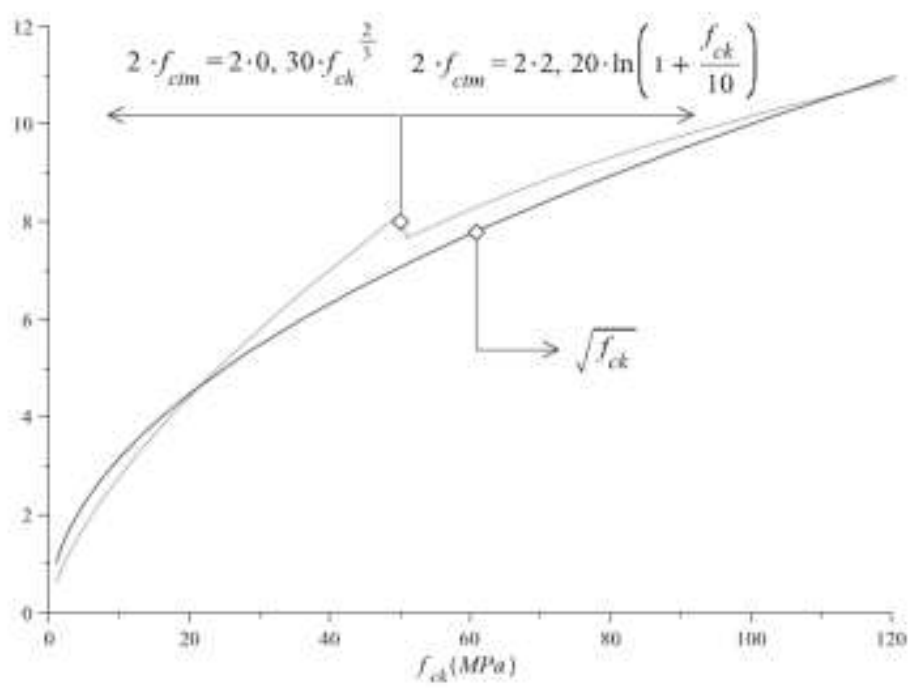

Fig.A. 74 Comparison between $f_{c k}$ relations [114] 
Coefficient $\beta$ can be calculated using Eq.A.127 (based on MCFT), where the first term models the strain effect and the second term the size effects.

$$
\beta=\frac{0.40}{\left(1+1500 \varepsilon_{x}\right)} \cdot \frac{1300}{\left(1000+s_{x e}\right)}
$$

The $\varepsilon_{\mathrm{x}}$ deformation can be calculated by Eq.A.128:

$$
\varepsilon_{x}=\frac{M_{d} / d_{v}+V_{d}-A_{p s} f_{p 0}(x)}{2 E_{p} A_{p s}}
$$

In this methodology for HCS, it is proposed that the term $\left(E_{c} \cdot b_{w} \cdot d_{v}\right) / 2$ should be added to the reinforcement stiffnesses in the denominator when the design bending moment is smaller than the cracking moment. Then, when the cross-section is uncracked, Eq.A.128 can be modified as follows:

$$
\varepsilon_{x}=\frac{M_{d} / d_{v}+V_{d}-A_{p s} f_{p 0}(x)}{2 E_{p} A_{p s}+0.5 E_{c} b_{w} d_{v}}
$$

The term $f_{p o}(x)$ is calculated assuming a linear variation in the transmission length, as presented in EC2. Accordingly, the shear depth $d_{v}$ is taken as 0.9.d.

The parameter $s_{x e}$, the size effect term, where the crack spacing $s_{x}$ can be taken as the distance between web layers of longitudinal reinforcing bars or equal to $d_{v}$ for members with longitudinal reinforcement on the flexural tension side only, as in the case of HCS $s_{x} \approx d_{v}=0.9 d$. The maximum coarse aggregate size $a_{g}$ should be taken as zero for highstrength concrete $\left(f_{c k}>70 \mathrm{MPa}\right)$ or lightweight concrete, according to the MCFT.

$$
s_{x e}=\frac{35 s_{x}}{15+a_{g}} \geq 0.85 s_{x}
$$

The section that should be checked depends on the type of loading and should be where the width of the critical shear crack can be satisfactorily evaluated by a linear strain diagram, according to Muttoni \& Ruiz [132]. In the methodology presented here, it was appropriate to considerer a section at a distance $d_{v} / 2$ from the point of application for a concentrated load and at two sections in the case of a uniformly distributed load. 


\section{A.8 Important note}

The author of this PhD thesis makes clear that to make the state-of-the-art of this APPENDIX A, fragments of the literature studied have been collected. Many of the pieces have been reproduced verbatim from the original source to directly transmit the idea of the original author, it is not intended to explain the literature with other words to avoid doubts or reproduce a different idea that is not exactly transmitting the original author. The sentences used from papers from other authors are always accompanied by their citation number, so that the reader can know at all times where the fragment has been extracted. The author of the thesis has done a great deal of consultation, study and subsequent analysis of the literature, which has been collected in this chapter completely updated. Under no circumstances, the author of this PhD thesis has tried to appropriate material that does not belong to her, for that, each fragment has been properly cited.

\section{A.9 References}

[1] MacGregor and Wight, Reinforced concrete. Mechanics and Design., Pearson Prentice Hall, 2005.

[2] Naaman, Prestressed Concrete Analysis and Design. Fundamentals., Mc-Graw Hill, 1982.

[3] Hassoun, Structural Concrete. Theory and design, Addison-Wesley, 1998.

[4] Nawy, Reinforced Concrete: A fundamental approach, New Jersey, USA: PearsonPrentice Hall, 2005.

[5] Taylor, Investigation of Forces carried across cracks in reinforced concrete beams in shear by interlock of aggregate, TRA 42.447, London: Cement and concrete association, 1970.

[6] Fenwick and Paulay, "Mechanisms of shear resistance of concrete beams," Proceedings of the American Society of Civil Engineers, vol. 94, no. 10, pp. 23252350, 1968.

[7] Park and Paulay, Reinforced concrete structures, New York: Wiley-Interscience Publication, 1975. 
[8] García-Meseguer, Morán-Cabré and Arroyo-Portero, Jiménez Montoya. Hormigón Armado., Gustavo Gili, 2009.

[9] Sagaseta and Vollum, "Shear design of short-span beams," Magazine of concrete research, vol. 62, no. 4, pp. 267-282, 2010.

[10] Russo, Somma and Angeli, "Design shear strength formula for high strength concrete beams," Materials and Structures, vol. 37, pp. 680-688, 2004.

[11] BS.8110, "BS 8110. Part 1: Structural use of concrete: code of practice for design and construction," British Standard Institution (BSI), 1997.

[12] Mörsch, Concrete-Steel Construction, New York: McGraw-Hill, 1909.

[13] Collins and Mitchell, Prestressed Concrete Structures, Response Publications, 1997.

[14] Zwoyer and Siess, "Ultimate strength in shear of simply-supported prestressed concrete beams without web reinforcement," ACl Journal, vol. 51, no. 2, pp. 181200, 1954.

[15] Bresler and Pister, "Strength of Concrete under Combined Stresses," ACl Journal, vol. 55, no. 3, pp. 321-345, 1958.

[16] Guralnick, "Shear Strength of Reinforced Concrete Beams.," Journal of the Structural Division, ASCE, vol. 85, no. 1, pp. 1-42, 1959.

[17] Walther, "Calculation of the Shear Strength of Reinforced and Prestressed Concrete Beams by the Shear Failure Theory.," Cement and Concrete Association, vol. 57, no. 11, pp. 261-271, 1962.

[18] Kani, "Basic facts concerning shear failure," Journal of the ACl, vol. 63, pp. 675-692, 1966.

[19] Kani, "The Riddle of Shear Failure and its solution.," ACl Journal, vol. 61, pp. 441-467, 1964.

[20] Kani, "How safe are our large reinforced concrete beams?," Proc., J. Am. Concr. Inst., vol. 64, no. 31, pp. 128-141, 1967. 
[21] Taylor, "The fundamental behavior of reinforced concrete beams in bending and shear," ACI Special Publication, vol. 42, pp. 43-78, 1974.

[22] Bazant and Yu, "Designing against size effect on shear strength of reinforced concrete beams without stirrups: II. Verification and calibration," Journal of structural engineering ASCE, vol. 131, no. 12, pp. 1886-1897, 2005.

[23] Walraven, "Fundamental analysis of aggregate interlock," Journal of the Structural Division, ASCE, vol. 107, no. 11, pp. 2245-2270, 1981.

[24] Dei.Poli, Gambarova and Karakoç, "Aggregate interlock role in R.C. thin-webbed beams in shear," Journal of Structural Engineering ASCE, vol. 113, no. 1, pp. 1-19, 1987.

[25] Nawy, Prestressed Concrete. A fundamental approach., New Jersey, USA: PearsonPrentice Hall, 2006.

[26] Muttoni and Fernández-Ruiz, "Shear in slabs and beams: should they be treated in the same way?," in Shear and punching shear in RC and FRC elements, 2010, pp. 105-128.

[27] ACl-ASCE, "Committee 426. The Shear Strength of Reinforced Concrete Members," Proceedings ASCE, Journal of the Structural Division, vol. 99, no. 6, pp. 1091-1187, 1973.

[28] Kotsovos, "Behavior of beams with shear span-to-depth ratios greater than 2.5," ACI Journal, pp. 1026-1034, 1986.

[29] Hawkins, Kuchma, Mast, Marsh and Reineck, "NCHRP Report 549: Simplified Shear Design of Structural Concrete Members," National Cooperative Highway research program. Transportation Research Board (TRB), Washigton, D.C., 2005.

[30] Cladera and Marí, "Experimental study on high-strength concrete beams failing in shear," Engineering Structures, vol. 27, pp. 1519-1527, 2005.

[31] Kuchma, Sun, Nagle and Kim, "Components of shear resistance in prestressed bulbtee girders," in Shear and punching shear in RC and FRC elements, fib bulletin 57, 2010, pp. 155-171. 
[32] Kupfer, Extension to the truss-analogy of Mörsch using the principle of minimum potential energy., vol. 40, CEB Bulletin d'Information, 1964.

[33] Nielsen, Limit Analysis and Concrete Plasticity., Prentice-Hall, 1984.

[34] Thürlimann, Marti, Pralong, Ritz and Zimmerll, Application of the theory of plasticity to reinforced concrete., Zurich, 1983.

[35] Marti, "Basic Tools of Beam Design," ACl Journal, vol. 82, no. 1, pp. 46-56, JanuaryFebruary 1985.

[36] Collins and Mitchell, "Shear and Torsion design of prestressed and non-prestressed concrete beams," PCl Journal, vol. 25, no. 5, pp. 32-100, 1980.

[37] Mitchell and Collins, "Diagonal Compression Field Theory - A Rational Model for Structural Concrete in Pure Torsion," ACl Journal, vol. 71, pp. 396-408, 1974.

[38] Collins, "Towards a rational theory for RC members in shear," Journal of the Structural Division, ASCE, vol. 104, pp. 649-666, 1978.

[39] Vecchio and Collins, "The response of reifnroced concrete to in-plane shear and normal stresses," Department of Civil Engineering, University of Toronto, vol. 82, no. 3, 1982.

[40] Wagner, "Metal beams with very thin webs," Zeitschrift für Flugtechnick und Motorluftschiffahr, vol. 20, no. 8-12, 1929.

[41] Vecchio and Collins, "The Modified Compression Field Theory for reinforced concrete elements subjected to shear," $A C l$ Journal, vol. 83, no. 2, pp. 219-231, 1986.

[42] ACl-Committee445, "Recent approaches to shear design of structural concrete," vol. 124, no. 12, pp. 1375-1417, 1998.

[43] Wei, Che and Gong, "Shear strength prediction for reinforced concrete beams without stirrups," Magazine of Concrete Research, vol. 63, no. 6, pp. 433-440, 2011.

[44] Bentz, "MC2010: Shear strength of beams and implications of the new approaches," in fib Bulletin 57: Shear and punching shear in RC and FRC elements. Shear 
Workshop, 2010, pp. 15-30.

[45] Bhide and Collins, "Influence of Axial Tension on the Shear Capacity of Reinforced Concrete Members," ACl Structural Journal, vol. 86, no. 5, pp. 570-581, 1989.

[46] Vecchio, Collins and Aspiotis, "High-strength concrete elements subjected to shear," ACl Structural Journal, vol. 91, no. 4, pp. 423-432, 1994.

[47] Taylor, "Some shear tests on reinforced concrete beams without shear reinforcement," Magazine of Concrete Research, vol. 12, no. 35, 1960.

[48] ACl-ASCE, "Committee 426. Suggested Revisions to Shear Provisions for Building Codes," ACl Journal, vol. 75, no. 10, pp. 563-569, 1978.

[49] Krefeld and Thurston, "Contribution of longitudinal steel to shear resistance of reinforced concrete beams," ACl Journal, vol. 63, no. 14, pp. 325-344, 1966.

[50] Mattock, "Diagonal tension cracking in concrete beams with axial forces," Journal of the Structural Division, ASCE, vol. 95, no. 9, pp. 1887-1900, 1969.

[51] Rajagopolan and Ferguson, "Exploratory shear tests emphasizing percentage of longitudinal steel," ACl Journal, vol. 65, pp. 634-638, 1968.

[52] Placas and Regan, "Shear failure of reinforced concrete beams," ACl Journal, pp. 763-773, 1971.

[53] Cladera and Marí, "Shear design procedure for reinforced normal and high-strength concrete beams using artificial neural networks. Part II: beams with stirrups," Engineering Structures, vol. 26, pp. 927-936, 2004.

[54] Saqan and Frosch, "Influence of flexural reinforcement on shear strength of prestressed concrete beams," ACI Structural Journal, vol. 106, no. 1, pp. 60-68, 2009.

[55] Collins, Mitchell and MacGregor, "Structural Design Considerations for HighStrength Concrete," Concrete International, pp. 27-34, 1993.

[56] Ahmad, Khaloo and Poveda, "Shear capacity of reinforced high-strength concrete beams," ACl Journal, vol. 83, no. 2, pp. 297-305, 1986. 
[57] Elzanaty, Nilson and Slate, "Shear capacity of reinforced concrete beams using highstrength concrete," ACl Journal, pp. 290-296, 1986.

[58] Mphonde and Frantz, "Shear tests of high- and low-strength concrete beams without stirrups," ACl Journal, vol. 81, no. 4, pp. 350-357, 1984.

[59] Moody, Viest, Elstner and Hognestad, "Shear Strength of Reinforced Concrete Beams, Part 1: Tests of Simple Beams," Journal of the ACl, vol. 51, no. 4, pp. 317333, 1954.

[60] Angelakos, Bentz and Collins, "Effect of concrete strength and minimum stirrups on shear strength of large members," Journal of Structural Engineering, vol. 98, no. 3, pp. 290-300, 2001.

[61] Kazemi and Broujerdian, "Reinforced concrete beams without stirrups considering shear friction and fracture mechanics," Canadian Journal of Civil Engineering, vol. 33, pp. 161-168, 2006.

[62] Shioya, Iguro, Nojiri, Akiyama and Okada, "Shear strength of large reinforced concrete beams, Fracture Mechanics: Application to Concrete," ACI SP-118, p. 309, 1989.

[63] Collins and Kuchma, "How safe are our large, lightly reinforced concrete beams, slabs, and footings?," ACl Structural Journal, vol. 96, no. 4, pp. 482-490, 1999.

[64] Bazant and Kim, "Size effect in shear failure of longitudinally reinforced beams," $\mathrm{ACl}$ Journal, vol. 81, no. 5, pp. 456-468, 1984.

[65] Lubell, Sherwood, Bentz and Collins, "Safe shear design of large, wide beams," Concrete International, vol. 26, no. 1, pp. 67-78, 2004.

[66] Cladera and Marí, "ULS of shear in beams: historical approach and experimental verification of the EHE procedure (in Spanish)," Hormigón y Acero, Vols. 221-222, pp. 43-61, 2001.

[67] Taylor, "The shear strength of large beams," Journal of the structural division, ASCE, 1972. 
[68] Cladera and Marí, "Shear design procedure for reinforced normal and high-strength concrete beams using aritificial neural networks. Part I: beams without stirrups," Engineering Structures, vol. 26, pp. 917-926, 2004.

[69] Regan, "Research on shear: A benefit to humanity or a waste of time?," The Structural Engineer, vol. 71, no. 19, pp. 337-347, 1993.

[70] Frosch, "Behavior of large-scale reinforced concrete beams with minimum shear reinforcement," ACl Structural Journal, vol. 97, no. 6, pp. 814-820, 2000.

[71] Bazant, "Scaling of structural strength," Elsevier, 2005.

[72] Yu and Bazant, "Can stirrups suppress size effect on shear strength of RC beams?," Journal of Structural Engineering ASCE, vol. 137, no. 5, pp. 607-617, 2011.

[73] Gupta and Collins, "Evaluation of Shear Design Procedures for Reinforced Concrete Members under Axial Compression," ACl Structural Journal, vol. 98, no. 4, pp. 537547, 2001.

[74] Thürlimann, Bachmann, Kraus, Caflisch and Heimgartner, "Shear tests on partially prestressed beams," Institut für Bautechnik ETH Zürich, 1978.

[75] Balázs, "A historical review of shear," in Shear and punching shear in RC and FRC elements, 2010, pp. 1-13.

[76] Sagaseta and Vollum, "Influence of beam cross-section, loading arrangement and aggregate type on shear strength," Magazine of Concrete Research, vol. 63, no. 2, pp. 139-155, 2011.

[77] Zararis, Karaveziroglou and Zararis, "Shear strength of reinforced concrete Tbeams," ACl Structural Journal, vol. 103, no. 5, pp. 693-700, 2006.

[78] Leonhardt, "Reducing the shear reinforcement in reinforced concrete beams and slabs," Magazine of concrete research, vol. 17, no. 53, pp. 187-198, 1965.

[79] Leonhardt and Walther, "The Stuttgart Shear Tests 1961.," Beton und Stahlbetonbau, Vols. 56-57, 1961-1962. 
[80] Leonhardt, "Shear and Torsion in Prestressed Concrete," in VI FIP Congress, Prague, 1970.

[81] Haddadin, Hong and Mattock, "Stirrup effectiveness in reinforced concrete beams with axial forces," Journal of the Structural Division, ASCE, vol. 97, no. 9, pp. 22772298, 1971.

[82] Placas, Shear strength of Reinforced Concrete Beams, PhD thesis, London: Imperial College of Science and Technology, 1969.

[83] Tureyen, Wolf and Frosch, "Shear strength of reinforced concrete T-beams without transverse reinforcement," ACl Structural Journal, vol. 103, no. 5, pp. 656-663, 2006.

[84] Walraven, "Shear, background document for prENV 1992-1-1:2001," in Eurocode 2: Background documents from ENV to EN 1992-1-1, Whittle R ed., 2004.

[85] Pansuk and Sato, "Shear mechanism of reinforced concrete T-beams with stirrups," Journal of Advanced Concrete Technology, vol. 5, no. 3, pp. 395-408, 2007.

[86] Regan, "Shear in Reinforced Concrete. An experimental study," Construction Industry Research and Information Association (CIRIA), 1971.

[87] Hsiung and Frantz, "Transverse stirrup spacing in R/C beams," Journal of Structural Engineering, ASCE, vol. 111, no. 2, pp. 353-362, 1985.

[88] Muttoni, Schwartz and Thürlimann, Design of concrete structures with stress fields, Basel: Boston and Berlin, 1997.

[89] ACl.Committee.318, Building Code requirements for structural concrete ( $\mathrm{ACl} 318$ 11), American Concrete Institute, 2011.

[90] Lubell, Bentz and Collins, "Shear reinforcement spacing in wide members," $\mathrm{ACl}$ Structural Journal, vol. 106, no. 2, pp. 205-214, 2009.

[91] Eurocode.2, Eurocode 2: Design of Concrete Structures - EN 1992-1-1, 2005.

[92] EHE-08, Instrucción de Hormigón Estructural EHE-08, Ministerio de Fomento, 2008, p. 702 pp.. 
[93] MC2010, "fib Bulletins 55-56. Model Code 2010. First Complete Draft," 2010.

[94] Cladera and Marí, "Shear design of reinforced and prestressed concrete beams: a proposal for code procedure (in spanish)," Hormigón y Acero, vol. 242, no. 4, pp. 5163, 2006.

[95] Vecchio and Collins, "Predicting the Response of Reinforced Concrete Beams Subjected to Shear using the Modified Compression Field Theory," ACl Structural Journal, vol. 85, pp. 258-268, 1988.

[96] Dei-Poli, Gambarova and Karacoc, "Aggregate interlock role in RC thin-webbed beams in shear," J. Struct. Eng., ASCE, vol. 113, no. 1, pp. 1-19, 1987.

[97] Belletti and Damoni, "Some remarks concerning the shear failure in prestressed RC beams," Computational Modelling of Concrete Structures, pp. 581-590, 2010.

[98] CEB-FIP, Código Modelo CEB-FIP 1990 para hormigón estructural, Madrid: Colegio de Ingenieros de Caminos, Canales y Puertos, 1995.

[99] Walraven, "Eurocode 2: Basics and backgrounds," African Concrete Code Symposium, pp. 59-75, 2005.

[100] European-Concrete-Platform, Eurocode 2 Commentary, Brussels, 2008.

[101] Cladera and Marí, "Shear strength in the new Eurocode 2. A step forward?," Structural Concrete, vol. 8, no. 2, pp. 57-66, 2007.

[102] Lee and Hwang, "Maximum shear reinforcement of reinforced concrete beams," $\mathrm{ACl}$ Structural Journal, vol. 107, no. 5, pp. 580-588, 2010.

[103] Richard, An investigation of web stresses in reinforced condret beams., vol. 166, Engineering Experiment Station, University of Illinois, 1927.

[104] Bazant, Yu, Gerstle, Hanson and Ju, "Justification of ACl 446 Code provisions for shear design of reinforced concrete beams," ACl Structural Journal, vol. 104, no. 5, pp. 601-610, 2007.

[105] Collins, Bentz and Sherwood, "Where is shear reinforcement required? Review of research results and design procedures," ACI Structural Journal, vol. 105, no. 5, pp. 
590-600, 2008.

[106] R. Pendyala and P. Mendis, "Experimental Study on shear strength of high-strength concrete beams," ACl Structural Journal, vol. 97, no. 4, pp. 564-571, 2000.

[107] Khuntia and Stojadinovic, "Shear strength of reinforced concrete beams without transverse reinforcement," ACl Structural Journal, vol. 98, no. 5, pp. 648-656, 2001.

[108] Duthinh, "Sensitivity of shear strength of reinforced concrete and prestressed concrete beams to shear friction and concrete softening according to modified compression field theory (MCFT)," ACl Structural Journal, vol. 96, no. 4, pp. 495-508, 1999.

[109] Vecchio, "Analysis of shear-critical reinforced concrete beams," ACl Structural Journal, vol. 97, no. 1, 2000.

[110] Dei-Poli, Di-Prisco and Gambarova, "Stress field in web of RC thin-webbed beams failing in shear," Journal of Structural Engineering, ASCE, vol. 116, no. 9, pp. 24962515, 1990.

[111] Di-Prisco and Gambarova, "Comprehensive model for study of shear in thin-webbed RC and PC beams," Journal of Structural Engineering, ASCE, vol. 121, no. 12, pp. 1822-1831, 1995.

[112] Girhammar, "Design principles for simply supported prestressed Hollow Core Slabs," Structural Engineering Review, vol. 4, no. 4, pp. 301-316, 1992.

[113] Bertagnoli and Mancini, "Failure analysis of hollow-core slabs tested in shear," Structural Concrete (journal of the fib), vol. 10, no. 3, pp. 139-152, 2009.

[114] Menegazzo, Domingues and Matos, "Anchorage failure and shear design of hollowcore slabs," Structural Concrete, vol. 12, no. 2, pp. 109-119, 2011.

[115] Pajari, "Resistance of prestressed Hollow Core Slabs against web shear failure. Research notes 2292," VTT Building and Transport, Kemistintie, Finland, 2005.

[116] EN1168+A3, «Precast concrete products - Hollow core slabs,» AENOR, 2012. 
[117] Hawkins and Ghosh, "Shear Strength of Hollow-Core Slabs," PCI Journal, pp. 110114, 2006.

[118] PCI, PCI Manual for the design of Hollow Core Slabs, Chicago, Illinois, 1998.

[119] Di-Prisco, "Criteri progettuali e stati tensionali di trazione nel solaio alveolare (in Italian)," Dipartimento di Ingegneria Strutturale. Politecnico di Milano, Milano, Italy.

[120] Yang, "Design of prestressed Hollow Core Slabs with reference to web shear failure," Journal of Structural Engineering, ASCE, vol. 120, no. 9, pp. 2675-2696, 1994.

[121] Pisanty and Regan, "Direct assessment of the tensile strength of the web in prestressed precast hollow-core slabs," Materials and Structures, vol. 24, pp. 451455, 1991.

[122] Pisanty, "The shear strength of extruded hollow-core slabs," Materials and Structures, vol. 25, pp. 224-230, 1992.

[123] Brooks, Gerstle and Logan, "Effect of initial strand slip on the strength of HollowCore Slabs," PCl Journal, vol. 33, pp. 90-111, 1988.

[124] Walraven and Mercx, "The bearing capacity of prestressed Hollow Core Slabs," HERON, vol. 28, no. 3, pp. 1-46, 1983.

[125] FIP-Recommendations, Precast Prestressed Hollow Core Floors, 1988.

[126] Den-Uijl, "Tensile Stresses in the transmission zones of Hollow Core Slabs Prestressed with Pretensioned Strands. Report 5-83-10," Delft University of Technology, 1983.

[127] Pajari, "Design of Prestressed Hollow Core Slabs. Technical Report 657," Technical Research Centre of Finland, 1989.

[128] Becker and Buettner, "Shear tests of extruded Hollow-Core Slabs," Precast/Prestressed Concrete Institute Journal, vol. 30, no. 2, pp. 40-54, 1985.

[129] Pajari, "Web shear failure in prestressed hollow core slabs," Journal of Structural Mechanics, vol. 42, no. 4, pp. 207-217, 2009. 
[130] Walraven, "The shear resistance of prestressed hollow core slabs," in FIP Technical Paper "Design principles for hollow core slabs regarding shear and transverse loadbearing capacity, splitting and quality control"., 1982.

[131] CSA, CSA A.23.3-04: Design of concrete structures, Ontario, Canada, 2004.

[132] Muttoni and Fernández-Ruiz, "Shear strength of members without transverse reinforcement as function of critical shear crack width," ACl Structural Journal, vol. 105, no. 2, pp. 163-172, 2008. 


\section{APPENDIX B}

\section{FIBER REINFORCED CONCRETE.}

\section{ADDITIONAL INFORMATION}

\section{B.1 Important note}

The author of this PhD thesis makes clear that to make the state-of-the-art of this Appendix $B$, fragments of the literature studied have been collected. Many of the pieces have been reproduced verbatim from the original source to directly transmit the idea of the original author, it is not intended to explain the literature with other words to avoid doubts or reproduce a different idea that is not exactly transmitting the original author. The sentences used from papers from other authors are always accompanied by their citation number, so that the reader can know at all times where the fragment has been extracted. The author of the thesis has done a great deal of consultation, study and subsequent analysis of the literature, which has been collected in this chapter completely updated. Under no circumstances, the author of this PhD thesis has tried to appropriate material that does not belong to her, for that, each fragment has been properly cited.

\section{B.2 Other models according to different authors}

Tables B.1 to B.4 summarized other shear models for FRC (sorted chronologically).

On Shear Behavior of structural elements made of steel fiber reinforced concrete-PhD thesis 


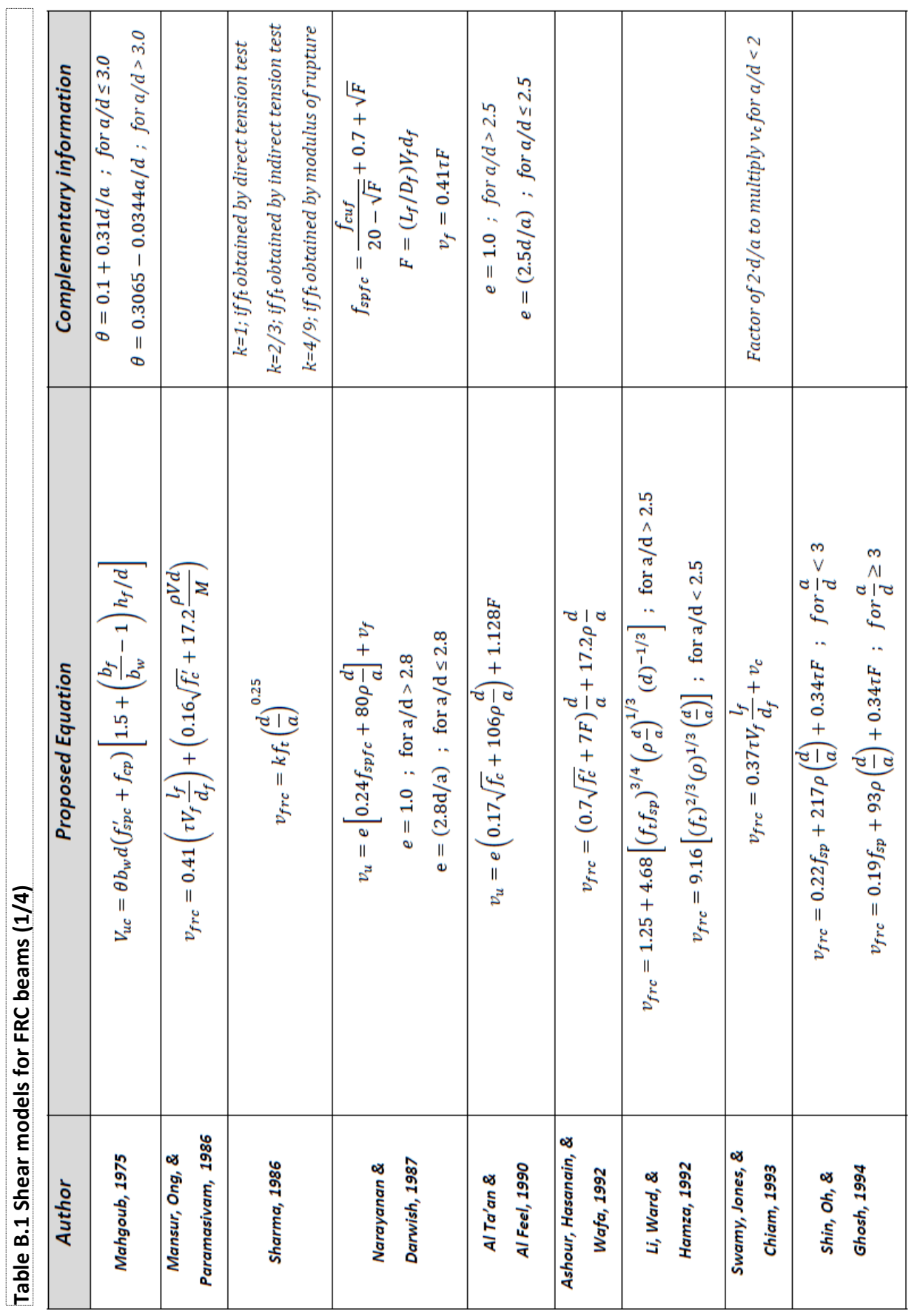




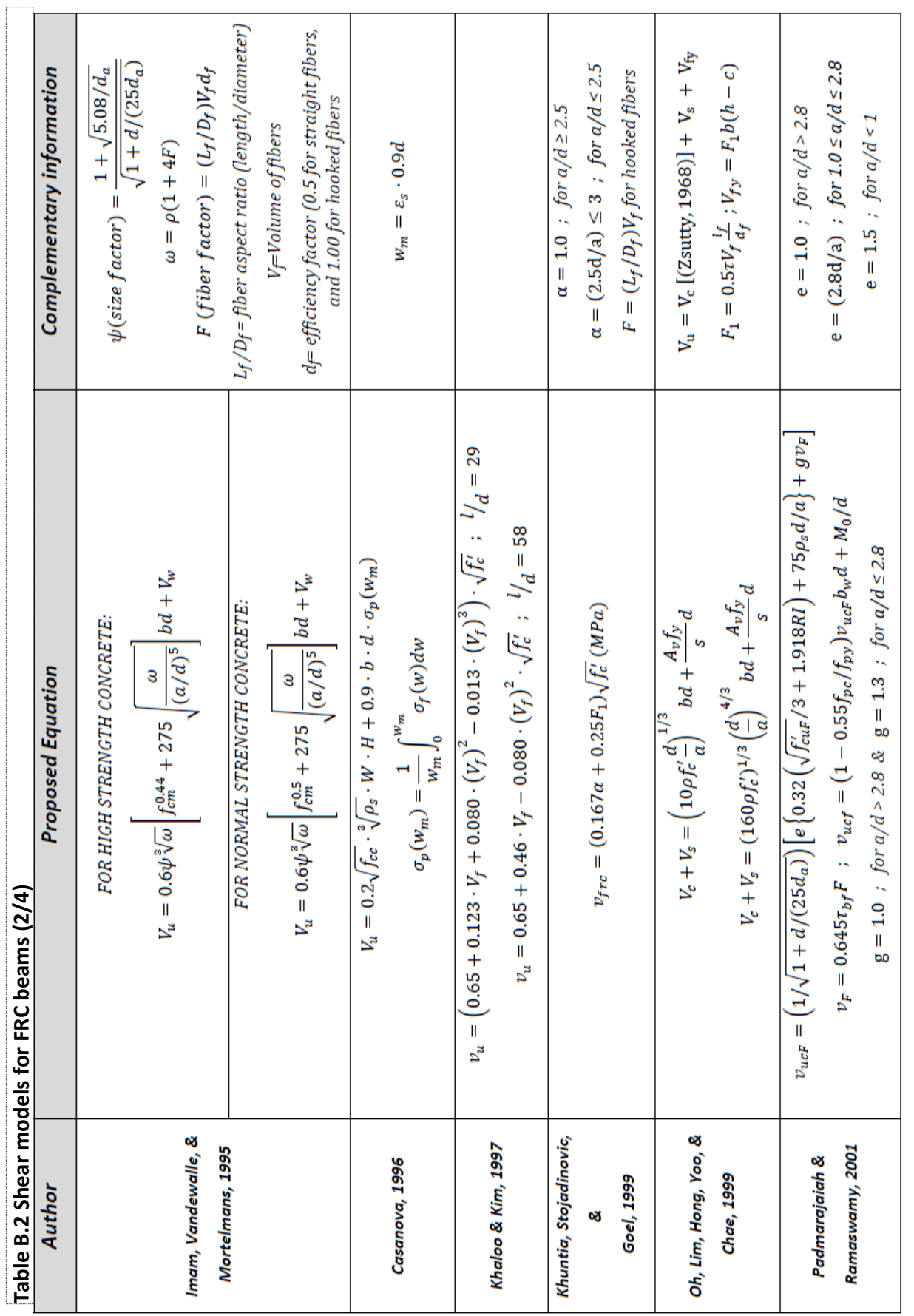




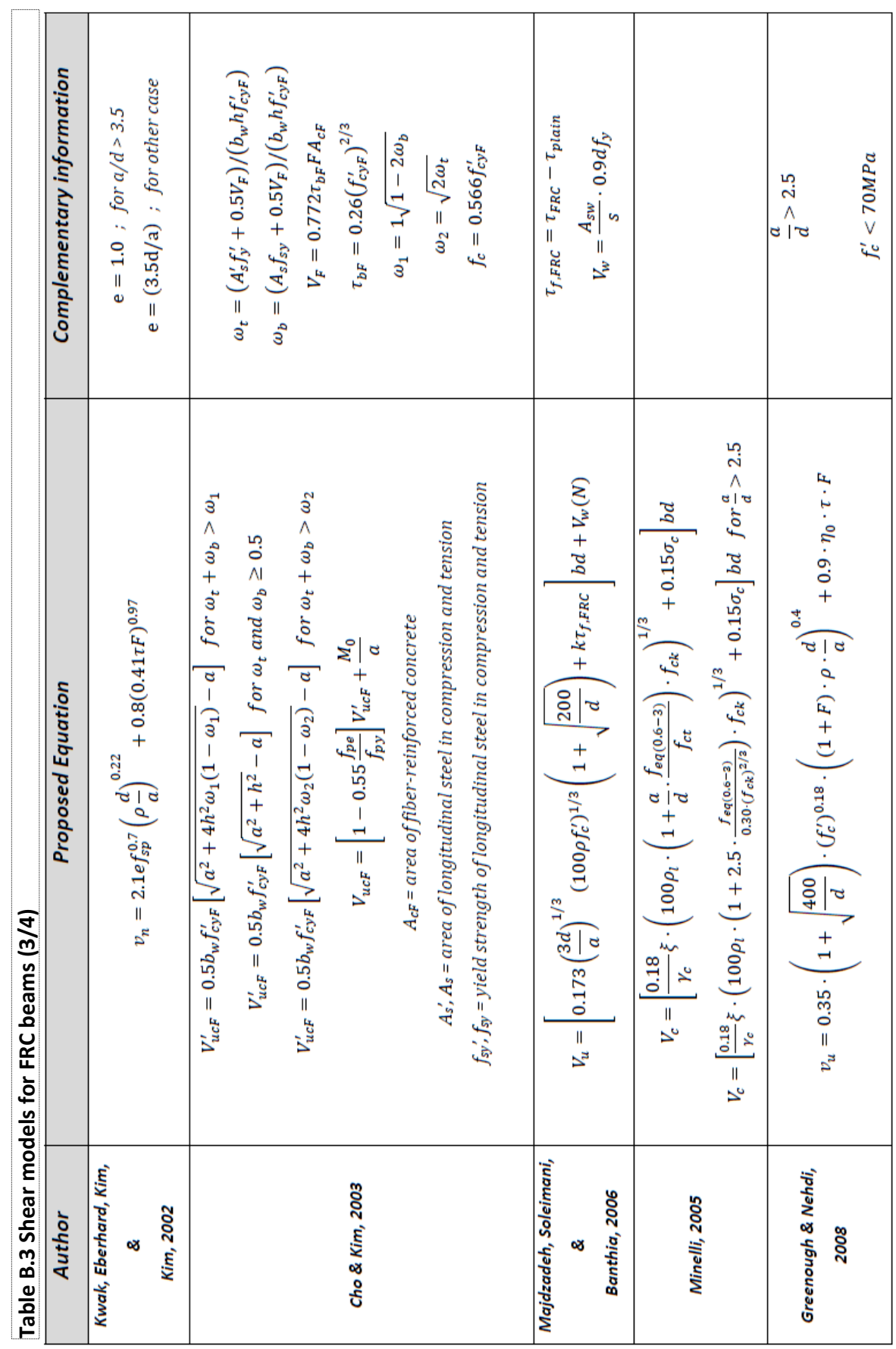




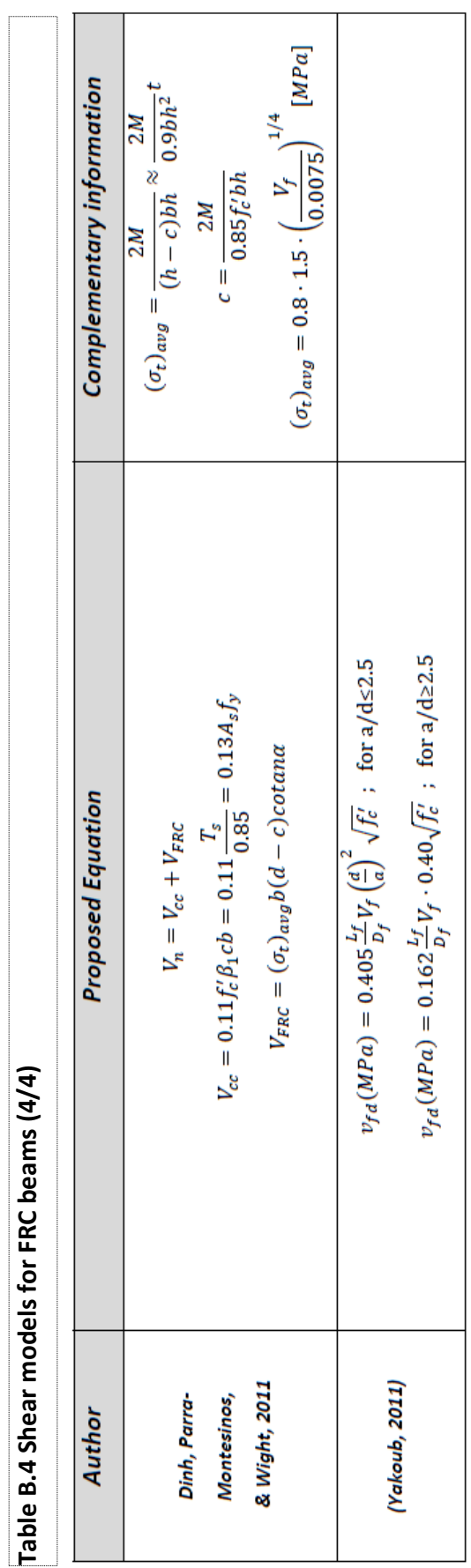

On Shear Behavior of structural elements made of steel fiber reinforced concrete-PhD thesis 


\section{B.3 Comments to shear models and to Design Codes}

One of the main reasons for the difficulties in finding good predictive formulations to describe the shear capacities may be that the empirical relations used to estimate the shear contribution of the concrete part, $V_{c}$, have been developed for normal strength concrete. As there are differences between normal and high strength concrete, in particular regarding the brittleness of the materials, the relations may not be valid. Also, the size effect seems to play a decisive role for the shear capacity. Thus, in order to find reliable methods to predict the shear capacity of fiber reinforced beams, it is important to take the effect of an increasing size under consideration [1].

\section{B.3.1 Comments to RILEM formula}

The RILEM's model gives good fitting of experimental results as well. However, it does not take into account the effect of fibers in a consistent and rational way [2].

The previous version RILEM2 [3] method was a conservative approach and could be considered as quite safe, whereas the revised model of Imam sometimes overestimated the failure load. The RILEM2 method was very conservative for small shear span to depth ratios. For most beams the underestimation was smaller when high fiber dosages were used. The influence of fibers was probably slightly overestimated when the longitudinal reinforcement ratio was low to normal, but that the real contribution of the fibers became more important with higher longitudinal reinforcement ratios. So, the interaction between steel fibers and longitudinal reinforcement was not taken into account [4].

There are two deficiencies in the current approach taken by the RILEM. First, because FRCs behave differently in shear that in flexure [5], the use of flexural properties to determine the shear response makes limited sense. Second, since fibers are an integral part of any FRC, their shear response should not be separated from that of plain concrete [6].

The RILEM proposal with the 3 additional terms is a simple way to calculate the shear resistance with a sufficient margin of safety [7].

Due to the fact that the RILEM proposal is a very conservative design method it can be assumed that the proposal also leads to a sufficient margin of safety for the cases of higher fiber contents, shear reinforcement ratios and longitudinal reinforcement ratios. Anyway the use of steel fibers as shear reinforcement is sensible in first line for members with low effects of actions [7]. 
The shear resistance for rectangular beams with stirrups and fibers is underestimated specially for beams with $\rho_{w}$ higher than the minimum reinforcement ratio. But this was also find for beams without fibers. It should be considered to take into account a different inclination of the compression strut [7].

There is a great influence of the presence of a flange on the shear resistance. With respect to the design formulas, the scatter makes the analysis difficult. It appears that tor the beams with wider flanges, the limitation of $\boldsymbol{k}_{f}$ of 1.5 leads to more conservative design. So this factor also will be retained [7].

\section{B.3.2 Comments to MC2010 formula for FRC (Minelli's formula)}

The Minelli's model includes fibers in the current EC2 formulation for shear as a function of the toughness provided by fibers to the concrete matrix. The toughness parameter is conventionally assumed as the equivalent post-cracking strength defined in the Italian Standard [8]. Italian Standard defines two equivalent post-cracking strengths, as shows Fig.B.1, where the equivalent strengths $f_{\text {eq(0-0.6) }}$ and $f_{\text {eq(0.6-3) }}$ concern the CTOD (Crack Tip Opening Displacement) ranges of $0-0.6 \mathrm{~mm}$ (related to the Serviceability Limit State-SLS) and $0.6-3 \mathrm{~mm}$ (related to the Ultimate Limit State-ULS), respectively. $U_{1}$ and $U_{2}$ are the areas of the P-CTOD curve, $I$ is the span $(450 \mathrm{~mm}), \mathrm{h}$ and $\mathrm{b}$ are respectively the height and the width (both $150 \mathrm{~mm}$ ) and $\boldsymbol{a}_{0}$ is the length of the notch $(45 \mathrm{~mm})$ of the beam specimen [2].

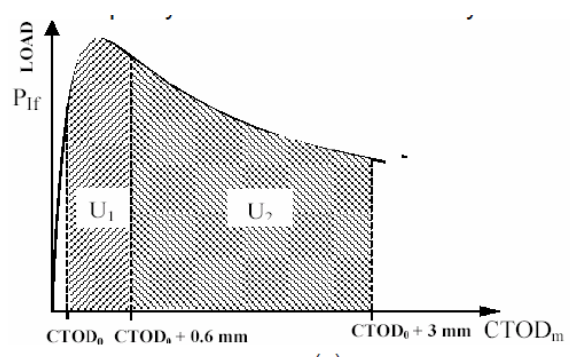

(a)

$$
\begin{aligned}
& f_{e q,(0-0.6)}=\frac{l}{b\left(h-a_{0}\right)^{2}} \cdot \frac{U_{1}}{0.6} \\
& f_{e q,(0.6-3)}=\frac{l}{b\left(h-a_{0}\right)^{2}} \cdot \frac{U_{2}}{2.4}
\end{aligned}
$$

Fig.B.1 Definition of $U_{1}$ and $U_{2}$ in a given experimental curve (a) and of the equivalent strength (b), according to the Italian Standard [2]

The presence of fibers all over the depth is relevant for the shear behavior, in the same way as placing longitudinal rebars at certain spacing along the depth of a member proved to be highly beneficial in terms of bearing capacity and overall ductility. Kuchma et Al. [9] demonstrated that adding three longitudinal layers of relatively low diameter bars over the depth of a specimen $1000 \mathrm{~mm}$ deep (this additional reinforcement did not significantly change the reinforcement ratio), increases the shear strength of about $50 \%$, doubled the

On Shear Behavior of structural elements made of steel fiber reinforced concrete-PhD thesis 
ductility and made possible the formation of a distributed crack pattern, without an early localization of any shear critical crack (Fig.B.2).
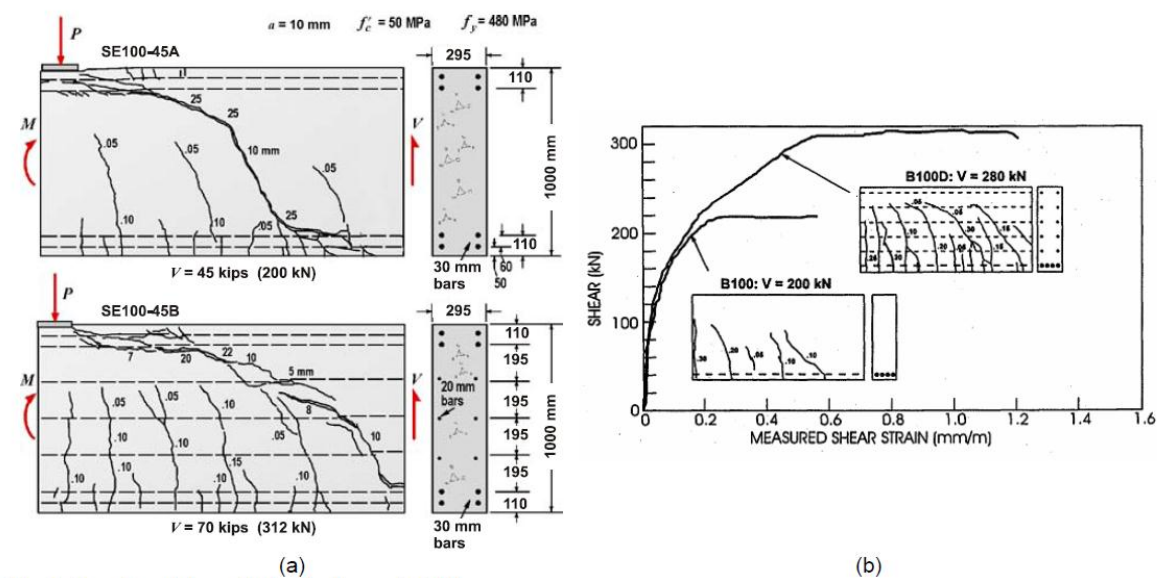

Fig.B. 2 Experimental results by Kuchma et al. [9]

Fibers act in providing a member with exactly the same effect; therefore, it seems correct modeling the shear contribution of fibers as a modifier of the longitudinal reinforcement ratio (as done also by Imam et Al. [10]) throughout a factor that includes the toughness properties of fibers. So, Minelli's formula models fibers contribution to shear as a part included in the concrete contribution, without using an independent contribution added to the concrete [11].

This was done aiming at a more representative modeling of the actual effect of fibers, which basically make the concrete matrix tougher after cracking, improving both the transfer of residual tensile stresses and the aggregate interlock (keeping cracks smaller) [2].

As the longitudinal reinforcement ratio goes up, the contribution of fibers significantly increases. This evidence was well modeled in the Minelli's model by including fibers as a modifier of the longitudinal reinforcement ratio [2].

\section{B.3.3 Comparison between RILEM and MC2010 formulas}

A comparison of 60 tests (43 from the RILEM database and 17 of the Brescia database), see Fig.B.3, shows that the proposed model agrees with experimental results, although they are always affected to an uncertainty closely linked to mechanisms dependent on the tensile strength of the concrete. RILEM's model gives good results compared with experimental results, but it is predominantly empirical and does not properly model real 
structural behavior of FRC beams without shear reinforcement. Note that RILEM's model defines a separate contribution for fibers, to be added to that of concrete and that of transverse reinforcement, if provided. Predictions of Minelli's formulation are quite satisfactory for all beams, even though the fitting results are less promising when dealing with high strength concrete specimens or prestressed members. A similar response is seen for the RILEM model, which turned out to be a little more refined for small size elements than for deep beams [2].

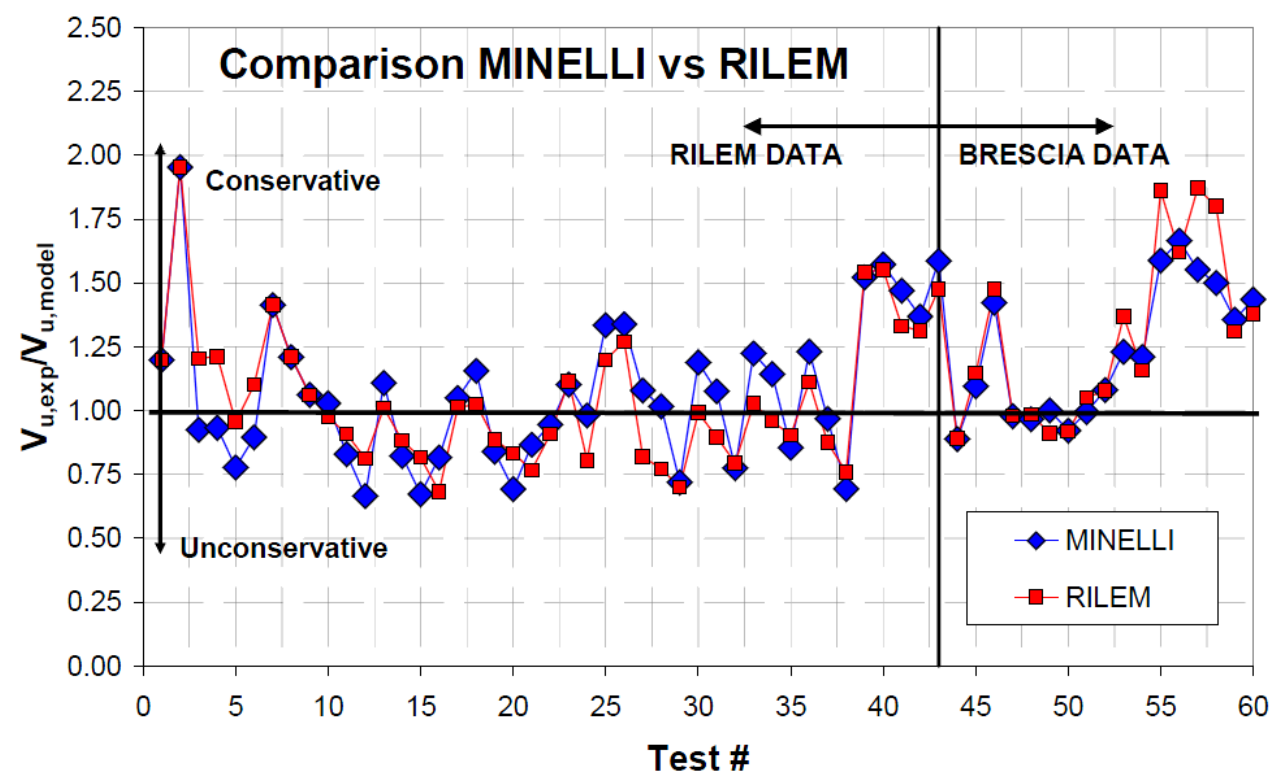

Fig.B. 3 Comparison between the predictions of RILEM's and MINELLI's models against 60 experiments belonging to RILEM or BRESCIA database [2]

\section{B.3.4 Comments to other models}

\section{B.3.4.1 Comments to Imam's model}

The model of Imam does not separate the contribution of the concrete, the stirrups and the fibers into 3 separate terms, but instead it combines the actions of the concrete and the fibers. The contribution of stirrups is calculated in the same way as RILEM [4].

The parameter $\omega$ symbolizes the combined effect of longitudinal reinforcement and steel fibers. It is very logical to consider the contribution of longitudinal reinforcement and steel fiber reinforcement together, since both parameters limit the width of the shear cracks [10]; [12].

On Shear Behavior of structural elements made of steel fiber reinforced concrete-PhD thesis 
From the results is observed that the contribution of fibers is slightly overestimated. In the definition of $\omega$ is implicit that the higher reinforcement ratios also enlarge the contribution of the fibers. The predicted contribution of the stirrups is underestimated. A rather large advantage of the model of Imam is that contrary to the RILEM method no bending tests on prisms have to be executed to determine the postcracking behavior of the steel fiber concrete. However, in this method the efficiency of the fibers is represented by its geometrical characteristics, i.e. fiber length and fiber diameter, and fiber volume fraction. The model of Imam provides rather good predictions of the ultimate shear capacity, the coefficient of variation is significantly smaller than for the RILEM2 method. The model also has the benefit that there is no need for beams test to determine the postcracking equivalent flexural tensile strength $f_{e q, 2}$ or $f_{e q, 3}$ [4].

\section{B.3.4.2 Comments to Dinh et Al's equation}

Recently, Dinh et Al. have proposed an equation to calculate shear in FRC beams [13]. The theoretical shear is calculated as the sum of fibers and compression region contribution:

$$
V_{n}=V_{c C}+V_{F R C}
$$

$\mathrm{V}_{\mathrm{cc}}=$ shear force across the compression region (see Fig.B.4);

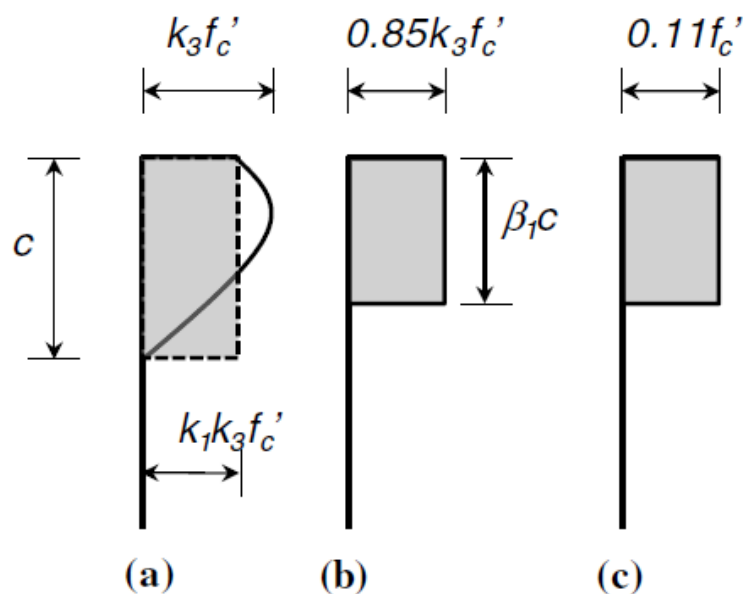

Fig.B. 4 Modelling of beam compression zone: (a) actual versus average compressive stress; (b) Whitney's stress block; (c) assumed shear stress distribution in compression zone [13]

$\mathrm{V}_{\mathrm{FRC}}=$ vertical component of the diagonal tension resistance provided by the fibers (Fig.B.5) 


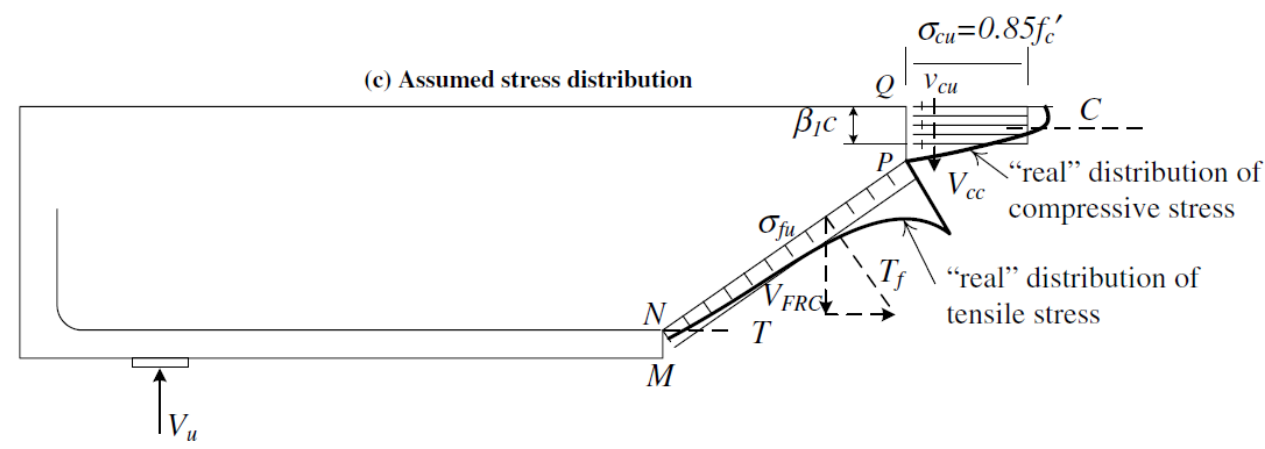

Fig.B. 5 Assumed failure mode and internal stresses in FRC beams [13]

$$
\begin{gathered}
V_{c c}=0.11 f_{c}^{\prime} \beta_{1} c b=0.11 \frac{T_{s}}{0.85}=0.13 A_{s} f_{y} \\
V_{F R C}=\left(\sigma_{t}\right)_{\text {avg }} b(d-c) \operatorname{cotan} \alpha
\end{gathered}
$$

For simplicity and conservatism, the use of $\alpha=45^{\circ}$ is recommended.

The $\sigma_{\mathrm{t}, \text { avg }}$ is determined from ASTM 1609 tests (Fig.B.6).

$$
\begin{aligned}
M & =T\left[h-k_{2}(h-c)-\frac{c}{2}\right] \\
& =\left(\sigma_{t}\right)_{\text {avg }}(h-c) b\left[h-k_{2}(h-c)-\frac{c}{2}\right]
\end{aligned}
$$
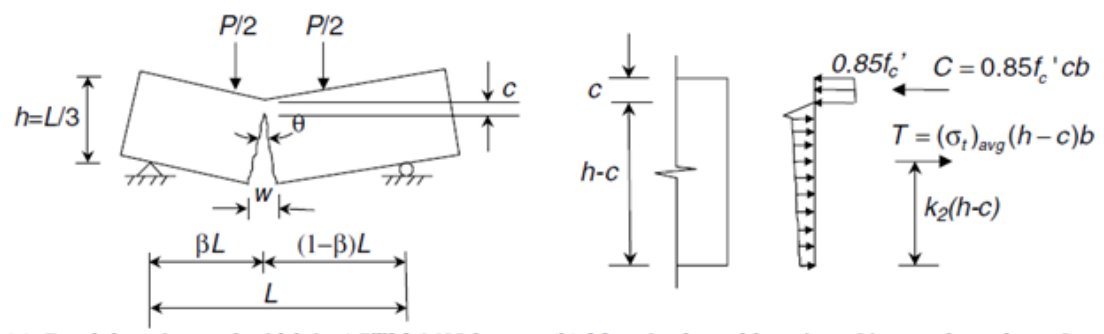

(a) Crack location and width in ASTM 1609 beam (b) Magnitude and location of internal resultant forces

Fig.B. 6 Derivation of uniform tensile stress versus crack width relationship from four-point bending tests [13]

$$
\left(\sigma_{t}\right)_{\text {avg }}=\frac{2 M}{(h-c) b h} \approx \frac{2 M}{0.9 b h^{2}} t
$$

where:

On Shear Behavior of structural elements made of steel fiber reinforced concrete - PhD thesis 


$$
c=\frac{2 M}{0.85 f_{c}^{\prime} b h}
$$

Because no data were available with regard to flexural performance of the FRC except for the beams tested in [13], the following expression was used to evaluate $\sigma_{t, \text { avg }}$ (in MPa), on the basis of results from ASTM 1609 tests performed on the materials used in this research:

Therefore:

$$
\left(\sigma_{t}\right)_{a v g}=0.8 \cdot 1.5 \cdot\left(\frac{V_{f}}{0.0075}\right)^{1 / 4}[M P a]
$$

- The shear strength of steel FRC beams can be reasonably estimated assuming the beam shear strength is provided by shear resisted over the compression zone and tension resisted by fibers bridging diagonal cracks, neglecting any contribution from aggregate interlock and dowel action.

- The average FRC tensile stress across the critical diagonal crack at beam shear failure can be estimated on the basis of an equivalent bending strength obtained from ASTM 1609 four-point bending tests. The use of an equivalent bending strength at a deflection equal to $1 / 24$ of the fiber length, compared to a crack width equal to $5 \%$ of the fiber length, led to reasonable shear strength predictions in the test beams.

\section{B.3.4.3 Comments to Casanova's equation}

In the Casanova shear model [14] the contribution of the steel fiber concrete to the shear capacity is based on the average pot-cracking residual strength, $\sigma_{p}(w)$, of the fiber concrete. This model assumes that a critical diagonal crack has formed and led to a block mechanism, see Figure B.7. The crack is assumed to be inclined 45 and the width varies linearly from a maximum at the level of the longitudinal reinforcement to zero at the bottom of the compression zone. By integrating the post-cracking tensile strength, $\sigma_{f}(w)$, along the crack and projecting it vertically, the average residual strength between $\boldsymbol{O}$ and $\boldsymbol{w}_{\boldsymbol{m}}$ is obtained, $\sigma_{\mathrm{p}}(w)$. 

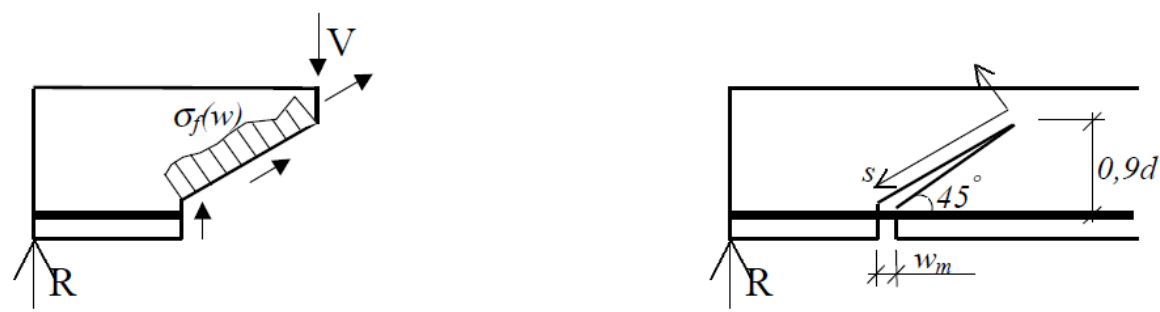

Fig.B. 7 Basic principles for estimating contribution of FRC to shear according to Casanova [14]

\section{B.3.4.4 Comments to Oh \& Lim's equation}

Oh \& Lim's model [15] is based in the following free body diagram of a part of shear span of a simply supported fiber reinforced concrete (FRC) beam.

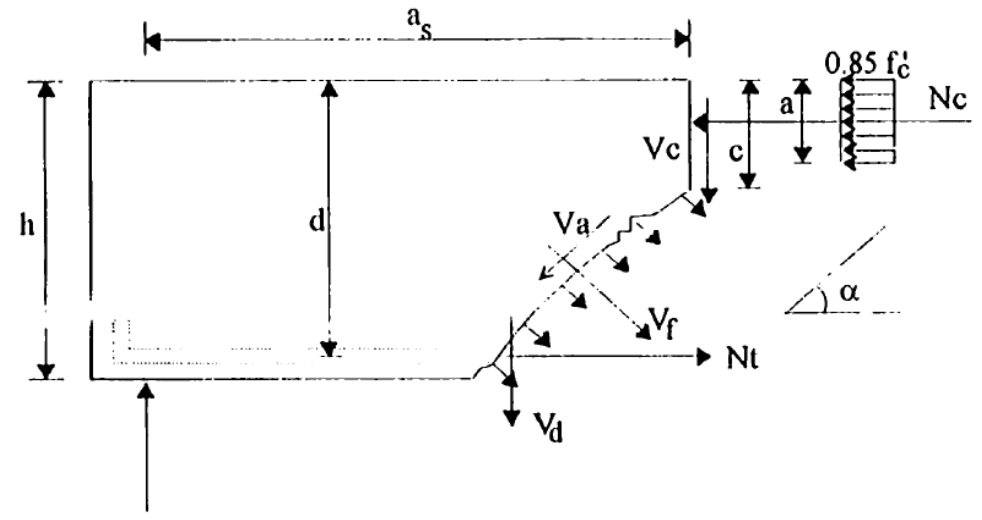

Fig.B. 8 Free body diagram of a part of shear span of a simply supported FRC beam [15]

In Fig.B.8 are showed the parameters involved in the model's formula $(c, a, d, h)$ and the following:

$V_{c}=$ shearing force across the compression zone resisted by the concrete; $V_{a}=$ aggregate interlocking force (vertical component); $V_{d}=$ dowel action force; $V_{f}=$ fiber pull out force along the inclined crack.

\section{B.3.4.5 Comments to Mansur's equation}

The proposed modeling of the stress-strain relationships of fiber concrete for the softened truss model accurately predicts not only of the ultimate shear strength but also the loaddeformation response for the entire range of loading [16].

On Shear Behavior of structural elements made of steel fiber reinforced concrete-PhD thesis 


\section{B.3.4.6 Comparison between RILEM and Imam's model}

Beams have been compared with calculated values according to two different empirical models: RILEM and Imam's model. It can be concluded that the contribution of the stirrups is underestimated. RILEM seems to be a conservative approach and can be considered as quite safe. The influence of small shear span to depth ratios is not well implemented. Also the interaction between steel fibers and longitudinal reinforcement is not taken into account [4]. The revised model of Imam provides rather good predictions of the ultimate shear capacity, the coefficient of variation is significantly smaller than for the RILEM. The model also has the benefit that there is no need for beam tests to determine the postcracking equivalent flexural tensile strength $\mathrm{f}_{\text {eq,2 }}$ or $\mathrm{f}_{\mathrm{eq}, 3}$ [4].

\section{B.3.4.7 Comments to other models}

It seems (Figure B.9) as if the Gustaffson \& Noghabai's formulas tend to underestimate the shear capacities of the smaller beams of series $S$ (small size beams), make fairly good predictions for beams in series $M$ (medium size beams) and slightly overestimate the capacities of the largest beams of series $L$ (large size beams). This development is quite dangerous considering that beams with depths of up to $1000 \mathrm{~mm}$ and above are frequently used in design. The best predictions were obtained by the Imam formulation [12].

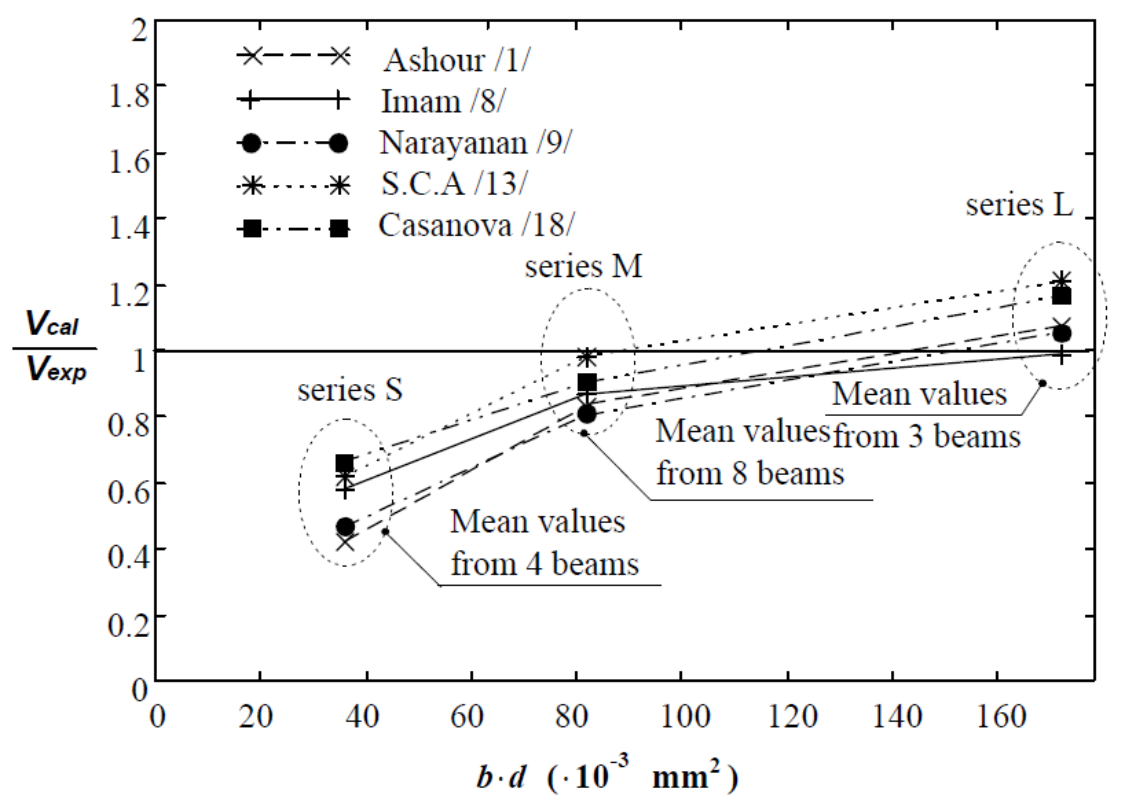

Fig.B. 9 Ratio of calculated, $v_{c a l}$, over experimental, $v_{\text {exp }}$, shear force as a function of the effective shear area, b·d, for some design formulations [1] 


\section{B.4 Analysis of failure modes}

The types of failure modes are strongly determined by the a/d ratio of the beam tested. This concept was clearly explained in 1964 by Kani [17], then Kani's concept was updated to FRC by some Authors like Narayanan \& Darwish [18] and, Imam \& Vandewalle ( [10], [19]- [21]).

\section{B.4.1 Analysis of failure modes by Narayanan \& Darwish [18]}

In the FRC beams with $\mathbf{a} / \mathbf{d} \geq 3$ [18], diagonal inclined cracks had generally initiated in the shear span at a depth of approximately $2 / 3$ of the total depth of the beam. In some beams these cracks were observed to form in the shear span as an extension of a flexural crack, which then bent over progressively until the inclined crack was formed. Following the formation of these cracks, a large proportion of the shear was transferred to the fibers, and, at this stage, the characteristic crinkling sound associated with the fibers being pulled out from the concrete can be heard. As the inclined cracks widened, the fiber pullout reached its final stages and the additional shear was carried by the concrete in the compression zone and by the dowel action. This was evidenced by the propagation of cracks, parallel to the beam axis, in the compression zone and along the main tensile reinforcement. These cracks continued to extend until either splitting (dowel) failure occurred or the compression zone failed, due to combined shear and compression (Fig.B.10-(a)).

On the other hand, in FRC beams with $a / d \leq 2.5$ [18], the first inclined cracks were observed in the shear span at approximately $2 / 3$ of the depth. These cracks extended diagonally toward the point of application of the load. Most of these specimens failed in accordance with the pattern typical of diagonal compression splitting, indicating thereby that the stresses along the diagonal had reached a maximum value in compression (see Type1, Fig.B.10-(b)). In some of the other beams, the inclined shear crack reached a slope when the available area of concrete in the vicinity of the point of application of the load became too small to resist the compression force and the beam failed by crouching (see Type 2, Fig.B.10-b). Finally, a number of specimens were observed to fail in flexural tension, which took place in the compression zone above the diagonal crack (see Type 3, Fig.B.10-(b)).

On Shear Behavior of structural elements made of steel fiber reinforced concrete - PhD thesis 

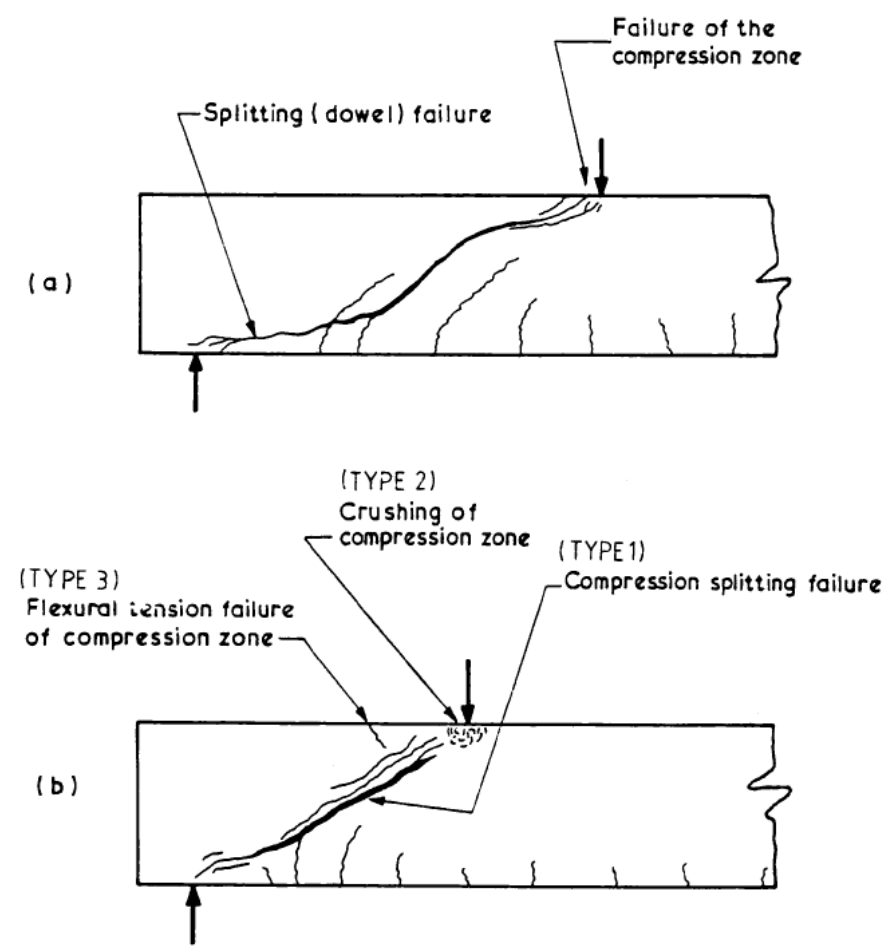

Fig.B. 10 (a) Patterns of shear failure in specimens with $a / d \geq 3.0$;

(b) patterns of shear failure in specimens with $\mathrm{a} / \mathrm{d} \leq \mathbf{2 . 5}$

\section{B.4.2 Analysis of failure modes by Imam \& Vandewalle [21]}

Inclusion of steel fibers in HSC beams without stirrups provides significant improvement of shear resistance and tends to increase the ultimate strength, $M_{u}$, in order to reach the nominal flexural capacity, $M_{f l}[10]$.

The ultimate capacity $\left(M_{u}\right)$ of a beam is strongly affected by the interaction of shear. When a beam without stirrups fails at $60 \%$ of its full flexural capacity $\left(M_{u}=60 \% M_{f l}\right)$, this means that it is just $40 \%$ short of the goal. The use of steel fibers is a possible solution to overcome this shortage since they are capable of increasing the beam strength up to its full flexural capacity $\left(M_{u}=100 \% \mathrm{Mfl}\right)$. The solid lines in Fig.B.11 present the border of the beam strength. This border consists of two parts. In the first part, steel fibers are not influential enough to increase the beam strength up to its full flexural capacity. Hence, in this part, $M_{u}<M_{f l}$ and shear failure is expected; in the second part, fibers are effective enough to provide a beam without stirrups with full flexural capacity and safe in shear 
$\left(M_{u}=M_{f l}\right)$. The point at which the two parts meet indicates the minimum percentage of fibers which is capable of increasing the beam strength up to $100 \% M_{f l}$ [21].

Fibre Volume, $V_{\mathrm{f}}(\%)$

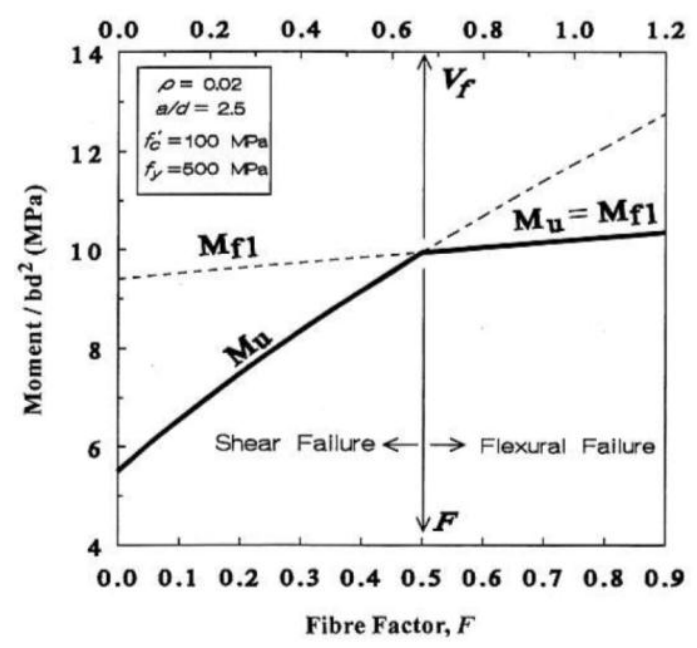

Fig.B.11 Fiber effect on both ultimate and nominal flexural moments (hooked fiber; aspect ratio=75), [21]

As $\rho$ increased and $F$ decreased, the reduction moment region (valley) deepened rapidly with a wider range of the two limiting values of $a / d$ (Fig.B.12 and B.13). The flexural moment $\left(M_{f l}\right)$ is directly proportional to the yield strength $\left(f_{y}\right)$, while $M_{u}$ is not influenced by the change of $f_{y}$ at all [21].

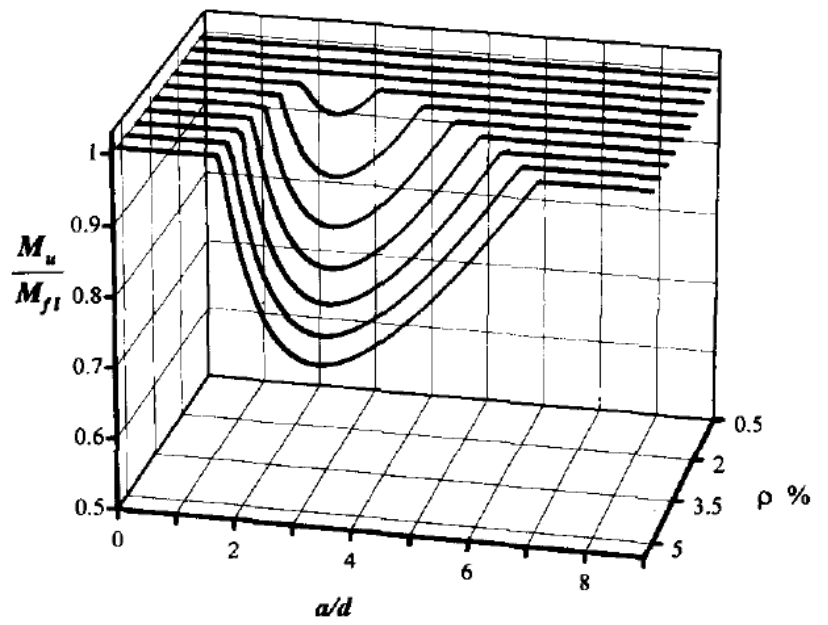

Fig.B.12 Combined effect of $a / d$ and $\rho$ on the relative flexural capacity $\left(f_{c}=110 \mathrm{MPa}, f_{y}=550 \mathrm{MPa}, \mathrm{F}=0.5625, d=300 \mathrm{~mm}, d_{a}=14 \mathrm{~mm}\right),[21]$ 


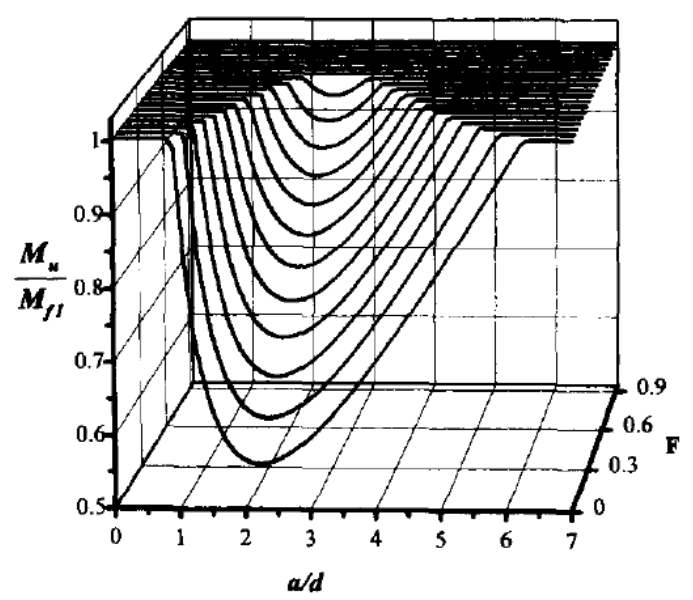

Fig.B.13 Combined effect of $a / d$ and $F$ on the relative flexural capacity $\left(f_{c}=110 \mathrm{MPa}, f_{y}=550 \mathrm{MPa}, p=0.0187, d=300 \mathrm{~mm}, d_{a}=14 \mathrm{~mm}\right),[21]$

The failure mode of a beam without stirrups is significantly affected by the ratio $a / d$. The relation between $M_{u} / M_{f l}$ and $a / d$ (Figure B.14) shows two different values of $a / d$ for the same value of $M_{u} / M_{f l}$

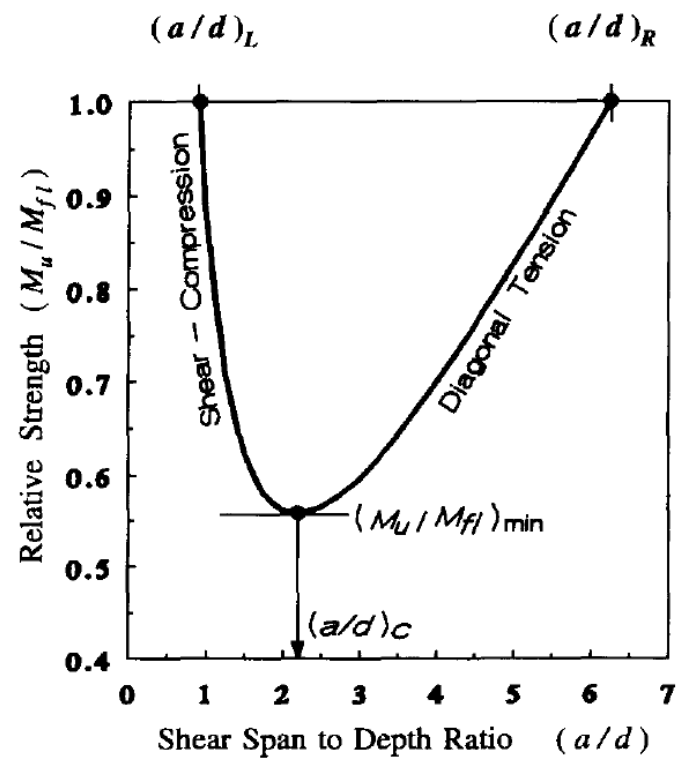

Fig.B.14 General relationship between $M_{u} / M_{f l}$ and $a / d$ 
Two different types of shear failure may be distinguished at the two different values of $a / d$. At the higher value of $a / d$, a flexural-shear crack initiates near the tip of an existing flexural crack in the shear span. With increasing applied load, the inclined crack propagates simultaneously in two directions: towards the load point and towards the support along the tensile reinforcement. The crack continues to propagate until the beam becomes unable to sustain further load. The failure is sudden and may cause separation of a large part of the shear span form the beam. This mode of failure is identified as diagonal-tension (DT). Whereas, at the lower value of $a / d$, the arch action is dominant and provides more load capacity for the beam in comparison with the higher $a / d$ value. The failure of this beam mainly occurs as a result of either concrete crushing above the upper end of a flexural-shear crack or splitting of concrete around the inclined crack itself. This failure mode is usually termed as shear-compression (SC). In both DT and SC failure modes, which have been frequently observed, the beam fails before its full flexural capacity is developed. At the minimum point $\left(M_{u} / M_{f l}\right)_{\min }=11.12 \cdot \omega^{0.2} \cdot \mathrm{f}_{\mathrm{c}}^{-0.176}$ becomes difficult to distinguish DT form SC failures. Fenwick et Al. [22] have pointed out the existence of a critical a/d ratio which separates beams that sustain further loading after diagonal cracking from those that fail at diagonal cracking.

\section{B.4.3 Analysis of failure modes by Brite-Euram [23]}

After shear tests in rectangular reinforced beams with different amounts of stirrups and fibers (Series 1 of Brite/Euram project 97-4163: Subtask 4.2: Trial Beams in Shear [23]) it must be highlighted, that the beams with steel fibers shows a more ductile failure than plain concrete beams. Further for the beams of Series 1 difference in the failure mechanism between beams without fibers and with fibers were observed (Fig.B.15). After the crack, which leads to the failure, started, the further crack propagation occurred in different ways. The course of the crack propagation was smoother for the beams with fibers. Further the time dependent crack propagation in the region of the uncontrolled crack propagation (Fig.B.15) could be followed for the beams with fibers while this was not possible for the beams without fibers. For the beams without fibers, the last step before the compression zone was chopped through, the crack propagation grows in a sudden way and it was not possible to distinguish between the region of the uncontrolled crack propagation and the region where the compression zone was chopped through [7].

On Shear Behavior of structural elements made of steel fiber reinforced concrete - PhD thesis 


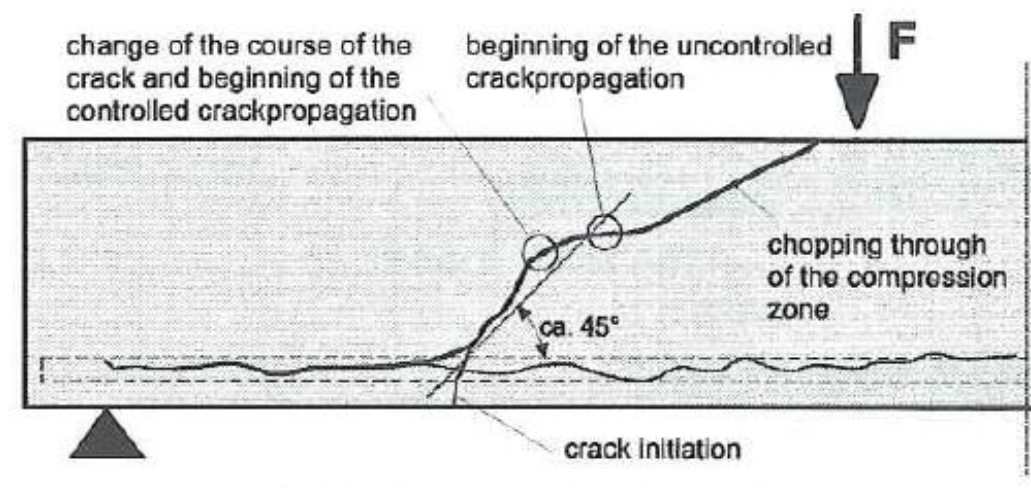

\section{beam without steel fibers}

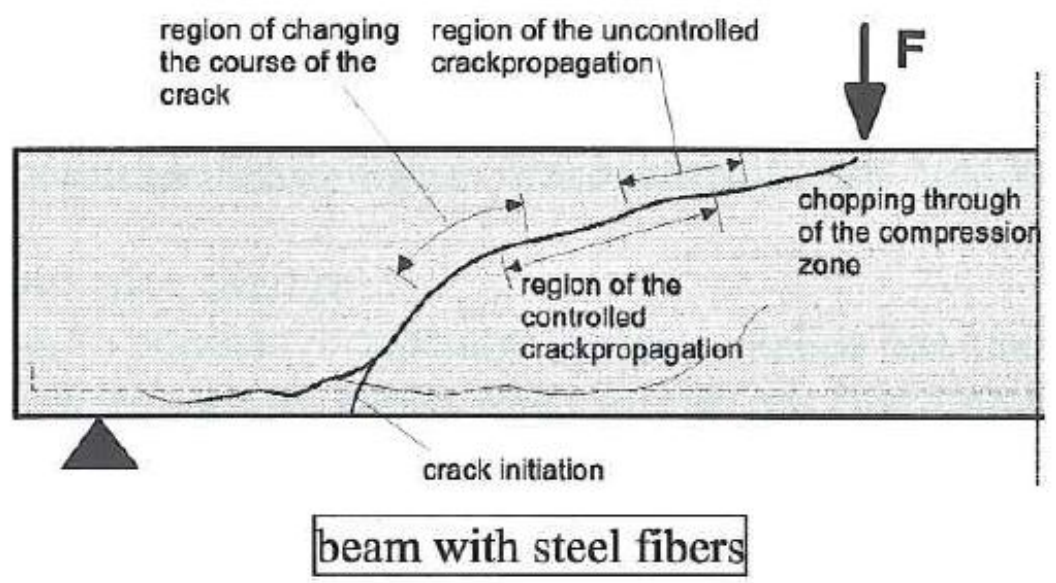

Fig.B.15 Failure mechanism observed at beams of Series 1 without stirrups [24]

\section{B.4.4 Analysis of failure modes by Campione [25]}

Results relative to the research of Campione et Al. [25] have shown that in the case of beams without fibers and stirrups, brittle and sudden failure in shear occurs, while if stirrups are added, shear failure is attained but higher strength and residual strength are observed. By adding fibers, shear strength increases up to when a flexural failure is reached and more ductile behavior as well as a higher residual strength is observed. 
Moreover, during the tests, ultimate deflection is reached when failure of stirrups in tension is observed and residual strength drops to zero values; the addition of fibers delays the failure point, ensuring higher ultimate deflections [26].

\section{B.4.5 Analysis of failure modes by Dinh, Parra-Montesinos \& Wight}

Different failure modes were observed in FRC beams [13]: in Fig.B.16-a and B.16-b, several diagonal cracks were observed in the FRC beams prior to failure. On the other hand, the regular concrete beams without stirrup reinforcement failed soon after the first diagonal crack formed. Once diagonal cracks formed in the FRC beams, the presence of fibers allowed the transfer of tension across these cracks, controlling their opening and helping maintain aggregate interlock [13].

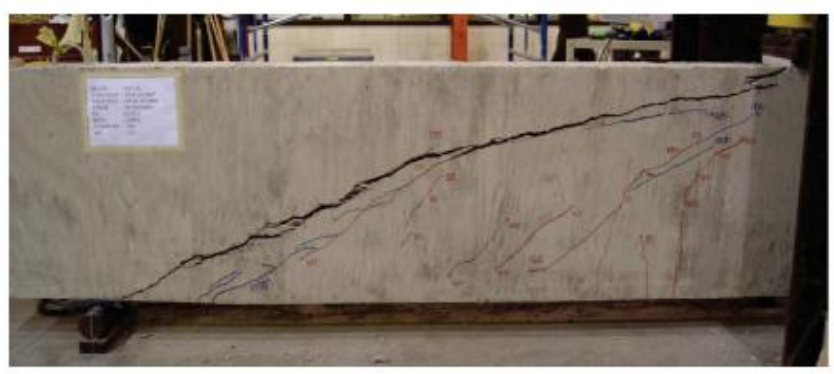

(a) Diagonal tension failure in FRC beam

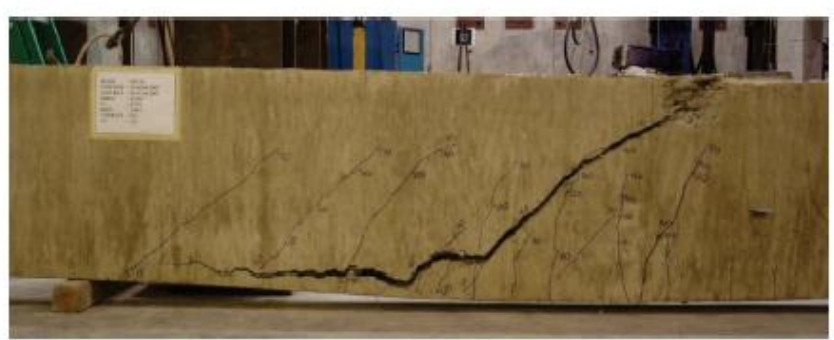

(b) Shear compression failure in FRC beam

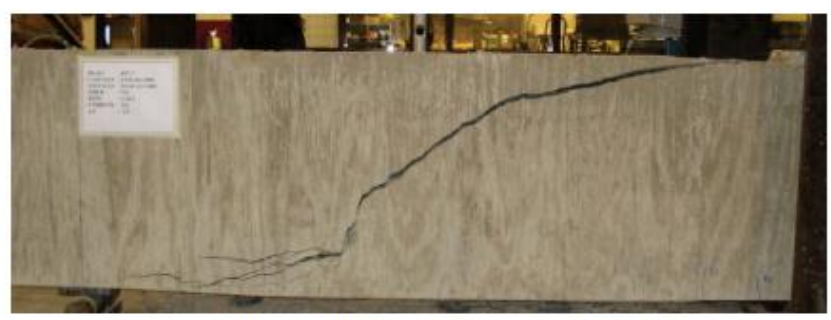

(c) Diagonal tension failure in $\mathrm{RC}$ beam without stirrups

Fig.B.16 Cracking pattern and failure mode in test specimens [13]

On Shear Behavior of structural elements made of steel fiber reinforced concrete - PhD thesis 
Three types of shear failures were observed: 1) diagonal tension; 2) a combination of diagonal tension and shear-tension; and 3) a combination of shear-compression and shear-tension. For a diagonal tension failure, the opening of the critical inclined crack occurred in the beam middepth region and propagated toward both the reinforcement level and the compression region. At failure, the critical crack extended through the beam compression zone without causing crushing of the concrete. When combined with a shear-tension failure, the critical diagonal crack propagated along the longitudinal reinforcement toward the support. The failure mode was a combination of shearcompression and shear-tension failures, the widening of the critical crack started at the reinforcement level and extended up, toward the loading point. Beam failure was triggered by the crushing of the concrete in the beam compression zone adjacent to the loading point, accompanied by a significant splitting along the top layer of longitudinal tension reinforcement. The fact that two different types of shear failures occurred in beams of the same pair is a clear indication of the impossibility of predicting one type of shear failure for a given beam [27].

\section{B.4.6 Analysis of failure modes by other authors}

Khuntia et Al. [27] ensured that four modes of failure of reinforced fiber HSC beams are clearly distinguished as diagonal tension, shear compression, shear flexural, and flexural failure.

Padmarajaiah et Al. [28] ensured that fully prestressed beams having no fiber or full depth fiber over full length, even with an a/d ratio less than 2.5 failed in flexure-shear mode. Beams with $a / d$ ratio reduced from 2.35 (in fully prestressed beams) to 1.98 in partially prestressed beams having fiber over the full length failed in diagonal tension. But when the fibers were provided only in the shear span, even though the $a / d$ ratio was less than 2.5 , the beams failed in a flexure mode indicating that fiber inclusion enhanced the shear strength. Thus, the presence of fibers alters the value of the $a / d$ ratio (critical $a / d$ ratio) dividing the flexure and shear critical failure mode.

\section{B.5 References}

[1] Gustafsson and Noghabai, "Steel fibers as shear reinforcement in high strength concrete beams," International Journal of Nordic Concrete Research, no. 22, 1999.

[2] Minelli and Plizzari, "Steel fibers as shear reinforcement for beams," in Proceedings of the Second fib Congress, Naples, Italy, 2006. 
[3] RILEM, "RILEM TC 162-TDF: Test and design methods for steel fiber reinforced concrete: Recommendations, Final Recommendations," 2002.

[4] Dupont and Vandewalle, "Shear capacity of concrete beams containing longitudinal reinforcement and steel fibers," ACl Special Publication, vol. 216, pp. 79-94, 2003.

[5] Mirsayah and Banthia, "Shear strength of steel fiber-reinforced concrete," $\mathrm{ACl}$ Materials Journal, vol. 99, no. 5, pp. 473-479, 2002.

[6] Majdzadeh, Soleimani and Banthia, "Shear strength of reinforced concrete beams with a fiber concrete matrix," Canadian Journal of Civil Engineering, vol. 33, pp. 726734, 2006.

[7] Rosenbusch and Teutsch, "Shear Design with sigma-epsilon method," in Test and design methods for steel fibre reinforced concrete -Background and Experiences-. Proceedings of the RILEM TC 162-TDF Workshop, Schnütgen and Vandewalle, Eds., RILEM Publications, 2003.

[8] UNI-11039, Steel fiber reinforced concrete-Part I: Definitions, classification, specification and conformity-Part II: Test method for measuring first crack strength and ductility indeces, Italian Board for Standardization, 2003.

[9] Kuchma, Végh, Simionopoulos, Stanik and Collins, "The influence of concrete strength, distribution of longitudinal reinforcement, and member size, on the shear strength of reinforced concrete beams," in Concrete Tension and Size Effect, CEB Bulletin 237, Lausanne, 1997, p. 258 pp..

[10] Imam, Vandewalle and Mortelmans, "Shear-moment analysis of reinforced highstrength concrete beams containing steel fibers," Canadian Journal of Civil Engineering, vol. 22, pp. 462-470, 1995.

[11] Minelli and Plizzari, "Un nuovo modello analitico per il progetto a taglio di elementi in calcestruzzo fibrorinforzato privi di armatura trasversale (in italian)," in Atti del 24o Convegno Nazionale Giornate AICAP, Salerno, Italia, 2007.

[12] M. Imam, Shear-Moment interaction of steel fiber high strength concrete, PhD thesis, Leuven, Belgium: Katholieke Universiteit Leuven, 1995. 
[13] Dinh, Parra-Montesinos and Wight, "Shear strength model for steel fiber reinforced concrete beams without stirrup reinforcement," Journal of Structural Engineering ASCE, vol. 137, no. 10, pp. 1039-1051, 2011.

[14] Casanova, Bétons renforcés de fibres métalliques du matériu à la structure. Dissertation, Paris, France: Laboratoire Central de Ponts et Chaussées, 1996.

[15] Oh, Lim, Hong, Yoo and Chae, "Structural behavior of steel fiber reinforced concrete beams in shear," ACl Special Publication, vol. 182, pp. 9-27, 1999.

[16] Mansur and Ong, "Behavior of reinforced fiber concrete deep beams in shear," $\mathrm{ACl}$ Structural Journal, vol. 88, no. 1, pp. 98-105, 1991.

[17] Kani, "The riddle of shear failure and its solution," $A C l$ Journal, vol. 61, no. 4, pp. 441467, 1964.

[18] Narayanan and Darwish, "Use of steel fibers as shear reinforcement," ACl Structural Journal, vol. 84, pp. 216-227, 1987.

[19] Imam, Vandewalle and Mortelmans, "Shear capacity of steel fiber high-strength concrete beams," ACI Special Publication, vol. 149, pp. 227-241, 1994.

[20] Imam, Vandewalle, Mortelmans and V. Gemert, "Shear domain of fibre-reinforced high-strength concrete beams," Engineering Structures, vol. 19, no. 9, pp. 738-747, 1997.

[21] Fenwick and Paulay, "Mechanisms of shear resistance of concrete beams," Proceedings of the ASCE, vol. 94, no. 10, pp. 2325-2350, 1968.

[22] Rosenbusch, Teutsch and e. Al., Trial Beams in Shear, Final Report Sub Task 4.2, Brite Euram project 97-4163: Test and design methods for steel fibre reinforced concrete, 2002.

[23] RILEM-TC-162-TDF, Test and design methods for Steel Fibre Reinforced Concrete Background and Experiences, Bagneux, France: RILEM Publications s.a.r.I., 2003.

[24] Campione, Cucchiara and La-Mendola, "Role of fibers and stirrups on the experimental behavior of reinforced concrete beams and flexure and shear," in Proc., 
of Int. Conf. on Composites in Construction, Rende, Italy, 2003.

[25] Campione, "Simplified flexural response of steel fiber-reinforced concrete beams," Journal of Materials in Civil Engineering, ASCE, vol. 20, no. 4, pp. 283-293, 2008.

[26] Dinh, Parra-Montesinos and Wight, "Shear behavior of steel fiber-reinforced concrete beams without stirrup reinforcement," ACl Structural Journal, vol. 107, no. 5, pp. 597606, 2010.

[27] Imam and Vandewalle, "Role of fibers in controlling failure modes of high-strength concrete beams," ACI Special Publication, vol. 193, pp. 503-515, 2000.

[28] Padmarajaiah and Ramaswamy, "Behavior of fiber-reinforced prestressed and reinforced high-strength concrete beams subjected to shear," ACI Structural Journal, vol. 98, no. 5, pp. 752-761, 2001.

On Shear Behavior of structural elements made of steel fiber reinforced concrete-PhD thesis 


\section{APPENDIX C}

\section{SHEAR DATABASE}

A great database was created to better analyze parameters influencing shear behaviour of structural elements (see its analysis in Chapter 8). The database consisted mostly of beams, although 26 of the 215 elements were hollow core slabs (those which specimen ID initiates with I or II). Table C. 1 and Table C. 2 contain the main parameters used in Chapter 8. These parameters are:

- Source: The author or institution that provided the details of their beams. Structural members corresponding to "UPV" (all elements) and "BRESCIA" (beams: H500 PC, H500 FRC 50, H500 FRC 75, H1000 PC, H1000 FRC 50, H1000 FRC 75, H1500 PC, H1500 FRC 50, H1500 FRC 75, H300, H300 FRC 50, H300 FRC 75) are those produced and tested on the framework of this PhD thesis.

- Specimen ID: The Specimen Identity is the name of each item in its original source.

- $\quad$ a/d: Shear span-to-depth ratio.

- $\mathbf{d}(\mathbf{m m})$ : effective depth, in millimeters.

- $\quad \mathbf{f}_{\mathrm{c}}(\mathrm{MPa})$ : concrete cylinder compressive stress, in MPa.

- $f_{\mathrm{R} 3}(\mathrm{MPa})$ : residual flexural tensile strength corresponding to a $\mathrm{CMOD}=2.5 \mathrm{~mm}$.

- $\quad \rho(\%)$ : reinforcement ratio for longitudinal reinforcement, in percentage.

- $\quad I_{\mathbf{f}}(\mathbf{m m})$ : fiber length, in millimeters.

- $\quad \mathrm{L}_{\mathrm{f}} / \mathrm{d}_{\mathrm{f}}$ : fiber slenderness, equal to (fiber length/fiber diameter) ratio.

- $\mathbf{d}_{\mathrm{f}}(\mathbf{m m})$ : fiber diameter, in millimeters. 
- Amount of fibers $\left(\mathrm{kg} / \mathrm{m}^{3}\right)$ : amount of steel fibers, in $\mathrm{kg} / \mathrm{m}^{3}$.

- $\quad \mathbf{V}_{\mathbf{f}}(\%)$ : volume of fibers, in percentage.

- Fibers type: fibers are classified in two groups, those produced with normal strength, low carbon steel (L.C.), and those produced with high strength, high carbon steel (H.C.).

- $\quad \sigma_{\mathrm{c}}(\mathrm{MPa})$ : average stress acting on the concrete cross-section for an axial force due to prestressing actions.

- $\mathbf{A}_{\mathrm{sa}} / \mathbf{s}\left(\mathrm{cm}^{2} / \mathrm{m}\right)$ : transverse reinforcement area per unit length.

- Section: cross-section shape: Rectangular $\{R\}$ or Double $T\{T\}$.

Also, Table C. 1 and Table C. 2 report, for all the elements, their corresponding values of safety margins (SM), defined as the $V_{\text {test }} / V_{\text {theo }}$ ratio, where $V_{\text {test }}$ is the test shear value and $V_{\text {theo }}$ is the theoretical shear value calculated according to some international Design Codes: the Spanish Code EHE08 (EHE-08, 2008), the Model Code 2010 (MC2010, 2010) and RILEM guidelines (RILEM, 2003) applying all their limitations (see Introduction to Part III). Also, shear stresses $\left(v_{u}=V_{\text {test }} / b \cdot d\right)$, reinforcement type (stirrups and/or fibers) as well as the presence of prestressing stresses are included.

In Table C. 1 and Table C. 2 in $\rho$ column, bold italics indicate that $\rho>2 \%$, but the actual value is unknown and, in $f_{R 3}$ column, bold italics indicate that actually are equivalent strength values, evaluated as average residual stress in a range of crack opening $\left(f_{\text {eq }}(0.6-3)\right)$.

Estefanía Cuenca Asensio - ICITECH - Universitat Politècnica de València 


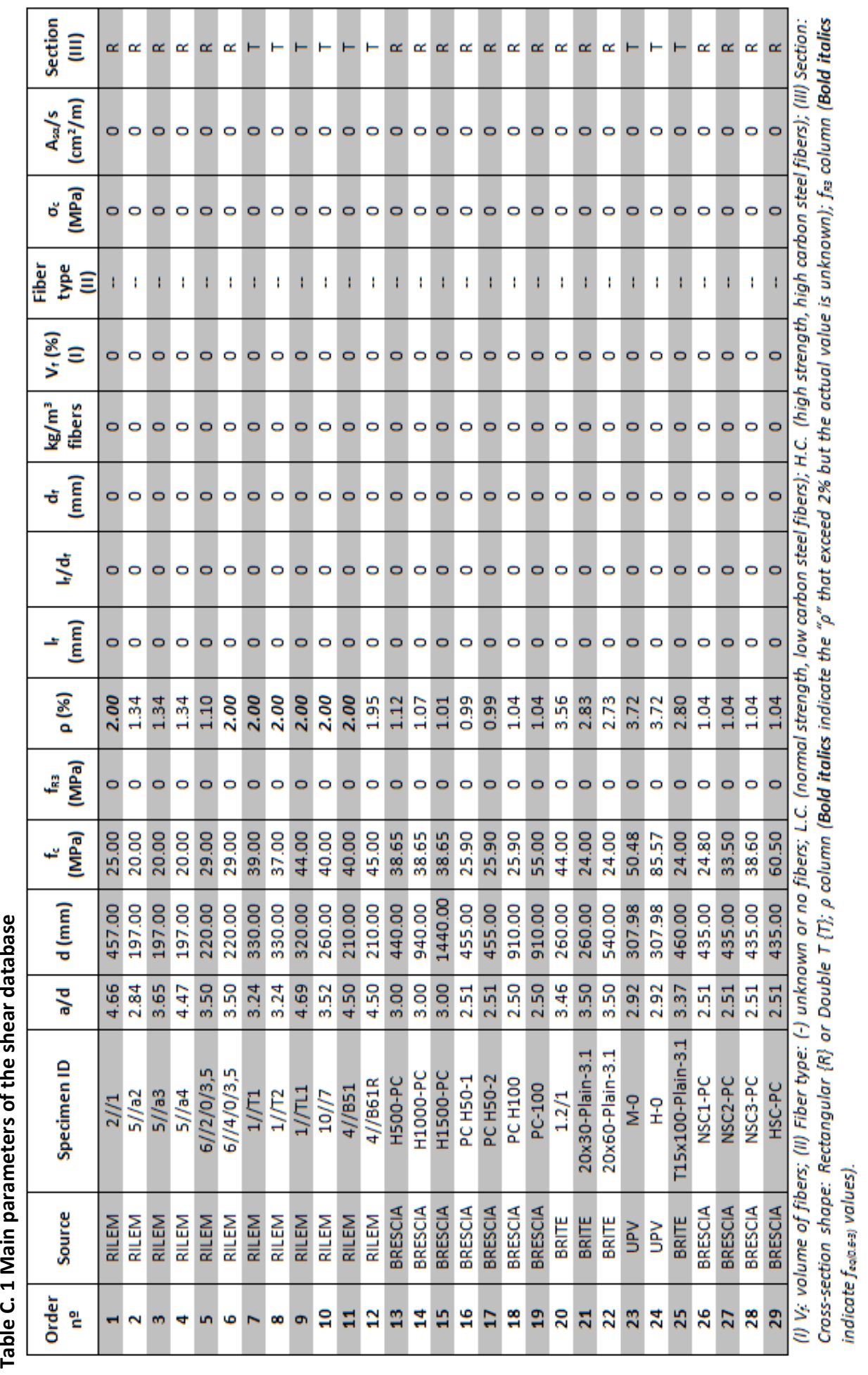




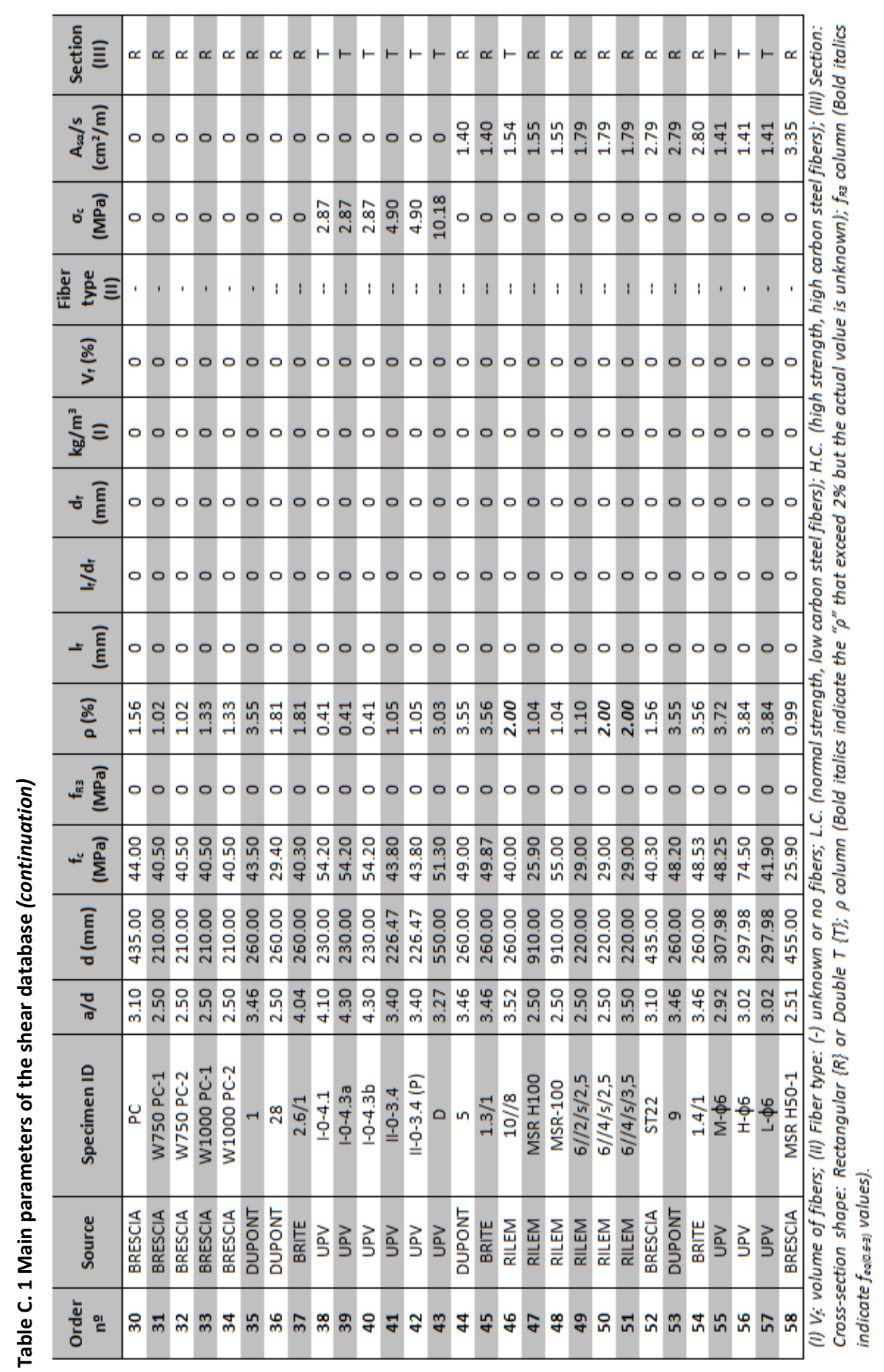




\begin{tabular}{|c|c|}
\hline 产 & $\alpha \vdash \vdash \vdash \vdash \vdash \alpha \propto \alpha \propto \alpha \alpha \vdash \vdash \alpha \alpha \alpha \alpha \alpha \alpha \propto \vdash \vdash \alpha \alpha$ \\
\hline 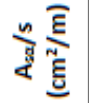 & 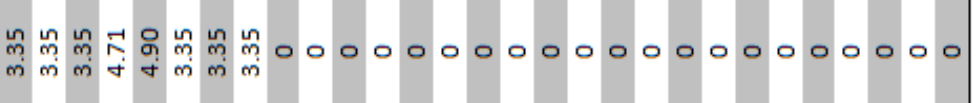 \\
\hline$\circ$ 离 & ○一○○䍗 \\
\hline & 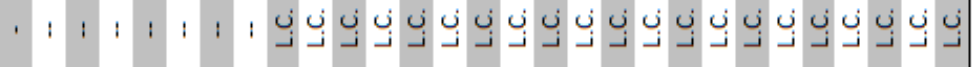 \\
\hline$\frac{\overline{0}}{5}$ & 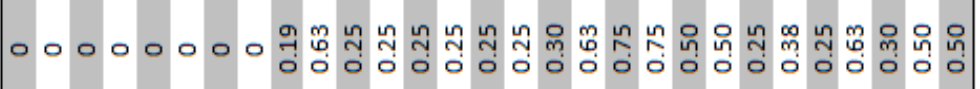 \\
\hline$\stackrel{m}{\xi} \equiv$ & 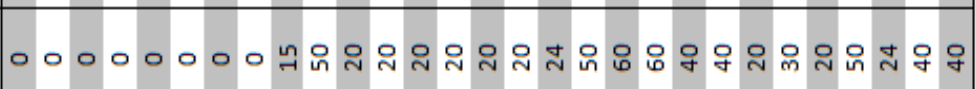 \\
\hline$\overline{\underline{\underline{E}}}$ & 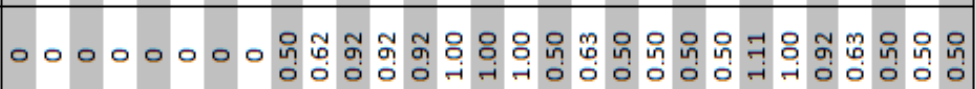 \\
\hline$\stackrel{2}{\Sigma}$ & 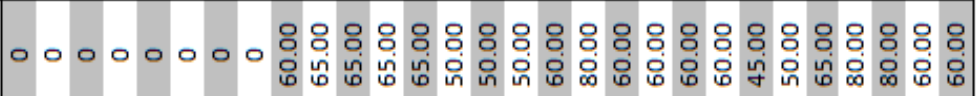 \\
\hline$=\overline{\underline{\varepsilon}}$ & 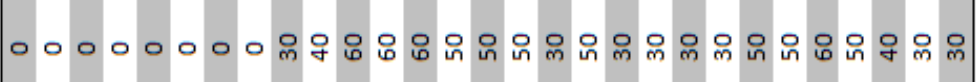 \\
\hline ळ & 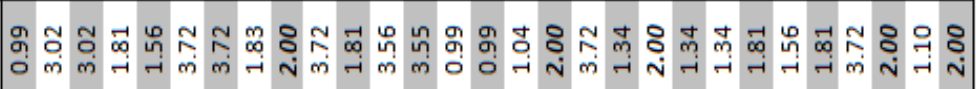 \\
\hline 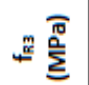 & 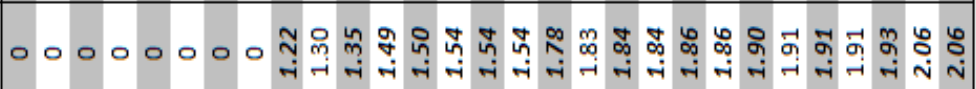 \\
\hline $4 \stackrel{\frac{\pi}{0}}{\underline{\Sigma}}$ & 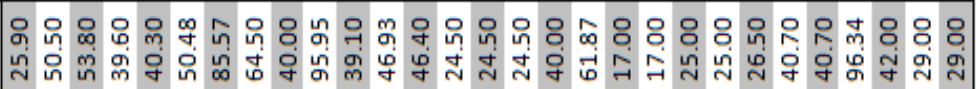 \\
\hline 高 & 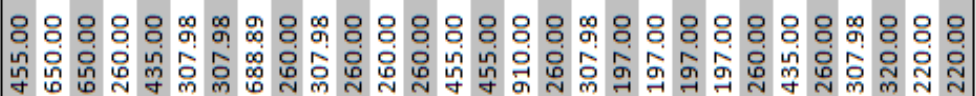 \\
\hline$\frac{\pi}{\pi}$ & 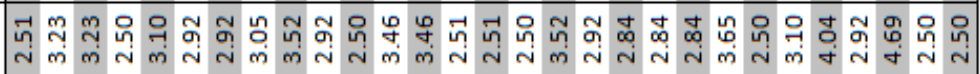 \\
\hline 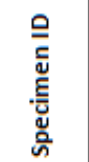 & 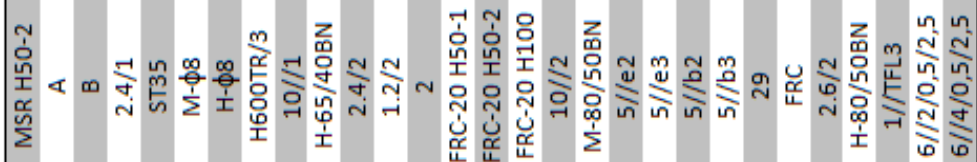 \\
\hline 气ัّ & 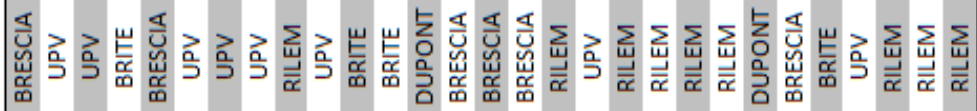 \\
\hline 害 읻 & 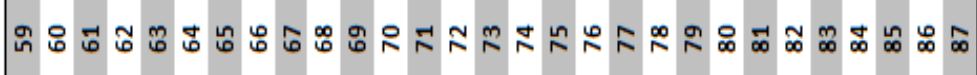 \\
\hline
\end{tabular}




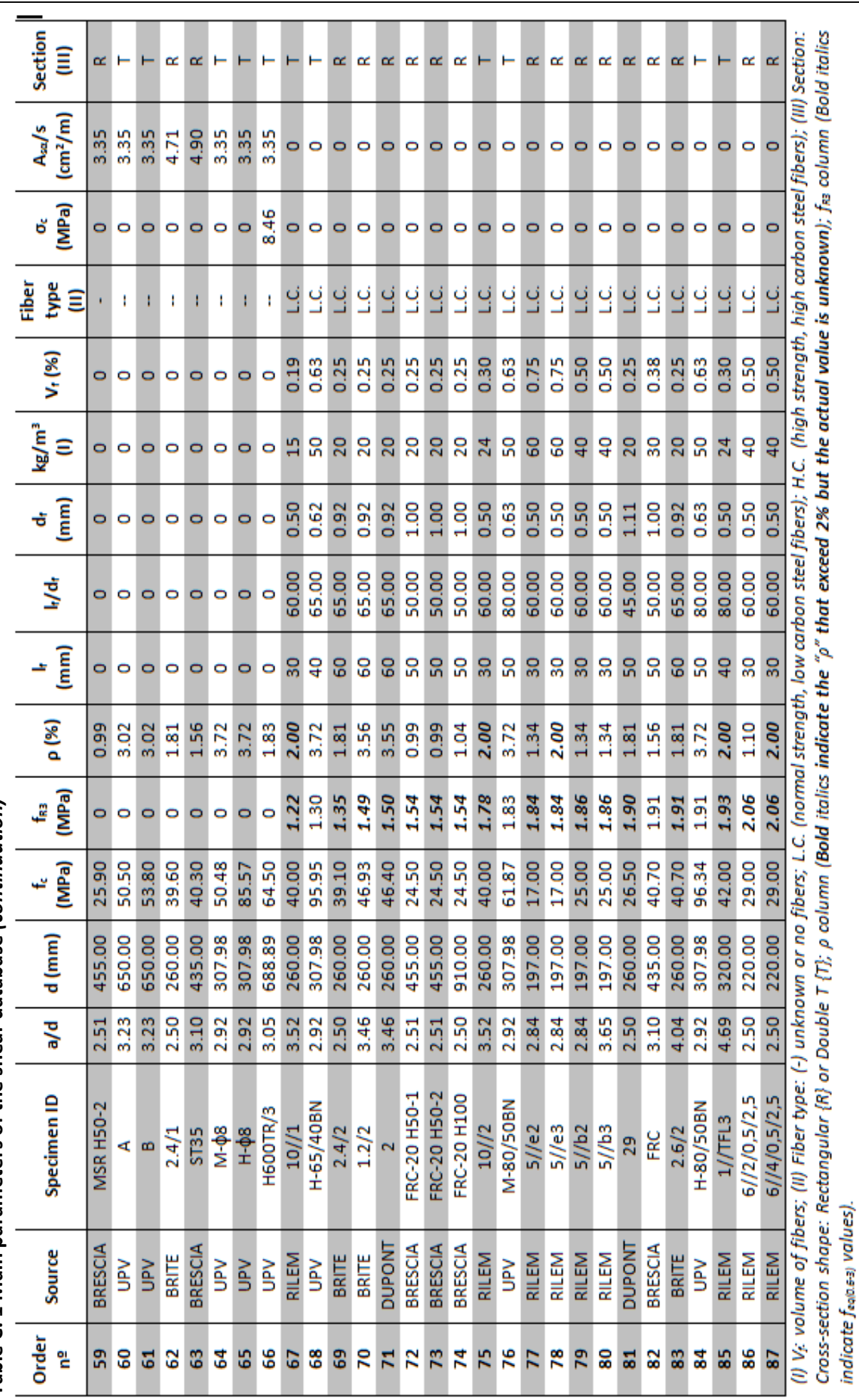




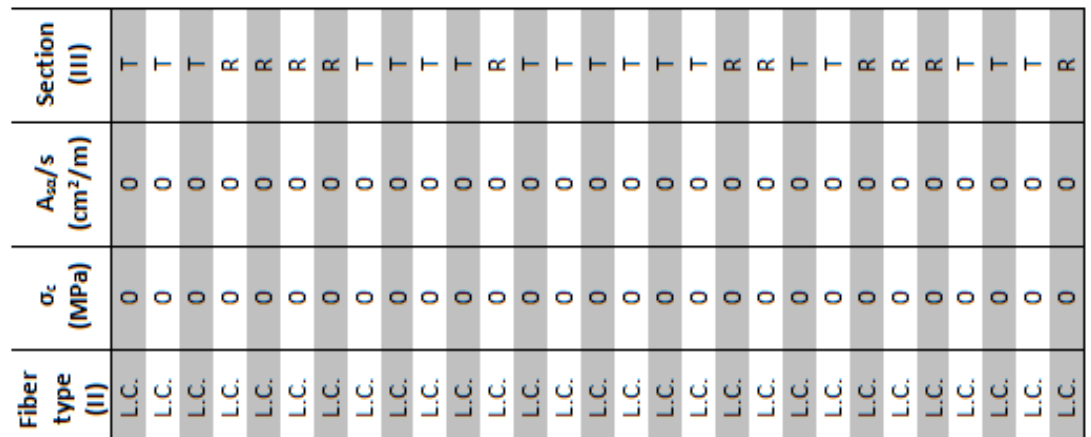

上诓

ฮำ

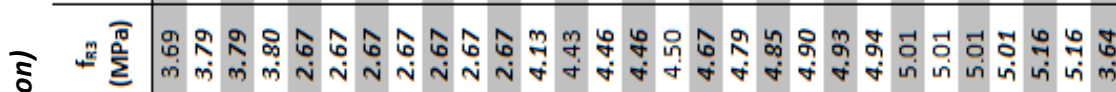

ब

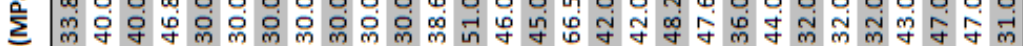
落

\begin{tabular}{|c|c|}
\hline $\begin{array}{l}\overline{\bar{E}} \\
\frac{\bar{E}}{\partial}\end{array}$ & 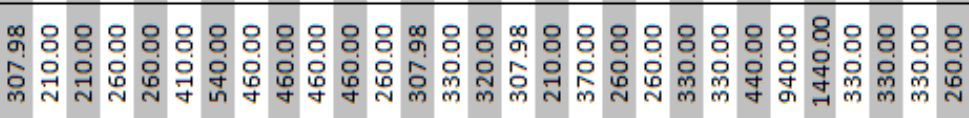 \\
\hline$\frac{\pi}{\pi}$ & 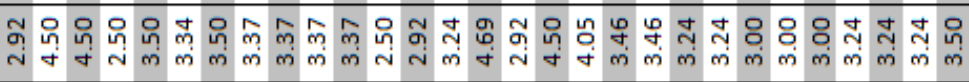 \\
\hline 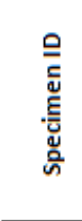 & 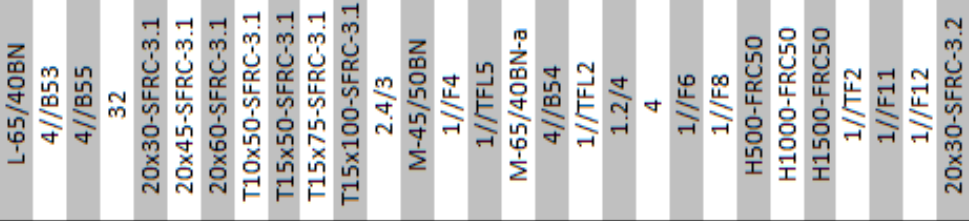 \\
\hline 总 & 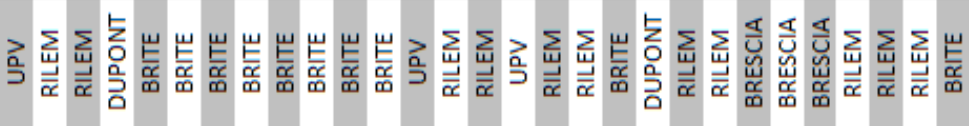 \\
\hline 密 잏 & 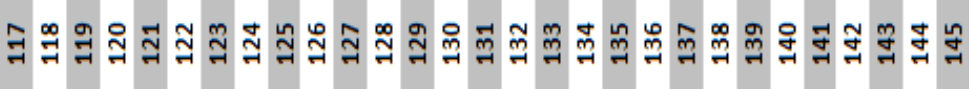 \\
\hline
\end{tabular}




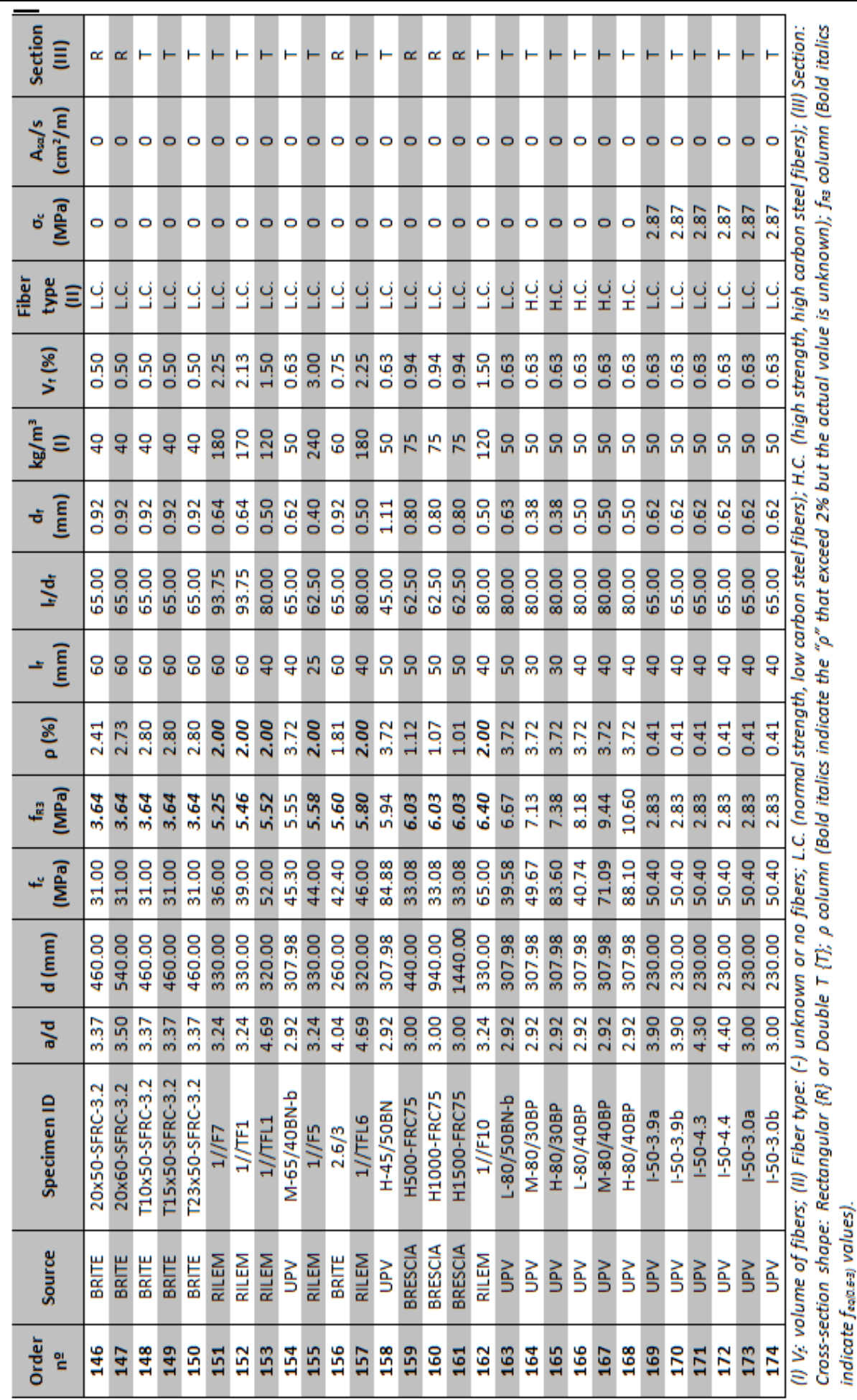




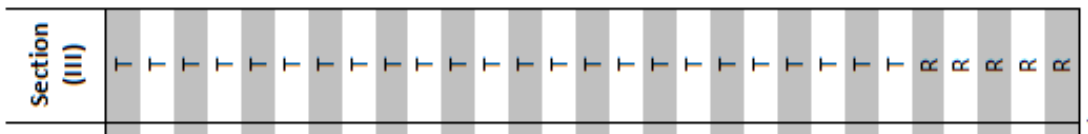

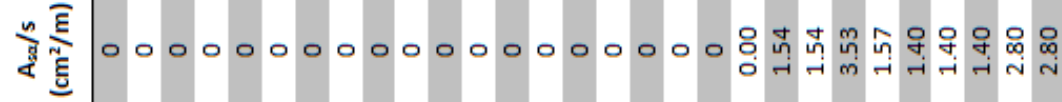

중

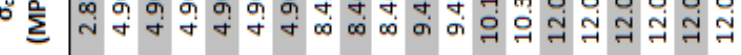

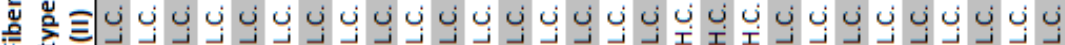

ฮ

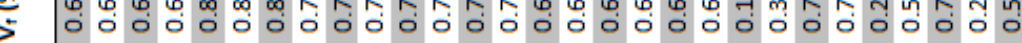

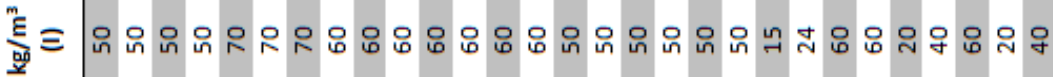

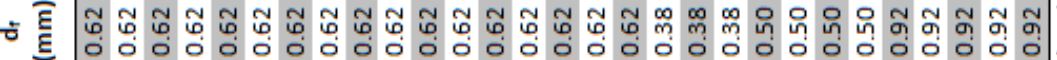

๖ ૬ ผ่

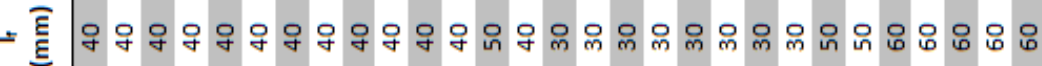

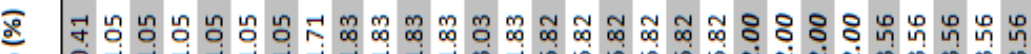

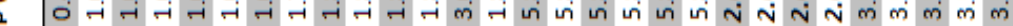

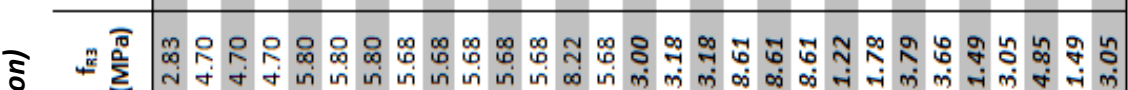
ก है

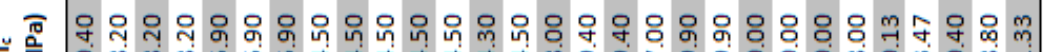
હ

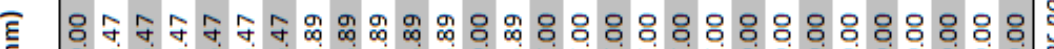

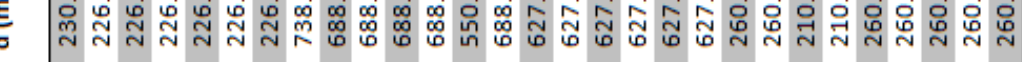

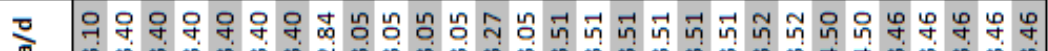

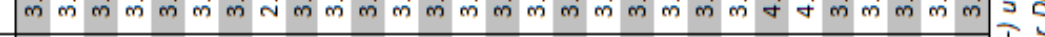

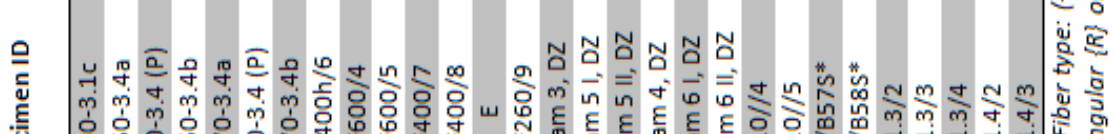

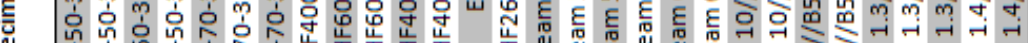

के

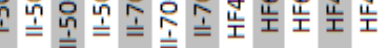

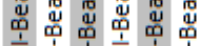

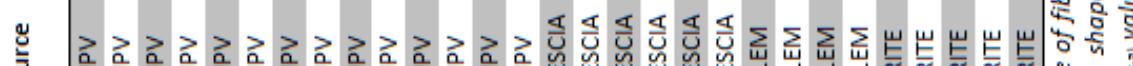

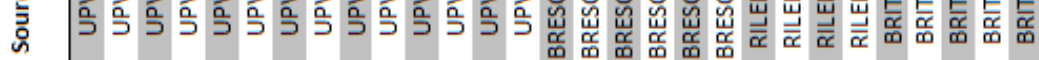
है

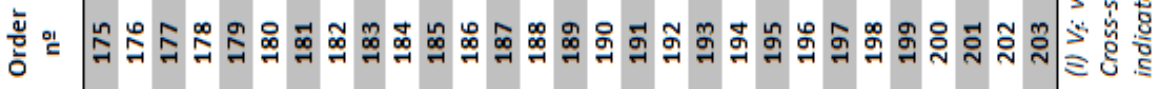




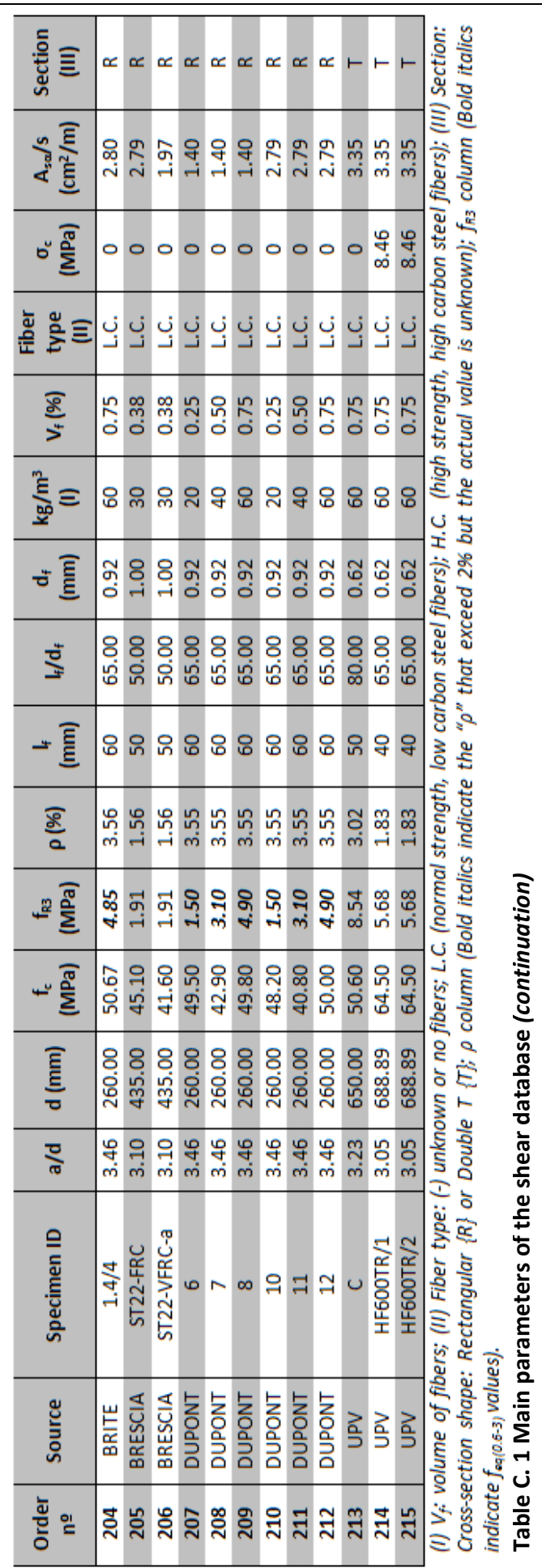




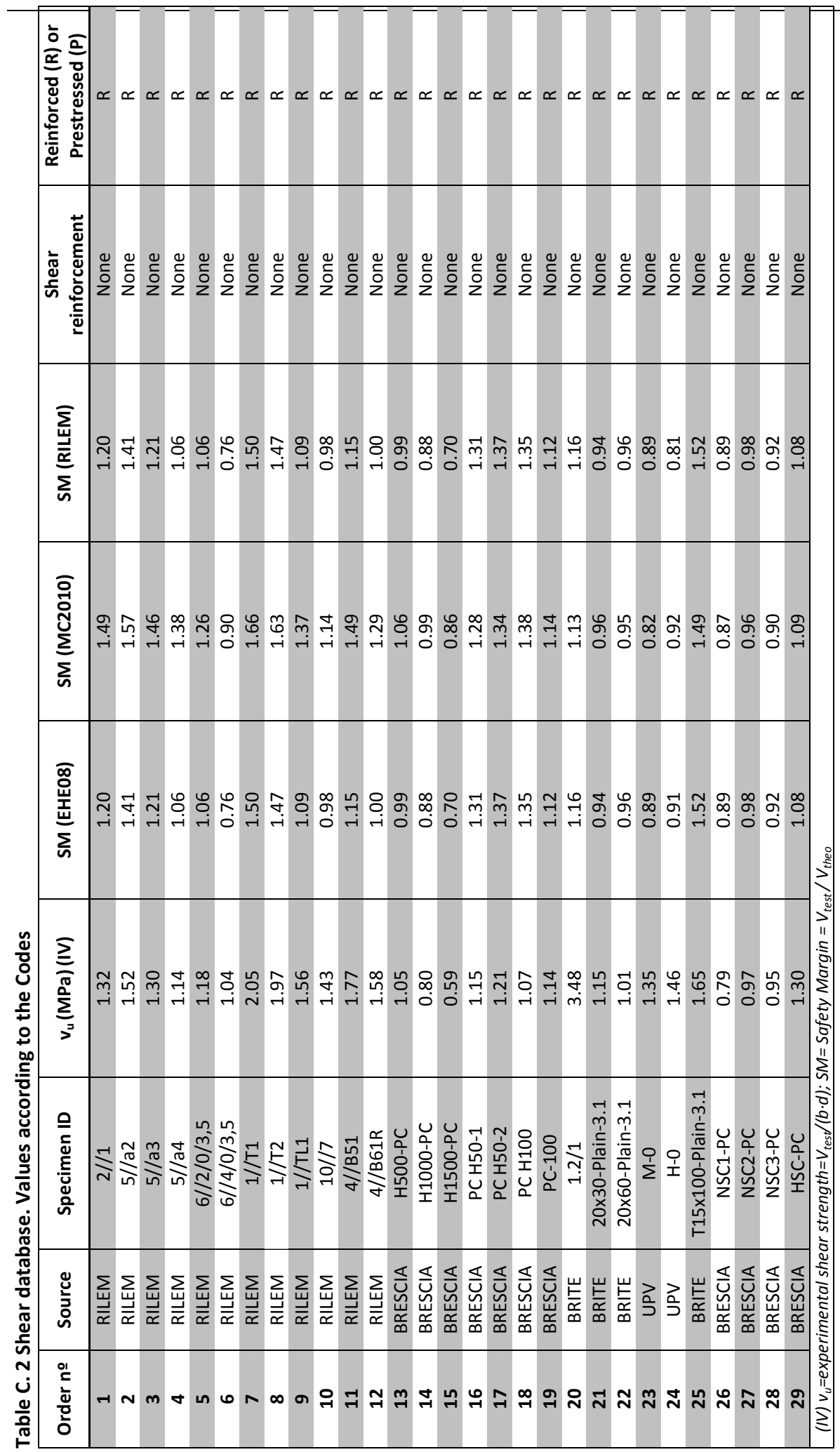




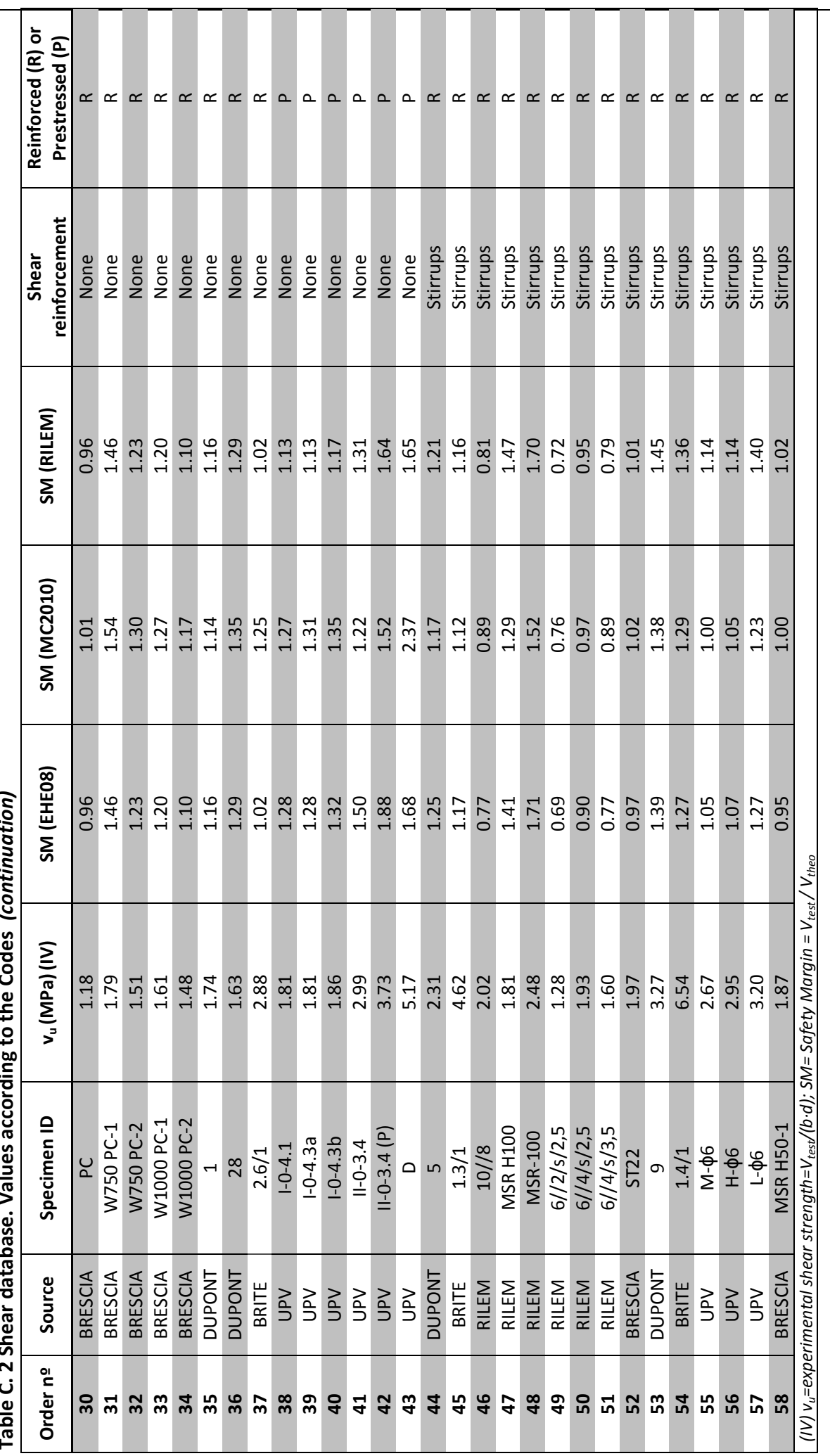

Estefanía Cuenca Asensio - ICITECH - Universitat Politècnica de València 


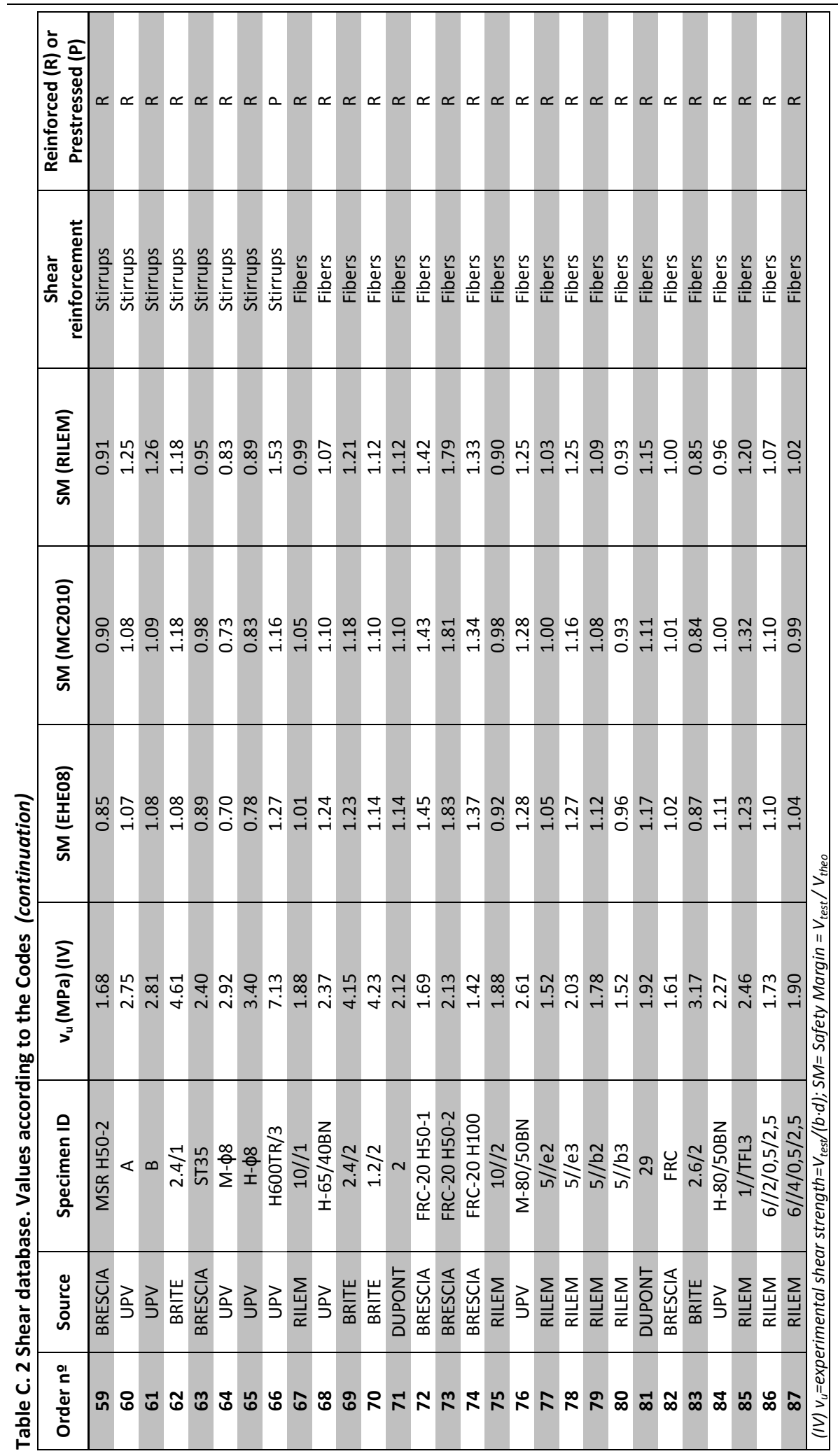




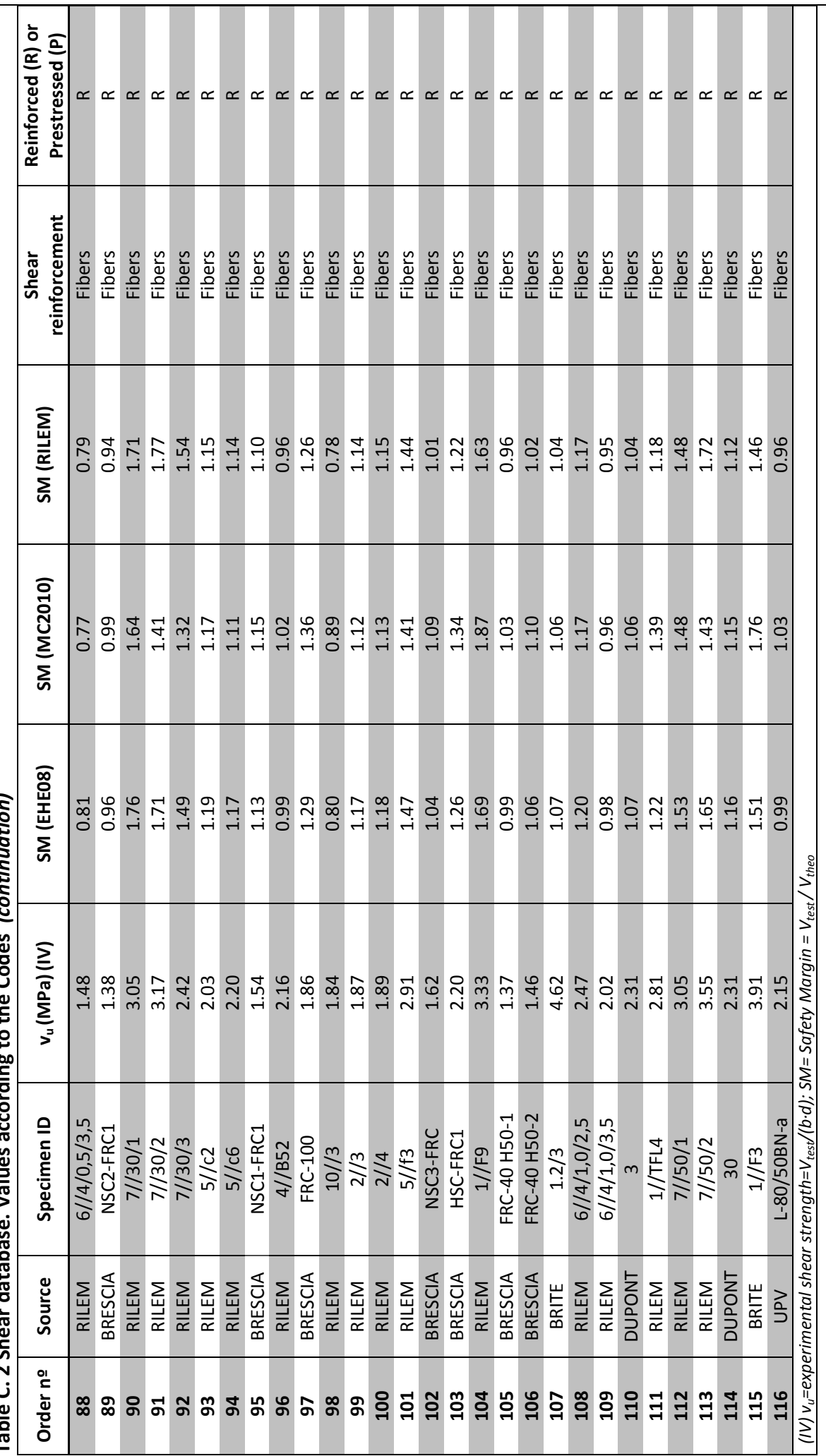

Estefanía Cuenca Asensio - ICITECH - Universitat Politècnica de València 


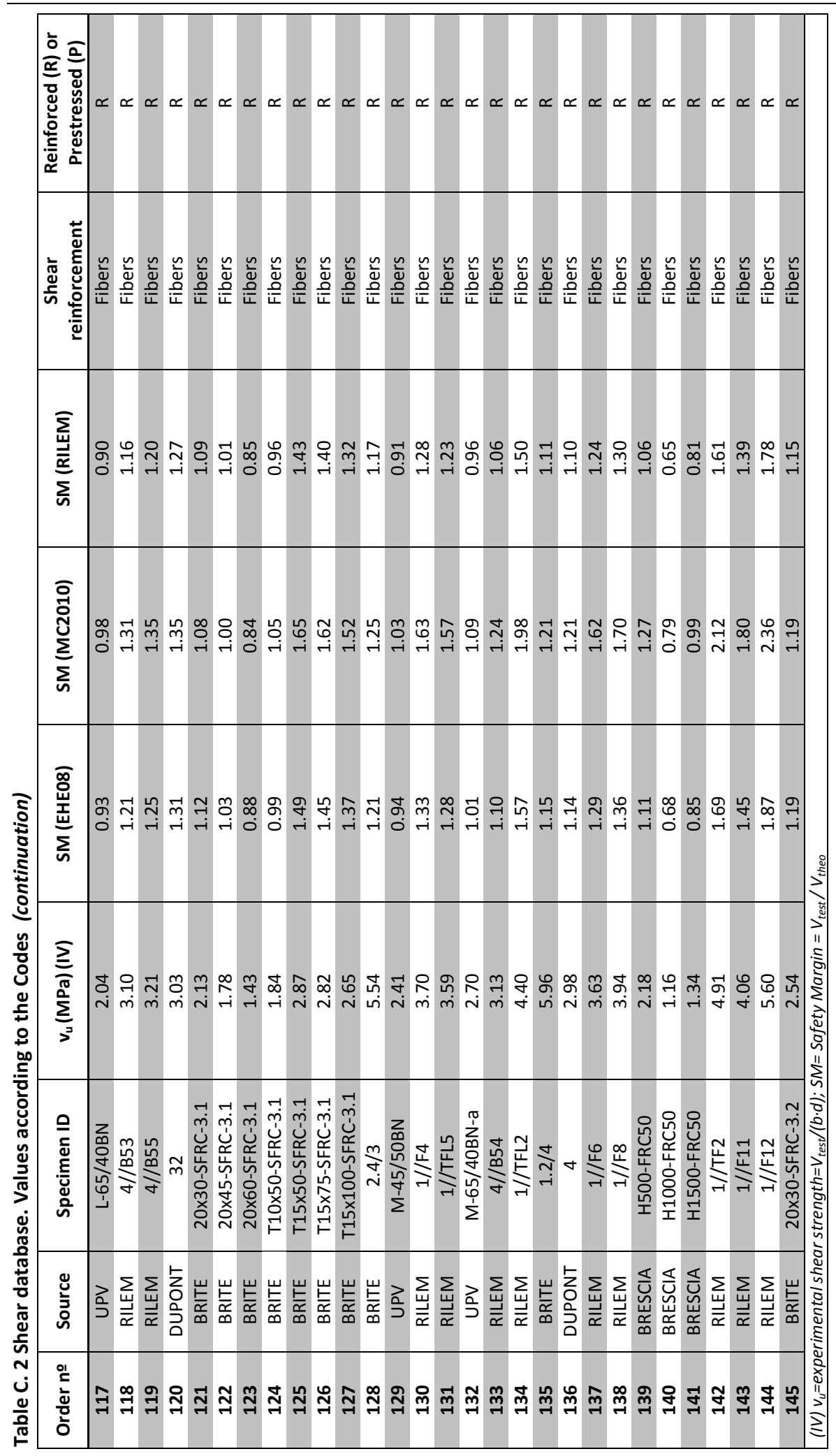




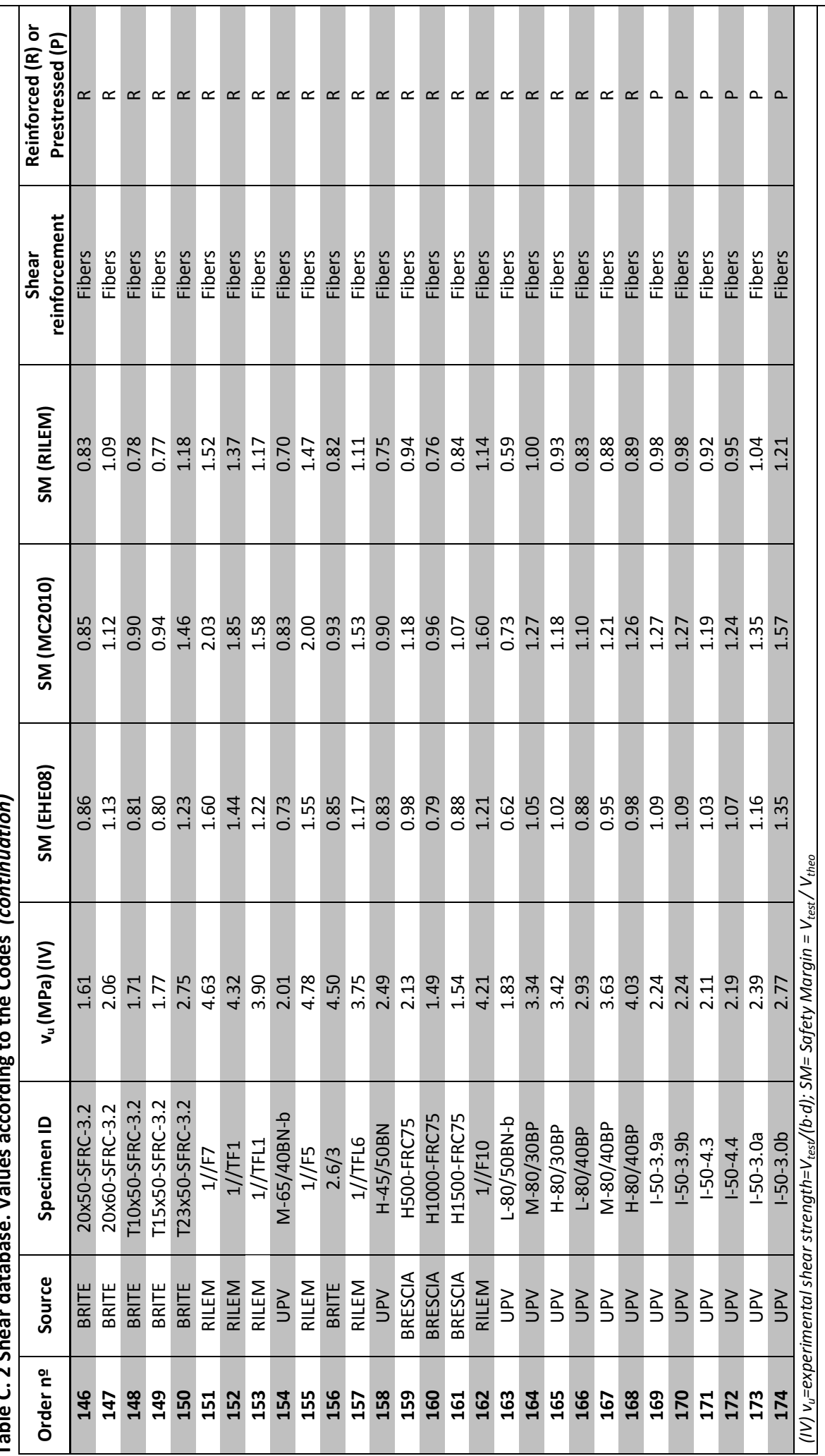

Estefanía Cuenca Asensio - ICITECH - Universitat Politècnica de València 


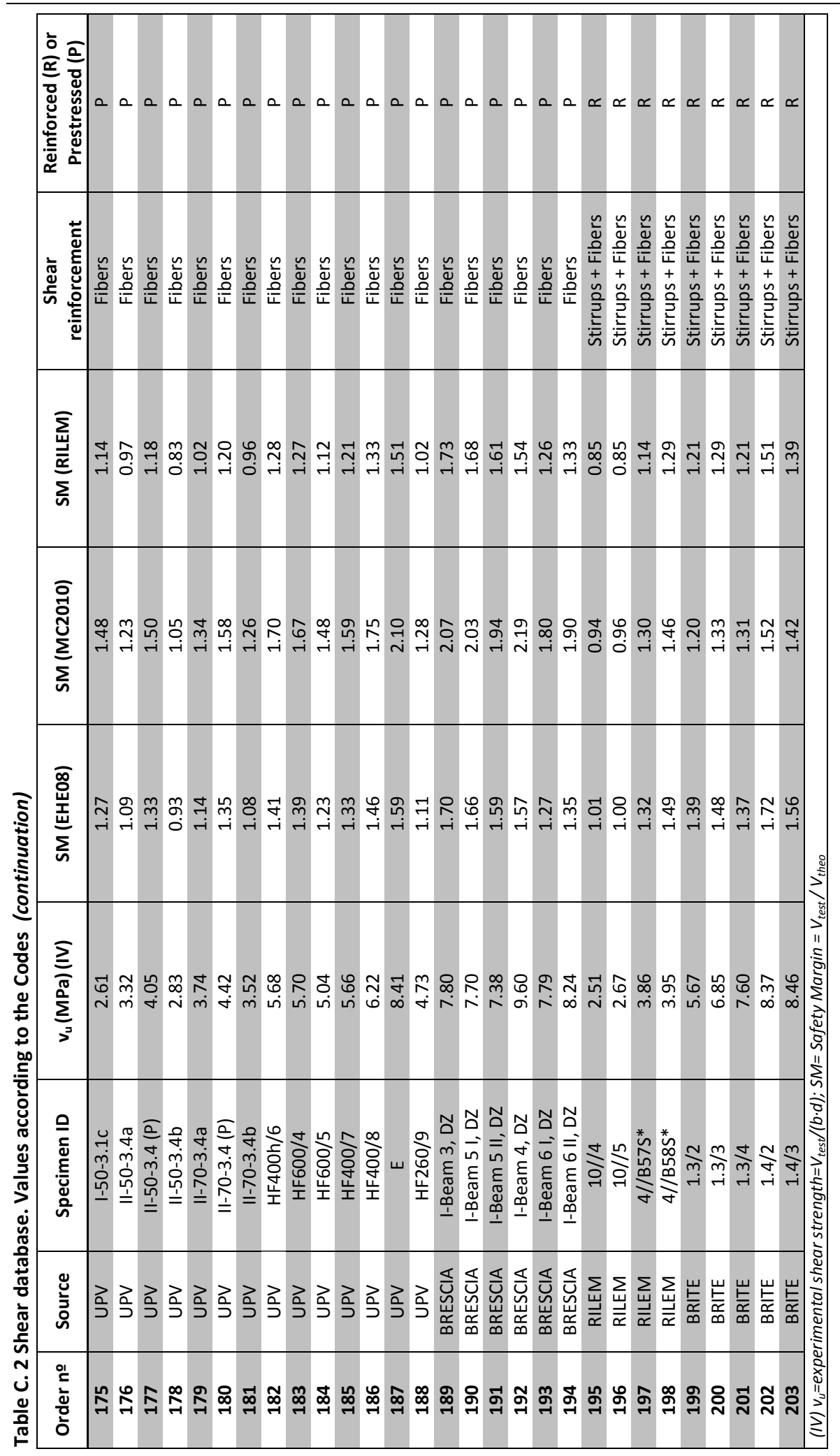




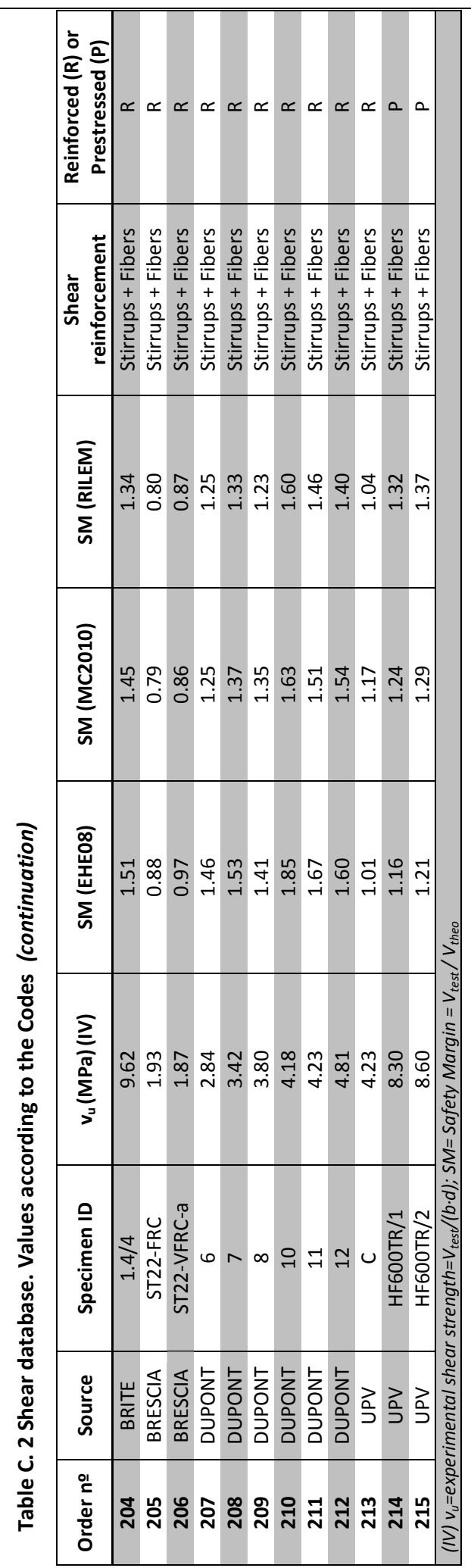

Estefanía Cuenca Asensio - ICITECH - Universitat Politècnica de València 